\title{
Life after Harry
}

\section{Eine Gattungsdiskussion zeitgenössischer Kinder- und Jugendliteratur in der Post-Potter-Ära}

Dissertationsschrift zur Erlangung des akademischen Grades

Doktorin der Philosophie (Dr. phil.)

der Philosophischen Fakultät der Georg-Augst-Universität Göttingen

vorgelegt von

Victoria Fitz

aus Kassel

Göttingen 2018

Erstgutachterin: Prof. Dr. Ina Karg

Zweitgutachterin: Prof. Dr. Simone Winko

Kontakt: vickyfitz@googlemail.com 



\section{Vorwort}

Die vorliegende Arbeit ist die leicht überarbeitete Fassung meiner Dissertationsschrift, die ich im Januar 2015 bei der Philosophischen Fakultät der Georg-August-Universität Göttingen vorgelegt habe. Die Arbeit bildet den Forschungsstand bis zu diesem Zeitpunkt ab, Primärund Sekundärliteratur, die danach erschienen ist, wurde nicht mehr berücksichtigt.

Viele Menschen haben zum Gelingen dieser Schrift beigetragen. Ihnen möchte ich meinen außerordentlichen Dank aussprechen. Zuallererst bedanke ich mich bei Prof. Dr. Ina Karg, die mich während meines Studiums und während meiner Promotionszeit stets unterstützt und gefördert hat und die mich als Fachdidaktikerin bis heute prägt. Prof. Dr. Simone Winko danke ich für die Übernahme der Zweitkorrektur.

Vielen Dank auch an die Abteilung Fachdidaktik des Seminars für Deutsche Philologie, meinen geschätzten Kolleginnen und Kollegen, die bei dem einen oder anderen Mensaessen Motivation gespendet haben! Für aufmunternden Zuspruch sei namentlich Ellen Schneidereit und Frerk Schäfers gedankt. Für hilfreiche Impulse, vor allem bei der Einleitung, Herrn Prof. Dr. Christoph Bräuer, der mich nach der Emeritierung von Frau Professorin Karg, auch durch die Verlängerung meiner Stelle, gefördert hat.

Ein herzlicher Dank gilt weiterhin den Korrekturlesern der Dissertationsschrift: René Anders, Sina Beutner und Andreas Hey. Außerdem bedanke ich mich bei Nils Jäger und Markus Raue, die mir in vielerlei Hinsicht geduldig in der intensiven Abschlussphase zur Seite gestanden haben. Für die Korrekturlektüre der überarbeiteten Fassung möchte ich mich bei Dagmar Gild-Christen bedanken, von deren Verbesserungsvorschlägen ich sehr profitiert habe. Schließlich bedanke ich mich bei meinem Verlobten René Buchterkirchen, der mich liebevoll zu Überarbeitung und Abschluss des Projekts angestoßen hat.

Meinen lieben Freunden, die ich gerne als „Wahlfamilie“ ansehe, sei diese Arbeit gewidmet. 


\section{Inhaltsverzeichnis}

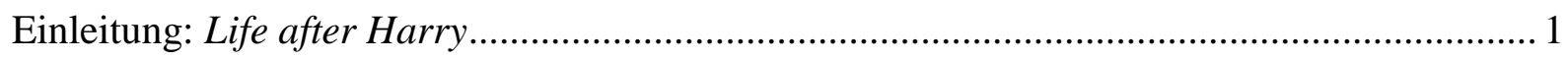

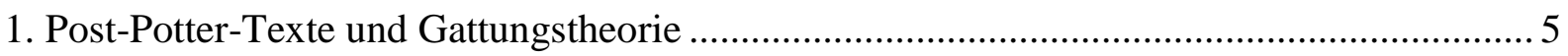

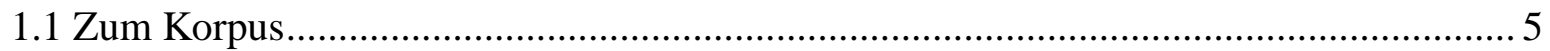

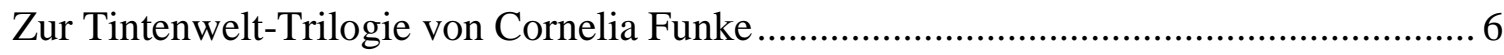

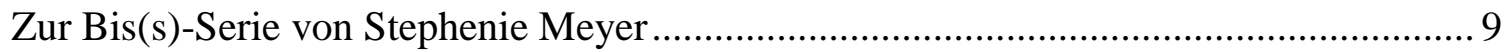

Zur Percy-Jackson-Pentalogie von Rick Riordan ..................................................... 12

Zur Panem-Trilogie von Suzanne Collins ............................................................. 14

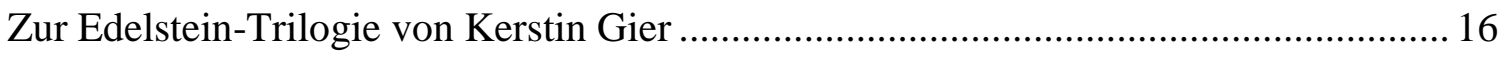

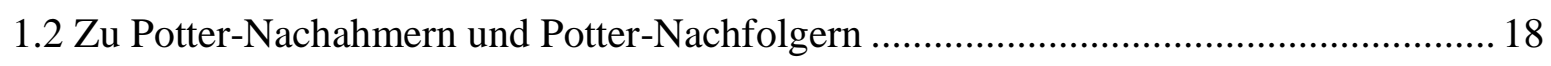

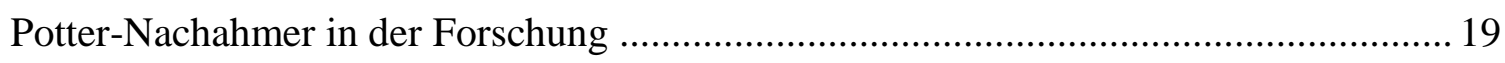

Potter-Nachfolger vs. Potter-Nachahmer: Rick Riordans Percy Jackson ....................... 21

$1.3 \mathrm{Zu}$ literarischen Gattungen und Gattungsmodellen............................................ 23

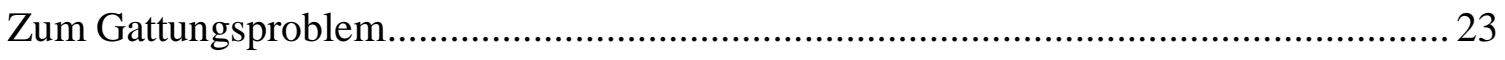

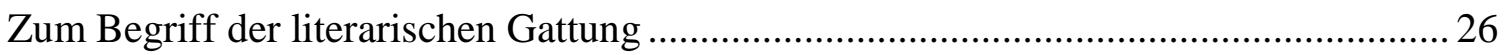

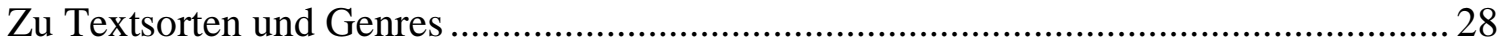

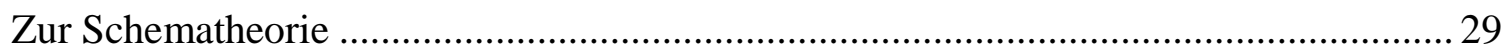

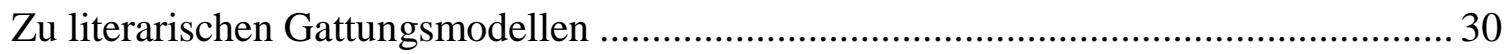

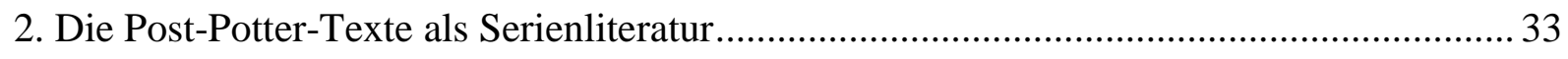

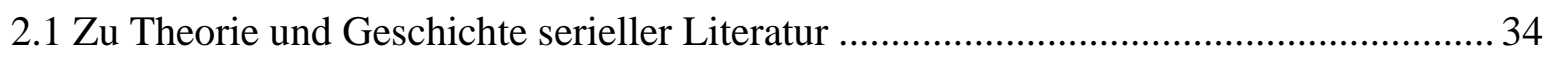

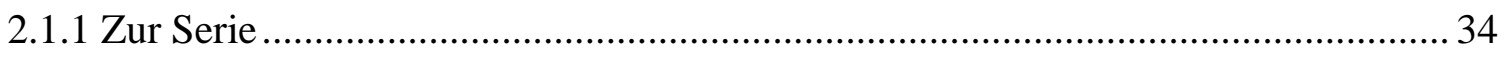

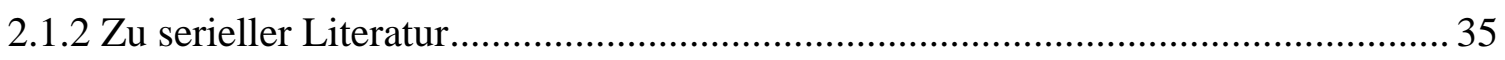

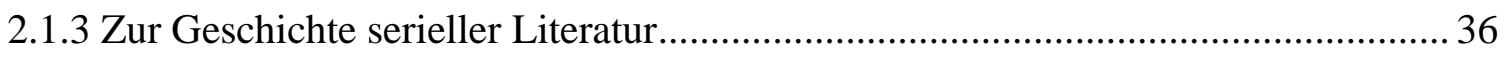

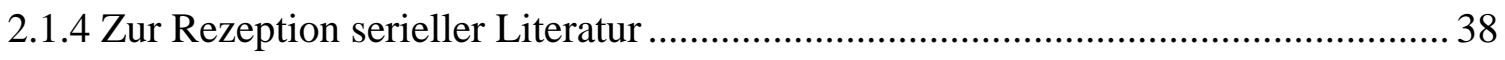

2.2 Zu den seriellen Strukturen von Harry Potter und seinen Nachfolgern ....................... 39

2.2.1 Zu literarischen Serialitätsstrukturen und ihrer Klassifikation ............................ 40

2.2.2 Zur seriellen Struktur von Harry Potter ............................................................. 45 


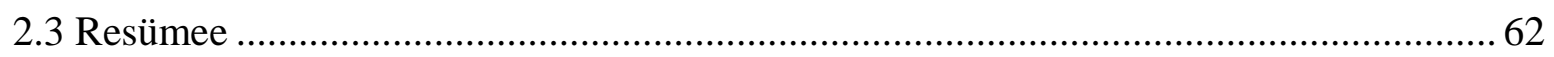

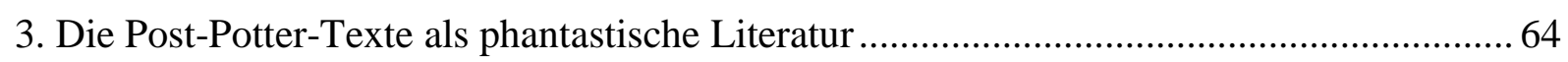

$3.1 \mathrm{Zu}$ Theorie und Geschichte der phantastischen Literatur....................................... 65

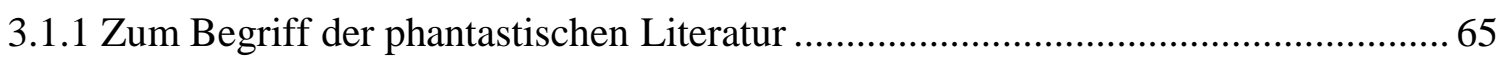

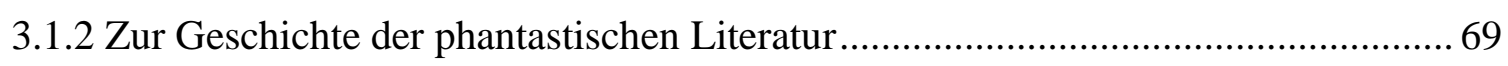

3.2. Zum phantastischen Genre von Harry Potter und den Post-Potter-Texten .................. 72

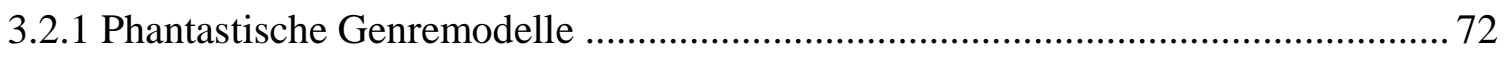

3.2.2 Ein Beispiel für ein phantastisches Genremodell ........................................... 75

3.2.3 Zur Zuordnung von Harry Potter zum phantastischen Genre ............................. 80

3.2.4 Zur Zugehörigkeit der Post-Potter-Texte zum phantastischen Genre .................... 83

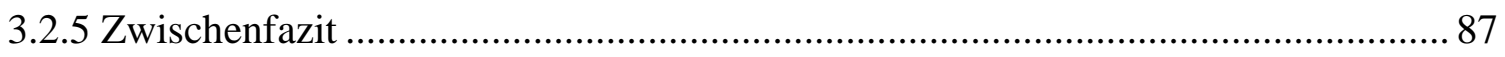

3.3 Zur Struktur der phantastischen Welten von Harry Potter und seinen Nachfolgern ..... 88

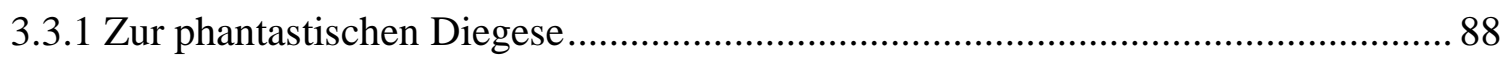

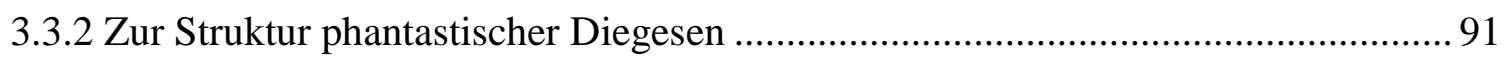

3.3.3 Analyse der Wirklichkeitsentwürfe von Harry Potter ...................................... 100

3.3.4 Analyse der Wirklichkeitsentwürfe in den Post-Potter-Texten............................ 103

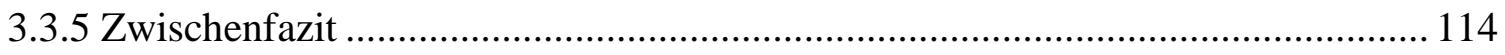

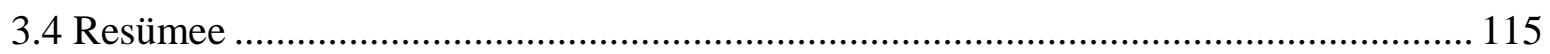

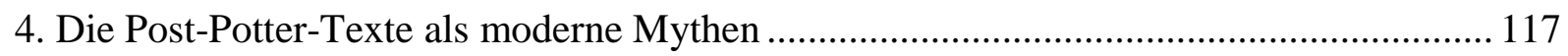

4.1 Zur begrifflichen und historischen Kontextualisierung von Mythen .......................... 118

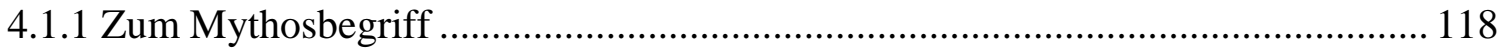

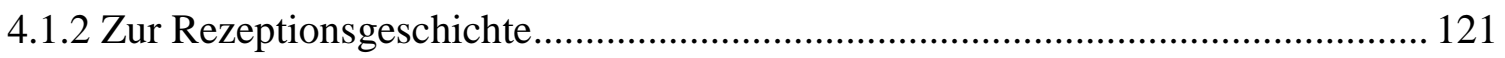

4.2 Zur Mythoshaltigkeit von Harry Potter und den Post-Potter-Texten ......................... 122

4.2.1 Zum Gattungsmodell der Mythoshaltigkeit ................................................... 123

4.2.2 Zur Mythoshaltigkeit von Harry Potter ......................................................... 126

4.2.3 Zur Mythoshaltigkeit der Post-Potter-Texte ................................................... 128 
4.3 Zum funktionsorientierten Gattungsmodell des Mythos ............................................ 156

4.3.1 Zum funktionsorientierten Mythosbegriff....................................................... 156

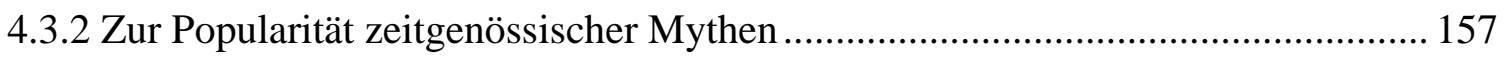

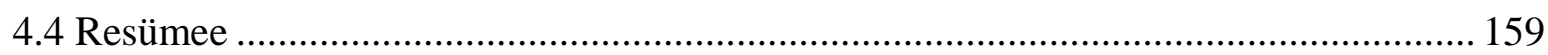

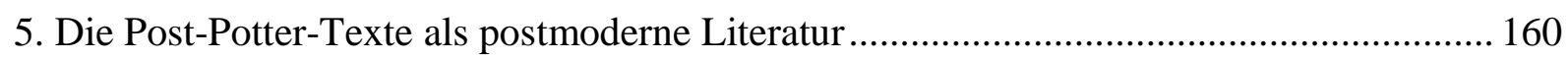

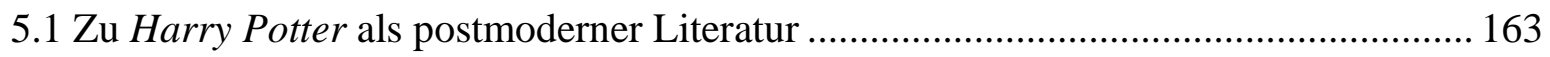

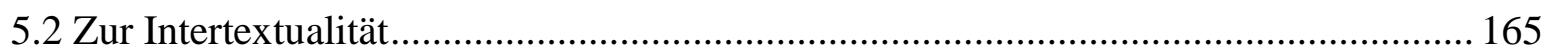

5.2.1 Zu den Funktionen von Intertextualität .......................................................... 165

5.2.2 Zu den verschiedenen Arten von Intertextualität ............................................. 166

5.3 Zum Genremix der Post-Potter-Texte …............................................................. 168

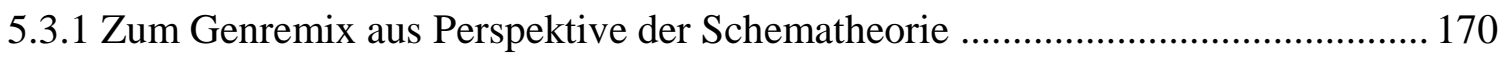

5.3.2 Zum Genremix der Post-Potter-Texte .............................................................. 171

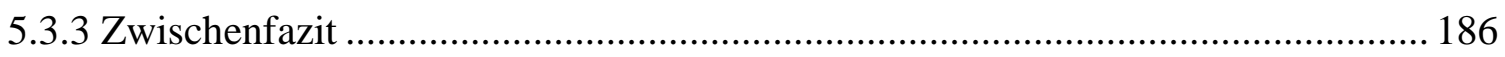

5.4 Zur Motiv- und Figurneuinterpretation in den Post-Potter-Texten ............................ 187

5.4.1 Zur Interpretation des Vampirs in Stephenie-Meyers Bis(s)-Saga ...................... 188

5.4.2 Zur Reflexion zeitgenössischer Mythenrezeption in den Post-Potter-Texten....... 195

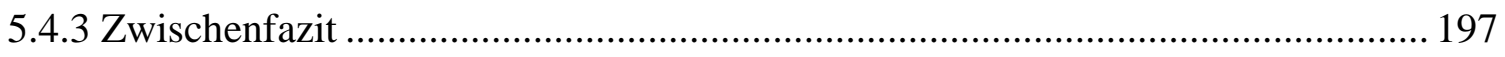

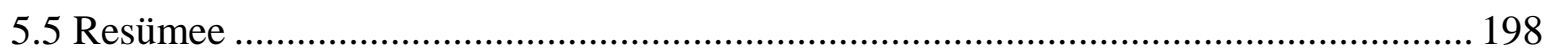

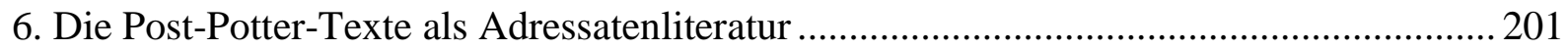

6.1 Zum impliziten Rezipienten und adressatenbezogenen Symbolsystemen .................. 203

6.2 Harry Potter und die Post-Potter-Texte als Kinder- und Jugendliteratur .................... 205

6.2.1 Zur Geschichte der Kinder- und Jugendliteratur............................................... 205

6.2.2 Zu den Konventionen von Kinder- und Jugendliteratur.................................... 208

6.2.3 Harry Potter als Kinder- und Jugendliteratur ................................................... 211

6.2.4 Die Post-Potter-Texte als Kinder- und Jugendliteratur ...................................... 213

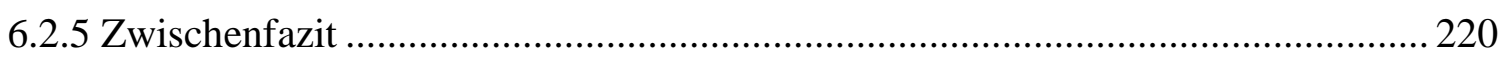


6.3 Harry Potter und die Post-Potter-Texte als All-Age-Literatur ................................... 221

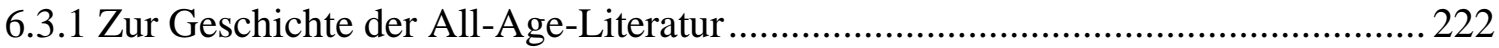

6.3.2 Zu den Charakteristika der All-Age-Literatur .................................................... 224

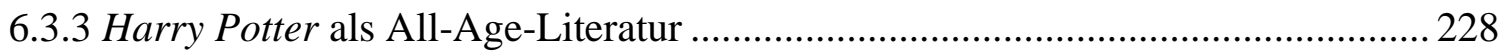

6.3.4 Die Post-Potter-Texte als All-Age-Literatur ................................................... 230

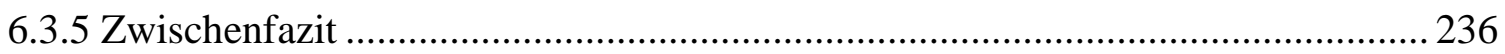

6.4 Die Post-Potter-Texte und Harry Potter als multiadressierte Literatur ...................... 237

6.4.1 Zur Geschichte übersetzter Kinder- und Jugendliteratur in Deutschland ............. 238

6.4.2 Zu den Charakteristika eines multiadressierten Textes ...................................... 240

6.4.3 Harry Potter als multiadressierte Literatur ..................................................... 243

6.4.4 Die Post-Potter-Texte als multiadressierte Literatur ........................................... 245

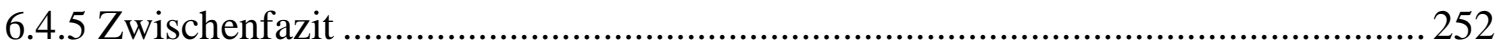

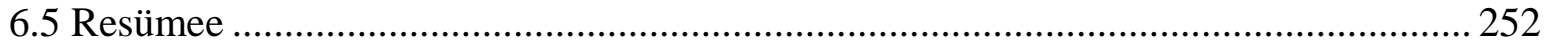

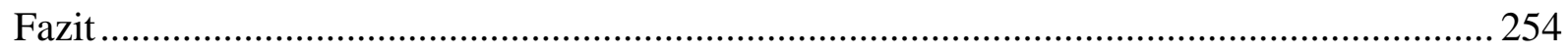

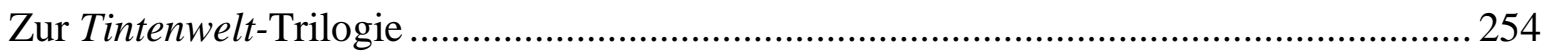

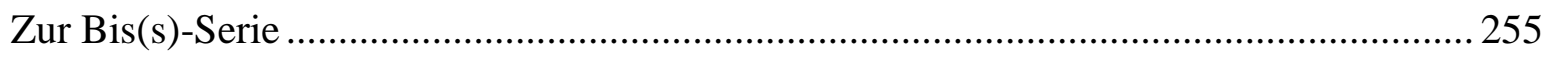

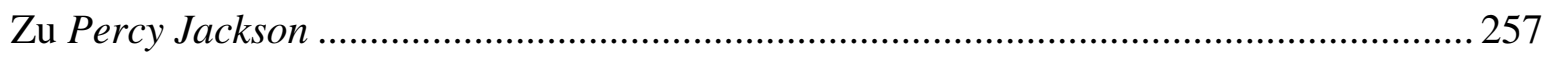

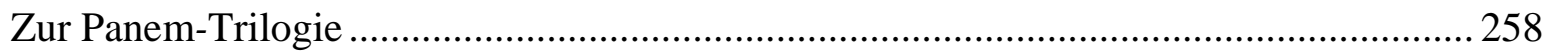

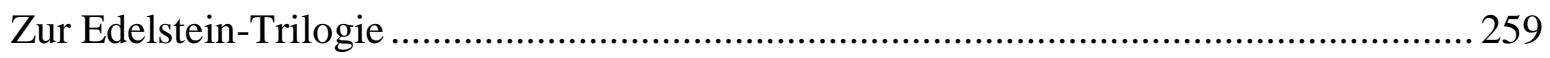

$\mathrm{Zu}$ den Ähnlichkeiten von Harry Potter und den Post-Potter-Texten .............................. 261

Ausblick: Harry Potter - ein prototypischer Text? .................................................... 263

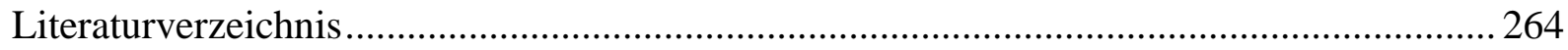




\section{Einleitung: Life after Harry}

Mit dem Slogan „Life after Harry“ bewarb die englische Buchhandelskette Waterstone’s im Jahr 2007 eine Reihe von Werken, die Harry-Potter-Freunde ansprechen sollten, welche den siebten und letzten Band des Verkaufsschlagers bereits gelesen hatten und auf der Suche nach der passenden Anschlusslektüre waren. ${ }^{1}$ Die Geschichte des jungen Zauberlehrlings, die so viele Menschen begeistert hatte, war abgeschlossen, und Waterstone's versuchte mit seiner Auswahl den Kunden entgegenzukommen, welche bereits kontrovers diskutierten: Was lesen wir nach den Harry Potter-Büchern? Auch in Deutschland setzte man sich umfangreich mit dieser Frage auseinander, und vor allem im Internet wurden ,,verzweifelt zurückgelassenen“ Fans zahlreiche Vorschläge unterbreitet. ${ }^{2}$ Empfehlungen auszusprechen war in diesem Fall nicht leicht, denn Harry Potter schien etwas Besonderes zu sein, etwas Neues, das zudem genau dem Zeitgeist entsprach. Welche Bücher konnten da mithalten?

Nur kurze Zeit später fanden sich auf den vordersten Plätzen der Bestsellerlisten gleich mehrere Romane, deren internationaler Erfolg mit dem von Rowlings Werk in Verbindung gebracht wurde: Erst Cornelia Funkes Tintenwelt-Trilogie, dann Stephenie Meyers Bis(s)-Serie und schließlich Suzanne Collins’ Die Tribute von Panem. Das Phänomen wurde zwar allgemein als „Fantasy-Welle“ ${ }^{* 3}$ bezeichnet, doch handelte es dabei nicht einfach nur um Literatur der Gattung „Phantastik““4 ${ }^{*}$ die sich erfolgreich auf dem Buchmarkt durchsetzte, sondern vornehmlich um phantastische Kinder- und Jugendliteratur ${ }^{5}$, welche in der Post-Potter-Ära zum neuen Trendgenre avancierte und seither die Aufmerksamkeit einer breiten Öffentlichkeit genießt. Heute, etwas mehr als zehn Jahre nachdem Rowling den letzten Band ihrer Heptalogie vorgelegt hat, weist der deutsche Buchmarkt eine ganze Reihe von Titeln dieser Art auf,

\footnotetext{
${ }^{1}$ Vgl. Karg/Mende (2010), S. 9.

${ }^{2}$ Vgl. http://hogwartsonline.de/2007/10/was-lesen-nach-harry-potter-5-martina.html (6.7.2014); www.parents.at/forum/showthread.php?t=418133 (3.8.2010); www.amazon.de/forum/eltern\%20diskutieren?_encoding=UTF8\&cdForum=Fx3AFWYF3B770HX\&cdThrea d=Tx39TYABKDG7I9P (6.7.2014). Focus stellt 2010 fest: „, Es gibt ein Lesen nach Harry Potter “ und gibt Anregungen: www.focus.de/familie/kinderspiele/es-gibt-ein-lesen-nach-harry-potter-buecher-fuerkinder_id_1941324.html (8.7.2014).

${ }^{3}$ Link/Brohn/Kutzmutz (2010), S. 43.

${ }^{4}$ Die Begriffe „Fantasy“ und „Phantastik“ werden in der Forschung nicht einheitlich verwendet. In dieser Arbeit bezeichnet „Fantasy“ eine Unterkategorie bzw. ein Genre der phantastischen Literatur. Zur genaueren Differenzierung siehe Kapitel 3.1.1 und 3.2.1.

${ }^{5}$ Die textuellen Merkmale sowie das implizierte Gattungsmodell der Kategorie „Phantastik“ werden in Kapitel 3 spezifiziert, die der Adressatengattung „Kinder- und Jugendliteratur“ in Kapitel 6. Vorerst soll ein intuitiver Zugang zum Begriff der ,phantastischen Kinder- und Jugendliteratur“ genügen: Gemeint sind damit zunächst einmal Texte, die von den Beteiligten am Publikationsprozess solchermaßen eingeordnet werden.
} 
die von Jung und Alt gern gelesen werden und durch hohe Absatzzahlen sowie eine breite Medienpräsenz auffallen. Ein Abklingen des Trends ist bis dato nicht in Sicht.

Umso erstaunlicher: Während sich die deutschsprachige literaturwissenschaftliche und didaktische Forschung vielfach Rowlings Vorreitern zuwandte, widmete sie sich sehr selten den Büchern der Post-Potter-Ära. Dabei lässt allein schon deren breite Resonanz eine Betrachtung als geboten erscheinen - haben sie doch großen Anteil an der Lesesozialisation von Heranwachsenden und bergen sie ungeheures didaktisches Potenzial, das erst adäquat zu begreifen ist, wenn man die Textstrukturen genauer analysiert, deren Ähnlichkeiten mit Harry Potter bereits an der Oberfläche erkennbar sind. Die vorliegende Arbeit nimmt sich der Vampire, Halbgötter und Zeitreisenden an, die im Anschluss an das Hogwartsfieber die Rankinglisten erklommen haben, um anhand verschiedener literaturwissenschaftlicher Modelle die Gattung und deren konstitutive Eigenschaften zu diskutieren.

Die Betrachtung verspricht zweierlei: Zum einen scheint ein solcher Zugriff geeignet, einen ersten Zugang zu den Texten zu eröffnen, indem die narrativen Strukturen im Fokus stehen. Zum anderen lässt sich ein möglicher Einfluss der Harry-Potter-Bücher auf die gattungskonstitutiven Eigenschaften der betrachteten Werke untersuchen. Denn es ist Konsens der PotterForschung, dass Rowlings innovativer Umgang mit Genrekonventionen eine Komponente ihres Erfolgskonzepts darstellt. Folglich liegt die Vermutung nahe, dass die Publikationen der Post-Potter-Ära vermehrt auf ähnliche Erzählstrukturen und -schemata zurückgreifen. Dieser These geht die vorliegende Arbeit in fünf Serien nach: Cornelia Funkes Tintenwelt-Trilogie, Stephenie Meyer Bis(s)-Serie, Rick Riordans Percy-Jackson-Pentalogie, Suzanne Collins’ Die Tribute von Panem und Kerstin Giers Edelstein-Trilogie. Sie alle werden als „Jugendliteratur“ sowie auch als „Literatur für junge Erwachsene“ und unter dem Schlagwort „Fantasy“ vertrieben, wobei das empfohlene Lesealter mindestens zehn Jahre beträgt. ${ }^{6}$ Sie waren mit mindestens einem Band auf Rang 1 einer Spiegel-Bestsellerliste vertreten und mit allen Bänden in den „Top Ten“. Mindestens zu einem Band liegt eine Verfilmung vor. Und: Alle Werke wurden in Presse, Onlinemedien und Fernsehen mit Harry Potter in Verbindung gebracht.

Ausgewählt wurden hier also Serien, die als Potter-ähnlich gelten und solcherart besprochen wurden. Die mehr intuitive Einordnung als Post-Potter-Texte soll im Zuge dieser Arbeit literaturwissenschaftlich reflektiert werden. Bereits an dieser Stelle sei dezidiert angemerkt: Sie

\footnotetext{
${ }^{6}$ Siehe die Altersempfehlung des Carlsen-Verlags für Harry Potter und der Stein der Weisen: www.carlsenharrypotter.de/taschenbuch/harry-potter-schuber (20.9.2012).
} 
werden hier nicht als Potter-Nachahmer im engen Sinne angesehen, das heißt, als Bücher, die eine so große Nähe zu Inhalt, Motivik, Setting und Figuren aufweisen, dass sie als Plagiat zu gelten hätten. Im hiesigen Korpus weist zweifelsohne Percy Jackson die auffälligste Nähe zu Harry Potter auf - er markiert gleichsam die Grenze, die in dieser Arbeit zwischen PotterNachahmern und Potter-Nachfolgern gezogen wird.

Die Potter-Forschung hat sich sehr früh mit gattungsrelevanten Eigenschaften von Rowlings Werk auseinandergesetzt und methodische Ansätze entwickelt, zeitgenössische Kinder- und Jugendliteratur daraufhin zu untersuchen. Dabei wurde unterschiedlichen Kategorien Beachtung geschenkt und die wissenschaftliche Einordnung der Serie in eine oder mehrere Gattungen aus höchst verschiedenen Perspektiven vorgenommen. Die parallel geführten Gattungsdiskurse zeigten deutlich, dass jedes an den Text herangetragene Gattungsmodell ihn nur so weit beschreiben konnte, wie es die Implikationen des jeweiligen Modells zugelassen haben: Der Teildiskurs beispielsweise, der Harry Potter als der phantastischen Literatur zugehörig besprochen hat, bezog zwangsläufig andere Textmerkmale in seine Argumentation ein als diejenigen, die das Werk als Serie oder als modernen Mythos behandelten. Die Diskussion, die es als Genremixtur betrachtete, betonte wiederum andere Gattungseigenschaften als diejenige, welche die doppelte Adressierung in den Blick nahm. Die Erkenntnisse und Beobachtungen, die in der Potter-Forschung zusammengetragen wurden, sind somit zwar in höchstem Maße unterschiedlich, widersprechen sich aber keineswegs. Vielmehr führten erst die verschiedenen Diskurse zu einem mehrdimensionalen Bild davon, welche gattungsweisenden Eigenschaften vorliegen. Ein solch mehrdimensionales Bild ist hier auch für die Texte des Korpus intendiert.

Zur Gliederung dieser Arbeit: Das folgende Kapitel gibt eine Inhaltsangabe aller Texte und stellt Percy Jackson in Abgrenzung zu Potter-Nachahmern gesondert vor. Anschließend werden die Begriffe „Gattung“, „Textsorte“, „Genre“ und „Gattungsmodell“ als theoretische Grundlagen der hier genutzten Methoden und Fragenhorizonte definiert und voneinander differenziert. Der mehrperspektivische Zugriff auf die Gattungsfrage bestimmt die weiteren Kapitel: Sie führen in die Geschichte der jeweils betrachteten Gattung ein und entwickeln im Folgenden eine Methodik, die sich auch, aber nicht nur an der Potter-Forschung orientiert. Die Methode wird dann ausführlich auf zwei Post-Potter-Serien angewendet und um Beobachtungen zum weiteren Korpus ergänzt. Auch Harry Potter selbst ist Gegenstand der Analyse; hierbei wird zum Teil auf Ergebnisse der Potter-Forschung zurückgegriffen, zum Teil ein eigener Beitrag geleistet. Die Fazits der Kapitel stellen Gemeinsamkeiten zwischen Harry 
Potter und den Korpustexten heraus, soweit sie aus der jeweiligen Analysenperspektive relevant erscheinen.

Im Einzelnen befasst sich die Arbeit mit den folgenden Aspekten: Kapitel 2 („Die Post-PotterTexte als Serienliteratur") widmet sich den seriellen Strukturen der Texte, Kapitel 3 („Die Post-Potter-Texte als phantastische Literatur“) analysiert sie in Bezug auf Eigenschaften und Konventionen phantastischer Literatur. Kapitel 4 („,Die Post-Potter-Texte als moderne Mythen“) diskutiert, inwiefern sie als moderne Mythen gelesen werden können. In Kapitel 5 („Die Post-Potter-Texte als postmoderne Literatur“) werden die Texte als Genremix betrachtet und ausgewählte Handlungsschemata nachgewiesen, die konventionell mit den Genres Liebesroman, Abenteuerroman und Kriminalroman assoziiert werden. Zudem widmet sich das Kapitel ausgewählten Motivinterpretationen, die eine Lesart der Korpustexte als postmoderne Literatur nahelegen. Kapitel 6 („Die Post-Potter-Texte als Adressatenliteratur“) beschäftigt sich mit den Genres Kinder- und Jugendliteratur, All-Age-Literatur sowie multiadressierte Literatur und untersucht Texte des Korpus auf Adressierungsstrategien, die damit assoziiert werden.

Das Fazit verhält sich in seiner Gliederung komplementär zu den Hauptkapiteln: Es ist gegliedert nach den Texten des Post-Potter-Korpus. Die Ergebnisse für jede einzelne Serie werden aus den Hauptkapiteln zusammengetragen. Abschließend werden noch einmal die Gemeinsamkeiten von Harry Potter und den Post-Potter-Texten herausgestellt und literaturhistorisch reflektiert. 


\section{Post-Potter-Texte und Gattungstheorie}

Da die ausgewählten Buchserien noch nicht so bekannt sein dürften wie Harry Potter, werden sie hier zunächst inhaltlich vorgestellt. Daran schließt sich jeweils eine Übersicht über ausgewählte Forschungsbeiträge an. Weiterhin wird der kommerzielle Erfolg aufgezeigt und die Verknüpfung mit Harry Potter im öffentlichen Diskurs herausgestellt. ${ }^{1}$ Kapitel 1.2 richtet einen Seitenblick auf solche Texte, die sich so eng an Rowlings Heptalogie anlehnen, dass sie als Imitate aufgefasst werden können. Auf die Vorstellung und Abgrenzung des Korpus folgt die theoretische Fundierung dieser Arbeit (Abschnitt 1.3): Ein historischer Abriss führt in das Konzept der literarischen Gattung ein, im Anschluss folgen Definitionen der Begriffe „Gattung“, „Textsorte“ und „Genre“. Schließlich wird die begriffliche Neuschöpfung „Gattungsmodell““ erläutert. Der Terminus dient dazu, die Grundlagen von Gattungszuweisungen präziser fassen zu können und somit die Voraussetzungen der in dieser Arbeit angewandten Methoden besser reflektieren zu können.

\subsection{Zum Korpus}

Wenn hier von den Korpus- bzw. den Post-Potter-Texten die Rede ist, sind im Speziellen die oben genannten fünf Serien gemeint, andere Texte werden ggf. explizit genannt. ${ }^{2}$ Diese Arbeit diskutiert die Gattung der literarischen Texte in Buchform; andere literarische Medien ${ }^{3}$ der literarischen Verbundsysteme bzw. Medienverbünde finden nur vereinzelt Beachtung. ${ }^{4}$

\footnotetext{
${ }^{1}$ Berücksichtigt werden vor allem Diskurse aus dem deutschsprachigen Raum, sowohl aus der Forschung als auch dem öffentlichen Raum. Zur Motivation dieser Selektionsentscheidung siehe unten, Kapitel „Zum Begriff der literarischen Gattung“".

2 „Post-Potter-Text“ ist ein von der Verfasserin kreierter Terminus, der sich an gesellschaftliche Sprachspiele anlehnt (wie z. B. im Slogan „Life after Harry“). Er wird hier zur Arbeitserleichterung verwendet und ist als neutral zu betrachten, da er auf keine Eigenschaften im Speziellen, sondern nur auf die Nachfolge im zeitlichen Sinne abhebt.

${ }^{3}$ Ein literarisches Medium ist ein intendierter Vermittler von Sinn- und Bedeutungszusammenhängen, die ihrerseits eindeutig auf eine konkrete literarische Idee referieren oder diese erstmals zur Verfügung stellen. Die Definition basiert auf dem Medienbegriff von Hallenberg (2000, S. 551). Der Terminus literarisches Medium soll der stringenten Trennung zwischen Vermittler und Vermitteltem dienen. Jene klare Abgrenzung zwischen Literatur und Schrift ist vonnöten, beobachtet man die aktuellen literarischen Verbundsysteme: Den Beteiligten am Vermarktungsprozess geht es nicht mehr nur um die Veröffentlichung von literarischen Texten in Buchform, sondern - und das ist das Besondere - um die Distribution einer literarischen Idee mithilfe einer großen Anzahl von Medienangeboten, die dem Konsumenten die jeweilige literarische Welt durch so viele verschiedene Wahrnehmungskanäle wie möglich zugänglich machen soll. Jahraus (2003), S. 13; Rusch (2007), S. 46.

${ }^{4}$ Der Begriff des literarischen Medienverbundes meint die plurimediale Mehrfachverwertung einer literarischen Idee, die sich entweder an ein erfolgreiches literarisches Pilotprodukt anschließt oder die bei großer Erfolgserwartung planmäßig im Voraus angelegt ist. Siehe Wermke (1998), S. 179. Schließt sich die plurimediale Mehrfachwertung an ein erfolgreiches literarisches Produkt an, ergibt sich ein literarischer Medienverbund aus der Transformation eines Ausgangstextes in Zieltexte. Entscheidend ist bei dieser Art von literarischem Verbundsystem, dass der Ausgangspunkt des ganzen Systems ,, ein medienspezifisch fixiertes Produkt“
} 


\section{Zur Tintenwelt-Trilogie von Cornelia Funke}

Die Tintenwelt-Serie von Cornelia Funke erschien erstmals im Dressler-Verlag Hamburg. Der erste Band Tintenherz wurde im Jahr 2003 veröffentlicht, ${ }^{5}$ Tintenblut folgte 2005, Tintentod 2007.6

Im Zentrum stehen der Buchbinder Mortimer Folchart - auch Mo genannt - und seine Tochter Meggie, die beide die seltene Gabe besitzen, Gegenstände und Figuren aus Büchern ,herauszulesen “ (TH, S. 418). Im Tausch dafür verschwindet etwas in die jeweilige Buchwelt, so auch Meggies Mutter Resa, die an Meggies drittem Geburtstag in die Tintenwelt verloren ging, nachdem Mo aus dem fiktiven Buch „Tintenherz“ vorgelesen hatte (TH, S. 97). Begebenheiten und Ereignisse können Realität werden, wenn der Meggie oder Mo vorgelegte Text nur gut genug ist. Mit Meggies Großtante Elinor Loredan, dem Feuerspucker Staubfinger aus der Tintenwelt, Farid - einem arabischen Jungen aus 1001 Nacht - und dem Autor von Tintenherz namens Fenoglio erleben Meggie und ihr Vater Abenteuer sowohl in der „realen“ als auch in der Tintenwelt.

Im ersten Band versucht der Bösewicht Capricorn alle Ausgaben von „Tintenherz“ zu vernichten, so auch das letzte Exemplar, das sich in Mos Besitz befindet. Sein Ziel ist, die Verbindungen zu seiner Heimatwelt zu kappen. Vorher jedoch soll sein Freund, der Schatteneine bösartige Kreatur -, ebenfalls aus der Tintenwelt herausgelesen werden. Durch Staubfingers Zutun, der zu seinem Widerwillen aus der Tintenwelt herausgelesen wurde, gelingt es Capricorn und seinen Männern, Mo, Meggie, Elinor und Fenoglio gefangen zu nehmen und das letzte verbliebene Exemplar in ihren Besitz zu bringen. Capricorn plant eine Hinrichtung, in der u. a. Meggies Mutter getötet werden soll. Meggie, die dazu gezwungen wird, den Schatten für Capricorn herauszulesen, trägt auf dieser Veranstaltung allerdings nicht die originale Fassung von Tintenherz vor, sondern eine von Fenoglio revidierte Version. So gelingt es ihr, den Schatten zu zerstören und Capricorn sowie die meisten seiner Männer zu töten. Fenoglio allerdings entschwindet bei Meggies Vortrag in die Tintenwelt.

darstellt, dessen „Produkt-Substrat in ein anderes, konventionell als distinkt wahrgenommenes Medium“ transformiert wird. Schaudig (1992), S. 134. Zitat: Rajewski (2002), S. 19. Ist die plurimediale Mehrfachverwertung Teil des literarischen Konzepts, so spricht Ewers auch von einem „Hypermedia-Genre“. Ewers (2006), S. 298 und Ewers (2004), S. 4.

${ }^{5}$ Das heißt, zu dem Zeitpunkt als der erste Band veröffentlicht wurde, lag bereits der fünfte Teil der HarryPotter-Serie in deutscher Sprache vor.

${ }^{6}$ Die Bände werden im Fließtext unter der Verwendung folgender Siglen zitiert: TH (Tintenherz), TB (Tintenblut) und TT (Tintentod). 
Der zweite Band, Tintenblut, spielt überwiegend in der Tintenwelt. Während sich Staubfinger von Orpheus in seine Heimatwelt zurücklesen lässt, tritt Meggie zusammen mit Farid - beide empfinden mittlerweile romantische Gefühle füreinander - aus Neugier die Reise in die Tintenwelt an. Aus Sorge um Meggie folgen Mo und Resa ihrer Tochter, später findet auch Elinor den Weg. Meggie kommt in der Tintenwelt bei Fenoglio unter, der immer wieder versucht, die Geschichte umzuschreiben, was allerdings nicht immer in gewünschter Weise gelingt. Nachdem Mo von Mortula - der Mutter Capricorns - angeschossen wurde, werden er und Resa in das geheime Lager der Spielleute gebracht und treffen dort auf den Schwarzen Prinzen, den Anführer der Räuber und Beschützer der Spielleute. Im Verlauf der Handlung gelingt es dem bösen Natternkopf - Schreckensherrscher über die Nachtburg und einen Teil der Tintenwelt -, Mo und Meggie gefangen zu nehmen. Diese können nur freikommen, wenn sie ihm ein leeres Buch binden, das ihm Unsterblichkeit verspricht. Farid kommt im Gefecht zwischen dem Natternkopf und den Spielleuten auf der Nachtburg ums Leben, aber Staubfinger geht einen Handel mit dem Tod ein und gibt sein eigenes Leben im Tausch gegen das des Jungen. Meggie liest Orpheus in die Tintenwelt, damit dieser Fenoglios Nachfolge antritt.

In Tintentod, dem dritten Band, kommt es zum Konflikt zwischen Fenoglio und Orpheus, denn Letzterer beginnt die von Fenoglio erdachte Tintenwelt zu seinen Gunsten umzuschreiben. Mo kämpft indessen in der Rolle des Eichelhähers - einer Heldenfigur aus Fenoglios Feder - zusammen mit dem Schwarzen Prinzen gegen den Natternkopf. Dieser musste feststellen, dass Mo das Buch der Unsterblichkeit manipuliert hat, sodass sein Körper - genau wie das Buch - nach und nach zu faulen beginnt. Durch eine List gelingt es Orpheus, dass Staubfinger von den Toten aufersteht. Allerdings wird Mo dafür von der „großen Wandlerin“ - einer Personifizierung des Todes - vor ein Ultimatum gestellt: Gelingt es ihm nicht, das Buch des Natternkopfes bis zum Ende des Winters zu zerstören, müssen er, seine Tochter und Staubfinger ihr Leben geben. Indessen plant der Natternkopf, alle Kinder der Stadt Ombra in Gefangenschaft zu nehmen. Meggie, Fenoglio sowie die Räuber und Spielleute versuchen ihr Möglichstes, um das Leben der Kinder zu schützen. Mo entschließt sich schließlich dazu, sich zu deren Schutze dem Natternkopf auszuliefern. In Gefangenschaft wird er von diesem gezwungen, das Buch der Unsterblichkeit zu restaurieren. Gerade noch rechtzeitig gelingt es ihm, die drei magischen Worte Herz, Blut und Tod in das Buch zu schreiben und damit das Leben des Natternkopfes auszulöschen. Mo, Resa, Meggie, Elinor, Farid und Fenoglio beschließen in der Tintenwelt zu bleiben. Meggie entdeckt, dass sie sich in den Räuber Doria 
verliebt hat, und trennt sich von Farid. Ihre Eltern bekommen ein weiteres Kind in der Tintenwelt.

Insbesondere im Zusammenhang mit der Tintenwelt-Serie wurde Funke in der Presse als ,,die deutsche Rowling “ betitelt. ${ }^{7}$ Im Magazin Focus erklärt sie 2007, wie sehr ihr der Erfolg von Harry Potter bei der Vermarktung ihrer Bücher geholfen und dass sie Rowling viel zu verdanken habe. ${ }^{8}$ In einem Interview mit dem Spiegel vergleicht sie 2008 ihre Tintenwelt inhaltlich sogar mit deren Zaubererwelt. ${ }^{9}$ Funke gilt als international erfolgreichste und bekannteste deutsche Kinder- und Jugendbuch-Autorin, ihre Bücher erscheinen in über 40 Ländern weltweit. ${ }^{10}$ Bereits 2012 hatte sich der Tintenwelt-Dreiteiler auf dem deutschsprachigen Markt insgesamt über 3,5 Millionen Mal verkauft. ${ }^{11}$ Tintenherz schaffte es 2005 in der SpiegelBestsellerliste Jugendbuch auf Platz 1, Tintenblut erreichte 2005 Platz 2, Tintentod belegte 2007 Platz 1 sowohl in der Bestsellerliste Jugendbuch als auch Hardcover/Belletristik. ${ }^{12}$

In der deutschsprachigen Forschung wurde die Trilogie mehrfach behandelt: Saskia Heber betrachtet in ihrer Dissertation Das Buch im Buch primär die Aspekte Intertextualität, Selbstreferenz und Mythenadaption. Judith Mohr widmet sich in Zwischen Mittelerde und Tintenwelt der Struktur der Buchwelten und vergleicht sie mit Werken von Jasper Fforde und Wieland Freund. Im Sammelband Zauberland und Tintenwelt, der sich mit phantastischer Kinder- und Jugendliteratur auseinandersetzt, wird der Dreiteiler von Maren Bonacker und

\footnotetext{
${ }^{7}$ Osberghaus, Monica: Cornelia Funke. Die deutsche Rowling. In: Frankfurter Allgemeine Zeitung, 19.7.2002. Auch der Fischer-Verlag benutzt die Umschreibung, um den großen Erfolg der Autorin zu unterstreichen: www.fischerverlage.de/autor/cornelia funke/1661 (6.5.2014).

8 Interview mit Jobst-Ulrich Brand: „Wir alle haben profitiert.“ In: Focus 29 (2007); online unter www.focus.de/kultur/buecher/kultur-wir-alle-haben-profitiert_aid_226916.html (18.11.2014).

${ }^{9}$ Interview mit Cornelia Funke, geführt von Katja Thimm und Susanne Weingarten: „Mein gefühltes Alter ist zehn.“ In: Der Spiegel 50 (2008); online unter www.spiegel.de/spiegel/a-595093.html (18.11.2014).

${ }^{10}$ Pressemappe des Dressler-Verlags zu Cornelia Funke: http://meta.verlagsgruppe-oetinger.de/fileadmin/verlagsgruppe-oetinger.de/pdf/autoren/3258.pdf (18.11.2014)

${ }^{11}$ Ebd.

${ }^{12}$ Bestsellerlisten von Der Spiegel, ermittelt von buchreport.de. Die Internetseite gewährt auch Einsicht in die Bestseller-Archive. $\mathrm{Zu}$ den Platzierungen von Tintenherz siehe: www.buchreport.de/bestseller/bestseller_einzelansicht.htm?no_cache=1\&tx_bestseller_pi1[isbn] $=978379150$ 4650 (17.11.2014); zu den Platzierungen von Tintenblut siehe: www.buchreport.de/bestseller/bestseller_einzelansicht.htm?no_cache=1\&tx_bestseller_pi1[isbn] $=978379150$ 4674 (17.11.2014); zu den Platzierung von Tintentod siehe:

www.buchreport.de/bestseller/bestseller_einzelansicht.htm?no_cache=1\&tx_bestseller_pi1[isbn] $=978379150$ 4766 (17.11.2014).

Laut Wikipedia hat sich Der Spiegel lange geweigert, die Titel von Cornelia Funke auf der Bestsellerliste Hardcover/Belletristik aufzunehmen, sodass erst der dritte Band der Serie hier berücksichtigt wurde: http://de.wikipedia.org/wiki/Cornelia_Funke (17.11.2014).
} 
Wolfgang Löffler analysiert. ${ }^{13}$ Die Qualität wird insgesamt kontrovers diskutiert: Rank konstatiert, dass Tintenherz durchaus originell sei, die Folgebände jedoch deutlich weniger gehaltvoll. ${ }^{14}$ Bonacker hingegen äußert sich positiv und hebt „Funkes Sprache und Fabulierkunst " lobend hervor. ${ }^{15}$ Die Parallelen zu Rowlings Texten werden beispielsweise von Nickel-Bacon betont. ${ }^{16}$ Auch in der didaktischen Forschung wurden die Bücher besprochen und ihr Potenzial als Unterrichtslektüre reflektiert. ${ }^{17}$

\section{Zur Bis(s)-Serie von Stephenie Meyer}

Die Romane der US-amerikanischen Autorin Stephenie Meyer erschienen in Deutschland von 2006 bis 2009 im Carlsen-Verlag (Hamburg). ${ }^{18}$ Die Serie umfasst vier Bände: Bis(s) zum Morgengrauen (2006), Bis(s) zur Mittagsstunde (2007), Bis(s) zum Abendrot (2008) und Bis(s) zum Ende der Nacht (2009). ${ }^{19}$

Im Zentrum der Handlung steht Isabella Swan, genannt Bella, die sich in den gutaussehenden Edward Cullen verliebt. Die Liebesgeschichte zwischen den beiden steht unter keinem guten Stern, denn Edward ist ein Vampir. Zusätzlich verkompliziert wird die Situation dadurch, dass sich Jacob Black, ein Werwolf des Quileute-Stammes, ebenfalls in Bella verliebt. Aber nicht nur deswegen ist Jacob Edwards Rivale, sondern auch weil Werwölfe und Vampire natürliche Feinde sind.

Im ersten Teil lernt die siebzehnjährige Bella Edward kennen, nachdem sie zu ihrem Vater Charly Swan in die verregnete Kleinstadt Forks umgezogen ist. Er fasziniert sie von Beginn an. Auch Bella erregt Edwards Aufmerksamkeit, denn normalerweise kann er Gedanken lesen, was ihm bei ihr einfach nicht gelingen will. Sie verlieben sich ineinander. Bella wird

\footnotetext{
${ }^{13}$ Bonacker (2006) befasst sich mit zeitgenössischer Phantastik bzw. der „neuen Fantasy Fiction“. Dabei fokussiert sie vor allem die Tendenz, mit Traditionen des Genres zu brechen. Wolfgang Löffler (2006) betrachtet das Motiv der Bücher und Bibliotheken in der phantastischen Kinder- und Jugendliteratur.

${ }^{14}$ Rank (2011), S. 186.

${ }^{15}$ Bonacker (2006), S. 69.

${ }^{16}$ So wird etwa darauf Bezug genommen, dass beide unterschwellig Jenseitserfahrungen thematisieren. NickelBacon (2008), S. $404 \mathrm{f}$.

${ }^{17}$ Siehe beispielsweise Gora (2007) und Bach (2014). Der Cornelsen-Verlag bietet auf seiner Homepage didaktisiertes Material für Unter- und Mittelstufe zum Download an: www.cornelsen.de/home/katalog/akd/1.c.1922958.de (9.11.2014).

${ }^{18} \mathrm{Da}$ in dieser Arbeit ausschließlich die deutschsprachigen Ausgaben verwendet werden, sind hier die deutschen Übersetzungen aufgeführt. Die englischsprachigen Erstausgaben Twilight (2005), New Moon (2006), Eclipse (2007) und Breaking Dawn (2008) erschienen bei Little, Brown and Company in New York. Die Publikation des ersten Teils in deutscher Sprache erfolgte also zu einem Zeitpunkt, als sechs Teile von Rowlings Serie in Deutschland bereits veröffentlicht waren.

${ }^{19} \mathrm{Im}$ Folgenden wird der erste Teil, Bis(s) zum Morgengrauen, mit BzMo abgekürzt, die weiteren Teile entsprechend mit BzMi, BzAb und BzEdN.
} 
durch Edward in die Geheimnisse der Familie Cullen eingeführt, die sich ausschließlich von Tierblut ernährt, was unter Vampiren eine Seltenheit darstellt. Als Bella einem Baseballspiel der Cullens beiwohnt, taucht unvermittelt ein gefährlicher Vampirnomade namens James auf. Nachdem dieser erkennt, dass Bella ein Mensch ist, beginnt er sie zu jagen und ihr nach dem Leben zu trachten. Es kommt zum Kampf, bei dem Bella gebissen wird. Edward rettet ihr Leben, bevor sie zum Vampir wird, und tötet James.

Im zweiten Teil Bis(s) zur Mittagsstunde trennt sich Edward von Bella und verlässt mit seiner Familie die Stadt, weil er sie vor der Gefahr, die seine Existenzform mit sich bringt, schützen möchte. Daraufhin fällt sie in eine monatelange Depression und vertreibt sich die Zeit mit Jacob, über den sie schließlich herausfindet, dass er ein Werwolf ist. Da Bella in Gefahrensituationen Visionen von Edward hat, sucht sie nach immer neuen Wagnissen und springt schließlich von einer Klippe, um ihn zu sehen. Edward erfährt durch seine Schwester Alice von Bellas Sprung und schließt daraus, dass sie tot sein muss. Von Trauer überwältigt, möchte auch er sterben. Das ist nur möglich, indem er den Zorn der mächtigen Vampirfamilie Volturi auf sich zieht. Bella kann ihn gerade noch rechtzeitig von seinem Vorhaben abhalten. Die Cullen-Familie fasst nun den Entschluss, Bella in einen Vampir zu verwandeln. Doch vorher will Edward sie heiraten.

In Bis(s) zum Abendrot wird Edwards und Bellas Liebe auf eine harte Probe gestellt. Jacob möchte aus Liebe zu Bella die Hochzeit verhindern und damit auch, dass sie zu einem Vampir wird. Neben der Rivalität zwischen Werwolf und Vampir müssen beide zu Bellas Schutz zusammenarbeiten, denn eine Armee neugeborener Vampire taucht auf, die dem Kommando von Victoria unterstellt ist, der ehemaligen Partnerin von James, die auf Rache sinnt und Bella umbringen will. Die Werwölfe und die Cullens kämpfen Seite an Seite gegen Victorias Gefolgschaft und siegen. Doch die Volturi tauchen auf und stellen ein Ultimatum: Bella solle bald zum Vampir werden.

Der letzte Teil beginnt mit der Hochzeit von Edward und Bella. In den Flitterwochen wird Bella schwanger. Der Fötus - halb Mensch, halb Vampir - scheint Bella von innen her auszusaugen, sie droht zu sterben. Gerade noch rechtzeitig wird Bella bei der Geburt in einen Vampir verwandelt. Andere Vampire fühlen sich von dem ungewöhnlichen Mädchen mit Namen Renesmee bedroht und alarmieren die Volturi, die es daraufhin töten wollen. Um zu bezeugen, dass von ihr keine Gefahr ausgeht, rufen die Cullens Freunde und Familie zusammen. Es gelingt ihnen schließlich zu beweisen, dass Renesmee ungefährlich ist. 
In der Presse wurde Stephenie Meyers Serie als „, schauderhafte Potter-Nachfolge“20 gehandelt. Die Frankfurter Allgemeine Zeitung fragte 2009 nach dem Erfolgsgeheimnis der Bücher, die ,, in vielem den Vergleich zu Harry Potter “ nahelegen würden. ${ }^{21}$ Die vier Bände wurden bis August 2010 in Deutschland rund 8,5 Millionen Mal verkauft, sie erschienen insgesamt in über 50 Ländern. Die Gesamtauflage liegt bei über 100 Millionen Exemplaren. ${ }^{22}$ Bis(s) zur Mittagsstunde, Bis(s) zum Abendrot und Bis(s) zum Ende der Nacht schafften es auf Platz 1 der Spiegel-Bestsellerlisten Jugendbuch sowie auch Hardcover/Belletristik. Bis(s) zum Morgengrauen belegte 2009 den ersten Platz in der Kategorie Taschenbuch. ${ }^{23}$

In der Forschung wurden unterschiedliche Aspekte der Werke beleuchtet: Köppls Monografie Der Vampir sind wir. Der unsterbliche Mythos von Dracula bis Twilight beschäftigt sich mit der Rezeption der Vampirfigur in zeitgenössischer Populärkultur. Katrin Manz untersucht in ihrer Dissertation den intertextuellen Einfluss sowohl von Meyers als auch Rowlings Romanen auf den deutschen Buchmarkt und kommt zu dem Ergebnis, dass signifikante Entlehnungen auf Handlungs- und Figurenebene zu beobachten sind, die explizit auf den Einfluss der Bestseller zurückzuführen seien. ${ }^{24}$ Birgit Schlachter greift in zwei Aufsätzen die Serie auf und nimmt sowohl das didaktische Potenzial im Kontext Deutschunterricht in den Blick als auch die Gattungsfrage in Bezug auf die Aspekte Intertextualität, Medialität und Serialität. ${ }^{25}$

20 Jobst-Ulrich Brand: Stephenie Meyer. Schauderhafte Potter-Nachfolge. Focus Online, 8.8.2008: www.focus.de/kultur/buecher/brands-buecher/stephenie-meyer-schauderhafte-potternachfolge_aid_323230.html (6.5.2014). Spiegel Online bezeichnete Meyer als ,legitime Nachfolgerin von Harry Potter-Mutter J. K. Rowling “: www.spiegel.de/kultur/literatur/horrorautorin-meyer-vampire-sindattraktiv-klug-und-cool-a-558826.html (18.11.2014).

${ }^{21}$ Tilman Spreckelsen: Das lange Warten auf den ersten Biss. In: Frankfurter Allgemeine Zeitung, 14.2.2009; online unter www.faz.net/aktuell/feuilleton/buecher/autoren/stephenie-meyers-erfolg-das-lange-warten-aufden-ersten-biss-1767243.html?printPagedArticle=true\#pageIndex_2 (18.11.2014).

22 Pressemappe des Carlsen-Verlags: www.carlsen.de/uploads/Presse/Pressemappe_Stephenie_Meyer.pdf (18.11.2014).

${ }^{23} \mathrm{Zu}$ den Platzierungen von Bis(s) zum Morgengrauen siehe: www.buchreport.de/bestseller/bestseller_einzelansicht.htm?no_cache=1\&tx_bestseller_pi1[isbn] $=978355135$ 6901 (18.11.2014); zu den Platzierungen von Bis(s) zur Mittagsstunde siehe: www.buchreport.de/bestseller/bestseller_einzelansicht.htm?no_cache=1\&tx_bestseller_pi1[isbn] $=978355158$ 1617 (18.11.2014); zu den Platzierungen von Bis(s) zum Abendrot siehe:

www.buchreport.de/bestseller/bestseller_einzelansicht.htm?no_cache=1\&tx_bestseller_pi1[isbn] $=978355158$ 1662 (18.11.2014); zu den Platzierungen von Bis(s) zum Ende der Nacht siehe:

www.buchreport.de/bestseller/bestseller_einzelansicht.htm?no_cache=1\&tx_bestseller_pi1 [isbn] $=978355158$ 1990 (18.11.2014).

${ }^{24}$ Manz (2011), S. 141.

${ }^{25}$ Zum Aspekt der Serialität und Distribution im Medienverbund siehe Schlachter (2013), S. 105-118. Zum didaktischen Potenzial siehe ebd., S. 1-11. 


\section{Zur Percy-Jackson-Pentalogie von Rick Riordan}

Die Serie des US-amerikanischen Schriftstellers Rick Riordan erschien von 2006 bis 2011 im Carlsen-Verlag (Hamburg) und umfasst fünf Bände: ${ }^{26}$ Percy Jackson-Diebe im Olymp (2006), Percy Jackson - Im Bann des Zyklopen (2006), Percy Jackson - Der Fluch der Titanen (2010), Percy Jackson - Die Schlacht um das Labyrinth (2011) und Percy Jackson - Die letzte Göttin (2011). ${ }^{27}$

Der zu Beginn zwölfjährige Percy Jackson ist ein Halbgott, denn er hat eine sterbliche Mutter und einen unsterblichen Vater: Poseidon, der nach einem Pakt mit seinen Brüdern Zeus und Hades eigentlich keine sterblichen Kinder haben sollte. Wie alle „Halbblute“ muss Percy sich gegen die Angriffe von Monstern zur Wehr setzen, die es auf Halbgötter abgesehen haben. In einem Trainingscamp für Halbblute wird Percy zum Heros ausgebildet und auf verschiedene Missionen geschickt. Er kämpft mit seiner Freundin Annabeth - Tochter der Athene und damit ebenfalls Halbgöttin - und dem Satyr Grover gegen Kronos, den Anführer der Titanen, der einen Aufstand gegen den Olymp plant. Einer Prophezeiung zufolge kommt Percy eine wichtige Rolle in diesem Krieg zu.

Im ersten Teil erfährt Percy, dass er ein Halbgott ist, und wird ins „Camp Half-Blood“ eingeführt. Seine Mutter Sally wurde von einem Minotaurus getötet, so macht er sich mit Annabeth und Grover auf in die Unterwelt, um sie zu retten. Dort angekommen, wird er beschuldigt, den Herrscherblitz des Zeus gestohlen zu haben, der sich wie durch Zauberhand in seiner Tasche befindet. In Wahrheit ist Luke - ein Sohn des Hermes, der sich Kronos angeschlossen hat - für den Diebstahl verantwortlich. Gerade noch rechtzeitig kann Percy Zeus seinen Blitz zurückbringen; ihm gelingt es sogar, seine Mutter zu retten.

Im zweiten Teil versuchen Annabeth, Percy und Percys Halbbruder Tyson, Grover zu retten, der auf der Suche nach Pan, dem Gott der Wildnis, von dem Zyklopen Polyphem gefangen genommen wurde. Bei ihrer Mission entdecken sie, dass Luke auf dem Schiff Prinzessin Andromeda eine Armee für Kronos aufstellt, wobei Letzterer mit jedem Rekruten mehr an Lebenskraft gewinnt. Bei der Rettung von Grover nehmen Percy und seine Freunde ein Gol-

\footnotetext{
${ }^{26}$ Die englischsprachigen Originalausgaben erschienen bei Hyperion Books (New York) unter den Titeln Percy Jackson and the Olympians - The lightning Thief (2005), Percy Jackson and the Olympians - The Sea of Monsters (2006), Percy Jackson and the Olympians - The Titan's Curse (2007), Percy Jackson and the Olympians - The Battle of the Labyrinth (2008) und Percy Jackson and the Olympians - The Last Olympian (2009).

${ }^{27}$ Die Bände werden im Folgenden unter Verwendung von Siglen zitiert: PJ 1, PJ 2, PJ 3, PJ 4 und PJ 5.
} 
denes Vlies mit, das die Macht besitzt, aus Thalia - einer Tochter des Zeus, die in einen Baum verwandelt wurde - wieder einen Menschen zu machen. ${ }^{28}$

Im dritten Band stoßen die Geschwister Bianca und Nico di Angelo, ebenfalls Halbgötter, zu Percy und seinen Freunden. Annabeth und die Göttin Artemis werden entführt. Die Jägerinnen der Artemis sowie Percy, Grover und Bianca wollen die beiden retten, Letztere kommt im Kampf mit einem Metallriesen ums Leben. Nach einem Gefecht zwischen Percy und seinen Freunden mit den Lakaien des Kronos gelingt es Luke, zu entkommen. Es stellt sich heraus, dass Nico ein Sohn des Hades ist. Aus Trauer um seine Schwester flieht er aus dem HalbblutCamp.

In Die Schlacht um das Labyrinth befürchten Percy und seine Freunde, dass die Armee des Kronos durch das Labyrinth des Dädalus direkt ins Camp gelangen könnte. So machen sich die Kinder auf die Suche nach Dädalus' Werkstatt, um den Faden der Ariadne zu beschaffen, der die Orientierung im Labyrinth ermöglicht. Sie gelangen zum Gott Pan und erleben mit, wie er stirbt. Letztendlich gelingt es ihnen, Dädalus zu überreden, auf ihrer Seite zu kämpfen, sodass sie die Schlacht im Camp für sich entscheiden können.

Im letzen Band entflammt der Krieg zwischen dem Olymp und Kronos. Die Götter mobilisieren alle Kräfte, um sich gegen Typhon, ein Monster des Kronos, zu verteidigen; der Olymp ist nahezu schutzlos. Kronos - der sich in Lukes Körper verbirgt - marschiert in New York ein und greift den Olymp an. Der Kampf gegen ihn scheint aussichtslos, aber Annabeth überzeugt Luke, sich selbst und damit Kronos zu töten.

Percy Jackson wurde vonseiten der Presse als „Nachfolger“ ${ }^{29}$ und ,göttliche[r] Bruder von Harry Potter “30 bezeichnet. Die Pentalogie wurde in über 40 Ländern verkauft. ${ }^{31}$ In Deutschland schafften es alle Titel in die Top Ten der Spiegel-Bestsellerliste Jugendbuch. Die Schlacht um das Labyrinth erreichte 2011 den zweiten Platz, Die letzte Göttin sogar den ersten. ${ }^{32}$ Die Bücher wurden indes nicht in die Liste Hardcover/Belletristik aufgenommen. Pra-

\footnotetext{
${ }^{28}$ Riordans Erzählung spielt auf antike Prätexte vom Goldenen Vlies an. Siehe auch Kapitel 5.4.2.

29 Susanne Klingenstein: Wenn das Zeus wüsste. in: Frankfurter Allgemeine Zeitung, 17.2.2010; online: www.faz.net/aktuell/feuilleton/jugendliteratur-wenn-das-der-zeus-wuesste-1939164.html (18.11.2014).

${ }^{30}$ Zit. wie Focus Online. Verglichen werden hier vor allem die Verfilmungen. www.focus.de/kultur/kino_tv/filmstarts/tid-17086/filmstarts-vom-11-februar-percy-jackson-diebe-imolymp_aid_476326.html (18.11.2014).

${ }^{31}$ www.carlsen.de/urheber/rick-riordan/17714 (18.11.2014).

${ }^{32} \mathrm{Zu}$ den Platzierungen von Diebe im Olymp siehe www.buchreport.de/bestseller/bestseller_einzelansicht.htm?no_cache=1\&tx_bestseller_pi1[isbn] $=978355155$ 4376 (18.11.2014); zu den Platzierungen von Im Bann des Zyklopen siehe
} 
xis Deutsch präsentierte einen Unterrichtsvorschlag von Ines Heiser zu dem Werk für die Jahrgänge sieben und acht. ${ }^{33}$

\section{Zur Panem-Trilogie von Suzanne Collins}

Die Serie Die Tribute von Panem der US-amerikanischen Schriftstellerin Suzanne Collins erschien im Hamburger Oetinger-Verlag. ${ }^{34}$ Die drei Bände heißen: ${ }^{35}$ Die Tribute von PanemTödliche Spiele (2009), Die Tribute von Panem - Gefährliche Liebe (2010) und Die Tribute von Panem - Flammender Zorn (2011). ${ }^{36}$

Die Nation Panem, die das zukünftige Nordamerika darstellt, ist in zwölf Distrikte unterteilt, die vom „Kapitol“ (TS, S. 10) regiert werden. Ursprünglich existierte ein 13. Distrikt, der gegen das Kapitol aufbegehrte, der Aufstand wurde jedoch von den Machthabern niedergeschlagen, das Gebiet zerstört. Seither gibt es die „Hungerspiele“ (TS, S. 11), die einschüchternd wirken sollen. In jedem Distrikt werden jährlich zwei Kinder, Tribute genannt, ausgewählt - ein Junge und ein Mädchen, jeweils zwischen 12 und 18 Jahren -, die alle in einer Hightech-Arena gegeneinander kämpfen müssen, bis nur noch ein Tribut übrigbleibt.

In Tödliche Spiele will Katniss Everdeen ihre kleine Schwester Primrose vor den Spielen bewahren und meldet sich freiwillig für Distrikt 12. Daneben wird der Junge Peeta als Tribut ausgewählt. Haymitch, ein ehemaliger Sieger der Spiele, bereitet die beiden auf den Wettkampf vor. In der Arena geben sich Katniss und Peeta als Liebespaar aus, um die Herzen der Zuschauer und Sponsoren zu gewinnen, die ihnen lebenswichtige Hilfsmittel zukommen lassen können. Die Strategie geht auf, sie setzen sich gegen die anderen Tribute durch und schaffen es sogar durch eine List, beide als Sieger hervorzugehen - sehr zum Ärger des Kapitols.

www.buchreport.de/bestseller/bestseller_einzelansicht.htm?no_cache=1\&tx_bestseller_pi1[isbn] $=978355155$ 4383 (18.11.2014); zu den Platzierungen von Der Fluch des Titanen siehe www.buchreport.de/bestseller/bestseller_einzelansicht.htm?no_cache=1\&tx_bestseller_pi1[isbn] $=978355155$ 5540 (18.11.2014); zu den Platzierungen von Die Schlacht um das Labyrinth siehe www.buchreport.de/bestseller/bestseller_einzelansicht.htm?no_cache=1\&tx_bestseller_pi1[isbn] $=978355155$ 4390 (18.11.2014); zu den Platzierungen von Die letzte Göttin siehe

www.buchreport.de/bestseller/bestseller_einzelansicht.htm?no_cache=1\&tx_bestseller_pi1[isbn] $=978355155$ 5854 (18.11.2014).

${ }^{33}$ Heiser (2014), S. 33-40.

${ }^{34}$ Zum Zeitpunkt der Publikation des ersten Teils lagen bereits alle Bände von Harry Potter in deutscher Sprache vor.

${ }^{35}$ Die englischsprachige Erstausgabe erschien beim Scholastic-Verlag, New York: The Hunger Games (2008), The Hunger Games - Catching Fire (2009) und The Hunger Games - Mockingjay (2010).

${ }^{36}$ Im Folgenden zitiert mit den Siglen: TS, GL und FZ. 
Im zweiten Teil erregt Katniss immer mehr den Zorn des Kapitols, da sie mittlerweile zum Symbol der Widerstandsbewegung in Panem geworden ist. Um die Unruhen im Volk unter Kontrolle zu bekommen, entschließen sich die Spielmacher dazu, ein außerplanmäßiges , $J u$ bel-Jubiläum “ (GL, S. 392) auszurichten, bei dem die Sieger der vergangenen Spiele gegeneinander antreten, so auch Katniss und Peeta, die nun erneut um ihr Leben kämpfen müssen. Doch im Untergrund formiert sich bereits eine Revolution, der auch einige ehemalige Tribute angehören. Sie helfen Katniss dabei, erneut aus der Arena zu entkommen. Peeta wird vom Kapitol entführt und festgehalten. Katniss' Heimatdistrikt 12 wird dem Erdboden gleichgemacht, in weiteren Distrikten herrscht Krieg.

In Flammender Zorn versteckt sich Katniss gemeinsam mit den Rebellen im ehemaligen Distrikt 13, der als zerstört gilt. Sie kommt ihrer Rolle als Anführerin zunächst nur halbherzig nach, bis sie Peeta in einem Fernsehinterview sieht, bei dem er als Fürsprecher des Kapitols agiert. So stellt sie die Untergrundbewegung vor die Wahl: Nur unter der Bedingung, dass Peeta, der in Ungnade gefallen ist, gerettet wird, will sie weiterhin die Leitfigur der Revolution spielen. Es gelingt den Rebellen, Peeta zu befreien, der jedoch einer Gehirnwäsche unterzogen wurde und versucht, Katniss zu töten, die gemeinsam mit anderen Aufständischen in den Untergrund des Kapitols flieht. Ihre Schwester Primrose kommt bei einem Bombenangriff ums Leben. Schließlich nehmen die Revolutionäre das Kapitol ein und töten sowohl dessen Präsidenten als auch die Präsidentin des Distrikts 13, welche zuvor geplant hatte, Katniss aus dem Weg zu räumen. Katniss und Peeta beginnen ein neues Leben im wiederaufgebauten Distrikt 12 und werden Eltern.

Die Welt titelte 2012: „Tribute von Panem lösen Harry Potter ab“, die Buchserie sei bei Amazon bereits öfter verkauft worden als Rowlings Werke. ${ }^{37}$ Die Hannoversche Allgemeine brachte Collins' Bücher mit Harry Potter, der Tintenwelt-Trilogie sowie der Bis(s)-Serie in Verbindung. ${ }^{38}$ Weltweit wurden sie in 51 Sprachen übersetzt; allein die Auflage der amerikanischen Originalausgabe umfasst mehr als 65 Millionen Exemplare. ${ }^{39}$ Im Januar 2012 hatten sich die deutschen Ausgaben bereits mehr als 700000 Mal verkauft. ${ }^{40}$ Alle Bänden der Pa-

\footnotetext{
${ }^{37}$ Die Welt, Feuilleton Kompakt, 18.8.2012: www.welt.de/print/die_welt/kultur/article108673487/FeuilletonKompakt.html (18.11.2014).

${ }^{38}$ Martina Sulner: Suzanne Collins’ zweiter „Tribute von Panem“-Roman erscheint. In: Hannoversche Allgemeine, 15.5.2010; www.haz.de/Nachrichten/Kultur/Uebersicht/Suzanne-Collins-zweiter-Tribute-von-PanemRoman-erscheint (18.11.2014).

${ }^{39}$ Die Angabe bezieht sich auf alle Bände und sowohl digitale als auch gedruckte Ausgaben. Pressemappe des amerikanischen Scholastic-Verlages; http://mediaroom.scholastic.com/hungergames (18.11.2014).

${ }^{40}$ Oetinger-Verlag (Hrsg.): Suzanne Collins. Die Tribute von Panem. Informationen für die Presse;
} 
nem-Trilogie schafften es in die Top Ten der Bestsellerlisten Jugendbuch und Hardcover/Belletristik von Der Spiegel. Auf Letzterer belegte Tödliche Spiele 2012 den zweiten Platz, Gefährliche Liebe und Flammender Zorn sogar jeweils Platz $1 .^{41}$ Gabriele Fenkart unterbreitete am Beispiel der Romane Vorschläge zur Schreib- und Leseförderung und entwarf Unterrichtsszenarien, die am Selbstkonzept der Schülerinnen und Schüler ansetzen. ${ }^{42}$ Eva Wiemers besprach das Werk als jugendliterarische Dystopie und lotete die Lernchancen im Deutschunterricht aus. ${ }^{43}$ Rank griff Collins' Serie in einem Aufsatz zu zeitgenössischen Dystopien auf. ${ }^{44}$ Birgit Schlachter widmete sich der Katniss-Figur und stellte Bezüge zu einer Vielzahl von Prätexten her, die in der Panem-Trilogie aufgerufen werden. ${ }^{45}$

\section{Zur Edelstein-Trilogie von Kerstin Gier}

Die Serie der deutschen Autorin Kerstin Gier umfasst die Bände Rubinrot-Liebe geht durch alle Zeiten (2009), Saphirblau - Liebe geht durch alle Zeiten (Januar 2010) und Smaragdgrün-Liebe geht durch alle Zeiten (Dezember 2010), erstmals erschienen im Arena-Verlag Würzburg. ${ }^{46}$

In der Edelstein-Trilogie ranken sich diverse Legenden und Prophezeiungen um zwölf „, GenTräger" (RR; S. 11), die in der Zeit reisen können, darunter die sechzehnjährige Gwendolyn Shepherd sowie der gutaussehende Gideon de Villiers, in den sie sich unsterblich verliebt. Ebenso der Graf von Saint Germain, Gründer der Loge, die sich um die Einhaltung des Kontinuums - die Chronologie der Geschichte - bemüht. Jeder Zeitreisende wird in der Geschichte mit einem Edelstein assoziiert, Gwendolyn etwa mit einem Rubin, sie hat einen besonderen Status im „Kreis der Zwölf“ und ist bemüht, die Geheimschriften des Grafen von Saint Germain zu deuten und damit ihr vorbestimmtes Schicksal zu verstehen.

www.dietributevonpanem.de/fileadmin/user_upload/Panem/Pressemappe_Collins_Die_Tribute_von_Panem. pdf (18.11.2014).

${ }^{41} \mathrm{Zu}$ den Platzierungen von Tödliche Spiele siehe: www.buchreport.de/bestseller/bestseller_einzelansicht.htm?no_cache=1\&tx_bestseller_pi1[isbn] $=978378913$ 2186 (18.11.2014); zu den Platzierungen von Gefährliche Liebe siehe:

www.buchreport.de/bestseller/bestseller_einzelansicht.htm?no_cache=1\&tx_bestseller_pi1[isbn]=978378913 2193 (18.11.2014); zu den Platzierungen von Flammender Zorn siehe:

www.buchreport.de/bestseller/bestseller_einzelansicht.htm?no_cache=1\&tx_bestseller_pi1[isbn] $=978378913$ 2209 (18.11.2014).

${ }^{42}$ Fenkart (2013), S. 30-34.

${ }^{43}$ Wiemers (2013).

${ }^{44}$ Rank (2014), S. 1.

${ }^{45}$ Vgl. Schlachter (2014), insbesondere S. 5.

${ }^{46}$ Bei Publikation des ersten Bandes waren bereits alle Teile der Potter-Serie in deutscher Sprache veröffentlicht. Giers Texte werden im Folgenden mit diesen Siglen zitiert: RR, SB und SG. 
Im ersten Teil erfährt Gwendolyn, dass sie das Zeitreisegen besitzt und nicht, wie alle in ihrer Familie vermutet hatten, ihre Cousine Charlotte. Die Wächter der Loge bringen ihre bislang unkontrollierten Zeitsprünge mithilfe des Chronografen unter Kontrolle, einer mysteriösen Apparatur, die das gezielte Springen in der Zeit ermöglicht. Zudem wird Gwendolyn durch entsprechenden Unterricht auf ihre Reisen in die Vergangenheit vorbereitet. Gideon begleitet sie auf ihren Abenteuern. Die Wächter beauftragen die beiden, Blut der zwölf Genträger zu beschaffen, das in den Chronograf eingelesen werden soll. Es stellt sich heraus, dass Lucy und Paul - Zeitreisende der Vorgängergeneration - in der Vergangenheit einen Chronografen gestohlen haben, in dem bereits fast alle Blutproben zusammengetragen waren.

In Saphirblau sollen Gwendolyn und Gideon ins 18. Jahrhundert zurückreisen, um den Grafen von Saint Germain zu treffen. Dies bedarf mehrerer Vorbereitungen. Gwendolyn beschließt, den Machenschaften des Grafen und den Geheimnissen von Paul und Lucy nachzugehen. Sie trifft ihren Großvater Lucas Montrose in der Vergangenheit und verabredet sich mit ihm zu regelmäßigen Treffen, um Informationen mit ihm auszutauschen. Auch der Wasserspeierdämon Xemerius und ihre Freundin Leslie unterstützen sie bei den Recherchen. Als der Graf ihr erzählt, dass Gideon ihr seine Gefühle nur vorgaukele, verfällt sie in Liebeskummer.

Im letzten Teil findet Gwendolyn schließlich den gestohlenen Chronografen in der Gegenwart. Sie besucht weiterhin die Loge, auch wenn das Verhältnis zu Gideon angespannt ist und sie mittlerweile stark an den guten Absichten des Grafen zweifelt. Auf einer ihrer Reisen in die Vergangenheit besuchen Gideon und sie einen Ball, bei dem sie tödlich verletzt wird. Da sie dennoch überlebt, kommt Gideon zu dem Schluss, dass Gwendolyn unsterblich ist. Aufgewühlt gesteht er ihr seine Liebe. Zusammen bringen die beiden in Erfahrung, dass Lucy und Paul Gwendolyns Eltern sind und die Welt vor einem großen Unheil bewahren wollten, indem sie die Machenschaften des Grafen boykottierten. Dieser spekuliert nämlich darauf, den Blutkreislauf in einem Chronografen zu schließen und so ein Pulver herzustellen, Stein der Weisen genannt, das ihn unsterblich macht. Zudem trachtet er nach Gwendolyns Leben. Es stellt sich heraus, dass er in der Gegenwart als ihr Lehrer Mr. Whitman agierte, um sie unbemerkt observieren zu können. Es gelingt Gideon und Gwendolyn, den Stein der Weisen herzustellen und den Grafen zu stellen. So ist auch Gideon am Ende unsterblich, nachdem er die Substanz zu sich genommen hat. Das glückliche Paar kann für immer zusammen sein.

Der Erfolg von Giers Büchern wurde in der Presse mit der allgemeinen Popularität von AllAge-Fantasy in Verbindung gebracht, der nach Harry Potter Einzug gehalten habe. Kultur- 
Spiegel lobte die „,gut erzählte[n] Geschichten“, die im Anschluss an die „Harry PotterHysterie“ den „,Nerv der Zielgruppe“ träfen. Giers Romane lägen ,Klassen über den Bis(s)Bestsellern der US-Amerikanerin Stephenie Meyer “. ${ }^{47}$ Die Edelstein-Trilogie wurde in fast 30 Sprachen übersetzt, bereits im März 2013 hatte sich die Serie millionenfach verkauft, ${ }^{49}$ allein in Deutschland mehr als zwei Millionen Mal. ${ }^{50}$ Alle drei Bände standen insgesamt über 350 Wochen auf der Spiegel-Bestsellerliste. Smaragdgrün-Liebe geht durch alle Zeiten belegte 2010 Rang 1 in der Kategorie Hardcover/Belletristik, Saphirblau - Liebe geht durch alle Zeiten den dritten Platz. ${ }^{51}$

In der deutschsprachigen Forschung greift Schlachter die Edelstein-Trilogie in ihrem Aufsatz für die Zeitschrift Leseräume auf, sie betrachtet ihn vor allem als „populärkulturelles Gewe$b e^{\text {،.52. }}$.

\subsection{Zu Potter-Nachahmern und Potter-Nachfolgern}

Bereits während der Publikation der Harry-Potter-Bücher, vor allem in der Wartezeit auf den nächsten Band, kam ein Diskurs ${ }^{53}$ auf, in dessen Zuge verschiedene Neuerscheinungen auf dem Jugendbuchmarkt erst als „Ersatzbücher"54, als „Nachahmer“ oder „Nachfolger“ bezeichnet wurden. ${ }^{55}$ Auch in der Forschung wurde unmittelbar auf die Anlehnung der Autoren

47 Christoph Dallach: Rubinrot, Saphirblau, Smaragdgrün \& 2 x Silber. In: KulturSpiegel 9 (2014); www.spiegel.de/spiegel/kulturspiegel/d-128809895.html (18.11.2014).

49 Hörbuchjournal (März 2013), hrsg. von MetaGIS-Systems, S. 22; www.metagis.de/fb03/HbJ03-2013.pdf (18.11.2014).

50 Die Angabe entstammt einem Artikel der dpa vom 7.8.2014, beispielsweise einsehbar unter www.svz.de/nachrichten/deutschland-welt/kultur/rubinrot-trilogie-millionenfach-verkauft-id7346851.html (18.8.2014).

${ }^{51} \mathrm{Zu}$ den Platzierungen von Rubinrot siehe:

www.buchreport.de/bestseller/bestseller_einzelansicht.htm?no_cache=1\&tx_bestseller_pi1[isbn]=978340106 3348 (18.11.2014); zu den Platzierungen von Saphirblau siehe:

www.buchreport.de/bestseller/bestseller_einzelansicht.htm?no_cache=1\&tx_bestseller_pi1[isbn]=978340106 3478 (18.11.2014); zu den Platzierungen von Smaragdgrün siehe:

www.buchreport.de/bestseller/bestseller_einzelansicht.htm?no_cache=1\&tx_bestseller_pi1[isbn] $=978340106$ 3485 (18.11.2014).

${ }^{52}$ Schlachter (2014), S. 3 f.

${ }^{53}$ Diskurse werden hier verstanden als „System [e] des Denkens und Argumentierens“, denen ein gemeinsamer „Redegegenstand“ bzw. ein gemeinsames Thema zugrundeliegt. Titzmann (1991), S. 406 und Karg (2005),

S. 16 f. Sie sind ,Komplexe, die sich aus Aussagen und den Bedingungen und Regeln ihrer Produktion und Rezeption in einem bestimmten Zeitraum zusammensetzen". Winko (1996a), S. 464.

${ }^{54}$ Siehe beispielsweise RP Online, wo eine Buchhändlerin Lesetipps für Potter-Fans gibt: www.rponline.de/kultur/buch/was-kommt-nach-harry-potter-aid-1.1593911 (7.5.2014), oder die 85 Titel starke Bücherliste „Was soll ich nach Harry Potter lesen?“ von LovelyBooks: www.lovelybooks.de/buecher/fantasy/Was-soll-ich-nach-Harry-Potter-lesen--464620402/ (7.5.2014).

${ }^{55}$ Beispielsweise verhandelte Focus 2008 Stephenie Meyers Twilight-Saga als langersehnte „Potter-Nachfolge“, die schon vor Abschluss der Potter-Heptalogie große weltweite Erfolge zu verzeichnen hatte. Der Artikel hebt vor allem auf die ähnlichen Marketingstrategien ab. www.focus.de/kultur/buecher/brandsbuecher/stephenie-meyer-schauderhafte-potter-nachfolge_aid_323230.html (6.5.2014). 
an Harry Potter hingewiesen: „In der Tat schießen Potter-Adaptationen wie Pilze aus dem Boden“.56; ,,[d] er Markt wurde mit neuen Potters überschwemmt. “57 Das begriffliche Inventar des Diskurses war facettenreich und reichte von positiv-assoziierten Titulierungen wie ,,deutsche[] J. K. Rowling“"58 für Cornelia Funke bis zu negativen Bezeichnungen wie „Potter clones “59, „,Fast-Plagiat“, „Mini-Potter“ oder „Anti-Potter“60. So kann man zwar konstatieren, dass es Teildiskurse gab, in denen die Parallelen positiv bewertet respektive die ähnliche literarische Leistung und der ähnliche Erfolg zum Tertium Comparationis erhoben wurden, in größerem Umfang, vor allem in den Massenmedien, aber wurden die auffälligen Analogien negativ gesehen und den Autoren mangelnde Kreativität vorgeworfen. ${ }^{61}$ Diese sahen sich in der Regel in Interviews oder Feuilletonartikeln mit kritischen Fragen konfrontiert und wurden nicht selten dazu aufgefordert, Stellung zu beziehen. Ihnen wurde vorgeworfen, dass sie Rowlings Ideen sowie ihr innovatives Erfolgskonzept unrechtmäßig kopierten. ${ }^{62}$ In der Regel wies man die Unterstellung nicht nur zurück, sondern bestritt auch vehement jede Ähnlichkeit. Eoin Colfer ${ }^{63}$ beispielsweise gab in Bezug auf seine Artemis-Fowl-Serie folgendes Statement ab, um seine eigenständige Leistung zu betonen: ,, Ich will nicht Harry Potter einholen oder Rowlings Bücher imitieren. Die Bücher sind - sowohl was den Plot, Stil und die Figuren betrifft-vollkommen verschieden. “64

\section{Potter-Nachahmer in der Forschung}

In der deutschsprachigen Potter-Forschung setzte sich Katrin Manz zunächst in einem Aufsatz aus dem Jahre 2008, dann in ihrer Dissertation 2011 mit Potter-Nachahmern auf dem deutschen Buchmarkt auseinander. ${ }^{65}$ In „Die Post-Potter-Ära. Ein Blick auf Ersatzlesestoffe und

\footnotetext{
${ }^{56}$ Elstner (2004), S. 8.

${ }^{57}$ Bergenthal (2008), S. 363.

${ }^{58}$ Vgl. S. 8, Fußnote 7.

${ }^{59}$ Beckett (2009), S. 115.

${ }^{60}$ Zit. wie Elstner (2004), S. 4 und S. 7, der sich auf eine Veröffentlichung im Buchjournal bezieht, die heute nicht mehr im Internet aufgerufen werden kann.

${ }^{61}$ Bei literaturkritik.de etwa wurde Nimmos Charlie-Bone-Serie in einem Zuge mit „Trittbrettfahrern“ genannt, die sich am Potter-Konzept bereicherten. Die Nähe zu Harry Potter sei ,fast unverschämt": literaturkritik.de/public/rezension.php?rez_id=6560 (7.5.2014).

${ }^{62}$ Die Vorstellung, dass hinter Rowlings Texten ein literarisches Konzept steht, das ihren Erfolg erklärt, greifbar und imitierbar ist, wird in vielen Beiträgen zu Harry Potter laut. Siehe beispielsweise Elstner (2004), S. 3-11; Jelinek (2006) und Rosebrock (2001).

${ }^{63}$ Eoin Colfer wurde häufig des Ideenklaus bezichtigt. Beckett (2009), S. 115.

${ }^{64}$ Aus einem Interview mit Nicola Bardola. In: Eselsohr 12 (2001), S. 29.

${ }^{65}$ Auch Heidi Lexe hat sich mit Thema auseinandergesetzt: „,Der globale Erfolg des Zauberlehrlings mit der blitzförmigen Narbe auf der Stirn hat jedoch sehr wohl den kinderliterarischen Markt verändert: [...] Und natürlich wird allerorts gehext und gezaubert: Allein die Durchsicht der Verlagsprogramme aus dem vergangenen Herbst eröffnet den Blick auf mehr als 50 Texte, die im Titel mit dem entsprechenden Codewort operieren. "Lexe (2004), S. 28.
} 
ihre Machart“ im Sammelband Harry, hol schon mal den Besen! Ein Kehraus nach zehn Potter-Jahren vergleicht sie vier Titel mit Harry Potter in Bezug auf textexterne Eigenschaften und ,,dominante Motive“: ${ }^{66}$ Jenny Nimmos Charly Bone und das Geheimnis der sprechenden Bilder (2003) ${ }^{67}$, Henry H. Neffs Schule der Magier - Das geheime Portal (2008), Angle Sages Septimus Heap - Magyk (2005) und Dean Loreys Monsterjäger Akademie - Das Portal des Barakkas (2008). Folgende Analogien stehen bei der Analyse im Fokus:

- problematische familiäre Verhältnisse

- Existenz von Primär- und Sekundärwelt

- Entdecken von besonderen (magischen) Fähigkeiten

- Besuch eines (Zauberer-)Internats

- Knüpfen von Freundschaften

- Bekanntschaft mit magischen Wesen

- (persönliche) Bedrohung durch das Böse

- Personifizierung des Bösen in einer „Leitfigur“

- Kampf und (vorläufiger) Sieg über das Böse ${ }^{68}$

Erkennbar ist, dass Manz, abgesehen vom Kriterium der Primär- und Sekundärwelt, weniger Textstrukturen als vielmehr Textmotive analysiert. Die Auswahl wird allerdings nicht hinreichend erläutert, ebenso wenig die Wahl des Korpus. ${ }^{69}$ Neben Ähnlichkeiten im Plot und den obigen Motiven verweist sie auf paratextuelle Ähnlichkeiten der Covergestaltung und der Titel. Sie kommt zu dem Ergebnis, dass Harry Potter den Buchmarkt maßgeblich beeinflusst habe und dass bei 75 Prozent der von ihr untersuchten Bücher - das heißt in diesem Fall: in drei Werken - sämtliche Motive, wenn auch in unterschiedlicher Ausprägung, vorkämen, lediglich das Motiv der Koexistenz von Primär- und Sekundärwelt fehle in einem der betrachteten Bücher. ${ }^{70}$

In ihrer Dissertation betrachtet Manz rund 200 Texte, unter denen sie fünf Titel als direkte Potter-Nachahmer identifiziert, ${ }^{71}$ die ,, außerhalb wissenschaftlicher Untersuchungen als Plagiat bezeichnet werden können “72. Auch hier legt sie nicht offen, nach welchen Kriterien genau ihre - wenngleich intuitiv nachvollziehbare - Beurteilung bzw. wertende (Gattungs-)In-

\footnotetext{
${ }^{66}$ Manz (2009), S. 68.

${ }^{67}$ Elstner (2004) weist ebenfalls auf inhaltliche Ähnlichkeiten zwischen Harry Potter und Charly Bone hin.

${ }^{68}$ Manz (2009), S. 68.

${ }^{69}$ Vgl. ebd.

${ }^{70}$ Vgl. Manz (2009), S. 84.

${ }^{71}$ Manz (2011), S. $141 \mathrm{f}$.

${ }^{72}$ Manz (2011), S. 136.
} 
terpretation zustande kommt. ${ }^{73}$ In ihrem Aufsatz reflektiert Manz selbst die Schwierigkeiten eines „objektiven“ inhaltlichen Vergleichs zweier Texte und betont, dass sie bei der Auswahl der Motive bewusst abstrahiert und sie „etwas weiter gewählt “ habe, da man exakt dieselben Umstände ,, bei den untersuchten Titeln kaum finden“ “werde, ,, da ein gewisser Spielraum der Handlung auch bei den Nachahmern (zum Glück) noch wahrgenommen wird “. ${ }^{74}$ Die Fragen, wie stark es zu abstrahieren gilt und welche Inhalte genau das „Wesen“ eines Textes ausmachen, kann Manz (modellbedingt) nicht beantworten. Ihre Ausführungen zeigen deutlich, dass es aus literaturwissenschaftlicher Perspektive höchst problematisch ist, inhaltliche Parallelen zwischen Texten systematisch aufzuzeigen, um eine Anlehnung oder gar Nachahmung eines erfolgreichen Prätexts plausibel zu belegen. Dies liegt schlichtweg daran, dass die Wahl der Parameter immer einer persönlichen Entscheidung unterliegt und die Reduktion auf die berücksichtigten Motive somit stets als exegetisch zu gelten haben. „Objektive“ dominante Motive gibt es solcherart nicht a priori, vielmehr sind sie das Ergebnis einer Interpretation.

\section{Potter-Nachfolger vs. Potter-Nachahmer: Rick Riordans Percy Jackson}

Anders als bei Manz soll es in dieser Arbeit in erster Linie nicht um inhaltliche Ähnlichkeiten zwischen Harry Potter und den Texten des Korpus gehen, der Blick richtet sich primär auf die gattungskonstitutiven Eigenschaften, welche Ähnlichkeiten struktureller Art offenbaren. Das Phänomen, dass Rowlings Serie eine Vielzahl von Büchern nach sich gezogen hat, die frappierende inhaltliche Parallelen aufweisen, bleibt hier somit peripher. Eine Gattungsdiskussion scheint in diesen Fällen unnötig, da trivial.

Mit Percy Jackson wurde ein Text in das Korpus aufgenommen, der sowohl strukturell als auch inhaltlich stark an Harry Potter erinnert und damit verdeutlicht, dass sich beides gegenseitig natürlich nicht ausschließen muss. Riordans Werk kann dementsprechend sowohl als Potter-Nachfolger als auch als Potter-Nachahmer betrachtet werden, je nachdem welchen Eigenschaften man Aufmerksamkeit schenkt und wie diese ausgelegt werden. Inhaltliche Analogien, die auf objektive Texteigenschaften verweisen, werden im Folgenden kurz vorgestellt, wenngleich sie hier nur eine untergeordnete Rolle spielen werden. Die Bezugnahme auf Rowlings Text ist als Interpretationsvorschlag zu verstehen.

\footnotetext{
${ }^{73}$ Ein Plagiat ist auch als Gattungs- bzw. Genrekategorie zu verstehen, die auf objektive Texteigenschaften abhebt und diese als gattungsweisend interpretiert.

${ }^{74}$ Manz (2009), S. 68.
} 
Percy und Harry ahnen zu Beginn beide nichts von ihren übernatürlichen Fähigkeiten und können nicht einordnen, warum - besonders wenn sie wütend sind - merkwürdige Dinge in ihrer Umgebung passieren: So weiß Percy nicht, wie er es bewerkstelligt hat, dass seine Mitschülerin Nancy Bobofit, die er nicht ausstehen kann, wie durch Zauberhand in einen Brunnen fällt (PJ 1, S. 19 f.). Ebenso ergeht es Harry, der seinem Cousin Dudley einen fürchterlichen Schrecken einjagt, als während eines Zoobesuchs die Glasscheibe des Schlangenterrariums wie durch Zauberhand verschwindet (HP 1, S. 34 ff.).

Bald wird beiden Protagonisten ihre wahre, ,übermenschliche“ Abstammung transparent gemacht: Harry erfährt, dass er als Kind von Zauberern selbst ein solcher ist und zur entsprechenden Ausbildung am Zaubererinternat Hogwarts antreten darf (HP 1, S. 58 ff.), und Percy, dass er Sohn eines Gottes ist und das Ausbildungscamp Half-Blood besuchen soll (PJ 1, S. 35, S. 73 ff.). Ähnlich wie in Hogwarts werden die Schülerinnen und Schüler in „Hütten “ (PJ 1, S. 101 ff., S. 105 ff.) eingeteilt, die jeweils einer Gottheit zugeordnet sind. Ein jeder Camper muss die Unterkunft seines göttlichen Elternteils besuchen, das jeweils mit bestimmten charakterlichen oder auch körperlichen Eigenschaften assoziiert wird. Die Hütten haben genau wie die Häuser in Hogwarts eigene Banner, Farben und Motive (PJ 1, S. 124 f.), und die Bewohner identifizieren sich auch hier mit der Unterkunft. Analog zum Wettkampf um den „Hauspokal“ (HP 1, S. 127) bei Harry Potter treten die insgesamt zwölf Hütten des Camps regelmäßig gegeneinander an und kämpfen um den „Lorbeer“ (PJ 1, S. 129, S. 144 ff.).

Wie Harry in der Zaubererwelt lernt Percy in der Welt der Götter viel Neues kennen: Es gibt Göttergeld (PJ 1, S. 181), Göttermedien (PJ 1, S. 438) und wunderliche Artefakte wie Tarnkappen (PJ 1, S. 182), ebenso phantastische Wesen wie Pegasi (PJ 3, S. 325). Der Olymp liegt im 600. Stock des Empire State Buildings - die Parallele zu Gleis 93/4, ebenfalls in einem real existierenden Gebäude, ist augenscheinlich (HP 1, S. 101) -, und die anderen Menschen wissen nichts von der parallelen Götterwelt (PJ 1, S. 195). Die Wahl der richtigen Waffe gestaltet sich ähnlich kompliziert wie die Wahl des richtigen Zauberstabes von Harry: Insbesondere beim Schwertkampf der Halbgötter ist es wichtig, dass sich das Schwert in der Hand „richtig anfühlt“ (PJ 1, S. 133, S. 186). Percy muss eine Zeit lang suchen, bis er das „richtige“ Schwert gefunden hat, bei dem sich herausstellt, dass nur dieses zu Percy passt (PJ 1, S. 186), wie schon ein besonderer Zauberstab für Harry genau der richtige war (HP 1, S. 96). Als Percy seine große Aufgabe antritt, die Menschheit vor dem schrecklichsten Krieg aller Zeiten zu bewahren, geht er in einem Dreiergespann auf diese Mission: mit Annabeth, die als Tochter Athenes besonders klug und intelligent ist (PJ 1, S. 180, S. 229), und Grover, der zwar 
tapfer und gutherzig ist, aber selten durch Erfolge glänzt (PJ 1, S. 231, S. 294). Beide erinnern stark an Hermine und Ron, die durch ähnliche Eigenschaften charakterisiert werden.

Sowohl Harry Potter als auch Percy Jackson haben einen Antagonisten, der ihnen nach dem Leben trachtet und im Zuge der Handlung zu immer mehr Macht gelangt. Analog zu Lord Voldemort kommuniziert Kronos oftmals mental (PJ 1, S. 428 ff.), auch schart er eine Menge von Gefolgsleuten um sich. Es stellt sich heraus, dass der junge Camp-Bewohner Luke sich für die Seite des Bösen entschieden hat, Kronos' Befehle ausführt, eine Armee für den Titanen zusammenstellt und ihm schließlich sogar seinen Körper als Wirt anbietet (PJ 4, S. 354). Auch Lord Voldemort hat sich in seinem Vasallen Quirrell eingenistet (HP 1, S. 313 ff.) Am Ende beider Serien steht eine große Schlacht, in der die Protagonisten verbissen um den Sieg gegen das Böse kämpfen: Während in Harry Potter sämtliche Statuen in Hogwarts zum Leben erwachen und sich als Rekruten zur Verfügung stellen, aktiviert Annabeth sämtliche Statuen von Manhattan, um die Stadt gegen Kronos’ Armee zu verteidigen (PJ 5, S. 210 f.).

\subsection{Zu literarischen Gattungen und Gattungsmodellen}

Eine literaturwissenschaftliche Gattungsdiskussion, wie sie den Kern dieser Arbeit darstellt, verlangt eine genaue Definition der verwendeten Terminologie sowie die Reflexion des methodischen Vorgehens. Die Begriffe Gattung und Genre sind in der Geschichte der Germanistik auf so unterschiedliche Weise verwendet und diskutiert worden, dass es unerlässlich ist, sich die Diskurse zu vergegenwärtigen. Im Interesse des Forschungsvorhabens soll hier vor dem Hintergrund der unterschiedlichen gattungstheoretischen Positionen ein Überblick darüber gegeben werden, welche Bedeutungen den Begriffen in der literaturwissenschaftlichen Forschung zugeschrieben werden.

\section{Zum Gattungsproblem}

Das sogenannte „Gattungsproblem“ gilt nach Wolfgang Kayser als eines der ältesten Probleme der Literaturwissenschaft überhaupt. ${ }^{75}$ Dabei ging es lange Zeit nicht nur um die Frage, was genau eine Gattung ausmacht und welche textimmanenten Strukturen ein Text aufweisen muss, um zu einer bestimmten Gattung zu zählen, sondern auch darum, ob man überhaupt von Gattungen sprechen sollte, ob sie also als existent zu betrachten sind. Die Diskurse, die zu den unterschiedlichen Zeiten geführt wurden, unterscheiden sich somit nicht nur in ihren Ergebnissen, sondern bereits grundlegend in ihrer Fragestellung, zudem in der Art und Weise, wie

\footnotetext{
${ }^{75}$ Kayser (1978), S. 332.
} 
sie mit der Gattungsthematik umgegangen sind. Nach Zymner lassen sich vor allem vier Diskurse ausmachen, die die Geschichte der Gattungsforschung geprägt haben: ${ }^{76}$

1. Von der Antike bis ins 18. Jahrhundert hinein dominieren normative Gattungspoetiken die literaturtheoretische Forschung. Während bei Aristoteles noch klar die Ästhetik im Mittelpunkt der Überlegungen steht, ${ }^{77}$ richten sich die Literaten des Klassizismus und der Frühaufklärung eher an festen Regeln aus. Ästhetik spielt nur insofern eine Rolle, als das Einhalten der Regeln als ästhetischer Wert begriffen wird. ${ }^{78}$ So verfassen Gottsched und Opitz sogenannte Anweisungspoetiken, die sich stark an antike Vorbilder anlehnen und die in letzter Konsequenz das Schreiben von Literatur als ein Handwerk ausweisen, das anhand eines Kriterienkatalogs beurteilt werden kann. ${ }^{79}$ Künstlerische Freiheit und Kreativität spielen bei der Produktion und Beurteilung von Literatur eine dementsprechend geringere Rolle. ${ }^{80}$

2. Mitte des 18. Jh. wird der Diskurs um normative durch den um systematische Gattungspoetiken abgelöst. ${ }^{81}$ Nunmehr, spätestens seit Baumgartens Aestetica (1750-1758) ist die philosophische Ästhetik wegweisend, was unweigerlich zu einer Hinwendung zu Prinzipienfragen führt. ${ }^{82}$ So lautet die entscheidende Frage u. a. bei Charles Batteux ${ }^{83}$ nicht mehr, wie Gattungen auszusehen haben, sondern vielmehr, wie sich die bestehenden voneinander unterscheiden, was ihr „Wesen“ ist. Diese neue Perspektive führt dazu, dass die Dichtkunst durch die Kriterien Fantasie und Kreativität eine Aufwertung erfährt und dass in der Gattungsfrage nicht mehr an hierarchischen Strukturen festgehalten wird. Die triadische Einteilung in Lyrik, Epik und Dramatik fällt genau in jene Zeit. Der Gattungsbegriff, der dem neuen Erkenntnisinteresse zugrunde liegt, zeigt sich dabei kaum praxisorientiert. Eine Gattung in diesem Sinne ist eher ein theoretisches Konstrukt, die Spezifika des einzelnen Kunstwerks finden dabei wenig Beachtung. Eine solche philosophische Perspektive hat zur Folge, dass kaum prägnante Aussagen zur Gattungsbestimmung von Einzeltexten getroffen werden kön-

\footnotetext{
${ }^{76}$ Zymner (2003a), S. 7-35.

${ }^{77}$ Aristoteles: Poetik, insbesondere Kap. 1-5 (1447a8-1449b20); Zymner (2003a), S. 10-13.

${ }^{78}$ Vgl. Zymner (2003a), S. 11.

${ }^{79}$ Siehe Opitz $\left(1949^{6}\right)$, insbesondere Kapitel 5, der, obwohl er einen Regelkatalog ausformuliert, dennoch betont, dass er durch diese Regeln und Gesetze niemanden zum Poeten machen könne. In Versuch einer kritischen Dichtkunst versucht Johann Christoph Gottsched, insbesondere im vierten Kapitel, die drei Gattungen Lyrik, Epik und Dramatik zu charakterisieren, dies geschieht hauptsächlich unter Rückbezug auf antike Poetiken.

${ }^{80}$ Horn (1998), S. 10.

${ }^{81}$ Zymner (2003a), S. 17.

${ }^{82}$ Vgl. ebd., S. 16.

${ }^{83}$ Batteux (1751).
} 
nen. Der systematische Gattungsdiskurs ist vielmehr als ein Diskurs auf der Metaebene zu begreifen.

3. Der Kritik an normativen Gattungspoetiken folgt der spekulative Gattungsdiskurs, der Ende des 18. Jahrhunderts aufkommt und bis zum 20. Jahrhundert andauert. ${ }^{84}$ Friedrich Gottlieb Klopstock und Johann Gottfried Herder regen den Gedanken an, dass die generelle Idee einer Gattung als systematischer Oberbegriff möglicherweise problematisch sei und vielmehr die Frage gestellt werden müsse, ob nicht jedes Werk für sich eine Gattung darstellt. ${ }^{85}$ Herder macht dabei auf die Historizität des Begriffs aufmerksam und unterscheidet zwischen ,philosophischen“ und „historischen“, also überzeitlichen und historisch veränderbaren Gattungen. ${ }^{86}$ Der Individualitätsstatus, welcher der Dichtung nun zugesprochen wird, resultiert aus der Prämisse, dass Literatur individuell unterschiedliche Empfindungen hervorruft und dass diese Eigenschaft die entscheidende bei der Betrachtung von Texten sein sollte. So gesehen, geht es stärker um die „Seele“ und den psychologischen Grundcharakter von Dichtung als um objektive äußerliche Formalia. Der rezeptionstheoretische Impetus dieser Vorstellung ist evident. $^{87}$

4. Was sich als Grundgedanke schon seit der Antike im sogenannten Universalienstreit abzeichnet und auch beim spekulativen Gattungsdiskurs mitschwingt, bestimmt spätestens im 20. Jahrhundert maßgeblich die Gattungsdiskussion. ${ }^{88}$ Zur zentralen Frage wird: „Gibt es Gattungen überhaupt?“ Als Fürsprecher, dass Gattungen im ontologischen Sinne nicht existent sind, gilt Benedetto Croce. Das analytische und kategorisierende Denken, das bei der Zuweisung von Gattungen zum Tragen komme, stehe im starken Gegensatz zum individuellen Charakter des Kunstwerks, ja zerstöre sogar, was als Ausdruck höchster Individualität zu gelten habe. ${ }^{89}$ Besonders fehlerhaft sei es, wenn eine Vokabel wie ein Gattungsname den Status einer wissenschaftlichen Definition erhalte. ${ }^{90}$

Auch die poststrukturalistischen Vertreter bestreiten - wenngleich aus anderen Gründen - die Existenz von Gattungen. So argumentiert Magrit Schnur-Wellpot in Anlehnung an Ferdinand

\footnotetext{
${ }^{84}$ Zymner (2003a), S. 22-24.

${ }^{85}$ Ebd., S. 24.

${ }^{86}$ Herder versucht dies u. a. am Beispiel der Ode, der Elegie und der Fabel zu verdeutlichen. Herder: Sämtliche Werke, Bd. XXXII, S. 62. Zymner (2003a), S. 25.

${ }^{87}$ Zymner (2003a), S. 24.

${ }^{88}$ Ebd., S. 34.

${ }^{89}$ Croce $\left(1930^{6}\right)$, S. 10-22.

${ }^{90}$ Ebd., S. 39 f.
} 
de Saussure, dass sich Texte eben nicht durch Gemeinsamkeiten auszeichnen würden, sondern im Gegenteil durch das, was sie voneinander unterscheidet. ${ }^{91}$ Eine Gattung sei demzufolge eine unnütze Vorstellung, verkenne sie doch das eigentlich Entscheidende eines Textes.

\section{Zum Begriff der literarischen Gattung}

Im Rahmen dieser Arbeit wird davon ausgegangen, dass literarische Gattungen kommunikative Modelle darstellen, die ein systematisches Klassifikationsbestreben zum Ausdruck bringen. Dass diese kommunikativen Modelle existieren, kann durch verschiedene Gattungsdiskurse hinreichend belegt werden, sodass die philosophische Frage, ob es Gattungen gibt oder nicht, aus literaturwissenschaftlicher Perspektive obsolet ist. Ein solches Gattungsverständnis findet sich beispielsweise bei Zymner, der darüber hinaus auf die Bedeutung des kulturellen Kontextes verweist, in den die kommunikativen Modelle eingebettet sind. Demnach könne man auch sagen, dass die Frage, ob Gattungen existieren oder nicht, von einem grundsätzlichen Missverständnis zeugen. Denn wesentlich sinnvoller sei es demgegenüber, zu fragen, unter welchen Bedingungen man von Gattungen spreche und welches die kulturell eingeübten und tradierten Regeln der Sprachspiele seien, mithilfe derer man sich über Gattungen verständigt. ${ }^{92}$

\section{Literarische Gattung Eine literarische Gattung ist als Oberbegriff für alle kulturell kon-} ventionalisierten kommunikativen Modelle zu verstehen, ${ }^{93}$ die der Kategorisierung literarischer Texte dienen bzw. die mehrere literarische Texte nach dem Prinzip der Ähnlichkeit zusammenfassen. ${ }^{94}$ Der Begriff subsummiert damit sowohl jene Modelle, die mit „objektiv nachweisbaren“ Kriterien als auch jene, die mit „subjektivinterpretativen“ Kriterien arbeiten. ${ }^{95}$ In der Geschichte der Literaturwissenschaft ha-

\footnotetext{
${ }^{91}$ Schnur-Wellpott (1983), S. 233.

${ }^{92}$ Zymner (2003a), S. 59.

${ }^{93}$ Müller (2010, S. 22) versteht unter dem Begriff wörtlich ,, kulturell konventionalisierte Formen der Strukturierung von Wirklichkeit".

${ }^{94}$ Zymner (2003a), S. 84. Zymner gibt eine Übersicht, nach welchen Kriterien literarische Texte üblicherweise zusammengefasst werden: Ebd., S. 82 ff. Prinzipiell wären aber auch weitere Klassifizierungskategorien denkbar, die auf andere Ähnlichkeiten zwischen Texten abheben. Zu den konventionalisierten Sortierungskriterien gehören nach Zymner u. a. Faktualität/Fiktionalität, Figural, Form, Funktion, Inhalt, Mündlichkeit/Schriftlichkeit, Prosa, Redekriterium, Selbstständigkeit, Stil, Textualität, Umfang und Vers. Vgl. dazu Zymner (2010), Aspekte der literarischen Gattungsbestimmung, Punkt 2 bis 2.13. Gattungen können daher verschiedene Dinge bezeichnen: Sammelbegriffe wie Lyrik, Epik und Dramatik, Klassenbildungen wie Gebrauchsliteratur und fiktionale Literatur, Grundqualitäten wie „das Lyrische“ oder „das Epische“, Schreibweisen wie „das Satirische“ und „das Komische“, historische Textgruppen wie die Verssatire und den Prosaroman, Untergruppen wie die anekdotische Ode oder den Briefroman, metrisch bestimmte Formen wie das Sonett oder das Rondeau. Siehe dazu Fricke (2010a), S. 10.

${ }^{95}$ Angelehnt an Zymner (2003a), S. 59 und Fricke (1981), S. 132 f. Fricke interpretiert diejenigen Kategorien, die auf objektive Eigenschaften abheben, als Textsorten und diejenigen, die auf subjektive abheben, als Genres. Für ihn ist der Begriff der Gattung der Oberbegriff von Textsorte und Genre. Fricke (1981), S. 133.
} 
ben sich einige dieser Modelle sowohl in Laien- als auch in Forschungsdiskursen begrifflich in Sammelnamen manifestiert. ${ }^{96}$ Ein solcher Sammelname bezieht sich in der Regel auf diejenige Eigenschaft der Texte, die vom Sprecher oder Diskursteilnehmer als dominant und damit gattungsweisend betrachtet wird. Der Begriff der Gattung kann auf strukturorientierte Kategorisierungsbestreben bezogen sein, aber etwa auch auf funktionsorientierte, narrative, formale, paratextuelle, wirkungsästhetische, stilistische oder inhaltsorientierte Differenzkriterien abheben, er ist daher insofern unpräzise, als er nichts über das Wesen der Textkategorisierung verrät, in deren Kontext er Verwendung findet. ${ }^{97}$ Gattungen erfüllen eine diskursive Funktion, die von gesellschaftlichen Rahmenbedingungen abhängig ist. ${ }^{98}$

Die Ausgangspunkte und Perspektiven der kommunikativen Modelle können, wie sich zeigen wird, mannigfaltig sein. In jedem Fall sind sie als literarisch diskursive Urteile und Zuordnungsentscheidungen zu begreifen, die signifikant kontextuellen Rahmenbedingungen unterliegen, da sie stets Ausdruck einer gesellschaftlichen und kulturellen Denkform sind. ${ }^{99}$ Bei der Zuweisung eines Textes zu einer literarischen Gattung besteht daher die Notwendigkeit, die literaturhistorische Konstellation genauer anzugeben, in der die Klassifikationsentscheidung getroffen wurde. ${ }^{100}$ Dies ist gerade dann wichtig, wenn ein Werk in anderen gesellschaftlichen Kontexten rezipiert wird. Denn es schreibt sich nicht nur in die Geschichte seines Herkunftslandes ein, sondern auch in die Literaturgeschichte derjenigen Länder, in deren Sprache es übersetzt und gelesen wird. In jedem dieser Länder trifft der Text auf Gattungserwartungen bzw. Gattungsmodelle ${ }^{101}$, die er bestätigt oder von denen er sich absetzt. Letzteres führt dazu, dass er neue bzw. andere Gattungserwartungen schafft. ${ }^{102}$

Die Gattungsdiskussion erfolgt hier dezidiert aus Perspektive des deutschen Sprach- und Kulturraums. ${ }^{103}$ Dementsprechend basiert sie auf deutschsprachigen Textausgaben. ${ }^{104}$ Die Arbeit

\footnotetext{
${ }^{96}$ Ist eine solche Gattung erst einmal (begrifflich) etabliert, kann man von einer institutionalisierten Gattung sprechen. Nach obiger Definition können auch sehr viele Textgattungen ausgemacht werden, die keinen etablierten Sammelnamen besitzen. Zymner (2003a), S. 84.

${ }^{97}$ Vgl. Fußnote 94 und Croce $\left(1930^{6}\right)$, S. 39 f.

${ }^{98}$ Voßkamp geht davon aus, dass Gattungen historisch wachsen und sich infolge des Zusammenspiels von Gattungserwartungen und Werkantworten einer Gesellschaft herauskristallisieren: Voßkamp (1977), S. 30.

${ }^{99}$ Diese Vorstellung macht eine historische Perspektive auf die jeweilige Gattung, die im Fokus des jeweiligen Kapitels steht, unerlässlich.

${ }^{100}$ Voßkamp (1977), S. 29.

${ }^{101}$ Der Begriff wird im nächsten Kapitel definiert.

${ }^{102}$ Vgl. Voßkamp (1977), S. 31 und Schmitz-Emans (2010), S. 111.

${ }^{103}$ Die Einschränkung auf einen Sprach- und Kulturraum ist gerade bei einer Gattungsdiskussion notwendig und sinnvoll, denn die betrachteten Modelle können keine internationale Gültigkeit beanspruchen, da sie als kul-
} 
nimmt vorwiegend diejenigen Texteigenschaften und -interpretationen in den Blick, die in deutschsprachigen Forschungsbeiträgen oder Laiendiskursen in Bezug auf Harry Potter und die Texte des Korpus zum Ausdruck gekommen sind. Auch deutschsprachige Verlage und Online-Dienste werden bei der Gattungsdiskussion mit einbezogen, ebenso wie deutsche FanSeiten und Presseartikel.

\section{Zu Textsorten und Genres}

Angelehnt an Fricke, soll im Folgenden zwischen Textsorte und Genre unterschieden werden.

Textsorte Ob ein Werk einer bestimmten Textsorte angehört, hängt von Merkmalen ${ }^{105} \mathrm{ab}$, die unabhängig vom historischen Kontext identifizierbar sind und damit als objektivgelten können, da die Sinnzuschreibung nicht an zeitabhängige Wahrnehmungs- und Denkmuster gebunden ist. ${ }^{106}$

Genre Die Kategorisierung zu einem Genre richtet sich indes nach Eigenschaften oder Eigenschaftskonstellationen, welche anhand historisch gebundener Wahrnehmungsund Denkmuster eruiert werden und somit oftmals auf die Wirkung oder Funktion eines Textes abheben. ${ }^{107}$ Die Zuweisung ist folglich als Interpretation und somit nicht als wissenschaftlich belegbar zu betrachten, sie kann aber plausibel begründet werden, wenn die Argumentation auf objektiven Texteigenschaften basiert, die als genreweisend gelten dürfen. ${ }^{108}$ Ein Text kann einem Genre nicht angehören, sondern ihm nur zugewiesen bzw. als einem Genre zugehörig empfunden werden. Literarische Genres manifestieren und etablieren sich in gesellschaftlichen Diskursen und provozieren Erwartungen und Vorstellungen, die an literarische Texte herangetragen werden. ${ }^{109}$ Genres verweisen auf „,Konturen und Funktionen, Institutionsweisen und Konventionen, die sich freilich nicht nur perfekt erfüllen, sondern auch absichtlich voll transzendieren, durchbrechen, erneuern oder vermischen lassen [...]. " "110 Wel-

turelle Konstrukte zu betrachten sind, die je nach Rezipient und Zielsprache anders gelesen werden. Ihrer Produktion und Rezeption geht immer eine spezifische Sozialisation voraus. Kaiser (1974), S. 36.

${ }^{104}$ Im Original englischsprachig sind Riordans Percy-Jackson-Serie, Meyers Bis(s)-Serie und Collins' Die Tribute von Panem. Bei Funkes Tinten- und Giers Edelstein-Trilogie ist die deutschsprachige Ausgabe gleichzeitig die Originalausgabe.

${ }^{105}$ Gemeint sind damit vor allem intersubjektive und zeitunabhängige Merkmale. Fricke (2010b), S. 20.

106 Vgl. ebd., S. 132.

${ }^{107}$ Vgl. ebd., S. 133.

${ }^{108}$ Dies ist beispielsweise möglich, indem man Schemata ausmacht, die gattungsweisend für Genres sind, und sie im Text aufzeigt.

${ }^{109}$ Fricke (2010b), S. 20.

${ }^{110}$ Lecke (2008), S. 11. 
che Eigenschaften mit einem Genre assoziiert werden, ist in vielen Fällen nicht nur diskurs-, sondern auch personenabhängig. Die Zuordnung ist daher nur plausibel zu machen, wenn angegeben wird, welches Gattungs- bzw. Genremodell der Entscheidung zugrunde liegt. ${ }^{111}$

\section{Zur Schematheorie}

Der Begriff Schema bezeichnet in der Psychologie und Hirnforschung Konzeptualisierungen von Informationen und Informationsstrukturen im Gehirn, die erlernt, modifiziert und abgerufen werden können. ${ }^{112}$ Sie müssen erworben werden, bevor sie wirken, und sind im höchsten Maße kulturabhängig, ${ }^{113}$ sie können künstlich geschaffen sein und müssen keinen direkten Bezug zur Alltagswelt besitzen. ${ }^{114}$ Nach der Schematheorie liegen jedem Genre sowohl kognitive als auch emotionale Schemata zugrunde, die unter bestimmten Voraussetzungen bei der Lektüre eines Textes aufgerufen werden, Orientierungshilfe bieten und den Verstehensprozess maßgeblich beeinflussen oder sogar gezielt steuern. ${ }^{115}$ Andererseits vermögen kognitive und emotionale Reaktionen ein bestehendes Genreschema zu modifizieren. Literarische Genres können daher als komplexe Skripts verstanden werden, deren Informationsgefüge vom Rezipienten während seiner Lesesozialisation erlernt, erweitert und revidiert wird. ${ }^{116}$ Ein Text, der sich eines genreweisenden Schemas bedient, deklariert sich selbst mittels Intertextualität bzw. Systemreferenz als genrezugehörig. Bei Rezipienten mit gleichem kulturellem Hintergrund und ähnlichen Lebensbedingungen ist demnach die Wirkung eines Textes zumindest zu Teilen reproduzierbar, da sie durch Schemata gesteuert wird. Diese können auf unterschiedlichen Hierarchieebenen wirken: ${ }^{117}$ Auf oberster Ebene sind Genreschemata praktisch in jedem Belegtext des betreffenden kommunikativen Modells vorhanden und zwingend notwendig, um beim Rezipienten das entsprechende Skript abzurufen, das dann seinen Leseprozess bestimmt. Auf niederer Hierarchieebene stellen sie hinreichende Gattungssignale dar, deren kumuliertes Auftreten - etwa durch wiederholte Verwendung von Teilschemata, beispielsweise Handlungsschema - zur entsprechenden Kategorisierung führt, welche indes mit einem Gat-

\footnotetext{
${ }^{111}$ Vgl. Müller (2003), S. 414 ff.

112 Skript und Frame werden oftmals synonym zum Begriff Schema verwendet, bezeichnen aber eigentlich bestimmte Arten von Schemata. Diese werden in der Schematheorie als erlernte Verallgemeinerungen des eigenen Selbst verstanden. Markus (1977), S. 64; Mohr (2012), S. $31 \mathrm{f}$.

${ }^{113}$ Manz (2011), S. 31.

114 Thornedyke (1984), S. 185.

${ }^{115}$ Vgl. ebd. Ein ähnliches Genreverständnis findet sich auch bei wissenschaftlichen Auseinandersetzungen mit Filmgenres. Siehe dazu beispielsweise Schick (2015), S. $104 \mathrm{f}$.

${ }^{116}$ Mohr (2012), S. 255 und Bergenthal (2008), S. 110.

${ }^{117}$ Angelehnt an Mohr (2012), S. 255 f., die sich auf Anderson/Pearson (1984), S. 268 bezieht.
} 
tungsschema höherer Ebene brechen kann. Ein Text vermag somit Schemata unterschiedlicher Genres in sich vereinen, da sie auf unterschiedlichen Hierarchieebenen realisiert werden. ${ }^{118}$

\section{Zu literarischen Gattungsmodellen}

Obige Definition zeigt, dass jede Textklassifikation vor dem Hintergrund eines bestimmten gedanklichen Modells getroffen wird, das aus einer Vielzahl potenziell zur Verfügung stehender Kategorien besteht, aus denen bei einer literarischen Gattungsentscheidung auswählt werden kann. Wird also zum Beispiel ein Werk der Fantasy-Literatur zugeordnet, ist das dahinterstehende Gattungsmodell zu beachten, bzw. was mit der Klassifikation konkret gemeint ist und welche Gattungen gleichzeitig ausgeschlossen werden. Gedankliche Modelle zeigen sich explizit oder implizit sowohl in Laien- als auch Forschungsdiskursen und weisen mal stärker, mal schwächer eine logische Struktur auf. Geht man davon aus, dass sich jeder literarische Text in seinen eigenen Metadiskurs einschreibt, indem darin auf bestimmte Gattungserwartungen der Rezipienten eingegangen wird, die durch entsprechende Schemata bestätigt, infrage gestellt oder innoviert werden, so folgt daraus, dass jeder Text nicht nur Einfluss auf die Vorstellungen der jeweils betrachteten Gattung ausübt, sondern zudem darauf, nach welchem System überhaupt Gattungen unterschieden werden bzw. welche Ordnungskategorien beim literarischen Urteil Verwendung finden. Er beeinflusst demnach auch die Gattungsmodelle selbst: die gedanklichen Konstrukte und damit das System, nach dem literarische Klassifikationsentscheidungen gefällt werden.

Gattungsmodelle Ein Gattungsmodell dient als System zur Klassifikation literarischer Texte. ${ }^{119}$ Oft sieht es die Organisation einer Gattung in verschiedene Subgattungen vor, deren Abgrenzung je nach Modell entweder als objektiv gelten kann oder, zumindest teilweise, eine personen- oder institutionsgebundene Interpretation darstellt. In der Regel sind die Modelle hierarchisch strukturiert, sodass zunehmend mehr Texteigenschaften berücksichtigt werden: In den höheren Hierarchieebenen finden sich Genres oder Textsorten mit allgemein gehaltenen Eigenschaften und in den niederen Ebenen spezifischere Kategorisierungsbegriffe, die als Subgattungen bezeich-

\footnotetext{
${ }^{118}$ Zum Genremix siehe Kapitel 5.3.

119 Üblich sind zudem die Begriffe Gattungssystematik oder Ordnungsmodelle. Dunker unterscheidet vier verschiedene Ordnungsmodelle: „die aufzählend nebenordnende Reihe“, „,das geschlossene Gattungsrad“, „, hierarchisierende Strukturbäume/Taxonomien“ sowie „, offene Familienähnlichkeit“. Dunker (2010), S. 12.
} 
net werden. In einem Gattungsmodell können verschiedene Kategorisierungsprinzipien miteinander kombiniert werden. ${ }^{120}$

Folgende Gattungsmodelle werden hier betrachtet:

Genremodelle ergeben sich explizit oder implizit aus hierarchisch organisierten Klassifikationsentscheidungen literarischer Texte, die an historische und gesellschaftliche Denk- und Sichtweisen gebunden sind; die Modelle sind daher in höchstem Maße diskurs- und kontextabhängig. Ihre Struktur besteht - analog zum Gattungsmodell aus Genres und Subgenres, die sich von Hierarchieebene zu Hierarchieebene ausdifferenzieren. Oftmals dient dabei die Kombination verschiedener Eigenschaften, Schemata und Motive als Klassifikationsargument. Genremodelle und ihre Kategorien bzw. Subgenres werden selten in Diskursen transparent gemacht, sodass die Systematik meist implizit erschlossen werden muss. Von Hierarchieebene zu Hierarchieebene entstehen immer spezifischere Eigenschaftskonstellationen, die zu immer spezifischeren Genrevorstellungen und -begriffen führen. Die Art und Weise der betrachteten Texteigenschaften kann bei Genremodellen höchst unterschiedlich sein und sowohl inhaltliche, strukturelle, stilistische, wirkungsästhetische als auch funktionale Aspekte berücksichtigen. Oftmals referiert dabei der Name eines Genres auf diejenige Eigenschaft, die als dominant und gattungsweisend im Gefüge erachtet wird. So werden beispielsweise Adressatengattungen oder Stilepochen in Genremodellen organisiert.

Hybridmodell/Genremixmodell Ein solches Modell ergibt sich aus dem Eindruck, dass sich ,ein Text aus mehreren, auf gleicher systematischer Ebene angesiedelten Gattungen zusammensetzt “121. Es versucht daher, die verschiedenen Gattungseinflüsse zu rekonstruieren und zu gewichten.

Andere Gattungsmodelle orientieren sich bei der Klassifikation ausschließlich an einem spezifischen Aspekt. In der Praxis fungiert meist ein Genre als Ausgangspunkt, das dann hinsichtlich eines bestimmten Aspekts in Subgattungen gegliedert wird. ${ }^{122}$ Auch sie können sich prin-

\footnotetext{
${ }^{120} \mathrm{Ebd}$.

${ }^{121}$ Baßler (2010), S. 52.

122 So hat beispielsweise Ewers ein Gattungsmodell zur Verfügung gestellt, das Jugendliteratur hinsichtlich Adressierung, Funktion und historischer Epoche in Subgattungen unterteilt. Ewers (2013), S. 89.
} 
zipiell an Textsorten anschließen. Im Rahmen dieser Arbeit werden vor allem strukturgeleitete Gattungsmodelle Beachtung finden.

Strukturgeleitete Gattungsmodelle klassifizieren Texte nach strukturellen Gesichtspunkten, etwa Schemata, welche Figur, Zeit, Raum und Handlung betreffen.

Funktionsorientierte Gattungsmodelle klassifizieren Texte nach ihrer gesellschaftlichen Funktion, wobei bestimmte Inhalte und Eigenschaften als funktionstauglich interpretiert werden. ${ }^{123} \mathrm{Ob}$ ein Text einer funktionsorientierten Gattung angehört, ist daher auch nur vor dem Hintergrund des Modells entscheidbar, das Grundlage dieser Interpretation ist. Da die Funktion eines Textes mit traditionellen literaturwissenschaftlichen Instrumentarien nicht zu ermitteln ist, wird funktionsorientierten Gattungsmodellen hier nur wenig Aufmerksamkeit zuteil; Beispiele dafür sind Schullektüre, Lehrbuch, Unterhaltungsliteratur und Lebensratgeber. ${ }^{124}$

${ }^{123}$ Gemeint sind die Funktionen in kulturellen und sozialen Kontexten. Lamping (2009), S. XVII.

${ }^{124}$ Ewers (2013), S. 89. 


\section{Die Post-Potter-Texte als Serienliteratur}

Joanne K. Rowling gelang es mit ihrer Romanreihe um die Heldenfigur Harry Potter, Millionen von Lesern an ihre Zaubererwelt zu binden. Bei der Analyse des Werks ging die Forschung auch der Frage nach, inwieweit das Serienkonzept für den Erfolg verantwortlich ist. ${ }^{1}$ Birgit Schlachter stellte die These auf, dass Harry Potter wegweisend für eine neue Generation von Serienliteratur im Bereich Kinder- und Jugendliteratur war und ist, und machte zudem auf die Strukturähnlichkeit zu zeitgenössischen Fernsehformaten aufmerksam. ${ }^{2}$ An Schlachters Überlegungen anknüpfend, sollen nun die Texte des Korpus auf signifikante Ähnlichkeiten zu Rowlings Werk hin untersucht werden. Im Fokus stehen Kriterien, mit denen Serienformate sinnvoll klassifiziert werden können.

Die Entscheidung, ein Buch der Gattung Serienliteratur zuzuordnen, basiert auf einer objektiven Texteigenschaft, nämlich der Publikationsform. Der Terminus bezeichnet daher eine Textsorte. ${ }^{3}$ In der literaturwissenschaftlichen Forschung haben sich hierzu allerdings noch Subgattungen herauskristallisiert, die, da kontext- und interpretationsabhängig, als Genres aufzufassen sind: Reihen, Familiensagas, Zyklen, ${ }^{4}$ Reprisen $^{5}$ und Sequels ${ }^{6}$ sind nur einige Beispiele. Wie alle Genres verweisen sie jeweils auf eine objektive Texteigenschaft, die zu einem gattungskonstitutiven Merkmal erhoben wird. Gerade bei Serien aber ist ein genregeleiteter Zugriff problematisch, da doch gerade die Konstellation verschiedener Strukturen das Format ausmacht, sodass die Konzentration auf ein Strukturmerkmal dem Erkenntnisprozess eher im Weg steht. Aus diesem Grund orientiert sich hier die Gattungsdiskussion nicht an Genrekategorien, sondern an einem strukturgeleiteten Gattungsmodell.

Um die seriellen Strukturen der hier betrachteten Texte aufzuzeigen, wird folgende Herangehensweise gewählt: Das erste Unterkapitel gibt eine Einführung in Theorie und Geschichte serieller Literatur und widmet sich zudem deren Rezeption. In Kapitel 2.2 wird ein strukturgeleitetes Gattungsmodell für serielle Literatur vorgestellt, das als Grundlage der vorgenomme-

\footnotetext{
${ }^{1}$ Zur Marketingstrategie, die das Serienformat explizit bewarb, siehe beispielsweise Bergenthal (2008), S. 449 f.; Fenske (2008), S. 59 ff.; vgl. Karg/Mende (2010), S. 49.

${ }^{2}$ Schlachter (2013), S. 109.

${ }^{3}$ Zum Begriff der Textsorte siehe Kapitel 1.3.

${ }^{4}$ Krah (2010).

${ }^{5}$ Umberto Eco führt in seinem Genremodell neben Serie und Saga noch die Reprise auf, worin erfolgreiche Themen vergangener Serien aufgenommen bzw. wiederverwendet werden. Demnach sind Remake, Neuinterpretation und Persiflage als Unterformen der Reprise zu begreifen. Vgl. Eco (1988), S. 158.

${ }^{6}$ Kümmerling-Meibauer (1997).
} 
nen Analyse dient. Ein Resümee fasst die Ergebnisse zusammen und macht auf Parallelen zwischen Harry Potter und den Texten des Korpus aufmerksam (Kapitel 2.3).

\subsection{Zu Theorie und Geschichte serieller Literatur}

An die hier folgende Definition serieller Literatur schließt sich ein geschichtlicher Abriss an, wobei vor allem die zyklischen Vorläufer zeitgenössischer Serienformate in den Blick genommen werden. Das letzte Unterkapitel widmet sich der Rezeption und stellt Theorien vor, die die Popularität serieller Literatur zu erklären suchen.

\subsubsection{Zur Serie}

Das Phänomen zeigt sich zunächst als ein profanes: Serialität ist als dominante, medienübergreifende Kulturpraxis zu betrachten, welche unseren heutigen Wahrnehmungsapparat maßgeblich mitbestimmt. ${ }^{7}$ Sie beherrscht zeitgenössische Produktions- und Distributionspraktiken, ebenso Technologien und Maschinen, ist aber auch zentrales Moment ritueller und kultureller Handlungen im Alltag. ${ }^{8}$ Selbst Freundschaften können als serielle Kommunikationsformen aufgefasst werden, ja sogar jede Form des menschlichen Erinnerungsapparates als serielle Arbeit, die unserem Denken Struktur verleiht. ${ }^{9}$ In Bezug auf künstlerische Zusammenhänge ist Serialität ein ,, grundlegendes Verfahren der Literatur “ ${ }^{10}$

Der Begriff Serie wird üblicherweise in zwei Kontexten verwendet: Es ist zu differenzieren zwischen Produktionen des immer gleichen Objektes - ein Prinzip, das sich hauptsächlich in der Industrie findet - und solchen, die auf die Ergänzung, Fortschreibung und Variation von Inhalten und Ausdrucksformen abzielen, wie es im literarischen Betrieb zu beobachten ist. ${ }^{11}$ Das Wesen der Serie im ersten Sinne ist Wiederholung und Reproduktion, im zweiten Sinne Mehr- oder zumindest Zweiteiligkeit. ${ }^{12}$ Die beiden unterscheiden sich im Grad der Explizitheit, in der sie Serialität als ästhetischen Operator markieren: Während sich der serielle Charakter von Massenprodukten erst durch eine Interpretationsleistung erschließt, wird Serialität in kreativen Zusammenhängen von den Beteiligten am Publikationsprozess als Merkmal explizit zum „Zweck der Selbstbeschreibung“ herausgestellt. ${ }^{13}$ Beide Formen verbindet ihre

\footnotetext{
${ }^{7}$ Siehe dazu Sielke (2012), S. 383; Faulstich (1994), S. 50; Kelleter (2012), S. 26.

${ }^{8}$ Sielke (2012), S. 390.

${ }^{9}$ Ebd. und Faulstich (1994), S. 50 f.

${ }^{10}$ Ebd.

${ }^{11}$ Eco (1988), S. 155.

${ }^{12}$ Weber/Junklewitz (2008), S. 14; Hickethier (1991), S. 8.

${ }^{13}$ Kelleter (2012), S. 14.
} 
aneinanderreihende oder auch parallelisierende Funktion: Sie sind Resultate von Zäsuren oder Pausen, die zwischen einer Wiederholung oder einer Fortsetzung stehen. Damit scheint die Zäsur das Hauptmerkmal von Serialität zu sein, ihr sollte also bei einer gezielten Untersuchung besondere Aufmerksamkeit gewidmet werden. ${ }^{14}$

Im Folgenden soll zum einen serielle Literatur betrachtet werden, zum anderen literaturwissenschaftliche Kategorien und Konzepte, die diese beschreiben. In der Forschungsliteratur ist die Tendenz auszumachen, sich mit der Fernsehserie auseinanderzusetzen. ${ }^{15}$ Daher werden hier auch Kategorien vorgestellt, die sich ursprünglich auf diese Gattung beziehen. Dass eine Übertragung auf literarische Texte im engeren Sinne möglich und sinnvoll ist, erschließt sich unmittelbar.

\subsubsection{Zu serieller Literatur}

Im Handbuch Populäre Kultur findet sich unter dem Stichwort „Serie“ folgende Definition:

Die Serie ist eine allgemeine Präsentations- und Vermittlungsform der Kultur, die dem Berichten und Erzählen der Geschehen der Welt innewohnt und die aus den Prinzipien der erzählerischen Sukzession und Kausalität entsteht. ${ }^{16}$

Literarische Texte gelten als Serie, wenn der Umfang des Erzählten den adäquaten Rahmen eines Bandes sprengt oder die Geschichte in der epischen Welt so angelegt ist, dass sie zum Lesen einer weiteren Begebenheit einlädt. ${ }^{17}$ Die sukzessive Distribution basiert entweder auf einem praktischen, medienspezifischen oder einem ökonomischen bzw. kommerziellen Interesse.

Literarische Serie Eine mehrteilige literarische Publikation wird dann zur Serie, wenn die Einzelbände oder -episoden in einem erzählerischen Gesamtzusammenhang zu verorten sind und von den Akteuren als einer Serie zugehörig, das heißt, explizit als serielle Versatzstücke markiert werden. ${ }^{18}$ Die Kennzeichnung kann durch unterschiedliche Techniken realisiert werden: auf textueller, metatextlicher oder materieller Ebene in Form von bestimmten Covergestaltungen, Logos, Slogans, Klappentexten bzw. Trailern, Titelmelodien und weiteren Techniken der Corporate Identity. ${ }^{19}$ Text-

\footnotetext{
${ }^{14}$ Türschmann (2007), S. 206 ff. Faulstich differenziert in drei Kategorien: „, Serie als fernsehtheoretische Kategorie“, „, Serie als Formprinzip des Erzählens “ und ,Serie als Gestaltungsprinzip von Kunst überhaupt“. Zu finden bei Faulstich (1994), S. 50.

${ }^{15}$ Siehe u. a. Hickethier (1991); Türschmann (2007), S. 201-219 und Kelleter (2012), S. 11-46.

${ }^{16}$ Hickethier (2003), S. 397.

${ }^{17}$ Vgl. ebd. sowie Eco (1988), S. 158.

${ }^{18}$ Kelleter (2012), S. 14.

${ }^{19}$ Vgl. Hickethier (2003), S. 398.
} 
immanent erfolgt sie etwa durch thematische Bezugnahme, Kausalitätsstrukturen, Einführung von feststehenden Haupt- und Nebenfiguren, durch repetitive narrative Schemata und iterative Strukturen sowie durch die sukzessive Etablierung und Ausgestaltung der epischen Welt, um nur einige Möglichkeiten zu nennen. ${ }^{20}$ Von einer Reihe unterscheidet sich die Serie darin, dass bei Ersterer die Verknüpfung der einzelnen Folgen hauptsächlich formaler und metatextueller Art ist. ${ }^{21}$ Somit weisen die einzelnen Ausgaben weniger inhaltliche Kohärenz auf, zumal sie keine Versatzstücke einer kohärenten Rahmenhandlung darstellen. ${ }^{22}$

\subsubsection{Zur Geschichte serieller Literatur}

Eine umfangreiche Auseinandersetzung mit der historischen Entwicklung serieller Narrationen hat Christine Mielke vorgelegt. ${ }^{23}$ Sie sieht die Ursprünge literarischer Serien vor allem in zyklischen Prätexten, die sie in Bezug auf Form und Struktur als Prototypen moderner Konzepte betrachtet. ${ }^{24}$ Insbesondere orientalische und mittelalterliche narrative Prätexte sollen hier aufgegriffen werden. Von Mielke kaum berücksichtigt werden nichtzyklische Vorläufer wie etwa das Feuilleton, das als frühe Form der Fortsetzungsserie angesehen werden darf, von ihr indes hauptsächlich als Weiterentwicklung zyklischer Urformen definiert wird.

Neben mündlich überlieferten Narrationen wie Homers Ilias und Odyssee, die vermutlich aufgrund ihres immensen Umfangs portioniert-rhapsodisch vorgetragen wurden, ${ }^{25}$ können morgenländische Zyklen als Vorbilder zeitgenössischer serieller Erzählungen ausgemacht

${ }^{20}$ Siehe u. a. Eco (1988), S. 159; Krützen (1998), S. 9; Kließ (1994), S. 175.

${ }^{21}$ Vgl. Schlachter (2013), S. 107.

${ }^{22}$ Mohr (2012), S. $218 \mathrm{f}$.

${ }^{23}$ Die Dissertation Zyklisch-serielle Narration: erzähltes Erzählen von 1001 Nacht bis zur TV-Serie erschien 2006 in Berlin.

${ }^{24}$ Der Begriff Zyklus ist ursprünglich eine Genrebezeichnung für serielle Texte, deren Rahmenhandlung in eine zyklische Erzählsituation eingebettet ist. Nach Mielke werden beim seriellen Zyklus relativ selbstständige Einzelerzählungen durch die erzählerische Rahmung in einen Gesamtzusammenhang zu einem geschlossenen Kreis zusammengefügt. Die Erzähler der Binnenhandlung könnten dabei wechseln, entstammten aber einem festen Figurenset der Rahmenhandlung. Wie interpretationsabhängig der Begriff Zyklus ist, zeigt Schlachter. Sie betrachtet vor allem die thematische Entfaltung bei literarischen Zyklen als gattungsweisend. Ihr zufolge (mit Bezug auf Henckmann und Krah) sind Zyklen um ein Grundthema zentriert, das sie in jeder Folge neu entfalten, sodass das jeweilige Thema zyklisch abgeschritten werde. Vgl. Schlachter (2013), S. 108. Krahs Definition betont die relative Autonomie der einzelnen Teile sowie den Stellenwert der Einzelfolge im Gesamtzusammenhang. Vgl. dazu Krah (2010), S. 101 f. Basierend auf diesem Zyklusbegriff, ordnet Schlachter Harry Potter, Die Tribute von Panem und die Bis(s)-Serie als literarische Zyklen ein und betont, dass Harry Potter dieses Serienformat in jüngster Zeit erst populär machte. Vgl. dazu Schlachter (2013), S. 108 f. Wenngleich die Beobachtungen zu den seriellen Strukturen dieser Texte zutreffend sein mögen, scheint die interpretationsgeleitete Zuordnung, zumindest vor dem Hintergrund der Tradition des Zyklus-Begriffs, wenig plausibel.

${ }^{25}$ Hickethier (2003), S. 397. 
werden. Dazu zählen u. a. die Märchen aus Tausendundeine Nacht, jene Sammlung, deren Ursprung in etwa auf das Jahr $250 \mathrm{n}$. Chr. datiert wird. Kompositorisch durch eine fiktionale Erzählsituation eingerahmt, zeigt sich das Werk als eine frühe Grundform von Fortsetzungsserien, als Schachtelrahmenerzählung. Jede neue Erzähleinheit beginnt mit der Komplettierung der vorangegangenen Binnengeschichte und mündet in der Etablierung einer neuen. ${ }^{26}$ Indem ,im spannendsten Moment“ mit dem Versprechen geschlossen wird, das „Beste“ werde noch folgen, ${ }^{27}$ darf Tausendundeine Nacht auch als Vorreiter der inszenierten Katapher und des Cliffhanger-Prinzips ${ }^{28}$ gelten, das spätestens in den Feuilletonromanen des 19. Jahrhunderts üblich wurde. ${ }^{29}$ Mielke identifiziert die Struktur zudem als Vorläufer der Kinoserie, des Radiohörspiels ab den 30er-Jahren sowie der Seifenopern in Radio und Fernsehen. ${ }^{30}$

Andere Vorläufer, etwa das Dekameron, das Heptameron und das Pentameron aus dem Spätmittelalter, arbeiten mit linear fortlaufenden, vollständig abgeschlossenen Binnengeschichten, deren Verknüpfung lediglich in Form von thematischen oder formal konzeptionellen Bezügen erfolgt. ${ }^{31}$ Serielle Konzeptionsformen finden sich dort primär in Form von spannungssteigernden Zäsuren, dem Prinzip des ständigen Abbruchs sowie verdeckten Spiegelungen zwischen Rahmen- und Binnenerzählung, Symmetrien und Asymmetrien, die den Einzelgeschichten je nach Zyklus eigene Regeln im narrativen Aufbau verleihen. ${ }^{32}$ Die Einheiten sind in fortlaufenden Wochentagen organisiert - die Fastentage Freitag und Samstag ausgenommen - und zeugen so bereits von der Tendenz, sich dem Biorhythmus der Rezipienten anzupassen. Solcherart Texte, so Mielke, üben Einfluss auf die Rahmenzyklen des 18. und 19. Jahrhunderts aus und wirken strukturgebend bis hin zur Etablierung des Feuilletonromans sowie der Endlosserie des 20. Jahrhunderts. Gemeinsam mit den orientalischen Vorläufern halten sie bereits die bedeutsamsten seriellen Strukturen der Literaturgeschichte vor, die im

\footnotetext{
${ }^{26}$ Mielke (2006), S. 55.

${ }^{27}$ Hickethier (2003), S. 397; ders. (1991), S. 17.

${ }^{28}$ Zum Begriff Cliffhanger siehe Fußnote 62, Seite 41.

${ }^{29}$ Mehr zur Überlieferungs- und Publikationsgeschichte von Tausendundeine Nacht bei Hickethier (2003), S. 398.

${ }^{30}$ Mielke (2006), S. 58.

${ }^{31}$ Mielke (2006), S. 70 f. Das Dekameron ist eine im 14. Jahrhundert entstandene Novellensammlung von Giovanni Boccaccio, die aus 100 Erzählungen besteht und die mit ihrer doppelten Formstruktur (von Rahmenhandlung und Binnenerzählungen) zum Vorbild für viele abendländische Märchensammlungen geworden ist. Vgl. Mielke (2006), S. 59 ff. So ist auch das Heptameron nach dem Vorbild des Dekamerons gestaltet. Es ist im 16. Jahrhundert entstanden und umfasst 72 kurze Erzählungen, die in einem „Rahmengespräch“ arrangiert sind. Vgl. Mielke (2006), S. 87ff., Zitat: S. 88. Bei der Konzeption des Pentamerons, einer im 17. Jahrhundert entstandener Märchensammlung von Giambatista Basile, ist ein inhaltlicher Bezug zwischen Rahmung und Binnenerzählungen zu erkennen. Vgl. Mielke (2006), S. 103.

${ }^{32}$ Mielke (2006), S. 74
} 
Zusammenspiel mit Entwicklungen neuer Medienformate und Rezeptionsgewohnheiten immer wieder aufgegriffen und weiterentwickelt worden sind. ${ }^{33}$

Als weiterer Prototyp zeitgenössischer Serienformate und Vorreiter der literarischen Massenproduktion, die den Buchmarkt heute dominiert, ist der Kolportageroman hervorzuheben, der im 17. Jahrhundert an Popularität gewann. ${ }^{34}$ Ausgehend von Frankreich, setzte sich der Trend im 19. Jahrhundert im Zeitungs- oder Feuilletonroman fort, dessen serielle Erzähltechniken bis heute in der Trivialliteratur sowie in der Abend- bzw. Endlosserie im Fernsehen gängig sind. ${ }^{35}$ Aus Gründen der Leserbindung erschienen zunächst portionierte Romane, dann auch extra verfasste serielle Geschichten. ${ }^{36}$ Sie waren zeitweilig so einflussreich, dass sie als hauptverantwortlich für den Erfolg mancher Zeitung galten. Beispielsweise verhalf die Serie Die Geheimnisse von Paris dem Journal des Debáts zu ungeheurer Popularität. ${ }^{37} \mathrm{Im}$ weiteren Verlauf, vor allem dank neuer technischer Möglichkeiten im 20. Jahrhundert, traten Comicstreifen, Radio- und Kinoserien neben den Zeitungsroman, das Unterhaltungstheater und den Kolportageroman, auch sie sind als Vorläufer moderner serieller Literatur zu betrachten. ${ }^{38}$

\subsubsection{Zur Rezeption serieller Literatur}

In der Forschung wurden zwei Theorien entwickelt, die die Popularität der Sparte zu erklären versuchen: Zum einen ermöglichten Serien den Ausbruch aus der eigenen Welt bei gleichzeitigem Eintauchen in eine zweite, fiktionale Welt. ${ }^{39}$ Zum anderen werde einem unterstellten menschlichen Grundbedürfnis nach Rhythmus, Harmonie und formaler Abgeschlossenheit entgegengekommen, in der Literaturwissenschaft auch „Sense of an Ending“ genannt. ${ }^{40}$ Periodisches Rezipieren erzeuge zudem Routine und Rituale, beides kulturelle Konzepte, die das Gefühl von Sicherheit vermitteln und den Menschen kognitiv und zeitorganisatorisch zu entlasten vermögen. ${ }^{41}$

\footnotetext{
${ }^{33}$ Mielke (2006), insbesondere S. 153 und S. 177.

${ }^{34}$ Vgl. Lecke (2008), S. 46.

${ }^{35}$ Ebd.

${ }^{36}$ Hickethier (2003), S. 398.

${ }^{37}$ Im Original Mystères de Paris von Eugène Sue. Der Roman wurde vom 19. Juni 1842 bis zum 15. Oktober 1843 fast täglich in der eher konservativen Tageszeitung abgedruckt.

${ }^{38}$ Kreuzer (1974), S. 2 ff.

${ }^{39}$ Giesenfeld (1994), S. 3. Siehe dazu auch Kapitel 3.3.

${ }^{40}$ Vgl. Kermode (1967); Kelleter (2012), S. 12.

${ }^{41}$ Siehe dazu beispielsweise Turner (2005) und Dücker (2006).
} 
Serielle Phänomene sind an Materialität gebunden, der hier fokussierte Bereich an literarische Medien. ${ }^{42}$ Die Rezeption wird zweifelsohne von den Spezifika des jeweiligen Trägermediums beeinflusst. Neben der sukzessiven Publikation zeichnen sie sich durch rezeptionsperspektivische Implikationen aus: Fernsehserien werden zu regelmäßigen Zeiten, meist in regelmäßigen Abständen bei einem bestimmten Sender ausgestrahlt, Printserien erscheinen in kalkulierten Abständen, auch Comics oder Merchandisingartikel. ${ }^{43}$ Der periodische Auftritt der Protagonisten ermöglicht einerseits eine Verzahnung mit der persönlichen Entwicklung der Leser oder Zuschauer bzw. Zuhörer, die die Illusion einer Parallelwelt unterstreicht, ${ }^{44}$ andererseits die Berücksichtigung von Reaktionen der Konsumenten, indem Autoren und Regisseure die Produkte deren Bedürfnissen kontinuierlich anpassen. Insofern beteiligen sich Serien am Prozess der ästhetischen Modernisierung und verrichten kulturelle Arbeit, indem sie neue Identifikationsmöglichkeiten schaffen und an aktuellen gesellschaftlichen Diskursen partizipieren. ${ }^{45}$ Zugleich wird durch die ständige Verschränkung von Produktion und Rezeption die Genese neuer Erzähltechniken und literarischer Innovationen vorangetrieben. ${ }^{46}$ Durch die Digitalisierung beschleunigte sich die Konsumierung literarischer Serien, festgelegte Rezeptionsabstände wurde somit obsolet: DVD-Boxen, E-Books, Onlinedienste wie Onlinevideotheken ermöglichen die selbstständige Kontrolle der Zeitabstände, sofern die jeweiligen Teilfolgen bereits erschienen sind. Zudem kann Bonusmaterial gesammelt und archiviert werden. Diese Umstände verleihen Serien heute eine sogenannte operationale Ästhetik, ein Zusatzvergnügen, das sich optimal in den Alltag einfügen lässt. ${ }^{47}$

\subsection{Zu den seriellen Strukturen von Harry Potter und seinen Nachfolgern}

Kapitel 2.2 nimmt die Serialität sowie Strukturähnlichkeiten von Harry Potter und den Texten des Korpus anhand eines strukturgeleiteten Gattungsmodells in den Blick. Dazu stellt es zunächst ein Klassifikationsmodell für serielle Literatur vor (Kapitel 2.2.1), daran schließt sich die Analyse der Werke an (2.2.2 und 2.2.3), ein Forschungsbericht stellt dabei die relevanten Ergebnisse der Potter-Forschung heraus.

\footnotetext{
${ }^{42}$ Zum Begriff des literarischen Mediums vgl. Fußnote 3, Seite 5.

${ }^{43}$ Vgl. Weber/Junklewitz (2008), S. 15.

${ }^{44}$ Hickethier (1991), S. 40 und Krützen (1998), passim. Bei Harry Potter etwa führte die jährliche Publikation der Teilbände dazu, dass die zumeist jungen Leser ihre Adoleszenz parallel zu den Protagonisten durchlebten. Siehe auch Kelleter (2012), S. 24; Giesenfeld (1994), S. 2.

${ }^{45}$ Klein (2012), S. 233.

${ }^{46}$ Kelleter (2012), S. 22-25.

${ }^{47}$ Mittel (2011), S. 140-143.
} 


\subsubsection{Zu literarischen Serialitätsstrukturen und ihrer Klassifikation}

Das hier vorgestellte strukturgeleitete Gattungsmodell basiert auf der Idee einer intraserialen Kohärenz. Es unterscheidet grob zwischen Episoden- und Fortsetzungsserien sowie feiner zwischen langlaufend angelegten und endlich angelegten Fortsetzungsserien (Kapitel 2.2.1.1). Zur Durchleuchtung der Strukturen werden verschiedene Parameter als Komponenten serieller Kohärenz vorgestellt (Kapitel 2.2.1.2).

\subsubsection{Zur Episoden- und zur Fortsetzungsserie}

Aus narratologischer Perspektive erfolgt die gängigste Unterscheidung von serieller Literatur zwischen Formaten mit abgeschlossener Episodenhandlung und solchen mit fortlaufenden Handlungssträngen; im Fokus steht also die Frage, ob ein Einzeltext inhaltliche Abgeschlossenheit aufweist oder als Versatzstück im Gesamtzusammenhang der Serie zu betrachten ist. ${ }^{48}$ Handlungsschemata auf der Ebene einer Episode sollen hier Folgenhandlungen genannt werden, diejenigen, die auf Ebene der kompletten Serie operieren, Serienhandlungen. Letztere strukturieren den Gesamtzusammenhang und sind ggf. für alle Bände relevant. ${ }^{49}$

Episodenserien Serienformate, die abgeschlossene Einzelfolgen verbinden, heißen Seri$\mathrm{al}^{50}{ }^{\text {Episodenserie }}{ }^{51}$ oder Serienmodell mit abgeschlossenen Folgenhandlungen ${ }^{52}$. Dabei besteht zwar stets prinzipiell ein inhaltlicher Bezug zwischen den Teilbänden - etwa bezüglich des Figurensets, der räumlichen Verortung oder auch in der Thematik -, eine Kausalverknüpfung ist allerdings nicht konstitutiv. Dementsprechend weisen die Episoden in der Regel keine komplexe Serienhandlung auf. Oft wird eine harmonische Ausgangssituation durch Konflikte gestört, welche sich im Zuge der Handlung lösen, sodass der Status quo am Ende wiederhergestellt ist. Gibt es ein festes Figurenensemble, so behandelt jeder Teil einen Fall, eine Begebenheit oder einen Konflikt aus dem Leben der oder des Protagonisten bzw. der Protagonistin. Eine Rezeptionsreihenfolge existiert nicht, die Folgen sind prinzipiell austauschbar. ${ }^{53}$ Oft va-

\footnotetext{
${ }^{48}$ Angelehnt an Weber/Junklewitz (2008), S. 19; vgl. dazu Ewers (2006), S. 301.

${ }^{49}$ Auch das bewusste Negieren oder Variieren von bekannten Handlungsschemata kann das Erkennungsmerkmal einer Serie sein und Kohärenz generieren, etwa indem die Erwartungen der Rezipienten gezielt bestätigt oder gezielt gebrochen werden. Beide Techniken, stringent verfolgt, verleihen einem Serienformat Struktur und erleichtern den Rezeptionsprozess durch Harmonie, Rhythmik und Symmetrie. Vgl. dazu Eco (1988), S. 167.

${ }^{50}$ Allrath/Gymnich/Suhrkamp (2005), S. 4 f.; Weber/Junklewitz (2008), S. 19.

${ }^{51}$ Weber/Junklewitz (2008), S. 22; Giesenfeld (1994), S. 2-4.

${ }^{52}$ Hickethier (2003), S. 401.

${ }^{53}$ Ebd.
} 
riieren solche Serien ein einziges narratives Schema, ${ }^{54}$ erzählen also die immer gleiche Geschichte und bestätigen damit die Erwartungen der Leser, deren Weltordnung und in aller Regel auch deren ethischen Grundsätze. ${ }^{55}$

Fortsetzungsserien Wird ein Teilplot einer die komplette Serie betreffenden Geschichte erzählt, spricht man von Series ${ }^{56}$, Fortsetzungsgeschichte ${ }^{57}$ oder Feuilleton $^{58}$. In diesem Format gibt es sowohl Episodenhandlungen als auch eine Serienhandlung, beide werden durch entsprechende Schemata organisiert. In der Regel bauen die Folgen aufeinander auf, oft in Form einer ,zukunftsorientierten Geschichte “59. Damit ist die Rezeptionsreihenfolge hier vorgeschrieben. Um dazu zu motivieren, möglichst viele, wenn nicht alle Episoden zu rezipieren, dienen Techniken der Spannungssteigerung, die langfristig an die Serie binden sollen. ${ }^{60}$ Es können verschiedene Arten von Fortsetzungsserien unterschieden werden: ${ }^{61}$ Baut der Fortgang der Geschichte auf Vermutungen auf, die im Rahmen eines binären Lösungsschemas anzusiedeln sind, nennt Walter dies „,klassischen Suspense “62. In diesem Fall wird der Protagonist zumeist vor Ende einer Folge vor ein Problem gestellt, das nur zwei Alternativen kennt. Welche er wählt bzw. welches Schicksal ihn ereilen wird, klärt sich häufig erst zu Beginn der nächsten Episode. Von „Bewegungs-Suspense“ spricht Walter, wenn am Ende einer Folge etwas in Gang gesetzt wird, dessen Zielpunkt klar in der nächsten Teilfolge liegt, damit kennzeichnet Zwangsläufigkeit die Handlung. Der Begriff Bewegung umfasst hier auch die Entwicklung von Situationen und Beziehungen. Als weitere Fortsetzungsstrategie macht Walter die mehr oder weniger zuverlässige „Ankündigung unheilvoller Entwicklungen“ aus, sie reicht von zielsicheren Prognosen

\footnotetext{
${ }^{54}$ Giesenfeld (1994), S. 4.

${ }^{55}$ Die grundsätzliche Unterscheidung zwischen Serial und Series geht zurück auf Williams (1974). Siehe aber auch Eco (1988), S. 156, S. 159 f.; Weber/Junklewitz (2008), S. 19.

${ }^{56}$ Weber/Junklewitz (2008), S. 19.

${ }^{57}$ Hickethier (2003), S. 401.

${ }^{58}$ Türschmann (2007), S. $210 \mathrm{f}$.

${ }^{59}$ Mikos (1994), S. 353.

${ }^{60}$ Kelleter (2012), S. 19.

${ }^{61}$ Siehe dazu Walter (1986), S. 410 f.; vgl. auch Türschmann (2007), S. 219. Walter unterscheidet ursprünglich fünf verschiedene Strategien. Die Unterscheidung zwischen Ankündigung unheilvoller Ereignisse und plötzlicher, überraschender Ankündigung unheilvoller Ereignisse wurde aber zusammengefasst.

${ }^{62}$ Diese Fortsetzungsstrategie wird auch Cliffhanger genannt. Türschmann definiert Cliffhanger als Extremsituation mit binärem Lösungsschema zur Spannungssteigerung: „Die Verknüpfung von Raumverengung und Zeitdehnung ist das Hauptmerkmal von Extremsituationen mit binärem Lösungsschema. Es geht dabei um die Durchquerung von Raum sowie die Zeit, die dafür benötigt wird. “ Zitat: Türschmann (2007), S. 201. Er betrachtet den Cliffhanger als Phänomen audiovisueller Medien und postuliert, dass für den Feuilletonroman kein äquivalenter Begriff existiere. Vgl. ebd., S. 204.
} 
bis hin zu leeren Versprechungen oder Drohungen einzelner Figuren. Oftmals werfen die Ankündigungen Fragen auf und sind somit ebenfalls als spannungssteigerndes Element zu betrachten. Als letzte Strategie bezeichnet Walter diejenige, die das Erzählen selbst ins inszenatorische Zentrum einer Serie rückt. In diesem Fall steuert der Erzählende oder die Erzählsituation das Interesse des Rezipienten. Zäsuren können an beliebigen Stellen vorgenommen werden, um die Aufmerksamkeit auf eine extradiegetische Erzählinstanz zu lenken.

Wie stark die einzelnen Episoden einer Fortsetzungserie miteinander verknüpft sind, hängt vor allem davon ab, ob die Handlung auf einen konkreten Höhe- oder Endpunkt zuläuft oder unendlich angelegt ist bzw. ob das Ende bei der Planung der Einzelfolge von Relevanz ist. Es lässt sich modellhaft zwischen endlich und langlaufend angelegten Fortsetzungsserien unterscheiden, die Übergänge sind indes fließend. Bei kurzlaufenden Fortsetzungsserien sind die Einzelfolgen stark miteinander verknüpft, sodass ein Quereinstieg oder Pausieren des Rezipienten einem Ausstieg gleichkommt. Besitzt das Format ein offenes Ende, weist es oftmals zyklische Strukturen auf oder nutzt repetitive Schemata, womit immer wieder neue Konflikte und Themen ins Zentrum der Geschichte rücken. In diesem Fall erweist sich ein Quereinstieg der Rezipienten als leichter möglich, die sich an der Abwechslung erfreuen, wenngleich das narrative Schema faktisch dasselbe ist. ${ }^{63}$ Gerade die Ausgestaltung und Variation des Immergleichen macht offenbar den Reiz der Geschichten aus.

Langlaufend angelegte Fortsetzungsserien haben prinzipiell ein offenes Ende, gehen zumeist sehr kleinschrittig vor und vermeiden starke Zeitauslassungen. ${ }^{64}$ Die Inhalte sind in der Regel simpel, häufig steht die Episodenhandlung im Vordergrund. Oft werden an den Biorhythmus der Rezipienten angepasste Parallelwelten geschaffen und darin alltägliche Situationen und Konflikte zum thematischen Schwerpunkt erhoben. Im Fernsehen weisen Soap Operas oder Daily Soaps eine solche Struktur auf, deren Episoden oftmals mit einer sogenannten Zopfdramaturgie verbunden sind. ${ }^{65}$ Laufen die Fernsehserien auf ein Ende zu, spricht man von einer Telenovela, einen äquivalenten Begriff für literarische Texte in Buchform gibt es bislang nicht. ${ }^{66}$

\footnotetext{
${ }^{63}$ Eco (1988), S. 160.

${ }^{64}$ Hickethier (2003), S. 401.

${ }^{65}$ Vgl. dazu Weber/Junklewitz (2008), S. 24.

${ }^{66}$ Kelleter (2012), S. 20.
} 
Endlich angelegte Fortsetzungsserien sind auf eine bestimmte, überschaubare Folgenzahl hin konzipiert und laufen auf ein konkretes Ende zu. ${ }^{67}$ Episoden- und Serienhandlungen sind oft miteinander verschränkt und komplex gestaltet. ${ }^{68}$ Tendenziell wird in wesentlich größeren Schritten erzählt, sodass die Rezipienten angehalten sind, möglichst keine Folge zu verpassen, denn endlich angelegte Fortsetzungsserien sind kohärenter als langlaufende. ${ }^{69}$ Nicht selten werden ästhetische Prinzipien verfolgt, die sonst nur in nichtseriellen Texten und Monografien zum Tragen kommen. ${ }^{70}$ Verschiedene Genrebezeichnungen werden vergeben: Handelt es sich etwa um eine Familiengeschichte oder die Geschichte eines Familienmitgliedes mit großen zeitlichen Raffungen von der Vergangenheit bis zur Gegenwart, spricht man von einer Familiensaga oder kurz Saga. ${ }^{71}$ Die Darstellung kann dabei linear oder stammbaumförmig verlaufen $^{72}$ und die epische Welt einen starken oder schwachen Realitätsbezug aufweisen. Bezieht sich die inhaltliche Darstellung nicht ausschließlich auf eine Familiengeschichte, spricht man - vor allem bei drei- bis sechsteiligen Fernsehformaten von Miniserien. $^{73}$

\subsubsection{Zur intraserialen Kohärenz und doppelten Formstruktur}

Episoden- und Fortsetzungsserien stellen zwei Extremformen dar; faktisch sind die meisten Serien aber als Mischformen zu betrachten, die auf einer stufenlosen Skala dazwischen einzuordnen sind. ${ }^{74}$ Der Grad der erzählerischen Kontinuität kann dabei zur Skalierung verwendet werden: Je stärker die intraseriale Kohärenz, desto eher handelt es sich um eine Fortsetzungsserie. ${ }^{75}$ Den theoretischen Nullpunkt stellt so gesehen die Episodenserie dar, deren Einzelbände nur auf formaler Ebene Kohärenz aufweisen. Die Einordnung nach dem Grad intraserialer Kohärenz begründet sich in der strukturellen Eigenheit serieller Literatur: der doppelten Formstruktur, womit der dramaturgische Zusammenhang zwischen einer Einzelfolge und dem Mainplot gemeint ist, welche in ständiger Wechselwirkung stehen. Die Einzelfolge zielt einerseits auf eine inhaltliche Abgeschlossenheit, leistet aber andererseits einen Beitrag zur Se-

\footnotetext{
${ }^{67}$ Vgl. Karstens/Schütte (2010), S. 211.

${ }^{68}$ Klein (2012), S. 228.

${ }^{69}$ Der Begriff der Kohärenz wird im folgenden Kapitel (2.2.1.2) geklärt.

${ }^{70}$ Mittel (2011), S. $146 \mathrm{f}$.

${ }^{71}$ Hickethier (2003), S. 401.

${ }^{72}$ Vgl. Eco (1988), S. 162.

${ }^{73}$ Reinecke (2007), S. 9; Hickethier (2007), S. 196.

${ }^{74}$ Kotzloff (1992) und Allrath/Gymnich/Suhrkamp (2005) haben ein Modell vorgeschlagen, das die Oppositionen zwischen Serials und Series in Mischformen auffächert.

${ }^{75}$ Weber/Junklewitz (2008), S. 24.
} 
rienhandlung. ${ }^{76}$ Je intensiver sich diese doppelte Funktion zeigt, desto kohärenter ist die Serie. Und andersherum: Je weniger die Doppelstruktur zur Geltung kommt, desto episodenhafter ist die Struktur und desto geringer die Bedeutung des Gesamtzusammenhangs. Bei der Diskussion um die Kohärenzstärke können verschiedene Parameter einbezogen werden. Angelehnt an Weber und Junklewitz, sollen hier folgende Aspekte Berücksichtigung finden: ${ }^{77}$

- Handlungsschemata, die auf Ebene der Serienhandlung operieren, erzeugen einen Kausalzusammenhang zwischen den einzelnen Bänden und somit Kohärenz. Auch die frequentierte Verwendung gleicher Handlungsschemata auf Ebene der Folgenhandlungen kann zur Kohärenz beitragen, vor allem wenn diese Strategie zum Wiedererkennungsmerkmal der Serie wird.

- Verweisstrukturen zwischen einzelnen Folgen schaffen intraseriale Kohärenz, indem sie die Zugehörigkeit zum Gesamtzusammenhang bzw. zur Serienhandlung betonen. Dabei kann entweder auf Schemata oder Motive aus vorangegangenen Bänden referiert werden - im Sinne einer Analepse - oder aber auf Schemata späterer Folgen im Sinne einer Prolepse. ${ }^{78}$ Fast immer finden sich Kurzzusammenfassungen der vorangegangenen Handlung zu Beginn einer neuen Folge. Sie stellen sicher, dass handlungsrelevante Ereignisse beim Rezipienten präsent sind. ${ }^{79}$ Außerdem ermöglicht diese Strategie potenziellen Neu- oder Wiedereinsteigern das Verfolgen des Hauptplots. ${ }^{80}$

- Auf der Ebene der Zeitarrangements kann seriale Kohärenz insbesondere durch den erzählerischen Rahmen geschaffen werden, indem er die Einzelfolgen miteinander verknüpft und in einen temporalen Kausalzusammenhang bringt, beispielsweise wenn der neue Band direkt zu dem Zeitpunkt einsetzt, an dem der vorige geendet hat, wenn also durchgängig chronologisch erzählt wird. Aber auch ein Zeitsprung zwischen zwei Bänden kann Kohärenz erzeugen, wenn die entstandene Ellipse rückwirkend gefüllt wird. ${ }^{81}$ Damit wird der Eindruck erweckt, dass die Figuren ein Leben außerhalb der erzählten Zeit besitzen, das sie in der Erzählpause - unabhängig vom Rezeptionsrhythmus - weitergeführt haben. ${ }^{82}$ Im Extremfall entsteht eine parallele fiktionale Welt mit einer Zeitstruktur, die sich an den Biorhythmus des Rezipienten anlehnt. ${ }^{83}$

- Auch räumlich kann Kohärenz evoziert werden, etwa durch immer wieder genutzte Schauplätze, die oftmals semantisch aufgeladen werden, sodass sie zu Trägern von handlungsrelevanten Informationen avancieren oder allein durch ihre Nennung eine bestimmte Atmosphäre erzeugen. Wird der Handlungsraum von Band zu Band erwei-

\footnotetext{
${ }^{76}$ Hickethier (2003), S. 398.

77 Siehe Weber/Junklewitz (2008). Weber und Junklewitz beziehen sich bei ihren Ausführungen auf Fernsehserien, die Kategorisierung ist jedoch eins zu eins auf Literatur übertragbar. Die nachfolgende Auflistung wurde durch Mohrs sowie eigene Überlegungen ergänzt. Bezüge zu Mohr (2012) sind gekennzeichnet.

${ }^{78} \mathrm{Zu}$ Analepse und Prolepse siehe Martinez/Scheffel (2005), S. 33.

${ }^{79}$ Mohr (2012), S. 249.

${ }^{80}$ Vgl. ebd. (2012), S. 246.

${ }^{81}$ Zur bestimmten Ellipse siehe Martinez/Scheffel (2005), S. 43.

${ }^{82} \mathrm{Vgl}$. Mohr (2012), S. 154.

${ }^{83}$ Weber/Junklewitz (2008), S. 20.
} 
tert und ausdifferenziert, ${ }^{84}$ also das verwendete Raumschema ergänzt, entsteht auch durch die konsequente Verwendung unterschiedlicher Schauplätze oder phantastischer Welten seriale Kohärenz, wird sie zum konstitutiven Konzept der Serie erhoben.

- Die Stabilität des Figurensets kann als Parameter intraserialer Kohärenz dienen. ${ }^{85}$ Das Spektrum reicht von Formaten ohne festes Figurenensemble über Serien mit teilweise wechselnden handelnden Personen bis hin zu Formaten mit stets denselben Personen. Auch durch die Entwicklung einer Figur kann Kohärenz versinnbildlicht werden. In Episodenserien wird am Ende der Status quo meist wiederhergestellt, was zur Folge hat, dass die Figuren statisch bleiben, weder eine psychologische Entwicklung noch die Adoleszenz durchlaufen und so Stereotype darstellen. ${ }^{86}$ In Fortsetzungsserien hingegen durchlaufen die handelnden Personen Lern- und Alterungsprozesse. ${ }^{87}$ Weber und Junklewitz postulieren, dass sogar Personen außerhalb der epischen Welt, also die Beteiligten am Produktionsprozess, zur Kohärenz einer Serie beitragen: Stammautoren bzw. Regisseure und Schauspieler vermögen durch den Wiedererkennungswert Homogenität zu erzeugen und damit die Wirkung von Serienformaten nachhaltig zu prägen. $^{88}$

\subsubsection{Zur seriellen Struktur von Harry Potter}

In Rowlings siebenteiliger Fortsetzungsgeschichte weist jeder Teilband inhaltliche Geschlossenheit auf, gleichzeitig handelt es sich jeweils um Versatzstücke der übergeordneten Serienhandlungen. ${ }^{89}$ Es finden sich Schemata der unterschiedlichsten Genres, die entweder auf Ebene der Folgen- oder aber der Serienhandlungen operieren. ${ }^{90}$ Der Stellenwert einzelner Episoden im Gesamtzusammenhang ist adäquat erst nach der Lektüre des siebten Bandes einzuordnen, ein differenzierter Überblick über die Gesamthandlung kann also nur retrospektiv oder aber bei erneuter Lektüre erfolgen. ${ }^{91}$

Judith Mohr hat verschiedene Fortsetzungsstrategien bzw. Verweisstrukturen nachgewiesen: In den Bänden zwei, drei und vier garantierten ausführliche Erzählerberichte das Verfolgen der Serienhandlung, indem die Ereignisse vorheriger Bände zusammengefasst werden. ${ }^{92}$ In Band fünf hingegen werde nur noch auf die Begegnung zwischen Harry und Lord Voldemort in Band vier referiert, ab dem sechsten Band blieben Zusammenfassungen gänzlich aus. ${ }^{93}$

\footnotetext{
${ }^{84}$ Mohr (2012), S. 247.

${ }^{85}$ Weber/Junklewitz (2008), S. 24 f. Zum Figurenset siehe auch Kapitel 3.3.2.5.

${ }^{86}$ Weber/Junklewitz (2008), S. 24 f.

${ }^{87}$ Hickethier (2003), S. 401.

${ }^{88}$ Ebd.

${ }^{89}$ Vgl. Karg/Mende (2010), S. 191 und Bergenthal (2008), S. 236.

${ }^{90}$ Bergenthal (2008), insbesondere S. 156 ff., S. 192 ff., S. 237 ff. Eine umfangreiche Analyse der Handlungsstrukturen hat Fenske (2008), S. 23 ff. vorgelegt.

${ }^{91}$ Vor allem weil nur so ein „,kohärente[r] Textsinn“ zu erfassen ist, wie es Bergenthal nennt, Bergenthal (2008), S. 156.

${ }^{92}$ Mohr (2012), S. 251.

${ }^{93} \operatorname{Mohr}(2012)$, S. 252.
} 
Offenbar sei davon ausgegangen worden, dass Rezipienten des fünften, sechsten und siebten Bandes die vorherigen Bände kennen, Quersteinsteiger habe man nicht mehr erwartet. ${ }^{94}$

Die Einzelfolgen werden von der Erzählinstanz in einen temporalen Kausalzusammenhang gebracht, die Serie spiegelt zudem einen realistischen Biorhythmus wider, indem jeder Teilband ein (Schul-)Jahr behandelt und solcherart analog zum Jahresrhythmus eines Teenagers gestaltet ist. In Hogwarts erstreckt sich ein Schuljahr vom 1. September bis zum 30. Juni und endet mit dem Entlassen der Schülerinnen und Schüler in die Sommerferien. ${ }^{95}$ Fenske macht folgende temporal strukturierende Schemata aus, die in fast jedem Teilband wiederholt werden: ${ }^{96}$ Beginnend in den Sommerferien, werden zunächst der Besuch in der Winkelgasse und anschließend die Anreise zur Schule geschildert, dort gibt es dann eine Eröffnungszeremonie. Es folgen Halloween und Weihnachten. Schließlich geht es an die Prüfungen und an den ,, $f i^{-}$ nal show-down "97 der jeweiligen Folgenhandlung. Den Abschluss bilden wiederum der Sommerferienbeginn sowie die Heimfahrt der Schüler.

Der Handlungsraum wird mit jedem neuen Band erweitert, indem nach und nach Schauplätze - Häuser, Straßenzüge und sogar ganze Ortschaften wie etwa das Zaubererdorf Hogsmeade in HP 3 - hinzukommen. ${ }^{98}$ Die Ausweitung bringt in aller Regel auch eine Aufstockung des Personals mit sich, wodurch der Kernbestand aus Hauptakteuren ergänzt wird, der durch stetige Präsenz zur Kohärenz der Serie beiträgt. ${ }^{99}$ Zum festen Ensemble zählen Harry, Ron und Hermine, die Familie Weasly, einige Lehrer wie Snape, McGonagall, Dumbledore sowie Hagrid und einige Mitschüler wie Neville Longbottom oder Draco Malfoy. ${ }^{100}$ Auch die Entwicklung einzelner Figuren trägt zum Zusammenhalt der Serie bei, werden die Charaktere doch im Lauf der Handlung facettenreich ausgestaltet. So bleiben diese keine schlichten Stereotype, sondern stellen jeweils komplexe Persönlichkeiten mit bestimmten Stärken und Schwächen dar. ${ }^{101}$

\subsubsection{Zur seriellen Struktur der Post-Potter-Texte}

Um das Serialitätskonzept der Texte mithilfe des strukturgeleiteten Gattungsmodells zu analysieren, stehen nun die Oberflächenstruktur sowie der Zusammenhang von Folgen- und Seri-

\footnotetext{
${ }^{94}$ Ebd.

${ }^{95}$ Vgl. Fenske (2008), S. 76 f.

${ }^{96}$ Fenske (2008), S. 77. Karg und Mende machen darauf aufmerksam, dass diese Ordnung insbesondere ab dem vierten Band durchbrochen wird. Karg/Mende (2010), S. 192.

${ }^{97}$ Fenske (2008), S. 77.

${ }^{98}$ Mohr (2012), S. 243.

${ }^{99}$ Ebd.

${ }^{100}$ Vgl. Karg/Mende (2010), S. 195.

${ }^{101}$ Fenske (2008), S. 276 f.
} 
enhandlungen im Mittelpunkt, beispielhaft aufgezeigt an Percy Jackson (Kapitel 2.2.3.2). Kapitel 2.2.3.2 widmet sich den verwendeten Fortsetzungsstrategien, und Kapitel 2.2.3.4 beleuchtet abschließend anhand ausgewählter Aspekte, wie seriale Kohärenz geschaffen wird.

\subsubsection{Zu endlich angelegten Fortsetzungsserien}

Es ist auffällig, dass alle Texte des Korpus analog zu Harry Potter als endlich angelegte Fortsetzungsserien mit überschaubarer Bandzahl veröffentlicht wurden. ${ }^{102}$ Sowohl vonseiten der Verlage als auch im öffentlichen Diskurs werden sie mit der Gattung assoziiert und entsprechend bezeichnet: Funkes Werk als „Tintenwelt-Trilogie“"103, Giers Bücher als „EdelsteinTrilogie“104 und Collins” Text als „Panem-Trilogie“105. Wikipedia spricht von Meyers „Bis(s)-Tetralogie“106 und bezeichnet Riordans Serie als „fünfbändige FantasyBuchreihe “107.

\subsubsection{Zum Zusammenhang von Folgen- und Serienhandlung}

Die intendierte Rezeptionsreihenfolge der Post-Potter-Serien wird strukturell durch Handlungsschemata provoziert, die auf der Ebene der Serienhandlung operieren. In der Regel weisen die Folgen inhaltliche Abgeschlossenheit auf, können aber auch als Versatzstück der Serienhandlungen angesehen werden, wobei sich bestimmte Handlungsschemata konsequent wiederholen: auf Ebene der Folgenhandlungen etwa „Rettung einer Person“ und „Suche“, im Rahmen der Serienhandlung ist ein Liebesplot gängig sowie „der Kampf zwischen Gut und Böse“, der in die Bestandteile „Vorbereitung“, „Schlacht“ und „Sieg“ segmentiert werden kann. ${ }^{108}$ Die Rettung einer Person ist zumeist in drei Teilschemata gegliedert: 1 . Eine Person schwebt in Gefahr; 2. ein Held versucht die Person zu retten; 3. die Person wird gerettet. Auch das Schema „Suche“ zeigt sich in der Regel dreischrittig: 1. Jemand oder etwas geht verloren;

\footnotetext{
${ }^{102}$ Ein solches Format wird auch als Mehrteiler bezeichnet. Siehe dazu Manz (2010), S. 224.

${ }^{103}$ Siehe etwa www.dressler-verlag.de/buecher/specials/tintenherz.html (24.10.2014); http://de.wikipedia.org/wiki/Tintenwelt-Trilogie (24.10.2014); www.kinderundjugendmedien.de/index.php/werke/178-die-tintenwelt-trilogie (24.10.2014).

${ }^{104}$ Wikipedia verweist auf die gängige Bezeichnung: http://de.wikipedia.org/wiki/Liebe_geht_durch_alle_Zeiten (24.10.2014); ebenso die größte deutsche Fanseite durch ihren Namen: http://die-edelsteintrilogie.blogspot.de/ (24.10.2014).

${ }^{105}$ Siehe dazu die Internetpräsenz zur Serie vom Oetinger-Verlag: www.dietributevonpanem.de/ (24.10.2014).

${ }^{106} \mathrm{http}: / /$ de.wikipedia.org/wiki/Bis\%28s\%29_zum_Morgengrauen (24.10.2014). Kinderundjugendmedien.de (Jacqueline Mende) bezeichnet Meyers Werk als ,vierbändige Romanreihe“: www.kinderundjugendmedien.de/index.php/werke/223-twillight-die-biss-reihe (24.10.2014).

${ }^{107} \mathrm{http}: / /$ de.wikipedia.org/wiki/Percy_Jackson (24.10.2014).

${ }^{108}$ Die aufgeführten Schemata können auch vor dem Hintergrund einer Genre-Institution gelesen werden. Das Schema „Rettung einer Person“ ist beispielsweise konventionell für Abenteuerromane, ein Liebesplot ist typisch für den Liebesroman. Die Schemata werden konkreter in Kapitel 5.3.2 erläutert und dort auch an anderen Texten des Korpus nachgewiesen.
} 
2. ein Held begibt sich auf die Suche; 3. ein Held entdeckt die Person oder den Gegenstand. ${ }^{109}$ Daneben finden sich auch andere Schemata im Korpus, beispielsweise „Prophezeiung“ und „Wettkampf“. ${ }^{110}$ Allen Serien gemein stets ein logischer Zusammenhang zwischen den Schemata der Folgen- und der Serienhandlung: Mit jeder Suche bzw. Rettung kommt sich das zentrale Paar näher, bis es schließlich am Ende glücklich vereint ist. ${ }^{111}$ Jede Rettung kann zudem als ein Teilsieg des Protagonisten betrachtet werden, als Beitrag zum endgültigen Sieg über den Antagonisten.

Der Zusammenhang von Folgen- und Serienhandlung soll nun an Percy Jackson exemplarisch vorgestellt werden. Untenstehende Tabelle gibt zunächst eine Übersicht über ausgewählte Handlungsschemata der Folgenhandlungen. Schemata der Serienhandlung werden im Anschluss behandelt.

\begin{tabular}{|c|c|}
\hline & Handlungsschemata der Folgenhandlungen \\
\hline PJ 1 & $\begin{array}{l}\text { Rettung von Percys Mutter: }{ }^{112} \text { Sally Jackson kommt im Kampf mit einem Minotaurus } \\
\text { ums Leben (PJ 1, S. 69); Percy beschließt, sie zu retten (PJ 1, S. 133). Er überlegt, in } \\
\text { die Unterwelt hinabzusteigen und mit Hades zu verhandeln (PJ 1, S. 315). Als er die } \\
\text { Wahl hat, entweder Grover oder seine Mutter zu retten, entscheidet er sich für Grover } \\
\text { (PJ 1, S. } 372 \text { f.). Als Ausgleich dafür, dass Percy Hades' gestohlenen Helm findet, lässt } \\
\text { Hades Sally Jackson frei (PJ 1, S. 405). } \\
\text { Die Suche nach Zeus' Blitz: Chiron unterrichtet Percy darüber, dass Zeus' Herrscher- } \\
\text { blitz gestohlen wurde und dass der Göttervater Percy des Diebstahls bezichtigt (PJ, } \\
\text { S. 165). Percy muss den Blitz bis zur Sommersonnenwende zurückbringen (PJ 1, } \\
\text { S 167). Er macht sich auf in die Unterwelt, weil Chiron in Hades den wahren Dieb } \\
\text { vermutet (PJ 1, S. 175). Das stellt sich als Irrtum heraus (PJ 1, S. 365), denn Kronos } \\
\text { hat den Diebstahl arrangiert (PJ 1, S. } 429 \text { ff.). Percy schafft es rechtzeitig, den Blitz } \\
\text { zurückzubringen und damit die Welt vor einem Krieg zu bewahren (PJ 1, S. 401). } \\
\text { Orakelprophezeiung von Percy: } \\
\text { Herrscherblitz, aber auch den Verrat Lukes vorweg (PJ 1, S. 192). }\end{array}$ \\
\hline
\end{tabular}

${ }^{109}$ Das Schema „Suche“ kann komplexer aufgefasst werden. Burkert spezifiziert: „Bewusstwerden des Bedürfnisses, Verlassen der Basis, Entdeckung des rechten Orts, Begegnung mit Konkurrenten und potentiell gefährlichen Gegnern, Erfolg, der das Bedürfnis stillt; die Rückkehr nach Hause kann schwierig werden, es kann Verfolgung durch Konkurrenten geben; das Ziel ist die Rettung, die Selbsterhaltung. “ Zitat: Burkert (1998, S. 82). Das Abenteuerliche Schema „Suche“ meint dort die abenteuerliche Suche, die auch als Quest oder Heldenreise bezeichnet wird. Vgl. Martinez/Scheffel (2005), S. 154. Zur Heldenreise siehe auch Kapitel 4.2.3.4.

${ }^{110}$ Das Schema „Wettkampf“ kann in die Bestandteile Vorbereitung, Wettkampf, Sieg/Niederlage segmentiert werden, es findet sich beispielsweise in der Panem-Trilogie bezüglich beider Hungerspiele sowie in Harry Potter beim Trimagischen Turnier. Zu den Prophezeiungen siehe Kapitel 4.2 und 4.2.3.1.

${ }_{111}$ Zum Liebesplot siehe Kapitel 5.3.2.1.

${ }^{112}$ Zum Schema „Rettung einer Person“ siehe auch Kapitel 5.3.2.2.

${ }^{113}$ Siehe zu dieser Prophezeiung auch Kapitel 4.2.3.3. 


\begin{tabular}{|c|c|}
\hline PJ 2 & $\begin{array}{l}\text { Rettung von Grover: Dass Grover sich in Gefahr befindet, erfährt Percy in seinen } \\
\text { Träumen (u. a. PJ 2, S. } 7 \text { f., S. } 87 \text { ff.). Percy und seine Freunde finden heraus, dass } \\
\text { Grover auf der Suche nach dem Gott Pan in die Falle von Polyphem getappt ist und } \\
\text { von dem Zyklopen gefangengenommen wurde (PJ 2, S. 90). Percy und seine Freunde } \\
\text { befreien Grover (PJ 2, S. } 253 \text { ff., S. } 260 \text { f.). } \\
\text { Rettung des Camps: Thalias Baum wurde vergiftet, wodurch das Camp in schwerer } \\
\text { Gefahr ist (PJ 2, S. } 59 \text { f.). Nur ein Gegengift kann das Camp noch retten (PJ 2, S. 66). } \\
\text { Annabeth identifiziert das Goldene Vlies als Gegengift (PJ 2, S. 104). Percy und seine } \\
\text { Freunde beschaffen das Vlies (u. a. PJ 2, S. } 262 \text { f.) und retten das Camp (PJ 2, } \\
\text { S. } 301 \text { f.). } \\
\text { Orakelprophezeiung von Clarisse: Clarisse wird hilflos und allein von ihrer Mission } \\
\text { zurückkehren. Percy will verhindern, dass sie bei ihrem Auftrag versagt, und händigt } \\
\text { ihr das Vlies aus (PJ 2, S. 114, S. 277). }\end{array}$ \\
\hline PJ 3 & $\begin{array}{l}\text { Rettung von Annabeth und Artemis: }{ }^{114} \text { Annabeth wird von Kronos' Armee gefangen } \\
\text { genommen (PJ 3, S. 76); Percy beschließt - obwohl er für diese Mission nicht vorgese- } \\
\text { hen ist -, sie zu finden und zu retten (PJ 3, S. 128). Auch Artemis wird entführt (PJ 3, } \\
\text { S. } 93 \text { f.) und dazu gezwungen, das Dach der Welt zu tragen (PJ 3, S. 302). Es gelingt } \\
\text { Percy und seinen Freunden, beide zu retten (PJ 3, S. } 310 \text { ff.). } \\
\text { Die Suche nach dem gefährlichsten aller Monster: }{ }^{115} \text { Dr. Thorn unterrichtet Percy, dass } \\
\text { das gefährlichste aller Monster zurückkehren wird (PJ 3, S. 31). Percy rettet eine } \\
\text { Schlangenkuh und nennt sie Bessie (PJ 3, S. 138). Es stellt sich heraus, dass Bessie das } \\
\text { gesuchte Monster ist (PJ 3, S. 246), aber nur zur Gefahr werden kann, wenn sie geop- } \\
\text { fert wird (PJ 3, S. 270). Zeus nimmt das Tier bei sich auf und unterstellt es seinem } \\
\text { Schutz (PJ 3, S. 341). } \\
\text { Orakelprophezeiung von Zoë: Camp und Jägerinnen werden zusammenarbeiten, um } \\
\text { Artemis zu retten; Bianca und Zoë werden sterben (PJ 3, S. } 108 \text { f.). }\end{array}$ \\
\hline & $\begin{array}{l}\text { Sicherung des Camps: Das Labyrinth stellt für das Camp eine Gefahr dar, da es dort } \\
\text { einen unmittelbaren Eingang besitzt. Percy und seine Freunde befürchten, dass Luke } \\
\text { mithilfe des Ariadne-Fadens seine Armee durch das Labyrinth leiten könnte (PJ 4, } \\
\text { S. 64). Annabeth und Percy beschließen, sich im Labyrinth umzusehen (PJ 4, S. 71) } \\
\text { und noch vor Luke Dädalus zu erreichen, um ihn um den Faden zu bitten (PJ 4, } \\
\text { S. } 85 \text { f.). Als sie dessen Werkstatt erreichen, besitzt Luke bereits den Faden (PJ 4, } \\
\text { S. 331). Es kommt zur Schlacht am Labyrinthausgang zum Camp (PJ 4, S. } 380 \text { ff.). } \\
\text { Das Camp kann sich behaupten, verliert allerdings zwei Schützlinge im Kampf (PJ 4, } \\
\text { S. 394). } \\
\text { Die (unmögliche) Rettung von Bianca: Nico beschließt, seine Schwester Bianca zu } \\
\text { retten, die in Band drei von einem Roboter getötet wurde, und plant, mit Hades um sie } \\
\text { zu verhandeln (PJ 4, S. } 56 \text { f.). Bianca will aber gar nicht von den Toten auferstehen. Sie } \\
\text { wendet sich an Percy, damit er Nico zur Vernunft bringt (PJ 4, S. } 193 \text { f.). Sie zeigt sich } \\
\text { als Geist und schafft es, ihren Bruder zu überzeugen (PJ 4, S. 199 f.). } \\
\text { Orakelprophezeiung von Annabeth: Kronos wird auferstehen (PJ 4, S. } 93 \text { f.). }\end{array}$ \\
\hline
\end{tabular}

\footnotetext{
${ }^{114}$ Siehe dazu auch Kapitel 5.3.2.2.

${ }^{115}$ Siehe dazu auch Kapitel 5.3.2.3
} 
PJ 5 Die Schlacht: ${ }^{116}$ Die Schlacht zwischen Kronos und dem Olymp steht unmittelbar bevor (PJ 5, S. 13). Zusammen mit Nico bereitet sich Percy darauf vor. Er lernt die Mutter von Luke kennen, um seinen Feind besser einschätzen zu können (PJ 5, S. 113 ff.), und begibt sich in die Unterwelt. Dort badet er in der Styx, damit er unbesiegbar wird (PJ 5, S. 161 ff.). Während die anderen Götter des Olymps versuchen, Typhon in Schach zu halten (PJ 5, S. 78), sind Annabeth und Percy bemüht, Manhattan und damit auch den Olymp vor Kronos' Angriffen zu schützen (PJ 5, S 189 ff.). Es kommt zur großen Schlacht, in der Nicos und Hades' Totenarmee auf der Seite der Olympier kämpft (PJ 5, S. 374 ff.). Percy trifft im richtigen Moment die Entscheidung, Luke zu vertrauen und ihm ein Messer zu reichen. Luke opfert sich selbst, um Kronos' Sieg zu verhindern (PJ 5, S. 398 f.). Percy und seine Freunde werden mit Geschenken der Götter belohnt (PJ 5, S. $401 \mathrm{ff}$.).

Die große Weissagung: Percy wird die Entscheidung treffen, Luke ein Messer zu reichen und beim Selbstmord zu assistieren (PJ 5, S. 70).

\section{Tabelle 1: Handlungsschemata auf Ebene der Folgenhandlungen von Percy Jackson}

Parallel zu den Schemata der Folgenhandlungen entspinnt sich auf Ebene der Serienhandlungen der Kampf zwischen Kronos und den Olympiern. In dieser Schlacht tritt vor allem die Figur Lukes hervor. Als Sohn von Hermes und Wirt von Kronos vereint er symbolisch beide Parteien, den Olymp und die Titanen. Zudem repräsentiert er in seiner persönlichen Entwicklung die Etappen des Krieges auf Ebene der Serienhandlung: Im ersten Band spricht Kronos im Traum zu ihm und bringt ihn dazu, den Herrscherblitz des Zeus zu stehlen (PJ 1, S. 429). Indem Luke Kronos gehorcht, stellt er sich explizit auf dessen Seite, um den Olymp zu stürzen (PJ 1, S. 432). Im zweiten Teil vergiftet Luke den Baum der Thalia, um das Camp der Halbblute zu zerstören (PJ 2, S. 152, S. 279), und stellt anschließend für Kronos eine Armee auf dem Schiff „Prinzessin Andromeda“ zusammen (PJ 2, S. 322). Im dritten Band baut er Kronos' Armee aus, hält Annabeth gefangen und navigiert das Kreuzfahrtschiff nach Kalifornien (PJ 3, S. 294). Im vierten Band stellt Luke seinen Körper als Wirt für Kronos zur Verfügung und verleiht dem Titanen damit die Macht, sich zu erheben (PJ 4, S. 354). Im fünften Band zieht er selbst als Kronos in den Krieg gegen den Olymp, gibt aber seine wahre Persönlichkeit nicht komplett auf, denn er opfert sich am Ende selbst, um Kronos zu stürzen (PJ 5, S. 398 f.).

Auch der Liebesplot um Percy und Annabeth verleiht dem Text auf Ebene der Serienhandlungen Struktur. Er kann modellhaft in die Phasen „Einführung des zentralen Liebespaars“, „das Auftreten von Hindernissen“ und „Happy End“ eingeteilt werden: ${ }^{117}$ Annabeth kann Percy am

\footnotetext{
${ }^{116}$ Zum Schema Schlacht siehe auch Kapitel 5.3.2.2.

117 Zur Struktur des Liebesplots siehe auch Kapitel 5.3.2.1. Dort wird es auch für die Edelstein-Trilogie und die
} 
Anfang nicht ausstehen, begibt sich aber dennoch mit ihm auf die Suche nach dem Blitz des Zeus (PJ 1, S. 179 f.). Die Abenteuer im Kampf gegen Kronos schweißen die beiden zusammen, es findet eine klare Annäherung statt. Im zweiten Band gibt Annabeth Percy einen freundschaftlichen Kuss auf die Wange (PJ 2, S. 317). Im dritten Teil werden ihre Gefühle füreinander expliziter (PJ 3, S. 19 f.); obwohl Percy nicht die Erlaubnis besitzt, macht er sich auf den Weg, um Annabeth zu retten (PJ 3, S. 79). Zu diesem Zeitpunkt hat Aphrodite die beiden bereits als Liebende identifiziert (PJ 3, S. 218 f.). Nach der Rettung überkommt Percy Angst, dass Annabeth sich Artemis anschließen könnte und damit auf ewig Single bleiben müsse (PJ 3, S. 338) - unnötigerweise, wie sich später herausstellen wird. Im vierten Band verhindern Eifersüchteleien das Zusammenkommen des Liebespaars: Während Annabeth eifersüchtig auf Rachel ist (PJ 4, S. 25 ff.), kann Percy nicht damit umgehen, dass Annabeth Gefühle für Luke hegt (PJ 4, S. 343). Dennoch senden beide eindeutige Signale, so legt Annabeth im Labyrinth ihre Hand in Percys (PJ 4, S. 77). Im fünften Band schlägt Percy das Angebot der Götter aus, unsterblich zu werden, weil er sich eine Beziehung mit Annabeth wünscht. Nach gewonnener Schlacht kommen sie schließlich zusammen (PJ 5, S. 440 ff.).

Das Schema „Prophezeiung“ findet sich bei Percy Jackson auf beiden Ebenen wieder: Orakel strukturieren nicht nur die Handlungen der jeweiligen Teilbände, sondern auch - analog zu Harry Potter - die Serienhandlung, indem die Weissagung lautet, dass ein Halbblutkind der Großen Drei an seinem sechzehnten Geburtstag eine Entscheidung fällen wird, die das Zeitalter der Götter entweder retten oder zerstören wird. Wer damit konkret gemeint ist, bleibt bis zum Schluss unklar (PJ 1, S. 177, S. 186, S. 435; PJ 2, S. 67, S. 154, S. 119 f., S. 295 f.; PJ 3, S. 118; PJ 4, S. 37, S. 52): Zwischenzeitlich richtet sich die Vermutung auf Thalia, die Tochter des Zeus (PJ 3, S. 274), welche sich dann aber Artemis anschließt und damit wegfällt (PJ 3, S. 399). Danach richtet sich der Fokus auf Nico, der sich als Sohn des Hades entpuppt (PJ 3, S. 357) und um jeden Preis das Leben seiner Schwester retten will (PJ 4, S. 56 f.). Im fünften Band stellt sich heraus, dass die Prophezeiung tatsächlich Percy betrifft, der die Entscheidung trifft, Luke zu vertrauen und ihm ein Messer zu reichen. Dieser erhält dadurch den Status eines Heros, da er mit dem Messer sein Leben opfert, um Kronos' Sieg über die Olympier zu verhindern (PJ 5, S. 398 f.). Percy und seine Freunde werden mit Geschenken der Götter belohnt (PJ 5, S. 401 ff.). Konstitutiv für das Schema „Prophezeiung“ ist, dass die vorher- 
gesagten Ereignisse immer eintreffen, nur so kann es die Handlung im Voraus strukturieren. Indem Ereignisse vorweggenommen werden, sorgt es für eine Wie-Spannung. ${ }^{118}$

Das Schema „Suche“ kann auf Ebene der Serienhandlung in Grovers Suche nach Pan identifiziert werden: Im ersten Band heißt es, dass sich sämtliche Satyre und Naturgeister seit 2000 Jahren weigern zu glauben, dass Pan, der Gott der Wildnis, tot ist, und seither Sucher aussenden, um ihn zu finden (PJ 1, S. 227). Grover erhält die Suchlizenz und macht sich auf den Weg (PJ 1, S. 428 f.). Im zweiten Band verschwindet er (PJ 2, S. 37), da er von Polyphem gefangen genommen wird. Es zeigt sich, dass dies das Schicksal aller bisherigen Sucher war und kein einziger Satyr von seiner Suche zurückkehrt ist (PJ 2, S. 90). Percy und seinen Freunden gelingt es jedoch, Grover zu befreien, der daraufhin seine Ermittlungen fortsetzt. Im dritten Teil spürt Grover die Nähe von Pan, während er einen Kaffee trinkt (PJ 3, S. 206). Da er zu Beginn des vierten Bandes noch immer keine befriedigende Spur vorweisen kann, wird ihm in der Ratsversammlung der Behuften Ältesten nur noch eine Woche die Suchlizenz gewährt (PJ 4, S. 43). Er richtet seine letzte Hoffnung auf das Labyrinth (PJ 4, S. 65) und stößt dort schließlich auf eine Fährte, die ihn direkt zu Pan bringt, der gerade im Sterben liegt (PJ 4, S. 368). Pan gibt Grover den Auftrag, Satyren und Dryaden die Botschaft zu verkünden, dass der Gott der Wildnis tot sei und sie von nun an auf sich gestellt seien (PJ 4, S. 368). Der Rat wird aufgelöst, und Grover macht sich daran, die Wildnis auf eigene Faust zu retten (PJ 4, S. 398). Grover wird für seine Heldentaten im Krieg gegen Kronos belohnt, er erhält einen Sitz im Rat der Behuften Ältesten und wird zum Herrn der Wildnis erhoben (PJ 5, S. 412).

\subsubsection{Zu den Fortsetzungsstrategien der Post-Potter-Texte}

Es lässt sich beobachten, dass die Texte des Korpus am Ende eines jeden Bandes auf Ebene der Serienhandlungen Spannung erzeugen. Sie greifen dabei jeweils auf unterschiedliche Fortsetzungsstrategien zurück, ${ }^{119}$ innerhalb einer Serie allerdings ähneln sich diese. So wird etwa der anfängliche Status quo am Ende eines Bandes nicht wiederhergestellt, zum anderen stehen stets zu Beginn und am Ende - d. h. vor Beginn und nach Abschluss der Folgenhandlung - die Serienhandlungen im Mittelpunkt. Werden zunächst Erzählerberichte eingesetzt, welche die relevanten Ereignisse aus vorherigen Bänden zusammenfassen, mehren sich zum Ende Cliffhanger oder andere spannungssteigernde Techniken. Die folgende Tabelle gibt eine

\footnotetext{
${ }^{118}$ Vgl. Martinez/Scheffel (2005), S. 153.

${ }^{119}$ Kapitel 2.2.1 gibt eine Übersicht über die verschiedenen Fortsetzungsstrategien.
} 
Übersicht der Strategien am Beispiel von Tintenwelt-, Panem- und Edelstein-Trilogie sowie der Bis(s)-Serie.

\begin{tabular}{|c|c|}
\hline Bandzusammenhang & Fortsetzungsstrategie \\
\hline \multicolumn{2}{|r|}{ Tintenwelt-Trilogie } \\
\hline $\mathrm{TH} \rightarrow \mathrm{TB}$ & $\begin{array}{l}\text { Sehr schwacher Bewegungs-Suspense: Am Ende von Tintenherz sind } \\
\text { Capricorn und seine Männer besiegt, Meggie und ihre Familie glück- } \\
\text { lich vereint. Farid ist mit Staubfinger gegangen (TH, S. 559), nur um } \\
\text { Fenoglio macht Meggie sich Sorgen, der in die Tintenwelt ent- } \\
\text { schwunden ist (TH, S. 560). Sie beschließt Geschichten zu schreiben, } \\
\text { wie Fenoglio es getan hat (TH, S. 566), und mit Mo und Resa „für } \\
\text { immer bei Elinor zu bleiben“ (TH, S. 566). }\end{array}$ \\
\hline $\mathrm{TB} \rightarrow \mathrm{TT}$ & $\begin{array}{l}\text { Bewegungs-Suspense: Enttäuscht von seiner Geschichte, beschließt } \\
\text { Fenoglio, mit dem Schreiben aufzuhören, woraufhin Meggie } \\
\text { Orpheus in die Tintenwelt liest, damit er in Fenoglios Schule gehen } \\
\text { kann (TH, S. } 689 \text { ff.). Farid fasst den Entschluss, Staubfinger von } \\
\text { den Toten zurückzuholen und sich so lange in die Dienste des } \\
\text { Orpheus zu stellen, bis ihm das gelungen ist (TB, S. 707). }\end{array}$ \\
\hline \multicolumn{2}{|r|}{ Die Tribute von Panem } \\
\hline $\mathrm{TS} \rightarrow \mathrm{GL}$ & $\begin{array}{l}\text { Erzählen und Ankündigung unheilvoller Entwicklungen: Das letzte } \\
\text { Kapitel widmet sich einer Fernsehshow und einem Interview zu den } \\
\text { Hungerspielen. Dieses Setting bietet Anlass, alle wichtigen Ereig- } \\
\text { nisse der Hungerspiele noch mal Revue passieren zu lassen. Gleich- } \\
\text { zeitig wird Katniss' innere Zerrissenheit thematisiert: Einerseits ist } \\
\text { sie bei den Auftritten dazu gezwungen, vor der Kamera ein Liebes- } \\
\text { paar mit Peeta zu spielen (TS, S. } 401 \text { f.), andererseits gibt ihr der } \\
\text { Körperkontakt zu ihm Halt und Geborgenheit, sie scheint tatsäch- } \\
\text { lich Gefühle für ihn zu hegen (TS, S. } 402 \text { f.). Im privaten Gespräch } \\
\text { zwischen Peeta und ihr wird deutlich, dass er in jedem Fall Gefühle } \\
\text { für Katniss entwickelt hat. Sie hingegen ist sich nicht im Klaren } \\
\text { darüber, was sie empfindet (TS, S. } 413 \text { f.). Dass sie mit ihrem Ver- } \\
\text { halten in der Arena den Zorn des Kapitols auf sich gezogen hat, } \\
\text { wird im Text angedeutet und eine mögliche Rache des Kapitols in } \\
\text { Betracht gezogen (TS, S. } 413 \text { ). Der Hinweis „Ende des ersten Bu- } \\
\text { ches“ markiert formal, dass es eine Fortsetzung gibt (TS, S. 415). }\end{array}$ \\
\hline $\mathrm{GL} \rightarrow \mathrm{FZ}$ & $\begin{array}{l}\text { Erzählen und Ankündigung unheilvoller Entwicklungen: Aus der } \\
\text { Arena der Jubiläumshungerspiele gerettet, erfährt Katniss, dass sich } \\
\text { eine Untergrundorganisation zusammengefunden hat, um die Tribu- } \\
\text { te aus den Spielen zu befreien und die Regierung zu stürzen (GL, } \\
\text { S. 424). Sie lässt die Spiele Revue passieren und erkennt, dass } \\
\text { Haymitch sie die ganze Zeit getäuscht hat (GL, S. 426). Außerdem } \\
\text { wird sie davon in Kenntnis gesetzt, dass Peeta gefangen genommen } \\
\text { wurde (GL, S. 427). Katniss verliert daraufhin ihren Lebenswillen, }\end{array}$ \\
\hline
\end{tabular}




\begin{tabular}{|c|c|}
\hline & $\begin{array}{l}\text { sie will lieber sterben, als in solch einer Welt zu leben (GL, } \\
\text { S. } 429 \text { f.). Zudem unterrichtet Gale sie darüber, dass ihr Heimat- } \\
\text { distrikt zerstört worden ist (GL, S. 431). Ihre Reaktion darauf er- } \\
\text { fährt man nicht mehr. Der Hinweis „Ende des zweiten Buches“ } \\
\text { markiert formal, dass es eine Fortsetzung gibt (GL, S. 431). }\end{array}$ \\
\hline \multicolumn{2}{|r|}{ Edelstein-Trilogie } \\
\hline $\mathrm{RR} \rightarrow \mathrm{SB}$ & $\begin{array}{l}\text { Bewegungs-Suspense: Gideon macht am Ende von RR erstmals } \\
\text { seine Gefühle für Gwendolyn deutlich und küsst sie (RR, S. 338). } \\
\text { Weitere Abenteuer mit Gideon und Gwendolyn werden in Aussicht } \\
\text { gestellt (RR, S. 337). } \\
\text { Erzählen: Der darauffolgende Epilog erzählt aus Perspektive eines } \\
\text { anderen Pärchens, das durch Interpretation, insbesondere wenn man } \\
\text { SB und SG kennt, als Lucy und Paul identifiziert werden kann. Dass } \\
\text { Gwendolyn ihre Tochter ist, wird hier bereits angedeutet (RR, } \\
\text { S. 342). }\end{array}$ \\
\hline $\mathrm{SB} \rightarrow \mathrm{SG}$ & $\begin{array}{l}\text { Bewegungs-Suspense: Gideon gibt zu, dass er geplant hat, Gwen- } \\
\text { dolyn in sich verliebt zu machen, weil es die Prophezeiungen und } \\
\text { der Graf so vorgesehen haben (SB, S. 371). Für Gwendolyn bricht } \\
\text { eine Welt zusammen, sie verfällt in Liebeskummer. Es bleibt offen, } \\
\text { ob Gideon nicht trotzdem Gefühle für sie hegt, er bekommt nicht } \\
\text { die Chance, sich zu erklären (SB, S. 371). } \\
\text { Erzählen und klassischer Suspense: Der darauffolgende Epilog er- } \\
\text { zählt aus der Perspektive Pauls. Er unterrichtet in einer seiner Zeit- } \\
\text { reisen Gideon davon, dass Gwendolyn sterben wird, wenn Gideon } \\
\text { weiterhin (genau wie alle Wächter) dem Grafen von Saint Germain } \\
\text { zuarbeitet (SB, S. 387). Ob Gideon ihm Glauben schenkt oder nicht, } \\
\text { erfährt man in SB nicht. }\end{array}$ \\
\hline \multicolumn{2}{|r|}{ Bis $(s)$-Trilogie } \\
\hline BzMo $\rightarrow$ BzMi & $\begin{array}{l}\text { Klassischer Suspense: Zwei mögliche Fortgänge werden zur Dispo- } \\
\text { sition gestellt: Wird Bella langfristig ein Mensch bleiben, oder wil- } \\
\text { ligt Edward ein, sie in einen Vampir zu verwandeln? (BzMo, } \\
\text { S. 511). }\end{array}$ \\
\hline $\mathrm{BzMi} \rightarrow \mathrm{BzAb}$ & $\begin{array}{l}\text { Klassischer Suspense und Ankündigung unheilvoller Entwicklun- } \\
\text { gen: Noch immer muss Bella sich entscheiden, ob sie zum Vampir } \\
\text { werden will. Sie hat sich zwar mit den Cullens dazu entschlossen } \\
\text { (BzMi, S. } 527 \text { ff.), ihr bester Freund Jacob jedoch will das unbe- } \\
\text { dingt verhindern, da sein Indianerstamm sie dann umbringen würde } \\
\text { (BzMi, S. 558). Die Volturi hingegen schicken sich an, Bella zu } \\
\text { töten, wenn sie nicht zum Vampir wird (BzMi, S. 558). Die böse } \\
\text { Vampirfrau Victoria ist immer noch auf freiem Fuß und bringt alle } \\
\text { in Bellas Umgebung in Gefahr (BzMi, S. 558). }\end{array}$ \\
\hline $\mathrm{BzAb} \rightarrow \mathrm{BzEdN}$ & $\begin{array}{l}\text { Bewegungs-Suspense: Bella weist Edwards körperliche Annähe- } \\
\text { rungen zurück. Sie entschließt sich dazu, erst mit ihm zu schlafen, }\end{array}$ \\
\hline
\end{tabular}




\begin{tabular}{|l|l|}
\hline & $\begin{array}{l}\text { wenn sie verheiratet sind, und sich auch erst danach in einen Vam- } \\
\text { pir verwandeln zu lassen (BzAb, S. 609 f.). Sie macht sich daran, } \\
\text { ihrem Vater von der Hochzeit zu erzählen, wohl wissend, dass er } \\
\text { nicht begeistert sein wird (BzAb, S. 611). } \\
\text { Erzählen und Ankündigung unheilvoller Entwicklungen: Der Epilog } \\
\text { wird aus Jacobs Sicht erzählt. Edward lädt ihn in Form eines Briefes } \\
\text { zur Hochzeit ein; Jacob reagiert emotional und beschließt, wegzu- } \\
\text { laufen (BzA, S. 616 ff.). Wie sich Jacob langfristig zu der Situation } \\
\text { verhalten wird, bleibt im Dunkeln. }\end{array}$ \\
\hline
\end{tabular}

Tabelle 2: Fortsetzungsstrategien der Post-Potter-Texte

Bei der Edelstein-Trilogie ist besonders signifikant, dass jeder Band mit einem Prolog beginnt und mit einem Epilog endet, die beide in der Vergangenheit zu verorten sind und - anders als die übrigen Kapitel - nicht aus Gwendolyns Perspektive erzählt werden. Es liegt dabei allein beim Rezipienten, die Ereignisse in Beziehung zu den jeweiligen Folgen- und Serienhandlungen zu setzen, eine Kontextualisierung wird von der Erzählinstanz nicht vorgenommen. Oftmals erschließt sich der Zusammenhang erst retrospektiv, d. h. wenn der Rezipient auf Wissen aus späteren Kapiteln zurückgreifen kann. Der Epilog des dritten und letzten Bandes bildet diesbezüglich eine Ausnahme: Obwohl in der Vergangenheit verortet, deutet er die Zukunft Gwendolyns und Gideons an. Im Rahmen der Serienhandlung arbeitet der Text vor allem mit der Strategie des Bewegungs-Suspense sowie der Fragestellung, ob Gwendolyn und Gideon ein Paar werden oder nicht, etwa indem am Ende einer Folge die Andeutung einer neuen Entwicklung bezüglich des Liebesglücks der beiden steht, wobei der weitere Verlauf erst im nächsten Band genauer einzuschätzen ist. Zu Beginn eines neuen Bandes fasst die IchErzählerin die Entwicklungen auf und fasst die wichtigsten Ereignisse des Vorbandes zusammen, womit dem Rezipienten der Einstieg in die Fortsetzung erleichtert wird. So berichtet Gwendolyn etwa in Saphirblau von Gideons Kuss:

Gideon de Villiers hatte mich - Gwendolyn Shepherd - geküsst. [...] Mir hätte auch zu denken geben
können, dass eine Wand mit einem Beichtstuhlfenster zwischen uns war, durch das Gideon seinen Kopf
und seine Arme gezwängt hatte, und dass das keine idealen Bedingungen für einen Kuss waren, mal
ganz abgesehen von dem Fakt, dass ich nicht noch mehr Chaos in meinem Leben brauchen konnte,
nachdem ich gerade erst vor drei Tagen erfahren hatte, dass ich das Zeitreise-Gen von meiner Familie
geerbt hatte. (SB, S. 19 f.) In Smaragdgrün wiederholt sie im Erzählerbericht des ersten Kapitels die Erkenntnis, dass Gideon ihr seine Gefühle nur vorgespielt habe:

Die Erlebnisse des gestrigen Tages (und die Tage davor) schrien nicht gerade danach, sich gemütlich unter der Decke zusammenzukuscheln [...]. Gideon hat mir nur etwas vorgespielt. Er liebt mich nicht. (SG, S. 18) 
In der Panem-Trilogie kann vor allem die Ankündigung unheilvoller Entwicklungen als dominante Fortsetzungsstrategie ausgemacht werden. Sowohl am Ende von Tödliche Spiele als auch von Gefährliche Liebe stehen einerseits ein Happy End - nämlich Katniss’ Überleben beider Hungerspiele -, andererseits eine Mangel- bzw. Notsituation: Während im ersten Band angedeutet wird, dass Katniss durch ihr Verhalten in der Arena den Zorn des Kapitols auf sich gezogen hat (TS, S. 413), erfährt sie im zweiten Band, dass Peeta vom Kapitol gefangen genommen wurde (GL, S. 426) und dass ihr Heimatdistrikt zerstört worden ist (GL, S. 431). Auch in dieser Serie werden zu Beginn eines neuen Bandes die wichtigsten Ereignisse des Vorbandes zusammengefasst (GL, S. 10 f.; FZ, S. 9 f.).

Die Fortsetzungsstrategie der Bis(s)-Serie besteht in erster Linie in der Fragestellung, ob sich Bella in einen Vampir verwandeln lässt oder nicht. Während am Ende von BzMo die Frage im Raum steht, ob Edward eine Verwandlung aus ethischen Gründen zulassen wird, verschiebt sich der Fokus am Ende von BzMi auf die Volturi und die Quileute und deren Einfluss auf Bellas Entscheidung. Sollte die Verwandlung ursprünglich direkt nach ihrem Schulabschluss erfolgen (BzMi, S. 527) und damit zeitlogisch am Ende des dritten Bandes, beschließt Bella die Verwandlung aufzuschieben. Auf diese Weise wird die Frage auch zum Cliffhanger zwischen BzAb und BzEdN.

In der Tintenwelt-Trilogie zeigt sich im Vergleich zu den anderen Texten des Korpus nur eine sehr schwach ausgeprägte Spannungssteigerung am Ende des ersten Bandes. Einzig, dass Fenoglio in die Tintenwelt abgetaucht ist, trübt das Happy End, und auch das nur in geringem Maße, denn er ,ist in keiner schlechten Geschichte gelandet“, wie Resa bemerkt (TH, S. 561). Zudem verweist der Entschluss, ,für immer bei Elinor zu bleiben “ (TH, S. 566), auf eine glückliche Zukunft von Meggies Familie und damit auf das Ende der Geschichte. So muss die bei einer Fortsetzung übliche Mangelsituation zu Beginn von Tintenblut nachgeholt werden: Funke bringt hier die Harmonie ins Wanken, die am Ende von Tintenherz geherrscht hatte: Mo macht sich große Sorgen um Meggie, denn seine Tochter hat nur noch die Tintenwelt im Kopf (TB, S. 36 ff.). Geschürt von den Ausführungen ihrer Mutter wird ihr Fernweh unerträglich, sodass sie sich entschließt, zusammen mit Farid in die Tintenwelt zu entschwinden, wohlwissend, was sie ihren Eltern damit antut (TB, S. 111 ff.). Das Tableau für Tinten- 
blut und Tintentod ist erst mit dieser Entscheidung bereitet, denn damit wird eine Situation hergestellt, die die Fortsetzung der Handlung motiviert. ${ }^{120}$

\subsubsection{Zur intraserialen Kohärenz der Post-Potter-Texte}

Zwei verschiedene Aspekte serialer Kohärenz stehen nun im Mittelpunkt: Die Verortung in einen temporalen Kausalzusammenhang soll anhand von Percy Jackson, der Bis(s)-Serie sowie der Edelstein-Trilogie aufgezeigt werden, die intraseriale Gestaltung von Handlungsraum und Figurenensemble anhand der Tintenwelt- sowie der Edelstein-Trilogie.

\section{Zum temporalen Kausalzusammenhang}

Die Texte des Korpus erzeugen Kohärenz, indem die Handlungen in einem temporalen Kausalzusammenhang stehen. Die Chronologie der Ereignisse ist grundsätzlich sowohl auf Ebene der Folgen- als auch der Serienhandlungen rekonstruierbar und lehnt sich an reale Zeitstrukturen sowie den Biorhythmus der Rezipienten an. Damit unterscheiden sich die Werke grundlegend von allen Serienformaten, deren Handlungen und Episoden nicht explizit in einen temporalen Kausalzusammenhang verortet werden. Die konkrete temporale Rahmung bei den hier betrachteten Werken ist allerdings von Serie zu Serie verschieden.

Percy Jackson folgt in seiner Grundstruktur dem Jahresrhythmus eines amerikanischen Schülers, der in den Sommermonaten mehrere Wochen unterrichtsfrei hat. ${ }^{121}$ Jeder Band spielt in den Sommerferien, wo Percy regelmäßig das Camp Half-Blood besucht (PJ 1, S. 439, PJ 2, S. 321; PJ 4, S. 13; PJ 5, S. 11). Eine Ausnahme stellt lediglich der dritte Band dar, der den Winter mit einbezieht, als Percy gerade vierzehn geworden ist (PJ 3, S. 7, S. 35, S. 358). ${ }^{122}$ Die Pentalogie deckt so eine Zeitspanne von insgesamt vier Jahren ab: Percy durchlebt auf Ebene der Serienhandlung die zentralen Jahre der Pubertät: Zu Beginn des ersten Bandes ist er zwölf Jahre alt (PJ 1, S. 10), im Finale des letzten Bandes wird er sechzehn (PJ 5, S. 440). Ausgespart bleibt das Schuljahr, welches Percy jeweils bei seiner Mutter verbringt. Der Er-

\footnotetext{
${ }^{120}$ Die Kritiken von Tintenblut und Tintentod sind im Vergleich zum ersten Band der Serie wesentlich schlechter ausgefallen. Alex Rühle kritisiert 2010 in der Süddeutschen Zeitung vor allem den dritten Teil: Man habe „, schnell Mitleid mit den Figuren, wie sie am Ende eines jeden Kapitels schon wieder am Cliff hängen und dann zehn, zwanzig Seiten warten müssen, was sich Fenoglio, Orpheus oder Cornelia Funke als Nächstes für sie ausdenken." Die Figuren würden „flach und plan durch 740 Seiten geschoben"; www.sueddeutsche.de/kultur/fantasy-roman-tintentod-genuscheltes-fantasy-esperanto-1.790358 (23.12.2014).

121 Je nach Bundesstaat liegen die Sommerferien unterschiedlich, füllen aber stets mehrere Wochen in der Zeit von Mai bis August.

${ }^{122}$ Der erste Band reicht beispielweise von Mai (PJ 1, S. 10) bis Juli (PJ 1, S. 418). Percys Geburtstag im August wird nicht erzählt. Band zwei setzt dann mit Ende des nächsten Schuljahrs ein, also im Juni des Folgesommers (PJ 2, S. 275), Band drei im Winter des gleichen Jahres (PJ 3, S. 7).
} 
zähler fasst die Ereignisse dieser Zeit stets in groben Zügen zusammen, was für die Rezipienten besonders bedeutsam ist, da die Erzählpausen gegenüber der erzählten Zeit eine große Zeitspanne in Anspruch nehmen. Die Zusammenfassung zwischen Band 1 und Band 2 stellt sich beispielsweise folgendermaßen dar:

Der letzte Schultag. Meine Mom hatte Recht. Ich hätte vor Begeisterung außer mir sein müssen. Zum ersten Mal in meinem Leben hatte ich ein ganzes Schuljahr durchgehalten, ohne von der Schule zu fliegen. Keine seltsamen Unfälle. Keine Kämpfe im Klassenzimmer. Keine Lehrerinnen, die sich in Ungeheuer verwandelten und versuchten, mich mit vergiftetem Mensaessen oder explodierenden Hausaufgaben umzubringen. Am nächsten Morgen würde ich mich auf den Weg zu dem Ort machen, der mir der liebste auf dieser Welt war - ins Camp Half-Blood. (PJ 2, S. 11)

Die Strategie, die Erzählpausen zwischen den Einzelbänden aus Perspektive der Erzählinstanz rückblickend zu füllen, findet sich regelmäßig bei den Texten des Korpus wieder. ${ }^{123}$ Eine solche Verknüpfung schafft nicht nur eine klare Zeitlogik und Orientierung für den Rezipienten, sondern erzeugt auch den Effekt, dass die Figuren ein Leben außerhalb der erzählten Zeit besitzen, das sie in der Erzählpause weitergeführt haben. Damit wird eine literarische Zeit etabliert, die simultan zu der des Rezipienten verläuft, wodurch der Eindruck von Authentizität entsteht.

Die Bis(s)-Serie deckt eine erzählte Zeit von insgesamt ungefähr zwei Jahren ab, wobei die erzählte Zeit in jedem Teilband unterschiedlich lang andauert: ${ }^{124}$ Während der zweite und vierte Band ungefähr acht Monate behandeln, umfasst der erste Band ca. fünf Monate, der dritte Band etwa einen Monat. Die temporale Einordnung der Ereignisse erfolgt hier genauso wie bei den anderen Texten des Korpus in Form von Figurenrede und Erzählerkommentar, seltener in Form von Paratexten. Auch hier folgt das Geschehen einer zeitlichen Logik, indem die Ich-Erzählerin Bella die Ereignisse der Erzählpause zu Beginn eines jeden neuen Bandes zusammenfasst. Temporale Kohärenz entsteht durch markierte Zeitraffungen und Zeitsprünge, wodurch die Ereignisse in das Raster einer realistischen Zeitzählung einpasst werden. ${ }^{125}$

\footnotetext{
${ }^{123}$ Vgl. auch beispielsweise BzMo, S. 12; BzEdN, S. 39; TB, S. 38 und S. 46.

${ }^{124}$ Die Bände fügen sich harmonisch in den Jahresrhythmus des amerikanischen Schulsystems ein: Bella steigt im Januar in das neue Schuljahr ein, im gleichen Monat rettet Edward ihr Leben (BzMo, S. 70), den Monat nach dem Unfall meidet Edward sie (BzMo, S. 74), im März bekommt sie einen Anruf von Jessica (BzMo, S. 77), am Ende des ersten Bandes geht sie mit Edward zum Jahresabschlussball (BzMo, S. 509 ff.), der sich auf Mai datieren lässt. Es folgt eine Erzählpause zwischen Band 1 und 2, die nach dem Muster des amerikanischen Schulsystems als die Schulferien zwischen Juni und August identifiziert werden können (BzMi, S. 12). BzMi beginnt am 13. September (BzMi, S. 12), Bellas achtzehntem Geburtstag. Edward verlässt sie, und sie verbringt die folgenden acht Monate allein (BzMi, S. 545). Der zweite Teil endet somit im April. Der dritte Band setzt kurz vor den Ferien, wenige Wochen vor Bellas Schulabschluss, ein (BzAb, S. 32, S. 43), also im Mai, und endet im Juni (BzAb, S. 466). Der letzte Band startet einen Tag vor Bellas Hochzeit am 13. August (BzAb, S. 603; BzEdN, S. 38, S. 66) und endet einen Tag nach Silvester (BzEdN, S. 706).

125 Zahlreiche Beispiele sind dazu aufzuführen. Am Ende des zweiten Bandes berichtet Bella etwa von ihren
} 
Eine Sequenz aus dem Gespräch zwischen Jacob und Edward am Ende von BzAb zeigt exemplarisch, wie im Rahmen einer Figurenrede temporale Kontinuität auf Ebene der Serienhandlung geschaffen wird: ,, Weißt du, wenn sie im März nicht von den Klippen gesprungen wäre ... “ (BzAb, S. 498) Jacob bezieht sich hier auf eine Begebenheit des zweiten Bandes und versieht sie mit einer temporalen Markierung. Mit dem Satz stellt er einen Zusammenhang zwischen beiden Bänden her und verschafft dem Rezipienten damit intraserial temporale Orientierung. Als paratextuelle temporale Markierungen haben in der Bis(s)-Serie vor allem die Kapitel „Oktober“ (BzMi, S. 91), „November“ (BzMi, S. 92), „Dezember“ (BzMi, S. 93) und „Januar“ (BzMi, S. 93) des zweiten Bandes zu gelten, die nur aus eben diesen Überschriften bestehen und damit lediglich eine leere Seite betiteln. Es liegt nahe, dass sie Bellas innere Leere versinnbildlichen sollen, nachdem Edward sie verlassen hat. Gleichzeitig schaffen die Kapitel temporale Orientierung, indem sie die Erzählpause visuell zum Ausdruck bringen.

Auch das weniger chronologisch als zyklisch erzählte Werk von Kerstin Gier stellt die Ereignisse in einen temporalen Kausalzusammenhang. Die Zeitsprünge ereignen sich in der Logik des Textes innerhalb von zwei Wochen und werden durch entsprechende Markierungen in eine chronologische Abfolge gebracht. Wie in der Bis(s)-Serie ist die erzählte Zeit nicht gleichmäßig verteilt: Während im ersten Band ca. zweieinhalb Tage verhandelt werden, nimmt der zweite ungefähr fünf Tage und der dritte fast eine ganze Woche in den Blick. ${ }^{126}$ Zwischen den einzelnen Bänden werden keine Erzählpausen eingeschoben, jeder neue Band schließt unmittelbar an die Ereignisse des vorigen an. Zum Serienkonzept gehören zudem fiktive Dokumente aus verschiedenen Zeiten, die von unterschiedlichen Personen, Institutionen und Organisationen stammen und meist am Ende eines Kapitels in Zitatform abgedruckt werden. Insbesondere die Dokumente aus den „Annalen“ (zum Beispiel RR, S. 31) und „Chroniken der Wächter“ (zum Beispiel SG, S. 167), die bestimmte Ereignisse der Vergan-

vergeblichen Versuchen, Kontakt zu Jacob aufzunehmen: „, Wochen vergingen, und Jacob ging immer noch nicht ans Telefon [...] “ (BzMi, S. 546). Nicht selten kommen konkrete Daten vor: „,Der kleine Kalender in der Ecke des Displays verriet mir, dass heute der dreizehnte September war “ (BzMi, S. 12). Auch Feiertage dienen zur Orientierung: „Ich verdrehte die Augen, aber in Wahrheit hatte ich völlig vergessen, dass bald Weihnachten war" (BzEdN, S. 663).

${ }^{126}$ Die Handlung von Rubinrot beginnt am Montagmorgen in Gwendolyns Schule (RR, S. 13) und endet zwei Tage später gegen Mittag mit einem kontrollierten Zeitsprung in das Jahr 1912, bei dem sich Gwendolyn und Gideon in der Kirche küssen (vgl. RR, S. 234, S. 308, S. 343). Saphirblau setzt unmittelbar mit dieser Kirchenszene ein (SB, S. 19) und verhandelt die Zeitspanne von Mittwochnachmittag über Donnerstag - an dem ein Zeitsprung ins Jahr 1953 stattfindet -, Freitag (SB, S. 177) - an dem ein Zeitsprung ins Jahr 1956 erfolgt -, Samstag (SB, S. 261), Sonntag (SB, S. 194) - Gwendolyn und Gideon reisen auf eine Soiree im Jahr 1782 - bis Montag, wo Gwendolyn ein Gespräch mit dem Grafen im Jahre 1782 führt (SG, S. 307). Smaragdgrün setzt am Tag danach, also Dienstag ein (SG, S. 18) und endet am Montag der darauffolgenden Woche in Gwendolyns Schule (SG, S. 471). 
genheit zusammenfassen und genau datieren, liefern einen Beitrag zur temporalen Einordnung der Geschehnisse. Der Zusammenhang dieser Dokumente mit der diegetischen Gegenwart muss allerdings vom Rezipienten selbst erschlossen werden. Nicht selten ist dies erst retrospektiv mit größerer Textkenntnis möglich.

\section{Zur Ausdifferenzierung und Erweiterung von Handlungsraum und Figurenen- semble}

In allen hier ausgewählten Serien kann beobachtet werden, dass die zugrundeliegenden Raumschemata ausgebaut oder ausdifferenziert werden und dass mit einem festen Figurenensemble gearbeitet wird, ${ }^{127}$ das von Band zu Band erweitert oder modifiziert wird.

In Funkes Trilogie etwa kommt im Übergang von Tintenherz zu Tintenblut ein gänzlich neuer Handlungsraum - hinzu, die Tintenwelt, welche in Tintentod noch erweitert wird. ${ }^{129}$ Visuell nachvollziehbar wird dies durch beigefügte Karten am Ende der Bände zwei und drei, wobei die Karte in Tintentod mit nur wenig Überlappung an die in Tintenblut anschließt. ${ }^{130}$ Beispielsweise werden die Burg am See oder der Baum mit den Nestern ergänzt, was sich insofern in das kohärente Raumschema der Serie einfügt, als in beiden Fällen bereits etablierte Schauplätze erweitert werden. Die Tintenwelt wird in Tintenherz als Bestandteil der Diegese eingeführt, wenn auch nicht explizit bespielt (TH, S. 363, S. 433, S. 561). Die Schauplätze in Tintentod passen sich in das Raumschema ein, indem sie sich topografisch in zuvor genannte Handlungsräume einordnen lassen: So befindet sich der Baum mit den Nestern ,,im Norden von Ombra “ (TT, S. 526), einer Stadt, die dem Rezipienten bereits aus dem zweiten Teil geläufig ist (zum Beispiel TB, S. 66) und auf der dortigen Karte markiert wurde (TB, S. 708).

Zum festen Figurenensemble, die in allen drei Bänden intraseriale Kohärenz gewährleisten zu nennen sind Mo, Meggie, Resa, Staubfinger, Farid, Elinor, Fenoglio, Darius, Basta und Mortula -, ${ }^{131}$ treten im zweiten Band u. a. Orpheus, der Natternkopf und seine Tochter Violante, Roxane, Baptista und der Schwarze Prinz hinzu, die dann sowohl in Tintenblut als auch in Tintentod eine zentrale Rolle spielen. Auch im dritten Band werden Personen eingeführt,

\footnotetext{
${ }^{127}$ Zur Kohärenz der Serien tragen auch die Beteiligten am Produktions- und Vermarktungsprozess bei, vor allem die Autorinnen und Autoren, Übersetzer sowie die Schauspieler der Verfilmungen. Vgl. dazu Bergenthal (2008), S. 424.

${ }^{128}$ Zum Begriff Ausgangswelt siehe Kapitel 3.3.2.1.

${ }^{129}$ Mohr (2012), S. 432.

${ }^{130}$ Vgl. ebd, TB, S. 708 und TT, S. 740.

${ }^{131}$ Vgl. die Namen- und Ortsregister am Ende der Bände: TB, S. 712 ff.; TT, S. 741 ff.
} 
beispielsweise Doria als jüngerer Bruder des Starken Mannes (TT, S. 124), welcher später Meggies Herz höherschlagen lässt. Darüber hinaus tauchen zwei phantastische Wesen auf und werden zu Handlungsträgern, ein Riese und ein Nachtmahr. ${ }^{132}$ Insgesamt wirkt der erste Band wie losgelöst von der Serie: Tintenherz besitzt im Vergleich zu den Folgebänden sowohl einen anderen Handlungsort als auch einen anderen Antagonisten. Zudem besteht durch das Happy End nahezu keine Notwendigkeit einer inhaltlichen Weiterführung (vgl. Tabelle 2), denn damit wird kaum Spannung erzeugt. Diese intraseriale Inkohärenz könnte der Tatsache geschuldet sein, dass die Autorin ursprünglich keine Trilogie geplant hatte, wie Funke in einem Interview verrät. ${ }^{133}$ In Giers Edelstein-Trilogie wird das Raumschema ebenfalls kontinuierlich ausdifferenziert, zudem schaffen oft verwendete Schauplätze Kohärenz: Der grundsätzliche Handlungsraum London bleibt während der ganzen Serie bestehen, wird aber detaillierter ausgestaltet, sowohl die gegenwärtige als auch die historische Metropole, wo neue Schauplätze wie der Hauptsitz der Wächter in Temple oder das Wohnhaus der Montroses das Stadtbild spezifizieren. In Saphirblau wird das Haus von Lord Brompton mit seinem Salon eingeführt (SB, S. 284 f.). Das Haupthaus der Wächter in Temple bekommt immer mehr Zimmer, sodass sich das Raumschema hier ständig ändert: In Rubinrot wird sowohl der „Dokumentenraum“ (RR, S. 147) als auch das „,Behandlungszimmer“ (RR, S. 162) von Dr. White vorgestellt, in Saphirblau erstmals „,das Alte Refektorium“ (SB, S. 123 f.) im Erdgeschoss sowie das Büro des Grafen im ersten Stock (SB, S. 353). Ist bis dato die Lage der einzelnen Räume, insbesondere des Chronografenraums, schwer zu orten (vgl. SG, S. 112 f., S. 179), taucht in Smaragdgrün ein Lageplan der unterirdischen Gänge von Temple auf, mithilfe dessen sich Gwendolyn und Gideon in der Anlage orientieren können (SG, S. 424). Die Ausdifferenzierung des Figurenensembles, wobei auch hier ein fester Kern für Kohärenz sorgt, wird in den Personenverzeichnissen der Einzelfolgen ersichtlich. Im zweiten Band kommen Mr. Marley und Giordano aus der zunächst diffusen Masse der Wächter hinzu, welche dann in Saphirblau ein konkretes Profil erhalten. ${ }^{134}$ In Smaragdgrün wird Gwendolyns Großvater Lucas Montrose ins Ensemble aufgenommen, der in der Vergangenheit ebenfalls ein Großmeister der Loge war.

\footnotetext{
${ }^{132}$ Vgl. Mohr (2012), S. 242 f.

133 www.kinderbuch-couch.de/interview-cornelia-funke.html (1.11.2014). Vgl. auch Mohr (2012), S. 226; www.sueddeutsche.de/kultur/fantasy-roman-tintentod-genuscheltes-fantasy-esperanto-1.790358. Es lässt sich mutmaßen, dass der kommerzielle Erfolg die Autorin dazu veranlasst hat, weiterzuschreiben.

${ }^{134}$ Vgl. die Personenverzeichnisse der drei Bände: RR, S. 344 f.; SB, 393 ff.; SG, S. 485 ff.
} 


\subsection{Resümee}

Harry Potter und die Korpustexte zeigen starke Ähnlichkeiten bezüglich der seriellen Strukturen: ${ }^{135}$ Alle liegen als Mehrteiler mit überschaubarer Bandzahl vor und werden als endlich angelegte Fortsetzungsserien vertrieben. Jeder Einzelband weist inhaltliche Geschlossenheit auf, die vor allem durch Handlungsschemata erreicht wird, die auf der Ebene der jeweiligen Folgenhandlung operieren. Häufig sind dort die Motive „Rettung einer Person“ und „Suche “ zu beobachten. Gleichzeitig fungiert jede Folge als Versatzstück der Serienhandlungen, die ebenfalls durch Handlungsschemata organisiert werden. Auf dieser Ebene ist mehrfach ein Liebesplot auszumachen sowie das Motiv „Kampf zwischen Gut und Böse“. Auch bezüglich der Zeit-, Raum- und Figurenkonzeption erweisen sich Harry Potter und die Texte des Korpus als kohärentes Serienformat. Zu beobachten ist, dass die Einzelbände in einen temporalen Kausalzusammenhang gestellt sind, der an außerdiegetische Biorhythmen angelehnt ist. Immer wieder genutzte Schauplätze und ein fester Kern von Handlungsträgern tragen ebenfalls zur Kohärenz bei, daneben erfahren alle Texte mit voranschreitender Erzählung sukzessiv Erweiterung und Ausdifferenzierung von Handlungsraum und Figurenensemble. Zusammen mit intraserialen Querverweisen ist damit strukturbedingt eine Rezeptionsreihenfolge vorgegeben, die einzuhalten ist, wenn sowohl Folgenhandlungen als auch die stetig voranschreitende Serienhandlung nachvollzogen werden wollen. Um den Einstieg bzw. Quereinstieg in die jeweilige Fortsetzung zu erleichtern, wird zu Beginn eines neuen Bandes stets eine Zusammenfassung vorangegangener Ereignisse gegeben. Darüber hinaus werden jeweils am Ende der Bände Fragen aufgeworfen, oder es kündigen sich unheilvolle Ereignisse an - hier zeigen sich traditionelle Strategien der Spannungssteigerung, wie sie in serieller Literatur häufig angewendet werden. Die Texte weisen zwar unterschiedliche Fortsetzungsstrategien auf, nutzen diese aber jeweils dominant als Komponenten ihres Serialitätskonzepts.

Im deutschsprachigen Raum hat sich bislang noch kein adäquater Genrebegriff etabliert, der die unterschiedlichen Komponenten des Serialitätskonzepts berücksichtigt. Sowohl in der literaturwissenschaftlichen Forschung als auch im öffentlichen Diskurs werden die hier betrachteten Werke unterschiedlich bezeichnet: Während Schlachter bei „Harry Potter, Twilight, Die Tribute von Panem \& Co “ von Zyklen spricht, ${ }^{136}$ behandelt Mohr Rowlings Werk als eine Kombination aus Mehrteiler und Episodenserie. ${ }^{137}$ Die Biss-Serie vermarktet sich auf

\footnotetext{
${ }^{135}$ Vgl. Schlachter (2013), S. 109.

${ }^{136}$ Schlachter (2013), S. $108 \mathrm{f}$.

${ }^{137}$ Mohr (2012), S. 224 f.
} 
ihrer Homepage bei Carlsen selbst als Saga. ${ }^{138}$ Zudem wird der Begriff der Reihe für diese Art serieller Literatur bemüht. ${ }^{139}$

${ }^{138}$ www.carlsen.de/blog/zehn-jahre-twilight, (11.7.2018).

139 Kinderundjugendmedien.de (Jacqueline Mende) bezeichnet Meyers Werk als „vierbändige Romanreihe“: www.kinderundjugendmedien.de/index.php/werke/223-twillight-die-biss-reihe (24.10.2014). Wikipedia nutzt den Begriff für Percy Jackson: http://de.wikipedia.org/wiki/Percy_Jackson (24.10.2014). 


\section{Die Post-Potter-Texte als phantastische Literatur}

Viele Forschungsdiskurse über zeitgenössische Kinder- und Jugendliteratur betrachten Harry Potter sowie sich anschließende Serien, die an Rowlings Werk erinnern, als innovative phantastische $^{1}$ Literatur bzw. als sich neu etablierendes Subgenre der Fantasy. ${ }^{2}$ Auch in den Massenmedien sowie den Kommunikationsorganen des deutschsprachigen wie internationalen Buchhandels werden sie so gekennzeichnet und in entsprechende Bestsellerlisten bzw. Buchhandlungsabteilungen eingeordnet. ${ }^{3}$ Phantastische Literatur ist damit die gängigste Variante, Harry Potter und seine Nachfolger einer Gattung zuzuordnen. ${ }^{4}$

Innerhalb der literaturwissenschaftlichen Forschung lassen sich grundsätzlich zwei Herangehensweisen unterscheiden, wenn es darum geht, „das phantastische Wesen“ eines Textes herauszuarbeiten und zur gattungsweisenden Eigenschaft zu erheben. Entsprechende Genremodelle fokussieren zumeist Inhalt und Wirkung, daneben gibt es abstraktere Vorgehensweisen im Kategorisierungsbemühen, welche die Struktur der phantastischen Welten in den Mittelpunkt stellen. Beide Perspektiven wurden bereits bei Harry Potter eingenommen, hier sollen nun die Ergebnisse der Potter-Forschung zusammengefasst und mit einer eigenen Analyse der Post-Potter-Texte abgeglichen werden: Welchem phantastischen Genre können Harry Potter und seine Nachfolger zugeordnet werden? Handelt es sich überhaupt um dasselbe Genre? Welche gemeinsamen gattungsweisenden Charakteristika sind auszumachen? Weisen die Werke diesbezüglich ähnliche Strukturen auf?

Im Anschluss an eine kurze Einführung in die Theorie und Geschichte der Phantastik (Kapitel 3.1) sollen phantastische Genremodelle im Zentrum stehen, um anschließend, ausgehend von einem ausgewählten Genremodell, die Zugehörigkeit der Post-Potter-Texte zum phantastischen Genre zu diskutieren (Kapitel 3.2). Dabei soll vorerst geklärt werden, wie eine solche Klassifizierung aus wissenschaftlicher Perspektive zu bewerten ist. Der sich anschließende Teil verfolgt eine strukturgeleitete Analyse der Korpustexte als phantastischer Wirklichkeitsentwürfe (Kapitel 3.3). Der Klassifizierung liegt die Vorstellung einer phantastischen Diegese

\footnotetext{
${ }^{1}$ In dieser Arbeit wird - Zitate ggf. ausgenommen - die traditionelle Schreibweise verwendet.

${ }^{2}$ Zu Harry Potter als Fantasy-Roman siehe u. a. Elstner (2004), 3-11; Bergenthal (2008), S. 337; de Grandpair (2011); Fenske (2008), S. 382 f.; Karg/Mende (2010), S. 186 ff.; zu den Post-Potter-Texten im Kontext phantastischer Literatur siehe u. a. Bergenthal (2008), S. 400; Heber (2010), S. 9 f.; Schlachter (2014), S. 1.

${ }^{3}$ Bei LovelyBooks wird Harry Potter unter der Kategorie „Die besten Fantasy-Reihen und Serien aller Zeiten Fantasy Bestseller" auf Platz 2 gelistet: www.lovelybooks.de/buecher/fantasy/Die-besten-Fantasy-Reihenund-Serien-aller-Zeiten-Fantasy-Bestseller-464906403/ (26.8.2014); auf FictionFantasy taucht der dritte Band der Serie auf Platz 12 auf: www.fictionfantasy.de/die-besten-fantasy-buecher (26.8.2014).

${ }^{4}$ Vgl. Bürvenich (2001), S. 163.
} 
zugrunde, die als gattungsweisend betrachtet werden kann und deren Spezifizierung bei der Textbetrachtung herangezogen wird. Postuliert wird, dass jeder Diegese ein oder mehrere Wirklichkeitsentwürfe zugrundeliegen, die in Form verschiedener Repräsentanten realisiert werden. Indem die Analyse versucht, die Struktur in den Blick zu nehmen, setzt sie erst dann an, wenn ein Text bereits der Phantastik zugeordnet wurde.

Das Fazit am Ende des Kapitels fasst die Ergebnisse zusammen und zeigt die gemeinsamen phantastischen Elemente der hier betrachteten Texte auf (Kapitel 3.4).

\subsection{Zu Theorie und Geschichte der phantastischen Literatur}

Um das theoretische und begriffliche Fundament sowohl der Genrebetrachtungen als auch der strukturgeleiteten Analyse bereitstellen, wird zunächst der Begriff der phantastischen Literatur vorgestellt (Kapitel 3.1.1). Es folgt ein kurzer Abriss sowohl zur Forschung als auch zur Geschichte, wobei der Fokus auf Werken der Gattung bis Harry Potter liegt (Kapitel 3.1.2).

\subsubsection{Zum Begriff der phantastischen Literatur}

Je nach Forschungsinteresse werden die Begriffe „Phantastik“, „Phantastisches“, „Fantasie“ und „Fantasy“ unterschiedlich verstanden und verwendet. ${ }^{5}$ Der Terminus Phantastik bezeichnet in der Forschung nicht allein eine Gattung, eine Textsorte oder ein Genre im engeren Sinne, sondern etwa auch einen Modus, eine Schreibweise bzw. eine Stilkategorie ${ }^{6}-$ oder aber eine atmosphärische Textzugabe, die sich einer Klassifizierung und theoretischen Fundierung gänzlich entzieht. ${ }^{7}$ Dies ist vor allem dem Umstand geschuldet, dass es sich nicht um ein rein literarisches, sondern um ein medienübergreifendes Phänomen handelt, das in der Kunst generell zu finden ist. Zymner, der das Phantastische als „Schreibweise“ betrachtet, formuliert dazu:

Diese Schreibweisen sind dann jeweils medien- oder bereichsspezifische (eben literarische) Ausdrucksformen eines allgemeinen, übergreifenden Verfahrens, das in ganz unterschiedlichen künstlerischen Formen und Bereichen auftreten und sich ganz unterschiedlicher Mittel bedienen kann und das wir mit dem Ausdruck ,Phantastik“ bezeichnen. ${ }^{8}$

Horstkotte indes unterscheidet zwischen dem Modus des Phantastischen und des Realistischen. Ersteren bezieht er zwar ausschließlich auf literarische Werke, versteht darunter jedoch keine spezifische Textsorte, sondern meint, dass phantastische Texteigenschaften weder gen-

\footnotetext{
${ }^{5}$ Siehe u. a. Haas (2005), S. 117-134; Callois (1974), S. 44-84 und Kaulen (2004), S. 12-20.

${ }^{6}$ Vgl. Lehmann (2003), S. 25.

${ }^{7}$ Simonis (2005), S. 21, in Anlehnung an Howard Phillips Lovecraft.

${ }^{8}$ Zymner (2003b), S. 299.
} 
rebildend seien noch thematisch oder formal festgelegt werden könnten. Vielmehr trügen beide Modi, losgelöst von Gattungsgrenzen, zur Konstruktion literarischer Weltentwürfe bei. ${ }^{9}$ Beide Überlegungen mögen - vor allem aus kulturwissenschaftlicher Perspektive - durchaus berechtigt sein, verkennen jedoch den Sachverhalt, dass sich „Phantastisches“ sehr wohl als dominante Struktur in literarischen Texten verankern kann und eigene Genres zu prägen imstande ist, welche in der Öffentlichkeit auch als solche wahrgenommen werden, ${ }^{10}$ wie Fantasy-Literatur-Regale in Buchhandlungen oder Fantasy-Bestsellerlisten beweisen. ${ }^{11}$ Dementsprechend wird hier postuliert, dass das literarisch Phantastische nicht nur thematisch beschrieben werden kann, sondern auch tatsächlich spezifische Genres hervorbringt. Doch was zeichnet dann solche Texte aus?

Im künstlerischen Kontext wird die Phantastik zunächst als ein Prinzip verstanden, das es ermöglicht, ungewöhnliche Weltmodelle und Wirklichkeitsvorstellungen zu generieren. Sie erschafft dabei nicht nur ,,gebaute, strukturierte Imagination “12, sondern steht für einen ontologisch basierten Zweifel an der Wissenschaft, das produktive Prinzip , heterogene[r] Kombinatorik" ${ }^{\prime 13}$, und damit nicht nur das Erschrecken vor, sondern gleichsam den Protest gegen eine rationale Weltsicht. ${ }^{14}$ Durch Phantastik wird die Sicherheit der Weltordnung gestört oder sogar negiert; hieraus resultieren Angst, Verwirrung und Instabilität - oder eben ein Empfinden von Freiheit. ${ }^{15}$ Sie ist als Gegenpol der Realistik aufzufassen, die auf dem Erkenntniswert beruht, den die kunsteigene Wirklichkeit in ihrer Relation zur äußeren Realität bietet. ${ }^{16}$ Die Phantastik unterscheidet sich von der Fantasie insofern, als Letztere einen erkenntnistheoretischen Begriff darstellt, der die künstlerische Kompetenz, Imagination und Kreativität des Menschen umfasst, das heißt Aspekte, die potenziell für jedes künstlerische Produkt, jede Gattung relevant sind, also nicht ausschließlich für die Phantastik. ${ }^{17}$ Während der Begriff Fik-

\footnotetext{
${ }^{9}$ Horstkotte (2004), passim.

${ }^{10}$ Zum Genrebegriff siehe Kapitel 1.3.

${ }^{11}$ Siehe dazu beispielsweise die Fantasy-Bestseller-Liste von LovelyBooks: www.lovelybooks.de/buecher/fantasy/Die-besten-Fantasy-Reihen-und-Serien-aller-Zeiten-FantasyBestseller-464906403/ (14.03.2014); oder die Internetpräsenz von Amazon, die in ihrem Buchverkauf die Sparte „Fantasy, Science Fiction und \& Vampire“ aufgenommen hat: www.amazon.de/science-fictionfantasy-vampire/b?ie=UTF8\&node=142 (14.03.2014).

${ }^{12}$ Kesting (1975), S. 368 f.

${ }^{13}$ Lévi-Strauss (1973), S. 24.

${ }^{14}$ Rottensteiner (1987), S. 13 f.

${ }^{15}$ Vgl. Lehmann (2003), S. 30.

${ }^{16}$ Kohl (1977), S. 194.

${ }^{17}$ Vgl. Rank (2011), S. 169.
} 
tionalität als literaturtheoretische Kategorie zu betrachten ist, die einen ontologischen Status von Erzählungen beschreibt, ${ }^{18}$ meint Phantastik eine Darstellungskunst.

Phantastik (oder auch Fantastik ${ }^{19}$ ) bezeichnet eine Darstellungskunst von Wirklichkeitsmodellen, die sich ihrer Beschaffenheit und ihrem Wesen nach von der historischsozialen Wirklichkeitserfahrung unterscheiden. ${ }^{20}$ Phantastik ist somit die Kunst der Abweichung, die Abweichung von einer bestimmten Norm bzw. die bewusste Überschreitung und Infragestellung derselben, sie ist damit als Ambivalenz- und Schwellenphänomen aufzufassen. ${ }^{21}$

Ein künstlerisches Element, das diese künstlerische und/oder bewusste Abweichung bewirkt, wird als phantastisch bezeichnet. Literatur gilt demzufolge als phantastisch, wenn jenes Wirklichkeitsmodell, das sich empirisch-rationalen Regeln entzieht, erzählerisch geschaffen wird. Ein Text wird also als phantastisch bezeichnet, wenn er viele phantastische Elemente aufweist, die dies vermögen. Das Wesen der Phantastik ist so gesehen das Spiel mit der erdachten Regel, der imaginierten Norm, den sich daraus entspinnenden Konsequenzen, Implikationen und Situationen. Sie ist die immer wieder neu paraphrasierte Antwort auf die Frage „Was wäre, wenn?“, die sich in einem erzählten Gedankenspiel offenbart.

Tzvetan Todorov, der die Gattungsdiskussion um phantastische Texte mit seiner im Jahre 1970 erschienenen Abhandlung angestoßen hat und bis heute maßgeblich prägt, stellt die Unschlüssigkeit des Lesers, die phantastische Elemente ihm zufolge bei der Lektüre hervorrufen, in den Mittelpunkt seiner Definition. So grenzt er das Phantastische vom „,Wunderbaren“،22 ab, bei dem sämtliche Ereignisse als zweifelsfrei übernatürlich markiert sind. ${ }^{23}$ Der Eindruck des Phantastischen ergebe sich, wenn das Unmögliche, Unheimliche und Unaufgeklärte in Bezug auf Raum-, Zeit- und/oder Figuren- und Handlungskonzeption vorliegt, ${ }^{24}$ ohne dass dafür eine realistisch-logische oder übernatürlich-irrationale Erklärung geliefert wird, woraufhin der Leser in Bezug auf die erzählten Normabweichungen unschlüssig zurückgelassen werde. Ein Text sei dann als phantastisch anzusehen, wenn die irritierenden Elemente signifi-

\footnotetext{
${ }^{18}$ Martinez/Scheffel (2005), S. 19.

${ }^{19}$ So zum Beispiel bei Buddecke (1993).

${ }^{20}$ Rank (2011), S. 171.

${ }^{21}$ Vgl. Lehmann (2003), S. 30.

${ }^{22}$ Durst (2001), S. 99.

${ }^{23}$ Die Erstausgabe seiner Abhandlung ist unter dem Titel Introduction à la littérature fantastique erschienen und wird nach wie vor im zeitgenössischen Forschungsdiskurs standardmäßig aufgegriffen.

${ }^{24}$ Nach Todorov (1970) ist das rein Phantastische erst dann gegeben, wenn nicht aufgeklärt wird, ob das übernatürlich erscheinende Ereignis tatsächlich übernatürlich ist oder rational erklärbar wäre.
} 
kant den Gesamteindruck prägten. ${ }^{25}$ Todorov legt in seiner Definition das Augenmerk auf die Rezeption, was bei einer literaturwissenschaftlichen Analyse, die bestrebt ist, Sachverhalte am Text zu belegen, sicherlich heikel ist. Die Wirkung eines Textes ist bei der Identifizierung phantastischer Elemente immer von Bedeutung, zumal Phantastisches immer die Abweichung von einer Norm darstellt; diese modellbedingte Problematik kann nicht zur Gänze umgangen werden. Indem die Klassifizierung auf individueller Wahrnehmung basiert, ist sie zwar prinzipiell begründbar, aber schwerlich belegbar, und deshalb als Genrezuweisung zu verstehen, ${ }^{26}$ als rekursives Urteil. Ein Text ist phantastisch, wenn er als phantastisch wahrgenommen wird, und als phantastisch wahrgenommen wird das, was die fiktionsexterne empirische Wirklichkeit $^{27}$ des Rezipienten unterläuft und daher als phantastisch bewertet wird. ${ }^{28}$ Auch wenn die Identifizierung unpräzise wirkt, scheint die Begründung mithilfe konventionalisierter, als phantastisch erachteter Motive (im Sinne des Common Sense) die beste Lösung darzustellen. Ein Gegenmodell, wie es Durst vorschlägt, das versucht, ein Bezugssystem zu begründen, „, das ausschließlich innerhalb der Texte existiert, nicht im außerfiktionalen Wirklichkeitsempfinden des Lesers [... “'29, kann wenig überzeugen, da es bei der Definition des Wunderbaren, das sich in gleicher Weise zirkulär innerhalb der textimmanenten Realität zeigt, außer Acht lässt, dass die Kategorie Phantastik begrifflich bereits auf Wirkung, Empfindung oder Beurteilung abhebt. Diese (modellbedingte) Problematik sei im Folgenden außen vor gelassen. Folgende Definition soll hier als Basis dienen, die Zuordnung der Korpustexte zur phantastischen Literatur zu untersuchen: ${ }^{30}$

Phantastische Literatur ist der Oberbegriff für ein literarisches Genre, in dem ein alternatives, von der Realität abweichendes literarisches Wirklichkeitsmodell entworfen wird. ${ }^{31}$ Dieses gründet sich auf phantastische Elemente (Motive, Figuren, Schauplätze usw.), die von einem kulturell verbundenen Rezipientenkreis als solche bewertet

\footnotetext{
${ }^{25}$ Vgl. Abraham (2010), S. 41.

${ }^{26}$ Siehe Kapitel 1.3.

${ }^{27}$ Dieser Begriff ist als Gegenbegriff zur textimmanenten Wirklichkeit zu verstehen, die innerhalb der Diegese Maßstab allen Denkens ist. Er meint daher die empirische Realität.

${ }^{28}$ Eine textimmanente Variante, phantastische Elemente in einem Text zu identifizieren, hat Durst (2001) vorgelegt.

${ }^{29}$ Durst (2001), S. 88.

${ }^{30}$ Auf eine klare Zuordnung zur Phantastik wird hier verzichtet. Dafür erfolgt an späterer Stelle eine Zuweisung zur Fantasy. Bei der Begründung, das Korpus der Phantastik zuzuordnen, könnten lediglich konventionell als phantastisch bewertete Elemente herangezogen werden, Dazu zählen u. a. der Verweis auf Vampire, Werwölfe, Zeitsprünge, übernatürliche Fähigkeiten, Magie, Parallelwelten - ein solche Analyse wäre ein wenig erkenntnisgenerierendes Prozedere.

${ }^{31}$ Dies hängt insbesondere vom kulturellen Kontext des Rezipienten ab.
} 
werden, ${ }^{32}$ das heißt, die den kulturell etablierten Realitätsbegriff samt seiner logischen und naturgesetzlichen Implikationen unterlaufen. ${ }^{33}$ Nach heutigem, modernem Verständnis sind dies primär Elemente, die sich rationalen Begründungszusammenhängen, vor allem naturwissenschaftlichen Regeln entziehen und als unerklärlich, übernatürlich, unvorstellbar und daher unwirklich betrachtet werden. Dazu zählen Magie, übernatürliche Wesen, fiktionale Länder und Welten sowie zyklische Zeitstrukturen. Von phantastischer Literatur soll erst dann gesprochen werden, wenn die übernatürlichen Geschehnisse und phantastischen Darstellungsmittel eine dominante, für die gesamte Textstruktur konstitutive Bedeutung erlangen. ${ }^{34}$ Der phantastischen Literatur gegenübergestellt ist die realistische Literatur, die modellbedingt „Possible Worlds“ in ihren Narrationen etabliert, das heißt, nicht unbedingt aktuelle, aber durchaus mögliche Varianten unserer Alltagswelt. ${ }^{35}$

\subsubsection{Zur Geschichte der phantastischen Literatur}

In Deutschland ist die Vorstellung phantastischer Texte mit der Wiederentdeckung der Ballade in den 1770er-Jahren in Verbindung zu bringen, bei der phantastische Elemente von Anfang an eine zentrale Rolle spielten, die sich vor allem in situationsbezogenen Gefühlen zeigten. ${ }^{36}$ Die sich parallel entwickelnde phantastische Novelle, wie sie zum Beispiel in Goethes Unterhaltungen deutscher Ausgewanderten (1795) auszumachen ist, hat laut Freund ihren Höhepunkt in der Romantik und ihren Abschluss im Werk Theodor Storms. Sie betont stärker als die Ballade den Prozess, den phantastische Elemente provozieren und der zu einer Verstrickung führt, aus der sich das Individuum nicht befreien kann. ${ }^{37}$ Der Eigentümlichkeit des deutschen Romans im 19. Jahrhundert sei es geschuldet, dass sich die Verknüpfung mit der Phantastik, wie sie in Kubins Die andere Seite (1909) erstmals realisiert ist, hierzulande später als beispielsweise in England etablierte. ${ }^{38}$

Phantastische Kinder- und Jugendliteratur taucht in Deutschland ab dem 17. Jahrhundert auf; ihren ersten deutlichen Anstoß erfährt auch sie mit der Romantik, die als erste Blütezeit des

\footnotetext{
${ }^{32}$ Vgl. Zgorzelski (1987), S. 23, Fludernik (1996), S. 37 f.

${ }^{33}$ Vgl. Zymner (2003b), S. 300.

${ }^{34}$ Vgl. Kaulen (2004), S. 14.

${ }^{35}$ Der Begriff „Possible Worlds“ stammt von Ryan (2005) und gründet ebenfalls auf subjektiven Beurteilungen: Was als „Possible Worlds“ zu betrachten ist, bleibt daher genauso strittig wie das, was als ,impossible“ bzw. phantastisch gilt. Vgl. Mohr (2012), S. $28 \mathrm{f}$.

${ }^{36}$ Freund (1999), S. 15.

${ }^{37}$ Ebd., S. 127.

${ }^{38}$ Ebd., S. 194.
} 
Genres zu verstehen ist. ${ }^{39}$ Die zeittypische starke Begeisterung für Märchen und Mythen war für die phantastische Kinder- und Jugendliteratur prägend. ${ }^{40}$ Von Anbeginn war der Diskurs um das Genre, der seit dem 18. Jahrhundert andauert, mit starken Vorurteilen belastet. Während in englischsprachigen Ländern gattungsweisende Texte entstanden, zum Beispiel von Edith Nesbit, die die Zeitreise in der Kinderliteratur populär machte, oder Alices Abenteuer im Wunderland (1869) von Lewis Carroll, die alle zu zeitlosen Klassikern avancierten, ${ }^{41}$ führte das realistisch geprägte Literaturverständnis hierzulande dazu, dass sich bis ins 20. Jahrhundert hinein sehr wenige Autoren dem Genre widmeten, dies betraf ebenso die Erwachsenensparte. ${ }^{42}$ Bis heute wird mitunter ein Trivialitätsvorwurf laut und den Texten vor allem im Bereich der Kinder- und Jugendliteratur jegliche ästhetische und pädagogische Qualität abgesprochen. ${ }^{43}$ Haas dazu:

Dies gilt auch für die lange Zeit durch bürgerlich-konservative Komponenten stark bestimmte Kinderund Jugendliteratur. Die meist niedlich-märchenhaften, von Zwerglein, sprechenden Tieren oder Pflanzen und Ähnlichem bevölkerten Bilderbuchgeschichten für Kinder, die es natürlich gab (und gibt), stellten kein Äquivalent dar für echte und profilierte fantastische Texte. Erst ab Mitte der 60er-Jahre des 20. Jahrhunderts beginnt sich das zu ändern. ${ }^{44}$

In den 1960er-Jahren entdeckten Autoren wie Otfried Preußler allmählich die Möglichkeiten des Phantastischen. Bücher wie Michael Endes Jim Knopf und Lukas der Lokomotivführer (1960) knüpften direkt an der Romantik an, indem sie märchenhafte Spiel- und Spiegelwelten erschufen, die pointiert Parallelen zur Realität herausstellten. ${ }^{45}$ Hierauf folgten problemorientierte, dann stark psychologisierte Texte, die nicht mehr das als eindimensional angesehene Märchen, sondern die Sage zum Vorbild hatten. ${ }^{46}$ Das Trost- und Entlastungspotenzial, welches phantastische Literatur für Kinder- und Jugendliche zweifelsohne besitzt, wurde in hohem Maße in den 70ern ausgeschöpft. Im Zuge der gescheiterten antiautoritären Bewegung und einer zunehmenden Hinwendung zur „Neuen Subjektivität“ stellt sich ein Held ${ }^{47}$ Problemen und belastenden familiären Schwierigkeiten, die im Schutzraum des Phantastischen Lösungen finden und dort spielerisch eine kindgerechte, antirealistische Entlastung erfahren. ${ }^{48}$

\footnotetext{
${ }^{39}$ Haas (2001), S. 16.

40 Tabbert (2000), S. 192.

${ }^{41}$ Ebd., S. 192.

${ }^{42}$ Haas (2001), S. 20.

${ }^{43}$ Ebd., S. 18.

${ }^{44}$ Ebd., S. 19.

${ }^{45}$ Rank (2011), S. 181.

${ }^{46}$ Ebd., S. 183.

${ }^{47}$ Der Begriff „Held“ wird hier als Sammelname für weibliche und männliche Protagonisten in der Tradition des Abenteuerromans verwendet.

${ }^{48}$ Nickel-Bacon weist auch darauf hin, dass erst sehr viel später in der Geschichte der Kinder- und Jugendliteratur die Verunsicherung thematisiert wird, die Lösungswege im Schutzraum des Phantastischen für ein aufge-
} 
Die Werke von Astrid Lindgren sind hier als Beispiel zu nennen. Darüber hinaus erscheinen Bücher mit aufklärerischem Impetus, welche die Parallelwelt nutzen, um gesellschaftliche Konflikte parabelhaft zu verdeutlichen, ${ }^{49}$ so etwa in Nöstlingers Wir pfeifen auf den Gurkenkönig (1972). ${ }^{50}$ Diese Tendenz verstärkt sich noch in den 80ern durch erfolgreiche Dystopien wie Die Wolke (1987). Exemplarisch für den sich seit den 80ern etablierenden psychologischen Kinderroman kann Der Wunschpunsch (1989) gelten. Und mit der Publikation von Der Herr der Ringe (1969/1970) wurde wohl das Gattungsparadigma der Fantasy-Literatur geschaffen, die sich mit einiger Verzögerung auch auf dem deutschen Buchmarkt durchsetzte. ${ }^{51}$ Insbesondere das Werk der Hohlbeins sowie von Kai Mayer und Peter Freund setzten ab den 90ern die Tradition fort. Um die Jahrtausendwende zeichnete sich phantastische Kinder- und Jugendliteratur dann in Anpassung an die neuen Chancen und Herausforderungen der postmodernen Mediengesellschaft im Allgemeinen durch stilistische und thematische Umschwünge aus. Harry Potter ist hierfür das beste Beispiel. Es etablierten sich postmoderne Erzählstrukturen wie semantische Unbestimmtheit, interpretatorische Offenheit, Intertextualität, Polyphonie, Metafiktion oder eine gewollte und initiierte Leserbeteiligung. ${ }^{52}$ Auch wenn das Kino längst als Vorbild diente, resümiert Gansel, wurden von den Kinder- und Jugendbuchautoren nur vereinzelt narrative Verfahren des Films auf ihre Texte übertragen. Er schreibt über die Literatur Mitte der 90er:

Das Wie der literarischen Darstellung bleibt letztlich weitgehend traditionell, die schnelle Schnittfolge, das Auflösen narrativer Strukturen, Montageformen und Multiperspektivik finden sich nur in Ansätzen. $^{53}$

Laut Ewers gibt es - und das nicht nur im Bereich der phantastischen Kinder- und Jugendliteratur - eine klare Tendenz zur Unterhaltung, zur Trivialität, die sich den anspruchsvollen Themen unserer Zeit entziehe oder sie flach und undifferenziert behandle. So verschlössen sich die Texte zwar nicht thematisch dem medialen Umbruch, verhandelten ihn aber unreflektiert, indem sie die Medienkultur pauschal herabwürdigten und aus unnachvollziehbaren Gründen fast im Sinne einer Konvention herabsetzten. ${ }^{54}$

\footnotetext{
klärtes Weltbild eigentlich bedeuten. Siehe dazu und zum vorigen: Nickel-Bacon (2008), S. 393 f.

${ }^{49}$ Ebd., S. 393.

${ }^{50}$ Tabbert (2000), S. 193.

${ }^{51}$ Vgl. Seibel (2004), S. 11.

${ }^{52}$ Rank (2011), S. 184.

${ }^{53}$ Gansel (1998a), S. 79.

${ }^{54}$ Vgl. Ewers (2000a), S. 11.
} 


\subsection{Zum phantastischen Genre von Harry Potter und den Post-Potter-Texten}

Bevor hier die Zuordnung von Harry Potter (Kapitel 3.2.3) und den Post-Potter-Texten (Kapitel 3.2.4) zum phantastischen Genre diskutiert wird, erfolgt zunächst eine allgemeine Einführung in phantastische Genremodelle (Kapitel 3.2.1), so auch in jenes, das die Grundlage dazu liefern soll (Kapitel 3.2.2). Ein Zwischenfazit fasst anschließend die Ergebnisse der Analyse zusammen (Kapitel 3.2.5).

\subsubsection{Phantastische Genremodelle}

Einem Genremodell der Phantastik steht implizit oder explizit immer ein Genremodell der Realistik gegenüber, eine Konsequenz der Vorstellung, dass sich literarische Erzähltexte disjunktiv in diese zwei Gattungen trennen lassen. ${ }^{55}$ Anschließend können beide wiederum in verschiedene (Sub-)Genres untergeteilt werden. Insgesamt scheinen Genremodelle der realistischen Literatur in der literaturwissenschaftlichen Forschung etablierter zu sein, zumindest werden sie wesentlich häufiger und umfangreicher besprochen. ${ }^{56}$ Das grundsätzliche Kriterium, nach dem ein Text der realistischen oder phantastischen Literatur zugeordnet wird, ist, wie sich zeigen wird, stark definitionsabhängig und unterliegt je nach Modell zahlreichen Kontextbedingungen. Die Zuweisung erfolgt zudem in der Regel aufgrund einer bewussten Konzentration auf ein bestimmtes Thema oder Motiv, welches als dominant und gattungsweisend erachtet wird. Eine solche Reduzierung ist immer eine Entscheidung, die zwar plausibel gemacht werden, aber keine Objektivität beanspruchen kann.

Bei der realistischen Literatur bestimmt der Inhalt die Einordnung in Gattungskategorien wie beispielsweise Krimi, Pferdeliteratur, Horrorgeschichte, Liebesroman, Internats- oder Adoleszenzroman, je nachdem welches Thema als dominant erachtet wird. Ähnlich verhält es sich bei der Klassifizierung phantastischer Texte, wobei - so viel sei vorweggenommen - eine sinnvolle thematische Unterteilung wesentlich schwerer zu begründen ist.

Aus der Art und Weise, wie der phantastische Weltentwurf beschaffen ist oder in welcher Form er vermittelt wird, haben sich in der Geschichte vor dem Hintergrund unterschiedlicher sozialer Kontextbedingungen zahlreiche Genrevorstellungen herausgebildet, anhand derer die

\footnotetext{
${ }^{55}$ In den meisten Fällen wird daher implizit das Gattungsmodell „Epik, Lyrik und Dramatik“ zugrunde gelegt, das entsprechend weiter spezifiziert wird: In aller Regel bezieht sich die Klassifikation zwischen realistischer und phantastischer Literatur nur auf Erzähltexte, nicht aber auf Lyrik und Drama, so auch bei Mohr (2012), S. 28.

${ }^{56}$ Mohr (2012), S. 28. Grundsätzlich sind aber auch da die genauen Kriterien umstritten, welche Genres vor dem Hintergrund welcher Texteigenschaften auszumachen sind.
} 
Unterteilung der phantastischen Literatur in divergente Subgattungen erfolgt. Genau wie bei der realistischen Literatur sind die Unterscheidungskriterien und Klassifikationssysteme stark individuell geprägt und können solcherart schwerlich Objektivität beanspruchen, auch wenn zahlreiche Modelle hier einen gegenteiligen Eindruck erwecken. In der Regel erfolgt die Entscheidung, verschiedene Texte demselben Genre zuzuordnen, aufgrund wahrgenommener Ähnlichkeiten, die sich auf das alternative Wirklichkeitsmodell beziehen und die als personen- oder institutionsgebundene Interpretation zu begreifen sind. Nach der Schematheorie liegt jedem Genre ein Schema zugrunde, das unter bestimmten Voraussetzungen aufgerufen werden kann und den Verstehensprozess des Rezipienten nicht unerheblich beeinflusst oder sogar gezielt steuert. ${ }^{57}$ So führen spezifische Eigenschaftskonstellationen mal mehr, mal weniger komplexer Art zu spezifischen Genreschemata, die sich entweder natürlich oder fremdbestimmt aus dem Gefüge von Gattungserwartungen und Werkantworten ergeben. ${ }^{58}$ Aus literaturwissenschaftlicher Perspektive ist es nicht möglich, die Existenz einzelner Genre zu belegen. Nachweisbar sind nur die ähnlichen Eigenschaften der Texte, nicht aber die Wahrnehmung dieser Ähnlichkeiten oder die Entscheidung der jeweiligen Diskursteilnehmer, den Text vor dem Hintergrund einer bestimmten Genre-Tradition zu lesen. Es bleibt an dieser Stelle daher nur, zu spekulieren, welche spezifischen Eigenschaftskonstellationen als Gattungsbzw. Genresignale wahrgenommen werden und welche Erwartungen diese beim Rezipienten in Bezug auf Handlungsverlauf, Figurenkonzeption und Motivik während der Lektüre wecken. Es verwundert nicht, dass die von den Diskursteilnehmern vorgeschlagenen Genrekategorien der Phantastik stark variieren, können diese doch modellbedingt keine Objektivität beanspruchen. ${ }^{59}$ Allerdings scheinen manche Zuteilungen auf einem breiteren Konsens aufzubauen als andere, vor allem folgende Genres werden im deutschsprachigen Diskurs vermehrt verwendet: Volksmärchen, Kunstmärchen, Fantasy, Science Fiction, (Anti-)Utopie, Schauerroman (bzw. Horrorerzählung) und phantastische Erzählung. ${ }^{60}$ Daneben ist aber auch die Kategorisierung in andere Grundtypen üblich, je nach Klassifikationsschema. ${ }^{61}$ Weiterhin werden Sage, Legende und Mythos zur Phantastik gezählt, wobei eine solche Kategorisierung

\footnotetext{
${ }^{57}$ Vgl. beispielsweise Ingarden (1968) und Thornedyke (1984).

${ }^{58}$ Siehe hierzu Kapitel 1.3.

${ }^{59} \mathrm{Vgl}$. dazu Weinkauff/von Glasenapp (2010), S. 100.

${ }^{60}$ Rank (2011), S. 171; Weinkauff/von Glasenapp (2010), S. 101; Mohr (2012), S. 28.

${ }^{61}$ Siehe zum Beispiel Rank (2011), S. 127-141 oder Lypp (1984), S. 105, die zwischen „Phantastik des Übergangs “ und „Phantastik des Kontrasts “ unterscheidet, oder Tabbert (2000), S. 187, der von „fantastischwunderbaren“" und „,fantastisch-unheimlichen“ Erzählungen spricht; auch die Unterscheidung „,komischfantastische Erzählung“ vs. Schauerroman findet sich in der Forschung, etwa bei Klingberg (1984), S. 269; Hume (1984, S. 18) unterteilt die Phantastik schließlich in Literatur der Illusion, der Vision, der Re-Vision und der Desillusion; Gansel (1998a, S. 78) ergänzt beispielsweise die Computer-Novel.
} 
stärker umstritten ist als die vorherigen Beispiele, da sie noch stärker vom gesellschaftlichen und historischen Kontext ihrer Produktion und Rezeption abhängen. ${ }^{62}$

Nach der hier zugrundeliegenden Definition werden nur die Texte als phantastisch angesehen, die durch übernatürliche und unheimliche Textelemente den zur Entstehungszeit gängigen Realitätsbegriff zugunsten eines Gegenentwurfs unterlaufen, also jenen Realitätsbegriff, der während der Literaturproduktion gesellschaftlichen Konsens gefunden hat und Maßstab allen Denkens war. Demnach werden mittelalterliche Texte wie der Parzival - wie es auch Forschungskonsens ist - nicht als phantastisch eingestuft, da sie zu ihrer Zeit kein gegenläufiges Weltmodell literarisch etablierten oder auf diese Weise gelesen wurden. ${ }^{63}$ Ohne entsprechendes historisches Vorwissen können solcherart Texte allenfalls aus heutiger Perspektive als phantastisch wahrgenommen werden. Bei Mythen wiederum ist einstweilen strittig, inwiefern sie dem Genre zuordbar sind. Wurden die klassischen Werke hier zu unterschiedlichsten Zeiten und von unterschiedlichsten Gesellschaften, also unter unterschiedlichsten Rahmenbedingen auf unterschiedlichste Weise rezipiert und interpretiert, werden rezent die unterschiedlichsten Auffassungen in der Forschung vertreten, welche Texte und Textsorten eigentlich als Mythos zu bezeichnen sind. So gibt es Klassifizierungsdiskurse, die unter Mythen auch zeitgenössische Texte verstehen, die eine Weltdeutung zur Verfügung stellen, auch solche, die dies auf allegorische Weise bewerkstelligen. ${ }^{64}$ Doch auch wenn diesen eine ähnliche Grundfunktion wie ihren antiken Vorläufern zu eigen ist, so kennzeichnet sie doch ein klarer Unterschied in Bezug auf ihre Botschaft: Während die klassischen Mythen eine wörtliche und im religiösen Sinne „wahre“ Aussageabsicht verfolgten, weichen die modernen Vertreter zugunsten einer verständlichen Bildsprache bewusst von der Realität ab. Die Frage also, ob Mythen phantastisch sind oder nicht, kann mit dem oben aufgezeigten kommunikativen Modell nicht eindeutig beantwortet werden. Ihm zufolge gäbe es moderne, phantastische und antike nichtphantastische Mythen, ein Ergebnis, das in vielerlei Hinsicht nicht zufriedenstellt. ${ }^{65}$ Gleiches gilt für Sagen, bei denen ebenso zweifelhaft ist, ob sie als phantastische Texte betrachtet werden können. ${ }^{66}$

\footnotetext{
${ }^{62}$ Vgl. Rank (2011), S. 171 und Weinkauff/von Glasenapp (2010), S. $191 \mathrm{ff}$.

${ }^{63}$ Callois (1974), S. 52 und Wyss (2003), S. 42.

${ }^{64}$ Vgl. Wodianka (2009).

${ }^{65}$ Da sich Kapitel 4 dieser Arbeit mit der Mythoshaftigkeit zeitgenössischer Texte beschäftigt, soll an dieser Stelle nicht weiter auf das Thema eingegangen werden. In jedem Fall fallen im hiesigen Gattungsbegriff klassische Mythen nicht unter Phantastische Literatur.

${ }^{66}$ Vgl. Pohlmann (2004), S. 19 und Durst (2001), S. 318 f.
} 


\subsubsection{Ein Beispiel für ein phantastisches Genremodell}

Grundsätzlich ergibt sich die Mehrzahl phantastischer Genremodelle explizit oder implizit aus hierarchisch organisierten Entscheidungen, welche Texteigenschaften bei der Klassifikation als genreweisend betrachtet werden. Immer differenziertere Eigenschaftskonstellationen führen dabei zu immer spezifischeren Genrevorstellungen und -begriffen. Die folgende Darstellung zeigt beispielhaft, wie die Gattung der Phantastik in zwei Hierarchieebenen organisiert werden kann.

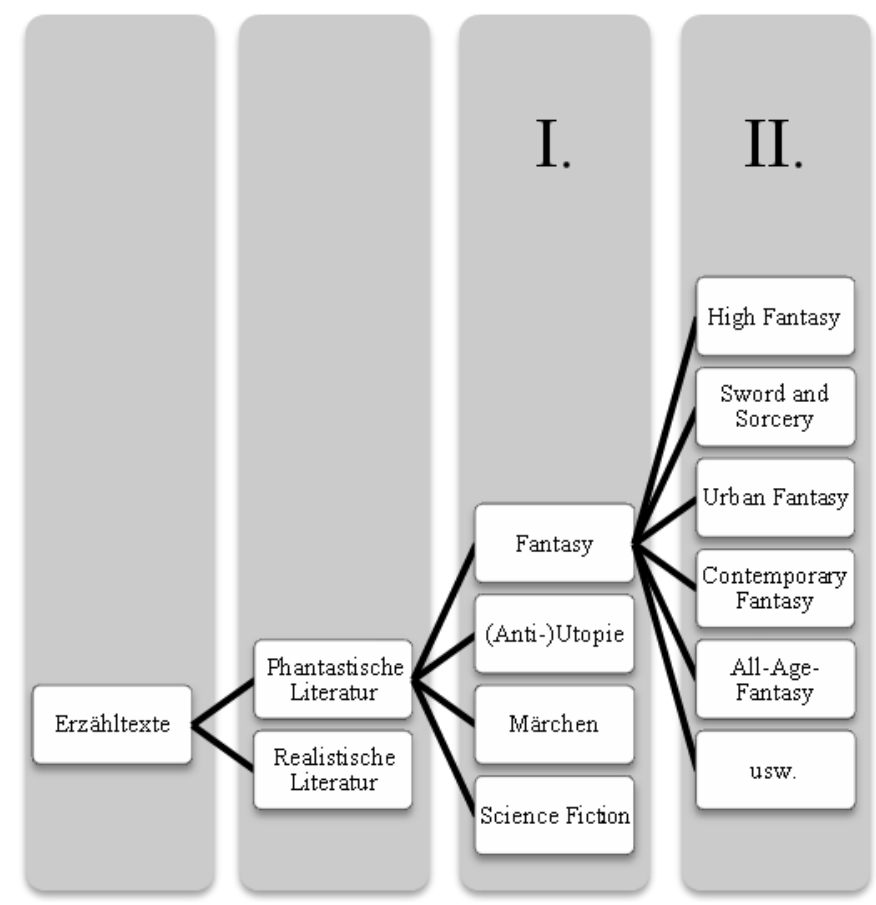

Abbildung 1: Genremodell der Phantastik mit zwei Hierarchieebenen

Eine überzeugende Legitimation, warum eine konkrete, objektiv belegbare Texteigenschaft als genreweisend betrachtet wird, erfolgt in aller Regel nicht. So kann bei der Klassifizierung mal das Setting (zum Beispiel High Fantasy), mal der Handlungsort (zum Beispiel Urban Fantasy), mal der Handlungsverlauf, der Inhalt ${ }^{67}$, die Thematik (zum Beispiel Sword and Sorcery), mal die Zeitwelt (zum Beispiel Contemporary) oder die Adressierung (zum Beispiel All-Age-Fantasy oder Children's-Fantasy ${ }^{68}$ ) betont werden - alles Eigenschaften, die nicht die phantastische Dimension der Texte fokussieren, sondern auf andere Gattungsmodelle verweisen. ${ }^{69}$ Aufgrund der diskursiven Bedeutsamkeit solcher Genrevorstellungen sowohl in der

\footnotetext{
${ }^{67}$ Einen komplett inhaltsorientierten Vorschlag liefert beispielsweise Ewers (2011).

${ }^{68}$ Vgl. Manlove (1999), S. 4.

${ }^{69}$ Es sei an dieser Stelle erwähnt, dass es solche Versuche durchaus gab. Göte Klingberg unterschied beispielsweise zwischen „phantastischer“, ,surreal-komischer“ und „,mythischer Erzählung“. Eine trennscharfe
} 
englischsprachigen Forschung im Allgemeinen als auch in den zeitgenössischen Forschungsdiskursen der Potter-Forschung im Speziellen werden nun exemplarisch die in Abbildung 1 dargestellten Genres in den Blick genommen, die in Bezug auf Rowlings Serie am häufigsten diskutiert worden sind (entweder als einfache Zuweisung oder als Komponente des Genremix $)^{70}$ :

\section{Hierarchieebene I}

(Volks-)Märchen Der Terminus bezeichnet „phantast[ische], realitätsüberhobene“, immer wieder neu erzählte Erzählungen, ,deren Soff aus mündl[ichen] [v]olkstüml[ichen] Traditionen stammt" und deren konkrete mündliche oder schriftliche Realisierung je nach Erzähltalent und stilistischem Anspruch unterschiedlich ausfällt. ${ }^{71}$ Das Volksmärchen ist gekennzeichnet durch „,Raum- und Zeitlosigkeit, die wie selbstverständl[ich] wirkende Aufhebung der Natur- und Kausalgesetze [...], das Auftreten von Fabelwesen [...], Einschichtigkeit [...], Handlungsstereotypen " sowie den „,Sieg des Guten oder [die] Wiederherstellung einer harm[onischen] Ordnung, mit - z. T. grausamer-Bestrafung des Bösen" ${ }^{72}$. Die Figuren zeichnen sich oft durch Flachheit und einfache Funktionscharakteristik aus, Requisiten sind zumeist einfach zu deutende Symbole, das Wunderbare oder Übernatürliche wird nicht hinterfragt, ${ }^{74}$ es kann als Ausdruck einfacher Wünsche des Menschen oder der Menschheit gedeutet werden, zum Beispiel als Wunsch nach ewiger Jugend. ${ }^{75}$ Volkstümliche Märchen speisen sich aus einem Fundus immer gleicher Handlungs- und Motivkonstellationen, die neu variiert, formelhaft bzw. regelgeleitet zusammengesetzt und ausformuliert werden. $\mathrm{Zu}$ typischen Märchenplots bzw. bekannten Märchenmotiven zählen etwa „der Teufelspakt“, „die Verkörperung des Todes, der unter den Menschen weilt", „Vampire, die Blut trinken und damit eine ewige Jugend erhalten“, die Umkehrung von Traum und Wirklichkeit oder ,der Stillstand und die Wiederholung der Zeit"، 76

Klassifizierung der phantastischen Dimension eines Textes liegt aber auch hier nicht vor. Siehe Klingberg (1976), S. $222 \mathrm{ff}$. und $227 \mathrm{f}$.

${ }^{70}$ Zum Genremix siehe Kapitel 5.3.

${ }^{71}$ Schweikle (1990a), S. 292.

${ }^{72}$ Ebd.

${ }^{74} \mathrm{Vgl}$. Bergenthal (2008), S. 259.

${ }_{76}^{75}$ Callois (1974), S. 63.

${ }^{76}$ Ebd., S. 62-66. 
Fantasy Dieses Genre hat sich aus der Vermischung verschiedener literarischer Institutionen ergeben und in dieser spezifischen Mixtur etabliert. So trägt Fantasy-Literatur Spuren mittelalterlicher Ritterepen, der tradierten klassischen Mythologie, historischer Romane, von Märchen und Legenden, auf die sie immer wieder frei rekurrieren und von wo sich die Themen, Schauplätze und Figuren herleiten. ${ }^{77}$ Häufig werden mit dem Begriff Texte bezeichnet, die ,, ausschließlich oder zum überwiegenden Teil in einer Sekundärwelt spielen “78, deren wundersame Beschaffenheit oftmals auch in Bezug von Raum- und Zeitstruktur eigenen Gesetzmäßigkeiten unterliegt. ${ }^{79}$ Diese Gesetzmäßigkeiten werden im Laufe der Handlung von Figuren und Rezipienten erlernt wie hingenommen und bestimmen dann die Sinnhaftigkeit von Vorgängen. So werden Bedeutungsgefüge und Kausalitäten in der meist autonom funktionierenden phantastischen Welt mithilfe von imaginierten übernatürlichen Begründungszusammenhängen erklärt. Es gibt typische Motive - wie Artefakte, Magie oder Kriege und Figuren, etwa Drachen, Magier, Ritter, Priester, Riesen, Vampire, Elfen, Orks, Harpyen und viele mehr, die mit dem Genre in Verbindung gebracht werden. Oftmals dienen mythische und mittelalterliche Stoffe bzw. das, was dafür gehalten wird, als Grundlage. ${ }^{80}$ Ihre „spezifische Stimmung, ihr Kolorit“ erhält die Fantasy durch „,die Imitation volksliterarischer (mündlicher) Traditionen und teils abergläubisch anmutender Mythen- bzw. Legenden-Motive ${ }^{\text {“81 }}$. Zu nennen sind $\mathrm{u}$. a. die Bedrohung eines Volkes durch äußere Feinde, die Rückkehr des Königs, der schließlich sein rechtmäßiges Erbe antritt, oder die abenteuerliche Reise eines Auserwählten. ${ }^{82}$ Hinzu kommen das Entdecken einer Parallelwelt hinter einem Übergang, das Auftauchen eines Doppelgängers oder von Geistern, des personifizierten Todes, des Teufels (sowie der Pakt mit ihm) sowie Personen mit übernatürlichen Fähigkeiten und/oder Realitätsverlust, Menschen, die Tiergestalt annehmen können, personifizierte und belebte Gegenstände, das Spiel mit dem Sichtbaren und Unsichtbaren sowie Zeitstopps und Anachronismen. ${ }^{83}$

\footnotetext{
${ }^{77}$ Vgl. Bergenthal (2008), S. 336, S. 338, S. 351.

${ }^{78}$ Rank (2011) S. 173, vgl. auch Bonacker (2006), S. 64-70.

${ }^{79}$ Vgl. Sullivan (1996), S. 303.

${ }^{80}$ Vgl. Abraham (2010), S. 47.

${ }^{81}$ Bergenthal (2008), S. 338.

${ }^{82}$ Vgl. de Grandpair (2013), S. 30-55.

${ }^{83}$ Aufzählung folgt Fenske (2008), S. 383 f.
} 
Die Gattung Fantasy kann im engeren Sinne auch nur jene Texte umfassen, deren zahlreiche magische, übernatürliche und unheimliche (oftmals auch mythische) Elemente die naturwissenschaftlichen Gesetze, Kausalität und Logik außer Kraft setzen, ${ }^{84}$ jedoch keinen Konflikt mit der natürlichen Weltordnung heraufbeschwören. ${ }^{85}$ Alle Konflikte sind bei diesen Texten durch Vernunft und/oder Magie lösbar. ${ }^{86}$

Science Fiction Auch in der Science Fiction werden phantastische Sekundärwelten erschaffen, die auf eigenen Gesetzmäßigkeiten beruhen. Die räumliche und zeitliche Orientierung ähnelt stark Texten der Fantasy-Literatur, sie bemüht sich jedoch zumindest pseudowissenschaftlich $-{ }^{87}$ um rationale, oftmals futuristisch-technische Begründungen für die wundersamen, aus heutiger Sicht unwahrscheinlichen Elemente. Sie ist zudem verwandt mit der Utopie, die ebenfalls Zukunftsvisionen in den Blick nehmen kann.

(Anti-)Utopie $\quad \mathrm{Zu}$ den Utopien werden vor allem diejenigen Erzähltexte gezählt, die von negativen (Anti-Utopie) oder positiven (Utopie) Gesellschaften bzw. Gesellschaftsentwicklungen berichten, die den thematischen Schwerpunkt der Erzählung ausmachen. $^{88}$

\section{Hierarchieebene II}

High Fantasy Die mythisch-archaischen, meist geschlossenen Sekundärwelten der High Fantasy tragen in der Regel mittelalterliche Züge, sind bevölkert von phantastischen Wesen mit magischen Fähigkeiten wie Riesen, Feen und Einhörnern (angelehnt an Tolkien) und entsprechen häufig dem wissenschaftlichen Stand und der Gesellschaftsstruktur der Vormoderne. ${ }^{89}$ Dementsprechend ist die politische Struktur jener Welten meist feudal geprägt, und Magie wird als normal empfunden. ${ }^{90}$ Religion zeigt sich oftmals polytheistisch, kann aber auch dem christlichen Glauben nachempfunden sein. Die Story ist meist dem Schema Quest verpflichtet, ${ }^{91}$ handelt von der Konfrontation „Gut gegen Böse“ und neigt zu epischer Breite. „Das tragen-

\footnotetext{
${ }^{84}$ Vgl. Kellner (1990), S. 150.

${ }^{85} \mathrm{Vgl}$. Rottensteiner (1987), S. 20 f.

${ }^{86} \mathrm{Ebd}$.

${ }^{87}$ Mohr (2012), S. 24.

${ }^{88}$ Siehe zum Beispiel Biesterfeld (1993), S. 75.

${ }^{89}$ Vgl. Karg/Mende (2010), S. 185.

${ }^{90}$ Laue (2011), S. 191.

${ }^{91}$ Karg/Mende (2010), S. 187 f.; de Grandpair (2011), S. 6; vgl. auch Bergenthal (2008), S. 333.
} 
de Handlungsschema [...] ist die Quest-Struktur, welche in der Regel die Rettung/Wiederbeschaffung oder Vernichtung eines magischen Artefakts beinhaltet, wovon meist das Überleben oder Wohlergehen einer ganzen Nation oder auch der Welt abhängt. "92

Sword and Sorcery wird oft synonym zu Low Fantasy und Heroic Fantasy verwendet. ${ }^{93}$ Die Geschichte ist ebenfalls in einer fiktiven Sekundärwelt angesiedelt, meist mit mittelalterlichem Vorbild oder dem, was dafür gehalten wird. ${ }^{94}$ Anders als bei High Fantasy steht hier kein epischer Konflikt im Zentrum, sondern die persönliche Entwicklung des Helden, der zahlreiche Kämpfe absolviert, Abenteuer besteht und durch seinen Heldenmut brilliert. ${ }^{95}$

Urban Fantasy häufig synonym zu Contemporary Fantasy. Zeichnet sich durch die Vermischung von phantastischer und zeitgenössischer/realer Welt aus. Die Anlage kann dabei dem Prinzip der Open World, aber auch dem der Implied World folgen. ${ }^{96}$ Ein klarer Realitätsbezug ist durchgängig gegeben, es soll eine alltägliche Geschichte erzählt werden mit einem Helden, der großes Identifikationspotenzial in sich birgt. Die Urban Fantasy ist meist im städtischen Milieu situiert, das durch phantastische Elemente metaphorisiert, abstrahiert oder spielerisch umgestaltet wird. ${ }^{97}$

All-Age-Fantasy „Der Begriff [...] ist vergleichsweise jüngerer Prägung und steht im Grunde nicht für ein eigenständiges Subgenre, sondern ganz allgemein für FantasyWerke, die Rezipienten über alle Altersgrenzen hinweg ansprechen. “98

Darüber hinaus gibt es im zeitgenössischen Forschungsdiskurs vereinzelt Vorschläge, die zur Klassifikation der phantastischen Literatur auf das phantastische Moment eines Textes abheben. So hat beispielsweise Manlove (1999) sechs Genres ausgemacht, u. a. ,,children's fantasy“, ,emotive fantasy“, ,, secondary world fantasy“ und „,comic fantasy“. Während unter „secondary world fantasy“ Texte erfasst würden, die die Rezipienten in eine rein phantastische Welt entführen, die also explizit nicht mit der eigenen, als Wirklichkeit empfundenen

\footnotetext{
${ }^{92}$ Mohr (2012), S. 256. Die Nähe zum Schema der Heldenreise ist evident. Siehe Kapitel 4.2.1.

${ }^{93}$ De Grandpair (2011), S. 6.

${ }^{94}$ Friedrich (1995), S. 347.

${ }^{95}$ De Grandpair (2011), S. 6.

${ }^{96}$ Bergenthal (2008), S. 335.

${ }^{97}$ De Grandpair (2011), S. 7.

${ }^{98}$ De Grandpair (2011), S. 7. Zur All-Age-Fantasy siehe auch Becket (2009), S. 135.
} 
Welt in Beziehung steht, ${ }^{99}$ parodiere ,, comic fantasy “ die Alltagswelt und ziehe ihr komisches Potenzial aus deren Konfrontation mit einer phantastischen Welt, somit treffen die archaischen Konventionen der ,, secondary world fantasy “ auf profane Themen und Motive. ${ }^{100}$

\subsubsection{Zur Zuordnung von Harry Potter zum phantastischen Genre}

Analog zum Gattungsmodell erfolgt die Gattungsdiskussion um Harry Potter in zwei Schritten, die als Hierarchieebene I und II kenntlich gemacht sind. Bei den Post-Potter-Texten wird genauso verfahren.

\section{Hierarchieebene I}

In der öffentlichen Kommunikation, vor allem vonseiten institutioneller Autoritäten, ist die Zuordnung von Harry Potter zur Fantasy die gängigste Variante. Wikipedia etwa ordnet das Werk als „populäre Fantasy-Romanreihe“101 ein, der Carlsen-Verlag macht bei Aufruf der Harry-Potter-Seite die Kategorisierungsvorschläge ,,Fantasy, Spannung, Freundschaft, Abenteuer"102 und ordnet das Werk als Serie für junge Erwachsene ein. ${ }^{103}$ In der FanKommunikation taucht Harry Potter auf zahlreichen Listen auf, die Fantasy-Bücher empfehlen und diese nach unterschiedlichsten Kriterien ,ranken“. ${ }^{104}$

In der Forschung wird die Zuordnung zur Fantasy häufig anhand der ausgestalteten Sekundärwelt gerechtfertigt, aus der heraus sämtliche phantastischen Handlungs-, Figuren-, Motivund Raumelemente hergeleitet werden. ${ }^{105}$ Nel etwa betrachtet Harry Potter als Geschichte eines klassischen „fantasy hero“, der sich siegreich gegen seine Gegner durchsetzt, was in epischer Breite mit über einhundert Figuren erzählt wird. ${ }^{106}$ Fenske verweist auf zahlreiche traditionelle Fantasy-Motive wie das Eintauchen in eine phantastische Sekundärwelt, die Reise des Auserwählten, Geister und Werwölfe sowie etliche, die an ein mittelalterliches Setting

\footnotetext{
${ }^{99}$ Manlove (1999), S. 37.

${ }^{100}$ Vgl. Tolkien ([1936]1983), S. 5.

$101 \mathrm{http}: / /$ de.wikipedia.org/wiki/Harry_Potter (26.8.2014).

${ }^{102}$ www.carlsen.de/serie/harry-potter/17132\#In-dieser-Serie (26.8.2014).

${ }^{103}$ www.carlsen.de/junge-erwachsene/serien (26.8.2014).

${ }^{104}$ LovelyBooks listet Harry Potter unter „,Die besten Fantasy Reihen und Serien aller Zeiten - Fantasy Bestseller" auf Platz 2: www.lovelybooks.de/buecher/fantasy/Die-besten-Fantasy-Reihen-und-Serien-aller-ZeitenFantasy-Bestseller-464906403/ (26.8.2014); auf FictionFantasy taucht der dritte Band auf Platz 12 auf: www.fictionfantasy.de/die-besten-fantasy-buecher (26.8.2014).

105 Vgl. Mohr (2012), S. 184; zu Harry Potter als Fantasy-Roman siehe u. a.: Elstner (2004), 3-11; Fenske (2008), S. 382 f.; Karg/Mende (2010), S. 186 ff. Zu den Post-Potter-Texten im Kontext Phantastischer Literatur siehe u. a.: Bergenthal (2008), S. 400; Heber (2010), S. 9 f.; Schlachter (2014), S. 1.

106 Letzteres Kriterium dient auch zur Begründung, die Texte als „epic fantasy“ zu klassifizieren. Vgl. Nel (2001), S. 36.
} 
anknüpfen. ${ }^{107}$ Magie motiviert sämtliche Anders- und Fremdartigkeit sowie alle daraus entstehenden Konsequenzen für den Alltag der Figuren in der Diegese, da es für und gegen fast alles einen Zauber gibt, der erlernt werden kann und Regeln unterliegt. ${ }^{108}$ Gesetzmäßigkeiten, die die Rezipienten erst einmal erlernen müssen, bestimmen die Sinnhaftigkeit von Vorgängen sowie sämtliche Begründungszusammenhänge von Text- und Figurenhandlung. ${ }^{109}$ Rowlings Romane bestechen dabei durch ihr detailreiches und in sich kohärentes Set an Gesetzen und Regeln, was einen Beitrag zum Erfolg des phantastischen Gedankenspiels geliefert haben mag. So kann man beobachten, dass kleinste Abweichungen und Fehler in Forschungs- und Fan-Diskursen besprochen werden. ${ }^{110}$

Harry Potter beinhaltet neben Gattungssignalen der phantastischen Literatur auch andere Textelemente, die sich aus dem Fundus weiterer institutionalisierter Genres bedienen. Das Phantastische bleibt dabei stets wegweisend für die Haupthandlung, kann jedoch zeitweilig in den Hintergrund gedrängt werden. Der Text weist also mal stärker, mal schwächer ausgeprägt einen Genremix auf, in dem die Phantastik, spezifischer die Fantasy, eine dominierende Position innehat. ${ }^{111}$

\section{Hierarchieebene II}

Der kontrovers geführte wissenschaftliche Diskurs, welchem phantastischen Genre bzw. Subgenre der Fantasy Harry Potter zuzuordnen ist, konnte modellbedingt zu keinem eindeutigen Konsens führen, da sich die Vielschichtigkeit des Werks bereits von der Anlage her nicht mit dem Ansinnen verträgt, den Text auf ein oder zwei Hauptmerkmale zu reduzieren. So stellt Fenske fest: „Analysing Harry Potter, most of them are irrelevant [...]. " ${ }^{112}$ Häufig wird die Verwandtschaft zur High Fantasy sowie zur Contemporary/Urban/Comic Fantasy betont Letztere zielen auf die Einschreibung in die Alltagswelt ab. Karg und Mende stellen die Nähe zur High Fantasy heraus und legen dar, warum diese vor allem im sechsten und siebten Band, im Hauptkonflikt zwischen Harry und Lord Voldemort und der daraus resultierenden Schlacht in Hogwarts, immer evidenter wird. ${ }^{113}$ Auch die Quest-Struktur der Texte spricht für eine

\footnotetext{
${ }^{107}$ Fenske (2008), S. 382 f.

${ }^{108}$ Cornelius (2003), S. 87-92.

${ }^{109}$ Vgl. Sullivan (1996), S. 303.

110 Beispielsweise weist Cornelius (2003, S. 89) auf Inkonsequenzen in der Zauberwelt hin. Siehe auch www.fantasy-forum.net/showthread.php?p=125429 (7.7.2014).

${ }^{111}$ Vgl. beispielsweise Karg/Mende (2010), S. 184; Lafontaine (2009), S. 91-95.

112 Fenske (2008), S. 376. Fenske bezieht sich hier auf Genretypen, die Manlove (1999) aufstellt.

${ }^{113}$ Karg/Mende (2010), S. 186.
} 
Verwandtschaft zur High Fantasy, ${ }^{114}$ wobei dies teilweise kritisch gesehen wird: Rowling degradiere das Genre, vor allem durch die All-Age-Adressierung, ja mache es nahezu lächerlich. ${ }^{115}$ Bergenthal stellt fest, das Harry Potter ,, einige Regeln “ der Urban Fantasy erfülle, da London immer häufiger als Handlungsort diene; weiterhin weist sie auf Patterns hin, die für Contemporary Fantasy bedeutsam sind. ${ }^{116}$ De Grandpair hingegen stellt die Adressierung als genreweisendes Merkmal heraus und betrachtet die Buchreihe als Paradebeispiel für All-AgeFantasy. ${ }^{117}$ Eine Verwandtschaft mit Contemporary, Urban oder Comic Fantasy sei durch das komplex gestaltete Gedankenspiel gegeben, das vertraute Alltagssituationen in einen durch phantastische Elemente verfremdeten Kontext stellt. ${ }^{118}$ Die Verfremdung zentraler Themen der Jetztzeit ermögliche einen humorvollen Umgang sowie didaktische Entlastung durch Komplexitätsreduktion, die zur Reflexion gegenwärtiger gesellschaftlicher Zustände veranlasse. $^{119}$

Als gleichsam modellimmanenten Ausweg aus dem Diskursdilemma wurde schließlich postuliert, dass Harry Potter durch seine innovativen Strukturen die Wirkmacht bzw. das Potenzial besitze, eine neue Subgattung der Fantasy-Literatur zu begründen, wie es bereits beim erfolgreichen Vorläufer Der Herr der Ringe (1969/70) zu beobachten war. Die Idee wurde sogar schon während der ,akuten Potter-Hysterie“ geäußert, als noch keine bzw. bei weitem nicht so viele Vergleichstexte wie heute zur Verfügung standen. Bergenthal stellt etwa in ihrer 2008 publizierten Dissertation fest - zu einem Zeitpunkt, als nicht einmal alle Potter-Bände berücksichtigt werden konnten:

Festzuhalten bleibt, dass sich die Fantasy in enger Anbindung an den Buchmarkt entwickelt hat und dass die jeweiligen Subgenres je nach Bedarf und Zielpublikum dynamisch in einzelne Programmsegmente eingepasst werden können. Inzwischen gilt Rowlings Harry Potter-Serie als formgebend für ein eigenes Subgenre, das zahlreiche Verlage, selbst jene, die zuvor kein jugendliterarisches oder phantastisches Programm hatten, in ihr Angebot aufgenommen haben. ${ }^{120}$

Bergenthal wies zudem auf das medienästhetische Potenzial der Fantasy-Gattung hin und stellte Zusammenhänge zwischen phantastischem Genre und der Publikation im Medienverbund heraus. ${ }^{121}$

\footnotetext{
${ }^{114}$ Fenske (2008), S. 382 f.

${ }^{115}$ Vgl. Falconer (2009), S. 43 f.

${ }_{116}^{11}$ Bergenthal (2008), S. 342.

${ }^{117}$ De Grandpair (2012), S. 7.

${ }^{118}$ Vgl. Bergenthal (2008), S. 340.

${ }^{119}$ Ebd.

${ }^{120}$ Bergenthal (2008), S. 337.

${ }^{121}$ Bergenthal (2008), S. 329, S. 339, S. 341.
} 


\subsubsection{Zur Zugehörigkeit der Post-Potter-Texte zum phantastischen Genre}

\section{Hierarchieebene I}

In der Regel werden die Texte des Korpus als Fantasy-Literatur aufgefasst bzw. beworben. LovelyBooks führt nahezu alle in der Bestenliste „Die besten Fantasy Reihen und Serien aller Zeiten - Fantasy Bestseller“ auf. ${ }^{122}$ Der Carlsen-Verlag weist Percy Jackson die Schlagworte „Abenteuer“ und „Fantasy“ zu. ${ }^{123}$ Auch Schlachter erläutert, dass die Bis(s)-Serie sowie die Panem- und Edelstein-Trilogie als Fantasy bzw. Subgenres der Fantasy vermarktet werden. ${ }^{124}$ Gerade bei der Panem-Trilogie ist die Klassifikation indes diskutabel, kann sie doch auch als Science Fiction oder Utopie gelten, je nachdem ob man der futuristisch-technisierten Szenerie oder aber dem Entwurf einer futuristischen Gesellschaft eine gattungsweisende Bedeutung beimisst. ${ }^{125}$ In der deutschsprachigen Forschung wird der Text zudem als Dystopie besprochen. ${ }^{126}$ Andererseits ist die institutionelle Einordnung als Fantasy gängig. ${ }^{127}$

Dass die Texte des Korpus überwiegend als Fantasy-Literatur betrachtet werden, mag daran liegen, dass sich die Texte solcher Stoffe, Themen, Figuren und Motive bedienen, die konventionell als „fantasyweisend“ betrachtet werden: Während Harry Potter Zauberer in den Mittelpunkt der Handlung stellt, dreht sich die Bis(s)-Serie um Vampire, die Edelstein-Trilogie um Zeitreisen und die Tintenwelt-Trilogie um phantastische Buchwelten. Phantastische Schemata prägen die hier betrachteten Werke, die allesamt Welten mit eigenen Gesetzmäßigkeiten entwerfen. Es bricht in die zunächst als „Possible Worlds“ gekennzeichneten Settings unvermittelt das Phantastische ein, das die Weltsicht der Figuren ins Wanken bringt und mo-

${ }^{122}$ LovelyBooks listet etwa am 25.8.2014 Tödliche Spiele auf Platz 1, Harry Potter auf Platz 2, Rubinrot auf Platz 3, Bis(s) zum Morgengrauen auf Platz 4, Tintenherz auf Platz 7, Eragon auf Platz 8, Percy Jackson auf Platz 26 und Artemis Fowl auf Platz 53: www.lovelybooks.de/buecher/fantasy/Die-besten-Fantasy-Reihenund-Serien-aller-Zeiten-Fantasy-Bestseller-464906403/ (26.8.2014).

123 www.carlsen.de/serie/percy-jackson/17723\#In-dieser-Serie (26.8.2014). Artemis Fowl kommen die Gattungsschlagworte „Abenteuer, Fantasy, Spannung“ zu: www.carlsen.de/junge-erwachsene/serie/artemisfowl/18619\#In-dieser-Serie (26.8.2014). Eine solche Klassifikation ist sicherlich diskutabel, man käme auf Grundlage des Genremodells von Kapitel 3.2.2 zu einem anderen Ergebnis. Da Artemis Fowl einen futuristischen Wissenschaftsstand abbildet, legt das Modell die Zuordnung zur Science Fiction nahe. Colfers Personal, das Zwerge, Elfen und Zentauren umfasst, plausibilisiert aber grundsätzlich auch eine Zuordnung zur Fantasy. Wikipedia ordnet das Werk dementsprechend sowohl der Phantastik als auch der Science Fiction zu: http://de.wikipedia.org/wiki/Artemis_Fowl (12.0.2014).

${ }^{124}$ Vgl. Schlachter (2014), S. 4. Sie betrachtet die Subgenres der Fantasy in Anlehnung an Bergenthal als ,,verlagsprogrammatische Kategorien ".

125 Eine nähere Betrachtung der Genres Science Fiction und Utopie soll an dieser Stelle nicht vorgenommen werden. Siehe dazu Rank (2014), S. 1-11.

${ }^{126}$ Vgl. Rank (2014) und Wiemers (2013).

127 Vgl. die Liste der Auszeichnungen, die die Autorin für die Panem-Trilogie erhalten hat: www.dietributevonpanem.de/buecher/autorin/ (14.10.2014). 
difiziert. ${ }^{128}$ Dabei treten manche Spezifika der Fantasy-Literatur in innovativer Form auf, so auch in Funkes Tintenwelt: Insbesondere ab dem zweiten Band bedient sich die Serie eines klischeehaften Mittelaltersettings, das mit zahlreichen phantastischen Attributen ausgeschmückt wird: ${ }^{129}$ Herolde (TB, S. 82), Bader, Knochenflicker, Steinschneider, Wunderheiler sowie Gaukler (TB, S. 74), Henker (TB, S. 97) und Spielleute (TB, S. 73) treten auf, ebenso Feuerelfen (TB, S. 82), Borkenmänner (TB, S. 33), Nachtmahre (TB, S. 33), Glasmänner und blauhäutige Feen (TB, S. 113). Der Tod erscheint in Gestalt weißer Frauen (TB, S. 251), die den Sterbenden ,, weiße Worte“ (TB, S. 251) zuflüstern und sie zu überreden versuchen mitzukommen (TB, S. 204). Auch das Feuer ist personifiziert: Es kann beißen, singen und sprechen, es tanzt mit Staubfinger (TB, S. 78, S. 671), es will spielen und versteht nichts von der Angst (TB, S. 661). Fantasy-typisch sind zudem die Motive des Unsichtbarmachens und der Vermischung verschiedener Realitätsebenen. So kann Staubfinger in einer Zeremonie mit den Elementen Feuer und Wasser einen magischen Ruß hervorbringen, der denjenigen unsichtbar macht, der ihn auf die Haut aufträgt (TB, S. 548). Das Spiel mit Realität und Fiktion, Traum und Wirklichkeit sowie Leben und Tod ist in Funkes Text ein Leitmotiv. ${ }^{130}$ Es fügt sich harmonisch in das Gedankenexperiment der Buchwelten ein und kommt immer in Übergangssituationen zum Ausdruck, etwa wenn Farid nicht zwischen Traum und Realität zu unterscheiden vermag, sobald er aus seiner Geschichte gelesen wurde und damit die Grenze seiner gewohnten Buchwelt überschritten hat (TH, S. 222).

Auch Percy Jackson beinhaltet traditionelle Fantasy-Motive: Die dort gestaltete Welt ist unserer recht ähnlich, aber von den Launen griechischer Götter abhängig, die ins Geschehen eingreifen. Diese besitzen zwar magische Fähigkeiten und sind unsterblich, desgleichen aber auch Gesetzen und Regeln unterworfen. Zeus, Poseidon und Hades, ,, die Großen Drei “ (PJ 1, S. 139), haben den Pakt geschlossen, dass sie keine Kinder mehr zeugen dürfen, da diese schlicht zu mächtig werden und den „Verlauf der Weltgeschichte“ beeinflussen (PJ 1, S. 139). Der Mythologie entsprechend, symbolisiert Hades den Tod. Jeder der drei Figuren herrscht autark über ihr eigenes Reich und ist mit Artefakten und Symbolen der Macht ausgestattet: Zeus mit dem Herrscherblitz (PJ 1, S. 164), Hades mit einer Kappe, durch die er „,zur Finsternis “ werden kann (PJ 1, S. 265), und Poseidon mit dem Dreizack (PJ 1, S. 154). Auch manches Halbblut besitzt magische Artefakte, Annabeth etwa eine Tarnkappe (PJ 3, S. 45)

\footnotetext{
${ }^{128}$ Vgl. Grenz (1986), S. 456.

${ }^{129}$ Nähere Erläuterungen dazu in Kapitel 3.3.2.4.

${ }^{130}$ Heber (2010), S. $134 \mathrm{f}$.
} 
und Percy einen Kugelschreiber namens Springflut, der sich in Notsituationen in ein Schwert verwandelt, niemals verloren gehen kann und weitere erstaunliche Eigenschaften besitzt:

Dieses Schwert ist aus himmlischer Bronze. Geschmiedet von Zyklopen, im Berg Ätna gehärtet, im Fluss Lethe abgekühlt. Es ist tödlich für Ungeheuer und überhaupt für alle Geschöpfe aus der Unterwelt, falls sie dich nicht vorher umbringen. Aber durch Sterbliche wird die Klinge hindurchgleiten wie eine Illusion. Sie sind einfach nicht wichtig genug, als dass das Schwert sie töten würde. (PJ 1, S. 187)

Percy, der Protagonist der Geschichte, entdeckt auf seinen Reisen, in denen er sich einer Aufgabe nach der anderen bzw. einem Gegner nach dem anderen zu stellen hat, seine eigene Identität und reift zu einem Helden heran, der sich nicht nur durch Mut, sondern auch durch moralische Überlegenheit auszeichnet. Die Handlung bedient sich dabei der klassischen Quest-Struktur, wie sie mitunter auch in mittelalterlicher Literatur, zum Beispiel der Artus-Epik, die Handlung strukturiert. ${ }^{131}$ Im Mittelpunkt steht der Krieg zwischen Kronos und den Göttern des Olymps, der über die Zukunft der Menschheit entscheidet und der im fünften Band in der alles entscheidenden Schlacht endet. Die Stellvertreterkriege in Band eins bis vier werden meist zwischen Percy (bzw. seinen Freunden) und den Monstern bzw. Rekruten des Kronos geführt, die in der Regel mythischen Kreaturen und damit übernatürlich-phantastischen Wesen nachempfunden sind.

Alle Texte des Korpus können zudem als abenteuerliche Reise eines Auserwählten gelesen werden, die ein typisches Fantasy-Schema darstellt. Der konkrete Nachweis soll in Kapitel 4 erfolgen, das zudem die Ursprünge des Auserwähltenmotivs näher beleuchtet. ${ }^{132}$

\section{Hierarchieebene II}

Welchem Subgenre der Fantasy die Post-Potter-Texte zugeordnet werden, hängt als personenbzw. institutionsgebundene Entscheidung davon ab, welche Eigenschaften als dominant und gattungsweisend aufgefasst werden: Beachtet man primär die Adressierung, sind sie als AllAge-Fantasy aufzufassen, hebt man eher auf den Inhalt ab, können sie unter Sword \& Sorcery, Urban oder Contemporary Fantasy subsumiert werden, wenngleich die Bücher weder ausschließlich Kämpfe und Heldentaten thematisieren noch ausschließlich im städtischen Milieu oder einer zeitgenössischen Lebenswelt angesiedelt sind, sondern lediglich passagenweise. ${ }^{133}$ Bergenthals vorgenommene Klassifizierung von Tintenherz als Contemporary Fan-

\footnotetext{
${ }^{131}$ Zur Quest siehe u. a. Schulz (1981) und Schilken (2002), S. 16 f., S. 246 ff.

${ }^{132}$ Siehe Kapitel 4.2.3.4.

${ }^{133}$ Im Wikipedia-Artikel „Fantasy“ werden Harry Potter und Percy Jackson als bekannte Beispiele für das Genre der Contemporary Fantasy aufgeführt: http://de.wikipedia.org/wiki/Fantasy (11.11.2014).
} 
tasy ${ }^{134}$ ist sicher passend, ab dem zweiten Band aber dominiert das Mittelaltersetting, sodass die Serie als Ganzes nicht diesem Genre zuzuordnen ist. Für Die Tribute von Panem scheint eine Zuordnung zur Urban Fantasy nicht geeignet, wird dort doch gerade ein futuristisches Setting entworfen. Hebt man auf das Serienformat ab, so lassen sich alle Werke als (Fantasy)Sagas auffassen, ein Begriff, der auch im öffentlichen Diskurs in Bezug auf das Korpus auftaucht. $^{135}$

Eine eindeutige Klassifizierung der Bis(s)-Serie und der Edelstein-Trilogie lässt sich ebenso wenig vornehmen. Giers Text spielt zwar passagenweise im zeitgenössischen London, thematisiert aber mindestens genauso gewichtig städtisches Leben in England der letzten Jahrhunderte. Eine Zuordnung zur Urban oder Contemporary Fantasy ist daher zwar nicht abwegig, lässt aber den deutlich spürbaren Einfluss des historischen Romans völlig außer Acht. Da weder in Giers noch in Meyers Büchern geschlossene Sekundärwelten etabliert werden, scheint die Zuordnung zur High Fantasy nicht sinnvoll, auch aufgrund ihrer Nähe zur zeitgenössischen realen Welt. ${ }^{136}$ Eine Quest-Struktur ist zwar prinzipiell erkennbar, der epische Konflikt aber keinesfalls so handlungstragend, wie für High Fantasy typisch. Und auch wenn prinzipiell die Entwicklung der jeweiligen Heldenfiguren Bella und Gwendolyn im Mittelpunkt der Handlung stehen, so können die Texte nicht gänzlich zu Sword \& Sorcery gezählt werden, da es sich hier nicht um strategische, übermenschliche Kriegerinnen handelt, sondern um moderne, psychologisierte Protagonistinnen, die als Durchschnittsmenschen mit Fehlern und Schwächen behaftet sind.

Amazon listet alle hier betrachteten Titel unter dem Genre „Fantasy \& Science Fiction“, ${ }^{37}$ welches sich wiederum in die Subgenres „Fantasy“, „Science Fiction“ und „Vampirromane“ teilt. Die Bis(s)-Serie wird in diesem System als Vampirroman klassifiziert, die PanemTrilogie als Science-Fiction- und die Edelstein-Trilogie als Fantasy-Roman. Nach dem gleichen Prinzip sortiert Thalia die Bücher, was insofern interessant ist, als sich das Subgenre Vampirroman in der öffentlichen Kommunikation offenbar neben der Fantasy (im engeren Sinne) und der Science Fiction etabliert hat. ${ }^{138}$ Beide Onlinebuchhändler heben mit ihrer Gen-

\footnotetext{
${ }^{134}$ Bergenthal (2008), S. 340.

135 Amazon stellt zudem eine eine Bestenliste von Fantasy Sagas zur Verfügung: www.amazon.de/FantasySaga/lm/M7WMTH5MTKB4 (31.8.2014); der Begriff taucht auch in Verbindung mit Game of Thrones vermehrt auf, z. B. unter www.freundin.de/leben-kultur-game-of-thrones-die-fantasy-saga-geht-weiter191117.html (31.8.2014). Siehe hierzu auch Kapitel 2.2.2.1.

${ }^{136}$ Der detaillierte Nachweis dieser Behauptung erfolgt in Kapitel 3.3.4.3.

${ }^{137}$ www.amazon.de/gp/bestsellers/books/142/ref=zg_bs_unv_b_2_420066031_1 (25.8.2014).

${ }^{138}$ www.thalia.de/shop/fantasy-science-fiction-4/show/?hkkat $=$ special_1 (26.8.2014).
} 
rezuordnung weder auf den All-Age- noch den Serienaspekt der Texte ab, anders als die Verlage, die diese vertreiben: Oetinger macht etwa darauf aufmerksam, dass Die Tribute von Panem an „Jugendliche und Erwachsene“ gerichtet ist. ${ }^{139}$

\subsubsection{Zwischenfazit}

Harry Potter und die Post-Potter-Texte greifen häufig auf phantastische Darstellungsmittel und Figuren zurück, sodass eine Zuordnung zur Gattung der phantastischen Literatur plausibel erscheint. Die Klassifikation ist zudem institutionell gängig. ${ }^{140}$ Je nachdem welches Genremodell der Phantastik einer Gattungsdiskussion zugrunde gelegt wird, kann Die Tribute von Panem der Science Fiction und die Bis(s)-Serie dem Vampirroman zugeordnet werden, möglich ist in beiden Fällen auch die Zuordnung zur Fantasy-Literatur.

Eine differenziertere Einordnung erweist sich als schwerlich begründbar. Die Texte beinhalten zwar Schemata und Motive, die auf das ein oder andere Subgenre hindeuten, insgesamt zeigen sie sich jedoch als zu vielschichtig, als dass eines ihr Wesen adäquat beschreiben würde. Somit lassen sich lediglich Tendenzen ausmachen: Alle hier betrachteten Romane besitzen beispielsweise aufgrund ihrer Schlachten- und Kriegsthematik eine spürbare Nähe zur High Fantasy, weisen aber in der Überzahl keine geschlossenen Sekundärwelten auf. ${ }^{141}$ Auch Anleihen bei Sword \& Sorcery sind erkennbar, zumal stets die Entwicklung der Heldenfiguren im Mittelpunkt steht. Obwohl durchgängig ein Bezug zur rezenten Realität gegeben ist, thematisieren alle Werke nicht durchgängig zeitgenössisches bzw. urbanes Leben, eine klare Zuordnung zur Urban oder Contemporary Fantasy erscheint damit ebenso wenig adäquat. Prinzipiell denkbar ist die Klassifikation als All-Age-Fantasy ${ }^{142}$ bzw. als Fantasy-Saga ${ }^{143}$, allerdings beziehen sich diese Zuordnungen nicht auf den Inhalt, sondern heben formale Aspekte hervor, die sich zur Feinklassifizierung weniger eignen.

Vonseiten der Forschung wird als Trend hervorgehoben, dass sich die zeitgenössische Kinderund Jugendliteratur immer weniger an etablierte Genrekonventionen der Fantasy-Literatur

\footnotetext{
139 www.dietributevonpanem.de/buecher/flammender-zorn/ (31.8.2014).

${ }^{140}$ Vgl. Schlachter (2014), S. 4.

${ }^{141}$ Die Tribute von Panem stellt hier eine Ausnahme dar, dort wird eine geschlossene Sekundärwelt etabliert.

${ }^{142}$ Siehe auch Kapitel 6.

${ }^{143}$ Siehe auch Kapitel 2.2.2.1.
} 
hält. Bonacker konstatiert etwa, dass die Autoren zunehmend mit der Tradition brächen und „Fantasy Fiction “ durch immer neue hybride Formen im ständigen Wandel sei. ${ }^{144}$

\subsection{Zur Struktur der phantastischen Welten von Harry Potter und seinen Nach- folgern}

In diesem Kapitel sollen die phantastischen Welten der Korpustexte sowie ihre zugrundeliegenden Wirklichkeitsentwürfe im Mittelpunkt stehen. Dazu wird zunächst eine Einführung in die Theorie etablierter strukturgeleiteter Phantastik-Klassifikationsmodelle gegeben sowie der Begriff phantastische Diegese behandelt (Kapitel 3.3.1). Anschließend wird ein eigenes Strukturmodell vorgestellt (Kapitel 3.3.2), um es an Harry Potter (Kapitel 3.3.3) und die Texte des Korpus heranzutragen (Kapitel 3.3.4). Ein Zwischenfazit fasst die Ergebnisse dieser Betrachtungen zusammen (Kapitel 3.3.5).

\subsubsection{Zur phantastischen Diegese}

In der Geschichte der Literaturwissenschaft wurde eine Vielzahl von Vorschlägen zur Gliederung phantastischer Wirklichkeitsentwürfe unterbreitet. ${ }^{145}$ Das bekannteste Modell unterscheidet zwischen Primär- und Sekundärwelt, es postuliert damit ein dualistisches Ordnungssystem, das sich aus den phantastischen und realistischen Anteilen der literarischen Diegese ergibt, die in einem Spannungsverhältnis zueinander stehen und zur Feinklassifizierung der Texte fruchtbar gemacht werden können. Die Narration teilt sich demnach in zwei Sphären auf, die in der Forschung modellhaft als zwei Welten aufgefasst werden: die Primärwelt mit realer, aus heutiger Sicht kulturell etablierter, naturwissenschaftlich normierter Wirklichkeitsvorstellung und die darüber hinaus weisende wundersame, phantastische Sekundärwelt. Beide können explizit oder implizit nebeneinander existieren, aber auch ohne konkrete Etablierung des Gegenmodells ein Spannungsverhältnis ausdrücken. ${ }^{146}$

Es ist evident, dass eine solche „Spannung“ jeder Literatur innewohnt, in phantastischer indes in sehr viel stärkerem Maße präsent ist als in realistischer. ${ }^{147}$ Denn selbst in Werken mit spürbarer Realitätsnähe, beispielsweise Biografien oder historischen Romanen, wird niemals die Wirklichkeit als solche abgebildet: Die Diegese ist vielmehr stets als selbstständiger Wirklichkeitsentwurf zu betrachten, der mal näher, mal weniger nah an die Realität heranreicht.

\footnotetext{
${ }^{144}$ Bonacker (2006), S. 70.

${ }^{145}$ Siehe u. a. Callois (1974), Nikolajeva (1988), Lehmann (2003), S. 27 und Rank (2002).

${ }^{146}$ Kaulen (2004), S. 14.

${ }^{147}$ Mohr (2012), S. 28.
} 
Phantastische Texte spielen mit dieser Tatsache und strapazieren bewusst das Spannungsverhältnis zwischen Fiktion und Realität, indem sie einen zur Realität nahen und einen zur Realität weit entfernten Wirklichkeitsentwurf gegenüberstellen. Dabei sind hier die Primärwelten natürlich ebenfalls als literarisch konstruierte Universen zu begreifen, die die wirkliche Welt zwar repräsentieren, aber nie mit ihr identisch sind. Sie unterliegen jedoch den Gesetzen des empirischen Vorbilds. ${ }^{148}$ Sekundärwelten hingegen erschaffen eine eigene Realität zweiten Grades und folgen gänzlich eigenen Gesetzmäßigkeiten. Dem kommunikativen Modell liegt grundsätzlich die Vorstellung zugrunde, dass durch phantastische Elemente eine eigenständige „Anderswelt“149 etabliert wird. Das bekannteste „Zwei-Welten-Modell“ geht auf Nikolajewa zurück, ${ }^{150}$ die drei Typen einer Sekundärwelt vorsieht, je nachdem ob sie der Primärwelt gegenübergestellt wird oder eine Parallelwelt darstellt: ${ }^{151}$

1. Phantastische Texte mit geschlossener Sekundärwelt (,,closed world“) stellen in ihrer Narration ausschließlich die phantastische Anderswelt bzw. Sekundärwelt dar; es wird keine Beziehung zur Primärwelt etabliert, ja die Primärwelt kommt nicht einmal explizit im Text vor. In der angelsächsischen Forschung wird diese Kategorie mit dem Genre High Fantasy assoziiert. Beispiel: Der Herr der Ringe (1969/70).

2. Die offen konzipierte Sekundärwelt (,,open world") steht in direktem Kontakt zur Primärwelt. Beide Welten kommen explizit im Text vor und sind in vielen Fällen durch Übergänge, Grenzen oder Schleusen miteinander verbunden. Eine Reise von Primär- zur Sekundärwelt kann nach Tabbert „linear““ (nur hin), ,zirkulär“ (hin und zurück) oder „schleifenförmig“ (mehrfach hin und zurück) im Text gestaltet sein. U. a. wird das Genre Urban Fantasy diesem Typus zugeschrieben. Beispiel: Alices Abenteuer im Wunderland (1869).

3. In der dritten Variante (,, implied world “) ist nur implizit eine Sekundärwelt erkennbar, dadurch, dass Elemente von ihr in der Primärwelt präsent werden, zum Beispiel durch magische Figuren oder Gegenstände. In der angelsächsischen Forschung wird diese Sekundärweltstruktur beispielsweise dem Genre Low Fantasy zugeordnet. Beispiel: Eine Woche voller Samstage (1973).

Es zeigt sich, dass die Texte des Korpus nicht eindeutig mithilfe eines solchen Modells zu klassifizieren sind. ${ }^{152}$ Denn der Begriff der Sekundärwelt suggeriert Vorstellungen, die nicht mit dem Korpus in Einklang zu bringen sind: Bei Die Tribute von Panem bleibt unklar, ob der Weltentwurf als phantastisch und damit als abgeschlossene Sekundärwelt zu betrachten ist oder lediglich durch phantastische Elemente eine Sekundärwelt impliziert. Ähnliches gilt für

\footnotetext{
${ }^{148}$ Zgorzelski (1975), S. 58.

${ }^{149}$ Der Begriff wird u. a. von Nickel-Bacon (2006a), S. 41 f. genutzt.

${ }^{150}$ Ein weiteres Beispiel einer Kategorisierung stammt von Gansel (1998b, S. 22 f.), die letztlich aber auch auf Nikolajevas Modell basiert.

${ }^{151}$ Nikolajeva (1988), S. 36 ff. Vgl. auch Rank (2006), S. 17 und Mohr (2012), S. 183 f.

${ }^{152}$ Vgl. Ewers (2011), S. 3.
} 
die Edelstein-Trilogie, in der trotz realistischem Handlungsraum völlig eigene Kausalitätsprinzipien gelten. Bei der Bis(s)-Serie kommt eine Zuordnung zur Open World infrage, überträgt man das Modell auf die beiden kompilierten Welten „Mensch“ und „Vampir“. Allerdings wären in dem Fall Primär- und Sekundärwelt in keiner Weise räumlich voneinander abgegrenzt. Insgesamt ist am Begriff Sekundärwelt problematisch, dass er exakt auf zwei Welten verweist. Texte, die entweder mehrere Welten aufweisen, wie sie im Korpus zu finden sind, oder gar keine in sich zusammenhängende, geografisch eingrenzbare Welt, können damit nicht adäquat mit dem Modell betrachtet werden. Letzteres trifft vor allem auf Harry Potter zu, den Mohr als „Sonderfall“ auffasst. ${ }^{153}$ Deshalb wird hier anstelle von Sekundärwelt ein anderer Begriff präferiert und für eine phantastische Diegese als obligatorisch betrachtet, nämlich „phantastischer Wirklichkeitsentwurf“ ${ }^{\star 154}$, basierend auf der Schematheorie, wonach bestimmte Textelemente bzw. textuelle Markierungen Schemata oder Skripts aktivieren, die den Verstehensprozess strukturieren, lenken und beeinflussen. ${ }^{155}$ Typischerweise werden dabei Handlungssequenzen, Ereignisketten, Assoziationen oder Routinen mental aufgerufen, die als implizite Informationsergänzungen fungieren, indem der Rezipient damit die Sinnhaftigkeit von Vorgängen und Zusammenhänge herzustellen vermag, ${ }^{156}$ wodurch das Defizit an Wissen ausgeglichen wird, welches für die Vollständigkeit des mentalen Textbildes benötigt wird. Ein Schema steht also nicht für sich, sondern stellvertretend für ein Paket an Informationen und Details, welche der Rezipient zu dekodieren hat.

Phantastische Diegesen: Jeder phantastische Text etabliert eine Diegese, der mindestens ein phantastischer Wirklichkeitsentwurf zugrundeliegt. Es lassen sich grundsätzlich drei Arten von Diegesen unterscheiden: solche mit singulärer, solche mit binärer oder solche mit multipler Weltstruktur. Jede konstruierte Welt basiert auf einem eigenen Wirklichkeitsentwurf, der sich mal stärker, mal schwächer an der empirischen Realität orientiert oder an dem, was konventionell dafür gehalten wird. Kommen mehrere Welten innerhalb einer Diegese vor, werden sie durch Grenz- und Über-

\footnotetext{
${ }^{153}$ Mohr (2012), S. 184. Es fällt auf, dass Mohr der Sekundärweltbegriff bei ihren Betrachtungen im Weg steht. Beispielsweise beziehen sich ihre Kategorien der Raum- und Zeitwelt in den meisten Fällen auf die im Text etablierten Primärwelten und eben nicht auf die "phantastischen Welten “, die sie zu beschreiben versucht, vor allem weil sie keine strikte Trennung dessen vornimmt, was sie genau untersucht: den phantastischen Anteil der Primärwelt, die Primärwelt oder die Sekundärwelt an sich. Vgl. dazu ebd. S. 49-72.

${ }^{154}$ Der Terminus erinnert an Dursts Begriff des Realitätssystems, das er als Organisation der Gesetze definiert, die innerhalb einer fiktiven Welt gelten, meint aber nicht genau dasselbe. Vgl. Durst (2001), S. 81. Im Gegensetz zu der hiesigen Vorstellung zeichnet sich ein phantastischer Text gerade durch Inkohärenz, ein „Nichtsystem“ aus, das alle im Text realisierten Realitätssysteme unterwandert. Vgl. Durst (2001), S. 101.

155 Ingarden (1968), S. 50.

${ }^{156}$ Vgl. Müller (2003), S. 414 f.
} 
gangsmarkierungen als eigenständig gekennzeichnet. ${ }^{157}$ Ein Wirklichkeitsentwurf kann durch fünf unterschiedliche Größen repräsentiert werden, die ihn als Welt greifbar werden lassen: Kausalität, Raum, Zeit, Figur und Gegenstand. Somit kann von Kausalitätenwelten, Raumwelten, Zeitwelten, Figurenwelten und Gegenstandswelten gesprochen werden, ${ }^{158}$ je nachdem welche Repräsentationsform als dominant ausgemacht wird. Alle fünf können sich realistischer und phantastischer Schemata bedienen. Die genauere Bezeichnung des phantastischen Wirklichkeitsentwurfs erfolgt aufgrund der dominanten Repräsentationsform, wobei natürlich auch mehrere, streng genommen alle gleichberechtigt einen Wirklichkeitsentwurf beeinflussen können. Wirklichkeitsentwürfe, bei denen sich einer der fünf Repräsentanten Raum-, Zeit-, Figuren- oder Gegenstandskonzeption sowie Kausalitätsprinzip phantastischer Schemata bedient (das heißt, wenn diese aus Rezipientenperspektive den Grundsätzen der empirischen Realität widersprechen und sich phantastischer Schemata bedienen), sollen im Folgenden als phantastisch gelten. Ein Entwurf, der sich in Bezug auf alle fünf Repräsentanten an die empirische Realität anlehnt, soll im Folgenden realistisch genannt werden.

\subsubsection{Zur Struktur phantastischer Diegesen}

Bei der Analyse eines phantastischen Textes bzw. einer phantastischen Diegese sind also die phantastischen Wirklichkeitsentwürfe und deren Repräsentanten zu beachten. Diese kommen wie folgt zum Ausdruck:

- Die Versinnbildlichung eines Wirklichkeitsentwurfs durch Kausalitätsprinzipien kann auf unterschiedliche Weise realisiert sein. Ist ein Kausalitätsprinzip phantastisch, das heißt, beruht es nicht auf den rational-naturwissenschaftlichen Prinzipien, die heute als Konsens der empirischen Realität $\mathrm{zu}$ betrachten sind, werden übernatürliche (überrealistische) Ursache-Wirkungs-Gesetze wie Magie als Repräsentanten herangezogen.

- Die zugrundeliegende Raumvorstellung wird modellhaft durch Schemata realisiert, die die topografische Fläche und räumliche Ausgestaltung spezifizieren, welche dem jeweiligen Wirklichkeitsentwurf symbolisch zugrundeliegen. Die Verschmelzung von Wirklichkeitsentwurf und Raum ist deswegen als symbolisch zu betrachten, weil Ersterem in der Regel Raum zugewiesen wird, dieser aber nicht unbedingt als abgrenzbare Fläche, sondern als abstrakter Raum zu begreifen ist, der unter Umständen phantastischen Kausalitätsprinzipien unterliegt. Gleiches gilt auch für die

\footnotetext{
${ }^{157}$ Durst (2001, S. 144) legt diesen Sachverhalt als ,phantastischen Systemkampf“ aus.

${ }^{158}$ Die Begriffe sind angelehnt an Mohr (2012), die zwischen Raum-, Zeit- und Figurenwelten unterscheidet. Die Termini „Gegenstandswelten“ und „Kausalitätenwelten“ wurden hinzugefügt.
} 
Zeitvorstellung eines Wirklichkeitsentwurfs, die ebenfalls als symbolische Attribuierung $\mathrm{zu}$ betrachten ist. $\mathrm{Zu}$ den topografischen Markierungen einer Raumvorstellung gehören Land-, Stadt-, Orts-, Straßen- und Gebäudebezeichnungen, räumliche Relationsindikatoren bzw. allgemeine Raummotive. Dabei können jeweils realistische und phantastische Raumschemata verwendet werden.

- Auch durch zeitliche Markierungen sowie durch Zeitstrukturen kann ein Wirklichkeitsentwurf versinnbildlicht werden. Zu den temporalen Markierungen eines Wirklichkeitsentwurfs zählen explizite (zum Beispiel durch Daten, historische Personen) und implizite temporale Situierungen (zum Beispiel durch historische Gebäude, Kulturerzeugnisse, politische Systeme, Berufsbezeichnungen) sowie Zeitprinzipien wie Chronologie (realistisches Zeitschema) und Zeitsprung (phantastisches Zeitschema).

- Auch Figuren können die Wirklichkeitsentwürfe als Welt greifbar machen und dabei nach realistischen oder phantastischen Schemata realisiert sein: Aussehen, Fähigkeiten, Verhalten und vor allem Denkweisen vermögen dabei die grundlegenden Prinzipien eines Wirklichkeitsentwurfs auszudrücken.

- Schließlich dienen Gegenstände bzw. die Inventarien eines Wirklichkeitsentwurfs als Weltrepräsentanten. Bei ihnen hat vor allem der Nutzen und die Funktionsweise Symbolgehalt. Auch sie können auf realistischen und phantastischen Schemata beruhen.

Auf Grundlage der genannten Punkte ergibt sich eine Methode zur Betrachtung phantastischer Wirklichkeitsentwürfe, die sich an ein Instrumentarium anlehnt, das Judith Mohr in ihrer Dissertation erarbeitet hat. ${ }^{159}$ Die folgenden Unterkapitel werden sich den verschiedenen Aspekten der Methode zuwenden: der Weltstruktur phantastischer Diegesen, den Repräsentanten, die einen Wirklichkeitsentwurf zum Ausdruck bringen können, sowie der Konzeption von Grenzen und Übergängen.

\subsubsection{Zur Weltstruktur}

Im Sinne eines „Mehr-Welten-Modells“6160 werden grundsätzlich drei Typen von phantastischen Diegesen unterschieden:

1. Phantastischen Texten mit singulärer Weltstruktur liegt genau eine Welt, das heißt, ein Wirklichkeitsentwurf zugrunde, der mithilfe der Repräsentanten Kausalität, Raum, Zeit, Figur und Gegenstand versinnbildlicht wird. Der Weltentwurf kann sich durch entsprechende Markierungen in der Diegese mal stärker, mal weniger stark an die empirische Realität anlehnen. Beispiel: Pippi Langstrumpf (1949); Der Herr der Ringe $(1969 / 70)$

\footnotetext{
159 Siehe Mohr (2012), S. 169-216. Die folgenden Begrifflichkeiten sowie die Struktur phantastischer Welten sind an Mohrs Studie angelehnt und wurden ergänzt. Mohr bezieht sich hauptsächlich auf Titel, die zwischen 1997 und 2011 in deutscher Sprache erschienen sind, darunter auch Harry Potter und die Tintenwelt-Trilogie.

${ }^{160}$ Ewers (2011, S. 11) hat darauf hingewiesen, dass wir es in zeitgenössischer Phantastik oft damit zu tun haben.
} 
2. Texte mit einer binären Weltstruktur zeichnen sich durch zwei Welten aus, die sich durch zwei zugrundeliegende Wirklichkeitsentwürfe voneinander abgrenzen lassen. Diejenige Welt, die dem Protagonisten zuzuordnen ist oder in der Chronologie die erste Referenzwelt darstellt, soll im Folgenden Ausgangswelt genannt werden. Mitunter lässt sich das Bemühen beobachten, die Parallelität der beiden Wirklichkeitsentwürfe mithilfe des entworfenen Weltbilds zu plausibilisieren, indem etwa in Anlehnung an naturwissenschaftliche Konzepte erklärt wird, dass die binäre Weltstruktur aus dem Prozess einer Abspaltung entstanden sei oder auch durch eine historische Entwicklung, welche die alternativen Strukturen und Gesetzmäßigkeiten erklären sollen. ${ }^{161}$ Beispiel: Alice's Abenteuer im Wunderland (1869).

3. Texten mit multipler Weltstruktur liegen neben der Ausgangswelt mindestens zwei weitere Weltentwürfe zugrunde. Eine oft verwendete Variante stellen Buchwelten oder Zeitwelten dar, die parallel existieren und zwischen denen bestimmte Figuren hin und her wechseln können. Beispiel: Die unendliche Geschichte (1979).

Je nachdem auf welcher Weltstruktur eine phantastische Diegese basiert, können die einzelnen Wirklichkeitsentwürfe in Bezug auf ihre Repräsentationsformen weiter charakterisiert werden. Die Art der Weltstruktur bestimmt also die Anzahl der zu betrachteten Wirklichkeitsentwürfe.

\subsubsection{Zum Repräsentant „Kausalität““}

Ist ein dem Wirklichkeitsentwurf zugrundeliegendes Kausalitätsprinzip realistisch, beruht es auf den Ursache-Wirkungs-Beziehungen der rational-naturwissenschaftlich geprägten Denkweise. Phantastische Kausalitätsprinzipien folgen anderen Regeln, die mit gleicher Denkweise nicht plausibel gemacht werden können. Bekannte phantastische Kausalitätsprinzipien sind Magie, futuristische Technik und Pseudowissenschaften. Auch mythische Ursache-WirkungsBeziehungen wie Prophezeiungsstrukturen können entsprechende Schemata aktivieren, indem sich Zukünftiges im Sinne eines vorbestimmten Schicksals einstellt, das nicht umgangen werden kann. Die Kausalitätsprinzipien können aber auch auf kulturelle Eigenheiten oder Normen abheben, die in der Diegese einen gesellschaftlichen Konsens darstellen. Alternativ bemüht man sich, Begründungszusammenhänge darzulegen, mithilfe derer die Genese des Phantastischen aus der Imagination motiviert wird, das heißt, in denen die Verwandlung der Imagination zur Wirklichkeit plausibel gemacht wird. Dies ist zum Beispiel bei allen Geschichten der Fall, in denen Träume, Wünsche oder Gedanken Wirklichkeit werden.

\footnotetext{
${ }^{161}$ Angelehnt an Mohr (2012), S. $178 \mathrm{f}$.
} 


\subsubsection{Zum Repräsentant „Raum““}

Das Raumkonzept eines Wirklichkeitsentwurfs ergibt sich aus der zugrundegelegten Topografie: Die Fläche kann entweder zusammenhängend sein - was eine realistische Vorstellung eines Landes oder einer Welt evoziert - oder aber auch nicht, dann bleibt die Fläche räumlich abstrakt oder zerstückelt, die Vorstellung diffus. ${ }^{162}$

Je nachdem ob realistische oder phantastische Raumschemata den jeweiligen Wirklichkeitsentwurf dominieren, kann entweder gebundene, freie oder reale Topografie vorliegen. ${ }^{163}$ Während Letztere auf bestehende Ortsschemata, also auf reale Raum- und Ortsvorbilder zurückgreift, die unter Berücksichtigung der zeitlichen Einordnung und des entsprechenden Vorwissens (oder dem, was dafür gehalten wird) vom Rezipienten imaginiert werden können, nutzen gebundene Topografien zwar die bei entsprechender Nennung von Ortsnamen aktivierten Schemata als Ausgangspunkt, verändern sie jedoch spielerisch durch entsprechende, teilweise auch phantastische Ergänzungen. ${ }^{164}$ Beim Aufruf eines realen Raumschemas wird (modellhaft formuliert) beim Rezipienten ein Top-down-Prozess angestoßen: das persönliche Schema des realen Ortes wird über den Text gelegt. Bei der Verwendung von gebundenen Raumschemata verlaufen Top-down- und Bottom-up-Prozesse parallel: Der Text modifiziert ein bestehendes Raumschema. ${ }^{165}$ Beides ist auch möglich, wenn der Rezipient die reale Ortsvorlage nie gesehen hat. Dann speisen sich die Informationen aus individuellen Assoziationen und Fragmenten des kulturellen Gedächtnisses. Ein Beispiel für die Verwendung gebundener Topografien stellt die räumliche Einordnung einer Narration in ein städtisches oder dörfliches Raumschema dar, das sich an ein reales Vorbild anlehnen, aber völlig frei ausgestaltet sein kann. Freie Topografie greift auf rein fiktive Orte und Räume zurück, die zwar meist gängigen Raum- und Landschaftsschemata nachempfunden sind, aber nach Belieben gestaltet, angeordnet oder semantisch gefüllt werden. Hier sind detailreichere Beschreibungen notwendig als bei den anderen beiden Varianten, da der Rezipient sonst allgemeinere, ungenauere Raumschemata heranziehen muss. Gebundene und freie Topografien gehen nicht selten Hand in Hand, wie man auch bei Harry Potter beobachten kann. ${ }^{166}$ Mohr will diesbezüglich in zeitgenössischen phantastischen Texten einen Trend erkannt haben: ${ }^{167}$

\footnotetext{
${ }^{162}$ Vgl. den Absatz zur mythischen Diegese. Vgl. Kapitel 4.2.1

${ }_{163}$ Die Beschreibung von phantastischen Topografien lehnt sich an Mohr (2012, S. 50-60) an.

${ }^{164} \mathrm{Vgl}$. Hickethier (1991), S. 11.

165 Zum Zusammenspiel von Top-down- und Bottom-up-Prozessen siehe McCormick (1988), S. 108 und Karg (2005), S. 109.

166 Insbesondere an den Grenzübergängen wie beispielsweise am Gleis 9 3/4 ist eine solche Verschmelzung zu
} 
In den beiden Genres meiner Untersuchung nimmt die Verwendung von topographisch gebundenen Raumwelten erst in den letzten Jahren etwas zu, freie Welten überwiegen weiterhin, sodass vermutet werden kann, dass es sich um einen Trend handelt, der weiter ansteigt, doch wahrscheinlich nie die freie Topographie verdrängen wird. ${ }^{168}$

$\mathrm{Zu}$ den Raumschema aufrufenden Elementen gehören explizite Ortsbezeichnungen sowie Gebäude- und Landschaftsschilderungen, Raummotive und Raumsymbole.

\subsubsection{Zum Repräsentant „Zeit“6}

Bei den durch die abstrakte Größe Zeit dominierten Wirklichkeitsentwürfen gilt es genau genommen zwei Aspekte zu beachten: zum einen die temporale Verortung, das Zeitsetting, das nach historischem Vorbild, aber auch frei gestaltet sein kann, und zum anderen die Zeitstruktur, die die Handlungen und Ereignisse temporal organisiert.

Die Zeitstruktur kann, wenn sie einem realistischen Vorbild folgt, streng chronologisch organisiert sein oder aber auch auf phantastischen bzw. mythischen Prinzipien ${ }^{169}$ beruhen, also anachronistisch, das heißt, von einer logischen Chronologie abweichend, organisiert sein.

Das zeitliche Setting hat auch Auswirkungen auf die anderen Symbolsysteme eines Wirklichkeitsentwurfs, auf Kausalität, Raum, Figur und Gegenstand, es verleiht zugleich Struktur und Orientierung. Zeitwelten implizieren zumeist ein komplettes Setting von Schemata, das sich auf die unterschiedlichsten Kontexte bezieht. Hierzu Mohr:

Mit Zeitwelt meine ich die Einordnung einer Fantastischen Welt in eine realhistorische Epoche, was vor allem durch die Darstellung der Machtstrukturen, der Gesellschaftsordnung und des technischen Entwicklungsstandes sichtbar wird. ${ }^{170}$

Oft genutzte Zeitwelten sind nach Mohr das Mittelalter, die (späte) Neuzeit sowie die Neueste Zeit, seltener Antike und Zukunft. ${ }^{171}$ Der Rückgriff auf realhistorische Vorbilder geht dabei nicht immer einher mit historischer Genauigkeit, sondern ist stärker davon abhängig, was gesellschaftlich mit einer bestimmten Zeitstufe assoziiert wird. Das Mittelalterbild, das in zeitgenössischer phantastischer Literatur entworfen wird, ist mehr einem Klischee als der Historie nachempfunden; es speist sich aus der Film- und Literaturtradition und weicht solcherart stark von der Realität ab. ${ }^{172}$ Wirklichkeitsentwürfe nach mittelalterlichem Vorbild sind geprägt von

\footnotetext{
beobachten.

${ }^{167} \mathrm{Zu}$ beachten ist: Die Dissertation wurde 2012 verfasst und bildet den Wissensstand zu diesem Zeitpunkt ab.

${ }^{168}$ Mohr (2012), S. 60.

${ }^{169}$ Vgl. Kapitel 4.2.3.1.

${ }^{170}$ Mohr (2012) S. 65.

${ }^{171}$ Ebd.

${ }^{172}$ Sie fußen meist auf dem Klischee des ,dunklen Mittelalters“, das stark mit barbarischem Verhalten und Ge-
} 
Landwirtschaft und Handwerk bei Abwesenheit von Technik, die in vielen Fällen durch Magie ersetzt wird. Oft herrschen die Macht- und Gesellschaftsstrukturen einer Monarchie sowie eine barbarische, gewaltaffine Mentalität vor, Frauen spielen eine untergeordnete Rolle oder sind zumindest nicht die Heldinnen der Geschichten. ${ }^{173}$ Ken Follet beispielsweise greift des Öfteren auf ein solches Setting zurück. ${ }^{174}$

In der Zeitwelt „Neuzeit“ ist Technik in gewissem Maß bereits Bestandteil des Wirklichkeitsentwurfs, die fiktive Monarchie befindet sich meist im Übergang zur Demokratie, auch die Rolle der Frau ist im Wandel begriffen und gewinnt sukzessive an Bedeutung. Der primäre Wirklichkeitsentwurf in Der Goldene Kompass (1996) ${ }^{175}$ ist hier als Beispiel zu nennen. Bei der Zeitwelt Neueste Zeit ist das Setting von der Lebenswirklichkeit der westlichen Welt der letzten Jahrzehnte und aktuellen technischen Entwicklungen geprägt, Machtverhältnisse und Gesellschaftsordnung sind an der jüngsten Vergangenheit orientiert; in den meisten Fällen wird ein urbaner Schauplatz aufgerufen samt dazugehöriger Kulissen und Requisiten. ${ }^{176}$ Immer mehr Texte situieren mindestens einen ihrer Wirklichkeitsentwürfe in die Jetztzeit, indem sie gegenwärtige technische Entwicklungen, thematische Strukturen oder politische Ereignisse zum Thema ihrer Narration machen. Hier gehört Technik zum Alltag, die Gleichstellung von Mann und Frau ist gesellschaftlicher Konsens, und die gegenwärtige Populärkultur wird eingebunden, um bestimmte Schemata beim Rezipienten aufzurufen. ${ }^{177}$

Frei ausgestaltete zeitliche Settings können in einer Mixtur verschiedener Zeitwelten realisiert werden oder in Settings, die keinem historischen Vorbild nachempfunden sind und völlig fremde und unbekannte Attribute zur Ausgestaltung nutzen. $\mathrm{Zu}$ den zeitweltaktivierenden Elementen in einem Text - Mohr nennt sie auch „Zeitzeiger“ - gehören neben Jahreszahlen, historischen Personen und Ereignissen auch Regierungsformen, Berufe und Gegenstände. ${ }^{178}$

\subsubsection{Zum Repräsentant „Figur“6}

Die Ausgestaltung von Figuren vermag ebenfalls einen Wirklichkeitsentwurf zu konstituieren. Aussehen, Fähigkeiten, Verhalten, Wissen, Weltsicht und vor allem die Denkweise sind dabei

\footnotetext{
walt assoziiert wird und im 14. Jahrhundert verortet wird. In Deutschland hat vor allem Richard Wagner das Mittelalterbild geprägt. Siehe dazu Mende (2012), S. 69 ff. und S. 259.

${ }^{173}$ Mohr (2012), S. 66 f.

${ }^{174}$ Vgl. Mende: www.kinderundjugendmedien.de/index.php/stoffe-und-motive/527-das-mittelalter (19.8.2014).

${ }^{175}$ Mohr (2012), S. 67.

${ }^{176}$ Ebd., S. 66.

${ }^{177}$ Ebd., S. 66 f.

178 Ebd., S. 68 f.
} 
an Schemata gebunden, die entweder einen realistischen oder phantastischen Aspekt betonen. Auch die kulturellen Gepflogenheiten und die Wortwahl können als Repräsentationsfläche eines Wirklichkeitsentwurfs dienen, der in extremen Fällen lediglich in der Gedankenwelt einer einzigen Figur erkennbar wird. In den meisten Fällen repräsentieren jedoch mehrere Figuren einen Wirklichkeitsentwurf. Grenzgängerfiguren nehmen in der Diegese eine besondere Stellung ein: Auch wenn sie zunächst als Repräsentanten eines Entwurfs eingeführt werden, können sie letztlich keiner Welt eindeutig zugeordnet werden.

Die Autoren zeitgenössischer phantastischer Literatur greifen in aller Regel auf Figuren zurück, die den unterschiedlichsten literarischen Traditionen entspringen: mittelalterlichen Sagen, antiken Mythen, aber auch keltischen, nordischen, ägyptischen und indianischen Volkserzählungen sowie Märchen und Seefahrergeschichten. Die Anlehnung an jene Figurentraditionen ist von verschiedenen kulturhistorischen Kontexten beeinflusst worden und entwickelt sich ständig weiter. ${ }^{179}$ Dabei haben sich aus der stetigen Interaktion zwischen Rezipientenerwartung und Werkantwort mittlerweise Figurenkonzepte herauskristallisiert, deren konkreter literarischer Aufruf in Form von individuellen und/oder kollektiven Assoziationen und Vorannahmen (Schemata) begleitet wird, die im konkreten Text entweder bestätigt und ergänzt oder bewusst gebrochen werden. ${ }^{180}$ Es scheint einen regelrechten Katalog immer wieder tradierter und neu interpretierter phantastischer Wesen zu geben, deren fiktive Existenz im kollektiven Bewusstsein der Gesellschaft verankert ist und die in erheblichem Maße Genremodelle und Genrevorstellungen der Phantastik beeinflusst haben. Zu ihnen zählen u. a. Drachen, Hexen, Zauberer, Magier, Druiden, Menschen mit den verschiedensten übernatürlichen Fähigkeiten, Elben, Elfen, Feen, Zwerge und Riesen, Vampire und Werwölfe, Harpyen, Sirenen, Meerjungfrauen, Selkies, Zentauren, Faune, Greife, Nymphen, Dryaden, Kobolde, Goblins, Orks, Gnome, Trolle, geflügelte Pferde und Einhörner sowie sprechende Tiere aller Art und Spezies. Nicht selten bilden Figuren der gleichen oder unterschiedlicher Traditionen ein Figurenset, das sich in einem besonders erfolgreichen Text formiert hat und auch Implikationen für die Beziehungen zwischen den „Rassen“181 beinhaltet. ${ }^{182}$ Diese wurden in der Forschung bereits umfangreich diskutiert, etwa ihre Herkunft und Entstehung, Rezeption und Zugehörig-

\footnotetext{
${ }^{179}$ Zur Vampirfigur siehe Kapitel 5.4.1.

180 Jene Eigenschaften sind je nach literarischem Medium anders codiert und können sowohl Aussehen, Verhalten und Fähigkeiten als auch die Symbolkraft oder die narrative Funktion einer Figur betreffen.

${ }^{181}$ Der Begriff ist weder ideologisch noch politisch gemeint, sondern als biologische Kategorie.

182 Siehe Mohr (2012), S. 160. Sie spricht beispielsweise vom „Herr der Ringe-Set“", das vor allem in der Heroic-Fantasy Verwendung fände.
} 
keit sowie ihre konkrete Bedeutung und Neuinterpretierung in unterschiedlichen Belegtexten und zu unterschiedlichen Zeiten. ${ }^{183}$

\subsubsection{Zum Repräsentant „Gegenstand“6}

Gegenstände können realistische wie phantastische Welten evozieren, indem sie Einfluss auf andere Symbolsysteme ausüben. Eine Geschichte mit singulärer Weltstruktur beispielsweise, die nach realistischen Prinzipien ausgerichtet ist, aber von einem fliegenden Teppich berichtet, wird aufgrund der phantastischen Implikationen des Gegenstandes als phantastischer Text gekennzeichnet. Der fliegende Teppich versinnbildlicht hier einen Wirklichkeitsentwurf, in dem zumindest ausschnittweise das Prinzip der Schwerkraft außer Kraft gesetzt ist und in dem sich die Figuren des phantastischen Fortbewegungsmittels bedienen können. In den meisten Fällen sind Gegenstände als Inventarien an einen in der Diegese gestalteten Wirklichkeitsentwurf gebunden, können bei Grenzüberschreitungen aber auch mitgenommen werden und ihren Nutzen in dem (symbolischen) Raum eines anderen Wirklichkeitsentwurfs entfalten. In der Literaturgeschichte gibt es zahlreiche Gegenstände, die ein phantastisches Schema beim Rezipienten aufrufen, das Aussehen und Funktion impliziert. Dazu zählen fliegende Teppiche oder Autos sowie Zauberstäbe, magische Waffen, Zeitmaschinen und Ähnliches.

\subsubsection{Zur Gestaltung von Grenzen und Übergängen}

Die Übergänge zwischen den einzelnen Wirklichkeitsentwürfen gestalten sich in der Diegese auf unterschiedliche Weise und werden Figuren und Gegenständen auf unterschiedliche Weise ermöglicht: Es gibt direkte Über- bzw. Durchgänge, etwa in Form einer Tür oder eines Tunnels, oder auch indirekte Übergänge in Form einer körperlichen oder mentalen Reise. Beide können an gewöhnliche, aber auch ungewöhnliche Objekte oder Begleitfiguren gebunden sein, die entweder die Personenbeförderung an sich erledigen oder aber magisch initiieren. ${ }^{184}$ In der Regel sind die Grenzorte oder -gebiete eines Wirklichkeitsentwurfs symbolisch an Grenzräume gebunden und werden oft mit Magie verknüpft. ${ }^{185}$ Die Regeln, die in dem Grenzgebiet herrschen, können frei gestaltet sein und weder auf den Regeln des einen noch des anderen Entwurfs basieren.

\footnotetext{
${ }^{183}$ Ebd., S. 75-147.

184 Ebd., S. 190.

185 Ebd., S. 187.
} 


\section{Zur Klassifizierung phantastischer Wirklichkeitsentwürfe}

Mithilfe des folgenden Rasters lassen sich die Wirklichkeitsentwürfe in der Diegese auffinden und analysieren. Es zeigt nacheinander die verschiedenen Repräsentationsinstanzen eines Wirklichkeitsentwurfs sowie die Schemata, die diesen zugrunde liegen. ${ }^{186}$

\begin{tabular}{|c|c|c|}
\hline Repräsentant & Realistische Schemata & Phantastische Schemata \\
\hline Kausalität & $\begin{array}{l}\text { realistische Ursache-Wirkungs- } \\
\text { Beziehungen, motiviert durch: } \\
\text { - Naturgesetze } \\
\text { - Logik } \\
\text { - ökonomische Logik und Preis- } \\
\text { Leistungs-Prinzipien } \\
\text { - Zufall } \\
\text { - gesellschaftliche Normen } \\
\text { u. Ä. }\end{array}$ & $\begin{array}{l}\text { phantastische Ursache- } \\
\text { Wirkungs-Beziehungen, moti- } \\
\text { viert durch: } \\
\text { - } \quad \text { Magie } \\
\text { - } \quad \text { wahrgewordene } \\
\text { Imagination } \\
\text { - } \quad \text { transzendentale oder } \\
\text { religiöse Verhältnisse } \\
\text { - futuristische Technik } \\
\text { - Pseudowissenschaften } \\
\text { - Prophezeiungen } \\
\text { - Fügungen } \\
\text { - Normen phantastischer } \\
\text { Gesellschaften }\end{array}$ \\
\hline Raum & $\begin{array}{l}\text { Fläche } \\
\qquad \text { zusammenhängend } \\
\text { Topografie } \\
\text { • real } \\
\text { Raumlogik, die auf Naturgesetzen ba- } \\
\text { siert }\end{array}$ & $\begin{array}{l}\text { Fläche } \\
\text { - abstrakt } \\
\text { Topografie } \\
\text { - gebunden } \\
\text { - frei } \\
\text { Raumlogik, die auf phantasti- } \\
\text { schen Prinzipien basiert }\end{array}$ \\
\hline
\end{tabular}

${ }^{186}$ Die Tabelle gibt Beispiele für realistische und phantastische Schemata, sieht aber in offensichtlichen Fällen davon ab. Es werden daher einige gängige phantastische und realistische Schemata - wie beim Aussehen und Verhalten von Figuren - als bekannt vorausgesetzt. 


\begin{tabular}{|c|c|c|}
\hline \multirow[t]{2}{*}{ Zeit } & $\begin{array}{l}\text { Zeitstruktur } \\
\text { - chronologisch }\end{array}$ & $\begin{array}{l}\text { Zeitstruktur } \\
\text { - anachronistisch } \\
\text { - zirkulär } \\
\text { - diskontinuierlich }\end{array}$ \\
\hline & $\begin{array}{l}\text { zeitliches Setting nach historischem } \\
\text { Vorbild: } \\
\text { - Antike } \\
\text { - Mittelalter } \\
\text { - Neuzeit } \\
\text { - Neueste Zeit } \\
\text { - Jetztzeit } \\
\text { - Zukunft }\end{array}$ & $\begin{array}{l}\text { zeitliches Setting mit phantasti- } \\
\text { schen Attributen } \\
\text { - unrealistische Zeitwelt- } \\
\text { Mixtur } \\
\text { - fremdartiges Setting }\end{array}$ \\
\hline Figur & $\begin{array}{l}\text { realistisch gestaltet in: } \\
\text { - Aussehen } \\
\text { - Verhalten } \\
\text { - Fähigkeiten } \\
\text { - Wissen } \\
\text { - Weltsicht } \\
\text { - Denkweisen } \\
\text { - kulturellen Gewohnheiten } \\
\text { - Wortwahl } \\
\text { realistisches Figurenset mit Menschen } \\
\text { und Tieren }\end{array}$ & $\begin{array}{l}\text { phantastisch gestaltet in: } \\
\text { - } \quad \text { Aussehen } \\
\text { - } \text { Verhalten } \\
\text { - Wissen } \\
\text { - Weltsicht } \\
\text { - Denkweisen } \\
\text { - kulturellen Gewohnheiten } \\
\text { - Wortwahl } \\
\text { Figurenset als Kombination von } \\
\text { Wesen und Figuren aus den un- } \\
\text { terschiedlichsten Traditionen }\end{array}$ \\
\hline Gegenstand & $\begin{array}{l}\text { realistisch in: } \\
\text { - Aussehen } \\
\text { - Funktion }\end{array}$ & $\begin{array}{l}\text { phantastisch in: } \\
\text { - Aussehen } \\
\text { - Funktion }\end{array}$ \\
\hline
\end{tabular}

Tabelle 3: Raster zur Klassifizierung von phantastischen Wirklichkeitsentwürfen 


\subsubsection{Analyse der Wirklichkeitsentwürfe von Harry Potter}

Den Harry-Potter-Büchern liegt eine binäre Weltstruktur zugrunde, die in den meisten Forschungsbeiträgen modellhaft als Primär- und Sekundärwelt aufgefasst wird, so auch bei Mohr, deren Ergebnisse bezüglich der Potter-Texte im Folgenden kurz zusammengefasst und durch eigene Beobachtungen ergänzt werden sollen.

Die Ausgangswelt der Diegese kann als realistischer Wirklichkeitsentwurf betrachtet werden, der im heutigen England bzw. dem England der Neuzeit angesiedelt ist. Sie wird hauptsächlich durch die Weltsicht und Lebensweise der Familie Dursley repräsentiert. Die Dursleys haben beschlossen, Magie und Zauberei aus ihrem Leben zu verbannen, auch wenn die Ereignisse um sie herum das nahezu unmöglich machen (HP 1, S. 58 f.). Sie sind als britische Durchschnittsfamilie inszeniert, die sehr stolz darauf ist, „ganz und gar normal zu sein“ (HP 1, S. 5): Mr. Dursley arbeitet in einer Bohrmaschinenfirma, gibt jeden Morgen seiner Frau einen Abschiedskuss, wenn er zur Arbeit geht, und legt großen Wert darauf, was seine Nachbarn von ihm halten (HP 1, S. 5 f.). Die Ausgangswelt bedient sich realer Topografien, in die die phantastischen Räume der Zaubererwelt integriert werden. Gebundene und freie Topografien gehen so Hand in Hand, was zum Beispiel am Haus der Blacks sichtbar wird, das am „,Grimmauldplatz Nummer zwölf, London“ (HP 5, S. 75) gelegen ist, eine Ortsangabe, die keine eindeutige Entsprechung in der Realität besitzt. Das Haus wird durch einen Geheimniszauber geschützt, nur von Albus Dumbledore Befähigte vermögen es ausfindig zu machen. Es erscheint ,aus dem Nichts zwischen Nummer elf und Nummer dreizehn“ und durchbricht damit die realistische Topografie der unscheinbaren Straße (HP 5, S. 76). Der Text schreibt sich so in die Erlebniswelt der Rezipienten ein und überführt sie ins Phantastische. ${ }^{187}$

Der zweite Wirklichkeitsentwurf, der dezidiert als „Zaubererwelt“ (HP 2, S. 40) bezeichnet wird, ist als völlig eigenständig zu verstehen, da er primär auf der Fähigkeit zu zaubern basiert, das heißt, auf einem phantastischen Kausalitätskonzept. Harry muss sich in der zunächst für ihn unbekannten Umgebung bewähren, was als Wiederaufnahme eines klassischen Motivs betrachtet werden kann. ${ }^{188}$ Auch wenn die Zaubererwelt phantastische Schemata bemüht, erinnert sie strukturell stark an die empirische Realität: „Dem Leser wird eine ihm in den Grundzügen bekannte, lediglich ins Phantastische verschobene Alltagswelt präsentiert. “189

\footnotetext{
${ }^{187}$ Vgl. Mohr (2012), S. 327.

${ }^{188}$ Lexe (2003), S. $180 \mathrm{f}$.

${ }^{189}$ Mohr (2012), S. 244.
} 
Die Zaubererwelt gestaltet sich nicht als zusammenhängender Bereich, sondern in Form einer unzusammenhängenden, abstrakten Fläche, Mohr spricht von „,Sekundärwelt-Inseln “190. Logisch betrachtet, ist die Zaubererwelt räumlich in die Ausgangswelt integriert, sie ist für die Muggel lediglich nicht wahrnehmbar. Die Topografie des phantastischen Entwurfs schließt an reale Vorbilder an, die frei ausgestaltet und modifiziert werden. Die Winkelgasse, Hogsmeade und auch Hogwarts sind durch die Vorkehrungen des Zauberministeriums für Muggel unsichtbar, und Distanzen werden mit Besen, dem Flohnetzwerk, fliegenden Autos oder Portschlüsseln überbrückt. ${ }^{191}$

Das zeitliche Setting des Wirklichkeitsentwurfs setzt sich aus verschiedenen Zeitstufen zusammen und wirkt schon allein aufgrund dieser Mixtur phantastisch: Während Hogwarts und seine Architektur ein mittelalterliches Setting zur Verfügung stellen, unterstützt durch Gegenstände wie Tinte (HP 1, S. 89), Pergament (HP 1, S. 89), Rüstungen (HP 1, S. 145) und Kessel (HP 1, S. 56), gibt es zuhauf Zeitanzeiger, die auf Schemata der Moderne bzw. Neuzeit verweisen, wie Zonkos Zauberscherzladen (HP 4, S. 444), Autos (HP 2, S. 28) und Motorräder (HP 1, S. 20). ${ }^{192}$ Es herrscht grundsätzlich eine realistische Zeitstruktur, diese kann jedoch durch Magie überwunden werden. So lassen sich auch zyklische Zeitstrukturen - vor allem im dritten Band der Serie - ausmachen (HP 3, S. 407).

Die Figuren zeichnen sich durch ein Weltbild aus, das dem der Muggel überlegen ist: Letztere verfügen demnach nur über einen begrenzten Horizont, weil sie nichts von der Existenz der Zaubererwelt wissen und nicht an Magie glauben (HP 1, S. 61). Dass dies so bleiben muss, ist sogar eine Regel, es gibt ein Ministerium, das sich hauptsächlich mit dieser Angelegenheit beschäftigt (zum Beispiel HP 1, S. 74). In der Zaubererwelt werden Figurensets aufgerufen, die sich aus den unterschiedlichsten Traditionen herleiten. Neben menschlichen Hexen und Zauberern gibt es Kobolde (HP 1, S. 72), Zentauren (HP 1, S. 275), Einhörner (HP 1, S. 95), Elfen (HP 2, S. 183), Drachen (HP 4, S. 94), Hippogreife (HP 3, S. 121), Meerjungfrauen (HP 4, S. 479) und Phönixe (HP 1, S. 94). Rowling erfand zudem weitere Figuren wie die Dementoren (HP 2, S. 75) und neigt zur Neuinterpretation phantastischer Wesen, insbesondere bei denen, die handlungstragend sind. ${ }^{193}$

\footnotetext{
${ }^{190}$ Ebd., S. 184.

${ }^{191}$ Bürvenich (2001), S. 59; Cornelius (2003), S. 89.

${ }^{192}$ Mohr (2012), S. 70.

${ }^{193}$ Vgl. ebd., S. 153.
} 
Die Gegenstandswelt ist sehr facettenreich. Neben etabliertem phantastischem Inventar wie Zauberstäben und fliegenden Besen charakterisiert insbesondere Neuerdachtes die Zaubererwelt: Es gibt Zauberschach (HP 1, S. 217), bei dem die Figuren leben und sich gegenseitig bekämpfen, und Fotos (HP 1, S. 330), die eine bewegte Szene abbilden; weiterhin zahlreiche magische Scherzartikel (HP 4, S. 56) und andere Gegenstände, die den phantastischen Wirklichkeitsentwurf in Szene setzen.

Die Weltenübergänge sind allesamt nur mithilfe von Magie passierbar und erlauben keinen Zugang für Muggel oder Ungewollte. Als Übergangstore dienen Mauern (HP 1, S. 80) und eine Telefonzelle (HP 5, S. 151 ff.), als Objekte, die eine Übergangsreise gestalten, der Hogwarts-Express und ein fliegendes Auto (HP 2, S. 28), Kamine (HP 6, S. 63f), Portschlüssel (HP 4, S. 76) sowie die Kunst des Apparierens (HP 6, S. 387 ff.). ${ }^{194}$

\subsubsection{Analyse der Wirklichkeitsentwürfe in den Post-Potter-Texten}

Einige Beispiele aus dem Korpus sollen nun nach obigem Modell auf ihre verschiedenen Wirklichkeitsentwürfe untersucht werden, zunächst die Panem-Trilogie von Suzanne Collins (Kapitel 3.3.4.1), daran anschließend Meyers Bis(s)-Serie (Kapitel 3.3.4.2) und schließlich Giers Edelstein-Trilogie (Kapitel 3.3.4.3). Die einzelnen Texte werden zunächst einer Weltstruktur zugeordnet, danach die zugrundeliegenden Wirklichkeitsentwürfe spezifiziert. Am Schluss werden Grenzen und Übergänge analysiert.

\subsubsection{Zum Wirklichkeitsentwurf der Panem-Trilogie}

Der Serie Die Tribute von Panem liegt eine phantastische Diegese mit singulärer Weltstruktur zugrunde: Durchgängig wird nur ein Wirklichkeitsentwurf in den Repräsentationsinstanzen versinnbildlicht. Dieser konkretisiert sich vor allem im zeitlichen Setting der Narration, das in der Zukunft anzusetzen ist und Einfluss auf die Kausalitätsstrukturen sowie die Raum-, Zeit-, Figuren- und Gegenstandskonzeption der Diegese nimmt. Die geschilderte Welt kann daher modellimmanent als Zeitwelt aufgefasst werden, die sich aufgrund ihrer futuristischen Anlage logisch nicht an eine historische Vorlage halten kann. Da nicht begründet entschieden werden kann, inwieweit eine Possible World ausgestaltet ist, erfolgt die Einordnung der Schemata im Abgleich mit der gegenwärtigen empirischen Realität und dem derzeitigen Konsens darüber, was als realistisch und was als phantastisch gilt. Durchgängig lässt sich beobachten, dass die Narration an realistische Schemata anschließt, die sie ins Phantastische wendet.

\footnotetext{
${ }^{194}$ Ebd., S. 190.
} 
Die dargestellte Welt basiert auf realistischen Kausalitätsprinzipien, die durch phantastische Schemata unterlaufen werden. So sorgen Wissenschaftsutopie und eine futuristische Technik für phantastische Ursache-Wirkungs-Beziehungen: Die Arenen der beiden Hungerspiele zeigen sich als Meisterwerke der Technik, deren Aufbau und Funktionsweise nach heutigem Standard als unmöglich und daher als phantastisch einzustufen sind. Innerhalb der Diegese bilden sie jedoch den Stand der Technik ab. Die Arena des „Jubel-Jubiläums“ gestaltet sich als eine überdimensionale, zwei Tagesmärsche breite kreisrunde Fläche, die in zwölf unsichtbare, gleich große Sektoren eingeteilt ist, wobei zu jeder vollen Stunde in einem dieser Felder eine tödliche „Natur"-Katastrophe ausgelöst wird (GL, S. 361): darunter gigantische Blitze (GL, S. 329), Blutregen (GL, S. 359) und giftiger Nebel, der alles zu töten imstande ist (GL, S. 329). Zudem besteht die Option, die Wettkampffläche während der Spiele zu steuern und zu modifizieren: Sie kann auf unerträglich hohe Temperaturen erhitzt werden, Wasser, Nahrung und Schutz können sich plötzlich verknappen, mitunter kann aber auch den Teilnehmern eine einigermaßen sichere Lebensgrundlage zur Verfügung gestellt werden (TS, S. 79, S. 173, S. 420). Die Tribute wissen nie, welche Fallen die Spielmacher aufgestellt haben, damit bei den Zuschauern keine Langeweile aufkommt (TS, S. 158). Der Stand der Wissenschaft ist auch im Bereich der Medizin sehr weit fortgeschritten, sodass Heilungen erreicht werden, die nach heutigem Stand als phantastisch einzustufen sind. Katniss' Haut ist nach ihrer Ganzkörperbehandlung wieder makellos, was angesichts der Strapazen in der Arena aus heutiger Sicht unmöglich wäre (TS, S. 393). Zudem existieren Medikamente und Salben, die ungewöhnlich schnell wirken.

Die Geschichte spielt im zukünftigen Nordamerika, wo sich die Nation Panem, die aus mehreren Kriegen hervorgegangen ist, zum Zeitpunkt der Handlung (nach Zerstörung eines ursprünglich dreizehnten Distrikts) in zwölf Distrikte aufteilt (TS, S. 23). Die politische Elite, das „Kapitol“, wird mit Luxus überhäuft, während vor allem die Distrikte drei bis zwölf Hunger leiden und ihre Kinder für die Hungerspiele opfern müssen (TS, S. 24). Der Begriff Kapitol verweist auf das gleichnamige Kongressgebäude in Washington und stellt damit einen klaren Bezug zum heutigen Amerika her. ${ }^{195}$ Der futuristische Wirklichkeitsentwurf wird durch das topografische Vorbild konkret in einer zusammenhängenden Fläche repräsentiert,

\footnotetext{
${ }^{195}$ Aber auch die Bezugnahme zur Antike ist augenscheinlich: Das Setting der Hungerspiele erinnert stark an Gladiatorenspiele bzw. -kämpfe. Der Begriff „Panem“ spielt auf die Junktur „panem et circenses“ an („Brot und Spiele"), die sich beim römischen Satirendichter Juvenal findet (Sat. 10,81); Juvenal kritisiert die politischen Umstände der Kaiserzeit: Während zur Zeit der Republik das Volk maßgeblich an politischen Entscheidungen beteiligt gewesen sei, wünsche es „heute“ nur noch „Brot und Spiele“. Vgl. auch Kapitel 4.2.3.2.
} 
die sich in Form und Lage an die empirische Realität des Georaums Erde anlehnt. Das realistische Ortsschema „Nordamerika“ wird dem Rezipienten von Anfang an zur Verfügung gestellt und soll ihn offenbar bei seiner Lektüre begleiten, ihm Orientierung bieten. ${ }^{196}$ Dies ist deswegen interessant, weil die Ansiedelung in Amerika tatsächlich nur an einer Stelle explizit vorgenommen wird (TS, S. 23) und aufgrund dominierender freier, unbekannter, futuristischer Ortsschemata, die aus der futuristischen Anlage plausibilisiert werden, schnell in Vergessenheit geraten könnte. Die Anbindung an ein bekanntes Ortsschema steigert indes die Authentizität der Narration. Als Beispiel für ein phantastisches Raumschemata ist die Ausgestaltung das Kapitols zu betrachten, die unter Rückgriff auf gebundene Topografien folgendermaßen realisiert wird:

[...] das Kapitol. Die Herrscherin über Panem. Die Kameras haben ihre Erhabenheit nicht übertrieben. Wenn überhaupt, dann haben sie die Pracht der in allen Farben leuchtenden Gebäude, die in den Himmel ragen, nicht ganz erfasst, die glänzenden Autos, die über die breiten Asphaltstraßen fahren, [...]. Alle Farben wirken künstlich - das Rosa zu satt, das Grün zu knallig und das Gelb schmerzt in den Augen $[\ldots]$ (TS, S. 69).

Aufgerufen wird hier ein urbanes Raumschema, während die anderen Distrikte überwiegend ländlich bzw. dörflich ausgestaltet sind. Auch wenn kein realer Ortsname verwendet wird, knüpft die Beschreibung des Kapitols durch Schlagworte wie „Gebäude“, „Autos“ und „Asphaltstraßen“ unmittelbar an heutige, reale Stadtkonzepte an, ohne explizit ein konkretes Vorbild anzubieten. Sie werden als Ausgangspunkt für ein freies Raumschema genutzt, das sich etwa in der Farbgebung offenbart. Die Buntheit des Kapitols verfremdet das vertraute Raumschema und macht die Zukunftsorientierung der Narration für den Rezipienten sichtbar, der sich vorstellen dürfte, das eine zukünftige Stadt in vielen Aspekten anders gestaltet sein wird als heute. Der Verweis, dass die Farben künstlich wirken, knüpft an solche Vorstellungen an, die oftmals klischeebehaftet sind.

Auch die Figuren, allesamt menschliche und tierische Lebewesen, versinnbildlichen den Wissensstand und die Denkweisen einer zukünftigen Gesellschaft. Grundsätzlich nach realistischen Schemata gestaltet, besitzen sie auch phantastische Attribute, die durch die Verortung in der Zukunft als realistische Schemata etabliert werden: Die Bewohner des Kapitols werden als ,eigentümlich gekleidete[], wohlgenährte[] Leute mit wunderlichem Haar und bemalten Gesichtern“ (TS, S. 69) beschrieben. Es scheint normal zu sein, blaues oder rosa Haar (TS,

\footnotetext{
${ }^{196}$ In der Originalausgabe wird die Verortung der Narration auf dem Teil des Schutzumschlags vorweggenommen, der gleichzeitig als Lesezeichen dient und dem Rezipienten bei jedem erneuten Buchaufschlag präsent ist.
} 
S. 71; FZ, S. 74) zu tragen, auffällig geschminkt zu sein (TS, S. 140; FZ, S. 74) oder mithilfe von Schönheitschirurgie dünner und jünger zu wirken (TS, S. 140), was als ein Zeichen für Reichtum und Wohlstand zu verstehen ist. So ist das Aussehen der gestalteten zukünftigen Menschheit aus unserer Sicht nicht phantastisch im Sinne von nicht praktisch realisierbar, sondern lediglich fremd und ungewöhnlich. Die beschriebene Gesellschaft ist geprägt von den Kriegen der Vergangenheit, von Ressourcenknappheit und einer egoistischen, ungerechten politischen Elite. Dies plausibilisiert überhaupt erst das Ritual der Hungerspiele, das nach heutigen kulturellen, sozialen und moralischen Maßstäben nicht denkbar wäre. Technik und digitale Medien beeinflussen indes den Alltag der Figuren stark, so wie es auch die Rezipienten gewohnt sind. Das „Staatsfernsehen“ (TS, S. 23) ist eines der wichtigsten öffentlichen Medien, worüber die Hungerspiele sowie alle wichtigen politischen Ereignisse dem Volk vermittelt werden. Das Vokabular der Figuren beinhaltet Neologismen, vor allem für Gegenstände und Tiere. ${ }^{197}$

In der Tierwelt zeugen Mutationen (TS, S. 369) von futuristischer Normalität: Es gibt orangefarbene Affen in Menschengröße, die sehr aggressiv sind, sich lautlos fortbewegen und übernatürlich weit springen können (GL, S. 336), Jägerwespen, die für den Menschen sehr gefährlich sind, da sie ihre Opfer so lange jagen, bis sie tot sind (TS, S. 208), und Schnattertölpel, die ihr Gegenüber emotional quälen (GL, S. 367 ff.), indem sie die wehklagenden Stimmen von geliebten Menschen imitieren. Auch hier lässt sich die Anknüpfung an realistische Schemata erkennen.

Gleiches gilt für die Gegenstände, die sich harmonisch in das futuristische Setting der Serie einfügen: Die Kleidung der Kapitolbewohner beispielsweise ist nicht nur auffällig schrill und bunt - wie das gesamte Stadtbild selbst -, sondern wird nicht selten mit künstlich anmutenden technischen Details veredelt: Es gibt Kleidung, die mit ,,Tausenden von winzigen elektrischen Lämpchen“ (TS, S. 140) geschmückt ist. Katniss bekommt ein Kleid genäht, das anfängt zu brennen, wenn sie sich darin dreht (TS, S. 143 f.). Zum Inventar des Wirklichkeitsentwurfes gehören aber auch Requisiten, die zu den unterschiedlichsten Zeiten in der empirischen Realität von Bedeutung waren. So ist die Lieblingswaffe von Katniss Pfeil und Bogen (TS, S. 9,

\footnotetext{
${ }^{197}$ Insidervokabular, das sich in allen anderen Texten des Korpus findet, ist eine wichtige Komponente bei der Fan-Kommunikation und Imagebildung. Das Image eines Medienverbundes beeinflusst in hohem Maße den sogenannten Zusatznutzen (auch Consumer Benefit) eines literarischen Produkts. Dieser kommt zum Beispiel in Prestige, einem Zugehörigkeitsgefühl oder einem politisch-gesellschaftlichen Statement zum Ausdruck. Das Image eines Produkts kann ein Konsument durch den Kauf eines entsprechenden Produkts auf seine eigene Person übertragen. Vgl. Auer/Diedrichs (1993), S. 165 ff. und Frey (2006), S. 185 ff.
} 
S. 168), die eher vormodernen Zeitwelten zuzurechnen sind. Insgesamt werden auch hier hauptsächlich realistische Schemata bemüht.

\subsubsection{Zu den Wirklichkeitsentwürfen der Bis(s)-Serie}

Die Diegese von Stephenie Meyers Tetralogie basiert modellbedingt auf einer binären Weltstruktur, die zwei Wirklichkeitsentwürfe gegenüberstellt: den des „,normalen“ Menschen (BzMo, S. 180; BzA, S. 346) und den der Vampire und Werwölfe (BzAb, S. 308), wobei Letzterer hier besondere Beachtung finden soll. Da beide Entwürfe vornehmlich durch Figuren bzw. Figurengruppen zum Ausdruck kommen, kann modellimmanent von zwei verschiedenen Figurenwelten gesprochen werden, die in der Diegese der Geschichte ausgestaltet sind.

Die Ausgangswelt, aus Bellas Perspektive vermittelt, wird überwiegend durch realistische Schemata realisiert: Die Geschichte spielt zumeist in der amerikanischen Kleinstadt Forks (BzMo, S. 7, BzMi, S. 8, BzAb, S. 8, BzEdN, S. 8), die Menschen denken und handeln nach einem rationalen Weltbild und einem „Wissenschaftsglauben“ (BzEdN, S. 749), was beispielsweise an der Denkweise von Bellas Vaters vorgeführt wird. Dieser ist ein „pfiffiger, pragmatischer Mensch“ (BzEdN, S. 324) mit einer „,Skepsis gegenüber dem Übernatürlichen" (BzEdN, S. 659). Wie die anderen Menschen geht er davon aus, dass Vampire und Werwölfe nicht Teil der Wirklichkeit sind; sie gelten als „purer Mythos“ (BzEdN, S. 749). Das zeitgenössische Nordamerika, speziell das Kleinstadtleben, dient hier als Setting, das nah an der empirischen Realität gestaltet ist: Bella schreibt E-Mails und recherchiert im Internet (BzMo, S. 140), fährt einen alten Chevrolet (BzMo, S. 11), hört Rockmusik auf CD (BzMo, S. 137), isst Hamburger (BzMo, S. 80) und schaut DVDs (BzEdN, S. 115) an. Ihr Schulunterricht thematisiert den gängigen Schulstoff, sie nimmt Brontës Sturmhöhe ${ }^{198}$ im Englischunterricht durch, spielt Volleyball im Sportunterricht (BzMo, S. 34) und beschäftigt sich mit den verschiedenen Phasen der Mitose in Biologie (BzMo, S. 49). Die Frage, wer mit wem auf den Abschlussball geht, interessiert die Schülerinnen ihres Jahrgangs brennend (BzMo, S. 223), während Bella von Anfang an zu wissen glaubt, dass sie nicht zu der Welt um sie herum gehört. Denn sie kommt ,, mit Leuten generell nicht gut klar “ und fragt sich des Öfteren, ob sie dieselben Dinge sieht wie der Rest der Welt (BzMo, S. 15). Sie wird im Laufe der Geschichte zur Grenzfigur, indem sie zunächst die ,andere“ Welt kennenlernt (BzAb, S. 21) und dann durch Verwandlung ein Teil davon wird.

\footnotetext{
198 Die englischsprachige Originalausgabe dieses Romans erschien 1847 unter dem Pseudonym Ellis Bells. Die erste deutsche Übersetzung erschien 1851 und hat einen anonymen Übersetzer.
} 
Der Gegenentwurf zur Ausgangswelt, die „,Welt der Vampire“ (BzAb, S. 308), müsste eigentlich als „Welt der Vampire und Werwölfe“ bezeichnet werden. Alle phantastischen Aspekte der Diegese leiten sich logisch von diesen phantastischen Wesen her, die auch die dominanteste Repräsentationsinstanz sind: Ihr Aussehen, Verhalten, ihre Fähigkeiten und Denkweisen, ihre kulturellen Gepflogenheiten und ihr Vokabular etablieren einen phantastischen Wirklichkeitsentwurf, machen ihn greifbar - eine Welt, die sich höchst selten räumlich, zeitlich oder gegenständlich in phantastischen Schemata ausdrückt, im Gegenteil: Der besondere Reiz des Gedankenspiels liegt genau darin, dass Vampire und Werwölfe in das realistische Setting integriert werden: Sie gehen in gewöhnliche Schulen, tragen gewöhnliche Kleider, wohnen in gewöhnlichen Häusern und gehen gewöhnlichen Berufen nach. Daher tauchen auch keine anderen phantastischen Schemata auf. Nur sehr implizit, am Rande, wird der phantastische Wirklichkeitsentwurf räumlich, zeitlich und gegenständlich in der Diegese sichtbar: So besitzen die Cullens keine Betten in ihrem Haus, weil sie nicht schlafen (BzMo, S. 196), und müssen alle paar Jahre umziehen, weil sie nicht altern und dadurch Aufmerksamkeit auf sich ziehen würden (BzMo, S. 305 f.).

Das Aussehen der Vampire und Werwölfe lehnt sich zunächst an realistische Schemata an, die dann aber sehr frei ausgestaltet werden: ${ }^{199}$ Vampire haben zunächst eine ,normale“ Menschengestalt, werden aber als ,,überirdisch schön “ (BzMo, S. 24), ,elfenhaft“ (BzuMo, S. 23) und „kreidebleich“ beschrieben (BzMo, S. 23). Obwohl sie unterschiedliche Haarfarben besitzen, gleichen sie einander ,wie ein Ei dem anderen“ (BzMo, S. 23). Dass ihre Augen je nach Blutdurst die Farbe ändern, wirkt auf die Menschenwelt höchst befremdlich (BzMo, S. 51). Ihre körperlichen und geistigen Fähigkeiten sind klar übermenschlich: Sie sind unnatürlich stark und schnell (BzMo, S. 64), was sie neben der Tatsache, dass sie keine natürliche Nahrung verdauen können, zu verheimlichen versuchen (BzMo, S. 196). Weiterhin können sie Gedanken lesen (BzMo, S. 323) oder Gefühle beeinflussen (BzEdN, S. 626). Die Werwölfe sind strenggenommen „Gestaltwandler“ (BzEdN, S. 737), die je nach Vampiraufkommen zwischen Menschen- und Wolfsgestalt hin und her wechseln. Sie rekrutieren sich aus dem Stamm der Quileute, einem Indianerstamm, der auf Legenden zurückgeht, die dem Rezipienten im Laufe der Handlung nähergebracht werden (BzMi, S. 87). In Menschengestalt fallen sie vor allem durch ihre Muskeln und Körpergröße auf (BzMo, S. 193), in Wolfsgestalt besitzen sie die Fähigkeit der mentalen Kommunikation und werden von ihrem „,Alphatier“ gelei-

\footnotetext{
${ }^{199}$ Die Vampir-Figur und ihre literarische Tradition werden in Kapitel 5.4.2.1 verhandelt.
} 
tet (BzMi, S. 318 f.). Vampire wie auch Werwölfe besitzen ihre eigene Kultur, deren oberste Regel lautet, ihre Existenz vor den Menschen zu verheimlichen, vor allem weil sie sich von Blut ernähren (BzMo, S. 196). Vampire haben zudem eine politische Elite und eine königliche Familie, die sich um die Einhaltung der Regel kümmert, die Volturi (BzMi, S. 25). Eigene Freizeitaktivitäten wie Vampirbaseball (BzMo, S. 382 f.) und Vampirschach ${ }^{200}$ sind ihren Fähigkeiten angepasst. Werwölfe und Vampire sind in ihrer Welt natürliche Feinde, da sich die Wölfe zur Aufgabe gemacht haben, die Menschen vor den „Kalten Wesen“ (BzMo, S. 164) zu schützen. Beide haben analog zu den Zauberern in Harry Potter eine überlegene Weltsicht: Sie kennen die Welt der Menschen, umgekehrt aber bleibt den Menschen die Welt der Vampire verschlossen. Ihr Sonderwissen drückt sich auch in ihrem Vokabular aus, das Insider in der Diegese erkennbar macht: ${ }^{201}$ So bezeichnet der Begriff „Tracker“ Vampire, die einen starken Jagdtrieb haben und ihre Beute fixieren, bis sie sie überwältigen (BzMo, S. 397 f.). Werwölfe hingegen können ,geprägt“ (BzAb, S. 177) sein, das heißt, dass sie ihr komplettes Leben darauf ausrichten, die Person, auf die sie geprägt worden sind, zu schützen und deren Leben möglichst angenehm zu gestalten.

Beide Figurenwelten besitzen Grenzen und Übergänge, wenngleich diese nicht als Grenzräume oder Grenzgebiete zu verstehen sind, sondern sich vielmehr abstrakt und figurgebunden gestalten. So provoziert Bella, nachdem Edward sie verlassen hat, gefährliche Situationen, weil sie dabei das Gefühl hat, ihm nah zu sein und seine Stimme zu hören (BzMi, S. 244). Dabei handelt es sich um abstrakte Grenzsituationen, wo nicht klar wird, ob sie der Realität entsprechen oder nur Bellas Imagination entspringen. Zudem repräsentiert Renesmee, die Tochter von Edward und Bella, die halb Mensch, halb Vampir ist, eine Grenzfigur, da in ihr beide Welten miteinander vereinigt werden. Es ist lange nicht klar, welche körperlichen Merkmale und mentalen Eigenschaften dieses Kind entwickeln wird, da solche Hybridwesen in der Diegese kaum bekannt sind. Tatsächlich weist Renesmee Attribute beider Welten auf: Sie trinkt Blut (BzEdN, S. 364), glitzert in der Sonne, allerdings nicht so stark wie Vampire, und hat eine viel höhere Körpertemperatur (BzEdN, S. 397). Sie wird normal geboren und besitzt einen Herzschlag, wächst aber viel schneller als gewöhnliche Menschen.

Im Übrigen weist auch Percy Jackson eine phantastische Diegese mit binärer Weltstruktur auf: Dabei kann modellhaft zwischen dem Wirklichkeitsentwurf der Götter und dem der

\footnotetext{
${ }^{200}$ Die Parallele zum Zaubererschach in Harry Potter ist augenscheinlich.

${ }^{201}$ Vgl. Fußnote 197, Seite 106.
} 
Normalsterblichen unterschieden werden. Auch dort werden die Welten hauptsächlich durch die Figuren repräsentiert.

\subsubsection{Zu den Wirklichkeitsentwürfen der Edelstein-Trilogie}

Der phantastischen Diegese der Edelstein-Trilogie liegt der Idee nach eine multiple Weltstruktur zugrunde, die sich aus den verschiedenen Zeitreisen ergibt. Die Diegese kann vor dem Hintergrund des oben beschriebenen Modells - als Set von Zeitwelten aufgefasst werden, die innerhalb der Diegese nebeneinander existieren. Da die Geschichte in London spielt, stellt jedes London zu einem spezifischen Datum eine Welt dar, die einem von unzähligen Wirklichkeitsentwürfen zugrundeliegt. Oberflächlich lässt sich die Diegese in zwei Welten einteilen: Die der „Gegenwart“ (RR, S. 344) und die der „Vergangenheit““ (RR, S. 345), die sich in ihrer Repräsentation gut erkennbar voneinander differenzieren lassen.Der phantastischen Diegese der Edelstein-Trilogie liegt der Idee nach eine multiple Weltstruktur zugrunde, die sich aus den verschiedenen Zeitreisen ergibt. Die Diegese kann - vor dem Hintergrund des oben beschriebenen Modells - als Set von Zeitwelten aufgefasst werden, die innerhalb der Diegese nebeneinander existieren. Da die Geschichte in London spielt, stellt jedes London zu einem spezifischen Datum eine Welt dar, die einem von unzähligen Wirklichkeitsentwürfen zugrundeliegt. Oberflächlich lässt sich die Diegese in zwei Welten einteilen: Die der „Gegenwart“ (RR, S. 344) und die der „Vergangenheit“ (RR, S. 345), die sich in ihrer Repräsentation gut erkennbar voneinander differenzieren lassen.

Grundsätzlich folgen beide Wirklichkeitsentwürfe der Serie dem gleichen phantastischen Kausalitätsprinzip, das in weiten Teilen einem realistischen nachempfunden ist, aber durch ein mythisches Prophezeiungsschema ${ }^{202}$ verfremdet wird. Ursache und Wirkung sind jeweils vorherbestimmt, das heißt, relevante Ereignisse ergeben sich nicht aus Ursachen, sondern repräsentieren das vorbestimmte Schicksal, denn die Zukunft steht innerhalb der Diegese schon fest. In allen bzw. beiden Zeitwelten plausibilisiert die Möglichkeit des Zeitsprungs die Sinnhaftigkeit der Vorgänge (RR, S. 11). Das Springen in der Zeit obliegt eignen Regeln: Ist es unkontrolliert, kündigt es sich einige Minuten vorher durch ein Schwindelgefühl an, der „Initiationssprung“ findet zwischen dem „,16. und 17. Lebensjahr des Gen-Trägers“ (RR, S. 11) statt und geht nicht weiter als hundertfünfzig Jahre in die Vergangenheit zurück (RR, S. 41). Der kontrollierte Zeitsprung mithilfe des Chronografen (RR, S. 43), der den Genträger zielgerichtet in ein Datum seiner Wahl katapultiert, kann bei männlichen Genträgern eine

\footnotetext{
${ }^{202}$ Siehe Kapitel 4.2.1.
} 
Zeitspanne von 120 Sekunden bis 240 Minuten und bei den weiblichen Genträgern von 121 Sekunden bis 239 Minuten einnehmen (SG, S. 167). Das kontrollierte Springen mit dem Chronografen wird auch ,elapsieren“ (RR, S. 339) genannt. Die Genträger müssen mindestens 180 Minuten innerhalb von 24 Stunden elapsieren, damit unbeabsichtigtes Springen in der Zeit verhindert wird (SG, S. 167).

Die Ausgangswelt, das heutige London als zusammenhängende Fläche, folgt einem realistischen Raumschema, die Stadt ähnelt dem empirischen Vorbild, was durch zahlreiche topografische Marker - Straßen-, Orts- und Gebäudebezeichnungen - hervorgehoben wird, die das Lokalkolorit unterstreichen, zum Beispiel „Hyde Park“ (RR, S. 7), „Oxford Street“ (RR, S. 45), „Duke Street“ (RR, S. 61), „Fleet Street“ (RR, S. 117f), ,Wigmore Street“ (RR, S. 224), „Marylebone Street“ (RR, S. 250), „Fountain's Court“ (RR, S. 117), „, Grosvenor Square“ (RR, S. 62), ,, Big Ben“ (RR, S. 319), ,, Westminster Cathedral“ (RR, S. 113), ,Holy Trinity“ (RR, S. 333) und „St. Paul's Cathedral“ (RR, S. 94). Andere Markierungen sorgen für die Verortung in der Jetztzeit, beispielsweise „,Marks and Spencer“ (RR, S. 254) ,, Selfridges“ (RR, S. 45) oder „Pret a Manger“ (RR, S. 250). In diese Kulisse fügen sich fingierte Schauplätze harmonisch ein, deren ,wahre“ Existenz durch ihr reales Umfeld suggeriert wird. Unpräzise Angaben ermöglichen halb anonyme und damit glaubwürdige Raumschemata: So befindet sich der Hauptsitz der Wächter in Temple „,hinter [einer] Häuserreihe“ (RR, S. 117), Richtung ,,Temple-Church“, ,, links ab“, „, um mehrere Ecken“ (RR, S. 118). Schaut man aus den Fenstern des Gebäudes, hat man immer einen anderen Ausblick: mal in einen „,großen Garten, mal gegen ein anderes Gebäude oder einen kleinen Hinterhof" (RR, S. 131). Es ist zwar ein ,,schlichtes Haus, das trotz seiner tadellosen Fassade und der frisch gestrichenen Fensterrahmen sehr alt" aussieht (RR, S. 118), aber es hat eine ungeheure Größe (RR, S. 131). Ein solches Gebäude wirkt authentisch im Londoner Stadtschema, auch wenn genau dieses Haus vermutlich nicht existiert und damit auch keiner der beschriebenen Innenräume, weder die Flure mit Ölgemälden, ,Porzellanfiguren, Statuen und Ritterrüstungen “203 (RR, S. 131) noch der „Kellerraum“ (RR, S. 282) zum Elapsieren, noch „,der Drachensaal“ (RR, S. 170) oder die Nähstube von Madame Rossini (RR, S. 146). Obwohl sie Schauplatz sehr ungewöhnlicher, übernatürlicher Geschehnisse sind, fügen sich diese Räume stimmig in das Logenhaus ein und wirken authentisch, da sie einem realen und dem Rezipienten vertrauten Raumschema nachempfunden sind, nämlich dem eines Schlosses oder Klosters, wodurch

\footnotetext{
${ }^{203}$ Mit seinem Labyrinthcharakter, seinen Gemälden und Ritterrüstungen und seiner starken Symbolkraft insgesamt erinnert das Haus stark an Hogwarts.
} 
das entsprechende Schema aufgerufen wird und beliebig detailreich durch eigene Wissensbestände und Assoziationen ausgestaltet werden kann. Auf ähnliche Weise wird auch Gwendolyns Schule greifbar, die Saint Lennox High School (RR, S. 21), welche britischen Privatschulen nachempfunden ist, ${ }^{204}$ sodass sie ein realistisches Schema aufruft, wodurch sich das Gebäude ebenfalls harmonisch in das literarisch konstruierte London der Edelstein-Trilogie einfügt.

Die temporale Verortung der Ausgangswelt ist stärker noch als die anderen Texte des Korpus als unmittelbare Jetztzeit interpretierbar, wie verschiedene Marker zeigen: Leslie googelt nach Hinweisen, um ihrer Freundin zu helfen (RR, S. 58 f.), recherchiert bei Wikipedia (RR, S. 94) und schaut Filme mit Natalie Portman (RR, S. 94); ein Mitschüler von Gwendolyn verkauft ein Schulbuch mit Autogramm von Elisabeth II. (RR, S. 245) bei Ebay (RR, S. 246), und Gideon empfiehlt am 4. August 1953 den Kauf von Apple-Aktien (RR, S. 197), womit zum damaligen Zeitpunkt niemand etwas anfangen konnte. Die Inventarien ergänzen die Repräsentation des zeitgenössischen Wirklichkeitsentwurfs: Handys (RR, S. 9), Computer (RR, S. 58), Jumbojets (RR, S. 53), Kühlschränke (RR, S. 53) und Fernseher (RR, S. 53).

Der Wirklichkeitsentwurf des vergangenen Londons manifestiert sich durch Figuren und Gegenstände. Je nachdem in welches Jahr Gwendolyn gerade reist, ist das Stadtbild geprägt von Pferden (RR, S. 225) oder Oldtimern (RR, S. 49). Einmal sehen die Straßen auch aus wie die „, Kulissen eines Henry-James-Filmes “ (RR, S. 50). Das London des 18. Jahrhunderts wird als „, vollkommen andere Stadt“ (RR, S. 225) bezeichnet, es ist „,autofrei“ (RR, S. 224) und „, beschaulich“ (RR, S. 225) und besitzt wunderschöne Springbrunnen (RR, S. 221). Trotz ähnlicher Topografie - teilweise stimmen Straßen- und Gebäudenamen mit dem heutigen London überein - herrscht doch eine völlig andere Atmosphäre: Man sieht Männer mit Perücke (RR, S. 223), Gehrock (RR, S. 223) und Degen (RR, S. 222) und Frauen mit Reifrock (RR, S. 228) die Straßen entlangflanieren, „,Menschen mit Sonnenschirmen und Hüten [...], kein Abgasgestank, keine rücksichtslos rasenden Taxis“ (RR, S. 224). Auch auf den damaligen Straßen herrscht Chaos, es drängen sich „Kutschen und Karren aller Art dicht an dicht“ (RR, S. 225) und die Luft riecht ,faulig und zudem nach Pferde- und anderem Mist“ (RR, S. 225). Die Rede ist von Sekretären (RR, S. 225) und Lakaien (RR, S. 227) sowie von Siegelringen (RR, S. 208). Zudem herrscht eine völlig andere Kultur (RR, S. 228 f.): Bälle werden gefeiert (SG,

${ }^{204}$ Der Bezug zur amerikanischen Lennox High School liegt nahe. Vgl. http://lennox.k12.sd.us/LHS/default.aspx (23.12.2014). 
S. 245 f.), wo man Menuett tanzt (SG, S. 249), und es gilt als unhöflich, seine Zähne zu zeigen (SG, S. 250). 1602 lauert in jedem Winkel ,, ein Dieb oder Mörder“ (SB, S. 7). Lucy und Paul müssen sich bei ihrem „Abstecher ins 17. Jahrhundert“ (SB, S. 8) mit der London Bridge zufrieden geben, da die Southwark Bridge, ,, die eigentlich günstiger gelegen wäre, [...] zu diesem Zeitpunkt noch nicht gebaut worden “ (SB, S. 8) war. Grundsätzlich, so kann man sagen, werden auch hier realistische Schemata zur Repräsentation der vergangenen Zeitwelten genutzt, wobei die phantastischen Schemata aus dem Gedankenspiel des Zeitsprungs resultieren, das die komplette Diegese beeinflusst.

Jeder Band der Serie weist am Ende explizit darauf hin, welche Personen der Gegenwart und welche der Vergangenheit zuzuordnen sind, um dem Rezipienten eine Hilfestellung bei der Orientierung zu liefern (RR, S. 344 f.; SB, S. 393; SG, S485 f.). Alle bis auf die Grenzgänger - die zum Zeitsprung befähigten Genträger und Unsterbliche wie James - werden in einer der beiden Welten manifestiert, etwa „Nick und Caroline Shephard, Gwendolyns jüngere Geschwister “ (SG, S. 485) der Gegenwart oder „Lucas Montrose, Gwendolyns Großvater“ (SG, S. 487) der Vergangenheit. Diese Figuren repräsentieren in ihrem Aussehen (der Kleidung), ihren kulturellen Gewohnheiten, ihrer Denkweise und ihrem Wissenstand den jeweiligen Wirklichkeitsentwurf ihrer Welt: Der 32-jährige Lucas Montrose trägt 1956 einen Schnurrbart (SG, S. 87); er erkennt seine Enkeltochter zunächst nicht, da sie ihn zu einer Zeit besucht, in der er unverheiratet ist, noch lange kein Kind hat und noch nicht einmal weiß, wen er heiraten wird (SG, S. 86 ff.); Meggies Beziehungsprobleme mit Gideon tut er leichtfertig ab mit der Bemerkung „Backfische!! Als ob die Sache nicht schon kompliziert genug wäre“" (SG, S. 88). Die Figuren beider Zeitwelten können über die Möglichkeit des Zeitsprungs informiert sein oder auch nicht, also einen Zeitsprung für ausgeschlossen halten. Die Eingeweihten bedienen sich eines Insider-Vokabulars, das sich aus ihrem Wissen über Zeitreisen ergibt, die anderen können Anomalien, die sich aus den Zeitsprüngen ergeben, nicht einordnen. Außer Gespenstern bzw. Geistern zählen keine phantastischen Figuren zum Ensemble. Vampire beispielsweise existieren in der phantastischen Diegese nicht, wie in einem Gespräch zwischen Gideon und Gwendolyn deutlich wird:

„Er ist ein Vampir“, sagte ich. „Er kommt aus Transsilvanien.“ „Er kommt aus Transsilvanien. Aber er ist kein Vampir.“ „Woher willst du das wissen?“ „Weil es keine Vampire gibt, Gwendolyn.“ (RR, S. 255).

Grenzüberschreitungen finden in Form einer abstrakten Reise statt, es handelt sich daher um indirekte Übergänge: Den Betreffenden wird schwindelig, alles verschwimmt vor ihren Au- 
gen ,,zu einem grauen Fluss“ (RR, S. 46), bis sie sich in der neuen Welt wiederfinden. Gegenstände können mittransportiert werden, wie die Pistole zeigt, die Gideon in die Vergangenheit schmuggelt (SB, S. 28), und in der anderen Zeitwelt wirken, sie werden damit zu Grenzgegenständen erhoben. Grenzfiguren sind zum einen die Genträger, zum anderen Figuren, die aufgrund ihres hohen Alters oder ihrer übernatürlichen Lebensform sowohl der Vergangenheit als auch der Gegenwart zugeordnet werden, z. B. James' Geist. Sie vereinigen Wissensbestände und kulturelle Gewohnheiten beider Welten und repräsentieren allein schon deswegen beide Wirklichkeitsentwürfe.

Funke etabliert in ihrer Tintenwelt-Trilogie eine ähnliche phantastische Diegese. Auch dort findet sich eine multiple Weltstruktur, die durch parallel existierende Buchwelten zum Ausdruck gebracht wird. Prominent werden dort allerdings nur zwei Welten gemacht: die Ausgangswelt, die sich stark an die empirische Realität der Neuzeit anlehnt, und die Tintenwelt, die als Mittelalter-Zeitwelt betrachtet werden kann.

\subsubsection{Zwischenfazit}

Die Beschaffenheit von Harry Potter und den Texten des Korpus legt es nahe, sich vom Begriff der Sekundärwelt zu lösen und damit auch von Nikolajewas Sekundärweltenmodell, das hier nicht adäquat anzuwenden ist. Denn die betrachteten Werke realisieren ihre phantastischen Wirklichkeitsentwürfe nicht zwingend in einer zusammenhängenden Fläche, die einer primären Alltagswelt gegenübergestellt ist, sondern greifen auf unterschiedliche Repräsentationsinstanzen zurück, um phantastische Schemata zu versinnbildlichen. Stets findet sich eine dominante Repräsentationsinstanz, in der Folge können die Nation Panem in Collins' Büchern sowie die Stadt London in Giers Trilogie modellimmanent als Zeitwelt, die Vampirwelt der Bis(s)-Serie hingegen als Figurenwelt aufgefasst werden. Darüber hinaus findet sich nirgendwo eine eindeutige binäre Weltstruktur, sondern singuläre und multiple Weltstrukturen, worin sich Unterschiede bei den Korpustexten zeigen.

Ähnlichkeiten bestehen besonders bei der Situierung der Handlung sowie durch die häufig kombinierte Verwendung realistischer und phantastischer Schemata. Zudem lassen sich, was exemplarisch an drei Werken vorgestellt wurde, starke Tendenzen zu gebundenen Topografien ausmachen, was Mohrs im Jahre 2012 geäußerte Beobachtung und Prognose bestätigt. ${ }^{205}$ Mindestens ein Wirklichkeitsentwurf basiert jeweils auf „realen“ Ortsschemata, die durch den

\footnotetext{
${ }^{205}$ Mohr (2012), S. 60.
} 
Einfluss phantastischer bzw. imaginierter Schemata modifiziert und angepasst werden. ${ }^{206}$ Die Nennung realer Stadtnamen, Sehenswürdigkeiten oder anderer räumlicher Marker - unter Berücksichtigung der zeitlichen Einordnung - vermögen bestimmte Raumschemata zu aktivieren, die der Rezipient entweder durch eigene Erfahrungen bzw. Eindrücke kennt oder im Rahmen des kollektiven Bewusstseins oder einer Konvention erlernt hat. Es ist auffällig, dass vor allem Schauplätze aus dem englischsprachigen Raum ausgewählt wurden: Während die Bis(s)-Serie überwiegend in der amerikanischen Kleinstadt Forks spielt (BzMo, S. 7, BzMi, S. 8, BzAb, S. 8, BzEdN, S. 8) und Percy Jackson in New York (PJ 1, S. 10, S. 166, S. 179, PJ 2, S. 7, PJ 3, S. 7) bzw. der US-amerikanischen Ostküste, dienen der Edelstein-Trilogie (RR, S. 7, SB, S. 7, SG, S. 7) ebenso wie Artemis Fowl (AF 2, S. 11) und die Für-immerTrilogie (FI 1, S. 9) oder auch Harry Potter (HP 1, S. 23) London ganz oder teilweise als Schauplatz des Geschehens. Der Aufruf realer Stadtkonzepte dient als Ausgangspunkt für die räumliche Verortung der Geschehnisse. Diese Konzepte wiederum werden aber ständig mit phantastischen, imaginierten Elementen modifiziert.

Der Trend zur gebundenen Topografie erklärt sich vermutlich durch die dadurch geschaffene Nähe der Rezipienten zum Inhalt: Die Texte können sich problemlos in ihre Erlebniswelt einschreiben und damit ein Angebot zum Wiedererkennen, Spiegeln und Persiflieren liefern, das mehrere Lesarten und damit einen größeren Adressatenkreis ermöglicht. ${ }^{207}$ Das hat logischerweise nicht nur Auswirkungen auf die Topografie, sondern auch auf die Zeitwelten der im Text etablierten Wirklichkeitsentwürfe. Zudem weisen alle betrachteten Werke mindestens einen Wirklichkeitsentwurf auf, der in der Neuesten Zeit oder sogar Jetztzeit siedelt. ${ }^{208}$ Die Anbindung an die Erlebniswelt der Rezipienten ist daher unmittelbar, was als zentrale Gemeinsamkeit gelten darf. Inwiefern diese Eigenschaft als gattungsweisend zu betrachten ist, bleibt eine interpretatorische Entscheidung.

\subsection{Resümee}

Phantastische Darstellungsmittel besitzen in Harry Potter und den Texten des Korpus eine dominante, für die gesamte Textstruktur konstitutive Bedeutung, sodass die Zuordnung der Werke zur Gattung der phantastischen Literatur eine plausible Lesart darstellt. Sie greifen nicht nur auf vereinzelte Motive zurück, die konventionell als gattungsweisend für phantasti-

\footnotetext{
${ }^{206}$ Terminologie folgt Mohr (2012), S. 50 f.

${ }^{207}$ Vgl. Grossman (2005). Siehe auch Kapitel 6.3.

${ }^{208}$ Sogar Die Tribute von Panem, die in der Zukunft angesiedelt sind, knüpfen unmittelbar an die Erlebniswelt der Rezipienten an.
} 
sche Texte gelten, sie bemühen zudem mit der Phantastik assoziierte Motivkonstellationen und etablieren so ausdifferenzierte phantastische Wirklichkeitswürfe, ${ }^{209}$ welche (je nach theoretischer Grundlage) als phantastische Welten modelliert werden können. Zentral ist stets der Kontrast zur Realität, die implizit oder explizit als Referenz aufgerufen wird. ${ }^{210}$

Mittelalterliche Settings, der Rückgriff auf mythische Stoffe, das Kriegsmotiv, das Auserwähltenmotiv, das Spiel zwischen Traum und Wirklichkeit sowie der Aufruf von phantastischen Figuren und Artefakten können u. a. als Argumente herangezogen werden, Harry Potter und die Texte des Korpus dem Genre der Fantasy-Literatur zuzuordnen, das in Deutschland eine vergleichsweise junge Tradition aufweist. Die eindeutige Klassifikation der Texte zu einem Subgenre der Fantasy - wie vor allem in englischsprachigen Gattungsdiskursen gängig - ist schwerlich zu rechtfertigen, da sie auf lediglich eine Texteigenschaft abhebt, der ein gattungsweisendes Potenzial unterstellt wird. Zudem basieren die etablierten Genres der Phantastik auf der Vorstellung eines Sekundärweltmodells, das hier nicht adäquat anzuwenden ist: Die Texte konkretisieren ihre phantastischen Wirklichkeitsentwürfe nicht zwingend in einer zusammenhängenden Fläche und auch nicht zwingend in einer binären Weltstruktur, sie gehen dabei wesentlich abstrakter vor.

Eine strukturgeleitete Analyse konnte zeigen, dass Harry Potter und die Texte des Korpus durchaus Unterschiede in der Komposition ihrer phantastischen Diegesen aufweisen: Ihnen liegen verschiedene Weltmodelle zugrunde, und sie nutzen unterschiedliche Repräsentanten zur Versinnbildlichung ihrer phantastischen Welten. Gemein ist allen, dass sie mindestens einen phantastischen Wirklichkeitsentwurf etablieren. Ein Trend zu gebundenen Topografien ist bei den Texten ebenfalls auszumachen.

\footnotetext{
${ }^{209}$ Vgl. Stenzel (2001), S. 13.

${ }^{210}$ Lexe (2003, S. 84 f.) hebt die „, Gegenüberstellung konträrer Welten“ als Komponente von Motivkonstellationen der Klassiker der Kinderliteratur hervor.
} 


\section{Die Post-Potter-Texte als moderne Mythen}

Immer wieder wurde in der Potter-Forschung auf mythische Elemente hingewiesen, welche die Bücher auszeichneten. So entstand ein Diskurs um ,,zeitgenössische “l oder auch „Neomythen “2, womit man den Erfolg der Serie zu erklären versuchte. ${ }^{3}$ Genau betrachtet, wird die Einordnung - zunächst bei Harry Potter und später bei seinen Nachfolgertexten - von zwei Perspektiven aus vorgenommen, das gemeinsame Ergebnis, dass alle Texte als „neue Mythen " ${ }^{\text {4 }}$ aufzufassen seien, fußt also auf unterschiedlichen Beobachtungen. Der eine Diskurs fokussiert literaturhistorisch bedeutsame, oftmals antike, auf jeden Fall aber etablierte mythische Motive bzw. Archetypen ${ }^{5}$, die in zeitgenössischer Kinder- und Jugendliteratur aufgerufen und variiert werden, sowie mythische Plot- und Erzählstrukturen, die als allgemeine Grundmodelle epischen Erzählens betrachtet werden. ${ }^{6}$ Der andere nimmt die narrative Funktion der Texte in den Blick und vergleicht sie mit antiken Mythen und ihrer Präsentations- und Rezeptionssituation. ${ }^{7}$ Die einen erheben ein Werk zum Mythos, wenn es genug mythische Elemente, Motive oder Strukturen aufweist, wenn es also „mythoshaltig “ 8 ist, die anderen betrachten hingegen die narrative, „neomythische“ Funktion bzw. die daraus resultierende kontextgebundene Rezeptionsweise als gattungsweisend. ${ }^{9}$ Der Begriff Mythos bezeichnet dementsprechend keine Textsorte, die sich aus erzähltheoretischen Kategorien ergibt, sondern bezieht sich auf die dem Text innewohnende gesellschaftliche Bedeutung, seine erklärende und strukturierende Funktion sowie seine „symbolisch bedeutsame Form “10. Bei der folgenden Untersuchung sollen beide Perspektiven eingenommen und beide kommunikativen Modelle genutzt werden, um die hier betrachteten Werke zu charakterisieren.

Nach einigen Vorüberlegungen zum antiken und modernen Mythos (Kapitel 4.1) wird zunächst das Gattungsmodell der Mythoshaltigkeit mitsamt Implikationen und Instrumentarien

\footnotetext{
${ }^{1}$ Bergenthal (2008), S. 422.

${ }^{2}$ Schrödter (1991), S. 19.

${ }^{3}$ Vgl. u. a. Lexe (2003), S. 187; Herzog (2006), S. 213-243 und Dinter (2010), S. 15-40.

${ }^{4}$ Im Titel von Achtner (2004).

${ }^{5}$ Zum Begriff des Archetyps siehe Kapitel 4.1.1.

${ }^{6}$ Vgl. Rahner (2010), S. 191 und Bergenthal (2008), S. 375 ff.

${ }^{7}$ Vgl. Ewers (2006), S. 297-312 und Ewers (2011).

${ }^{8}$ Der Begriff ist übernommen von Bock-Lindenbeck (1999), S. 4 f. und Heber (2010), S. 23 ff., die sich beide auf Tepe (1996) beziehen. In Kapitel 4.2.1 wird er definiert.

${ }^{9}$ Die Vorstellung, dass literarische Texte eine „,mythische Funktion“ besitzen können, wird in Kapitel 4.3 problematisiert.

${ }^{10}$ Schrödter (1991), S. 17. Die Funktion eines mythischen Textes kann daher auch nicht am Text selbst belegt werden, sie ergibt sich aus seiner Rezeption. Ein Nachweis ist solcherart nicht mit literaturwissenschaftlichen Instrumentarien zu leisten und wird daher im Rahmen dieser Arbeit nicht erfolgen. Es sollen lediglich Vorschläge gemacht werden, auf welche Weise die Texte, bezogen auf ihre Funktionalität, als Mythen gelesen werden könnten.
} 
vorgestellt und auf Harry Potter sowie seine Nachfolger angewendet (Kapitel 4.2). Das zweite, funktionsorientierte Modell wird daran anschließend, Bezug nehmend auf die Ergebnisse des ersten Teils, im Mittelpunkt stehen (Kapitel 4.3). Am Ende wird reflektiert, inwiefern die Serien als zeitgenössische Mythen zu betrachten sind (Kapitel 4.4).

\subsection{Zur begrifflichen und historischen Kontextualisierung von Mythen}

Zunächst erfolgt die definitorische Annäherung an einen Mythosbegriff, der zwischen traditionellen und zeitgenössischen Forschungsansätzen vermittelt und damit eine adäquate begriffliche Grundlage für die hier betrachteten Texte und Gattungsmodelle liefert (Kapitel 4.1.1). Ein Abriss zur Rezeptionsgeschichte, der die gesellschaftliche Wahrnehmung und Bedeutungszumessung mythischer Erzählungen in einer historischen Entwicklung darzustellen versucht, schließt sich an (Kapitel 4.1.2).

\subsubsection{Zum Mythosbegriff}

Zum Begriff Mythos existieren verschiedene Vorstellungen parallel nebeneinander; darunter verstanden werden etwa religiöse Dokumente, die eine primitive Welterklärung liefern, oder Sachtexte bzw. Allegorien über die personifizierte Darstellung von Himmelsgestirnen bis hin zu Erzählungen, die menschliche und tiefenpsychologische Grundbedürfnisse aufzeigen, thematisieren oder versinnbildlichen. ${ }^{11}$ In der Klassischen Philologie ist in der Regel eine literarische Gattung gemeint. Je nach Forschungsausrichtung wird eine Textsorte bzw. ein Genre in den Blick genommen, griechische oder römische Göttererzählungen aus der Antike, die im Laufe der Literaturgeschichte immer wieder aufgegriffen worden sind.

Mythen Mythen meinen im engeren, literatur- bzw. kulturwissenschaftlichen Sinne meist eine Textgattung von mündlich oder schriftlich überlieferten Narrationen über die Götterwelt, die sich an ein „Kollektiv von Adressaten richtet und diverse individuelle und kollektive Funktionen erfüllt " ${ }^{\prime 2}$. Sie sind geprägt von einem starken Symbolsystem, das in Ding-, Raum-, Personen- und Handlungssymbole aufgeteilt werden kann, ${ }^{13}$ sowie vom Bestreben einer Weltdeutung vor dem Hintergrund eines , kosmischen und übernatürlichen Bezugsrahmens “, der sich aus dem Weltbild und vorwissenschaftlichen Horizont antiker Hochkulturen und Naturvölker, der Produzenten

\footnotetext{
${ }^{11}$ Meyer (2010), S. 69.

${ }^{12}$ Bleicher (1999), S. 19 f.

${ }^{13}$ Ebd., S. 20.
} 
bzw. Überlieferer, ergibt. ${ }^{14}$ Sie sind somit ursprünglich als Versuche der Weltentstehung und -deutung früherer Kulturstufen zu betrachten, wodurch sie Naturphänomene, die Entstehung von Göttern und Menschen sowie Moralisches und Existenzielles in Symbolen, Personifikationen und ausgeschmückten Ereignisfolgen zu erklären versuchten. Die Gesamtheit aller mythischen Überlieferungen eines Volkes wird als Mythologie bezeichnet. ${ }^{15}$ Je nach Definition werden unter dem Begriff Mythos auch zeitgenössische Göttererzählungen sowie Narrationen anderer Glaubens- oder Gesellschaftsstrukturen subsumiert. ${ }^{16}$ Heute meint der Terminus oft eine fiktive Biografie, die sich im göttlichen Milieu abspielt, oder einen Text, der eine zeitgenössische Weltdeutung oder ein Menschenbild, losgelöst von jeglicher religiöser Implikation, zur Verfügung stellt. ${ }^{17}$ Darüber hinaus bezeichnen Mythen Objekte oder Personen mit großer gesellschaftlicher Ausstrahlung, was den Begriff eng mit dem volkstümlichen Kult verbindet, mit Riten, Kunst, Tanz und Musik. ${ }^{18}$

Mythen zeichnen sich formal durch ein Changieren zwischen Beständigkeit und Variationsfähigkeit aus, was wohl zur Tradierung beigetragen hat: Die Beständigkeit des narrativen Kerns lädt ein zur Ritualisierung und ermöglicht das Wiedererkennen in bildender Kunst sowie intertextuelle Anspielungen im Sinne einer Systemreferenz ${ }^{19}$ und die Etablierung von Archetypen. Die Veränderbarkeit hingegen animiert zur ästhetischen Formung, künstlerischen Erprobung und zur Mehrfachrezeption. ${ }^{20}$

Archetypen Archetypen sind als wiederkehrende literarische oder anderen artifiziellen Vorstellungen entspringende Persönlichkeitsmuster, Grundfiguren, Typen, aber auch Figurenkonstellationen oder Beziehungen aufzufassen, ${ }^{21}$ die in ,,Märchen, Mythen und Sagen, auch in vielen modernen Geschichten, immer wieder vorkommen und als Charaktertypen ähnliche Züge und Funktionen aufweisen “22. Sie sind kulturelle Ur-

\footnotetext{
${ }^{14}$ Simonis (2013), S. 552.

${ }^{15}$ Däschler (1990), S. 316.

${ }^{16}$ Zimmermann (1993), S. 22 ff.

${ }^{17}$ Schwarzenau (1984), S. 9.

${ }^{18}$ Zöller (2000), S. 79.

${ }^{19}$ Intertextuelle Bezüge zu Mythen werden nach der Klassifizierung von Broich/Pfister (1985b) unterschieden in Einzeltext- und Systemreferenz. Letzteres trifft auf den intertextuellen Verweis auf Mythen zu, da sich dabei kein konkreter Referenztext, sondern nur mehrere Referenztexte ermitteln lassen. Vgl. Broich/Pfister (1985b), S. 48-77.

${ }^{20}$ Blumenberg (2006), S. 194.

${ }^{21}$ Diese Vorstellung lehnt sich an C. G. Jungs Archetypenlehre an, der den Begriff im Sinne archaischer Bildvorstellungen verwendet, die sich im kollektiven Unterbewussten verankert haben. Siehe Jung (1937).

${ }^{22}$ Schneider (2001), S. 66.
} 
bilder menschlichen Denkens und kollektive Fantasien: Sie bestechen durch ihre erstaunliche Beständigkeit über Zeiten und Kulturen hinweg, indem sie ,,sowohl in den Träumen und Persönlichkeitsbildern einzelner Menschen als auch in den mythischen Überlieferungen ganzer Völker und nahezu aller Kulturkreise“"23 vorkommen. Das kommunikative Modell von Archetypen kann dafür verwendet werden, die Funktion und Rolle einer Figur zu ermitteln sowie diese mit Figuren in anderen Narrationen zu vergleichen, Gemeinsamkeiten zu betonen und ein Klassifikationssystem zu konstruieren, das die Figur, ihre Funktion und auch ihre Stellung und Relevanz in der Literaturgeschichte herausstellt. ${ }^{24}$ Ein Archetypus kann im engeren Sinne drei Dinge bezeichnen: eine festgelegte Rolle, die eine Figur die gesamte Geschichte über einnimmt, eine Funktion, die ein Charakter vorübergehend einnimmt, oder eine Facette von vielen, die die Persönlichkeit des Protagonisten formieren, so gesehen ein personifiziertes Symbol einer menschlichen Eigenschaft. ${ }^{25}$ Vogler beispielsweise spricht von Archetypen als „Emanationen des Helden“ und nennt als typische Beispiele Held, Mentor (der/die weise Alte), das besondere Kind, Schwellenhüter, Herold, Gestaltwandler, Schatten und Trickster. ${ }^{26}$

Seine reiche Bildsprache macht den Mythos polyvalent. In ihm drücken sich, so Blumenberg, nicht nur die existenziellen Erfahrungen des Menschseins aus, wie beispielsweise Furcht oder Verbundenheit zur Natur, sondern es können diese auch im mythischen Narrativ überwunden bzw. bearbeitet werden. ${ }^{27}$ Durch den Akt des mythischen Erzählens, durch Metaphern, ja allein schon durch Namensgebung schaffe der Mensch Identitäten, mache Dinge kalkulierbarer und beherrschbarer, durch das Erzählen über den Schrecken der Welt werde der Schrecken selbst verbannt. ${ }^{28}$

In zeitgenössischen Kultur- und Medientheorien hat sich parallel hierzu eine andere Definition herausgebildet. Dort werden mythische Strukturen in text- und medienübergreifenden „Explikationsstufen und Explikationsweisen potentiell entfaltbarer Narrationen “ ausgemacht, deren Kern in unterschiedlichen Realisationen, Abwandlungen, Verkürzungen und Entfal-

\footnotetext{
${ }^{23}$ Ebd., S. 67.

${ }^{24} \mathrm{Ebd}$.

${ }^{25}$ Vogler (1999), S. 83.

${ }^{26}$ Ebd., S. 83 f.

${ }^{27}$ Blumenberg (2006), S. 40.

${ }^{28}$ Ebd., S. 60-65.
} 
tungsgraden gestaltet sein kann. ${ }^{29}$ Demnach wecken gesellschaftliche Veränderungsprozesse und neue Systemzustände ein Bedürfnis nach neuen Mythen bzw. Remythisierungen, die auf den Prinzipien ihrer literarischen Vorbilder beruhen, Sicherheit vermitteln und ähnliche Strukturen sowie eine ähnliche Bildsprache besitzen. ${ }^{30}$ Unter Mythen im weiteren Sinne werden also Symboltexte verstanden, die eine menschliche Weltsicht offenbaren und dem Bedürfnis nach Struktur und Ordnung entgegenkommen. Oft werden auch große populärkulturelle Phänomene als Mythen bezeichnet, die ein Kollektivbewusstsein schaffen, oder es wird von urbanen Mythen gesprochen, die, oftmals im städtischen Milieu angesiedelt, ohne nachweisbare Autorschaft, objektiv unwahre Erklärungen für alltägliche Situationen, Probleme und Irritationen liefern, aber einen Realitätsanspruch besitzen. ${ }^{31}$

\subsubsection{Zur Rezeptionsgeschichte}

Bildeten mythische Erzählungen in der Antike eine Art gesellschaftlichen Konsens darüber ab, wie man sich die Welt und ihr Gefüge vorzustellen hatte, so wandelte sich die Rezeptionshaltung zunehmend, etwa in der Renaissance, spätestens mit dem Voranschreiten der Aufklärung: Seither werden sie vermehrt als phantastische, in jedem Fall als metaphorische, nicht mehr jedoch als religiöse Texte gelesen. ${ }^{32}$ Der kommunalisierende und kollektive Glaube an jene ursprünglich religiös rezipierten ,großen“ Erzählungen sei im Zuge des wissenschaftlichen Denkens verloren gegangen, schreibt Meyer mit Bezug auf Lyotard, und zwar zugunsten vieler kleiner Erzählungen, deren Chor die gesellschaftliche Einheit festige und die Funktion großer mythischer Erzählungen übernehme. ${ }^{33}$ Vor allem im 18. Jahrhundert übernehmen im europäischen Raum Sagen diese Funktion, indem sie Identität stiften, Orientierung schaffen und volksnahe, kulturbedingte Weltdeutungen zur Verfügung stellen. Sie sind in Bezug auf ihre Funktion daher eng verwandt mit Mythen. Die Begriffe Sagen und Mythen werden in funktionsorientierten Gattungsmodellen häufig sogar synonym verwendet.

Sagen Der Begriff Sage oder auch Kunde, bis ins 18. Jahrhundert ein Synonym für eine anonym und kollektiv oral tradierte Erzählung, ist seit den Deutschen Sagen der Brüder Grimm semantisch eingeengt auf volkstümliche, knappe Erzählungen, die

\footnotetext{
${ }^{29}$ Wodianka (2009), S. 15.

${ }^{30}$ Blumenberg (2006), S. 195.

${ }^{31}$ Vgl. den Spiegel-Online-Artikel „Moderne Mythen. Zu schön, um falsch zu sein“ von Insa van den Berg: www.spiegel.de/einestages/moderne-mythen-zu-schoen-um-falsch-zu-sein-a-948288.html (15.10.2014).

${ }^{32}$ Seither haften dem Mythosbegriff pejorative Züge des Unwahren oder zumindest Vorläufigen an. Vgl. dazu Meyer (2010), S. 68.

${ }^{33}$ Ebd., S. 72, mit Bezug auf Lyotard (1982), S. 33 f., S. 53 f.
} 
numinose und mythische Orte, Figuren und Ereignisse thematisieren und gleichzeitig den Anspruch auf Glaubwürdigkeit erheben. ${ }^{34}$ Sagen schöpfen aus denselben Stoffen und phantastischen Motiven wie Märchen, erheben aber durch explizite Datierungen und Verortungen einen viel höheren (fingierten) Realitätsanspruch. ${ }^{35}$

Seit dem 16. und 17. Jahrhundert werden klassische Mythen vor dem Hintergrund humanistischer Ideale in der Kunst adaptiert und nachgeahmt, einer Bewegung, die davon ausgeht, dass nur in der Wiederaneignung der klassischen Antike die Verpflichtung des Menschen zur „, Selbstvollkommung“ erfüllt werden kann. ${ }^{36}$ Die neuhumanistische Bewegung im späten 18. und frühen 19. Jahrhundert setzte das Bestreben fort und konzipierte ein Bildungskonzept, das die Kenntnis und Rezeption antiker Kulturen populär machte und zeitweise das pädagogische Denken maßgeblich bestimmte. ${ }^{37}$ Noch heute wird die Kenntnis antiker Mythen als wichtiger Bildungsinhalt ernstgenommen. Die Adaption mythischer Motive und Elemente in Kunst und Literatur insbesondere seit der Renaissance kann daher als Erbe des Humanismus betrachtet werden und findet sich noch heute, in kurzlebigen Erzeugnissen neuzeitlicher Populärkultur sogar in besonders auffälliger Weise. Gerade im Kinder- und Jugendbuchbereich hat sie seit der Jahrtausendwende enorm zugenommen, insbesondere beim Fantasy-Genre. Die Verwandtschaft von phantastischen Texten und Mythen wird heute immer öfter im Forschungsdiskurs betont. $^{38}$

\subsection{Zur Mythoshaltigkeit von Harry Potter und den Post-Potter-Texten}

Die Tendenz zur Mythoshaltigkeit ist sowohl bei Harry Potter als auch den Post-PotterTexten festzustellen. Im Folgenden werden zunächst literaturwissenschaftliche Instrumentarien als Grundlage einer Gattungsdiskussion vorgestellt (Kapitel 4.2.1), um sich dann der Analyse zu widmen, erst bezüglich Rowlings Serie (Kapitel 4.2.2), dann der anderen Werke (Kapitel 4.2.3). Neben mythischen Motiven und Einzelelementen werden mythische Motivkonstellationen und Handlungsstrukturen in den Blick genommen. Ein Zwischenfazit fasst die Ergebnisse zusammen und stellt die Gemeinsamkeiten der hier betrachteten Werke in Bezug auf die Mythoshaltigkeit heraus (Kapitel 4.2.4).

\footnotetext{
${ }^{34}$ Schweikle (1990b), S. 405.

${ }^{35}$ Ebd.

${ }^{36}$ Zichy (2010), S. 29-32; Zitat: S. 32.

${ }^{37}$ Detjen (2013), S. 32.

${ }^{38}$ Schon Meißner (1989, S. 32 f.) weist darauf hin; in jüngerer Zeit definiert Ewers (2011, S. 3) Fantasy als Parodie auf den antiken Heldenepos. Zum Begriff Fantasy siehe auch Kapitel 3.2.2.
} 


\subsubsection{Zum Gattungsmodell der Mythoshaltigkeit}

Um beurteilen zu können, inwiefern die Texte des Korpus als Mythen zu betrachten sind, gilt es, sich die Implikationen des Gattungsmodells zu vergegenwärtigen, auf dessen Grundlage eine solche Klassifizierung vorgenommen wird. Dabei soll hier auf ein Modell zurückgegriffen werden, das die genannten unterschiedlichen Perspektiven vereint und einen literarischen Text als Mythos bezeichnet, wenn er mythoshaltig ist. ${ }^{39}$ Das ist genau dann der Fall, wenn entweder eine mythische Diegese, eine konkrete Mythenadaption bzw. mythische Erzähloder Handlungsstrukturen nachgewiesen werden können oder aber, als Kombination aus alldem, ein Set aus mythischen Motivkonstellationen und Erzählstrukturen, wie es beispielsweise das Schema der Heldenreise aufweist. ${ }^{40}$ Das Ganze ist als strukturgeleitetes Gattungsmodell zu verstehen, das zwischen mythischen und nichtmythischen Texten unterscheidet. Die Implikationen des Mythosbegriffs sollen nun kurz umrissen werden:

- Eine mythische Diegese ist als Spezialfall einer phantastischen Diegese zu betrachten. ${ }^{41}$ Sie liegt vor, wenn ein Wirklichkeitsentwurf etabliert wird, in dem mythische Raum-, Zeit- und Denkstrukturen vorherrschen bzw. Gegenstände und Figuren transzendentale Kausalitätsprinzipien zum Ausdruck bringen. Die Raumstruktur ist als mythisch anzusehen, wenn Räume und Schauplätze einer Erzählung semantisch, symbolisch oder emotional aufgeladen sind oder zur Personalisierung oder Beseelung tendieren. Dies kann beispielsweise der Fall sein, wenn die Natur oder im Raum befindliche Gegenstände zum Leben erwachen oder wenn sich eine dominierende Grundemotion in der Ausgestaltung der Schauplätze symbolisch, zum Beispiel durch Raummotive, durch Farbwahl oder durch Funktionsattribuierungen ${ }^{42}$, niederschlägt. Eine mythische Zeitstruktur wiederum ist ästhetisch oder semantisch motiviert und beruht dezidiert nicht auf physikalischen, naturwissenschaftlichen Prinzipien. Dies kann der Fall sein, wenn der Plot nicht zeitlich eingeordnet wird, eine gedehnte Zeitlosigkeit bzw. eine ästhetische, anachronistische oder zyklische Zeitstruktur vorliegt oder eine Kongruenz von Zeit und Inhalt. Typische Motive, die sich aus einer solchen Anlage ergeben, sind der Zeitsprung, die Zeitreise sowie parallel verlaufende Zeitwelten. Mythische Raumoder Zeitstrukturen fügen sich erst harmonisch in die Diegese ein, wenn sie von den Figuren als normal empfunden werden oder wenn diese von ihrer Plausibilität überzeugt werden können. Kennzeichnend ist daher, dass die Figuren von mythischen Denkstrukturen geleitet sind: wenn alles Denken durch einen übergeordneten Sinn, ei-

\footnotetext{
${ }^{39}$ Der Begriff findet sich u. a. bei Bock-Lindenbeck (1999, S. 4), die sich auf eine Vorlesung von Tepe (1996) bezieht, und bei Heber (2010), S. 26.

${ }^{40}$ Vgl. Heber (2010), S. 23 f. und Langer (2005), S. 213. Das Modell wurde angepasst, es geht u. a. zurück auf Lugowski und Heber, die es modifiziert hat, sowie auf Bock-Lindenbeck (1999), die sich auf eine Vorlesung von Tepe (1996) bezieht.

${ }^{41}$ Siehe Kapitel 3.3.1.

${ }^{42}$ Eine Funktionsattribuierung liegt beispielsweise vor, wenn ein Raum eng mit einer bestimmten Handlung oder Funktion verbunden wird: So kann es Räume geben, an denen sich stets Liebende begegnen bzw. entdecken oder aber in denen stets getötet wird. In der mythischen Diegese werden solche Schauplatzwiederholungen nicht als Zufälle gewertet, sondern als Strukturgesetze, auf die sich die Figuren verlassen und die in der Regel auch nicht gebrochen werden.
} 
ne übergeordnete Macht oder eine übergeordnete Ordnung motiviert wird, die sämtlichem Denken und Handeln Struktur verleiht und zu einer bestimmten Sicht auf Mensch und Welt führt. Dies kann beispielsweise der Fall sein, wenn vom Erzähler oder den Figuren angenommen wird, dass alles, was passiert, vorherbestimmt ist bzw. von höheren, nicht rational herleitbaren und/oder nicht vorstellbaren Mächten gelenkt wird. ${ }^{43}$ In extremen Fällen kann dies über die Diegese hinausweisen und beim Rezipienten eine bestimmte Weltsicht entstehen lassen. Damit erfüllt der Text eine gesellschaftliche Funktion. ${ }^{44}$ Zudem kann die Namensgebung von Figuren in Form von sprechenden Namen die Sinnhaftigkeit allen Seins zum Ausdruck bringen. Auch Gegenstände können mythische Wirklichkeitsentwürfe repräsentieren. Sie fungieren dabei häufig als Symbole übermenschlicher, numinoser Mächte und verleihen ihrem Besitzer Unsterblichkeit, körperlicher Stärke und Zauberkraft. ${ }^{45}$

- Von einer Mythenadaption spricht man, wenn eine textuelle Übernahme, eine Bearbeitung oder eine Abwandlung von konkreten Figuren/Figurennamen, Handlungssträngen oder Motivkonstellationen mythologischer, klassischerweise antiker, aber auch mittelalterlicher Erzählungen nachzuweisen ist. ${ }^{46}$ Der Aufruf von Archetypen und mythischen Erzählschemata kann ebenfalls als Mythenadaption bezeichnet werden. In jedem Fall muss die Querverbindung zu Motiven oder einer konkreten Version der mythischen Vorlage eindeutig sein.

- Zu den mythischen Erzählstrukturen werden folgende Texteigenschaften gezählt, was auf Lugowski zurückgeht, dessen Ergebnisse auf der Vorstellung eines ,,mythischen Analogons " beruhen: ${ }^{47}$ Alles Geschehen sei im Mythos bzw. in der Literatur allgemein vorherbestimmt, das heißt final oder kompositorisch motiviert. ${ }^{48}$ Nicht der Zufall bestimme den Fortgang der Handlung und die Sinnhaftigkeit von Vorgängen, sondern alles fügt sich so, wie numinose Mächte es vorherbestimmt haben. Die Zukunft steht also innerhalb der Diegese schon fest, und alle Ereignisse laufen auf sie zu. Daraus ergeben sich die Vermischung von Realitätsebenen und eine stringente Linearität, kurz: Techniken, die auf die Vorwegnahme des Endes abzielen. ${ }^{49}$ Es ist zu beobachten, dass die finale oder kompositorische Motivierung bei Mythen oftmals mit ähnlichen Motiven realisiert wird, die selbst schon als gattungsweisend aufzufassen sind. Dazu zählen die Motive Orakel oder Prophezeiung, die Legende, der bedeutsame oder auch zukunftsweisende Traum, der Auserwählte, der sich siegreich durchsetzt sowie die Liebenden, die sich suchen und finden - allgemeiner formuliert: Motive des Grundvertrauens, dass das Gute über das Böse siegt und alles das ihm vorbestimmte Ende nimmt. Sie fügen sich in der Regel harmonisch in die mythische Diegese ein, die die finale oder kompositorische Motivierung plausibilisiert.

\footnotetext{
${ }^{43}$ Die Vorstellung der mythischen Diegese ist übernommen von Heber (2010), S. 26 f., die sich an Tepe (1996) und Cassirer (2002) anlehnt. In ihrem Projekt erläutert sie die mythische Diegese von Funkes Tintenwelt.

${ }^{44}$ Vgl. Wodianka (2009), S. 15.

${ }^{45}$ Als literaturhistorisch etablierte mythische Gegenstände sind etwa der heilige Gral, das Elixier, das ,,besondere" Schwert oder auch der Stein der Weisen zu nennen, die ursprünglich aus den unterschiedlichsten Quellen, z. B. Sagen und Legenden, stammen.

${ }^{46}$ Heber (2010), S. 23.

${ }^{47}$ Lugowski (1994, S. 12 f., passim) charakterisiert damit die allgemeine Beziehung von Menschen zu literarischen Texten, indem er sie mit dem Verhältnis von Menschen der Antike zu ihren Mythen vergleicht. Nach seinem Verständnis findet sich in den ästhetischen Strukturen literarischer Texte stets ein Restbestand mythischen Denkens wieder, Mythisches lebe in den formalen Gesetzen der Dichtung weiter.

${ }^{48}$ Heber (2010, S. 25 f.) schließt die kompositorische Motivierung als mythische Erzählstruktur mit ein.

${ }^{49}$ Lugowski (1994), S. 66.
} 
- Die Anlehnung an antike Mythen führte letztlich zu festen Erzählschemata in der zeitgenössischen Literatur, welche sich aus mehreren antiken Prätexten herleiten und immer wieder aufgerufen werden. Sie sind weniger als konkrete Motivadaptionen zu begreifen, sondern vielmehr als Aufruf von mythischen Motivkonstellationen und Plotstrukturen, wodurch Handlung, Thematik und Konzeption der Protagonistenfigur vorstrukturiert werden, was den Texten eine signifikante Struktur verleiht, an der sich der Rezipient orientieren kann. Zu diesen Schemata gehört auch die sogenannte Heldenreise, die sich auffällig oft in zeitgenössischen Texten und Filmen wiederfindet. Im Zentrum steht eine Abenteuerreise oder auch eine Reise des Gefühls, die einen Weg von einer Art des Seins zur nächsten bewirkt, beispielsweise den Weg von Schwäche zu Stärke oder von Liebe zu Hass. ${ }^{50}$ in der Regel steht der Held vor einem äußeren und einem inneren Problem, was die Hauptmotivation der Handlung darstellt: Das äußere Problem resultiert häufig aus dem Hauptkonflikt mit dem Antagonisten, das innere Problem ist oftmals ein Makel der Persönlichkeit oder ein moralisches Dilemma, das es zu überwinden gilt. Die Zeichnung der Heldenfigur folgt dabei häufig einem weiteren genreübergreifenden Schema, dem des besonderen Menschenkindes oder auch „Gottkind“"51, welches trotz seiner ungewöhnlichen Fähigkeiten starkes Identifikationspotenzial bietet. Der Protagonist erscheint menschlich mit Stärken und Schwächen, hat Ängste und Zweifel, ${ }^{52}$ ist oftmals in schwierigen sozialen Verhältnissen groß geworden (als Waise oder Halbwaise) und durchlebt die typischen Probleme und schönen Momente der Adoleszenz. Er wird zunächst in der Alltagswelt groß und entdeckt erst im Kontakt mit der unbekannten Anderswelt seinen Auserwähltenstatus ${ }^{53}$ und seine übermenschlichen Fähigkeiten, die er zunächst zu schulen hat. Die Etappen der Heldenreise $^{54}$ gestalten sich nach Vogler wie folgt:

1) gewohnte Welt

2) Ruf des Abenteuers

3) Weigerung

4) Begegnung mit dem Mentor

5) Überschreiten der ersten Schwelle

6) Bewährungsproben, Verbündete und Feinde

7) Vordringen zur tiefsten Höhle

8) entscheidende Prüfung

9) Belohnung

10) Rückweg

11) Auferstehung

12) Rückkehr

${ }^{50}$ Vogler (1999), S. 55.

${ }^{51}$ Mohr (2012), S. 73.

${ }^{52}$ Ebd., S. 25.

${ }^{53}$ Der Auserwähltenstatus der Protagonistenfigur ist gängig in der phantastischen Kinder- und Jugendliteratur. Vgl. Stenzel (2006), S. 183 und Meißner (1989).

${ }^{54}$ Vogler (1999, S. 159-384) hat das Modell nach eigenen Angaben aus den Vorüberlegungen von C. G Jung und den Mythosstudien nach Campbell entwickelt, er richtet sich an Drehbuchschreiber und Autoren. Siehe dazu Vogler (1999), S. 9f. Was unter den einzelnen Etappen der Heldenreise konkret zu verstehen ist, wird im Analyseteil erläutert. 


\subsubsection{Zur Mythoshaltigkeit von Harry Potter}

Sowohl im deutschen als auch im englischsprachigen Forschungsdiskurs wurde Rowlings Heptalogie auf unterschiedliche Weise mit Mythen in Verbindung gebracht bzw. als moderner Mythos besprochen ${ }^{55}$ sowie auch die oben genannten Aspekte herausgearbeitet.

Auch der mythische Wirklichkeitsentwurf bzw. die mythische Diegese des Werks wurden bereits thematisiert und plausibilisiert. ${ }^{56}$ Grundlage der Kausalitätsprinzipien ist das Zaubern, konkretisiert wird mithilfe von Figuren und Gegenständen sowie Raum-, Zeit- und Denkstrukturen. Eine mythische Raumstruktur zeigt sich u. a. an Schauplätzen wie Gleis 9 3/4, am Zugang zur Winkelgasse und dem Treppenhaus von Hogwarts, wo Treppen ständig die Richtung ändern, ${ }^{57}$ sowie durch das klischeehaftes Mittelaltersetting bzw. Ambiente. ${ }^{58}$ Räume stehen durch eine naturwissenschaftlich nicht erklärbare Logik in Verbindung miteinander, „, der Raum der Wünsche“ (HP 5. S. 453) offenbart sich nur demjenigen, der ihn benötigt, wird also durch eine numinose Macht gelenkt. Insbesondere die Goldkette mit Stundenglas (HP 3, S. 407) sorgt für mythische Zeitstrukturen. Figuren können in die Vergangenheit springen, in der sie sich selbst begegnen, und in die Chronologie von Ereignissen eingreifen, die sich eigentlich bereits zugetragen haben. Die Zeit der Muggel verläuft indes parallel zu der der Zauberer, die Rekonstruktion der Chronologie ist also prinzipiell möglich. ${ }^{59}$ Die mythische Denkweise der Figuren äußert sich primär in den Elementen Magie, Wahrsagen, bedeutsamer Traum, Fluch ${ }^{60}$ sowie dem Glauben an die Macht von Namen, ${ }^{61}$ der durch sprechende, verkörpernde oder mythische Namen versinnbildlicht wird. Vor allem sprechende Namen fügen sich harmonisch in die mythische Diegese ein, da sie ,, Selbstverständlichkeiten unserer Zeit einen sinnvollen Hintergrund zu geben “ scheinen. ${ }^{62}$ Gegenständlich manifestiert sich der mythische Wirklichkeitsentwurf etwa in Horkruxen, in denen Seelen bzw. Seelenanteile aufbewahrt werden können. Lord Voldemort stellt sechs Horkruxe her, die sein Fortleben sichern sollen. Ihm dienen dabei u. a. ein Buch, ein Ring, ein Medaillon, die in der Logik des Textes nach und nach vernichtet werden müssen, um seine Existenz endgültig auszulöschen. Harry Potter selbst ist auch ein Horkrux Voldemorts

\footnotetext{
${ }^{55}$ Mythische Strukturen wurden auch als eine Komponente des Genremix betrachtet. Siehe dazu Kapitel 5.1.

${ }^{56}$ Diese Einbettung wird oftmals als Märchensetting gedeutet oder mit Legenden in Verbindung gebracht, zum Beispiel von Cornelius (2003), S. $17 \mathrm{f}$.

${ }^{57}$ Lexe (2003), S. $181 \mathrm{ff}$.

${ }^{58}$ Bergenthal (2008), S. 352 und Karg/Mende (2010), S. 189.

${ }^{59}$ Vgl. Bürvenich (2001), S. 56.

${ }^{60}$ Cornelius (2003), S. $66 \mathrm{f}$.

${ }^{61}$ Bergenthal (2008), S. 74 ff., Cornelius (2003), S. 58-64.

${ }^{62}$ Bergenthal (2008), S. 74.
} 
Ebenso richtete sich bereits mehrfach die Aufmerksamkeit auf intertextuelle Bezüge zu verschiedenen klassischen und religiösen Mythen, Erzählungen und Legenden, die explizit und implizit in Harry Potter erkennbar sind. ${ }^{63}$ Cornelius beispielsweise schreibt, dass sich Rowling aus einem großen Fundus bediene, der über Schöpfungsmythen, der ,Legende der Rettung eines zur Rettung bestimmten Kindes “ bis hin zu den Wurzeln der Motive von Segen und Fluch reiche. ${ }^{64}$ Mattenklott verweist auf die Tradition des Gottkindmythos, in die sich Harry Potter einschreibt, ${ }^{65}$ während Karg und Mende „Aufrufe griechischer und römischer Mythologie sowie mittelalterlicher Literatur "66 aufzeigen, konkret die Artussage werde mehrfach adaptiert. Tatsächlich fällt auf, dass sich insbesondere das Personal aus diesem facettenreichen Mix speist: Argus Filch, dessen Name sich vom Riesen Argos ableiten lässt, die Dumbledore-Figur, die an Merlin erinnert, Lupin, der ein Werwolf ist, oder der Zentaur Firenze. Hinzu kommen Drache, Einhorn, Basilisk und Phönix: Sie alle haben eine lange kultur- und literaturgeschichtliche Tradition. ${ }^{67}$

Mythische Erzählstrukturen standen ebenfalls schon im Fokus der Wissenschaft: ${ }^{68}$ Nicht nur die Prophezeiungsstruktur, sondern auch Andeutungen und Anspielungen aller Art erzeugten eine finale Motivierungsstruktur, die als direkte Erzählstrategie ausgemacht werden könne. ${ }^{69}$ Zudem wurde gezeigt, dass die Serie den Prinzipien der Heldenreise folgt, die sich gleich aus mehreren Motiven und Strukturen antiker Mythen speist. ${ }^{70}$ In diesem Kontext wurde auf das moderne Heldenkonzept hingewiesen, das darin zum Ausdruck kommt: Harry Potter, der normale „Jüngling aus dem Mittelstand“, der ohne leibliche Eltern groß geworden ist, wählt sein Schicksal selbst und nimmt den Kampf gegen das Böse auf. ${ }^{71}$ Er entscheidet auf Grundlage seines Gerechtigkeitsempfindens, seiner Spontanität, seiner empathischen Fähigkeiten, aber auch aus Lust und Angst. ${ }^{72}$ Die Figur stehe damit in der Tradition mehrerer Archetypen, so auch in der des besonderen Kindes bzw. heldenhaften Gottkindes. ${ }^{73}$

\footnotetext{
${ }^{63}$ Huey (2005), S. 65-83.

${ }^{64}$ Cornelius (2003), S. 46-57, S. 70.

${ }^{65}$ Mattenklott (2001b), S. $38 \mathrm{f}$.

${ }^{66} \mathrm{Karg} /$ Mende (2010), S. 176.

${ }^{67}$ Siehe dazu Karg /Mende (2010), S. 176-190 und Bergenthal (2008), S. 356 f.

${ }^{68}$ So zum Beispiel bei Cornelius (2003), S. 18 f. und Karg/Mende (2010), S. 190-201.

${ }^{69}$ Karg/Mende (2010), S. 192 f. und Lexe (2001), S. 54.

${ }^{70}$ Bergenthal (2008), S. $375 \mathrm{ff}$.

${ }^{71}$ Ebd., S. 172 f.

${ }^{72}$ Vgl. Stenzel (2006), S. 184 f.

${ }^{73}$ Biskop (2012).
} 
Bezogen auf die narrative Funktion wurde postuliert, dass die Bücher Erwachsenen eine Möglichkeit böten, ihre sentimentale Kindheitssehnsucht auszuleben ${ }^{74}$ sowie die großen Fragen des menschlichen Lebens, „eternal mysteries“, zu thematisieren und damit eine in sich schlüssige Mensch- und Weltdeutung zur Verfügung zu stellen. ${ }^{75}$ Den Texten wurde eine „neomythische“ Grundfunktion zugesprochen und behauptet, dass sie zwar oberflächlich, aber dennoch zielgerichtet die „Sehnsucht nach Transzendenz und allumfassender Sinngebung“ stillten und damit dem gesellschaftlichen Bedürfnis nach Entschleunigung und Entrationalisierung entgegen kämen. ${ }^{76}$ Warum Harry Potter dies besser können soll als andere phantastische Texte, wird hingegen nicht plausibel gemacht. Der Erfolg der Texte lässt sich daher nicht allein aus diesen Beobachtungen begründen.

\subsubsection{Zur Mythoshaltigkeit der Post-Potter-Texte}

Im Folgenden werden nun ausgewählte Texte des Korpus auf ihre mythische Diegese (Kapitel 4.2.3.1) untersucht, um anschließend die mythologische Erzählstruktur allgemein (Kapitel 4.2.3.2) sowie ihre Anlehnung an die Erzählstruktur von Voglers Schema der Heldenreise (Kapitel 4.2.3.3) im Speziellen in den Blick zu nehmen. Besondere Aufmerksamkeit gilt hier der Tintenwelt-Trilogie, die sich hervorragend dazu eignet, darzulegen, in welcher Weise die hier untersuchten Texte als mythoshaltig zu betrachten sind, da sowohl allgemeine mythische Narrationsprinzipien als auch Motivkonstellationen und Archetypen Verwendung finden. Die Mythoshaltigkeit des Werks wurde von Heber bereits diskutiert, ${ }^{77}$ deren Ergebnisse hier zusammengefasst und um eigene Beobachtungen und weitere Beispiele aus dem Korpus ergänzt werden sollen, um die These zu belegen, dass die hier betrachteten Texte starke Analogien zu Harry Potter aufweisen, weil sie ähnlich mythoshaltig sind.

\subsubsection{Zur mythischen Diegese}

Die Tendenz der Texte des Korpus, ihre Handlung in eine mythische Diegese einzubetten, die auf mythischen Raum-, Zeit-, Denkstrukturen bzw. Figuren- und Gegenstandswelten basiert,

\footnotetext{
${ }^{74}$ Siehe dazu auch Kapitel 6.3.2 zur All-Age-Literatur.

${ }^{75}$ Vgl. Bergenthal (2008), S. 37; Grimes (2002), S. 90. Es ist klar, dass eine solche These schwerlich, wenn nicht sogar überhaupt nicht, zu belegen ist, da sie auf individuelle Rezeptionserfahrungen abzielt, die sich einer Erhebung mit literaturwissenschaftlichen Instrumentarien entziehen. Dennoch sind solche Überlegungen, wenngleich spekulativ, auch für literaturwissenschaftliche Beobachtungen nicht uninteressant und können eventuell Ansätze liefern, den Erfolg einiger Texte bzw. Gattungen zu erklären.

${ }^{76}$ Cornelius (2003), S. 70.

${ }^{77}$ Heber (2010), S. 132-189.
} 
welche transzendentale Kausalitätsprinzipien versinnbildlichen, soll nun exemplarisch an Funkes und Giers Werk gezeigt werden.

\section{Zur mythischen Diegese der Tintenwelt-Trilogie}

In Funkes Romanserie wird das Geschehen, ähnlich wie das antiker Mythen, von einer höheren Ebene, einer höheren Macht gelenkt, deren Wirken rational nicht zu erklären ist. ${ }^{78}$ Neben mythischen Kausalitätsprinzipien können mythisches Denken und eine mythische Raum- und Zeitstruktur ausgemacht werden. ${ }^{79}$ Numinose Mächte zeigen sich in verwunderlichen $\mathrm{Zu}$ sammenhängen zwischen der ,gewohnten Welt ${ }^{\star 80}$ der Figuren und den Bücherwelten sowie in einer Fügung des Schicksals zum Positiven, das in der textimmanenten Werteskala polar dem Negativen gegenüber gestellt ist. Mythische Denkstrukturen spiegeln sich in Äußerungen der handelnden Figuren wider, etwa dass alles Geschehen vorherbestimmt ist; sie vertrauen ihrer Intuition und sind abergläubisch. So merkt Fenoglio sehr schnell, dass Mo bei seinem Besuch nicht die ganze Wahrheit berichtet, er beruft sich auf sein Bauchgefühl und behält damit recht (TH, S. 277). Die Bewahrheitung von Prophezeiungen und Spekulationen sowie das Eintreten des von Fenoglio vorgesehenen Fortgangs der Geschichte versinnbildlichen mythische Kausalitätsprinzipien und eine mythische Raum-Zeit-Logik, die für die mythische Diegese konstitutiv sind. ${ }^{81}$ Die Zukunft steht in der Logik der Diegese schon fest. Sie ist lediglich davon abhängig, was der jeweilige Autor in Bezug auf die fokussierte Welt vorgesehen hat: Fegnolio schreibt den Figuren seiner Geschichte zahllose Volkslieder und Volksmärchen, die zukunftsweisend sind und Einfluss auf den Fortgang der Handlung nehmen. Sie werden in der Tintenwelt als Legenden bzw. Gerüchte aufgefasst, die in dieser ,, wie in jeder anderen Welt die Wahrheit oft wie einen gut versteckten Kern “ (TT, S. 207) in sich tragen. So muss Mo die ihm zugedachte Rolle des Eichelhähers spielen (TT, S. 88) und Staubfinger mit den Weißen Frauen um Farids Leben verhandeln (TB, S. 671 f.). Das vorgesehene Schicksal muss hingenommen werden, der Einfluss der einzelnen Figur im Kausalgefüge ist nicht transparent. Auch Raum und Zeit sind dem Willen des Autors und nicht naturwissenschaftlichen Prinzipien unterworfen: Blumen wachsen genau da, wo Fenoglio es vorsieht (TT, S. 458), sämtliche Schauplätze entstammen seiner Feder (zum Beispiel TT, S. 469). Er kann in seiner Rolle als Autor und Kommandant über die Tintenwelt seinen Figuren Zeit verschaffen (TT,

\footnotetext{
${ }^{78}$ Heber (2010), S. 134.

${ }^{79}$ Ebd.

${ }^{80}$ Der Begriff ist angelehnt an Vogler (1999), S. 159.

${ }^{81}$ Zum Kontingenzproblem der Tintenwelt-Trilogie siehe auch Kapitel 6.3.4.2.
} 
S. 522), eine Größe, die für die Figuren nicht greifbar ist: „Zeit-was immer das auch war. “ (TT, S. 701).

Die mythischen Raumschemata offenbaren sich auch hier in der Tendenz zur Personalisierung und symbolischen Aufladung. Räume und Dinge werden personalisiert und beseelt, ihre Bedeutung für die Geschichte betont. Capricorns Dorf ist nicht ohne Grund „eine Ansammlung verfallener Häuser", das in einer Straße liegt, die keinen Namen verdient (TH, S. 115), es ist das in Raumsymbolen ausgestaltete Böse, durch Gitter ,,abgesperrt“ (TH, S. 127). Elinors „Haus voller Bücher" (TH, S. 39) ist weniger Schauplatz der Handlung als vielmehr eine räumliche Versinnbildlichung von Elinors Leselust: Wo andere Menschen Tapeten haben, erstrecken sich bei ihr Bücherregale bis zur Decke (TH, S. 46). Zudem erscheinen die Bücher lebendig: „Fast kam es ihr vor, als könnte sie die Bücher durch die halboffene Tür flüstern hören. Tausend unbekannte Geschichten versprachen sie ihr, tausend Türen zu tausend nie geschauten Welten “ (TH, S. 48).

Die Fähigkeit, Figuren aus Büchern bzw. ihren Bücherwelten herauszulesen, basiert auf mythischen Ursache-Wirkungs-Beziehungen. Das Phänomen wird von den Protagonisten - deren Reaktion dem Rezipienten als Modell dient - im Laufe des Geschehens mehr und mehr akzeptiert, obgleich jene unerklärlichen, den Naturgesetzen widersprechenden Geschehnisse zunächst noch im Widerspruch zur Primärwelt stehen, die in groben Zügen mit der Realität als deckungsgleich angenommen werden kann. Die Personen witzeln beispielsweise zu Beginn noch über die Existenz von Werwölfen, die als abwegige Hirngespinste abgetan werden (TH, S. 12), doch im späteren Verlauf nimmt Meggie die Existenz von Feen, Kobolden und Riesen einfach hin und integriert sie in ihr bestehendes Weltbild (TH, S. 265; TB, S. 31; TT, S 13). Gegen Ende von Tintenherz stellt sie fest: „Wo konnte man das besser lernen als in einem Haus, in dessen Garten Feen ihre Nester bauten und Bücher nachts in den Regalen flüsterten?" (TH, S. 566). Den Lesern wird auf diese Weise ein Rezeptionsmodus nahegelegt, der die phantastische Dimension des Textes zugunsten einer mythischen Lesart ausblendet. Dazu wird bewusst die erzählte Geschichte als Beleg für eine Parallelwelt ins Licht gerückt, die von höheren Mächten gelenkt wird und deren Eigenschaften schlüssig sind.

Auch figural und gegenständlich wird ein mythischer Wirklichkeitsentwurf zum Ausdruck gebracht: Capricorn im ersten Band und der Natternkopf in Band zwei und drei werden als Personifikation des schlechthin Negativen angesehen, das von „den Guten“ überwunden werden muss. Die beiden bilden in der mythischen Diegese den Gegenpol zu Gott, zu allem bild- 
haft Guten, und symbolisieren Tod und Verderben. Die Namen stehen für die Sinnhaftigkeit und Symbolhaftigkeit allen Seins. ,Capricorn nennt er sich, seit er fünfzehn ist, nach dem Sternzeichen, unter dem er geboren wurde ${ }^{\text {(82 }}$ (TH, S. 363). Staubfinger und Zauberzunge verdanken ihre Benennung ihren herausragenden Talenten, und Orpheus verweist mit seinem Namen direkt auf den antiken mythischen Stoff, in dem der gleichnamige verzweifelte Sänger in die Unterwelt steigt, um Hades dazu zu bewegen, ihm seine verstorbene Frau Eurydike zurückzugeben. Insbesondere Bücher werden zu mythischen Gegenständen stilisiert, indem sie zu (Seelen-)Körpern erhoben werden, in denen das Leben einer Figur aufbewahrt werden kann. ${ }^{83}$

\section{Zur mythischen Diegese der Edelstein-Trilogie}

In Giers Serie manifestiert sich die mythische Diegese primär durch anachronistische Zeitstrukturen, die sich aus den Zeitsprüngen ergeben. Das Springen in der Zeit ist Grundlage aller mythischen Kausalitätsprinzipien, die auch in der Denkweise der Figuren sichtbar werden: Prophezeiungen ranken sich um die Anomalie (zum Beispiel RR, S. 92; RR, S. 137; SG, S. 102), die Eingeweihten wissen um den Einfluss dieser Schriften, über Auswirkungen auf die Menschheitsgeschichte wird spekuliert (RR, S. 316). Die Zeitstruktur ist klar zyklisch: Ständig wird in die Chronologie der Ereignisse eingegriffen, Vergangenes beeinflusst Gegenwärtiges, verschiedene Versionen der gleichen Figur existieren in verschiedenen Zeitwelten nebeneinander und haben einen unterschiedlichen Wissensstand: Gwendolyn gibt beispielsweise ihrer früheren, unwissenden Version ein Zeichen, dass sie sich verstecken soll, als sie sich selbst dabei beobachtet, wie sie einen ihr noch unbekannten Jungen küsst (RR, S. 100 ff.). Vereinzelt werden Schauplätze personifiert: Das Haupthaus der Loge wirkt beseelt, Gwendolyn beschreibt ihre Eindrücke folgendermaßen: „, Aber nicht nur der Ausblick und das Licht wirkten heiter, auch die Schnitzereien strahlten etwas Fröhliches aus, trotz vereinzelter gruseliger Fratzen und Totenköpfe. Es war, als würden die Wände leben" (RR, S. 132). Das Haus gestaltet sich als großes unüberschaubares Labyrinth mit starker symbolischer Attribution, die sich aus phantastischen, spirituellen, religiösen und kosmologischen Symbolen speist, die ein mystisches Setting mit rätselhaft-transzendentaler Aura kreieren: „,Tierköpfe“, ,geflügelte Löwen“, „,Sterne, Sonne und Planeten, Drachen, Einhörner, Elfen,

\footnotetext{
${ }^{82}$ Gemeint ist das Sternzeichen Steinbock.

${ }^{83}$ Dass der Natternkopf den Tod überlisten möchte und daher sein Leben an ein Buch bindet, erinnert stark an Tom Riddles Tagebuch aus Harry Potter, das sich als Horkrux erweist.
} 
Feen, Bäume und Schiffe“ zieren das Haus, wobei ,eine Schnitzerei lebendiger als die andere" aussieht (RR, S. 132).

Auch Figuren und Gegenstände repräsentieren den mythischen Wirklichkeitsentwurf: Figuren, indem sie in der Zeit springen und sprechende Namen besitzen, Gegenstände, indem sie zu Symbolen numinoser Mächte erhoben werden. Der Name der Protagonistin selbst ist sprechend. Gwendolyn leitet sich aus dem Walisischen her und bedeutet so viel wie „weißer

Kreis“ bzw. „weißer Ring“, ${ }^{84}$ „Shephard“ stammt aus dem Englischen und bedeutet „Hüterin“. Ihr Name kann als Anspielung auf den Kreis der zwölf Genträger gelesen werden sowie auf die zyklische Zeitstruktur der Diegese. Ihre helle Haut (RR, S 39) im Kontrast zu ihren schwarzen Haaren (RR, S. 39) könnte zudem die Farbassoziation „weiß“ nahelegen. Als Beispiel für einen als mythisch markierten Gegenstand kann insbesondere der Stein der Weisen dienen, der hier ein Pulver ist, das analog zur Tradition Unsterblichkeit symbolisiert.

\subsubsection{Zur Mythenadaption}

In den Post-Potter-Texten finden sich vermehrt Mythenadaptionen, das heißt Figuren- oder Motivaufrufe, die eine konkrete Querverbindung zu mythischen Erzählungen ziehen. ${ }^{85}$

\section{Zur Mythenadaption in der Tintenwelt-Trilogie}

Heber, die in ihrer Dissertation die Verarbeitung verschiedener Mythen in Funkes Serie verhandelt und auf die besondere Stellung des Orpheus-Mythos verwiesen hat, wie er in Ovids Metamorphosen $^{86} \mathrm{zu}$ finden ist und dessen Adaption sich über drei Bände hinweg nachweisen lasse ${ }^{87}$ beruft sich bezüglich ihrer Herangehensweise auf die strukturale Mythenanalyse nach Lévi-Strauss, in der davon ausgegangen wird, dass ein Mythos in Mytheme zu gliedern ist kleinste Handlungseinheiten oder Leitmotive -, die in den unterschiedlichen Versionen aufgerufen werden können und Strukturen menschlichen Denkens offenbaren. ${ }^{88}$ Heber ermittelt in Bezug auf Ovids Orpheus-Mythos 41 Mytheme, von denen sie 16 in der TintenweltTrilogie nachzuweisen sucht. ${ }^{89}$ Verglichen werden u. a. Eurydikes Schlangenbiss und ihr Ent-

\footnotetext{
${ }^{84}$ Das große Vornamenlexikon des Duden-Verlags (3. Auflage 2007 S. 187) schlägt unter dem Stichwort „Gwendolin“ vor, den Namen in die zwei Bestandteile zu segmentieren: gwen bedeute so viel wie ,weiß, schön, gesegnet, heilig“ und dolen so viel wie „Ring, Bogen“.

${ }^{85}$ Zur Intertextualität siehe Kapitel 5.2.

${ }^{86}$ Eine empfehlenswerte Übersetzung ist: P. Ovidius Naso: Metamorphosen. Lateinisch/Deutsch, übersetzt und hrsg. von Michael von Albrecht. Stuttgart 1994.

${ }^{87}$ Heber (2010), S. 141-189 und Anhang.

${ }^{88}$ Lévi-Strauss (1972), S. 25-46.

${ }^{89}$ Heber (2010) präsentiert diese Ergebnisse im Anhang, in Tabelle 2.
} 
schwinden in die Unterwelt mit Resas Schlangenbiss (TH, S. 356) und deren Entschwinden in die Tintenwelt (TH, S. 367, TB, S. 334) sowie Orpheus' Sangeskünste mit Mos Vorlesekünsten (TH, S. 191 ff., TH, S. 542). Der Fährmann, der Orpheus in die Unterwelt bringt, wird mit Fenoglio in Verbindung gebracht, der durch seine Schreibkunst Mo und Resa wieder zusammenbringen kann (TT, S. 188, S. 205, S. 737). ${ }^{90}$ Zudem wird Funkes Orpheus direkt mit der mythologischen Gestalt in Beziehung gesetzt. Weiterhin sieht Heber bei den Figuren des Eichelhähers, Resas und Mortulas einen intertextuellen Bezug zu den Metamorphosen, ,da sich auch dort die Figuren häufig in Vögel verwandeln “91.

\section{Zur Mythenadaption in Percy Jackson}

Der Autor, der sich im hier betrachteten Korpus am meisten durch Mythenadaption auszeichnet, ist zweifelsohne Rick Riordan. Der Mix aus Figuren, Motiven und Handlungselementen mythischer Erzählungen ist sogar der eigentliche Clou, das Alleinstellungsmerkmal seiner Texte: In Percy Jackson finden sich zuhauf Lokalitäten, Personal, vereinzelte Handlungselemente und sogar kurze Nacherzählungen antiker Mythologie: Percys Freund Grover ist ein Satyr (PJ 1, S. 59), ihm erscheinen die Moiren (PJ 1, S. 61) und schneiden vor seinen Augen den Lebensfaden durch, auf seinen Missionen stößt er u. a. auf Medusa (PJ 1, S. 216), Polyphem (PJ 2, S. 91) und Echidna (PJ 1, S 251) sowie auf sämtliche Götter des Olymps. Das Ausbildungscamp für Halbblute besitzt einen Sicherheitschef namens Argus (PJ 1, S. 190) und wird von Dionysos und Chiron (PJ 1, S. 80) geleitet. Letzterer ist in der antiken Mythologie Erzieher eines anderen berühmten Gottkindes, nämlich von Achill, literarisch ausgestaltet zum Beispiel im 1. Buch der unvollendeten Achilleis von Statius.

Neben Olymp (PJ 1, S. 394 ff.) und Hades (PJ 1, S. 333 ff.), wo sich unter anderem „Sisyphos [...] damit abmüht[ ], seinen Felsblock nach oben zu rollen“ (PJ 1, S. 354) und auch der „, Garten der Persephone“ (PJ 1, S. 361) gelegen ist, verweisen viele andere Schauplätze auf mythische Erzählungen: Grover, Annabeth und Percy gelangen auf ihrer Durchreise ins Lotus Hotel und Kasino, in dem Jugendliche von Video- und Automatenspielen berauscht werden und alles andere um sich herum vergessen (PJ 1, S. 304 ff.). Nur mühevoll schafft es Percy, sich aus der Trance zu befreien und sich wieder seiner Aufgabe zu widmen (PJ 1, S. 312). Die Episode spielt explizit - bedenkt man den Namen des Hotels - auf das Volk der Lotophagen

\footnotetext{
${ }^{90}$ Auch wenn jener strukturanalytische Zugang zur Thematik der Mythenadaption klare Schwächen besitzt, - so wird beispielsweise nicht überzeugend deutlich gemacht, wie genau die Art und Anzahl der Mytheme des Orpheus-Mythos zustande kommen - wird die Adaption oder zumindest mythische Motiventlehnungen in Funkes Texten hinreichend belegt und plausibel gemacht.

${ }^{91}$ Heber (2010), S. 170.
} 
(auch Lotusfresser genannt) an, das in mehreren antiken mythischen Erzählungen vorkommt. In der Odyssee berauschen sie Odysseus und seine Mannschaft mit Lotus, die daraufhin den Grund bzw. das Ziel ihrer Reise vergessen und nicht mehr an eine Heimkehr denken, sondern in der Gemeinschaft der Lotophagen bleiben und ihr Leben lang Lotus pflücken wollen. ${ }^{92}$

Gelegentlich werden sogar kurze Nacherzählungen antiker Mythen bzw. Mytheme geliefert und in die Haupthandlung integriert. So fasst Annabeth für Percy kurz die Geschichte von Hephaistos zusammen, um seinen Auftrag zu plausibilisieren, den er von Ares erhalten hat. Dieser bittet ihn darum, seinen Schild aus ,einem stillgelegten Wasserpark“ zu holen, den er bei einem „Date“ mit seiner Freundin dort vergessen hat (PJ 1, S. 270). Auffällig ist hier vor allem die Verwendung eines jugendsprachlichen Registers:

\begin{abstract}
„Ares und Aphrodite“, sagte ich, um nicht daran denken zu müssen, dass es bald ganz dunkel sein würde, ,die haben also was miteinander?“ „Das ist doch uralter Klatsch, Percy“, sagte Annabeth. „Dreitausend Jahre alter Klatsch.“ „Und was ist mit Aphrodites Mann?“ „Na ja“, sagte sie, „Hephaistos. Der Schmied. Er wurde als Baby zum Krüppel, als Zeus ihn vom Olymp geworfen hat. Also sieht er nicht gerade gut aus. Sehr geschickt, klar, aber Aphrodite steht nun mal nicht auf Grips und Geschicklichkeit, weißt du.“ „Sie mag Motorradfahrer.“ „Scheint so.“ „Weiß Hephaistos Bescheid?““ „Klar doch“, sagte Annabeth. „Er hat sie einmal zusammen erwischt. Ich meine, er hat sie gefangen, in einem goldenen Netz, und dann hat er alle anderen Götter eingeladen, sie sich anzusehen und auszulachen. Hephaistos versucht immer, sie lächerlich zu machen. Deshalb treffen sie sich an abgelegenen Orten." (PJ 1, S. 276).
\end{abstract}

Auf diese Weise wird nicht nur die Erzählung um Hephaistos, die sich u. a. im ersten Buch der Ilias findet, aufgerufen, die mythische Vorlage wird sogar als Handlungsmotivation genutzt. Dadurch wird der Mythos nicht nur adaptiert, sondern sogar eine Fortsetzung geschrieben. Eine ausgesprochene Affinität zur antiken Mythologie zeigt Riordan auch in seiner Serie Die Helden des Olymp (2012-2014), die als Nachfolgereihe zu Percy Jackson gehandelt wird.

\title{
Zur Mythenadaption in der Panem-Trilogie
}

Schlachter zeigt einige Bezüge zu konkreten mythischen Erzählungen in der Panem-Trilogie auf. Sie sieht in Katniss nicht nur einen weiblichen Spartakus, sondern auch einen weiblichen Theseus: ${ }^{93}$

So ist Katniss ein weiblicher Theseus, der sich freiwillig meldet, um das Unheil von der Schwester abzuwenden und um die Hungerspiele schließlich ganz zu beenden, genauso wie der Theseus der griechischen Mythologie nach Kreta auszog, um dem von König Minos befohlenen Unrecht der jährlichen Opferung von sieben Jünglingen und sieben Jungfrauen im Labyrinth des Minotaurus ein Ende zu setzen. ${ }^{94}$

\footnotetext{
${ }^{92}$ Die sicherlich bekannteste Version findet sich in Homers Odyssee, IX. Gesang, V. 82-104.

${ }^{93}$ Schlachter (2014), S. 4 ff.

${ }^{94}$ Ebd., S. 5.
} 
Die Parallele zur Sage des Minotaurus drängt sich auf: Sind ihm jährlich sieben Jünglinge und Jungfrauen zu opfern, so müssen in Panem jährlich ein Junge und ein Mädchen aus jedem der zwölf Distrikte bis zum Tode gegeneinander antreten. Die Arena der Hungerspiele erinnert zudem an das Labyrinth aus dem antiken Mythos, ${ }^{95}$ beide bergen todbringende Gefahren. Zudem ist die Parallelität zwischen Artemis, der römischen Göttin der Jagd, und Katniss augenscheinlich: Beide sind mit Pfeil und Bogen ausgestattet und symbolisieren weibliche Unabhängigkeit und Stärke. ${ }^{96}$ Auch die Trainerfigur des Haymitch erlaubt eine Querverbindung zu antiken Prätexten. ${ }^{97}$

\subsubsection{Zur mythischen Erzählstruktur}

Es lässt sich beobachten, dass die betrachteten Texte des Korpus zu mythischen Erzählstrukturen tendieren, indem sie auf finale Motivierungsstrategien zurückgreifen, die vor allem durch etablierte mythische Motive verwirklicht werden. Realisiert wird dies vor allem durch die Logik, dass sich der Protagonist den Sieg bzw. das erstrebenswerte Ziel erst verdienen muss; Bewährungsproben lenken die Dramaturgie der Erzählungen, indem sich die Belohnung kontinuierlich nach hinten verschiebt. Dies soll nun an Funkes Tintenwelt- und Giers Edelstein-Trilogie sowie an Percy Jackson aufgezeigt werden.

\section{Zur mythischen Erzählstruktur der Tintenwelt-Trilogie}

Cornelia Funkes Werk folgt mythischen Erzählstrukturen, indem sämtliche Handlungsstränge final oder kompositorisch motiviert werden, was an zahlreichen Vorausdeutungen und Vorwegnahmen im Text belegt werden kann; alles motiviert sich im Sinne eines Schicksals, das höhere Mächte vorbestimmt haben. Ein Erzählerkommentar deutet etwa bereits im ersten Teil der Trilogie an, dass Meggie viele Jahre später einmal Kinder haben werde (TH, S. 149 f.). ${ }^{98}$ Die Möglichkeit, dass sie die Begegnung mit Capricorn sowie die Abenteuer in der Tintenwelt nicht überleben könnte, wird im ersten Drittel logisch ausgeschlossen. Die Leser haben somit von vornherein die Gewissheit, dass alles ein gutes Ende nehmen wird. Die Spannung

\footnotetext{
${ }^{95}$ In der Vorlage ist Minotaurus in einem von Dädalus konstruierten Labyrinth gefangen und erhält jährlich sieben Jungfrauen und Jünglinge als Opfer. Theseus gelingt es mithilfe von Ariadne bzw. ihres Fadens, den Minotaurus zu töten und wieder aus dem Labyrinth herauszufinden. Den Mythos überliefert u. a. der Mythograph (Pseudo-)Apollodor (3,11; 3,213-215; Epitome 1,8-9).

${ }^{96}$ Das Motiv der Jägerin findet sich auch in Percy Jackson wieder, wo die Symbolkraft explizit gemacht wird: Dort können weibliche Halbblute dem „Mädchenclub“ (PJ 3, S. 56) der Artemis beitreten und ihr Leben der Jagd und dem Schutz der Göttin widmen. Damit verbunden sind ewige Keuschheit und das Kontaktverbot zu Männern jeder Art (PJ 3, S. 49). Die Jägerinnen werden dafür mit Unsterblichkeit entlohnt.

${ }^{97}$ Siehe dazu Kapitel 5.2.

${ }^{98}$ Vgl. Heber (2919), S. 135.
} 
des Textes ergibt sich daher aus der Frage, wie die Auflösung erreicht wird, und nicht, ob überhaupt. ${ }^{99}$ Zudem kann sich der Rezipient darauf einstellen, dass sich die Geschichte über mehrere Bände entspinnen wird, da Fenoglio in einem selbstreferenziellen Figurenkommentar darauf angespielt. Er berichtet Meggie: ,, Ich habe damals lange mit der Idee gespielt, eine Fortsetzung von Tintenherz zu schreiben [...] ““(TH, S. 281). Diese Information, die sich eigentlich auf das fiktionale Buch „Tintenherz“ bezieht, ist als Metakommentar zu verstehen, der die Mehrteiligkeit von Funkes Werk vorwegnimmt und damit den Rezeptionsprozess zu beeinflussen vermag. Die finale Motivierung drückt sich zudem in zahlreichen Anspielungen aus: Schon sehr früh wird angedeutet, dass Meggie genau wie ihr Vater die Fähigkeit besitzt, Dinge aus Büchern heraus- und hineinzulesen (TH, S. 269). Zudem wartet der Rezipient immer wieder geradezu auf die Herausgabe zunächst zurückgehaltener Informationen, ${ }^{100}$ deren Bedeutung für den Fortgang der Geschichte vom Erzähler angedeutet wird. So weiß man zunächst nicht, welche Gedanken und Pläne Mo verfolgt oder ob er in gewissen Situationen lügt oder die Wahrheit sagt (zum Beispiel TH, S. 23, S. 296 f.).

Die finale Motivierung wird weiterhin durch zukunftsweisende Träume und das Prophetenmotiv realisiert: Meggies Träume werden mit Elementen ausgestaltet, die aus der Diegese stammen und für den Fortgang der Geschichte von Bedeutung sind (TH, S. 168). Das Prophetenmotiv klingt in stark abgewandelter Form an. Sämtliche Figuren, die „Tintenherz“ gelesen haben, können den Fortgang der intradiegetischen Geschichte vorhersagen und damit auch die persönliche Entwicklung der dort beheimateten Figuren (TB, S. 184, S. 363, S. 486 und TT, S. 374, S. 471). Sie werden damit zu Propheten der verschiedenen intradiegetischen Buchwelten (TH, S. 279, S. 281, S. 283 f.).

\section{Zur mythischen Erzählstruktur der Edelstein-Trilogie}

In Kerstin Giers Serie werden explizit zwei Prophezeiungsinstanzen genutzt, die Handlungselemente vorwegnehmen und zu einer finalen Motivierung beitragen: Die Geheimschriften des Grafen von Saint Germain (u. a. RR, S. 73, S. 105; SB, S. 243) beinhalten zahlreiche Vorhersagen und allegorische Zukunftsbeschreibungen, die den Kreis der Zwölf und die Welt insgesamt betreffen. Das Befolgen dieser Schriften stellt das übergeordnete Ziel der Wächter dar, welche auch für die Einhaltung des sogenannten Kontinuums (RR, S. 173) Sorge tragen, dem Ablauf der Weltgeschichte, wie er sich in der Vergangenheit bereits zugetragen hat. Die

\footnotetext{
${ }^{99}$ Martinez/Scheffel (2005), S. 153.

${ }^{100}$ Zur Informationslenkung siehe Kapitel 5.3.2.3.
} 
Wächter handeln dementsprechend nach diesen Schriften und beziehen in ihre Entscheidungen ihren eigenen Chroniken und Annalen - Berichterstattungen aus der Vergangenheit - mit ein, die sukzessive und auszugsweise präsentiert werden (zum Beispiel RR, S. 11, S. 89; SB, S. 215; SG, S. 137). Die Geheimschriften besitzen eine allegorische, zukunftsweisende Bedeutung, die sich im Laufe der Geschichte nach und nach entfaltet. ${ }^{101}$ Gwendolyn steht vor der Aufgabe, diese zu durchdringen und darin ihr zukünftiges Schicksal zu erkennen; sie selbst wird als Rabe dargestellt, der wie sie selbst mit Toten bzw. Geistern zu kommunizieren vermag; Gideon wird als Löwe codiert, der durch seine Schönheit besticht. Folgende Schrift im zweiten Band prophezeit, dass Gwendolyn am Ende sterben wird: ${ }^{102}$

\footnotetext{
Der Rabe auf seinen rubinroten Schwingen

Zwischen den Welten hört Tote er singen,

Kaum kennt er die Kraft, kaum kennt er den Preis,

Die Macht erhebt sich, es schließt sich der Kreis.

Der Löwe - so stolz das diamant'ne Gesicht,

Der jähe Bann trübt das strahlende Licht,

Im Sterben der Sonne bringt er die Wende,

Des Raben Tod offenbart das Ende (SB, S. 244).
}

Dass diese und ähnliche Allegorien vor allem deswegen geschrieben wurden, damit die Wächter dem Grafen zuarbeiten, der niedere Absichten verfolgt, wird erst am Ende des dritten Bandes aufgelöst (SG, S. 462 ff.); warum sich die Schriften ungeachtet dessen dennoch größtenteils bewahrheiten, wird in den Texten nicht geklärt. Neben den Geheimschriften sorgen Tante Maddys Visionen (zum Beispiel RR, S. 77; S. 78; SB, S. 332 f.) für eine finale Motivierungsstruktur, deren Glaubwürdigkeit zwar angezweifelt wird, die sich aber durchgängig als zukunftsweisend und damit verlässlich erweisen. Doch muss ihre Bedeutung zunächst entschlüsselt werden, denn sie haben ebensfalls allegorischen Charakter, sie bedienen sich sogar derselben Bildsprache. Auch das Motiv des bedeutsamen Traums, der die Zukunft vorhersagt oder zumindest bedeutsame Geschehnisse andeutet (zum Beispiel SG, S. 17 f.), findet sich in der Edelstein-Trilogie.

\section{Zur mythischen Erzählstruktur von Percy Jackson}

In Riodans Romanserie wird gleichfalls auf final ausgerichtete mythische Erzählstrukturen zurückgegriffen, auch er hat bedeutsame Träume (zum Beispiel PJ 1, S. 55 ff., S. 73 ff.; PJ 2, S. 7 ff., 89 ff.; PJ 3, S. 88 ff., 186 ff.), sie sind sogar fester Bestandteil des Serialitäts-

\footnotetext{
${ }^{101}$ Bei den zukunftsweisenden Schriften kommt es im Text dabei zwangsläufig zu logischen Inkonsistenzen, da sie nicht mit der zyklischen Zeitstruktur der Texte in Einklang zu bringen sind.

${ }^{102} \mathrm{Da}$ die Handlung streng einem Happy End verpflichtet ist, erweist sich diese Sorge natürlich als unbegründet.
} 
konzepts. ${ }^{103}$ Zudem wird die Handlung durch Orakelprophezeiungen motiviert, welche sowohl die Folgenhandlungen der Einzelbände als auch die Serienhandlungen des Gesamttextes strukturieren. Die Bewahrheitung derselben ist, in Analogie zu antiken Mythen, in der Diegese Gesetz. Die Weissagung des ersten Teils der Serie gestaltet sich folgendermaßen:

Du gehst gen Westen, zu dem Gott, der sich gewendet. [...]

Das, was gestohlen, legst du in die richt'gen Hände. [...]

Ein Freund begeht an dir Verrat, der bitter schmerzt. [...]

Und du versagst just dort, wo es betrifft dein Herz. (PJ 1, S. 172)

Auch hier wird sich die Prophezeiung erfüllen: Um ,, den größten Krieg in der Geschichte der Menschheit“ (PJ 1, S. 190) zu verhindern, macht Percy sich daran, Zeus seinen Herrscherblitz, der gestohlen wurde (PJ 1, S. 165), zurückzubringen, was ihm am Ende auch gelingt (PJ 1, S. 400 ff.). Er begibt sich dazu nach Westen, Richtung Unterwelt, in dem Glauben, dass Hades der Dieb ist, was sich als Irrtum herausstellt (PJ 1, S. 365 ff.). In der Verhandlung mit Hades „versagt“ Percy vorerst, weil er sich dafür entscheidet, nicht das Leben seiner Mutter, sondern sein eigenes zu retten (PJ 1, S. 373). Es stellt sich heraus, dass Percy von seinem Freund Luke betrogen wird, der sich gegen den Olymp und auf die Seite des bösen Kronos stellt. So laufen sämtliche Handlungsstränge final auf die Ereignisse „Percy rettet seine Mutter“ und „Percy bringt den Herrscherblitz zurück“ zu. Analog dazu lassen sich in den folgenden Bänden andere Motivationsursachen ausmachen. Percy reflektiert immer wieder die Prophezeiung des Orakels und versucht sie auf seine jeweilige Situation und Bewährungsproben anzuwenden, so auch im ersten Band:

Tatsache war: Es interessierte mich einen Dreck, ob ich Zeus' Blitzstrahl finden [...] konnte. [...] Ich interessierte mich ausschließlich für meine Mom, Es war nicht fair, dass Hades sie sich geholt hatte, und Hades würde sie wieder hergeben müssen. Ein Freund begeht an dir Verrat, der bitter schmerzt, flüsterte das Orakel in meinen Gedanken. Und du versagst just dort, wo es betrifft dein Herz. Halt die Klappe, sagte ich. (PJ 1, S. 193 f.)

\subsubsection{Zum mythischen Erzählschema der Heldenreise und zum besonderen Kind}

Anlehnungen an antike Mythen prägen entscheidend den Plot, die Thematik und die Konzeption der Protagonistenfigur, zudem geben sie literarischen Texten durch den Aufruf von Schemata eine signifikante Struktur, an der der Rezipient sich orientieren kann. Im Folgenden

\footnotetext{
${ }^{103}$ Kontinuierlich verwendete Motive schaffen intraseriale Kohärenz. Siehe dazu Kapitel 2.2.1.2.
} 
werden die Schemata „Heldenreise“ und „Das besondere Kind““104 mitsamt Ursprüngen vorgestellt, denn sie prägen signifikant Harry Potter und die Texte des Korpus.

\section{Zum Schema der Heldenreise}

Zentrales Thema der Heldenreise ist die Biografie des Protagonisten, oftmals Titelhelden ${ }^{105}$, der sich dem Kampf gegen das Böse stellt, diesen Kampf gewinnt und so zur Heldenfigur wird. ${ }^{106}$ Bergenthal wies in ihrer Dissertation auf den großen Einfluss des CampbellHollywood-Schemas ${ }^{107}$ hin, welches nicht nur amerikanische Blockbuster oder die Arbeiten Christopher Voglers, einem der einflussreichsten Drehbuchautoren Hollywoods, maßgeblich beeinflusst habe, sondern auch zeitgenössische Literatur, die sich an den Schemata der Filmindustrie orientiert und multimedial anschlussfähig bleiben will. ${ }^{108}$

Das Schema basiert auf verschiedenen mythischen Erzählungen aus dem Leben von besonderen Kindern, in den meisten Fällen „Gottkindern“, die einen starken Reiz auszuüben und ein ästhetisches Grundbedürfnis des Menschen zu befriedigen scheinen - Eigenschaften, die Vogler seinerzeit für große Hollywood-Produktionen fruchtbar machen wollte. ${ }^{109}$ Er verfasste in Anlehnung an die tiefenpsychologischen Untersuchungen von Campbell und die MythosStudien von C. G. Jung einen Ratgeber, der sich an Filmemacher, Autoren und Drehbuchschreiber richtete und den konkreten ästhetischen Wert und die Struktur des Schemas zu plausibilisieren suchte. Seine Erläuterungen waren offenbar noch eindrücklicher als die Ergebnisse von Campbell selbst, denn es existieren zahlreiche Produktionen, die sich an Voglers Heldenzyklus orientieren, dessen Struktur auch heute noch Drehbuchautoren unterrichtet wird. ${ }^{110}$ „Es gilt inzwischen als einer der Hollywood-Standards. “111 Aufgrund der großen Popularität der Filme scheint sich die Heldenreise im kollektiven Bewusstsein verankert zu haben, sodass zeitgenössische Autoren und Filmemacher immer wieder gerne darauf zurückgreifen. ${ }^{112}$

\footnotetext{
${ }^{104}$ Siehe dazu beispielsweise Bleicher (1999) und Campbell (1999).

${ }^{105}$ Mit dem Begriff Held werden hier weibliche und männliche Protagonisten einer Geschichte bezeichnet. Er soll vor allem die Funktion und nicht das Geschlecht der jeweiligen Figur hervorheben.

${ }^{106}$ Vgl. Elstner (2004, S. 5), der den biografischen Charakter von Harry Potter als hilfreich für die internationale Vermarktung der Texte herausstellt.

${ }^{107}$ Campbell (1999) arbeitet in seinen Studien anthropologische Konstanten in der Literaturgeschichte, bezogen auf Mythen, Märchen und auch zeitgenössische Texte, heraus, die die signifikantesten Überschneidungen in der Konzeption von Literatur generell darstellen.

${ }^{108}$ Ursula Bergenthal hat die Verwendung des Schemas in der Potter-Serie nachgewiesen. Bergenthal (2008), S. 375-380.

${ }^{109}$ Vogler (1999), S. 9 f.

${ }^{110}$ Vgl. Martinez/Scheffel (2005), S. 154; Vogler (1999), S. 12; Schneider (2001), insbesondere S. 10, S. 53, S. $67 \mathrm{f}$.

${ }^{111}$ Vogler (1999), S. 12.

${ }^{112}$ Ebd., passim; Bergenthal (2008), S. 391.
} 
Durch seinen Genre-, Figuren- und Mythenmix zeigt sich Voglers Schema als gattungs- und genreübergreifendes Grundmodell, das nach Belieben variiert werden kann, ja variiert werden soll. ${ }^{113}$ Es ist als umfassende Crossover-Strategie zu betrachten. ${ }^{114}$ Vogler gibt folgenden Hinweis an Drehbuchautoren: ,, Sie sollten dieser Vorlage aber auf keinen Fall sklavisch folgen; achten Sie darauf, dass die Grundstruktur sich nicht in den Vordergrund drängt und alle Aufmerksamkeit auf sich zieht. " ${ }^{115}$ Das Schema zeigt zwölf Etappen, die sich so oder ähnlich, zur Gänze oder in Teilen, in allen Texten des Korpus wiederfinden: ${ }^{116}$

1. ,Gewohnte Welt“

Die Heldenreise beginnt meist in der aus Perspektive des Helden gewohnten Welt; diese stellt in aller Regel die Primärwelt zur Jetztzeit ${ }^{117}$ bzw. für den Helden relevante Auszüge aus der Primärwelt dar. Nach Vogler sollte bereits bei der Eröffnungssequenz eine Identifizierung zwischen Rezipient und Titelheld hergestellt werden, indem seine Ziele, Konflikte, Wünsche und Gedanken allgemein anschlussfähig sind und von möglichst vielen Rezipienten nachempfunden werden können. ${ }^{118}$ Der Held hat dabei einen tragischen Charakterfehler, der ihn menschlich erscheinen lässt. Die gewohnte Welt ist „Kontext, Ausgangspunkt und Hintergrund des Helden “.119 und Grundlage für den Kontrast zur Anderswelt, dem Zielpunkt der Heldenreise. Je größer die Unterschiede zwischen beiden Welten, desto drastischer die Grenzerfahrung des Helden. Die Heldenreise ergibt sich aus einer Mangelsituation der Helden, ,, in vielen Fällen haben sie einen Familienangehörigen verloren, Mutter oder Vater sind gestorben, oder ein Geschwister ist entführt worden "120.

2. ,Ruf des Abenteuers“"

Die Aufforderung zum Abenteuer offenbart, um welchen Preis es bei der Heldenreise gehen wird: entweder um Rache, eine Belohnung oder den Ausgleich eines Mangels oder aber um einen hohen Lohn wie einen Schatz oder die Anerkennung, die beim Bestehen einer bestimmten Herausforderung winkt. ${ }^{121}$ Manchmal erfolgt der Ruf auch in Form einer Warnung.

3. , Weigerung (der widerstrebende Held) “

Der Held weigert sich zunächst aus Angst vor der ihm bevorstehenden Aufgabe und sucht nach ,fadenscheinigen " Ausflüchten. ${ }^{122}$

4. , Begegnung mit dem Mentor"

Der Mentor ist dazu da, den Helden auf die Begegnung mit dem Unbekannten ${ }^{123}$ vorzubereiten.

5. , Überschreiten der ersten Schwelle“

Der Held überwindet seine Zweifel und lässt sich auf das Abenteuer ein. ${ }^{124}$ Die Schwellen zwischen gewohnter Welt und Anderswelt können konkret durch (räumliche) Grenzgänge oder durch abstrakte und semantische Brüche realisiert sein.

\footnotetext{
${ }^{113}$ Vgl. Höcker (2010), S. 23 und Vogler (1999), S. 55.

114 Dies zeigt sich in den hier betrachteten Serien etwa daran, dass die unterschiedlichsten Genre-Pattern und Schemata kombiniert und verwendet werden.

${ }^{115}$ Vogler (1999), S. 75.

116 Zusammengefasst nach Vogler (1999), S. 57-77 bzw. S. 159-361. Wörtliche Übernahmen sind durch Anführungszeichen und Kursivschrift gekennzeichnet.

${ }^{117}$ Siehe Kapitel 3.3.2.4.

${ }^{118}$ Vgl. Vogler (1999), S. 175. Dabei ist zu beachten, dass eine psychische Disposition klar kulturellen Einflüssen ausgesetzt ist.

${ }^{119}$ Ebd., S. 167.

${ }^{120}$ Ebd., S. 175. Auch Lexe (2003, S. 78 ff.) hat „Elternferne“ als prominentes Motiv in den Klassikern der Kinderliteratur betont.

${ }^{121}$ Vogler (1999), S. 58, S. 196.

${ }^{122}$ Ebd., S. 60, S. 203.

123 Ebd., S. 62.

${ }^{124}$ Ebd., S. 63.
} 


\section{Die Post-PotTER-TeXTE ALS MODERnE MYTHEN}

\section{6. „,Bewährungsproben, Verbündete und Feinde“"}

In der neuen Welt angekommen, hat sich der Held ersten Bewährungsproben zu stellen, er lernt allmählich die Regeln seiner neuen Umgebung und erwirbt sich Freunde und Feinde, ständige Begleiter und Rivalen. ${ }^{125}$

7. ,,Vordringen zur tiefsten Höhle (zum empfindlichsten Kern) “

Schließlich passiert der Held die zweite Schwelle und dringt in den ,gefährlichsten Ort “ ein, um sein Hauptziel zu erreichen. Doch bevor dies so weit ist, warten noch viele Risiken, Täuschungen, Bewährungsproben oder Verteidigungsattacken. Eine gängige Strategie der Verbündeten ist es, sich in den Feind hineinzuversetzen. ${ }^{126}$

\section{8. ,Entscheidende Prüfung “}

Diese Etappe thematisiert die entscheidende Konfrontation zwischen Gut und Böse bzw. zwischen Leben und Tod. Der Held muss seine größte Angst bezwingen, um siegreich aus der Situation hervorzugehen. ${ }^{127}$

9. „, Belohnung (Ergreifen des Schwertes) “

Der Held nimmt den Schatz, die Belohnung oder Entlastung entgegen, weswegen er überhaupt die Heldenreise angetreten hatte. Der Schatz kann abstrakt sein, den Held etwa durch emotionale Stärke, die Einsicht in ein Geheimnis oder grundlegende Selbsterkenntnis bereichern, aber auch symbolischen Wert haben. Er kann als Gral, als Elixier, als eine besondere übermenschliche Fähigkeit oder als mächtige Waffe codiert sein. ${ }^{128}$ Ist alles überstanden, werden in Feier- und Lagerfeuerszenen (oder Szenen, die eine Lagerfeueratmosphäre schaffen) die jüngsten Ereignisse vom Protagonisten und den Beteiligten reflektiert. Es kann zum Streit um die Beute kommen; auch Wehmut über das Vergangene kann geäußert oder die Prognose in den Raum gestellt werden, dass nichts mehr so sein wird, wie es einmal war. ${ }^{129}$ Dies ist der Zeitpunkt, wo sich Liebespaare finden und der Held als gottähnlich erkannt wird oder sich im Sinne einer Selbsttäuschung unbegründet dazu erhebt. ${ }^{130}$

10. ,,Rückweg“

Nachdem der Held Lehren aus seiner siegreichen Prüfung gezogen hat, steht er vor der Entscheidung, wie er damit umzugehen hat: Tritt er die Rückreise in der gewohnte Welt an, oder bleibt er in der Anderswelt? Welche Konsequenzen haben die Ereignisse für sein zukünftiges Leben? Wird man ihm in der gewohnten Welt glauben, was ihm passiert ist? Entscheidet er sich für den Rückweg, werden oftmals Verfolgungsjagden mit feindlichen Mächten gestaltet, die Rache nehmen wollen. ${ }^{131}$ Ebenso gängig ist, dass die Bösewichte fliehen und zu einem späteren Zeitpunkt mächtiger zurückkehren. ${ }^{132}$ Außerdem ist ein bekanntes Motiv bei jenen Verfolgungsjagden ist, dass der Held zur Ablenkung der Verfolger Gegenstände hinter sich werfen muss, die für ihn ein Opfer bedeuten. ${ }^{133}$

\section{1. „Auferstehung (Resurrektion)“}

Bevor der Held in seine gewohnte Welt zurückkehren darf, muss er oft nochmals eine allerletzte Prüfung, seine konkret körperliche oder abstrakt symbolische Auferstehung, durchleben. ${ }^{134}$ „Die Auferstehung soll den Helden vom Geruch des Todes befreien, ihn aber nicht die Lehren aus seiner Prüfung vergessen lassen. " 135 Die Auferstehung bildet den Höhepunkt der Heldenreise, ist Augenblick der größten Spannung, des höchsten Gefühls oder des letzten großen Ereignisses des Werks. ${ }^{136}$ Sie ist auch Höhepunkt des Entwicklungsbogens des Heldencharakters, der Entwicklung des inneren Gemütszustandes des Helden, die parallel zu den Etappen der Heldenreise verläuft. ${ }^{137}$ An diesem Punkt angelangt, zeigt der Held, dass er sich wirklich verändert hat, dass er eine schlechte Angewohnheit abgelegt und die Lehren seiner Reise verinnerlicht hat.

\footnotetext{
${ }^{125}$ Ebd., S. 63, S. 245-247.

126 Ebd., S. 260-270.

${ }^{127}$ Ebd., S. 67.

${ }^{128}$ Ebd., S. 69.

${ }^{129}$ Ebd., S. 310-314.

${ }^{130}$ Ebd., S. 315 f.

${ }^{131}$ Ebd., S. 71.

132 Ebd., S. 331.

133 Ebd., S. 330.

${ }^{134}$ Ebd., S. $71 \mathrm{f}$.

${ }^{135}$ Ebd., S. 337.

${ }^{136}$ Ebd., S. 344.

${ }^{137}$ Ebd., S. 349.
} 


\section{2. ,,Rückkehr“}

Der moderne Held fügt sich jedoch nicht in sein Schicksal, er entscheidet sich aus freien Stücken für die Aufgabe, auch wenn der Ausgang der Geschichte aus seiner Perspektive ungewiss ist. ${ }^{138}$ Es ist also eine bewusste und freiwillige Annahme der Prüfung, die auch Harry Potter und seine Nachfolger auszeichnet. ${ }^{139}$

Die Übertragbarkeit des Schemas ist offensichtlich, zumal es sich als ungeheuer flexibel erweist. In Die Tribute von Panem - Gefährliche Spiele wird es folgendermaßen umgesetzt:

1. Gewohnte Welt: Katniss Everdeen wächst im Distrikt 12 der Nation Panem auf, dem Distrikt der Kohlearbeiter (TS, S. 8). Sie wird in ärmlichsten Verhältnissen groß, lebt mit Schwester und Mutter zusammen, für die sie seit dem Tod ihres Vaters - sie war gerade elf Jahre alt (TS, S. 9) - die Verantwortung übernommen hat. Ihr kommt die , die Rolle des Familienoberhauptes“ zu (TS, S. 33).

2. Ruf des Abenteuers: Katniss tritt anstelle ihrer Schwester, deren Leben sie unbedingt schützen möchte, die Hungerspiele an (TS, S. 27 f.). Es ist klar, dass die Chancen, die Spiele zu überleben, sehr gering sind, da jährlich 23 von 24 Tributen darin umkommen.

3. Weigerung: Sie ist zunächst überzeugt, dass sie die Spiele nicht gewinnen kann (TS, S. 43), was nichts an ihrer Entscheidung ändert, sich für ihre Schwester zu opfern.

4. Begegnung mit dem Mentor: Ihr wird Haymitch zur Seite gestellt, der sie auf den Wettkampf vorbereiten soll (TS, S. 30 f.).

5. Überschreiten der ersten Schwelle: Im Zug zum Kapitol macht Katniss sich Gedanken, wie sie den Wettkampf angehen wird (TS, S. 60 ff.). Der Zug ist als Grenzraum zwischen gewohnter Welt (Distrikt 12) und unbekannter, neuer Welt (Kapitol) zu verstehen.

6. Bewährungsproben, Verbündete und Feinde: Im Trainingscenter des Kapitols angekommen, werden die Tribute einzeln vor die Spielmacher gerufen, um ihr Können erstmals unter Beweis zu stellen und bewertet zu werden (TS, S. 113). Katniss schießt aus Wut einen Pfeil in die Ränge der Veranstalter (TS, S. 115) und erregt damit unmittelbar Aufmerksamkeit. Im Trainingscenter bekommt sie Gelegenheit, ihre Rivalen näher zu begutachten. Hier beginnt sich das Verhältnis zu Peeta zu intensivieren (TS, S., 159 ff.).

7. Vordringen zur tiefsten Höhle: In der Arena muss Katniss zahlreiche Prüfungen bestehen: Sie muss sich mit Nahrung und Wasser versorgen (TS, S. $174 \mathrm{ff}$.), sich ein sicheres Lager

\footnotetext{
${ }^{138}$ Vgl. Bergenthal (2008), S. 173.

${ }^{139}$ Stenzel (2006), S. 185.
} 
herrichten (TS, S. 175 f.) und sich eine Überlebensstrategie zurechtlegen. Sie geht ein Bündnis mit Rue ein und vernichtet Vorräte von gegnerischen Tributen (TS, S. 233 ff.). Sie spielt ein Liebespaar mit Peeta, um die Gunst des Publikums und der Sponsoren zu bekommen (TS, S. 292). Den Rivalen Cato befreit sie durch einen tödlichen Pfeil von seinem Leiden, als dieser von einer Meute mutierter Wölfe gequält wird (TS, S. 379). Nach und nach fallen alle Rivalen, bis nur noch Katniss und Peeta übrig sind. Da den Regeln zufolge nur ein Tribut gewinnen kann, stehen beide nun vor der problematischen Entscheidung, ihr eigenes Leben oder das des anderen zu retten.

8. Entscheidende Prüfung: Katniss beweist außerordentlichen Mut und greift zu einer List. Sie reicht Peeta giftige Beeren, und beide mimen, ihr Leben bereitwillig für den anderen opfern zu wollen (TS, S. 383). So stehen die Ausrichter der Hungerspiele vor der Wahl, entweder mit keinem oder gleich zwei Siegern die Spiele zu beenden.

9. Belohnung (Ergreifen des Schwertes): Das Druckmittel zeigt die erwünschte Wirkung: Katniss' List hat Erfolg. Sie und Peeta gewinnen die Hungerspiele und werden zu Siegern gekürt (TS, S. 384 f.).

10. Rückweg: Nachdem Katniss für kurze Zeit nach Hause zurückkehren durfte, tritt sie mit Peeta die „, Tour der Sieger“ (TL, S. 10) an. Es stellt sich heraus, dass sie im Volk als „, Symbol der Revolution " gehandelt wird (TL, S. 426).

11. Auferstehung: Das Kapitol will die Aufstände kleinhalten, indem es JubiläumsHungerspiele ausrichtet und damit Katniss und Peeta dazu zwingt, abermals in die Arena zu gehen (TL, S. 155 ff.), was beide unverhofft überleben. Katniss wird zur Anführerin einer Revolution in Panem: ,,Volk von Panem, wir kämpfen, wir wagen, wir machen unserem Hunger nach Gerechtigkeit ein Ende“ (FZ, S. 85). Es kommt zum Krieg gegen das Kapitol.

12. Rückkehr: Die Leitfiguren des Kapitols, Coin und Snow, sterben bei den Aufständen, was das Ende des Krieges einleitet. Katniss und Peeta schaffen sich ein Heim und bekommen zwei Kinder (FZ, S. 427 f.). 


\section{Zur Motivkonstellation des besonderen Kindes}

Das Schema Heldenreise geht nach Vogler auch auf den Archetyp des besonderen Kindes zurück. Er ist im Erkenntnisinteresse dieses Projekts deswegen so zentral, weil er maßgeblich die Konzeption moderner Heldenkonzepte beeinflusst, so auch im hiesigen Korpus.

Bei den Protagonisten handelt es sich um heranwachsende Kinder und/oder Jugendliche, die in ihrer aus der realen Welt bekannten und mit entsprechender Konnotation versehenen Adoleszenz begriffen sind und sich im Laufe ihrer Geschichte als „besonders“ erweisen. „Das besondere Kind““140 ist ein klar erkennbares Symbol, ${ }^{141}$ welches eine lange Tradition besitzt, die bis in älteste religiöse Erzählungen und Mythen zurückreicht, es ist daher als ein Archetyp der Literaturgeschichte zu betrachten. ${ }^{142}$ Als literarisches Motiv zeichnet es sich auf der einen Seite durch seine spezielle, symbolische, aus übernatürlichen, oftmals mythischen Beweggründen hergeleitete Macht aus, ,die im Gegensatz steht zu seiner realen Schwäche, seiner Hilflosigkeit und seinem Angewiesensein auf Schutz und Pflege “"143, sein Reiz und ästhetischer Wert liegen im Aufeinandertreffen dieser beider Extreme. ${ }^{144}$

In der Genese der Handlung wird das besondere Kind zur Grenz- bzw. Schwellenfigur, die zwischen gewohnter Welt und Fremdwelt/Anderswelt ${ }^{145}$ vermittelt; es ist überhaupt erst der Auslöser für das Entdecken des Anderen:

Entsprechend dem romantischen Kindheitsmythos bewegt sich eine kindliche Zentralfigur neben der Alltagswirklichkeit auch in einer magischen Anderswelt, die sich ebenso aus individuellen Fantasien wie den Mythen und Märchen des Abendlandes zusammensetzt und in der eigene Normen und Werte gelten. $^{146}$

Der Rezipient lernt die unbekannte Welt meist aus der Sicht des besonderen Kindes kennen, was dazu einlädt, sich mit ihm zu identifizieren und gedanklich in die geschilderte Parallelwelt abzutauchen. Die Geschichte kann damit zum Spielplatz werden oder, pessimistisch formuliert, zur gezielten Realitätsflucht dienen (vor allem für jugendliche Leser), ein Umstand, der im Diskurs um phantastische Kinder- und Jugendliteratur kontrovers diskutiert wird. ${ }^{147}$

\footnotetext{
${ }^{140}$ Das strikt als Motiv und nicht als empirisch zu betrachten ist.

${ }^{141}$ Schwarzenau (1984), S. 9.

142 Bergenthal (2008), S. 381.

${ }^{143}$ Mattenklott (2001b), S. 36.

${ }^{144}$ Mattenklott (2001a), S. 37 ff.

${ }^{145}$ In der griechischen Mythologie stellen sich die zwei Welten meist als Menschen- und Götterwelt dar, also in Form einer binären Struktur. Zur binären Weltstruktur siehe Kapitel 3.3.2.1.

${ }^{146}$ Nickel-Bacon (2008), S. 401 und Karg/Mende (2010), S. 209 f.

${ }^{147}$ Es gibt durchaus Stimmen, die die Vorteile des Fluchtpotenzials phantastischer Literatur herausstellen, beispielsweise Petzold (2004). Andere warnen vor der Realitätsflucht; siehe dazu Nickel-Bacon (2003), S. 147.
} 
Damit der Informationsfluss von Protagonist und Rezipient tatsächlich gleichgeschaltet verläuft, setzen die Geschichten in der Regel in der Primärwelt ein, die die gewohnte Welt darstellt, und markieren den Übergang zur Sekundärwelt als ungeheures Ereignis. Dem Helden kommen Anderswelt und Magie fremd und unwahrscheinlich vor, und er reagiert stellvertretend für den Rezipienten, wenn er sich entrüstet und ungläubig gebärdet. Motiviert werden die übernatürlichen Begebenheiten durch seinen Auserwähltenstatus. Sein Schicksal ist in der Logik der Texte zwar als unwahrscheinlich, aber nicht als unmöglich gekennzeichnet. Ja gerade die Ungeheuerlichkeit der Ereignisse unterfüttert die Glaubhaftigkeit der Erzählung, da sie das besondere Kind in den Mittelpunkt stellt.

Spekuliert wird, dass das Motiv auf ein ,,in der Psyche verankertes Urbild“" referiert, ,das, wo es in Kunst, im Kult, im Mythos oder in der in der Legende auftritt [...], auf ein Geschehen der seelischen Tiefe des Menschen zurückweist" und daher attraktiv sei. ${ }^{148}$ Dafür spricht, dass in ihm die beiden zentralen, in die Zukunft gerichteten menschlichen Emotionen versinnbildlicht werden: Hoffnung und Angst. Denn mit seinem jugendlichen Alter verweist das besondere Kind motivisch in die Zukunft und synthetisiert durch die ihm zugeschriebenen Attribute beide menschlichen Gemütszustände zu einem stimmigen Sinnbild: Seine Schutzlosigkeit und Bedürftigkeit können symbolisch als die Angst des Menschen vor dem Versagen, vor dem Bösen und Ungewissen gelesen werden, während es mit seinen besonderen Fähigkeiten zum Hoffnungsträger wird, zum etwaigen Erlöser der Menschheit, zum Glücks- und Heilbringer. ${ }^{149}$ Die Nähe des Symbols zu religiösen Bildern und Texten ist evident, tatsächlich ist das besondere Kind motivisch vor allem als „Gottkind“ oder „göttliches Kind“ in die Literaturgeschichte eingegangen, wo seine übermenschlichen Fähigkeiten durch Einfluss eines Gottes bzw. durch göttliche Macht und Güte hergeleitet werden. Als Grundmotiv zahlreicher mythischer und religiöser - nicht nur christlicher - Erzählungen, zeigt sich darin auch eine deutliche Nähe zu Schöpfungsmythen ${ }^{150}$ und der Idee des Goldenen Zeitalters. ${ }^{151}$ Gott, Buddha, Krischna, Horus, Dionysos und Merlin offenbaren in diesen Geschichten ihre schöpferische Macht und Überlegenheit im scheinbar Schwächsten. Das besondere Kind wird dabei zum Urbild „göttlicher Seinssicherheit “152. Ein prominentes Beispiel stellt der Herakles-Mythos

\footnotetext{
${ }^{148}$ Schwarzenau (1984), S. 8. Ein Beleg dafür ist allerdings schwerlich zu erbringen, da die Wirkung des Motivs nicht mit wissenschaftlichen Instrumentarien zu erfassen ist.

${ }^{149}$ Vgl. Alefeld (1996), S. 176.

${ }^{150}$ Beispielsweise bei Jesaja 11, 5-9.

${ }^{151}$ Vgl. Jung/Kerényi (1951). Eine Schilderung des Goldenen Zeitalters findet sich in Hesiod: Werke und Tage, Verse 106-201.

152 Ebd.
} 
dar, der zahlreiche Strukturen, Symbole und Motive aufweist, die schematisch in Voglers Heldenreise einfließen und sich häufig bei zeitgenössischen Protagonistenfiguren wiederfinden. Im Folgenden soll die Geschichte aus der griechischen Mythologie kurz umrissen und sein konzeptueller Aufruf in den Post-Potter-Texten belegt werden.

\section{Der Herakles-Mythos als Vorbild moderner Heldenkonzepte}

Der Mythos um den Halbgott Herakles, Sohn des Göttervaters Zeus und der Menschenfrau Alkmene, der nach seinen Taten in den Olymp aufgenommen wird, ist sicherlich eine der bekanntesten Gottkindmythen des klassischen Altertums. Die Post-Potter-Literatur verweist vielfach auf diese Kindfigur, deren Funktionalisierung je nach Verfasser völlig unterschiedlich realisiert ist. ${ }^{153}$ Herakles wird in Ilias und Odyssee erwähnt, taucht bei Hesiod, Euripides, Aristophanes, Theokrit und Kallimachos und natürlich auch in mythologischen Handbüchern auf sowie in Vergils Aeneis und Ovids Metamorphosen. Der literarische Aufruf der Figur in nachantiker Zeit reicht über Boccaccio, Shakespeare, Wieland und Goethe bis hin zu Wedekind, Walser und Dürrenmatt. Um die zeitgenössischen Anlehnungen an den Mythos genauer in den Blick nehmen zu können, wird hier der Kern der Narration wiedergegeben: ${ }^{154}$

Die Göttin Hera, betrogene Gattin des Zeus, verfolgt eifersüchtig und missgünstig den aus dem Verhältnis zwischen dem Göttervater mit der Menschenfrau Alkmene entstandenen Sprössling Herakles und fügt ihm schon Unheil zu, bevor er überhaupt auf der Welt ist, indem sie seine Geburt verzögert und dafür sorgt, dass gemäß der Prophezeiung von Zeus später ein anderer, nämlich Eurystheus, zum Herrscher über Mykene wird und Herakles somit sein Untertan. Alkmene setzt ihren Sohn aus Angst vor der Rache Heras aus, Athene, seine Halbschwester, ${ }^{155}$ bringt ihn besorgt zu Hera, die Herakles nicht erkennt, ihn sogar stillt und durch ihre göttliche Muttermilch dafür sorgt, dass er übermenschliche Kräfte erlangt. Von Athene zurückgebracht, wächst Herakles dann schließlich doch bei seiner leiblichen Mutter und deren Ehemann Amphytrion auf. ${ }^{156}$ Er hat schon mit acht Monaten genug Kraft, zwei Schlangen zu erdrosseln, die ihm Hera in die Wiege schickt. Er erhält vom Seher Teiresias die Weissagung, dass er später einmal ungeheure Taten vollbringen, Unsterblichkeit empfangen und Hebe, die ewige Jugend, als Gemahlin bekommen werde. ${ }^{157}$ Amphytrion beschließt, seinem Stiefsohn

\footnotetext{
${ }^{153}$ Vgl. Galinsky (1972).

154 Die Sage von Herakles ist zusammengefasst nach Guggenmos/Schwab (2006), S. 159-217. Davon abweichende Varianten oder Ergänzungen werden im Fußnotentext kenntlich gemacht.

${ }^{155}$ Es gibt auch eine Version, in der Hermes dafür sorgt, dass Herakles von Hera gestillt wird.

${ }^{156}$ Vgl. Schadewaldt (1956), S. $86 \mathrm{f}$.

${ }^{157}$ In der Antike noch als Inbegriff des Gewaltherrschers gelesen, wird der Herakles-Mythos in der Romantik
} 
eine würdige, umfassende Erziehung zu ermöglichen. Er ruft Helden aus allen Gegenden zusammen, die ihn unterrichten sollen; er selbst zeigt ihm, wie man einen Wagen lenkt. Herakles lernt Singen und das Spiel der Leier, das Lesen der Buchstabenschrift und außerdem, wie man sich siegreich im Kampf zur Wehr setzt. Dabei zeigt er sich zwar gelehrig, kann jedoch die Härte im Unterricht nicht ertragen, weswegen er Linos, einen Sohn des Apoll, der ihm das Lesen beigebracht hat, mit einer Leier erschlägt. Amphytrion schickt ihn daraufhin aufs Land, und dort wächst Herakles heran. Mit 18 Jahren übertrifft er bereits alle an Schönheit und Stärke und muss sich alsbald entscheiden, ob er seine Kraft und Stellung in seinem Leben zum Guten oder zum Bösen gebrauchen möchte. Es erscheinen zwei Frauen, die ihn beide zur Vermählung auffordern. Die eine, von ihren Freunden Glück, von ihren Feinden Laster genannt, verspricht ihm, dass er bei ihr ein lustvolles und glückliches Leben ohne Mühsal und Fleiß führen werde, die andere, Tugend genannt, dass er bei ihr Glück im Sinne der Götter finden werde, allerdings als Lohn für Mühsal und Fleiß. Er entscheidet sich für Letztere und damit für ein tugendhaftes Leben, verteidigt siegreich die Stadt Theben und setzt sich erfolgreich gegen die Giganten zur Wehr, die aus der Unterwelt hervorgebrochen sind, um den Himmel zu stürmen, wofür ihn sein Vater Zeus zum Olympier ernennt. Bevor Herakles jedoch der Unsterblichkeit teilhaftig und Hebe seine Gemahlin wird, bekommt er von den Göttern mitgeteilt, dass er zuvor zwölf Aufgaben auf Erden erledigen müsse, eine Bedingung, die ihn zunächst schwermütig und dann durch den Einfluss Heras rasend macht. Er tötet seinen Neffen Jolaos, und als er wieder bei Sinnen ist, erfassen ihn ungeheurer Schmerz und Reue; er tritt die Aufgaben an und wird am Ende mit der ihm zugesagten Belohnung gewürdigt.

Bereits mithilfe dieser kurzen Zusammenfassung können zahlreiche Motive, Symbole und Handlungsstrukturen ausgemacht werden, die eine direkte Verbindung zu den Post-PotterTexten herstellen und die für deren Heldenkonzeption von großer Bedeutung sind. Bedenkt man, dass die Erzählung um Herakles nur einen einzigen Gottkindmythos darstellt, der nach jenen Strukturen aufgebaut ist, erstaunen die Gemeinsamkeiten umso mehr. Folgende Parallelen sind besonders augenscheinlich:

hauptsächlich als Erlöser-Kind-Mythos betrachtet. Seit dem Barock wurde der Aufstieg des Halbgottes auf den Olymp als Allegorie kosmologischer Macht, Kraft, Tugend und Weisheit verwendet, im Sinne eines absolutistischen Weltbildes, das den machtvollsten Einzelmenschen an die Spitze des Staates setzt. Vgl. dazu Alefeld (1996), S. $161 \mathrm{ff}$. 
1. Der Handlungsraum der Erzählung ist in zwei Sphären geteilt, die unterschiedlich beschaffen sind; das besondere Kind wird zum Grenzgänger zwischen den Welten, weil es beiden zugehörig ist.

Die logische bzw. semantische Teilung in zwei Sphären findet sich in allen Texten des Korpus wieder. Sie kann mit einer räumlichen Polarität, das heißt, einer binären Weltstruktur zusammenfallen - was als Spezialfall zu betrachten ist -, aber auch losgelöst davon zum Ausdruck kommen. ${ }^{158}$ So liegt dem Wirklichkeitsentwurf von Funkes Tintenwelt-Trilogie zwar prinzipiell eine multiple Weltstruktur zugrunde, sie lässt sich aber auch logisch in die Sphären Gewohnte Welt und Buchwelt(-en) einteilen, wobei Letztere auch als „andere Welt" (TH, S. 11) oder als „Labyrinth der Buchstaben“ (TH, S. 11) bezeichnet werden. Meggie steht in die Tradition des besonderen Kindes, indem sie die Grenze zur Tintenwelt passieren kann. Gleiches gilt für Gwendolyn in der Edelstein-Trilogie, Grenzgängerin zwischen den Zeitwelten. Analog dazu wechselt Percy in Riordans Romanen zwischen der Götterwelt und der der Normalsterblichen hin und her, und Bella in Meyers Werk überwindet die Grenze zwischen Vampir- und Menschenwelt. In Die Tribute von Panem können die Sphären von Privilegierten bzw. Reichen (TS, S. 65) und Armen, ,wo man gefahrlos verhungern kann“ (TS, S. 10), ausgemacht werden. Katniss wird in Letzterer groß, lernt aber im Laufe der Handlung immer besser die andere Sphäre kennen, indem sie als Siegerin der Hungerspiele den Luxus des Kapitols hautnah miterlebt.

2. Das besondere Kind leidet einen Mangel an Fürsorge, kennt seine leiblichen Eltern nicht oder ist als Halbwaise oder Vollwaise groß geworden.

Die meisten hier betrachteten Protagonisten sind Halbwaisen oder werden nur bei einem leiblichen Elternteil groß. Der Aufstieg von einer prekären in eine privilegierte Position kann auch als „Aschenputtelgeschichte“ identifiziert werden. ${ }^{159}$ Die Unkenntnis der leiblichen Eltern ist ein auffälliges Motiv der Texte: Percy Jackson, der 12 Jahre (PJ 1, S. 49) alt ist und „, ein Internat für Problemkinder“ (PJ 1, S. 10) besucht, berichtet zu Beginn des ersten Bandes, dass er seine Mutter, ,, die liebste Frau der Welt“ (PJ 1, S. 45), ,, seit Weihnachten nicht mehr gesehen “ (PJ 1, S. 18) habe. Er glaubt, dass sein Vater im Anschluss an eine Geschäfts-

\footnotetext{
${ }^{158}$ Siehe dazu auch Kapitel 3.3.2.1. Bei Artemis Fowl lässt sich dieser Spezialfall beobachten: Dort wird zwischen der Welt der Menschen und der Welt der Unterirdischen (AF 1, S. 16), des „Erdvolks “ (AF 1, S. 22) unterschieden. In diesem Fall liegt der Diegese eine binäre Weltstruktur zugrunde, die auch logisch in zwei Sphären geteilt ist.

${ }^{159}$ Bürvenich (2001), S. 184.
} 
reise ,, auf See geblieben“ und nie zurückgekommen ist (PJ 1, S. 41), er kann sich nicht einmal an ihn erinnern, nur noch an eine diffuse Wärme (PJ 1, S. 41). Sein Ziehvater Gabe lässt ihm nicht die nötige Fürsorge zuteilwerden, er trinkt, raucht, schlägt ihn und gibt sein Geld für Pokerrunden aus (PJ 1, S. 43). Das Rätsel um den leiblichen Vater bleibt zunächst ungelöst, selbst als Percy davon Kenntnis erhält, dass dieser wohl ein Gott ist, denn er weiß noch immer nicht, welche der möglichen Gottheiten ihn gezeugt hat (PJ 1, S. 117 ff.). Dass sein Vater Poseidon (PJ 1, S. 154) ist, kann dem Rezipienten hingegen lange vor Percy klar werden, denn entsprechende Hinweise sind eingestreut: Warum sonst sollte Percy Brunnen- und Toilettenwasser steuern können? (PJ 1, S. 19 f.; S. 113) Auch Gwendolyn (RR, S. 34) aus der Edelstein-Trilogie, Meggie aus der Tintenwelt-Trilogie (TH, S. 92) und Katniss (TS, S. 9) aus Die Tribute von Panem werden als Halbwaisen groß bzw. in dem Glauben, dass einer ihrer Elternteile verstorben ist.

3. Die Laufbahn des Kindes ist durch eine Prophezeiung oder seinen Auserwähltenstatus vorherbestimmt und stellt sich am Ende in diesem Sinne ein.

Die Prophezeiungsstruktur bzw. -logik ist grundlegend für jedwede mythische Diegese und wurde hier bereits an einigen Texten aufgezeigt. ${ }^{160}$ Liegt keine explizite Prophezeiung vor, wird die Geschichte durch den Auserwähltenstatus der Protagonisten plausibilisiert, den diese aus unterschiedlichen Gründen erlangen oder bereits erlangt haben. Als halbgott ist Percy von Beginn an, seit seiner Geburt und ohne sein Zutun, etwas Besonderes (PJ 1, S. 53). Anders ist es bei Katniss in Collins' Serie. Sie meldet sich freiwillig für die lebensgefährlichen Hungerspiele, um ihre Schwester Prim zu schützen, auf die die Wahl der Lostrommel gefallen war (TS, S. 27 f.). Katniss macht sich also durch ihre Anmeldung selbst zur Auserwählten, was seit Jahrzehnten im Distrikt 12 nicht mehr vorgekommen ist (TS, S. 28): „, Etwas hat sich verändert, seit ich vorgetreten bin und Prims Platz eingenommen habe, [...], jetzt sieht es so aus, als wäre ich auf einmal was Besonderes “ (TS, S. 30). Der Fortgang der gesamten Geschichte wird durch diese Szene vorstrukturiert: Katniss nimmt an den Hungerspielen teil, gewinnt sie (TS, S. 380 f.) und ist zudem letztendlich siegreich im Kampf gegen das Kapitol. Ihre Moralität führt nicht nur zu ihrem Überleben, also dem Sieg im Kleinen, sondern auch dem Sieg im Großen, indem sie zur Leitfigur, zum „Symbol der Revolution“ (GL, S. 426) erhoben wird (GL, S. 271), was ihren freiwilligen Auserwähltenstatus von außen legitimiert.

${ }^{160}$ Vgl. Kapitel 4.2.3.2. 
Auch die Handlung der Bis(s)-Serie motiviert sich aus dem vorgezeichneten Weg des Auserwählten: Bella spürt schon lange, dass sie „,anders“ ist. Sie fragt sich, ob sie mit ihren Augen das Gleiche sieht wie der Rest der Welt (BzMo, S. 15). Sie will von Edward gebissen und „ein Monster“ (BzMo, S. 195) werden, damit sie „auf eine messbare Weise“ zu ihm gehört (BzA, S. 324). Wie die anderen Heldenfiguren wird sie sogar zur Auserwählten unter Auserwählten: Harry hat unter den Zauberern und Gwendolyn unter den Zeitreisenden einen Sonderstatus inne, Bella sticht unter den Vampiren hervor, denn sie besitzt die Fähigkeit, einen Schutzschild heraufzubeschwören (BzEdN, S. 624), und bringt Renesmee - halb Mensch, halb Vampir - zur Welt, eine Ausnahme in der Diegese, denn: „,,Körperliche Verbindungen zwischen Menschen und Vampiren sind eher selten: [...] ,Noch seltener ist es, dass ein Mensch eine solche Liaison überlebt. "“ (vgl. BzEdN, S. 617)

4. Das Kind besitzt Fähigkeiten oder Begabungen, die über die eines gewöhnlichen Menschen weit hinausgehen.

Diese Begabungen müssen sich nicht in körperlicher Überlegenheit ausdrücken, sondern können auch moralische oder kognitive Fähigkeiten sein, die den Auserwähltenstatus der kindlichen Protagonisten legitimieren. ${ }^{161}$ Gwendolyn etwa kann nicht nur in der Zeit springen, sondern ist zudem unsterblich. In der Regel zeichnen sich die Protagonisten zudem durch überdurchschnittlichen Mut, große Willensstärke, ein starkes Moralempfinden und Selbstlosigkeit aus. So wird Meggies Besonderheit nicht nur dadurch betont, dass sie Figuren aus Büchern herauslesen kann (TH, S. 388 f.), sondern auch durch ihr gutes Herz und ihre überdurchschnittlich Fähigkeit, zu lieben (TH, S. 19). Ähnlich bei Percy Jackson, dem das Element Wasser hörig ist (z. B. PJ 1, S. 318 f.; PJ 2, S. 263) und dessen Treue gegenüber den Freunden ihm als seine größte Schwäche ausgelegt wird. Athene macht Percy darauf aufmerksam, dass seine Loyalität und Emotionalität für einen Heros problematisch sind: ,,,Dein fataler Fehler ist persönliche Treue, Percy. Um einen Freund zu retten, würdest du die Welt opfern. Und für einen Heros der Weissagung ist das sehr, sehr gefährlich. “ (PJ 3,S. 347).

5. Das besondere Kind muss seine Fähigkeiten zunächst schulen, es bekommt auf ihn und seine Begabungen zugeschnittenen Unterricht.

${ }^{161}$ Bei Artemis Fowl wird dieser Aspekt besonders deutlich: Er ist ein „,Wunderkind“ (AF 1, S. 7), ein „, Genie“ (AF 1, S. 7), das mit seinen zwölf Jahren überdurchschnittlich intelligent ist und über den ,, Wortschatz eines Erwachsenen “ (AF 1, S. 11) verfügt. Der Leser wird gleich zu Beginn des ersten Teils durch einen Erzählerkommentar von dieser außerordentlichen Begabung unterrichtet, die den Ausgangspunkt und das Gerüst der Serienhandlung vorstrukturiert: ,, Wenn es überhaupt jemanden gab, der in der Lage war, den Unterirdischen einen Teil ihres magischen Golds abzuluchsen, dann war des Artemis Fowl der Zweite“ (AF 1, S. 23). 
Die Ausbildung des Protagonisten erfolgt auf unterschiedliche Weisen. Oftmals übernehmen Schulen oder Ausbildungsstätten die Aufgabe, unter Umständen aber auch eine Mentorenoder Lehrerfigur ohne konkrete institutionelle Rahmung. Beides in Kombination kommt ebenfalls vor.

Bei Percy Jackson erfolgt die Ausbildung streng institutionalisiert am Camp Half-Blood (PJ 1, S. 75), wo Halbgötter trainiert werden (PJ 1, S. 116 f.), um sich gegen Monster in der wirklichen Welt verteidigen zu können (PJ 1, S. 140 f.). Es ist für die Halbgötter der ,einzig sichere Ort auf der Erde“ (PJ 1, S. 116). Die unterrichteten Fächer ergeben sich aus den Talenten der zwölf Götter des Olymps, welche ihre Begabungen - so die Textlogik (PJ 1, S. 144) - an ihre Kinder, die Camp-Mitglieder, vererben: Gelehrt werden Schmiedekunst (PJ 1, S. 132), die auf Hephaistos zurückgeht, Weinanbau (PJ 1, S. 132), der besonders den Kindern des Dionysos liegt, und Bogenschießen, in Anlehnung an Apoll (PJ 1, S. 132). Dazu Fächer, die für alle Helden und Götter sinnvoll erscheinen: Altgriechisch, Götterkunde und Laufen (PJ 1, S. 131), Ringen und Rudern (PJ 1, S. 132) sowie Schwertkampf (PJ 1, S. 133). Das Camp wird von „Mr. D.“ alias Dionysos und Chiron geleitet. Dionysos ist dem Alkohol sehr zugetan und verkörpert in der Diegese auch den Gott des Weines (PJ 1, S. 80), die Figur des Chiron kann in Verbindung gebracht werden mit dem Erzieher des Achill.

Etwas freier gestaltet sich die Ausbildung von Gwendolyn, die zu spät von ihrem Zeitreisegen erfährt und sich dadurch nicht der normalen Ausbildung einer Zeitreisenden unterziehen kann, die aus Fecht- und Mysterienunterricht, Geschichts- und Tanzstunden sowie Instrumentenunterricht besteht (RR, S. 254). Ziel der Ausbildung ist es, sich unbemerkt durch die Zeit zu bewegen, die Kultur, Gewohnheiten und gesellschaftlichen Regeln der verschiedenen vergangenen Jahrhunderte zu erlernen und dadurch das Kontinuum zu schützen (RR, S. 173). Gwendolyn wird zeitweilig von Mr. Giordano unterrichtet, der ihr in wenig Zeit das Notwendigste beibringen soll, so zum Beispiel das Menuetttanzen, damit sie auf Tanzbällen in der Vergangenheit nicht negativ auffällt (SB, S. 123).

In Die Tribute von Panem bekommen die Tribute jeweils einen Mentor bzw. Trainer zur Seite gestellt, welcher selbst einmal siegreich aus den Hungerspielen hervorgegangen ist und nun mit ihnen die Strategien des Wettkampfes erarbeiten soll (TS, S. 25, S. 65 f.). Haymitch, der Trainer von Katniss, rät vor allem zur Strategie der medienwirksamen Selbstinszenierung, die die Sympathien der Zuschauer sicherstellen und die Sponsoren dazu animieren soll, Distrikt $12 \mathrm{zu}$ unterstützen. Peeta und Katniss spielen daraufhin ein tragisches Liebespaar vor, ,die 
beiden Liebenden aus Distrikt 12, die nicht zusammenkommen können!" (TS, S. 153). Haymitch prophezeit, dass die Sponsoren Schlange stehen und die Zuschauer aus dem Kapitol bezaubert sein würden (TS, S. 155). Tatsächlich soll er recht damit behalten, dass die Inszenierung der ausschlaggebende Punkt sein wird, damit Peeta und Katniss überleben. Ihre Medienkompetenz bzw. Medienwirksamkeit wird sie von den anderen teilnehmenden Wettbewerbern unterscheiden.

6. Das besondere Kind steht stets im moralischen Konflikt und muss sich zwischen dem Guten und dem Bösen entscheiden, das heißt, für welche Seite es seine Fähigkeiten einsetzen wird. Trotz einiger Zweifel und Irrwege entscheidet es sich letztendlich für einen tugendhaften Lebensweg und setzt sich siegreich gegen das Böse, das doch zu Teilen in ihm steckt, durch.

Die besonderen Kinder müssen im Laufe der Geschichte unter Beweis stellen, dass sie nicht nur körperlichen Fähigkeiten besitzen, welche sie als Helden auszeichnen, sondern auch dass sie die psychischen, mentalen und moralischen Voraussetzungen dazu mitbringen. Moralische Prüfungen, bei denen sie sich klar auf der Seite des Guten positionieren müssen, verlangen in vielen Fällen mehr von ihnen ab als solche, in denen sie im Kampf zu brillieren haben. So müssen sie sich in bestimmten Situationen für das Gute, das moralisch richtige Verhalten, entscheiden, obwohl dieses für sie persönliche Opfer bedeutet. Sie ringen mit sich und ihren Prioritäten, denn Egoismus und Rachsucht sind ihnen nicht fremd, sie entscheiden sich nur immer wieder bewusst gegen solche Triebe: Suzanne Collins konstruiert im ersten Teil der Tribute von Panem ein Setting, in dem der Kampf ums Überleben, und zwar im Format jeder gegen jeden, zum Thema gemacht wird: „Über mehrere Wochen müssen hinweg müssen die Konkurrenten einander bis auf den Tod bekämpfen. [...] Der Tribut, der als letzter übrig bleibt, hat gewonnen. “ (TS, S. 24). Töten wird in diesem Gedankenexperiment nachvollziehund schwerlich verurteilbar, da die Tribute allein deswegen töten, um selbst zu überleben. Katniss jedoch, die im Laufe der Hungerspiele ein strategisches Bündnis mit der kleinen Rue eingeht, sorgt sich um ihre Verbündete und deren Leben, was sie moralisch auszeichnet: „, Und was ist mit Rue? Sie ist so klein. Es brauchte nicht viel Gift um sie zu töten. Andererseits... Sie hatte einen ordentlichen Vorsprung, die Jägerwespen hätten sie erst einmal einholen müssen “ (TS, S. 220). Und mehr noch: Als Rue tatsächlich vor Katniss in der Arena ums Leben kommt, singt sie für sie, um ihr das Sterben zu erleichtern (TS, S. 262 f.), bettet sie auf Blumen, um die Ausrichter der Hungerspiele zu beschämen (TS, S. 265), und beschließt für sich, die Hungerspiele zu gewinnen, um Rues Tod zu rächen (TS, S. 271). Auch Peeta hat 
Skrupel, das Leben eines Menschen auszulöschen. Und er entscheidet sich wie Katniss dafür, zunächst einmal das eigene Leben zu retten, bevor er das Leben der anderen schützt: „Nein, wenn die Zeit kommt, werde ich sicherlich töten wie die anderen auch. Ich kann nicht kampflos untergehen" (TS, S. 160).

In der Edelstein-Trilogie reist Gwendolyn extra in die Vergangenheit, um ihren Geisterfreund James gegen seinen Willen einen Impfstoff zu verabreichen, damit er später nicht erkranken und bis ans Ende der Zeit das Dasein eines Geistes fristen muss (SG, S. 438 ff.). Nicht nur dass diese Mission wertvolle Zeit kostet, sie ist auch in höchstem Maße unangenehm: James kann natürlich den Sinn nicht begreifen, weil er zum Zeitpunkt der Impfung Gwendolyn noch gar nicht kennt und die Situation als einen gefährlichen Überfall deutet (SG, S. 440). Gwendolyn nimmt zum Wohle ihres Freundes nicht nur Strapazen auf sich, sondern akzeptiert auch, dass sie James niemals wiedersehen wird, weil sein Dasein als Geist mit der Aktion beendet ist.

Ein häufig verwendetes Motiv, das das gute Herz des Helden unter Beweis stellt, ist zudem die Verschonung des Gegners bzw. die moralischen Bedenken des Helden, das Leben des Antagonisten auszulöschen, selbst wenn die Tötung die einzige sinnvolle Lösung darstellt. ${ }^{162}$ In den Tintenwelt-Trilogie findet sich das Motiv gleich mehrfach: So verschont Staubfinger Bastas Leben, als er ihn in seiner Gewalt hat - ein folgenschwerer Fehler, wie sich im zweiten Band herausstellen wird -, mit dem Kommentar: „Ach was, du hast recht, ich versteh nichts vom Töten [...] Und für dich werd ich es nicht lernen “ (TH, S. 483). Staubfingers moralische Bedenken siegen über den Hass, den er für Basta empfindet. Er lässt ihn gehen, obwohl er „Basta sterben sehen“ will, ein Gedanke, bei dem sich Staubfinger nicht wohlfühlt (TH, S. 552). Auch Meggie bringt die tötenden Worte gegen Capricorn, die Fenoglio sich zu diesem Zweck ausgedacht hatte, nicht über die Lippen, auch wenn sie damit den Sieg des Guten über das Böse herbeiführen kann (TH, S. 542). Mo muss für sie einspringen und den Mord auf sich nehmen.

Die Cullens in der Bis(s)-Serie wollen nach dem großen Kampf gegen Victoria und ihre Neugeborenenarmee die letzte übriggebliebene Antagonistin, Bree Tanner, verschonen. Dass die Volturi sie letztendlich doch töten, liegt nur an deren Boshaftigkeit (BzAb S. 570 f.).

\footnotetext{
${ }^{162}$ Bergenthal (2008), S. 175.
} 
7. Das besondere Kind hat einen Rivalen/eine Rivalin aus der Anderswelt, der/die Rache nehmen will für etwas aus der Vergangenheit, auf das es niemals Einfluss hatte; der Antagonist symbolisiert das Böse und macht dem Protagonisten das Leben schwer.

Die Rivalen der hier betrachteten Heldengeschichten stammen aus der Sphäre der Anderswelt und haben zumeist ein ungerechtes Rachemotiv, was den Hass auf den Protagonisten motiviert. Dieses erscheint insofern unfair, als die Begebenheit, auf der sich die Missgunst gründet, nicht oder zumindest nicht absichtlich im Verschulden der Protagonisten liegt. Besteht kein Rachemotiv, wird das Handeln des Antagonisten vor allem durch Habgier plausibel gemacht. Im ersten Teil von Percy Jackson sind es gleich zwei Antagonisten, die ein unfaires Rachemotiv antreibt: Zum einen geht Zeus davon aus, dass ihm sein Herrscherblitz (PJ 1, S. 164) von Percy, dem Sohn seines Bruders Poseidon, mit dem er schon lange im Streit steht (PJ 1, S. 167 f.), gestohlen wurde. Obgleich diese Annahme falsch ist, droht ein gewaltiger Krieg auszubrechen, wenn Percy den Blitz nicht ausfindig macht und bis zur Sommersonnenwende zurückbringt (PJ 1, S. 178). Gelingt ihm das nicht, wird Zeus Percy umbringen (PJ 1, S. 168). Auch Hades treibt ein ungerechtes Motiv an, den Halbgott zu ermorden: Er glaubt ebenfalls, dass Percy den Blitz gestohlen hat, zudem noch Hades' Helm (PJ 1, S. 370 f.). Folglich muss sich Percy gleich gegen die Mordlust zweier, mit Ares sogar dreier Götter durchsetzen, obwohl er natürlich nicht der Dieb der Artefakte ist. Zudem trägt Percy die Bürde, dass seine Geburt an sich ein Ärgernis für die Brüder seines Vaters darstellt, die sich darauf geeinigt hatten, keine Halbblute mehr in die Welt zu setzen: Er ist eine „Missetat“, „,das Ergebnis eines göttlichen Fehltritts“ (PJ 1, S. 400), was ihm die Missgunst von Zeus und Hades einbringt, ohne dass er auch nur im Geringsten Einfluss darauf nehmen könnte (PJ 1, S. 403).

Das Rachemotiv des Grafen von Saint Germain in der Edelstein-Trilogie ist gleichfalls als unfair anzusehen: Er will Gwendolyn töten, weil ihm dies Unsterblichkeit ermöglicht.

7. Der Held muss sich den Olymp bzw. das erstrebenswerte Ziel erst verdienen. Bewährungsproben lenken die Dramaturgie der Erzählung, indem sie die Belohnung des Helden hinauszögern. $^{163}$

Eine Belohnungs- bzw. Bewährungsstruktur ist evident bei allen Korpustexten. Diese Beobachtung deckt sich damit, dass Mythen nahezu ausschließlich auf finale Motivierungsstruk-

\footnotetext{
${ }^{163}$ Alefeld (1996), S. 165.
} 
turen zurückgreifen. Die Bewährungsproben, denen sich der Held zu stellen hat, müssen nicht so stringent strukturiert sein wie im Herakles-Mythos durch die Nummerierung der zwölf Aufgaben. Dennoch liegen sie in der Regel in einer geordneten Abfolge vor.

Die hier aufgezählten Motive stellen eine unmittelbare Verbindung zum Herakles-Mythos her. Darüber hinaus ließen sich problemlos weitere Elemente aufzeigen, die dem Archetyp des besonderen Kindes bzw. Gottkindes zuzuordnen sind. Der Ödipus-Mythos beispielsweise verhandelt gleich mehrere Motive, die in Harry Potter und seinen Nachfolgern von großer Bedeutung sind: Nicht nur dass Ödipus großes Unheil prophezeit wird, dem er sich in der Logik der Erzählung nicht entziehen kann (so auch bei Harry Potter und der EdelsteinTrilogie), er ist zudem in völliger Unwissenheit darüber, wer seine leiblichen Eltern sind, dasselbe gilt für die Protagonisten in Harry Potter, der Tintenwelt-Trilogie und Percy Jackson.

\subsubsection{Zwischenfazit}

Da die Texte des Korpus analog zu Harry Potter klar zur Mythoshaltigkeit tendieren, sind sie im Sinne der gegebenen Definition als zeitgenössische Mythen zu betrachten. Sie zeichnen sich durch ein umfangreiches Symbolsystem aus, das sich in den Repräsentanten Kausalität, Raum, Zeit, Figur und Gegenstand ausdrückt, die in einer mythischen Diegese zu Bedeutungsträgern transzendentaler, numinoser Mächte erhoben werden. Typisch für die mythischen Wirklichkeitsentwürfe sind personifizierte Räume, zyklische Zeitstrukturen, sprechende Namen und Gegenstände, die übermenschliche Kräfte, magische Fähigkeiten und Unsterblichkeit symbolisieren. Ferner evozieren sie ein Kontingenzproblem, das für mythische Kausalprinzipien konstitutiv ist. Harry Potter und seine Nachfolger weisen mythische Erzählstrukturen auf, indem ihre Handlungen finalen Motivierungsprinzipien unterworfen sind. Prophezeiungen, bedeutsame Träume, Weissagungen und Legenden sind in die Diegese eingebettet, in der sich die Zukunft nach Willen einer numinosen Macht einstellt.

Zudem zeugen alle hier betrachteten Texte von Mythenadaptionen, da sie explizite oder implizite Bezüge zu antiken literarischen Prätexten herstellen. Besonders häufig ist der Aufruf des Orpheus- und des Theseus-Mythos zu beobachten, aber auch Bezüge zu anderen Mythen sind erkennbar. Bei der Konzeption der Heldenfiguren ist vor allem der Vorbildcharakter von Gottkindmythen hervorzuheben, da hierzu auffällig viele Motive und Motivkonstellationen aufgerufen werden. Exemplarisch wurden Motive des Herakles-Mythos in Augenschein genommen und bei den Texten des Korpus nachgewiesen: Die kindlichen bzw. jugendlichen Protagonisten werden meist in prekären Verhältnissen groß, sind Halb- oder Vollwaisen und 
besitzen übermenschliche Fähigkeiten. Sie werden zunächst geschult, bevor sie sich dem Kampf gegen den Antagonisten stellen und zum Retter der Welt avancieren. Sie sind Auserwählte, und ihr Schicksal ist durch Prophezeiungen vorbestimmt. Die Entwicklung der Protagonisten ist mit Voglers Schema der Heldenreise in Verbindung zu bringen, das sich aus unterschiedlichen antiken mythischen Vorlagen speist.

\subsection{Zum funktionsorientierten Gattungsmodell des Mythos}

Ein zweiter Diskurs, der zeitgenössische Kinder- und Jugendliteratur als Mythen bespricht, nimmt vor allem die gesellschaftliche Funktion und Wirkung der Texte in den Blick. Obwohl beides mit literaturwissenschaftlichen Instrumentarien nicht adäquat zu ermitteln ist, da weder Funktion noch Wirkung am Text belegt werden können, wird hier dennoch zu diesen Ansätzen Stellung bezogen, da der Diskurs darum gleichwohl zur Gattungsdiskussion beiträgt, die im Zuge des Erfolgs der hier betrachteten Werke in Forschung und Öffentlichkeit entbrannt ist. Nach einer Einführung in die Idee eines funktionsorientierten Mythosbegriffs (Kapitel 4.3.1) werden nachfolgend Thesen zur neomythischen Grundfunktion zeitgenössischer Kinder- und Jugendliteratur vorgestellt, die aus Forschungsbeiträgen zum Thema zusammengetragen wurden. Unter Einbeziehung voriger Ergebnisse wird schließlich der Versuch unternommen, die Popularität der betrachteten Serien mit ihrer Ähnlichkeit zu antiken Mythen zu begründen (Kapitel 4.3.2).

\subsubsection{Zum funktionsorientierten Mythosbegriff}

Seit dem ausgehenden 20. Jahrhundert rücken ,zeitgenössische Mythen“ zunehmend in den Mittelpunkt von Laien- und Expertendiskursen, die vor allem durch Kriterien wie Popularität, Medienwirksamkeit und individuelle und kollektive Identitätsstiftung auszeichnen. In der Regel werden dabei nicht nur literarische Texte als Mythen aufgefasst, sondern sämtliche Kulturerzeugnisse, die durch die Medien bzw. eine von ihnen gesteuerte Rezeptionsweise zu Mythen erhoben und inszeniert werden, so auch multimediale Narrationen wie Berichterstattungen, die eine Weltdeutung zur Verfügung stellen ${ }^{164}$ und die Auseinandersetzung des Menschen mit seiner Sinn- und Schöpfungsordnung, seiner Weltsicht, sichtbar machen. ${ }^{165}$ Argumentiert wird, dass ein Mythos in diesem Sinne, ,die Transzendenzerwartungen unserer hochtechnokratischen Gesellschaft" befriedige. ${ }^{166}$ Mythische Narrationsstrukturen auf mo-

\footnotetext{
${ }^{164}$ Ebd.

165 Zöller (2000), S. 78.

${ }^{166}$ Cornelius (2003), S. 70.
} 
derne multimediale Massenkommunikate zu beziehen ist in der Film- und Fernsehwissenschaft seit vielen Jahren gängige Praxis. ${ }^{167}$ In jüngerer Zeit finden sich ähnliche Überlegungen auch in der Kinder- und Jugendbuchforschung, und zwar insbesondere in Bezug auf Rowlings Serie: ${ }^{168}$

Die Harry Potter- bzw. die Herr der Ringe-Welten stellen einen nicht mehr wegzudenkenden Bestandteil heutiger Jugend- und Erwachsenenkultur dar und haben die durch die postmoderne Philosophie totgesagten narrativen „Großerzählungen“ im 21. Jahrhundert zur neuer Blüte gebracht - allerdings in Gestalt von artifiziellen Mythen. Fantasy-Geschichten wie Harry Potter und Herr der Ringe werden als Projektionsfläche jugendlicher Sehnsüchte wichtig und sind Teil jugendlicher Kontingenzbewältigung. ${ }^{169}$

Aber nicht nur bezüglich der Funktion, sondern auch der Wirkung wurden Parallelen zwischen Rowlings Werk und antiken Mythen gezogen. Gängig ist dabei vor allem der Hinweis auf multimediale Distribution. ${ }^{170}$ Das Phänomen, dass literarische Werke auf Grundlage ihrer Popularität, multimedialen Wirksamkeit und Anschlussfähigkeit als Mythen inszeniert bzw. als solche wahrgenommen werden, findet sich bereits seit Längerem in der Geschichte des literarischen Marktes und kann daher auch nicht als ein erst durch Harry Potter initiiertes Novum betrachtet werden. Zahlreiche frühere Titel, insbesondere Serien, sind da zu nennen, die ebenso als Mythen anzusehen sind, zum Beispiel Herr der Ringe, Star Wars oder Mickey Mouse. ${ }^{171}$

\subsubsection{Zur Popularität zeitgenössischer Mythen}

Sowohl auf inhaltlicher als auch auf formaler Ebene sind zahlreiche Parallelen zwischen klassischen Mythen und zeitgenössischen Kinder- und Jugendbüchern beobachbar. ${ }^{172}$ Da die Wirkung und Funktion eines Textes nicht mithilfe literaturwissenschaftlicher Instrumentarien zu bestimmen sind, mögen die folgenden Thesen als Interpretationsangebote verstanden werden. Um die hier betrachteten Texte als zeitgenössische Mythen ansehen zu können, sollen folgende Aspekte herangezogen werden, welche die Popularität der Werke vor dem Hintergrund ihrer Mythoshaltigkeit erklären:

\footnotetext{
${ }^{167}$ Vgl. Bleicher (1999), S. 15-28, Vogler (1999), S. 9-34, Schneider (2001), S. 47-134; Schmitz (1995), S. 117.

${ }^{168}$ Siehe zum Beispiel Ewers (2006), S. 297-312; O’Sullivan (1997), S. 86-104.

${ }^{169}$ Dinter (2010), S. 41.

${ }^{170}$ Siehe dazu u. a. Bergenthal (2008), S. 422 und S. 375 ff. und Ewers (2006), S. 297-312. Mythen sind genau wie zeitgenössische literarische Medienverbünde nicht an ein Medium wie das Buch gebunden, sondern wurden und werden in verschiedenen Medien dargeboten.

${ }^{171}$ In Bezug auf diese Medienverbünde liegen literaturwissenschaftliche Untersuchungen vor, die sich mit der Mythoshaltigkeit und der mythischen Funktion der Texte auseinandersetzen. Siehe dazu beispielsweise Deyneka (2012), S. 31-46 und Magdanz (2012), insbesondere S. 96 f.

172 Die Parallelen wären auf ähnliche Weise zwischen Mythos und Fernsehen oder Mythos und Film aufzeigbar.
} 
- Wie herausgearbeitet, operieren sowohl Mythen als auch die hier betrachteten zeitgenössischen Werke mit Symbolsystemen. Symbole werden im Erzählzusammenhang zu Trägern übergeordneter Bedeutung, sie markieren, dass nichts in der Welt bedeutungslos ist und alles miteinander in Zusammenhang steht, und sie schaffen Orientierung. Handlungen beschreiben stets die Modellhaftigkeit der erzählten Ereignisfolgen, die vom Personensymbol ausgeführt werden, dessen Charaktereigenschaften wiederum zum positiven oder negativen Exempel erhoben werden. ${ }^{173}$

- Beide Textkorpora enden positiv, genauer: mit einem Ausblick in eine angenehme Zukunft, mit dem Sieg des Guten über das Böse. ${ }^{174}$ Die Rezipienten finden daher meist aus christlichen Kontexten stammende moralische Grundsätze bestätigt, ebenso ihr Moral- und Werteempfinden, das auf einem positiven Selbstbild basiert, sodass die Lektüre mit einer positiven Erfahrung einhergeht, zumal das bestehende Moralsystem keiner Überarbeitung bedarf.

- Auf formaler Ebene können in beiden Textkorpora additive Strukturen ausgemacht werden. Beide arbeiten mit aufeinanderfolgenden Einzelnarrationen: Ependichtung in Form der Abfolge der einzelnen mythischen Erzählungen, Serien durch aufeinander aufbauende Einzelbände. ${ }^{175}$ In beiden Fällen kommt der visuellen Darstellungsebene eine besondere Bedeutung zu.

- Sowohl antike Mythen als auch die hier betrachteten Werke sind als medienübergreifende Narrationen zu begreifen, da sie nicht an ein spezifisches Medium gebunden sind. ${ }^{176}$

- Beide erfüllen kollektive Funktionen, indem sie auf einen Austausch zwischen den Rezipienten abheben, eine Art soziales Gedächtnis bereitstellen und Werte vermitteln. ${ }^{177}$ Den Anlass zur Anschlusskommunikation bieten beide vor allem in Bezug auf die Kategorie „wahr oder falsch“, die sich für als Beurteilungsschema nach erfolgter Rezeption in beiden Fällen nahezu aufdrängt: ${ }^{178}$ Die Zuhörer von Mythen und Epen pflegten bei jeder Erzählung zu prüfen, ob der Stoff sinngemäß wiedergeben wird, den sie bereits aus anderen ähnlichen Erzählungen kannten. Ähnliches passiert beim betrachteten Korpus, zum einen bezüglich der verschiedenen medialen Versionen der literarischen Idee, zum anderen der Verwendung von Stoffen und Motiven, die eine lange literaturgeschichtliche Tradition aufweisen und deren realisierte Neuinterpretation mit der Erfahrung der Rezipienten in Abgleich gebracht wird.

- Beide thematisieren zentrale menschliche Erfahrungen wie Liebe, Krankheit und Tod, aber auch öffentliche Aspekte des gesellschaftlichen Wandels wie Politik und Autoritätsstrukturen, die Stellung des Individuums, Medienkultur und soziale Interaktion. ${ }^{179}$ Diese universellen Themen sind vor dem Hintergrund eines multikulturellen Rezipien-

\footnotetext{
${ }^{173}$ Bleicher (1999), S. 20.

${ }^{174}$ Siehe dazu auch Kapitel 5.3.2.1.

${ }^{175} \mathrm{Zu}$ den Serialitätsstrukturen der Post-Potter-Texte siehe auch Kapitel 2.2.3.

${ }^{176}$ Es handelt sich hierbei um literarische Medienverbünde, in denen eine literarische Idee in verschiedenen medialen Varianten zur Verfügung gestellt wird. Vgl. auch Frederking/Josting (2005), S. 7.

${ }^{177}$ Ebd.

${ }^{178}$ Ewers (2006), S. 300.

${ }^{179}$ Bleicher (1999), S. 21.
} 
tenkreises sinnvoll und bilden den Ausgangspunkt für eine ,globale Kodierung “ bzw. die Tradierung einer ,,globalen Populärkultur “"180.

- Beide Textkorpora zeichnen sich durch intendierte Mehrfachrezeption aus. ${ }^{181}$ Dies ist vor allem deswegen der Fall, da beide als Dichtungen „extensiver Totalität“ zu betrachten sind, das heißt, als Narrationen mit großer Komplexität. Begleitliteratur, Lexika und Sachtexte zu den zeitgenössischen literarischen Verbundsystemen erinnern funktional an Sagenlexika und Sagenlehren, indem beide dazu dienen, die Komplexität für den Rezipienten überschaubar zu machen. Totalität entwickeln beide Narrationen mithilfe großer Figurenensembles und einer Vielzahl von Handlungssträngen, die sich um die zentrale Heldenfigur ranken. ${ }^{182}$

\subsection{Resümee}

Sowohl Rowlings Serie als auch die Texte des Korpus können vor dem Hintergrund obigen Modells als moderne Mythen aufgefasst werden. Als gattungskonstitutive Eigenschaften haben zu gelten, dass alle eine mythische Diegese auszeichnet, dass sie mythischen Erzählstrukturen folgen und allgemein zur Mythenadaption tendieren, indem sie auf Motive und Motivkonstellation antiker mythischer Vorbilder zurückgreifen. Insbesondere die Konzeption der Protagonisten kann auf mythische Schemata zurückgeführt werden, die ihren Ursprung vor allem in antiken Gottkindmythen haben.

Zudem existieren formale Parallelen zwischen den Prätexten und den hier betrachteten Serien, die eine analoge mythische Lesart beider nahelegen: Als additive Erzählungen im Medienverbund sind beide als Erzählungen extensiver Totalität zu begreifen, die sich durch intendierte Mehrfachrezeption auszeichnen. Sie bieten Anlass zur Anschlusskommunikation und bestätigen etablierte Moral- und Wertevorstellungen, indem sie die Geschichte „Das Gute siegt über das Böse“ immer wieder neu erzählen. Die These, dass zeitgenössische Texte analog zu antiken Vorbildern eine sinnstiftende gesellschaftliche Funktion einnehmen, indem sie beispielsweise zur Kontingenzbewältigung beitragen und transzendentale Bedürfnisse befriedigen, kann mit literaturwissenschaftlichen Mitteln nicht hinreichend belegt werden.

\footnotetext{
${ }^{180}$ Schlachter (2014), S. 3 und Karg/Mende (2010). Siehe dazu auch Kapitel 6.4.

${ }^{181}$ Ewers (2006), S. 298.

${ }^{182}$ Ewers (2006), S. $302 \mathrm{ff}$.
} 


\section{Die Post-Potter-Texte als postmoderne Literatur}

Die Zuweisung von Harry Potter zur postmodernen Literatur ist gängig, ${ }^{1}$ sie soll hier zum Anlass genommen werden, auch die Texte des Korpus auf eine solche Einordnung hin zu untersuchen. Die Klassifikation basiert entweder auf dem Zeitpunkt der Publikation - Harry Potter entstand zu einer Zeit, die in der Literaturgeschichte als Postmoderne bezeichnet wird - oder aber, das ist der häufigere Fall, es wird auf Texteigenschaften verwiesen, die mit postmodernen Texten assoziiert werden. ${ }^{2}$ In diesem Fall bezeichnet die Gattung eine Stilepoche, ein Text wird einem solchen Verständnis zufolge aufgrund seiner Stilistik der Postmoderne zugeordnet.

Postmoderne Literatur meint meist literarische Texte, die je nach Klassifizierungsschema nach den 50er- oder 60er-, oft auch nach den 80er-Jahren des 20. Jahrhunderts erschienen sind. Oftmals wird die Bezeichnung aber auch einfach auf zeitgenössische Texte bzw. die Literatur des kybernetischen Zeitalters oder der Gegenwart angewendet. ${ }^{3}$ Postmoderne Literatur nutzt narrative Modelle der Moderne, um sie zu innovieren und mit ihnen zu spielen, dazu gehört auch das Sprengen konventioneller Genre- und Gattungsgrenzen und die Adressierung an unterschiedliche Alters- und Personengruppen. Der Leser wird dabei nicht mit Welterklärungen befriedigt, sondern muss sie aktiv aus den „Spielvorschlägen“, Spiegelungen, Anspielungen, der Zeichensprache und den narrativen Schemata konstruieren. ${ }^{4}$ Die Werke haben eine kollektive und eine individuelle Komponente, indem sie intertextuell sind und damit auf ein Gruppenbewusstsein hindeuten und sich gleichzeitig durch Alleinstellungsmerkmale von der Masse abzuheben versuchen. ${ }^{5}$

Postmoderne Texte behandeln als Kritik an einer Moderne, die sich durch die Suche nach der tieferen Bedeutung eines jeden Dinges auszeichnet, die Oberfläche, das Hedonistische, Chao-

\footnotetext{
${ }^{1}$ Beispielsweise durch Just (2006); Lundt (2011); Schlachter (2013) und Schlachter (2014).

${ }^{2}$ Wobei es bei der genaueren Datierung der Postmoderne in der Forschung selbstverständlich unterschiedliche Auffassungen gibt. Oft sieht eine zeitliche Einordnung die Jahre 1959 oder 1969 (sie sollen das Aufkommen der Popkultur in Amerika markieren) bis zur Gegenwart vor, inhaltlich wird meist die Kritik am Vernunftprojekt der Moderne hervorgehoben, so zum Beispiel bei Baldick (2008), S. 175 und Gross (1998), S. 382; beide machen aber auch darauf aufmerksam, dass eine konkrete zeitliche Einordnung oder Definition des Begriffes große Schwierigkeiten bereitet.

${ }^{3}$ Zum Beispiel Picandet (2011), S. $131 \mathrm{f}$.

${ }^{4}$ Ortheil (1990), S. 107.

${ }^{5}$ Vgl. Durzak (1994), S. 815.
} 
tische, gerne auch den Prunk und unnützen Überfluss. ${ }^{6}$ Hieraus legitimiert sich der narzisstische Grundtonus: Der Autor und seine Selbstinszenierung werden selbst Teil des Kunstwerks. Politische, religiöse und philosophische Themen verlieren an Bedeutung, stattdessen gewinnen Entertainment und oberflächliche Ästhetik. Postmoderner Literatur wird daher des Öfteren Inhaltsleere vorgeworfen: Zugunsten von formaler Präzision und Innovation würden das Thema, der Inhalt und die literarische Aussage hintangestellt, es fehle Leidenschaft und Tiefe. ${ }^{7}$

Die Vorstellung, was postmoderne Literatur ausmacht, ist besonders stark von subjektiven und kulturellen Kontexten abhängig, die Grenzen zu anderen Stilepochen sind fließend. Es verwundert daher nicht, dass sehr unterschiedliche Texteigenschaften als gattungskonstitutiv erachtet und bei der Argumentation herangezogen werden. ${ }^{8}$ Weist man einen Text der Postmoderne zu, so geschieht dies stets modellimmanent. Es ist als eine Interpretation zu betrachten, die indes auf objektiven Texteigenschaften beruht, welche dann vor dem Hintergrund eines bestimmten Gattungsmodells interpretiert werden.

Diese Arbeit legt ein Modell zugrunde, das insbesondere diejenigen Eigenschaften, Motive und Schemata bei zeitgenössischen Texten als gattungskonstitutiv für die Postmoderne erachtet, die auf das Innovieren und Sprengen institutionalisierter Genre(-vorstellungen) hindeuten. ${ }^{9}$ Postmoderne Texte tendieren demnach $\mathrm{zu}$

- intertextuellen Bezügen und Querverweisen, insbesondere zu anderen Texten der Postmoderne

- einer kritischen Hinterfragung der kulturellen Funktion von Literatur in zeitgenössischen Medienkontexten

- dem Entwurf moderner Identität vor dem Hintergrund eines gegenwärtigen Menschenbildes

- der Reflexion zeitgenössischer Medien

- Bricolage und Motivneuinterpretation

- parodistischen und ironischen Untertönen

- Sprachspielen jeglicher Art

- der Sprengung von konventionalisierten Gattungs- und Genregrenzen (bzw. zum Pastiche $^{10}$ )

\footnotetext{
${ }^{6}$ Just (2006), S. 57.

${ }^{7}$ Vgl. Durzak (1994), S. 815.

${ }^{8}$ Vgl. Wagner (2007), S. 153.

${ }^{9}$ Eine solche Vorstellung der Postmoderne findet sich mehrfach in der Sekundärliteratur. Der Katalog wurde auf Grundlage von Just (2006), S. 55-66, Blume (2005). S. 65-114; Wagner (2007), S. 121-198; Lützeler (1991), S. 13 f. und Schlachter (2014) zusammengestellt. Postmoderne wird oftmals auch als Mischgattung aufgefasst. Vgl. Baßler (2010), S. 53.

${ }^{10}$ Der Begriff meint die Tendenz zur Hybridisierung, Rekombination und Reintegration, das heißt, er betitelt das
} 
- Mehrfachadressierung und Polyvalenz ${ }^{11}$

Zwei Punkte des Katalogs erweisen sich als besonders erkenntnisfördernd in Bezug auf die hier diskutierten Texte: das Sprengen von Genregrenzen und das Prinzip der Motivneutinterpretation. Diese sollen im Folgenden im Zentrum der Betrachtungen stehen. Zudem wird ebenso das Phänomen Intertextualität zum Thema gemacht, das gleich auf unterschiedliche Weise für die betrachteten Texte relevant ist. In Kapitel 6, welches sich mit der Adressierung der Korpustexte befasst, werden daneben noch weitere Aspekte Beachtung finden, u. a. intertextuelle Bezugnahmen zu anderen Werken zeitgenössischer Populärkultur, der Entwurf moderner Identitäten sowie Mehrfachadressierung und Polyvalenz als Strategien der Post-Potter-Texte. Auch wenn die in Kapitel 6 aufgeführten Aspekte nicht mehr explizit als postmoderne Verfahren markiert sind, können sie sehr wohl mit der Epoche der Postmoderne in Verbindung gebracht werden. ${ }^{12}$

Kapitel 5 geht daher aufgrund dieser Überlegungen folgendermaßen vor: Unterkapitel 5.1 liefert einen Forschungsüberblick über den Diskurs, der Harry Potter als postmoderne Literatur bespricht. Darauf folgt eine theoretische Einführung in das Prinzip der Intertextualität (Kapitel 5.2). ${ }^{13}$ Anschließend stehen die Texte des Korpus im Mittelpunkt: Kapitel 5.3 behandelt das hier vermehrt beobachtbare Sprengen von Genregrenzen, Kapitel 5.4 betrachtet die Tendenz zur Motivneuinterpretation anhand ausgewählter Beispiele. Kapitel 5.5 diskutiert abschließend, inwiefern Harry Potter und seine Nachfolger als postmoderne Texte aufgefasst werden können. ${ }^{14}$

Sprengen von Begriffen und Differenzierungsbestrebungen. Vgl. Vester (1993), S. 29.

${ }^{11}$ Siehe dazu Kapitel 6.

${ }^{12}$ Es sei angemerkt: Durch die Fokussierung auf lediglich zwei Aspekte des oben vorgestellten Katalogs wird im Folgenden keine umfassende Gattungsdiskussion in Bezug auf die Postmoderne erfolgen. Es können lediglich Eigenschaften der Texte benannt werden, die als gattungsweisend für die Postmoderne interpretiert werden können. An dieser Stelle wäre es auch möglich gewesen, dem Sprengen von Genregrenzen ein eigenes Gattungsmodell zu widmen und auf andere oben aufgeführten Aspekte gänzlich zu verzichten. Da in dieser Arbeit aber gerade eine gattungsbetreffende Einordnung und damit auch ein kontextueller Interpretationsvorschlag der betrachten Texte angestrebt werden, wurde diese Variante nicht verfolgt.

${ }^{13}$ Die Einführung ist auch für Kapitel 6.4.4.1 („Die Post-Potter-Texte als populärkulturelles Gewebe“) relevant.

${ }^{14}$ Weitere, für die Stilepoche der Postmoderne relevante Aspekte werden unter einem anderen Fokus in Kapitel 6 (Adressatenliteratur) thematisiert, nämlich Multiadressierung, Etablierung und Tradierung populärkultureller Gewebe sowie Reflexion moderner Identitäten im Zuge digitaler Medien. 


\subsection{Zu Harry Potter als postmoderner Literatur}

Aufgrund von Entstehungszeit sowie auch der Stilistik kann Rowlings Serie der Gattung Postmoderne zugeordnet werden. Just hat folgende Beobachtungen gemacht, die diese Klassifikation nach obigem Verständnis von Postmoderne rechtfertigen: ${ }^{15}$

- Rowlings Texte sind geprägt von Bricolage bzw. der Neuinterpretation literaturgeschichtlich etablierter Motive und Figuren, wie sie sich beispielsweise ursprünglich in der Tolkien- oder auch Mittelaltertradition bewegen. Vor allem durch ihren Bezug zur zeitgenössischen Lebens- und Erfahrungswirklichkeit können sie als postmodern interpretiert werden. Verweise auf literarische Traditionen und Vorläufer sind teilweise deutlich markiert, in den meisten Fällen jedoch nur implizit, ${ }^{16}$ sodass der Rezipient auf sein Vorwissen angewiesen ist, um intertextuelle Bezüge identifizieren zu können. ${ }^{17}$

- Parodistische und ironische Untertöne tragen zum Unterhaltungscharakter des Werkes bei, indem etwa mit den Erwartungshaltungen der Rezipienten gespielt wird. So wird die stereotype Mentorenfigur Dumbledore immer wieder mit inkongruenten Elementen versehen und persifliert, beispielsweise indem die Passwörter für seine Räume Namen von Süßigkeiten tragen, was ihm kindliche und hedonistische Attribute verleiht. Damit verweigert sich Rowling der konsequenten Traditionsübernahme und geht stattdessen kreativ mit dem literaturhistorischen Stoff um, auf den die DumbledoreFigur verweist. Rowling nutzt die phantastische Welt als Projektionsfläche, um vielerlei gesellschaftliche Felder zu reflektieren und ironisch aufzuarbeiten: sei es durch die Karikatur des englischen Durchschnittsbürgers, die durch die Darstellung der Familie Dursley realisiert wird, oder die humoristische Behandlung der Themen Politik, Bildung, Sozialisation, Presse, Medien allgemein, Sport und Kultur, Freundschaft, Liebe und Hass - man denke man nur an die Abhandlungen über das Zaubereiministerium, der Schulleitung von Hogwarts, den Tagespropheten (und die Figur Rita Kimmkorns), Quidditch, Zaubererschach sowie alle komödiantischen Überzeichnungen von Figuren und zwischenmenschlichen Beziehungen. ${ }^{18}$ Besonders hervorzuheben ist die Behandlung der Themen Starkult, Sportbegeisterung und Medienmacht, die - übliche Praxis der Postmoderne - moderne Inhalte in einer altmodischen „Verpackung“ präsentieren und damit eine in die Vergangenheit gerichtete Nostalgie mit dem Wunsch nach Innovation und neuester Technik miteinander versöhnen. ${ }^{19}$

- In ihren intertextuellen Anspielungen bedient sich die Autorin aus einem reichen Fundus der Literaturgeschichte, zum Beispiel aus Sagen, Märchen und Legenden. Die einzelnen Elemente werden von ihr weder explizit zitiert noch wird von der Erzählinstanz oder im Paratext direkt Bezug zu den Prätexten hergestellt. Die Verbindung muss also allein vom Leser kreiert werden, der (so Justs These) die Rekonstruktion genießt, da

\footnotetext{
${ }^{15}$ Vgl. Just (2006), S. 59-70, etwaige Ergänzungen sind entsprechend gekennzeichnet.

${ }^{16}$ Bei einer impliziten Markierung wird die Textreferenz nicht im inneren Kommunikationssystem des Textes thematisiert. Siehe Kapitel 5.2.2.

${ }^{17}$ Die wissenschaftliche Aufarbeitung literarischer Figuren und Motive in Rowlings Texten ist umfangreich und kann hier nicht zur Gänze abgebildet werden. Siehe beispielsweise Ehgartner (2006); Köhler (2004); Joannidis/Weppler (2014), Burkhardt (2012).

18 Zur parodistischen und karikaturartigen Schreibweise Rowlings siehe auch Cornelius (2003), S. 85 f. Zur Behandlung multikulturell anschlussfähiger Themen siehe Karg/Mende (2010).

${ }^{19}$ Blake (2002), S. 17 und Petzold (2004), S. 87.
} 
sie ihm eine aktive Leserolle zuweist. Doch auch wer die Verweise nicht zu decodieren weiß, kann Freude an Rowlings Texte finden, die, trotz ihrer Dichte, offen für fantasievolle Deutungen und Sinnzumessungen sind.

- Harry Potter tendiert zum Genremix. Die Übergänge zwischen den eingebundenen literarischen Gattungen sind dabei für den Rezipienten kaum wahrnehmbar. Der Text wirkt trotz seiner komplexen Rezeptur organisch und kohärent. ${ }^{20}$ Silvia Lafontaine versuchte mithilfe einer empirischen Studie nachzuweisen, dass insbesondere der Aufgriff und die Verschmelzung unterschiedlicher Genres und Genreschemata als eine Komponente des Welterfolgs der Serie zu betrachten sind. ${ }^{21}$ Welche Genreschemata eingebunden sind, wurde im Forschungsdiskurs auf unterschiedliche Weise beantwortet. $^{22}$ Eine umfangreiche Analyse hat Ursula Bergenthal vorgelegt, die zu folgendem Ergebnis gekommen ist: die School Story ${ }^{23}$ (auch Internatsgeschichte ${ }^{24}$ oder Internatsroman $^{25}$ genannt), der Abenteuerroman, der Adoleszenzroman (bei Cornelius Entwicklungsroman $^{26}$ genannt), der Mythos, der Liebesroman, der Kriminalroman (bzw. Thriller oder Detektivroman ${ }^{27}$ ), das Märchen, ${ }^{28}$ die Fantasy-Literatur und der Schauerroman; sie alle lieferten mit unterschiedlicher Gewichtung ihren Beitrag zur Serie. ${ }^{29}$ Durch den gezielten Einsatz der Genres wecke Rowling Erwartungen beim Rezipienten, die den konstruktiven Lektüreprozess lenken würden. Die jeweiligen Genrevorgaben - übernommen oder bewusst variiert - nutze sie dabei zur Motivation der Haupthandlung bzw. einzelner Episoden und auch zur Konzeption von Räumen und Kulissen. Andererseits begünstige der Genremix die multimediale Distribution der Romanserie und liefere Anknüpfungspunkte für Merchandisingprodukte. ${ }^{30}$ Die Figur Harry Potter werde als psychologisierter, moderner Held und damit als perfekte Identifikationsfigur gezeichnet. ${ }^{31}$

Die ausladende Verwendung von Wortspielen, Neologismen, sprechenden Namen und überraschenden Wortkombinationen wird insbesondere auch dafür benutzt, die Zaubererwelt von der gewohnten Welt abzuheben bzw. sprachlich zu manifestieren. Damit liefert sie eine Art „Expertenvokabular“, dessen Anwendung „Eingeweihte“, sprich Harry-Potter-Kenner, von „Unwissenden“ unterscheidet und in der Fan-Kommunikation eingefleischte Fans auszeichnet, die ihr Wissen um die Zaubererwelt zu perfektionieren suchen, während Durchschnittsrezipienten den Erwerb so vieler Wissensbestände über die Texte nicht anstreben.

\footnotetext{
${ }^{20}$ Vgl. Maar (2002), S. 29.

${ }^{21}$ Lafontaine (2009), S. 100-102.

${ }^{22}$ Siehe u. a. Bergenthal (2008), Bürvenich (2001), S. 157-170; Just (2006).

${ }^{23}$ Auch belegt bei Karg/Mende (2010), S. 184.

${ }^{24}$ Elstner (2004), S. 6.

${ }^{25}$ Cornelius (2003), S. 20.

${ }^{26}$ Ebd., S. 19.

${ }^{27}$ Ebd., S. 20.

${ }^{28}$ Ebd., S. 17.

${ }^{29}$ Vgl. Kapitel 4 in Bergenthal (2008), S. 105-110. Auf eine konkretere Analyse von Harry Potter vor dem Hintergrund eines Genremixmodells wird im Folgenden verzichtet. Bergenthal hat dies in ihrer Dissertationen bereits mehr als zufriedenstellend behandelt.

${ }^{30}$ Ebd., S. 113-116.

${ }^{31}$ Bürvenich (2001), S. 184.
} 


\subsection{Zur Intertextualität}

Nahezu alle Werke des betrachteten Korpus zeugen von expliziter oder impliziter Intertextualität. Im Rahmen dieses Forschungsvorhabens wird Folgendes darunter verstanden:

Intertextualität meint die bewusste Bezugnahme auf konkrete andere, real existente literarische Primärtexte sowie auf „,tradierte und im kulturellen Gedächtnis gespeicherte Stoffe “, Inhalte, Formen und Texte wie Sagen, Mythen oder Märchen. ${ }^{32}$ Der aufgerufene Text wird hier als Prätext, der aufrufende als Folge- oder Posttext bezeichnet.

Es folgt eine kurze Einführung zu den Funktionen (Kapitel 5.2.1) und Arten (Kapitel 5.2.2) von Intertextualität.

\subsubsection{Zu den Funktionen von Intertextualität}

Neben primären oder auch poetischen Funktionen - oft wird argumentiert, dass die intertextuelle Relation zur Konstruktion der Textwelten beiträgt und den thematisierten Sinngehalt entweder bestätigt oder radikal dekonstruiert und damit Interpretationsangebote liefert ${ }^{33}-$ besitzt $^{3}$ Intertextualität auch sekundäre, kulturelle bzw. kulturhistorische Funktionen, die gerade in der Kinder- und Jugendliteratur von besonderer Bedeutung zu sein scheinen. Zum einen wird auf das kulturelle Gedächtnis einer Gesellschaft zurückgegriffen und das identitätsstiftende Moment derselben betont, zum anderen werden gesellschaftliche Diskurse aufgerufen, ohne deren Inhalte dezidiert abbilden zu müssen. ${ }^{34}$ Zudem kann mittels Intertextualität einem literarischen Vorbild Ehrerbietung entgegengebracht werden - oder ein Verweis etabliert einen Prätext erst als Vorbild, bekräftigt eine in den Hintergrund geratene literaturhistorische Tradition oder bringt sie neu auf den Weg. Intertextualität kann als selbstreferenzielle Reflexion, als Hommage an die Literatur, das Lesen und das Narrativ im Allgemeinen verstanden werden und dem Autor des Posttextes zu einem bibliophilen, belesenen und versierten Image verhelfen. ${ }^{35}$ Aus didaktischer Perspektive bieten die Verweise viele Lernchancen, und zwar sowohl in inhaltlicher und literaturhistorischer als auch rezeptionsästhetischer und formaler Hinsicht,

\footnotetext{
${ }^{32}$ Die Einschränkung auf die Bezugnahme zu literarischen Texten geht u. a. auf Stierle (1984) und Lachmann (1984) zurück und steht im Gegensatz zu Kristeva (1972), die einen sehr weiten Textbegriff postuliert. Dass die Bezugnahme bewusst erfolgt, geht auf Broich (1985), S. 31 zurück. Die Einschränkung auf real existente Primärtexte ist angelehnt an Heber (2010), S. 19.

${ }^{33}$ Vgl. Plett (1985), S. 90, Stocker (1998), S. 119 f. und Buß (2005), S. 52.

${ }^{34}$ Vgl. Lachmann/Schahadat (1995), S. 680.

${ }^{35}$ Helbig (1995), S. 181.
} 
zumal das Nichtidentifizieren unmittelbar mit Problemen im Textfluss oder einem erschwerten Textverstehen sanktioniert wird, wodurch Lernanreize geschaffen werden können. ${ }^{36}$

\subsubsection{Zu den verschiedenen Arten von Intertextualität}

Die Klassifizierung intertextueller Bezugnahmen kann aus unterschiedlicher Perspektive und auf unterschiedlichen Ebenen vorgenommen werden. Als Arbeitsdefinition bietet sich die Unterscheidung von zwei Typen an, eine Grobkategorisierung, die auf Broich und Pfister zurückgeht und die Beschaffenheit des Prätextes fokussiert: Liegt ein konkreter Text-TextBezug, ein Bezug zu einem identifizierbaren Prätext, vor, so bezeichnen Broich und Pfister diesen Aufruf als Einzeltextreferenz. Der Bezug zu mehreren Texten, einem nicht identifizierbaren Text, einem Stoff, einer Gattung, einem Mythos oder Topos wird als Systemreferenz bezeichnet. ${ }^{37}$ Letztere zeigt sich im Korpus bei den Mythenadaptionen. ${ }^{38}$

Ort und Intensität der Bezugnahme können auf unterschiedliche Weise gestaltet sein: ${ }^{39}$ als explizite, implizite oder unmarkierte Intertextualität. Durch explizite Markierungen erbringt der Autor nicht nur ein Indiz, sondern einen unmittelbaren Beweis, dass er sich auf einen anderen Text bezieht. ${ }^{40}$ Er kann dazu auf onomastische Markierungen zurückgreifen, also die Nennung oder gar das Auftreten von anderen Figuren oder Autoren sowie auf Codewechsel oder graphemische Kennzeichnungen wie Spiegelstriche, Anführungszeichen, Kursivsetzungen. Eine Steigerung wird noch erreicht, wenn der intertextuelle Bezug im Posttext expressis verbis hervorgehoben wird. ${ }^{41}$ Dies ist beispielsweise dann der Fall, wenn Figuren den Prätext rezipieren. Eine explizite Markierung kann im Nebentext/Paratext vorgenommen werden, also etwa durch Signale im Vorwort, Nachwort, Einleitung, Klappentext, in den Fußnoten, Nebentexten, dem Motto oder auch im Titel. Bei intertextuellen Bezugnahmen innerhalb des Haupttextes bestehen zwei Optionen: als Markierung im inneren Kommunikationssystem, das heißt, der Prätext wird von den Figuren explizit aufgerufen, gelesen, kommentiert - oder Figuren des Prätextes treten im Folgetext auf. Zeigt sich die Markierung implizit im äußeren Kommunikationssystem des Textes, verfügen allein die Rezipienten, nicht aber die literarischen Figuren selbst über das Wissen um die intertextuelle Bezugnahme. Ein solcher Fall liegt etwa vor,

\footnotetext{
${ }^{36} \mathrm{Vgl} . \mathrm{Bu}$ (2005), S. 50.

${ }^{37}$ Die Unterscheidung von Einzeltextreferenz und Systemreferenz findet sich bei Broich/Pfister (1985b), S. 4857. Als Grenzphänomene machen die Autoren Pastiche, Allusion, Parodie und Travestie aus.

${ }^{38}$ Zur Mythenadaption siehe auch Kapitel 4.2.3.2.

${ }^{39}$ Broich (1985), S. 31-47.

${ }^{40}$ Helbig (1995), S. 112.

${ }^{41}$ Ebd., S. $91 \mathrm{f}$.
} 
wenn Letztere die Namen anderer literarischer Figuren tragen. Helbig bezeichnet all diejenigen Markierungsformen als implizit, die auf Paraphrasierungen, stilistische Veränderung oder stoffliche Verarbeitungen des Prätextes zurückgreifen und dabei den Rezipienten auf die Bezugnahme aufmerksam machen, zum Beispiel durch einen emphatischen Gebrauch oder durch linguistische oder graphemische Inferenzen, die dazu einladen, am intellektuellen Spiel der Intertextualität teilzunehmen, um beim Aufspüren der Bezüge Freude zu empfinden. ${ }^{42}$ Ohne jegliche Markierung liegt die Identifizierung der Bezugnahme allein beim Rezipienten, der dazu seine Leseerfahrung in die Lektüre einbringen muss, Helbig spricht hier von unmarkierter Intertextualität. ${ }^{43}$ Ist der Rezipient nicht in der Lage, die Referenz zu entdecken oder einzuordnen, kann sie ihre Wirkung kaum oder gar nicht entfalten. ${ }^{44}$ Im extremsten Fall hat sich ein Autor dazu entschlossen, seine Bezugnahme gar nicht kenntlich zu machen, sondern die Fremdtextelemente sprachlich zu transformieren und nicht durch grammatikalische oder graphemische Signale zu kennzeichnen, evtl. weil er seinen Text explizit an eine literarisch gebildete Leserschaft adressiert oder aber weil er den Prätext für so bekannt hält, dass eine Markierung gar nicht nötig ist.

Genette unterscheidet fünf Typen von „, Transtextualität“. ${ }^{45}$ In seinem Systematisierungsvorschlag, bei dem Intertextualität als Unterkategorie dient, stellt nicht der Ort der Markierung das unterscheidende Kriterium dar, sondern die Relation von Prä- und Folgetext. Zu den Relationstypen zählen:

(1) Intertextualität, das heißt, die zum Beispiel durch Zitat, Plagiat oder Anspielung herbeigeführte Einzeltextreferenz;

(2) Paratextualität, das heißt, die Einrahmung eines Textes durch intertextuelle Aufrufe im Paratext;

(3) Metatextualität, das heißt, der kommentierende, kritische oder interpretierende Aufruf eines Werkes im Folgetext;

(4) Architextualität, das heißt, die Zugehörigkeit eines Textes zu einer bestimmten Gattung oder Schreibweise;

\footnotetext{
${ }^{42}$ Ebd., S. 93, S. 97.

${ }^{43}$ Ebd., S. 59, S. 52, S. 158.

${ }^{44}$ Vgl. Buß (2005), S. 44.

${ }^{45}$ Genette (1992), S. 7-15.
} 
(5) Hypertextualität, das heißt, die Beziehung eines Textes zweiten Grades zu seinem Prätext. Gemeint sind Transformationen wie Parodie und Travestie und Nachahmungen wie Persiflage und Pastiche.

\subsection{Zum Genremix der Post-Potter-Texte}

Beim derzeitigen Diskurs über zeitgenössische Kinder- und Jugendliteratur, insbesondere zu Harry Potter, wird die Tendenz zum Genremix als postmodernes Phänomen benannt und als eine Komponente der erfolgreichen Vermarktung des Medienverbunds betrachtet. ${ }^{46}$ Meist wird der Begriff ohne definitorische Präzisierung verwendet und auch ohne konzeptuelle oder theoretische Einbettung, die beispielsweise auf die rezeptionsästhetischen Implikationen des gedanklichen Modells einzugehen versucht. Vielmehr scheint sich en passant die Vorstellung manifestiert zu haben, wonach zeitgenössische literarische Texte - auch Filme und Serien jeder Art - als Mosaik ${ }^{47}$ von Gattungs- und Genrekonventionen zu begreifen sind bzw. als Neu- und Rearrangements etablierter Handlungsschemata und Motive, sozusagen als Genrehybride, die „das Beste“ in sich vereinen. Behauptet wird dabei, wie die Bezeichnungen Genremix bzw. hybrides Genre schon nahelegen, dass jedes Arrangement wiederum als eigenständiges Genre zu betrachten ist, dessen Hauptmerkmal ebenjene Mixtur von literarischen Ingredienzien darstellt. ${ }^{48}$ Folgende Arbeitsdefinition des Formats kann dahinter erahnt werden, deren Einzelaspekte, so kann man sagen, in Rowlings Texten geradezu inflationär verwendet werden.

Genremix/hybrides Genre bezeichnet literarische Texte, die Merkmale unterschiedlicher literarischer, institutionalisierter, auf gleicher systematischer Ebene angesiedelter Gattungen in sich vereinen und ,daher mit den traditionellen Gattungsbegriffen westlicher Poetik nicht mehr adäquat beschrieben werden können “49. Der Begriff Genremix wurde in der Fachgeschichte vor allem für den (zeitgenössischen) Roman verwendet, insbesondere dann, wenn er eine „,über eine realistische Darstellung hinausgehende Mischung von Fakt und Fiktion" bereithält. ${ }^{50}$ Heute wird er oft im Zusammenhang mit zeitgenössischer Kinder- und Jugendliteratur gebraucht, mit Medi-

\footnotetext{
${ }^{46}$ Vgl. Brown (2005); Karg/Mende (2010), insbesondere S. 7-47; Huber (2004); Jelinek (2006); Bak (2004), S. 169-178; Elstner (2004), S. 6.

${ }^{47}$ Vgl. Alton (2003). Die Vorstellung eines Mosaiks findet sich auch bei Theorien zur Intertextualität, beispielsweise bei Kristeva (1972), S. 348.

${ }^{48}$ Bergenthal (2008, S. 363) verwendet auch den Begriff Crossover.

${ }^{49}$ Vgl. Nünning/Nünning (2013), S. 251 und Baßler (2010), S. 52.

${ }^{50}$ Ebd.
} 
enverbünden im Serienformat, mit serieller Trivialliteratur für Erwachsene, aber auch in Bezug auf Fernsehserien und Filme. Die Vermarktung von literarischen Ideen im Genremix geht einher mit dem bewussten Einsatz verschiedener textueller und paratextueller Gattungsmerkmale, die beim Rezipienten verschiedene Erwartungen miteinander konkurrieren lassen und damit den Rezeptionsprozess stark beeinflussen. ${ }^{51}$

Die Anlage einer Geschichte im Genremix bietet Anknüpfungspunkte für eine multimediale Distribution, gibt Anlass für literarische Anschlusskommunikation, bedient gleichzeitig unterschiedliche Vorlieben und Interessen und scheint daher ein heterogenes Massenpublikum, eine größere Zielgruppe anzusprechen - ein Umstand, der bis dato nicht nur in der Literatur, sondern vor allem auch in Film und Fernsehen, vorwiegend im Bereich des Quality TV, genutzt wurde. ${ }^{52}$

Die Vorstellung von zeitgenössischer Kinder- und Jugendliteratur als Genre-Collage impliziert, dass jedes Genre statische und dominierende Eigenschaften aufweist, die disjunkt verschiedenen Genres zuzuweisen sind (das heißt, dass jede Struktur genau auf ein und nicht mehrere Genres referiert), und dass jene Texteigenschaften dezidiert von den Rezipienten als Teil einer literarischen Institution, also klar als Gattungssignale wahrgenommen werden und eine „Schablone“, ein mentales Modell, hervorrufen, nach dessen Struktur sich der Leseprozess gestaltet. ${ }^{53}$ Ein bestimmtes Motiv oder eine spezifische Handlungsstruktur weist demnach immer auf ein bestimmtes Genre hin und kann weder unabhängig von ihm Verwendung finden noch unabhängig von seinem Einfluss rezipiert werden. Die Vorstellung lässt indes dabei völlig unbeachtet, dass zum einen jedweder Text die Merkmale mehrerer Genres aufweist, da es „den“ Kriminalroman, „den“ Abenteuerroman und „den“ Adoleszenzroman in prototypischer Reinform schlichtweg nicht gibt, ${ }^{54}$ zum anderen, dass ein bestimmtes Motiv, ein Schema, eine Handlungsstruktur oder eine Figur durchaus konstitutiv für mehrere Genres sein kann. Diese modellbedingte Inkonsistenz muss hingenommen werden, lässt man sich auf das Gattungsmodell Genremix ein.

Wenn hier die Post-Potter-Texte als Genremix besprochen werden, dann legitimieren sich die Ergebnisse der Betrachtungen modellimmanent. Es gilt: Die aufgezeigten Eigenschaften der Post-Potter-Texte dürfen als objektiv gelten, wohingegen die Zuordnung zu einem Genre bzw.

\footnotetext{
${ }^{51}$ Vgl. Wrobel (2010), S. 6.

${ }^{52}$ Bergenthal (2008), S. 108 f.; Blanchet (2011), S. 45.

${ }^{53}$ Van Dijk/Kintsch (1983) gehen davon aus, dass jedes mentale Modell im ständigen Abgleich mit Vorwissen, Weltwissen und Neuinformation revidiert und angepasst wird. Siehe auch Bergenthal (2008) S. $50 \mathrm{ff}$.

${ }^{54}$ Vgl. Weinkauff/von Glasenapp (2010), S. 124.
} 
Genremix als Interpretationsvorschlag aufzufassen ist, also modellbedingt keine Objektivität beanspruchen kann. Ziel ist es, Genreschemata zu identifizieren, die besonders häufig in den Texten zu beobachten sind.

Dazu wird zunächst ein Zusammenhang zwischen dem Gattungsmodell Genremix und der Schematheorie hergestellt (Kapitel 5.3.1). Es folgt eine Gattungsdiskussion der Korpustexte mit dem Fokus auf Genrehybridität (Kapitel 5.3.2). Ein Zwischenfazit fasst die Ergebnisse der Betrachtungen zusammen (Kapitel 5.3.3).

\subsubsection{Zum Genremix aus Perspektive der Schematheorie}

Aus Perspektive der Schematheorie hat das Phänomen des Crossover noch andere Implikationen: ${ }^{55}$ Genre wird dort als eine Gruppe von Texten aufgefasst, die bestimmte literarische Schemata aufweisen, welche vom Rezipienten in Form von Skripts erlernt werden können. Diese beeinflussen dann zukünftige Rezeptionsprozesse, indem sie Orientierung liefern und ein bestimmtes Raster auf die Narration legen, die ständig mit diesem abgeglichen wird. Die Skripts können durch wiederholte Rezeption angepasst, archiviert oder vernetzt werden und hinterlassen damit Gedächtnisspuren im menschlichen Gehirn. ${ }^{56}$ Ein Text, der sich eines genreweisenden Schemas bedient, das heißt, der ein solches durch architextuellen Verweis in einem Posttext aufruft, weist sich durch diese Systemreferenz selbst als genrezugehörig aus. Der Verweis auf unterschiedliche genreweisende Schemata führt zur Wahrnehmung eines Textes als Genremix. Genreweisende Schemata sind als hierarchisch höher oder niedriger zu betrachten, je nachdem ob sie die Gesamtwirkung eines Textes prägen, zum Beispiel die Rahmenhandlung strukturieren, oder aber nur bestimmte Teilaspekte wie ausgewählte Figuren, Handlungsstränge oder Motive beeinflussen und so den Rezeptionsprozess nur in geringerem Maße mitbestimmen. Nach diesem Prinzip können Genres in einem Text auf unterschiedlicher Ebene realisiert sein und dennoch in ihrem Bereich Orientierung schaffen. Dominierende, hierarchisch höher anzusetzende Genreeinflüsse betreffen nach diesem Verständnis das Grundgerüst eines Textes, seine Grundstimmung und -struktur, sein Grundgenre, das durch die Einflüsse hierarchisch niederer Genreschemata innoviert wird. Bei Serien lässt sich unterscheiden, ob ein Schema auf Ebene der Serienhandlung oder nur auf Ebene einer Folgenhandlung operiert, wobei ersterer Einfluss höher einzustufen ist. Eine objektive Skala, die den Einfluss eines Genres auf die Mixtur misst, liegt beim Gattungsmodell nicht vor, zumal er

\footnotetext{
${ }^{55}$ Zugrunde liegt hier die Schematheorie von Anderson/Pearson (1984), S. 255-291.

${ }^{56}$ Vgl. Bergenthal (2008), S. 110 f.
} 
objektiv nicht messbar ist. Sind bestimmte Genremixe bereits so etabliert, dass ihre Mixtur nicht mehr als von der Leseerfahrung abweichend wahrgenommen wird, so wird diese oftmals als Subgenre der dominierenden literarischen Gattungsinstitution eingeordnet und nicht mehr als Hybrid. $^{57}$

\subsubsection{Zum Genremix der Post-Potter-Texte}

Mohr postuliert, dass phantastische Kinder- und Jugendliteratur nach der Jahrtausendwende ${ }^{58}$ die Aufsplittung in zahlreiche Subgenres erlebt hätte, was auf die Variationsmöglichkeiten zurückzuführen sei, die sich aus der Vermischung von Genreschemata ergäben. ${ }^{59}$ Jedes beteiligte Genre liefere dabei seinen Beitrag zu den jeweiligen phantastischen Weltentwürfen, indem es auf die beteiligten Repräsentationsinstanzen - Figur, Handlung, Zeit, Kausalität und Gegenstand - Einfluss nehme. ${ }^{60}$ Prinzipiell sei im zeitgenössischen Jugendbuchsegment jede Kreuzung mit phantastischer Literatur denkbar, so gibt es bereits Vertreter wie Die Schule der Drachenreiter (2007), eine Mixtur aus Pferdeliteratur und Fantasy. ${ }^{61}$

Im Korpus finden sich bestimmte Genreeinflüsse regelmäßig, der Beitrag eines Einzelgenres zum Gesamteindruck variiert dabei sehr stark und reicht vom Aufruf einzelner institutionalisierter Figuren und Motive bis hin zur Realisierung von komplexen genreweisenden Handlungsstrukturen. Wie in Kapitel 3 und 4 dargelegt, bedienen sich Harry Potter und die PostPotter-Texte sowohl der Schemata als auch der Erzählstrukturen von phantastischer und mythischer Literatur, und zwar so signifikant, dass diese als Grundgenres (Schemata höchster Ebene) betrachtet werden können. ${ }^{62}$

Hier sollen nun die architextuellen Aufrufe weiterer Genres nachgewiesen werden, die häufig im Korpus auszumachen sind. Die Gewichtung spielt dabei eine Nebenrolle, stattdessen wird analysiert, welche genreweisenden Schemata sich auffällig oft wiederholen. Zunächst werden Einflüsse des Liebesromans aufgezeigt, die konstant in allen Texten auszumachen sind (Kapi-

\footnotetext{
${ }^{57}$ Wenn eine Gattungshybrid musterbildend wirkt, kann er eine Mischgattung etablieren. Vgl. Baßler (2010), S. 52.

${ }^{58}$ Eine Gattungsbezeichnung, die auch für die Texte des Korpus passend ist, zumal diese sowohl als phantastische Literatur (Kapitel 3) als auch als Kinder- und Jugendliteratur (Kapitel 6.2) aufzufassen sind.

${ }^{59}$ Mohr (2012), S. 256.

${ }^{60} \mathrm{Vgl}$. Mohr (2012), S. 325.

${ }^{61}$ Mohr (2012), S. 259.

${ }^{62}$ Dies hat auch Ewers beobachtet, der heutige Fantasy als mythische Erzählungen identifiziert, die ähnliche Funktionen aufweise wie die antiken Vorläufer. Siehe Ewers (2011), S. 3ff. Siehe auch Kapitel 4.3. Dass die Texte zudem im jugendlichen Milieu angesiedelt sind und zentrale Themen der Adoleszenz verhandeln, wird in Kapitel 6.2.4 behandelt. Die dortigen Ergebnisse legen es nahe, die Texte gleichermaßen dem Adoleszenzroman zuzuordnen, der eine feste Komponente im Genremix einnimmt.
} 
tel 5.3.3.1), anschließend Einflüsse des Abenteuerromans (Kapitel 5.3.3.2) und des Kriminalromans (Kapitel 5.3.3.3) ${ }^{63}$ Ein letztes Unterkapitel widmet sich speziell dem Genremix der Bis(s)-Serie, dessen spezifische Komposition ein eigenes Subgenre etablieren konnte (Kapitel 5.3.3.4).

\subsubsection{Zum Einfluss des Liebesromans in den Post-Potter-Texten}

Zimmermann identifiert drei Sequenzen als gattungsweisend für Liebesplots: die Einführung des zentralen Liebespaares, das Auftreten von Hindernissen und das Happy End. ${ }^{64}$

1) Einführung des zentralen Liebespaares

Nach Zimmermann wird in der ersten Sequenz eines Plots die Ausgangssituation für die Liebesgeschichte geschaffen, indem - meist getrennt voneinander oder mit zeitlichen Abstand - zwei Figuren vorgestellt werden, die „, alle Voraussetzungen für eine potenzielle Liebesbeziehung erfüllen "65. Es folgt das Aufeinandertreffen, wobei sich „, die Liebenden sehen und erkennen “66. Dieses „Erkennen“" kann mal mehr, mal weniger explizit gemacht werden, sodass die Frage „Wer kommt letztendlich mit wem zusammen?“ zu den spannungssteigernden Momenten eines Liebesplots gehört. ${ }^{67}$

2) Das Auftreten von Hindernissen

In der zweiten Phase treten Hindernisse in beliebiger Kombination auf, die das Happy End nach hinten verschieben. ${ }^{68}$ Oft kann eine der beiden Figuren ihre Gefühle nicht ausdrücken, hat Angst vor Ablehnung oder ist von anderen, für sie zunächst übergeordneten Beweggründen geleitet, die die Zusammenführung der Liebenden unmöglich machen. Das können finanzielle Sorgen sein, aber auch gesellschaftliche Hindernisse wie der drohende Statusverlust, die eine Figur des Liebespaars als „romantischen Held“ stilisiert, der die äußeren Problematiken erst überwinden muss. ${ }^{69}$ Manchmal verlieben sich die Figuren erst in den Falschen, bevor sie die wahre Liebe erkennen. ${ }^{70}$ In der Regel basieren auftretende Hindernisse auf falscher und mangelnder Information bzw. missglückter Kommunikation, die zu Verwicklungen, falschen Spekulationen und Streitigkeiten führt, bei denen nicht selten die Antagonisten als Urheber ausgemacht werden können. ${ }^{71}$

3) Das Happy End

Hat das Paar endlich alle Hindernisse überwunden, kann es unbeschwert seine Liebe genießen. Klassischerweise wird das Happy End durch einen Kuss, daneben auch mit der vollzogenen Heirat und Kindern verdeutlicht. ${ }^{72}$

Die drei skizzierten Phasen sind sowohl bei Harry Potter als auch den Texten des Korpus verwirklicht; jeder Protagonist ist Bestandteil eines zentralen Liebespaares, das parallel zur Abenteuerhandlung die drei Phasen eines prototypischen Liebesplots durchläuft. Der Einfluss

\footnotetext{
${ }^{63}$ Mit dem Liebesroman, dem Kriminalroman und dem Abenteuerroman wurden drei Genreeinflüsse gewählt, die dezidiert auf die Handlung der Post-Potter-Texte Einfluss nehmen. Daneben könnten noch andere Einflüsse thematisiert werden, die nicht so handlungsweisend, aber dennoch klar belegbar sind: So zum Beispiel das Märchen (bei der Tintenwelt-Trilogie) oder der historische Roman (bei der Edelstein-Trilogie).

${ }^{64}$ Zimmermann (1982), S. 78 f. Von Zimmermann werden zunächst fünf Phasen vorgesehen, in die ein Dreierschema eingebettet ist. Ähnlich wie Bergenthal hält die Verfasserin das Dreierschema für geeigneter, da es sich als charakteristischer für Liebesplots erweist, während das Schema in fünf Phasen auf nahezu alle Romane übertragbar ist. Siehe dazu auch Bergenthal (2008), S. 192, Fußnote 255. Die folgenden Ausführungen stützen sich sowohl auf Zimmermann (1982) als auch auf Bergenthal (2008).

${ }^{65}$ Bergenthal (2008), S. 192.

${ }^{66}$ Zimmermann (1982), S. 78 f.

${ }^{67}$ Bergenthal (2008), S. $195 \mathrm{f}$.

${ }^{68}$ Zimmermann (1982), S. 72. So ist der prototypische Liebesplot final motiviert.

${ }^{69}$ Bergenthal (2008), S. $194 \mathrm{f}$.

${ }^{70}$ Ebd., S. 193 f.

${ }^{71}$ Ebd., S. 194.

${ }^{72}$ Zimmermann (1982), S. 79.
} 
des Liebesromans kann damit konstant als Bestandteil des Genremix ausgemacht werden. ${ }^{73}$ Exemplarisch soll dies an der Edelstein-Trilogie und der Bis(s)-Serie belegt werden.

\section{Zum Einfluss des Liebesromans auf die Edelstein-Trilogie}

In Giers Büchern ist der Einfluss des Liebesromans unübersehbar, der Liebesplot zwischen Gwendolyn und Gideon zentraler Bestandteil der Serienhandlung. Die beiden werden als Figuren eingeführt, bei denen die Voraussetzungen für eine Liebesbeziehung nicht besser sein könnten: Gideon stellt schon formal das „männliche Gegenstück“ zu Gwendolyn, der jüngsten Genträgerin ihrer Familie, dar - in der Familie Montrose wird das Zeitreisegen unter den Frauen weitervererbt -, weil er der jüngste Genträger der Familie de Vellier ist, in der das Gen ausschließlich an männliche Nachkommen weitergegeben wird (RR, S. 42). Dadurch, dass beide die außergewöhnliche Fähigkeit besitzen, in der Zeit zu reisen, können sie auf gemeinsame Missionen geschickt werden, sich zusammen auf ihre Zeitreisen vorbereiten, für eine gemeinsame Sache kämpfen - und sich ineinander verlieben. Diese guten Prämissen werden durch die Prophezeiung von Mr. de Vellier unterlaufen, der beteuert, dass „Liebesbeziehungen zwischen den de Velliers und den Montroses [] unter keinem guten Stern “ stehen und ,,von vornherein zum Scheitern verurteilt sind“, eine Negativprognose, die beim Annäherungsprozess des Liebespaares immer mitschwingt und das Happy End als ungewiss markiert (RR, S. 196). Die oben beschriebenen Phasen des Liebesromans sind in der Serie folgendermaßen realisiert:

\section{Die Einführung des zentralen Liebespaars}

Bereits bei der ersten Begegnung der beiden deutet sich an, dass Gwendolyn an Gideon Gefallen findet und ihn als potenziellen Partner identifiziert: Sie bekommt nur ein heiseres „Hallo“ (RR, S. 143) heraus und stellt mit Bedauern fest, dass sie seiner intensiven Musterung nur mit einfältigem Zurückglotzen (RR, S. 144) zu begegnen imstande ist sowie dass Charlotte einfach die längeren und schöneren Beine hat (RR, S. 162). Sie fühlt sich unvollkommen neben ihm und seinem „hübsche[n] Gesicht“ (RR, S. 176) und sucht vergebens nach irgendetwas, das ihr an ihm nicht gefällt (RR, S. 177). Er hingegen ist zunächst alles andere als angetan von ihr, sondern überzeugt, den Missionen des Grafen ohne sie viel besser gewachsen zu sein, vor allem weil er lange darauf vorbereitet worden ist, während sie nicht mal wisse, worum es gehe (RR, S. 159). Sie sei ein Kind, das keine Ahnung habe (RR, S. 179). Folglich wehrt sich Gideon vehement, mit ihr gemeinsam zu elapsieren und den „Babysitter“ (RR, S. 186) zu

\footnotetext{
${ }^{73}$ Bergenthal hat das Schema ihrerseits für Harry Potter nachgewiesen. Siehe Bergenthal (2008), S. 192-196.
} 
spielen. Er gebärdet sich Gwendolyn gegenüber lange arrogant, schnalzt verächtlich mit der Zunge (RR, S. 169) und scheint eindeutig an Charlotte mehr Gefallen zu finden, mit der er betont freundlich (RR, S. 170) spricht, Gwendolyn geht sogar davon aus, dass er in sie ,verknallt“ (RR, S. 170) ist. Erst am Schluss des ersten Bandes endet die Einführung des zentralen Liebespaares ab, indem nun deutlich wird, dass auch Gideon Gefühle für Gwendolyn hegt und sie als potenzielle Gefährtin erkennt. Er entschuldigt sich für sein grobes Verhalten, beteuert, dass sie für ihn etwas Besonderes sei, und küsst sie (RR, S. 338).

\section{Das Auftreten von Hindernissen}

Gideons Prognose im ersten Band: „ich glaube, das wird ganz schön spannend mit uns zwei“ (RR, S. 337) nimmt bereits vorweg, dass sein Kuss nicht das glückliche Ende der Liebesgeschichte ist, sondern vielmehr der Anfang. Tatsächlich hat sich das Paar in den Folgebänden zunächst einmal zu bewähren, bevor es zum Happy End kommt. So stehen ihm zunächst zahlreiche Hindernisse, Missverständnisse und Fehlinformationen im Weg, die es zu überwinden gilt: Gideon reagiert zusehends gereizt darauf, dass sich Gwendolyn nach und nach gegen den Grafen von Saint Germain stellt, da er davon überzeugt ist, dass dieser die Menschheit retten wird. Er kehrt sehr aufgebracht von einer Zeitreise zurück, weil er glaubt, in Erfahrung gebracht zu haben, dass Gwendolyn den Grafen bei einer ihrer Zeitreisen umbringen lassen will, ein Missverständnis, wie sich herausstellt. Er selbst wird vielmehr derjenige sein, der sein Alter Ego außer Gefecht setzt (SB, S. 260; SG, S. 430). Gwendolyn trinkt auf einer Soiree vor Eifersucht zu viel Alkohol und gefährdet damit das Kontinuum (SB, S. 313). Der Graf von Saint Germain streut zudem Zwietracht unter den beiden. Er relativiert die Liebeserklärung, die Gideon Gwendolyn in Saphirblau macht, indem er behauptet, Gideon hätte sich nur in seinem Auftrag um sie bemüht - so wie vorher um Charlotte. Seine Bemühungen um sie seien lediglich Teil der Prophezeiungen, die in jedem Fall eingehalten werden müssten (SB, S. 365 f.). Gwendolyn ist am Boden zerstört. Als Gideon die Aussage bestätigt (SB, S. 371) und sie um ihre Freundschaft bittet (SG, S. 69 f.), verliert sie jede Hoffnung. Es kommt zu einem heftigen Streit (SG, S. 219f). Erst sehr spät stellt sich heraus, dass Gideon so abweisend reagiert, um Gwendolyn zu schützen, da eine Prophezeiung vorhersagt, dass sie ihr Leben aus Liebe für Gideon lassen wird (SG, S. 308 f.).

\section{Das Happy End}

Durch strategisches Vorgehen gelingt es den beiden schließlich, den Grafen zu überwältigen und damit ihrer ewigen Liebe den Weg zu ebnen, und zwar im wörtlichen Sinne, da Gwen- 
dolyn als Rubin unsterblich ist und Gideon durch den Stein der Weisen ebenfalls unsterblich geworden ist (SG, S. 470). Das Happy End ist perfekt, und Paul stellt das Kinderglück der beiden in Aussicht, indem er feststellt, dass es nur noch eine Frage der Zeit zu sein scheint, bis er Großvater wird (SG, S. 481).

\section{Zum Einfluss des Liebesromans auf die Bis(s)-Serie}

In der Twilight-Saga ist der Einfluss des Liebesromans ebenfalls stark spürbar, die Liebesbeziehung zwischen Edward und Bella die zentrale Thematik. Die Haupt- bzw. Serienhandlung lebt über weite Strecken vom „Sich-Finden“ der beiden Protagonisten, deren Ausgangssituation nicht ungünstiger sein könnte: Die sich entwickelnde Liebe zwischen Mensch und Vampir, zwischen Jäger und Beute, erzeugt zahlreiche innere und äußere Konflikte. Noch angespannter wird die Situation, als Bellas bester Freund Jacob seine Gefühle für sie offenbart und Edward den Kampf um die schöne Heldin ansagt (BzAb, S. 341). Die Frage „Wen wird Bella erwählen: Edward oder Jacob?“ ist über weite Strecken, insbesondere im zweiten und dritten Teil, sowohl handlungsweisend als auch leserlenkend und nimmt zudem in der FanKommunikation einen großen Platz ein. ${ }^{74}$ Die oben beschriebenen Phasen strukturieren dabei die Haupthandlung, die dem Liebesroman streng verpflichtet ist:

\section{Einführung des zentralen Liebespaars}

Fast im kompletten ersten Teil wird das „Sich-Suchen-und-Finden“ der Liebenden zum Gegenstand gemacht. Dabei sind Edwards Gefühle Bella gegenüber lange unklar, sein Verhalten schwer zu deuten. ${ }^{75}$ Sein abweisendes Verhalten wird dem Rezipienten durch Gestik und Mimik verdeutlicht: „Ich sah, dass er die Hand auf seinem linken Oberschenkel zur Faust geballt hatte“ (BzMo, S. 29) und ,wieder war der Blick seiner schwarzen Augen voller Abscheu“ (BzMo, S. 30). Ähnlich wie Gideon kämpft auch Edward gegen seine Gefühle an, um Bella zu schützen. Analog zur Edelstein-Trilogie werden auch Edwards wahre Gefühle für sie immer offensichtlicher durch Sätze wie ,,ich hätte schwören können, dass ich ihn aus den Augenwinkeln lachen sah“ (BzMo, S. 56) und „er lächelte sein schiefes Lächeln“ (BZMo, S. 116). Bei der Vermittlung von Bellas Gefühlen wird ähnlich verfahren. Sie werden dem

\footnotetext{
${ }^{74}$ Die Fan-Gemeinschaft teilt sich selbst in drei „Teams“ ein: Team Edward, Team Jacob und Team Neutral. Die Frage der Teamzugehörigkeit hat sich in der Fan-Kommunikation derart etabliert, dass sie sich auf das Marketingangebot übertragen hat. Will man die DVD des zweiten Teils anschauen, muss sich der Konsument vor dem Hauptfilm entscheiden, welchem Team er angehört. Merchandising-Produkte weisen sich als zugehörig zu Team Jacob oder Team Edward aus und geben dem Konsumenten die Möglichkeit eines öffentlichen Statements zu dieser Diskussion.

${ }^{75}$ Auch wenn es zahlreiche Indizien dafür gibt, werden Edwards Gefühle erst verhältnismäßig spät explizit zum Thema gemacht. Siehe BzMo, S. 29-34.
} 
Leser auch nicht sofort offenbart, wenngleich eine Reihe von Indizien auf ihre Liebe hindeutet: „, Mein Blick fiel in traumwandlerischer Sicherheit auf seinen Tisch - und dann durchfuhr mich die Enttäuschung: die anderen vier waren da, doch er fehlte“ (BzMo, S. 93). Eindeutig Stellung bezieht Bella etwa nach der Hälfte des ersten Bandes, sodass der Leser nicht mehr auf Spekulationen angewiesen ist:

Es gibt drei Dinge, derer ich mir absolut sicher war: erstens, Edward war ein Vampir. Zweitens, ein Teil von ihm - und ich wusste nicht, wie mächtig dieser Teil war - dürstete nach meinem Blut. Und drittens, ich war bedingungslos und unwiderruflich in ihn verliebt (BzMo, S. 206).

Die Exposition der Liebesgeschichte ist damit abgeschlossen, die Ausgangssituation für den weiteren Verlauf abgesteckt. Mit der Vampirproblematik wird gleichzeitig die zweite Phase des Liebesplots eingeleitet: das Auftreten von Hindernissen.

\section{Das Auftreten von Hindernissen}

Auf der Makroebene der Geschichte kann man beobachten, dass jeder Band ein großes Hindernis thematisiert, das von den Liebenden überwunden werden muss, damit sie schließlich vereint ihr ewiges Glück zu teilen vermögen. So strukturiert der Liebesplot die gesamte Handlung der Serie, indem das große Happy End immer wieder hinausgezögert wird; jeder Band endet mit der Bewältigung des jeweiligen Hindernisses, so entsteht eine Verkettung von Abenteuern, die auch für den Abenteuerroman gattungsweisend ist:

- BzMo: James, der ein Tracker ist, ${ }^{76}$ hat es auf Bella abgesehen und versucht alles, um sie zu töten. Letztendlich können ihn Edward und seine Familie überwältigen und vernichten.

- BzMi: Edward verlässt Bella, weil er glaubt, dass es für sie besser ist. Als er durch ein Missverständnis annimmt, dass Bella tot sei, will er sich selbst bei den Volturi das Leben nehmen; gerade noch rechtzeitig kann er von Bella gerettet werden.

- BzAb: Bella und Edwards Freude über ihre Wiedervereinigung hält nicht lang an. Victoria, die Gefährtin von James im ersten Teil, will den Mord ihres Ehemanns rächen und schmiedet einen Plan, wie sie Bella umbringen kann. Edwards Familie und die Werwölfe stehen Bella jedoch bei. Victoria stirbt.

- BzEdN: Die Volturi haben Sorge, dass durch die Tochter von Edward und Bella, das Mischwesen Renesmee, das Geheimnis der Vampire in Gefahr ist, und rücken an, um sie zu töten. Doch Bella und die Cullen-Familie können die Volturi letztendlich überzeugen, dass von Renesmee keine Gefahr ausgeht.

\footnotetext{
${ }^{76}$ Tracker sind Vampire mit ausgeprägtem Jagdtrieb. Einmal auf eine Beute fixiert, sind sie nicht abzubringen.
} 
Parallel zu diesen äußeren Konflikten untergräbt Jacob als Nebenbuhler das Liebesglück zwischen Bella und Edward, indem er sich vor allem durch seine Fürsorge im zweiten Band als alternativer Partner präsentiert. Die Entscheidung zwischen Jacob und Edward könnte schwerer nicht sein, da beide reinen und guten Herzens sind. Die Situation wird gelöst, indem auch Jacob letztlich die wahre Gefährtin zur Seite gestellt bekommt. Er wird auf Renesmee geprägt, die Tochter von Edward und Bella.

\section{Das Happy End}

Bella, mittlerweile ein Vampir, und Edward sind glücklich verheiratet, haben ein Kind und können nun ohne Sorgen zusammenleben. Alle Konflikte wurden gelöst, auch der Streit mit Jacob.

Die Protagonistinnen der Panem- und der Tintenwelt-Trilogie sind gleichfalls in Liebesgeschichten verwickelt: Meggie verliebt sich zunächst in Farid, der ihre Gefühle zwar erwidert, aber nur wenig Zeit für sie aufbringt. Sie löst sich nach und nach von ihm, bis sie schließlich im letzten Band erkennt, das ihr Herz für Doria schlägt. In Collins' Text werden Katniss und Peeta ein Paar. Hier ist sich vor allem Katniss lange Zeit ihrer Gefühle nicht sicher (zum Beispiel TS, S. 413).

\subsubsection{Zum Einfluss des Abenteuerromans auf die Post-Potter-Texte}

In Kapitel 4 wurde der Einfluss des Abenteuerromans auf die Post-Potter-Texte bereits angerissen, welcher sich auch im Schema der Heldenreise sowie im Gottkindmotiv zeigt. Doch gibt es weitere vielerlei für den Abenteuerroman typische Skripts und Schemata, welche die Handlung strukturieren.

Die Lust an der Abenteuerliteratur wird in der Wissenschaft häufig als „elementarer Trieb“ erklärt, der sich insbesondere im jugendlichen Alter herausbildet und durch entsprechende Romane kompensiert werden kann, ${ }^{77}$ indem der Rezipient die abenteuerlichen Reisen und Begegnungen durch die Augen des Protagonisten miterlebt.

Der Begriff des Abenteuers ist bestimmt durch das Wagnis u. die Preisgabe des Sicheren u. Gewohnten; fast immer ist das Abenteuer mit einer Reise ins Unbekannte verbunden. Die Abenteuerreise wird in literar. Darstellungen für den Helden häufig zu einem Initiationsprozess, der seine Persönlichkeit ausbildet u. seine Stellung in der alltägl. Erfahrungswelt bestimmt. ${ }^{78}$

\footnotetext{
${ }^{77}$ Siehe dazu Maier (1980), S. 150-155.

${ }^{78}$ Steinbrink (2005), S. 13.
} 
Im Zentrum steht also das Abenteuer, durch dessen Bewältigung der Held eine bestimmte kognitive oder gesellschaftliche Entwicklung durchläuft. ${ }^{79}$ Es kann von unterschiedlicher Gestalt sein: Während Steinbrink oben von der „Preisgabe des Sicheren u. Gewohnten “ und einer „Reise ins Unbekannte“ spricht, sieht Grimm es als „,eine bunte Kette von Ereignissen oder Irrfahrten “ ${ }^{\prime 80}$. Nicht allein das einzelne Abenteuer ist demnach spezifisch für diese Art von Literatur, sondern eher eine Verknüpfung vieler. Bergenthal sieht diese auch bei den Potter-Romanen. Aus Episodenhaftigkeit entstehe eine spannende Lektüre, die neugierig auf die nächsten Abenteuer und den Ausgang der übergeordneten Makrohandlung macht. ${ }^{81}$ Ebenso lässt sich bei den Post-Potter-Texten eine Verkettung aufregender Einzelepisoden feststellen: Die Protagonisten durchleben Abenteuer unterschiedlicher Intensität und Spannweite, die auf einen großen Höhepunkt, nämlich die letzte, entscheidende Konfrontation zulaufen. Percy Jackson beispielsweise wandert geradezu von einem Monster zum nächsten, das es zu überwinden gilt, um am Ende gegen Kronos zu kämpfen; in der Edelstein-Trilogie kann jeweils ein Zeitsprung als Abenteuer gewertet werden, der je nach Länge und Verlauf mehr oder weniger aufregend verläuft. Am Ende steht auch hier die Konfrontation mit dem Grafen von Saint Germain, genauer: mit seiner Gegenwartsidentität Mr. Whiteman, Gwendolyns Lehrer. ${ }^{82}$ Analog zu Harry Potter sind die Protagonisten bei ihren abenteuerlichen Reisen allesamt mit einem psychologischen Profil ausgestattet, das ihre Handlungen motiviert und dem Rezipienten durch die Erzählperspektive nahegebracht wird. In aller Regel wählen sie ihr Schicksal selbst: ${ }^{83}$ Nicht nur Bella entscheidet sich bewusst dazu, dem Vampirjäger James gegenüberzutreten, um die Menschen zu schützen, die ihr wichtig sind (BzMo, S. 7), auch Katniss wählt selbstbestimmt ihre Teilnahme an den Hungerspielen, um das Leben ihrer Schwester zu retten (TS, S. 27 f.). Die Psychologisierung hat zwei wichtige Konsequenzen: Zum einen werden die Protagonisten dadurch zu modernen Helden stilisiert, die Identifikationspotenzial bieten. Sie sind keine überstarken oder übernatürlichen Helden wie Superman oder Batman, zu denen der Leser aufschauen muss, weil sie ihn an Stärke und Mut überragen, sondern sie werden als Durchschnittsmenschen mit Ängsten und Charakterschwächen inszeniert - denkt man nur an Gwendolyn, die neben ihrer Cousine ständig Komplexe hat, was ihr Äußeres betrifft (RR, S. 14). Ihre körperlichen Fähigkeiten sind teilweise sogar unterdurchschnittlich entwickelt,

\footnotetext{
${ }^{79}$ Siehe auch Weinkauff/von Glasenapp (2010), S. 120.

${ }^{80}$ Grimm (1990), S. 1.

${ }^{81}$ Bergenthal (2008), S. 156.

${ }^{82}$ Weinkauff und von Glasenapp sehen den historischen Roman als Subgenre des Abenteuerromans an. Vgl. Weinkauff/von Glasenapp (2010), S. 122.

${ }^{83}$ Siehe Bergenthal (2008), S. 159 und S. 172.
} 
z. B. bei Bella, die so tollpatschig ist, dass sie ständig durch die Gegend stolpert (BzMo, S. 60), oder Percy, der als verhaltensauffälliger Legastheniker eingeführt wird (PJ 1, S. 9 f.). Zum anderen ermöglichen die Reflexionspassagen eine minutiös gestaltete Informationsweitergabe, die die Spannung steigert und eine gezielte Leserlenkung ermöglicht. „Die lose verknüpften, in sich geschlossenen Ereignisepisoden verlangen nur relativ kurze Aufmerksamkeitsspannen “ und kommen unerfahrenen oder jungen Rezipienten entgegen. ${ }^{84}$

Die Einflüsse des Abenteuerromans auf die Texte werden besonders in der Verwendung typischer Schemata und Motive spürbar, die meist in untergeordneter Hierarchie auf die Haupthandlung oder aber auf Nebenhandlungen Einfluss nehmen. Auch sie strukturieren den Text in überschaubare Abschnitte und erzeugen zugleich Spannung und Dynamik:

\section{Die Reise ins Unbekannte}

Für den Abenteuerroman ist das Spannungsverhältnis von Nähe und Ferne, Heimat und Fremde signifikant. ${ }^{85}$ In den meisten Fällen vollzieht der Held eine Reise in ferne Welten, in denen er sich zu bewähren hat. Nicht selten wird auch die Rückkehr zum Thema gemacht, sodass der Dreischritt 1) Reise ins Unbekannte - 2) Bewährung - 3) Heimkehr ein gängiges Schema darstellt. ${ }^{86}$ In den hier betrachteten Texten ist vor allem das Hin- und Herwechseln signifikant: Percy wechselt kontinuierlich zwischen normaler Schule (Menschenwelt) und Halbblut-Camp (Götterwelt), und auch Gwendolyn hält sich fast zu gleichen Teilen in der Vergangenheit und in der Gegenwart auf. Dem erstmaligen Aufbruch bzw. der Initiationsreise kommt oftmals besondere Aufmerksamkeit zu, stellen sie doch ein einschneidendes Erlebnis für die Protagonisten dar. Analog zu Harry Potter fällt bei den Post-Potter-Texten auf, dass sich die Helden zu guter Letzt für die Anderswelt entscheiden: Meggie bleibt in der Tintenwelt und wird dort vermutlich eine Familie gründen, Bella wird unwiderruflich zum Vampir, und Gwendolyn reist mit Gideon bis in alle Ewigkeit durch die Zeit.

\section{Die Rettung einer Person}

War das Genre des Abenteuerromans früher geprägt von einem konventionellem Rollenverständnis bzw. Rollenklischee, wobei der männliche Held meist das Leben eines weiblichen Opfers errettet und als Dank für Mut und Tapferkeit die Liebe der Jungfrau erhält, ${ }^{87}$ findet sich heute zuhauf die umgekehrte Rollenverteilung. Oftmals ist die Motivkonstellation „Erret-

\footnotetext{
${ }^{84}$ Bergenthal (2008), S. 151.

${ }^{85}$ Weinkauff/von Glasenapp (2010), S. 121.

${ }^{86}$ Das Schema wird auch auch ,, seperation - initiation - return“ genannt. Vgl. Larsson (1996), S. 4.

${ }^{87}$ Vgl. Bergenthal (2008), S. $167 \mathrm{f}$.
} 
tung einer Person“ verknüpft mit dem Motiv der Entführung, sodass das Opfer zunächst einmal gefunden werden muss; oder die Rettung erfolgt durch die Opferung des eigenen Lebens, das der tapfere Held zu geben bereit ist. Beide Varianten können vor allem auf Ebene der Folgenhandlung im Korpus beobachtet werden. In Percy Jackson wird das Schema gleich mehrfach verwendet: Gilt es im ersten Band Percys Mutter Sally Jackson vor dem Tode zu bewahren, ist die Folgenhandlung durch Grovers Rettung strukturiert. Im dritten Band wird Annabeth entführt, für die Percy bereits romantische Gefühle hegt, sodass er sich, obwohl er nicht die Erlaubnis des Campleiters hat, auf den Weg macht, um sie zu finden und zu retten; ein Unterfangen, das Aphrodite vollends unterstützt (PJ 3, S. 220) ${ }^{88}$ Funke spielt in der Tintenwelt-Trilogie mit dem Motiv der heroischen Selbstopferung: Staubfingers Schicksal scheint dahingehend vorbestimmt, dass er sein Leben für das eines kleinen Marders, vermutlich Gwins, lässt, da Fenoglio seinen Tod auf diese Weise vorgesehen hat (TH, S. 279). Tatsächlich wird Staubfinger im Laufe der Geschichte sein Leben aus Liebe opfern, allerdings nicht für einen Marder, sondern für Farid, den er wie einen Sohn ins Herz geschlossen hat (TB, S. 676). In der Bis(s)-Serie wird Bellas Leben gleich mehrfach gerettet, ebenso das von Renesmee, Charly, Jacob, Edward und der gesamten Familie Cullen. Auch die Panem-Trilogie ist durchzogen von diesem Schema: Bei Hungerspielen und Krieg gegen das Kapitol geht es hauptsächlich darum, wer überlebt.

\section{Die Schlacht, der letzte Kampf und die Konfrontation mit dem Tod}

Den Antagonisten in Harry Potter und den Korpustexten geht es aus unterschiedlichsten Motiven heraus im Aushandlungsprozess vorrangig darum, die Protagonisten zu töten. Sämtliche Abenteuersequenzen und Binnenhandlungen laufen dementsprechend auf den Höhepunkt am Schluss zu: das letzte Aufeinandertreffen der beiden Parteien, die große Schlacht, in der nur eine Seite überleben kann. ${ }^{89}$ Diese muss am Ende stehen, symbolisiert sie doch die Auflösung aller Konflikte, ja mitunter die Errettung der Menschheit. Der Held durchläuft so in der Regel sowohl in Bezug auf die Haupt- als auch die Nebenhandlungen die drei Phasen Vorbereitung, Schlacht und Sieg, denen je nach Gewichtung unterschiedlich viel Aufmerksamkeit zukommt. Das Schema findet sich sowohl auf Ebene der Folgen- als auch auf Ebene der Serienhandlungen. In Die Tribute von Panem beispielsweise nimmt die zweite Phase den größten Teil ein, die Hungerspiele und der Krieg gegen das Kapitol dominieren lange Zeit Haupt- und Nebenhandlungen; beide bedrohen nicht nur das Leben von Katniss, sondern auch das Leben derer,

\footnotetext{
${ }^{88}$ Siehe auch Kapitel 2.2.3.2.

${ }^{89}$ Bergenthal (2008), S. $174 \mathrm{f}$.
} 
die sie liebt, sowie das Wohlergehen von ganz Panem. Als psychologisierte Heldin geht die ständige Todesangst nicht spurlos an ihr vorbei: Noch zwanzig Jahre nach errungenem Sieg wird sie von Albträumen geplagt und leidet an depressiven Verstimmungen (FZ, S. 427 f.). In der Edelstein-Trilogie hingegen nimmt die eigentliche Konfrontation mit dem Grafen von Saint Germain eine sehr kleine Rolle ein, dort dominiert klar die Vorbereitung auf die Konfrontation. Dennoch ist auch hier klar: Beim letzten Aufeinandertreffen geht es um Leben und Tod, denn die Prophezeiung lautete so. Nur einer, entweder der Graf oder Gwendolyn, kann überleben, wenn der Kreis der Zwölf vollendet wird und der oder die Überlebende als Belohnung das ewige Leben erhält (SG, S. 43; S. 325).

\subsubsection{Zum Einfluss des Kriminalromans auf die Post-Potter-Texte}

Ähnlich wie Detektive suchen Harry Potter und die Protagonisten des Korpus Gegenstände, Schurken, Schuldige, Verräter, Diebe und Mörder, spekulieren, ermitteln und recherchieren, verhören, belauschen, observieren, analysieren Indizien, ziehen Schlussfolgerungen und erbringen intellektuelle Rätselarbeit. ${ }^{90}$ Die Anleihen beim Kriminalroman bzw. der Detective Story sind evident, zumal von den Autoren gestreute Informationen auch gerne mal in die Irre führen. Nicht jede Spur erweist sich als richtig, nicht jeder Verdächtige als wirklich schuldig. ${ }^{91}$ Falsche Fährten werden gelegt, handlungs- und lösungsrelevante Informationen zurückgehalten und dafür lösungsirrelevante nahegelegt, um falsche Hypothesen beim Rezipienten zu provozieren. ${ }^{92}$ Hinzu kommt ein prototypisches Krimipersonal: „ein Detektiv, Assistenten, ein Verbrecher bzw. eine Verbrecherbande, Opfer, unschuldige Verdächtige, die Polizei “all diese Rollen bzw. Figurenschemata finden sich bei Harry Potter und seinen Nachfolgern wieder. ${ }^{93}$ Im Vergleich zum Liebes- oder Abenteuerroman sind die Einflüsse allerdings als niedriger einzustufen.

\section{Zum Recherchieren und Sammeln von Indizien und zum Lösen von Rätseln}

Die Protagonisten des Korpus ermitteln trotz ihres jugendlichen Alters und ihrer Unerfahrenheit ohne professionelle Unterstützung. Die Polizei, die in Kriminalromanen prototypisch den Detektiv unterstützt, häufig auch allein die Ermittlerrolle übernimmt, fällt als rettender Ausweg aus akuten Bedrohungssituationen weg, zählen Polizisten doch zu den Uneingeweihten in

\footnotetext{
${ }^{90}$ Bürvenich hat u. a. diese Einflüsse des Kriminalromans auf Harry Potter herausgearbeitet. Siehe Bürvenich (2001), S. 160 und Bergenthal (2008), S. 218-255.

${ }^{91}$ Bürvenich (2001), S. 161.

${ }^{92}$ Bergenthal (2008), S. 227.

${ }^{93}$ Ebd., S. 222.
} 
der Ausgangswelt, sodass ihnen die nötige Expertise zur Aufklärung der Verbrechen fehlt. Die Fälle, denen sich die Protagonisten widmen, reichen von Diebstahl und Entführung über Körperverletzung und Mord bis hin zur geplanten Vernichtung ganzer Völker. Auffällig ist dabei, dass Observieren und Belauschen bei der Informationsbeschaffung eine wichtige Rolle einnehmen. ${ }^{94}$ In Percy Jackson umgibt die Sterblichen „, eine magische Kraft namens Nebel“ (PJ 2, S. 28), sodass sie weder Gottheiten noch Monster wahrnehmen können. Die Polizei wird daher von diesen als rechtschaffende Exekutive nicht ernstgenommen (PJ 2, S. 31, S. 36), denn sie kommt gegen die Macht von Unsterblichen nicht an (PJ 2, S. 236). Percy macht sich mit jeweils anderer Begleitung an die Auflösung seiner Fälle, die u. a. Diebstahl, Entführung und Mord beinhalten. Als wichtigste Informationsquelle dient das Orakel, dessen Weissagungen in Form von metaphorischen Rätselsprüchen dargeboten werden, die es von Percy und seinen Freunden auszulegen gilt. Da Annabeth im Besitz einer Tarnkappe ist, ${ }^{95}$ können Gegner unbemerkt ausspioniert werden (PJ 3, S. 95, S. 155 ff.). Zudem wenden sich die Jugendlichen an Informanten wie Nereus, die sie erst aufsuchen und um Hilfe bitten müssen (PJ 3, S. 185). Auch in der Edelstein-Trilogie gehört die Polizei zu den Uneingeweihten und fällt als unterstützende Ermittlungsinstanz weg: So geht sie beispielsweise davon aus, dass Gwendolyns Großvater Lucas Montrose eines natürlichen Todes gestorben ist, denn nichts spricht für einen Mord, und die Polizei findet auch keine Spuren dafür, dass etwas Wertvolles am Tatort entwendet wurde (SG, S. 127). Gwendolyn übernimmt zusammen mit Leslie und Xemerius alle Ermittlungen um den Grafen von Saint Germain selbst, der sich letztendlich als der Mörder ihres Großvaters herausstellt (SG, S. 467). Leslie liebt das Recherchieren und will unbedingt später ein Detektivbüro eröffnen. Als Informationsquellen dienen neben dem Internet auch Zeitzeugen wie Gwendolyns Großvater, die zu unterschiedlichen Zeiten besucht werden, wodurch unterschiedliche Wissensbestände akquiriert werden können. Der Geist Xemerius erweist sich als äußerst nützlich, denn er kann unbemerkt Gespräche belauschen und Wände passieren (SB, S. 164; SG, S. 30 f.). Die Auswertung der Indizien gestaltet sich als höchst komplexe Angelegenheit, zumal das Springen in der Zeit und die verdrehten Ursache-Wirkungs-Beziehungen sogar eigene Taten und deren Konsequenzen schwer nachvollziehbar machen: Dass der Zettel, der Lucas Montrose dazu veranlasste, sich zu einer bestimmten Zeit im Alchemielabor einzufinden, von Gwendolyn selbst geschrieben wurde, kann sie zum Zeitpunkt des Treffens nicht wissen, da sie die Nachricht erst in der Zu-

\footnotetext{
${ }^{94}$ Bürvenich (2001), S. 161.

${ }^{95}$ Die Parallele zu Harry Potter, wo ein Tarnumhang genutzt wird, ist augenscheinlich.
} 
kunft verfassen wird (SB, S. 78). Auch in Die Tribute von Panem werden Schemata des Kriminalromans bemüht: Im Jubel-Jubiläum müssen die Teilnehmer der Hungerspiele erst einmal die Prinzipien durchblicken, nach denen sich die Arena gestaltet, um ihr Leben zu schützen. Katniss zieht schließlich die richtigen Schlussfolgerungen aus ihren Beobachtungen, nämlich dass die Arena als überdimensionale Uhr funktioniert, die zu jeder vollen Stunde eine tödliche Gewalt auslöst (GL, S. 361). Den entscheidenden Hinweis verdankt sie Wiress, einer verwirrten und labilen früheren Siegerin aus Distrikt drei, die sich nicht adäquat mitteilen kann, aber eine gute Intuition besitzt. ,Wir schauten hinüber zu Wiress, die, mit getrocknetem Blut bedeckt, im Kreis herumirrt und die ganze Zeit ,Tick, tack. Tick, tack'vor sich hin murmelt. “(GL, S. 354) Während die anderen Verbündeten Wiress’ Signale nicht ernstnehmen, kombiniert Katniss alle Erlebnisse richtig:

Eine Uhr. Auf einmal sehe ich fast, wie die Zeiger über das zwölfgeteilte Antlitz der Arena laufen. Zu jeder neuen Stunde beginnt ein neuer Horror der Spielmacher und löst den vorangegangenen ab. Blitze, Blutregen, Nebel, Affen - das sind die vier ersten Stunden auf der Uhr. Und um zehn die Welle. Ich weiß nicht, was in den anderen sieben passiert, aber ich weiß, dass Wiress recht hat. (GL, S. 361).

In Collins' Serie findet sich zudem verstärkt das Spionagemotiv. So wird berichtet, dass das Kapitol mutierte Vögel gezüchtet hat, die sich Wörter merken und wiederholen können, um gezielt potenzielle Rebellen auszuhorchen (GL, S. 107). Auch Katniss belauscht Gespräche und spioniert (sogar schon vor den eigentlichen Hungerspielen) ihre Konkurrenten aus (TS, S. 91).

\section{Zu falschen Fährten und zurückgehaltenen Informationen}

Analog zu Harry Potter weisen einige Texte des Korpus zudem für den Kriminalroman typische Techniken der Leserlenkung auf. Eine gezielte Informationsvergabe führt zu Hypothesen, die im weiteren Verlauf bestätigt oder verworfen werden: Sogenannte Red Herrings, bewusst gesetzte falsche Fährten, finden sich zuhauf: ${ }^{96}$ Informationen, die handlungsirrelevante Schemata aktivieren, von handlungsrelevanten Fakten ablenken und so Spannung erzeugen: In Der Fluch des Titanen sind Percy und seine Mitstreiter auf der Suche nach einem gefährlichen Monster, das, von Kronos erweckt, die Welt in Schrecken zu versetzen und den Olymp zu stürzen vermag. Die Suche stützt sich auf eine Aussage Dr. Thorns, die sich als falsche Fährte erweist:

„Das Beben der Monster.“ Dr. Thorn lächelte hinterhältig. „Die Schlimmsten, die Mächtigsten wachen jetzt auf. Monster, die seit Jahrtausenden nicht mehr gesehen worden sind. Sie werden Tod und Zerstö-

\footnotetext{
${ }^{96}$ Vgl. Bergenthal (2008), S. 229.
} 
rung mit sich bringen, wie die Sterblichen sie noch nie erlebt haben. Und bald wird das wichtigste Monster von allen zurückkehren - das, das den Sturz des Olymps herbeiführen wird.“ (PJ 3, S. 31)

Artemis bestätigt die Aussage, sie ist sehr besorgt ob der drohenden Gefahr und meint, sie selbst habe die ganze Zeit die Anzeichen für die Katastrophe nicht erkannt (PJ 3, S. 51). Aktiviert wird ein Schema, das auf ein ,riesiges, gefährliches Ungeheuer“ (PJ 3, S. 270) warten lässt, das gefunden und dann im Kampf überwunden werden muss. Weder Percy noch der Leser können in Bessie, der Schlangenkuh, dieses Monster erkennen, da es bei seiner Einführung ein gänzlich anderes Schema aktivierte, nämlich das eines lieben, niedlichen Tierchens: „, , Muuuuh!' Die Schlangenkuh stupste mich mit der Schnauze und sah mich aus großen braunen Augen an. “(PJ 3, S. 138). Sie ist eine „brave und schöne Kuh“ (PJ 3, S. 138) und zudem Percys „Freundin“ (PJ 3, S. 269). Die Suche nach dem „,Monster“ (PJ 3, S. 262) erweist sich somit als Sackgasse: Zum einen hatte Percy Bessie längst gefunden (PJ 3, S. 246), zum anderen war die anfangs nahegelegte Hypothese unzutreffend, denn das Ungeheuer ist nur gefährlich, wenn es geopfert wird, und nur so kann es den Sturz der Götter herbeiführen. Von ihm geht keinerlei körperliche Gefahr aus (PJ 3, S. 270). In diesem Fall hatten weder Percy noch der Leser die Chance auf eine korrekte Hypothese, denn es gab neben der falschen Fährte keine richtige. Die Information, dass das Monster im Akt des Opferns seine Macht entfaltet, wird vor der Auflösung weder erwähnt noch angedeutet, sondern bewusst zurückgehalten, sodass es keine erkennbare Verbindung zwischen Bessie und dem gesuchten Monster gab.

Analog dazu suchen Gwendolyn und ihre Freunde in der Edelstein-Trilogie einen Komplizen des Grafen de Saint Germain, der als verantwortlich für den Mord an Lucas Montrose gilt. Die Hypothese stützt sich auf eine Aussage Lady Tilneys, der unmittelbar Glauben geschenkt wird:

„Das heißt, das Schließen des Blutkreises wird von beiden Seiten aus vorangetrieben“, sagte Lady Tilney nachdenklich. „In der Vergangenheit zieht der Graf von Saint Germain die Fäden und in der Zukunft gibt es einen oder sogar mehrere Verbündete, die seine Pläne unterstützen.“(SG, S. 394)

Gesucht wird also ein Verräter unter den Wächtern, der in der Gegenwart im Sinne des Grafen agiert. Spekulationen, wer das sein könnte, werden im Erzählstrang immer wieder aufgegriffen:

„Vor allem die Sache mit diesem Verbündeten des Grafen unter den Wächtern bereitet mir Kopfzerbrechen.“ Sie kaute einen Moment an dem Bleistift. „Wobei auch das auf einer Vermutung beruht, aber egal. Im Grunde könnte es jeder sein, oder? Der Gesundheitsminister, der komische Doktor, der freundliche Mr. George, Mr. Whiteman, Falk ... - und der rothaarige Trottel, wie heißt er noch mal?" (SG, S. 416) 
Auch hier liegt eine falsche Hypothese vor: Der Gesuchte befindet sich weder unter den Wächtern, noch kann er überhaupt mit der Gegenwart bzw. Zukunft in Verbindung gebracht werden, vielmehr ist es der Graf selbst, der ebenfalls in der Zeit springen kann und sich in der Gegenwart als Gwendolyns Lehrer ausgibt, um sie zu observieren und Kontrolle auszuüben (SG, S. 265).

In der Tintenwelt-Trilogie werden ebenfalls häufig wichtige Informationen zurückgehalten. Der Verbleib von Meggies Mutter beispielsweise ist von Anfang an rätselhaft. Zu Beginn von Tintenherz, wird folgendes Gespräch zwischen Mo und Meggie geschildert, das die Grundlage für Spekulationen jeder Art liefert:

„Sie musste fort, als du gerade drei Jahre alt warst.“- „Warum?“ - „Sie musste eben fort.“- „Weit fort?“ - „Sehr weit.“- „Ist sie tot?“- „Nein, ganz bestimmt nicht.“ Meggie war es gewohnt, dass Mo auf manche Fragen seltsame Antworten gab. Und mit zehn Jahren glaubte sie nicht mehr an eine Mutter, die Mo nur erfunden hatte, sondern an eine, die einfach fortgegangen war. (TH, S. 92).

Spätestens wenn klar ist, dass Mo Figuren aus Büchern heraus- und hineinlesen kann (TH, S. 166), liegt nach diesem Gespräch die Vermutung nahe, dass Resa sich in der Tintenwelt befindet, denn in diesem Falle wäre sie zwar nicht tot, aber dennoch unerreichbar. Die entscheidende Information, dass sie von Darius in Capricorns Dorf gelesen wurde und seither dort als seine Magd dient, wird lange zurückgehalten (TH, S. 418), die Figur der stummen Magd als eine Freundin Staubfingers eingeführt (TH, S. 337), ohne dass der Leser ahnt, dass es sich um Meggies Mutter handelt (TH, S. 353). Erst nach und nach werden Indizien gestreut, die eine solche Hypothese zulassen: So hat Resa ein auffälliges Interesse an den neuen Gefangenen Capricorns, insbesondere an Zauberzunge (TH, S. 353), und scheint darüber hinaus Meggie sehr ähnlich zu sehen (TH, S. 356). Zudem bietet der Sachverhalt, dass Staubfinger in sie verliebt ist, ein Motiv, warum er ihren Verbleib vor Mo geheim gehalten hat $\mathrm{TH}$, S. 381).

\subsubsection{Zur schaurigen Vampirromanze als etabliertem Genremix}

Innovative Genremixe mitsamt ihren bewusst erzeugten Kontrasten und unkonventionellen Schemataverknüpfungen sind offenbar so reizvoll, dass gleich mehrere Autoren auf genau jene Mixtur zurückgreifen und sie zum Trend erheben. ${ }^{97}$ So leiteten Stephenie Meyers Vorläufer eine Ära von Vampirromanen ein, worin Liebesroman, Abenteuerroman, Thriller und

\footnotetext{
${ }^{97}$ Vgl. Mohr (2012), S. 258 f.
} 
Schauerroman miteinander vermischt werden, ${ }^{98}$ wobei der Einfluss des Letzteren, oftmals auch als Gothic Novel identifiziert, ${ }^{99}$ vor allen auf Figurenebene wirkt. ${ }^{100}$ Die Texte erzählen die Liebesgeschichte zwischen Mensch und Vampir, zwischen Opfer und Täter, und pervertieren das eigentlich Unheimliche und Schreckliche der Vampirfigur zur erotischen Aura. Der Erfolg des Konzepts konnte bereits 2010 nachgewiesen werden: Manz macht neunzehn Werke aus, die sich sehr dicht am ersten Band der Bis(s)-Serie bewegen und eine ,hohe bis sehr hohe intertextuelle Dichte" aufweisen. ${ }^{101}$ Sie nennt u. a. die Romane Der Kuss des Dämons (2008), Die Vampirschwestern (2008) und Vollmondkuss (2008), deren Nähe zu Meyers Werken erstaunlich ist: Die weiblichen Protagonistinnen stoßen zumeist auf „äußerst attraktive, zunächst spröde, dann dafür umso fürsorglichere Vampire " und verfallen ihnen restlos. ${ }^{102}$ Auch Dämonen, Mörder oder Schattenjäger - wie im Falle von City of Bones (2008) - können die Auserwählten sein, in jedem Fall sind es düstere Gestalten, die zu geheimnisvollen Frauenträumen stilisiert werden. Manz stellte 2010 fest, dass ein Ende des Trends nicht abzusehen ist, ${ }^{103}$ und tatsächlich hat sich das Genre der Vampirromanze heute derart etabliert, dass es als eigene Sparte in den Buchhandlungen Deutschlands angekommen ist. ${ }^{104}$

\subsubsection{Zwischenfazit}

Die Analysen haben gezeigt, dass die Texte des Korpus nicht allein als phantastisch bzw. mythisch aufzufassen sind, sondern daneben auch Schemata aufrufen, die konventionell als genreweisend für den Liebesroman, den Abenteuerroman und den Kriminalroman gelten. Die Schemata nehmen dabei unterschiedlich viel Einfluss auf die Haupthandlung, sind jedoch bei allen identifizierbar, sodass die Werke analog zu Harry Potter als Genremix aufgefasst werden können. Auffällig ist, dass dabei auf die gleichen Schemata zurückgegriffen wird, welche die Handlungen strukturieren: Die Protagonisten sind ein Part des zentralen Liebespaars, dessen Zusammenführung parallel zur Abenteuerhandlung verläuft. Letztere verknüpft abenteuerliche Begebenheit verschiedener Komplexität und Spannweite. „Das Retten einer Person“, „die Reise ins Unbekannte“ und „die Schlacht“ lassen sich als Schemata besonders häufig beobachten. Aus dem Kriminalroman werden vor allem das Motiv der Ermittlung und Re-

\footnotetext{
${ }^{98}$ Rank (2011), S. 186; auch Ernst (2008), S. 21.

${ }^{99}$ Siehe beispielsweise Grün (2007), S. 11.

${ }^{100}$ Mohr (2012), S. 96.

${ }^{101}$ Manz (2011), S. 137.

102 Ebd., S. 139.

103 Ebd., S. 141.

${ }^{104}$ Beispielsweise hat die Buchhandelskette Thalia die Kategorie in ihre Bücherklassifizierung aufgenommen, in der vordergründig moderne Vertreter des Genres aufgeführt werden, die eine Mixtur zwischen Schauer- und Liebesroman aufweisen; www.thalia.de/shop/vampirromane-11344/show/ (8.5.2014).
} 
cherche entlehnt und krimitypische Strategien der Leserlenkung und Informationsgabe angewandt, wichtige Informationen zurückgehalten, handlungsirrelevante hingegen besonders hervorgehoben. Damit sind Harry Potter und die Texte des Korpus nicht nur als Genremixe zu betrachten, sondern sogar als ähnliche Genremixturen. Die Bis(s)-Serie verdient besondere Beachtung, da ihre Mixtur ein eigenes Trendgenre hervorgebracht hat, das sich aus dem Kontrast von Liebes- und Schauerroman speist.

Die Tendenz zum Genremix bzw. der freie Umgang mit Genreschemata kann zudem als Argument herangezogen werden, die Texte des Korpus der Postmoderne zuzuordnen, denn dieses nicht zuletzt intertextuelle Phänomen ist mit eben dieser Stilepoche verbunden. Das Sprengen von Genregrenzen begünstigt dabei nicht nur die multimediale Distribution, sondern auch die globale Vermarktung der betrachteten Serien: Es ermöglicht eine Multiadressierung, die in Kapitel 6 noch einmal explizit zum Thema gemacht werden wird.

\subsection{Zur Motiv- und Figurneuinterpretation in den Post-Potter-Texten}

Sowohl bei Harry Potter als auch den Texten den Korpus ist das postmoderne Verfahren der Motiv- bzw. Figurneuinterpretation nachweisbar. Die Neudeutungen knüpfen an etablierte Traditionen der Literaturgeschichte an und modifizieren sie so, dass sie sich in die Lebensund Erfahrungswelt der Rezipienten einpassen. Damit wird einerseits der Bezug zur Jetztzeit betont, der, wie in Kapitel 3 herausgearbeitet, die phantastischen Welten prägt, andererseits das selbstreferenzielle Moment der Texte. Denn auffällig oft werden intertextuelle Systemreferenzen auf bestimme Motiv- und Figurentraditionen im inneren Kommunikationssystem der Werke markiert und sogar explizit zum Thema gemacht.

Die Konzeption der Vampirfigur in der Bis(s)-Serie soll nun genauer in den Blick genommen werden, um deren Neuinterpretationen beispielhaft aufzuzeigen, dazu wird Meyers Vampir nun auf seine literarischen und cineastischen Vorlagen hin untersucht und seine Kennzeichnung mit literaturhistorisch etablierten Vampirattributen abgeglichen (Kapitel 5.4.1). Daran anschließend soll in Kapitel 5.4.2 gezeigt werden, dass der Bezug zu literarischen Vorlagen in den Texten des Korpus explizit im inneren Kommunikationssystem verhandelt wird. Dabei liegt der Fokus insbesondere auf der Strategie, zeitgenössische Mythenrezeption zu reflektieren, nicht zuletzt um Authentizität zu erzeugen. 


\subsubsection{Zur Interpretation des Vampirs in Stephenie-Meyers Bis(s)-Saga}

Das von Meyer entworfene Vampirbild eignet sich hervorragend als Beispiel für das postmoderne Verfahren der Motiv- bzw. Figurneuinterpretation, wodurch etablierte literarische Motive oder Figuren eine ,zeitgemäße“ Um- oder Neudeutung erfahren. Die Vampirfigur steht in der Bis(s)-Serie im Mittelpunkt der Handlung - ähnlich wie die Zaubererfigur in Harry Potter -, sie ist Ausgangspunkt der Figurenwelt und damit gleichsam logischer Ursprung sämtlicher phantastischer Erzählelemente. Meyers Vampire sind grundsätzlich menschenähnlich und biologisch-lebenspraktisch ausgestaltet, sie folgen damit einer Tendenz, die in zeitgenössischer phantastischer Literatur häufig ausgemacht werden kann. Mohr stellt diesbezüglich fest, dass Anatomie, Morphologie und Lebensweise einer phantastischen Figur meist explizit thematisiert werden, seltener verbleibe die Attribuierung bei einer märchenhaft-abstrakten oder symbolischen Aufladung. ${ }^{105}$ Zudem seien die Wesen häufig mit rationalem Verstand und menschenähnlichen Emotionen und Denkstrukturen ausgestattet. ${ }^{106}$ All dies trifft uneingeschränkt auch auf Meyers Vampire zu, deren Alltagswelt anhand der Familie Cullen im Allgemeinen und Edwards Leben im Speziellen vorgeführt wird: Dieser besitzt zwar den Körper eines übermenschlich starken und blutbedürftigen Vampirs, aber das Denken eines verliebten Teenagers, der ohne seine Angebetete nicht sein will (BzMi, S. 504). Er geht zur Schule, liebt es, Klavier zu spielen (BzEdN, S. 61), und hat einen Faible für schnelle Fahrzeuge (BzMo, S. 188). ${ }^{107}$ Mit seiner menschlichen Emotionalität, seiner gefährlichen Aura und seinen übermenschlichen Kräften wird er zur Projektion eines „Traumboys“, der seine Beschützerrolle sehr ernstnimmt und dessen Gefühle unerschütterlich sind.

Meyers Vampire basieren auf einer Vielzahl von Prätexten, die dann als Ausgangspunkt eigener Interpretation instrumentalisiert werden. Die Figurenkonzeption kann somit als ästhetisches Spiel, als Changieren zwischen Tradition und Innovation betrachtet werden, indem intertextuell auf literarische oder filmische Traditionen verwiesen und auch bewusst mit ihnen gebrochen wird. Eine solche interpretierende Systemreferenz ist paradigmatisch für die Texte des Korpus und kann nach Genette auch als metatextuelles Phänomen identifiziert werden.

\footnotetext{
${ }^{105}$ Mohr (2012), S. 73, S. 151.

${ }^{106}$ Ebd., S. 73.

${ }^{107}$ Vgl. Manz (2011), S. 138.
} 
Die Attribute der Bis(s)-Wesen sollen nun zusammengestellt und mit literarischen, mythischen oder cineastischen Vorlagen verglichen werden, um beispielhaft aufzuzeigen, wie literaturgeschichtlich etablierte Motive neu interpretiert werden. ${ }^{108}$

Die Vampire ernähren sich von Blut, vornehmlich von Menschenblut; es gibt unter ihnen jedoch auch sogenannte ,Vegetarier“, die aus moralischen Gründen auf Tierblut zurückgreifen, das ihnen nicht die gleiche, aber eine hinreichende Versorgung ermöglicht (BzMo, S. 198). Nach natürlicher Nahrung haben sie keinen Drang, denn sie schmeckt ihnen nicht (BzMo, S. 25, S. 145).

In der Historie und Literatur zahlreicher Kulturen erzählen Sagen und Legenden von abnormalen Wesen, die sich von Menschenblut ernähren: In Japan gibt es die Hannya-Gestalt, einen weiblichen, bösartigen Vampir, der auch Kinder nicht verschont. In Afrika kursiert seit Jahrhunderten die Sage vom Ovenuga-Dämon, in Europa vom Nachzehrer, der der Legende nach ein walisisches Dorf komplett entvölkert haben soll. ${ }^{109}$ Auch im alten Griechenland wurde bereits von Vampiren berichtet. ${ }^{110}$ Insgesamt liegen den Quellen mythische Elemente und Erzählstrukturen zugrunde, was vonseiten der Forschung meist auf ihre narrative Grundfunktion zurückgeführt wird. ${ }^{111}$ Es wird vermutet, dass Gerüchte oder Erzählungen über Vampire gerade dann laut wurden, wenn massenhaft „unerklärliche“ Todesfälle oder auch Epidemien auftraten, für die die Vampirsagen greifbare Begründungszusammenhänge lieferten und damit als Angstbewältigungsstrategien fungierten. ${ }^{112}$ Gómez-Alonso behauptet sogar, dass der volkstümliche Vampirglaube (er bezieht sich auf Südosteuropa) im Zuge von Tollwut und anderen Epidemien, die durch Speichel und Tierbisse übertragen wurden, entstanden ist. ${ }^{113}$ Gestützt wird die These dadurch, dass sich einige Symptome der Tollwut - ,,gerötete Bissstellen, Unruhe, Lichtempfindlichkeit, Schlaflosigkeit, (brennender Durst) “ - in Sagen und Legenden bis hin zu heutigen Adaptionen festgesetzt haben. ${ }^{114}$

\footnotetext{
108 Ähnlich ließe sich mit dem Götterbild in Percy Jackson, dem Stein der Weisen in der Edelstein-Trilogie oder dem Motiv der Jägerin in Die Tribute von Panem verfahren.

${ }^{109}$ Klewer (2007), S. S. 13-51, hier S. 18.

${ }^{110}$ Ebd., S. 25.

${ }^{111}$ Ulonska (2012), S. 315 f.

112 Siehe dazu Köppl (2010, S. 228 f.), der darauf aufmerksam macht, dass ,, weltliche und kirchliche Mächte die antisemitische Vampirhysterie jahrelang Hand in Hand vorangetrieben " haben; ebenso Klewer (2007), S. $37-$ 40.

${ }^{113}$ Kreuter (2001), S. 100.

${ }^{114}$ Ulonska (2012), S. 314
} 
Vampire sind insbesondere in Film und Fernsehen populär geworden, wo ihr Mythos ständig neu erfunden wird. ${ }^{115}$ Nosferatu ${ }^{116}$ und Bram Stroker's Dracula ${ }^{117}$ sind wohl die bekanntesten Werke, die maßgeblich zum zeitgenössischen Vampirbild beigetragen haben: ${ }^{118}$ eine typische Horrorgestalt des Schauerromans, blutrünstig, gefährlich und abstoßend. ${ }^{119}$ Als Graf Dracula erfährt die Figur bereits eine Umdeutung, da sie dort zwar noch immer als gefährlich, daneben aber als intelligent und kultiviert dargestellt wird. Dracula ist ein snobistischer Aristokrat, von dem eine diffuse Gefahr ausgeht. ${ }^{120}$ Meyers Wesen schließt an diese Interpretation an und greift zudem das Vampirbild zeitgenössischer Fernsehserien auf, z. B. aus Moonlight, das zunächst im amerikanischen und später auch im deutschen Fernsehen lief und die Lebensgeschichte eines Vampirs erzählt, der sich mit Konservenblut ernährt, um keine Menschen töten $\mathrm{zu}$ müssen, und sich in eine Normalsterbliche verliebt. In True Blood entsagen die Vampire dem Menschenblut zugunsten künstlicher Alternativen. ${ }^{121}$ Noch stärker zeigen sich Parallelen zu Vampire Diaries, worin sich eine Schülerin in ihren Vampirmitschüler verliebt. ${ }^{122}$ Dass Meyers Vampire lediglich Tierblut konsumieren, spricht - sogar begrifflich - den Vegetarierdiskurs an, der im beginnenden 21. Jahrhundert eine Hochphase erlebt. ${ }^{123}$

Die Augenfarbe der Vampire verändert sich, je nachdem wie „durstig“ sie sind: Haben sie gerade erst Beute gemacht, sind sie karamellfarben, andernfalls werden sie dunkel (BzMo, S. 198).

Das Motiv der sich wandelnden Augenfarbe ist eine innovative Komponente und in anderen Erzählungen nicht geläufig. Die Vorstellung aber, dass Vampire eine ungewöhnliche Augenfarbe besitzen, ist etabliert. In Filmen werden sie oft mit roten oder blutunterlaufenen Augen dargestellt, zum Beispiel in Dracula ${ }^{124}$ aus dem Jahre 1958.

\footnotetext{
115 Ebd., S. 317.

116 Der Klassiker ist als DVD erhältlich: Nosferatu - Phantom der Nacht, dir. Werner Herzog, wr. Werner Herzog, pr. Werner Herzog (Twentieth Century Fox 5.10.1979; DVD: Arthaus Collection, 12.10.2007).

117 Der Film geht zurück auf die literarische Vorlage von Bram Stoker. Der Film ist u. a. auf DVD erhältlich: Bram Stoker's Dracula, dir. Francis Ford Coppola, wr. James V. Hart, Bram Stoker, pr. Francis Ford Coppola, Fred Fuchs (Columbia Pictures 13.11.1992; DVD: Sony Pictures Home Entertainment, 21.3.2002).

${ }^{118}$ Ein weiterer bekannter Vertreter des reuigen Vampirs ist sicherlich der auf Anne Rice zurückgehende Protagonist aus dem Film Interview mit einem Vampir, dir. Neil Jordan, wr. Anne Rice, pr. David Geffen (Warner Bros., 11.11.1997). Siehe dazu Köppl (2010), S. 187-223.

${ }^{119}$ Bergenthal (2008), S. $312 \mathrm{ff}$.

120 Ebd.

${ }^{121}$ Siehe auch www.hbo.com/true-blood (9.7.2014).

${ }^{122}$ Siehe dazu www.vampire-diaries.net (9.7.2014).

${ }^{123}$ Siehe beispielsweise den Bestseller Tiere essen (2009) von Jonathan Safran Foer.

${ }^{124}$ Christopher Lee spielt in diesem Film die Hauptrolle: Dracula, dir. Terence Fisher, wr. Jimmy Sangster, pr. Michael Carreras (Universal Pictures, 8.5.1958).
} 
Vampire schlafen nie (BzMo, S. 195).

Verbreiteter ist, dass die Blutsauger in Särgen nächtigen - eine Legende, die ihren Ursprung u. a. in China und Bulgarien zu haben scheint, ${ }^{125}$ und in Bis(s) zum Morgengrauen in einem selbstreferenziellen Kommentar von Edward als Mythos abgetan wird (BzMo, S. 195). In der literarischen Überlieferung gibt es zudem die Vorstellung, dass Vampire tagsüber schlafen und nachts wach sind ${ }^{126}$ um dann ihre Opfer überfallen. ${ }^{127}$ Edwards Schlaflosigkeit dient vor allem seiner Beschützerrolle: So kann er nachts auf Bella aufpassen und ihr beim Schlafen zusehen (BzMo, S. 308).

Vampire haben keinen Herzschlag und keinen Blutkreislauf; sie müssen nicht atmen (BzMo, S. 354). Ihre Haut ist kalt und weiß (BzMo, S. 145).

Diese Eigenschaften folgen vermutlich der Tradition, dass Vampire als „Untote“ gelten. ${ }^{128}$ Es gibt Varianten, in denen kürzlich verstorbene Personen für eine gewisse Zeit als Vampire auferstehen, hier werden sie oft als weiß und kalt wie Leichen beschrieben. ${ }^{129}$ Edwards Blässe wird indes nicht mit Tod, sondern, gänzlich entgegengesetzt, mit Reinheit, Unschuld und Perfektion bzw. mit Engeln assoziiert: Bella betont mehrfach, dass sein Antlitz „engelhaft“ (BzMo, S. 277) sei bzw. dass kaum ein „Engel mehr Herrlichkeit ausstrahlen“ könne (BzMo, S. 254).

Vampire sind übermenschlich schnell und stark (BzMo, S. 145).

Körperliche Stärke und Schnelligkeit werden in vielen Filmen und Serien als Charakteristika aufgegriffen, etwa in Vampire Diaries. In traditionellen Vampirmythen kommen des Öfteren Vampire vor, die fliegen können, zum Beispiel die Obayifo und die Shtria. ${ }^{130}$ Das Motiv wird insbesondere bei der Edwarddarstellung in den Bis(s)-Filmen aufgegriffen, aber nicht explizit gemacht. ${ }^{131}$ Die körperliche Stärke betont die Männlichkeit Edwards und wird dazu genutzt, ihn zum heroischen Retter zu stilisieren: So rettet er gleich mehrfach Bellas Leben (BzMo, S. 504; BzMi, S. 346).

\footnotetext{
${ }^{125}$ Klewer (2007), S. 29 f.

${ }^{126}$ Dieses Motiv unterstreicht auch ihre Ähnlichkeit zu Fledermäusen.

${ }^{127}$ Klewer (2007), S. 30-33.

${ }^{128}$ Vgl. Köppl (2010), S. 100 ff.

${ }^{129}$ Klewer (2007), S. 35, S. 40.

${ }^{130} \mathrm{Zu}$ finden auch im Online-Vampirlexikon: www.aeterni.de/Vampires/Lexikon/Lexikon.html (9.7.2014).

${ }^{131}$ Im Buch hingegen kann Edward nicht fliegen.
} 
Ihre Haut glitzert, wenn sie in die Sonne kommen, daher meiden sie sonnige Plätze, um ihre Identität geheim halten zu können (BzMo, S. 275).

Lichtempfindlichkeit gehört zu den am häufigsten aufgerufenen Attributen überhaupt. ${ }^{132}$ Das Motiv geht auf eine Sage aus China zurück, die davon berichtet, dass Vampire durch Sonnenstrahlen oder Mondlicht getötet werden können und deshalb dazu verdammt seien, Lichtquellen fernzubleiben. ${ }^{133}$ In der Bis(s)-Serie wurde die Tradition aufgegriffen und auf ästhetische Weise umgedeutet, was vor allem der multimedialen Distribution entgegenkommt: Dass Vampire glitzern, macht sie nicht nur insgesamt reizvoller für visuelle literarische Medien, sondern erhöht auch ihren Wiedererkennungswert und unterstreicht ihre Attraktivität. Da Glitzern ein Alleinstellungsmerkmal der Bis(s)-Vampire darstellt, kann jedwede visuelle Darstellung sofort auf die Buchvorlage zurückgeführt werden, ein Vorteil, der bei der Vermarktung des kompletten Labels genutzt wird. Interessanterweise fehlt bei Meyer das traditionellste Erkennungsmerkmal, das von nahezu allen Vorgängern aufgegriffen wurde: die Fangzähne. Die bewusste Abkehr kann nur als gezieltes Brechen mit der literarischen Tradition gewertet werden, zumal kein anderes Attribut derart stark mit Vampiren assoziiert wird. ${ }^{134}$ Der Verzicht ist auf alle Fälle folgender Eigenschaft zuträglich, auf die Meyer großen Wert zu legen scheint:

Vampire sind wunderschön. Sie ziehen Menschen des anderen Geschlechts an, was ihre Jagd auf Menschenblut erleichtert (BzMo, S. 278f.).

Schönheit als Lockmittel bei der Jagd ist schon bei frühen Vampirmythen belegt: Es gibt Sagen, die von weiblichen Vampiren berichten, die durch ihre Reize besonders leicht männliche Opfer anlocken können. Hier sind u. a. die Empusen-Erzählungen aus Libyen oder die russischen Wurdaklaken-Gestalten zu nennen. ${ }^{135}$ Köppl postuliert, dass der Vampir im Laufe seiner Entwicklung einer immer stärkeren sexuellen Aufladung ausgesetzt ist. ${ }^{136}$ Berichtet die Überzahl der Legenden noch von furchteinflößenden, hässlichen Kreaturen, so füllen heute stetig jüngere Schauspieler die Figur aus, die immer mehr zum Objekt der Begierde avanciert. In der Bis(s)-Serie findet diese Tendenz laut Köppl ihren Höhepunkt.

\footnotetext{
${ }^{132}$ So auch in den oben genannten Vampirfilmen.

133 Klewer (2007), S. 30.

${ }^{134}$ Köppl (2010), S. 231.

${ }^{135}$ Klewer (2007), S. 25f, S. 34.

${ }^{136}$ Köppl (2010), S. 235 f.
} 
Vampire besitzen zumeist, aber nicht immer besondere Fähigkeiten bzw. können sie ausbilden; diese beruhen meist auf Eigenschaften, die sie in ihrem menschlichen Leben ansatzweise schon besaßen (BzMo, S. 323). So kann beispielsweise Alice Cullen in die Zukunft sehen, Aro von den Volturis kann Gedanken lesen und Jasper Hale die Stimmung seines Gegenübers beeinflussen. Wovon das konkrete Auftreten abhängt, wird im Text nicht geklärt.

Einzelne Legenden berichten davon, dass Vampire Begabungen oder Sonderfähigkeiten besitzen oder ausbilden, etwa dass sie fliegen, sich in Luft auflösen oder mit Blicken töten können. ${ }^{137}$ Auch im oben bereits erwähnten Fernsehformat True Blood kommen Vampire vor, die Gedanken lesen können. Zu beobachten ist, dass die in der Bis(s)-Serie eingepflegten besonderen Attribute nicht auf körperliche, sondern mentale Fähigkeiten abheben. Kombinationen entfalten dabei interessante Interdependenzen und Synergieeffekte, etwa Edwards und Alices Fähigkeiten: Er kann Gedanken lesen und sie in die Zukunft sehen. Ein Umstand, der Vampirschach zu einem nachgerade absurden Spiel macht:

Ich hatte selten so was Witziges gesehen wie Edward und Alice beim Schachspiel. Sie saßen fast reglos da und starrten auf das Schachbrett, während Alice die Züge voraussah, die er machen wollte, und er die Züge, die sie machen wollte, in ihren Gedanken las. Den größten Teil der Partie spielten sie im Kopf sie hatten jeder zwei Bauern bewegt, als Alice plötzlich ihren König umstieß und sich geschlagen gab (BzAb, S. 65). ${ }^{138}$

Ausgerechnet Bellas Gedanken aber kann Edward nicht lesen und sich dadurch nie sicher sein, was in ihr vorgeht. Sie wiederum ist gänzlich immun gegen alle Vampirspezialfähigkeiten (BzMo, S. 211). Da Edward jedoch mental mit den Wölfen kommunizieren kann, besitzt er Zugang zu allen Gedanken des Rudels, inklusive zu denen Jacobs, der zu Edwards Missfallen unentwegt von seiner Freundin Bella schwärmt (BzAb, S. 148). Alices Sonderfähigkeit wiederum setzt in Gegenwart von Werwölfen gänzlich aus (BzMo, S. 499).

Die natürlichen Feinde der Vampire sind die Werwölfe (BzMi, S. 87).

Werwölfe und Vampire wurden in der Geschichte oftmals in Verbindung gebracht, allerdings weniger als natürliche Feinde. ${ }^{139}$ In Filmen wurden vielmehr die Parallelen betont. Allein dass beide Wesen sich den meisten Legenden zufolge mithilfe von Bissen ausbreiten, schafft eine

\footnotetext{
${ }^{137}$ Klewer (2007), S. 33, S. 36 f.

${ }^{138}$ Dieses Motiv erinnert stark an Zaubererschach bei Harry Potter, das auch durch die Gesetzmäßigkeiten der fiktionalen Welt eine eigene Dynamik erhält. Siehe HP 1, S. 217 f.

${ }^{139}$ Klewer (2007), S. 36.
} 
Motivnähe, die eine narrative Verknüpfung motiviert, so zum Beispiel im Film Underworld, in dem wie in der Bis(s)-Serie Hybridwesen, halb Vampir und halb Werwolf, vorkommen. ${ }^{140}$

Stephenie Meyer schuf einen Vampirtypus, der zwar eine Vielzahl literarischer Traditionen aufgreift, aber ein ganz eigenes Arrangement der ,erfolgreichsten Horrorfigur der Filmgeschichte" darstellt. ${ }^{141}$ Edward wird zum Inbegriff des schönen, starken und sogar moralisch überlegenen Traummanns stilisiert. Seine phantastischen Attribute erinnern zwar noch an die Schauererzählungen von gefährlichen Monstern, sind aber gänzlich der neuen Lesart verschrieben: Die animalischen Anteile sind bedrohlich, zugleich aber auch reizvoll, denn Edward ist gewillt, sie zu unterdrücken. Er ernährt sich zwar von Blut, das Töten von Menschen verstößt jedoch gegen seine Grundsätze, weswegen er zum „Vegetariertum“ übergegangen ist. Seine übermenschlichen Kräfte nutzt er hauptsächlich, um Bella zu beschützen. Er meidet Tageslicht, nicht weil er ein nachtaktiver, untoter Jäger ist, sondern seine Schönheit ihn verraten würde. Die neue Lesart der Figur spiegelt postmoderne Lebens- und Erfahrungswirklichkeit wider: Edward ist kein verstaubter Vampir aus grauer Vorzeit oder dem Mittelalter, er ist ein Teenager, der das Leben eines heutigen Jugendlichen lebt, und zwar mit allen Konsequenzen.

Die Neuinterpretation der Vampirfigur kommt der Vermarktung von multimedialdistribuierter Literatur entgegen. ${ }^{142}$ So wie in aktuellen Fernsehserien sind die CullenVampire nicht hässlich, grauenvoll und furchteinflößend, vielmehr werden sie als grazile und engelsgleiche Gestalten beschrieben - ein Umstand, der natürlich auch die Besetzung der Filme beeinflusst hat - , die in der Sonne glitzern. Damit liefern sie visuelle Schlüsselreize, die gerade auf eine weibliche Rezipientenschaft zielen und den Wert des Labels steigern. ${ }^{143}$ Stärke und Schnelligkeit eignen sich hervorragend für filmische Codes, ebenso ihre Wandelbarkeit, ein Umstand, der den Vampir wohl seit Anbeginn der Filmgeschichte für Moving Pictures empfiehlt. ${ }^{144}$ Eine ähnliche multimediale Anschlussfähigkeit lässt sich in der filmischen

\footnotetext{
${ }^{140}$ Underworld, dir. Len Wiseman, wr. Kevin Grevioux u. a., pr. Robert Bernacchi (Screen Gems Pictures, 19.9.2003).

${ }^{141}$ Köppl (2010), S. 190.

142 Bergenthal (2008, insbesondere S. 400 ff.) hat herausgearbeitet, wie sehr sich Harry Potter für eine multimediale Distribution empfiehlt.

${ }^{143}$ Die Süddeutsche Zeitung berichtete von Robert Pattinson und seiner Wirkung auf das weibliche Geschlecht: www.sueddeutsche.de/kultur/Bis(s)-star-robert-pattinson-vampirchen-mit-beisshemmung-1.139979 (15.7.2014).

${ }^{144}$ Köppl (2010), S. 189 und Ulonska (2012), S. 318.
} 
Adaption der Bis(s)-Serie auch für die Werwolf-Figuren belegen, die sich durch muskulöse und nackte Oberkörper hervorheben. ${ }^{145}$

\title{
5.4.2 Zur Reflexion zeitgenössischer Mythenrezeption in den Post-Potter- Texten
}

Indem Meyers Wesen auf unterschiedliche Mythen, Sagen und Filme verweisen, liegt eine Systemreferenz vor, an die sich die Neuinterpretation anschließt. Diese wird explizit zum Thema gemacht, was sie nach Genette strenggenommen als metatextuelle Bezugnahme auszeichnet. Denn der Aufruf verschiedener Prätexte wird expressis verbis im inneren Kommunikationssystem markiert: Bella recherchiert im Internet Vampirlegenden (BzMo, S. 142) und versucht die Informationen mit ihrer Weltvorstellung in Einklang zu bringen, die anfangs mit der des Rezipienten übereinstimmt:

\begin{abstract}
Das Erste, was ich anklickte, war der Mythos von Danag, einem philippinischen Vampir, der angeblich vor langer Zeit die Wasserbrotwurzel auf die Insel brachte und anpflanzte. Dem Mythos zufolge arbeiteten der Danag und die Menschen viele Jahre lang Seite an Seite, doch die friedliche Gemeinschaft endete, als sich eines Tages eine Frau in den Finger schnitt und ein Danag, der ihre Wunde aussagte, den Geschmack so unwiderstehlich fand, dass er nicht aufhörte, bis ihr Körper blutleer war. Ich las mir die Beschreibungen sorgfältig durch und suchte nach irgendwas, das mir bekannt vorkam, wenn schon nicht plausibel. (BzMo, S. 142)
\end{abstract}

Die Neuattribuierung des etablierten, historisch gewachsenen Vampirbilds wird damit im Text indirekt thematisiert. Zusammenfassungen garantieren, dass die zugrundeliegenden Traditionen beim Rezipienten bekannt sind und zwar in der Varainte, die als Grundlage der Neuinterpretation dient. Edward klärt Bella etwa darüber auf, welche Informationen als Aberglaube abzutun seien und welche der Realität nahekämen (BzMo, S. 196):

\footnotetext{
„Bitte nicht lachen - aber wie kommt es, dass du tagsüber rausgehen kannst?“

Er lachte trotzdem. „Alles Mythos.“

„Ihr werdet nicht von der Sonne verbrannt?“

„Mythos.“

„Ihr schlaft auch nicht in Särgen?“

„Mythos.“ Er zögerte einen Moment, dann bekam seine Stimme einen eigenartigen Klang. „Ich kann nicht schlafen.“ (BzMo, S. 196).
}

Die explizit markierte intertextuelle Bezugnahme baut dem Rezipienten durch den klaren Bezug zur Jetztzeit ${ }^{146}$ eine Brücke zwischen phantastischer Diegese und realistischer Alltagswelt. Der phantastische Anteil wird hier geradezu verschleiert, denn die Neuinterpretation

\footnotetext{
145 Taylor Lautner, der den Jacob in den Bis(s)-Verfilmungen verkörpert, erhielt den MTV Mowie Award in der Kategorie „Best Shirtless Scene“ in Anspielung auf seine zahlreichen Auftritte mit nacktem Oberkörper. Siehe www.mtv.com/news/1705547/taylor-lautner-shirtless-movie-award/ (15.7.2014).

${ }^{146}$ Zum Begriff Jetztzeit siehe Kapitel 3.3.2.4.
} 
scheint auf aufgeklärtem, zeitgenössischem Denken zu basieren, das mythischen Elementen skeptisch gegenübersteht oder deren Wahrheitsgehalt sogar verleugnet. Ein solches Verfahren ist - analog zu Harry Potter - typisch für alle Texte des Korpus, in denen mythische Stoffe bzw. Motive und Figuren aus Sagen und Legenden nicht nur auffällig oft adaptiert, sondern als kulturelle Wissensbestände reflektiert und im inneren Kommunikationssystem des Haupttexts explizit zum Thema gemacht werden.

Auch Riordan präsentiert griechische Mythologie in ihrer heutigen Rezeption: Die Jugendlichen in Percy Jackson kommen mit dem „,Götterkram“ (PJ 4, S. 26) hauptsächlich im Lateinunterricht (PJ 1, S. 10) oder auch durch einen Besuch im Metropolitan Museum of Art (PJ 1, S. 10) in Kontakt. Manche sammeln Mythomagic-Figurinen (PJ 3, S. 46, S. 78) eines holografischen Götterkartenspiels, das stark an zeitgenössische Sammelkartenspiele wie $M a$ gic the Gathering erinnert. Zusammenfassungen garantieren auch hier das Wissen um das Fundament der Neuinterpretationen, die sich über das komplette Personal und die gesamte Motivik antiker Mythologie erstrecken. ${ }^{147}$ Kriegsgott Ares etwa erscheint als Motorradfahrer mit Muskelshirt und Ledermantel (PJ 1, S. 268 f.), die vampirähnlichen Empusen als gutaussende und anschmiegsame Cheerleaderinnen mit betörendem Duft (PJ 4, S. 20) und Zerberus als übergroßer, verspielter Rottweiler mit drei Köpfen, der sich nur zu gern mit einem roten Bällchen von seiner Aufgabe ablenken lässt, die Eingänge ins Totenreich zu bewachen (PJ 1, S. 345 ff.). ${ }^{148}$ Als Percy und seine Freunde ins Labyrinth gelangen wollen - es handelt sich um das Labyrinth von Dädalus, aus dem Theseus seinerzeit mithilfe des Ariadnefadens entkommen konnte -, haben sie zunächst die Quizshow der Sphinx zu überstehen, die zeitgenössischen Fernsehproduktionen nachempfunden ist: Die Kandidaten müssen zwanzig Fragen richtig beantworten (PJ 4, S. 216), ,, willkürliche Sachfragen“ aus Politik, Mathematik und Erdkunde, die richtigen Antworten sind anzukreuzen. Annabeth, die als gebildet und mythenkundig dargestellt wird, ist irritiert und macht die moderne Sphinx-Interpretation sofort zum Thema, indem sie sich beschwert, dass ihr Wissensfragen und keine Rätsel vorgelegt werden, wie es die Tradition der Figur vorgegeben wäre:

\footnotetext{
„Moment mal“, protestierte Annabeth. „Was ist mit ,was geht am Morgen auf vier Beinen“?“ „Bitte?“, fragte die Sphinx und war jetzt hörbar verärgert. „Das Rätsel über den Menschen. Er geht morgens auf vier Beinen, als Baby, mittags auf zwei Beinen, als Erwachsener, und abends auf drei Beinen, als Greis mit einem Stock. Das ist das Rätsel, das du immer gefragt hast.“ „Genau deshalb haben wir den Test ja

${ }^{147}$ Etwa zum Mythos der Hesperiden: PJ 3, S. 241; zur Kalypsos-Figur: PJ 4, S. 248, S. 256, S. 264; zum Goldenen Vlies: PJ 2, S. 104 f., $181 \mathrm{ff}$.

${ }^{148}$ Eine ähnliche Auslegung findet sich bei Harry Potter, wo sich der dreiköpfige Wachhund Fluffy durch Musik von Hagrids Flöte von seiner Wache ablenken lässt. HP 1, S. 299.
} 
verändert“, rief die Sphinx. „Du hast die Antwort doch schon gewusst. Und jetzt zur zweiten Frage. Was ist die Quadratwurzel von sechzehn?“ (PJ 4, S. 218)

Neuinterpretationen von Motiven und Figuren, Zusammenfassungen und moderne Mythenrezeption charakterisieren auch die Edelstein-Trilogie. Bei den Recherchen nach dem Stein der Weisen beispielsweise stößt Gwendolyns Freundin Leslie im Internet auf vielerlei Informationen zu dem Motiv: ${ }^{149}$

\begin{abstract}
„Alchemie - das hat was mit diesem Stein der Weisen zu tun, oder?““,Genau. Und mit Magie. Der Stein der Weisen bedeutet aber für jeden etwas anderes. Die einen wollen nur künstlich Gold herstellen, was zu den merkwürdigsten Auswüchsen geführt hat. [...]“ „Aber in Wirklichkeit ging es den Alchemisten gar nicht um Gold. Der Stein der Weisen ist vielmehr ein Synonym für Unsterblichkeit.“ (RR, S. 286)
\end{abstract}

Der Stein bzw. das salzähnliche Elixier wird mithilfe einer Apparatur namens Chronograf gewonnen, der dazu das Blut der zwölf Zeitreisegenträger benötigt. Schließt sich der Blutkreis, beginnt ein halbminütiger Produktionsprozess, bis das Granulat einer dafür vorgesehenen Schublade entnommen werden kann (SG, S. 375). Der Bezug zur Alltagswirklichkeit ist evident, denn es wird ein industrialisiertes technisches Verfahren geschildert, wie es dem Rezipienten aus zahlreichen Kontexten bekannt ist: Maschinen verarbeiten selbstständig die $\mathrm{Zu}$ taten zu einem Produkt, der technische Vorgang ist dabei für außenstehende Laien nicht nachvollziehbar.

\title{
5.4.3 Zwischenfazit
}

Die Texte des Korpus tendieren analog zu Harry Potter zur Motiv- und Figurenneuinterpretation und greifen dabei auf ähnliche Strategien zurück. Sie alle verweisen auf literarische und cineastische Vorlagen und reflektieren ihre Neukonzeption explizit. Auf Grundlage westlich-aufgeklärter Denkweisen wird Mythenrezeption zum Thema gemacht, was nicht zuletzt die Authentizität der Werke steigert. Zusammenfassungen im inneren Kommunikationssystem garantieren, dass die historisch etablierte Variante eines Motivs dem Rezipienten geläufig ist. Die Neudeutungen schließen an diese Traditionen an und heben dabei auf eine zeitgenössische Erfahrungswirklichkeit ab, auf einen deutlichen Bezug zur Jetztzeit. In der Bis(s)-Serie beispielsweise wird ein Vampirbild etabliert, das den Blutsauger zu einem betörend schönen und gleichzeitig gefährlichen Frauentraum stilisiert. Meyer greift dazu auf etablierte Attribute der Figur zurück und instrumentalisiert sie in diesem Sinne. Sie

\footnotetext{
${ }^{149}$ Bei Harry Potter wird eine ähnliche Zusammenfassung geliefert: „, Die alte Wissenschaft der Alchemie befasst sich mit der Herstellung des Steins der Weisen, eines sagenhaften Stoffes mit erstaunlichen Kräften. Er verwandelt jedes Metall in reines Gold. Auch erzeugt er das Elixier des Lebens, welches den, der es trinkt, unsterblich macht. "HP 1, S. 240.
} 
erschafft so einen Vampir, der nicht nur perfekt auf eine weibliche Zielgruppe zugeschnitten ist, sondern der sich auch als ausgesprochen medienkompatibel erweist.

Die Tendenz zur Motiv- und Figurneuinterpretation allein ist kein Argument, die hier betrachteten Serien der Postmoderne zuzuordnen, da literarische Texte zu allen Zeiten Stoffe, Figuren und Motive neu interpretieren. Der bewusste Bruch etablierter Lesarten hingegen plausibilisiert die Zuordnung sehr wohl, vor allem wenn die Neuinterpretation an eine zeitgenössische Lebenswelt Anschluss sucht und findet.

\subsection{Resümee}

Die Analyse der Post-Potter-Texte hat gezeigt, dass sie als Genrehybride betrachtet werden können, die als Grundgenres Fantasy (Kapitel 3) und Mythos (Kapitel 4) aufweisen und darüber hinaus Schemata niedrigerer Ordnung aufrufen: des Liebesromans, des Abenteuerromans und des Kriminalromans. Gleiches gilt, so zeigt der Forschungsüberblick, auch für Harry Potter, sodass diesbezüglich klare Ähnlichkeiten zwischen den Werken bestehen. Selbstverständlich sind nicht alle Genremixe gänzlich gleich, so können die Einflüsse der Genres unterschiedlich stark sein oder auch weitere signifikant handlungsweisende Genreeinflüsse ausgemacht werden. In der Bis(s)-Serie zum Beispiel ist etwa noch der Einfluss des Schauerromans spürbar, der sich insbesondere in der Figurenwelt niederschlägt.

Analog zu Harry Potter weisen die betrachteten Texte zudem vermehrt Systemreferenzen zu literaturhistorisch etablierten Motiven und Figuren auf, die sie im Sinne zeitgenössischer Lebensart neu auslegen. Sie brechen also nicht komplett mit traditionellen Lesarten, sondern modifizieren sie. Zusammenfassungen und die Thematisierung im inneren Kommunikationssystem der Texte garantieren dabei, dass die Rezipienten das nötige Wissen um die Vorlagen besitzen, um die Neuinterpretation adäquat in Text- und Weltbild einordnen zu können.

Die Tendenz von Harry Potter und seinen Nachfolgern, sowohl zum Sprengen von GenreGrenzen als auch zur Motiv- bzw. Figuren-Neuinterpretation, können - nach obiger Auslegung der Stilepoche - als Argumente herangezogen werden, die Texte der Gattung der Postmoderne zuzuordnen, zumal beide Verfahren an eine zeitgenössische Erfahrungswirklichkeit anschließen. Beide intertextuellen Spielarten zielen in ihrer jeweiligen Realisation auf eine Reflexion zeitgenössischen Lebens ab; sie reflektieren nicht nur Medien, Technik und Erzeugnisse zeitgenössischer Populärkultur, sondern auch heutige westlich-aufgeklärte Denkweisen insgesamt sowie die Haltung des Individuums gegenüber Mythen und Phantasmen. 
Damit bedienen sich die Texte signifikant postmoderner Verfahren, insbesondere der Pastiche, indem sie etablierte Gattungs- und Motivtraditionen sprengen. Dass sie Gleiches auch in Bezug auf die Adressierung tun und adressatenbezogene Gattungskonventionen infrage stellen, soll Thema des folgenden Kapitels sein. 



\section{Die Post-Potter-Texte als Adressatenliteratur}

Eine Besonderheit des Kulturphänomens Harry Potter ist zweifelsohne seine kaum einzugrenzende Leserschaft. Die Attraktivität der Serie scheint nicht nur altersunspezifisch, sondern auch kulturübergreifend zu wirken. In der Forschung und im öffentlichen Diskurs wurden deshalb diverse Theorien darüber aufgestellt, welche Eigenschaften für den Erfolg bei Rezipienten unterschiedlichen Alters und unterschiedlicher Herkunft verantwortlich zu machen sind. ${ }^{1}$ Dazu wurden die Texte aus verschiedenen Perspektiven beleuchtet, Bedeutungsebenen herausgestellt sowie die Anknüpfungspunkte für die unterschiedlichen Lesergruppen diskutiert. Die wichtigsten Ergebnisse sollen nun für die Texte des Korpus fruchtbar gemacht werden. Dabei wird die These vertreten, dass die Werke nicht nur an eine ähnlichen Zielgruppe gerichtet sind, sondern dabei auch ähnliche Strategien verfolgen. Vor dem Hintergrund unterschiedlicher Gattungsmodelle sollen diejenigen Eigenschaften im Mittelpunkt stehen, die als gattungsweisend im Sinne einer Adressatengattung betrachtet werden können und die eine Einordnung der Serien als Kinder- und Jugendliteratur, als All-Age-Literatur und schließlich als „,multiadressierte“ ${ }^{\text {2 }}$ Texte plausibel machen. Da ein Werk gleichzeitig verschiedene Adressatengruppen anzusprechen vermag, kann es auch gleichzeitig verschiedenen Adressatengattungen zugeteilt werden. Der Klassifizierung liegt abermals eine personen- bzw. institutionsgebundene Entscheidung zugrunde, die auf objektiven Texteigenschaften beruht, welche vor dem Hintergrund bestimmter Vorstellungen interpretiert werden. Dieser Aspekt ist hier besonders hervorzuheben, denn gerade Entscheidungen, die zu einer Gattungsklassifikation führen, sind besonders interpretationsgeleitet und kontextabhängig. Werden Texte etwa der Kinder- und Jugendliteratur zugeordnet, basiert dies zum einen darauf, das „Kindheit“ und „Jugend" als Denkkategorien existieren und zum anderen darauf, was der Interpret unter diesen Begriffen versteht; das wiederum folgt in der Regel einem gesellschaftlichen Konsens. ${ }^{3}$ Die Kategorien Kinder- und Jugendliteratur, All-Age-Literatur und multiadressierte Literatur sind daher letztlich nichts anderes als kommunikative Modelle, deren Bedeutung sich erst aus ihrer diskursiven Verwendung ergibt, während Adressatengattungen immer als Genres angesehen

\footnotetext{
${ }^{1}$ U.a. Karg/Mende (2010); Bergenthal (2008), insbesondere S. 490ff und Beckett (2009); siehe auch einen Artikel der Zeit mit dem Titel „Die Welt liest“ von Susanne Gaschke: www.zeit.de/2007/30/01-Harry-Potter (17.5.2014).

2 Der Begriff der Multiadressierung ist in diesem Zusammenhang übernommen von Bergenthal (2008) und Karg/Mende (2010) und meint hier die Adressierung an Rezipienten unterschiedlichster Herkunft mit unterschiedlichen kulturellen Hintergründen.

${ }^{3}$ Adressatengattungen sind daher nach Fricke allesamt als Genre aufzufassen, denn sie fußen auf interpretierbaren Kategorien. Siehe Kapitel 1.3 „Zu Textsorten und Genres“.
} 
werden müssen, weil ihre Differenzkriterien an gesellschaftliche und historische Denk- und Sichtweisen gebunden sind, sodass sie keine Objektivität beanspruchen können.

Bei einer adressatenbezogenen Gattungsdiskussion besteht stets die Gefahr, problematische Verallgemeinerungen vorzunehmen oder sogar mit Klischees zu hantieren, etwa bei der Klassifizierung in Mädchen- und Jungenliteratur, die hier aber nur am Rande behandelt wird. In vielen Forschungsbeiträgen, nicht zuletzt in der Potter-Forschung, finden sich Versuche, die Wirkung von Büchern auf bestimmte Personengruppen zu verallgemeinern, und zwar im Sinne einer überindividuellen literarischen Erfahrung, die sich bei Rezipienten der gleichen Altersstufe, des gleichen kulturellen Hintergrunds oder des gleichen Geschlechts sehr ähnlich gestalte. Das Problem solcher Ansätze ist, dass sehr schnell der Eindruck entsteht, dass textuelle Bedeutungsebenen analytisch ermittelbar seien und damit letztlich auch alle Sinnzuweisungen und literarischen Urteile. Es vermag sogar suggeriert werden, dass die Wirkung eines Textes vorhersehbar ist und dass er nur eine bestimmte Anzahl von Interpretationsmöglichkeiten biete. Es ist offensichtlich, dass dies nicht so ist, sodass solche Behauptungen und Vorstellungen zu Recht sehr umstritten sind. ${ }^{4}$ Es sei daher darauf hingewiesen, dass die hier gemachten Beobachtungen auf einer anderen Vorstellung beruhen: Ein Text besitzt keine Bedeutung an sich, sondern bekommt diese vom Rezipienten zugewiesen. Die Wirkung ist konsequenterweise nicht verallgemeinerbar oder objektiv, da sie aus einem individuellen Prozess hervorgeht, einem Zusammenspiel von Top-down- und Bottom-up-Prozessen, die bei jeder Lektüre parallel verlaufen und sich bei jedem Lesenden anders gestalten. ${ }^{5}$ Die reale Wirkung eines Werkes kann somit nicht Gegenstand einer rein literaturwissenschaftlichen Analyse sein, sondern bedarf externer Daten, z. B. aus einer Befragung. Die implizierte Wirkung kann jedoch sehr wohl mit literaturwissenschaftlichen Verfahren zum Thema gemacht werden, denn die Tatsache, dass sich nicht immer die gleiche Wirkung bei ähnlichen Adressaten einstellt, bedeutet natürlich nicht, dass ein Werk nicht eine bestimmte Zielgruppe verfolgen kann bzw. mehrere Lesarten zur Verfügung stellt oder verschiedene Interpretationspotenziale besitzt. Es bedeutet lediglich, dass die Adressierung nicht immer „gelingt“ oder dass sich die intendierte Wirkung nicht immer einstellt. ${ }^{6}$

\footnotetext{
${ }^{4}$ Blume (2005, S. 34) stellt generell infrage, dass es eine spezifische Kinder- und Jugendliteratur gibt.

${ }^{5}$ Das Zusammenspiel von Top-down und bottom-up-Prozessen beim Lesen wird auch als ,,interagieren“ verstanden. Vgl. McCormick (1988), S. 108 und Karg (2005), S. 109.

${ }^{6}$ Natürlich kann man in dem Sinne nicht wissen, ob ein Text tatsächlich eine Zielgruppe intendiert, auch das ist sicherlich ein Stück weit Behauptung. Dennoch scheint dies eine sinnvolle Strategie zu sein, zumindest vor dem Hintergrund, dass die hier diskutierte Literatur auch immer eine Ware darstellt, die von den Beteiligten
} 
Im Anschluss an einen einleitenden Kommentar zu adressatenbezogenen Symbolsystemen und implizitem Rezipienten (Kapitel 6.1) soll hier die Adressierung der Korpustexte diskutiert werden. Dabei widmen sich die Unterkapitel dem Genre der Kinder- und Jugendliteratur (Kapitel 6.2), der All-Age-Literatur (Kapitel 6.3) und schließlich dem multiadressierten Text (Kapitel 6.4), wobei jedes prinzipiell gleich vorgeht: Nach einem kurzen historischen Abriss sollen die jeweiligen gattungsweisenden Eigenschaften den Ausgangspunkt für Analyse und Interpretation liefern. Die Zugehörigkeit von Harry Potter zu der Adressatengattung wird dann wieder in Form eines Forschungsberichts zum Thema gemacht, der die markantesten Adressierungsstrategien aufzeigen soll. Es folgt die jeweils modellspezifische Analyse ausgewählter Korpustexte, die Ergebnisse liefern soll, von denen ausgehend Aussagen über die Adressierung der Texte und ihrer Gattung gemacht werden können. Im letzten Kapitel wird folgenden Fragen nachgegangen (Kapitel 6.5): Welchen Adressatengattungen können die Post-Potter-Texte zugeordnet werden? Und: Verfolgen die sie ähnliche Adressierungsstrategien wie Rowlings Texte?

\subsection{Zum impliziten Rezipienten und adressatenbezogenen Symbolsystemen}

Der Kategorie Adressatenliteratur liegt die Vorstellung zugrunde, dass jedem Werk ein impliziter Rezipient bzw. - bei Literatur in Buchform - ein impliziter Leser zugehört. Ein Text wird dabei als Kommunikat betrachtet, das sich an eine bestimmte oder auch mehrere Adressatengruppen richtet und dabei ein oder auch mehrere Symbolsysteme zur Verfügung stellt, die jeweils eine oder auch gleichzeitig mehrere Lesarten vermitteln. Link definiert den impliziten Leser als „,dasjenige Leserbewusstsein, das mit seiner Kompetenz den Strategien und Eigenschaften des Textes gewachsen ist "7 und damit den Vorstellungen des Autors oder Urhebers entspricht. Der implizite Rezipient stellt folglich ein gedankliches Modell dar, welches die intendierte Lesart und Bedeutungszumessung eines Textes vornimmt. ${ }^{8}$ Ewers erweitert mit Blick auf die Kinder- und Jugendliteratur, wo in der Regel eine doppelte Adressierung - an erwachsene Vermittler und jugendliche Rezipienten - vorliegt, das Modell, indem er postuliert, dass ein Werk mehrere implizite Leser aufweisen kann, je nachdem wie viele verschiedene Rezeptionsweisen darin angelegt sind, die entweder jeweils ein eigenes Symbolsystem darstellen ${ }^{9}$ oder in einem komplexen, differenzierenden Symbolsystem zusammenkommen. ${ }^{10}$

\footnotetext{
am Publikationsprozess verkauft werden will.

${ }^{7}$ Link (1976), S. 23.

${ }^{8}$ Vgl. Kahrmann/Reiß/Schlachter (1986), S. 52.

${ }^{9}$ Siehe Ewers (2000c).
} 
Grundsätzlich entstehen so zwei Varianten, Adressatengattungen mithilfe von Symbolsystemen zu modellieren, wobei der ersteren in diesem Kapitel eine Schlüsselrolle zukommt. ${ }^{11}$

Geht man davon aus, dass ein Text gleichzeitig mehrere Symbolsysteme zur Verfügung stellt, beispielsweise eines speziell für Kinder, eines speziell für Erwachsene, eines für Mädchen, eines für Schüler oder auch für Rezipienten mit einem bestimmten kulturellen Hintergrund, so liegt dem eine Entscheidung zur bewussten Komplexitätsreduktion zugrunde, die in Kauf genommen wird. ${ }^{12}$ Die Vorteile liegen in der geschaffenen Struktur, die es ermöglicht, die verschiedenen Bedeutungsebenen eines Textes systematisch aufzuzeigen. Dabei sollte man sich aber auch der Problematiken bewusst sein: Wenn man behauptet, dass ein Text gleichzeitig mehrere Modellrezipienten impliziert, also gleichzeitig mehrere Symbolsysteme und Bedeutungsebenen zur Verfügung hält, stellt sich die Frage, wie die verschiedenen Symbolsysteme im realen Rezeptionsprozess miteinander in Beziehung stehen. Ewers behauptet diesbezüglich, die Gesamtbotschaft eines Textes bleibe für alle Empfänger eingeschränkt, da sich jeder stets auf das eigene Symbolsystem, auf das für ihn vorgesehene Signal im Text konzentriert und andere Symbolsysteme mit weniger Aufmerksamkeit beachtet. ${ }^{13}$ Die Grenzen dieser modellgeleiteten Argumentation sind offensichtlich, denn normalerweise kann der reale Rezipient im Gegensatz zum Gedankenmodell durchaus Signale unterschiedlicher Symbolsysteme wahrnehmen, also beispielsweise ein kindlicher Leser den Signalen des erwachsenen Kommunikationssystems Beachtung schenken. ${ }^{14}$ Im Rahmen dieser Arbeit aber ist das zu vernachlässigen, denn Ziel soll es sein, eine mehrfache Adressierung der Texte des Korpus plausibel zu machen, also auf diejenigen Eigenschaften hinzuweisen, die auf eine Etablierung mehrerer Symbolsysteme hindeuten. Darüber, wer nun tatsächlich welche Bedeutungsebene wahrnimmt oder nicht, sollen keine Aussagen getroffen werden. Da die verschiedenen Symbolsysteme nicht gekennzeichnet sind, ist die Hervorhebung als interpretatorischer Vorgang zu betrachten, der sich zwar auf Textbelege stützt, aber eben nicht durch sie bewiesen werden kann. Die aufgezeigten Lesarten erheben daher auch keinen Anspruch auf Vollständigkeit.

\footnotetext{
${ }^{10}$ Siehe Ewers (2012).

${ }^{11}$ Letzteres wird lediglich bei der All-Age-Literatur zum Thema gemacht werden.

${ }^{12}$ Ewers (2000c), S. 113.

${ }^{13}$ Ebd., S. 114.

${ }^{14}$ Ebd.
} 


\subsection{Harry Potter und die Post-Potter-Texte als Kinder- und Jugendliteratur}

Entsprechende Altersempfehlungen der jeweiligen Verlage und Medienunternehmen zeigen, dass sowohl Harry Potter als auch seine Nachfolger primär auf eine junge bzw. jugendliche Leserschaft abzielen. ${ }^{15}$ Seit jeher sieht sich Kinder- und Jugendliteratur Normen ausgesetzt, die ihre Adäquanz und Funktion betreffen, woraus sich eine doppelte Adressierung ergibt, welche als gattungsweisend zu betrachten ist: Die Bücher richten sich zugleich an Kinder und Jugendliche, die sie zum Lesen bringen und unterhalten wollen, und an erwachsene Vermittler. Die Texte weisen also immer zwei Symbolsysteme auf, die nun zum Gegenstand der Betrachtung gemacht werden sollen.

Nach einem kurzen Abriss der Geschichte der Kinder- und Jugendliteratur (Kapitel 6.2.1), sollen die Normen ebenjener Adressatengattung in den Blick genommen werden, die, in einem Katalog zusammengefasst, die Grundlage der folgenden Analysen bilden (Kapitel 6.2.2). Es folgt der Überblick über den Forschungsdiskurs, der Harry Potter vor dem Hintergrund seiner Adressierung an Kinder- bzw. Jugendliche in den Blick nimmt (Kapitel 6.2.3). Im anschließenden Kapitel wird die Zugehörigkeit der Korpustexte diskutiert (Kapitel 6.2.4). Leitfrage ist, inwiefern die in Kapitel 6.2.2 aufgezeigten Normen nachweisbar sind. Ein Zwischenfazit geht auf die Gemeinsamkeit und Unterschiede zwischen Harry Potter und seinen Nachfolgertexten in Bezug auf die Adressierung an Kinder bzw. Jugendliche ein (Kapitel 6.2.5).

\subsubsection{Zur Geschichte der Kinder- und Jugendliteratur}

Seit es Kinder- und Jugendliteratur gibt, soll sie vor allem eine Funktion erfüllen: der heranwachsenden Generation zu mehr Bildung verhelfen - oder ihr in der natürlichen Entwicklung und Reifung zumindest nicht schaden. Die „Belehrungs- und Erziehungsfunktion“ ist somit „,gattungs- und strukturbildend“" ${ }^{16}$. Spezifische Kinderliteratur entstand in der Mitte des 18. Jahrhunderts, was einher ging mit der Einführung der allgemeinen Schulpflicht sowie der Entdeckung der Kindheit als eigener Lebensphase und dem pädagogischen Interesse, das aus diesen Errungenschaften entspringt. ${ }^{17}$ Dem Medium Buch wurde zunächst lange keine bildende Rolle zugesprochen. Lesen, vor allem das „Viellesen“ von Unterhaltungsliteratur, war ver-

\footnotetext{
${ }^{15}$ Dass die Texte nicht nur eine Adressierung an Kinder bzw. Jugendliche vornehmen, sondern zusätzlich auch Lesarten für Erwachsene zur Verfügung stellen, wird im Folgekapitel thematisiert.

${ }^{16}$ Kümmerling-Meibauer (2003), S. 33.

${ }^{17}$ Ebd.
} 
pönt, und speziell die Mädchen wurden kritisch dabei beäugt. ${ }^{18}$ Schon im 18. Jahrhundert hat die Lektüreempfehlung für Mädchen eine größere gesellschaftliche Relevanz als die für Jungen, weil die jungen Frauen

[...] als unerfahrene Leserinnen erst zum Lesen gebildet werden müssen, weil sie aufgrund ihrer Fixierung ans Haus besonders häufig lesen, weil sie aufgrund der ihnen zugeschriebenen schönen Weiblichkeit in einer ganz bestimmten Weise gebildet sein sollen oder weil sie (wiederum aus den verschiedensten Gründen) durch Lektüre besonders gefährdet erscheinen. ${ }^{19}$

Bücher wurden schon früh genutzt, die Heranwachsenden nach damaligen Vorstellungen auf ihre Geschlechterrollen vorzubereiten. Als Beispiel für Mädchenliteratur des 19. Jahrhunderts kann Der Trotzkopf (1885) genannt werden, der die Verwandlung des spontanen, unangepassten Mädchens zur sittsamen Dame vor dem Hintergrund zweier unterschiedlicher pädagogischer Traditionsstränge vorführt. ${ }^{20}$ Die sozialisierende Funktion wird im ausgehenden 18. Jahrhundert durch den Aspekt der „Kindgemäßheit“ ergänzt, womit man die Fantasie als ästhetische Kategorie ernst zu nehmen beginnt. ${ }^{21}$ In der späten Aufklärung stellen Erzieher, die sich auch als Kinder- und Jugendbuch-Autoren hervortun, zum Beispiel Johann Christoph Adelung und Heinrich Campe, die Weichen für die Kanonisierung jugendliterarischer Texte, deren Stellung als eigenständige Gattung jedoch lang umstritten bleibt, da Lesen weiterhin negativ konnotiert ist. ${ }^{22}$

Mit der Wende zum 20. Jahrhundert beginnt die professionelle Beschäftigung mit Kinder- und Jugendliteratur, die sich in wissenschaftlichen Beiträgen zum Thema manifestiert. ${ }^{23}$ Die frühe Reformpädagogik dominiert den Diskurs der Umbruchsituation der Industriegesellschaft und zollt nicht nur dem Entwicklungspotenzial eines jeden Menschen Tribut, indem sie der geistigen Welt des Kindes mit Respekt begegnet, sondern räumt auch dem Lehrer eine hohe Stellung ein, der als entscheidender Vermittler von Literatur angesehen wird. ${ }^{24}$ Ihm wird Vorbildfunktion im Bereich der Kunstproduktion zugesprochen, seine Dichtkunst, meist verwendet als Unterrichtsmaterial, nimmt nämlich einen Großteil der Lektüre damaliger Kinder und Jugendlicher ein. ${ }^{25} \mathrm{Zu}$ den didaktischen Zielen zählt u. a. eine angemessene Sprache: Berthold Otto, prominenter deutscher Vertreter der Reformpädagogik, geht davon aus, dass sich der

\footnotetext{
${ }^{18}$ Vgl. Wilkending (1996b), S. 111.

${ }^{19}$ Grenz (1997a), S. 16.

${ }^{20} \mathrm{Vgl}$. Grenz (1997b).

${ }^{21}$ Ebd.

${ }^{22}$ Kümmerling-Meibauer (2003), S. 34.

${ }^{23}$ Vgl. Wilkending (1996b), S. 105.

${ }^{24}$ Gansberg (1912), S. 59; vgl. auch Wilkending (1996a), S. 31.

${ }^{25}$ Wilkending (1996a), S. 39.
} 
Erzieher der „Kindesmundart“ - gemeint ist die jeweilige Sprachstufe des Kindes - zu bedienen habe, um sich dann gleichsam mit dem Kind der „Sprechsprache“ - gemeint ist die Normsprache der Erwachsenen - nähern zu können. ${ }^{26}$ Zudem soll in dieser Zeit vor allem der „,gesunde[ ] Instinkt “27 in der literarischen Urteilsfähigkeit geschult.

Während 1933 bis 1945 die Literatur für die Jugend vor allem der Vermittlung nationalsozialistischem Gedankenguts und damit einhergehend einem bestimmten Menschenbild verpflichtet ist, kristallisiert sich ab Mitte der 50er-Jahre eine Tendenz zur Entdidaktisierung heraus, die in der Proklamierung des ,guten Jugendbuches“ ${ }^{\text {(28 }}$ mündet. Diese dominiert in den 60erJahren stark die pädagogischen Diskurse und übt noch in den 70ern und 80ern großen Einfluss auf die literarische Bildung, vor allem in der Bundesrepublik und Österreich. ${ }^{29}$ Im Zentrum steht die Idee einer konsequent kindgemäßen, der Tendenz nach antisozialisatorisch bzw. antiautoritär gestalteten Literatur, die sich als ,philanthropisch-reformpädagogisch oder romantisch geprägte Kinderliteratur der Kindheitsautonomie“ präsentiert. ${ }^{30}$ Dank derartiger Vorstellungen kann sich nun auch das Genre der phantastischen Kinder- und Jugendliteratur behaupten, nachdem es lange Zeit von Kritikern und Pädagogen gering geschätzt worden ist. ${ }^{31}$ Zeitgleich entwickelt sich die Tendenz zum psychologischen Realismus, sodass zusehends Probleme und zwischenmenschliche Konflikte im Kinder- und Jugendbuch zum Thema gemacht werden. Der Einfluss digitaler AV-Medien führt zudem zu intermedialen Verflechtungen, neuen Buchtypen und Erzählformen und damit einhergehend zu einer veränderten Jugendmedienkultur, die die späteren Generationen beeinflussen wird. ${ }^{32}$

Die Kinder- und Jugendliteratur in der DDR zeigt derweil einen ,, völlig anderen Kommunikations- und Funktionszusammenhang “, indem sie vor allem als politisches Organ fungiert, um ,junge Menschen zu aktiven Gestaltern der sozialistischen Gesellschaft “ zu erziehen. ${ }^{33}$ Die Bedeutung, die dem Genre zugewiesen wird, zeigt sich in der Vorstellung, dass Literatur mit der ,neuen geistigen Reife der Kinder “ mitzuhalten habe. ${ }^{34}$ Ziel dabei ist, den qualitativen

\footnotetext{
${ }^{26}$ Otto (1908), S. 50 ff.; siehe auch dazu Wilkending (1996a), S. 32 f.

${ }^{27}$ Scharrelmann (1906), S. 7.

${ }^{28}$ Ewers weist darauf hin, dass mit dem Begriff damals das gemeint war, was heute unter Kinder- und Jugendliteratur verstanden wird, also diejenige Literatur, die von Kindern (bis etwa 12) und Jugendlichen (bis ca. 15/16 Jahre) gelesen wird. Siehe dazu Ewers (1996), S. 165, Fußnote 2.

${ }^{29}$ Ewers (1996), S. 165.

${ }^{30}$ Ebd., S. 175 f., Zitat: S. 176.

${ }^{31}$ Vgl. Kümmerling-Meibauer (2001), S. 1585.

${ }^{32}$ Kümmerling-Meibauer (2001), S. 1587.

${ }^{33}$ Richter (1996), S. $191 \mathrm{f}$.

${ }^{34}$ Ebd., S. 193.
} 
Vorsprung der Erwachsenenliteratur zu überwinden. Damit verfolgt man in der DDR eine einheitliche Nationalliteratur, die die Besonderheiten ihrer Adressaten zwar berücksichtigt, aber gleichzeitig nach Angleichung strebt. ${ }^{35}$

Ende der 80er-Jahre wird verstärkt, vor allem vonseiten linksradikaler Gruppierungen, Kritik an sexistischen und rassistischen Inhalten in Kinder- und Jugendbuchklassikern laut. ${ }^{36}$ Die Forderung nach Political Correctness etabliert sich nachfolgend als Standard, auch unter dem Einfluss der Cultural Studies - geht man doch weiterhin davon aus, dass der Kinder- und Jugendliteratur eine entscheidende Sozialisationsfunktion zukommt. ${ }^{37}$

\subsubsection{Zu den Konventionen von Kinder- und Jugendliteratur}

Die Geschichte zeigt deutlich, wie das Genre vor dem Hintergrund seiner Sozialisationsfunktion in beiden Teilen Deutschlands instrumentalisiert wurde. Noch heute wird Kinder- und Jugendbüchern die Aufgabe zugeteilt, ein Menschen- und Weltbild zu vermitteln, das nach moralischen und ethischen Maßstäben konsensfähig ist. Für die jugendlichen Adressaten ist das wohl eher marginal, wollen sie doch früher wie heute primär unterhalten werden. Für Autoren sowie die Beteiligten am Vermarktungsprozess, für Eltern, Großeltern, Erzieher und Lehrer trägt die Funktion hingegen enorme Bedeutung, deren Ansprüche Auswirkungen auf den Vertrieb, die Marketingstrategie und letztlich auch auf die Inhalte besitzen. So entsteht eine Kommunikationssituation, über die O'Sullivan sagt, dass ihr auffälligstes Merkmal die „Asymmetrie [ ] zwischen den an ihr beteiligten Kommunikationspartnern “38 sei, verfügt doch der kindliche bzw. jugendliche Adressat bei weitem nicht über das gleiche ökonomische und kulturelle Kapital wie die Erwachsenen, damit ist er auch letzten Endes nicht der entscheidende Adressat im Aushandlungsprozess. Als gattungsweisend für Kinder- und Jugendliteratur erweist sich indes vor allem die Einhaltung der auferlegten Normen bezüglich Funktion, Adäquanz und Poetik, ${ }^{39}$ Letztere gewährleisten in der Regel überhaupt erst das literarische Prestige eines Textes. Ob ein Buch veröffentlicht, gekauft, verschenkt oder vorgelesen werden soll, wird letztlich von Erwachsenen entschieden: ${ }^{40}$

Die erwachsenen Vermittler stellen also den ersten Adressaten von Kinder- und Jugendliteratur dar. [...] Erst wenn die Vermittler die Botschaft wenn nicht als wertvoll, dann zumindest als unbedenklich erach-

\footnotetext{
${ }^{35}$ Richter (1996), S. 202 f.

${ }^{36}$ Kümmerling-Meibauer (2001), S. 1588.

${ }^{37}$ Ebd.

${ }^{38}$ O’Sullivan (2000), S 122 ff., Zitat: S. 111.

${ }^{39}$ Vgl. Blume (2005), S. 32.

${ }^{40}$ Ebd.
} 
ten, eröffnen sie den Weg für die literarische Kommunikation zwischen dem Sender und den kindlichen und jugendlichen Adressaten. ${ }^{41}$

Die Durchsetzung auf dem Buchmarkt wird so gesehen wesentlich davon beeinflusst, ob ein Werk bestimmte Normen einhält und welchen Wert es von den erwachsenen Diskursteilnehmern zugesprochen bekommt. ${ }^{42}$ Daneben müssen die Bücher die Bedürfnisse ihrer kindlichen und jugendlichen Leser bedienen. ${ }^{43}$ Somit kann hier von einer Doppeladressierung gesprochen werden, wobei - anders als bei All-Age-Literatur - der erwachsene Rezipient einen inoffiziellen Adressaten darstellt. ${ }^{44}$ Geht man davon aus, dass ein Text an beide implizite Rezipienten Signale sendet, müssten also zwei verschiedene Symbolsysteme identifizierbar sein: ${ }^{45}$ Das eine richtet sich mit Thema und Handlung an seine jugendlichen Rezipienten, das andere durch Einhaltung bestimmter Normen an die erwachsenen Vermittler. Die doppelte Adressierung kommt dabei nicht nur innerhalb des Textes selbst, sondern auch epi- und paratextuell zum Ausdruck, indem sich Prospekte, Einband- und Schutzumschlag eines Werkes in der Regel an die Käufer bzw. erwachsenen Vermittler wenden, während Titel, Untertitel, Merchandisingprodukte und Autorenlesungen eher an die kindlichen oder jugendlichen Rezipienten richten. ${ }^{46}$ Inhaltlich waren und sind beide Symbolsysteme immer vor dem Hintergrund historischer Kontextbedingungen zu betrachten. ${ }^{47} \mathrm{Zu}$ denken ist zum Beispiel an literarische Trends in der Jugendkultur, an Werbung, an pädagogische und didaktische Diskurse, entwicklungspsychologische Erkenntnisse, das kulturelle Konstrukt von Bildung sowie an den gesellschaftlichen Konsens darüber, welche Kompetenzen als erstrebenswert erachtet werden.

In der Geschichte der Kinder- und Jugendliteratur entstand ein Katalog von Anforderungen, der beide Symbolsysteme betrifft und an dem sich die Bücher offenbar auch heute noch zu messen haben, da er in entsprechenden Diskursbeiträgen immer wieder anklingt. Ausgehend von zeitgenössischen Forschungsbeiträgen, soll Kinder- und Jugendliteratur ${ }^{48}$

- Kindern und Jugendlichen gefallen, ihnen Vergnügen bereiten, und zwar unter Berücksichtigung ihrer geschlechts-, alters- und kulturspezifischen Interessen (damit die

\footnotetext{
${ }^{41}$ Ewers (2000c), S. 105.

${ }^{42}$ Vgl. Blume (2005), S. 27.

${ }^{43}$ Ewers (2000c), S. 114.

${ }^{44}$ Ebd.

${ }^{45}$ Link (1976), S. 23.

${ }^{46}$ Ewers macht darauf aufmerksam, dass in allen Epi- und Paratexten auch beide Teilkommunikationen realisiert sein, also beide Signalbereiche gleichermaßen angesprochen werden können. Siehe dazu Ewers (2000c), S. 112, Schaubild 9.

${ }^{47}$ Ewers modelliert den Inhalt als textuelle Signalbereiche der kinder- und jugendliterarischen Kommunikation.

${ }^{48}$ Es wird sowohl hier als auch später von der deutschsprachigen Gesellschaft, Forschung und Rezeption ausgegangen. Die folgenden Normen entstammen dementsprechend auch aus deutschsprachigen Forschungsbeiträgen.
} 
Rezeption überhaupt erst zustande kommt); da die Bücher in der Regel von Erwachsenen verfasst werden, bauen die an Kinder und Jugendliche adressierten Symbolsysteme auf Vermutungen auf, was von interesse sein könnte. Oft sind so die gewählten Schwerpunkte und Motive klischeebehaftet.

- ein für Kinder und Jugendliche adäquates Thema behandeln. ${ }^{49}$ Dazu zählen solche, die unmittelbar deren Erfahrungswirklichkeit ansprechen, etwa Pubertät, Adoleszenz, die Suche nach der eigenen Identität, ${ }^{50}$ der eigenen Geschlechterrolle sowie nach der eigenen Stellung in der Gesellschaft, die Auseinandersetzung mit Vorgesetzten und Vorbildern (oft vorgeführt im Handlungsraum Schule, der einen großen Platz in der Erfahrungswirklichkeit von Kindern und Jugendlichen einnimmt). ${ }^{51}$ Fenske nennt als weitere typische Motive einen kindlichen Protagonisten, Geburtstag, Weihnachten, Halloween, Reisen, Überleben, den Kampf zwischen Gut und Böse (wobei das Gute gewinnt), Motive der Artussaga, Tod, Verlusterfahrungen, Träume und Unwirklichkeitswahrnehmungen. ${ }^{52}$ Die Verwendung solcher Themen scheint für beide Symbolsysteme von Bedeutung zu sein, erscheinen sie doch dem inoffiziellen Adressaten angemessen und sprechen gleichzeitig die aktuelle Erfahrungswirklichkeit der offiziellen Adressaten an und laden zur Identifikation ein.

- ein positives Ende nehmen und in seiner Gesamtaussage einen erzieherischen Wert besitzen, ${ }^{53}$ für die Heranwachsenden als mentaler „Trainingsort“ für moralische Fragestellungen dienen sowie konsensfähige (handlungsfeldspezfische) Moralvorstellungen vermitteln. ${ }^{54} \mathrm{Ob}$ ein jugendliterarischer Text dies vermag, kann aus dem Symbolsystem erschlossen werden, das sich an die erwachsenen Mitleser richtet, und verlangt Interpretationsarbeit. Gleiches gilt auch für die folgenden Anforderungen.

- bildungsrelevantes Wissen und kulturelle Werte vermitteln. ${ }^{55}$ Dazu zählen Inhalte des Bildungskanons, religiöse und politische Werte, Political Correctness sowie die Gleichstellung der Geschlechter, aber auch Weltwissen, das die Erschließung historischer und/oder geografischer Alterität ermöglicht. ${ }^{56}$

- literarisch und literaturästhetisch schulen, so etwa Sprachfertigkeit, ${ }^{57}$ Sensibilität für unterschiedliche Bedeutungsebenen sowie für rhetorische Mittel und Genrekonventionen, das Wahrnehmen und Formulieren von Kommunikationsbedürfnissen und literarischen Urteilen. ${ }^{58}$ Zudem sollen Lesekompetenz sowie die Rezeption anderer literarischer Medien geschult werden, als Fernziel wird meist eine stabile Leseaffinität verfolgt. $^{59}$

\footnotetext{
49 Dass diese Auffassung vor dem Diktum der Objektivität im höchsten Maße problematisch ist, soll an dieser Stelle nicht diskutiert werden. Siehe dazu Ewers (2000b), S. 112.

${ }^{50}$ Vgl. Wrobel (2010), S. 11.

${ }^{51}$ Vgl. Petzold (2004), S. 85 f.

${ }^{52}$ Fenske (2008), S. 420 f., die sich auch auf Nikolajeva (1988) bezieht.

${ }^{53}$ Vgl. Ewers (2000c), S. 114.

${ }^{54}$ Mohr (2012), S. 329.

${ }^{55}$ Vgl. Ewers (2000c), S. 74 f.; Mohr (2012), S. 332.

${ }^{56}$ Wrobel (2010), S. 11.

${ }^{57}$ Ebd.

${ }^{58}$ Hurrelmann (2000), S. 904.

${ }^{59}$ Ewers (2000c), S. 178 ff., Maiwald (2009), Markert (1998), S. 41 ff. und Wrobel (2010), S. 11.
} 
Insbesondere die letzten beiden Aspekte beeinflussen heute maßgeblich die Entscheidung, ein bestimmtes Buch im Unterricht zu behandeln. Die Auswahl kann als eine von vielen parallel verlaufenden Handlungen aufgefasst werden, die zur Kanonisierung eines literarischen Werkes in einer bestimmten Gesellschaft, einem bestimmten Kulturkreis oder, allgemeiner formuliert, einem bestimmten Handlungsfeld beiträgt. ${ }^{60}$ Denn ob ein Werk tatsächlich in der Schule thematisiert wird, hängt entscheidend davon ab, ob die jeweilige Gruppe an dessen Überlieferung an weitere Generationen interessiert ist, das heißt, ob sie den jeweiligen Text für bedeutsam genug erachtet. ${ }^{61}$

\subsubsection{Harry Potter als Kinder- und Jugendliteratur}

Der Altersempfehlung nach richtet sich Harry Potter an heranwachsende Kinder bzw. Jugendliche - je nachdem wo man die Grenze zieht. Der Carlsen-Verlag empfiehlt sie dezidiert für Kinder ab zehn Jahren. ${ }^{62}$ Bergenthal nimmt an, dass die Bücher ursprünglich für eine männliche Leserschaft gedacht waren, doch haben sie sich bei männlichen wie weiblichen Rezipienten gleichermaßen durchgesetzt. ${ }^{63}$ Die Filme weisen verschiedene Altersempfehlungen auf: Beim ersten Teil ist von Kindern ab sechs Jahren die Rede, der letzte sei für Jugendliche ab zwölf Jahren. ${ }^{64}$ Damit können sie als Kinder- oder als Jugendmedien betrachtet werden. Die Uneindeutigkeit in der Zuordnung wurde in der Forschung durch die mitwachsenden Rezipienten sowie das sich stetig steigernde Niveau der Texte erklärt: ${ }^{65}$ Harry reift während der siebenbändigen Serie vom Kind zum jungen Erwachsenen heran und mit ihm die Rezipienten. ${ }^{66}$ Von Band zu Band wird der Inhalt gehaltvoller und brutaler. ${ }^{67}$ Falconer zieht eine klare Grenze zwischen Band drei und vier, indem er behauptet, die ersten drei Bände seien vom kindgerechten Motiv und Prinzip der Leichtigkeit geprägt, die letzen vier vom Motiv des Todes, das sich an ältere Rezipienten richte. ${ }^{68}$

Man kann sagen, dass Harry Potter zu weiten Teilen die Normen eines kinder- und jugendliterarischen Kommunikats einhält. Thematisiert werden die Identitätsfindung Harrys, die noch bis zum siebten Band reicht, sowie typische Phänomene der Adoleszenz: Schule, erste Liebe,

\footnotetext{
${ }^{60}$ Vgl. Winko (2002), S. $10 \mathrm{f}$.

${ }^{61}$ Vgl. Winko (1996b), S. 585.

${ }^{62}$ www.carlsen-harrypotter.de/taschenbuch/harry-potter-schuber (7.9.2014).

${ }^{63}$ Bergenthal (2008), S. $14 \mathrm{f}$.

${ }^{64}$ Die Angabe befindet sich auf der Rückseite der jeweiligen DVD-Cover.

${ }^{65}$ Auch Rahner (2010, S. 192) ordnet die ersten Bände als Kinder- und die letzten als Jugendbücher ein.

${ }^{66}$ Beckett (2009), S. 114.

${ }^{67}$ Vgl. Falconer (2009), S. 45.

${ }^{68}$ Ebd.
} 
Freundschaften und die Suche nach der eigenen Stellung in der Gesellschaft. Die Zauberer leben in der Fiktion ein unbemerktes Parallelleben, was ,, gerade Kinder und Heranwachsende faszinieren muss, kapseln doch auch sie sich gerne von der verachteten Welt der Erwachsenen $a b^{\text {“69. }}$. Die Zaubererschule Hogwarts ist dabei gleichzeitig vertraut und nicht vertraut, in jedem Fall werden dort aus der Alltagswelt bekannte Themen verhandelt:

[...] Freundschaften, Rivalitäten und Konflikte zwischen den Schülern, die Existenz von Machtstrukturen, die zum Scheitern verurteilten Disziplinierungsversuche mancher Lehrer, ja sogar der seltene Fall des engagierten, gerechten und deshalb geliebten Pädagogen, usw. ${ }^{70}$

Harry Potter habe viel „Suspense“, erläutert Böhme-Dürr, erzähle dramatische Situationen mithilfe intensiver Bilder und verhandele Themen, die Kindern und Jugendlichen eine starke emotionale Anbindung und Identifizierung ermögliche. ${ }^{71}$

Auch Aspekte, die das Symbolsystem der erwachsenen Vermittler betreffen, wurden in der Forschung umfangreich zum Thema gemacht, etwa das vermittelte Frauen- und Mädchenbild der Texte kritisch betrachtet, das u. a. Schoefer als nicht zeitgemäß betrachtet. Weibliche Figuren würden ,,immer schlechter dargestellt [ ] als die männlichen in der jeweils vergleichbaren Position “72. Andererseits, so betont Just, illustriere Rowling, indem sie Hermine vor ähnliche Aufgaben wie ihre männlichen Freunde stellt, ,,dass es in vielen Bereichen keinerlei geschlechtsspezifischen Unterschiede gibt “"73. Petzold kommt zu dem Ergebnis, Harry Potter sei dazu geeignet, ,,unterstützenswerte“ Haltungen zu vermitteln, insbesondere die bürgerlichen Tugenden „Ehrlichkeit, Fairness, Gruppensolidarität, Verantwortungsbereitschaft, Rücksichtnahme, Toleranz, Gerechtigkeit “74; gleichzeitig übe das Werk das Unterscheiden von Gut und Böse, die beide begründbar in den Texten auszumachen seien. ${ }^{75}$ Insbesondere der Handlungsort einer phantastischen Parallelwelt sei dazu geeignet, Wissen und moralische Werte zu vermitteln, so Nickel-Bacon, indem sie auf einer teils fremden, teils bekannten Bühne vorgeführt würden, die zum Übertragen auf die eigene Erfahrungswirklichkeit einlade. ${ }^{76}$ Andererseits fänden sich viele Trivialisierungen und ,problematische Heilsversprechen “, was nur unter entsprechender Anleitung als Ausgangspunkt zur Reflexion dienen könnte. ${ }^{77}$ Die

\footnotetext{
${ }^{69}$ Petzold (2004), S. $86 \mathrm{f}$.

${ }^{70}$ Ebd.

${ }^{71}$ Böhme-Dürr (2000), S. 25.

${ }^{72}$ Just (2001b), S. 53 mit Bezug auf einen taz-Artikel von Schoefer (2000), S. 11.

${ }^{73}$ Ebd., S. 69.

${ }^{74}$ Petzold (2004), S. $88 \mathrm{f}$.

${ }^{75}$ Nickel-Bacon (2006b), S. 289.

${ }^{76} \mathrm{Vgl}$. Mohr (2012), S. 332.

${ }^{77}$ Nickel-Bacon (2006b), S. 289.
} 
Komplexität der Bücher, ihre intertextuelle Praxis und Ironie würden indes zur Mehrfachrezeption einladen und so zur ästhetischen Bildung der Leser beitragen, wie Petzold konstatiert. $^{78}$

Karg und Mende stellen 2010 fest, dass trotz der vergleichsweise jungen Rezeptionsgeschichte von Harry Potter viele, für eine Kanonisierung relevante Faktoren erkennbar seien. Andere Aspekte, etwa die Aufnahme in Anthologien, wären indes noch nicht auszumachen, wobei es fraglich bleibe, ob das jemals der Fall sein werde. ${ }^{79}$ Im Handlungsfeld deutscher Schulen jedenfalls scheint Harry Potter als Lektüre angekommen zu sein, zumindest gibt es - sogar seitens der Deutschdidaktik - zahlreiche Unterrichtsvorschläge, die auf das didaktische Potenzial des Werks eingehen. ${ }^{80}$ Dabei sind nicht alle Vorschläge gleichermaßen sinnvoll, zum einen muss mit einer großen Textmenge im Unterricht hantiert werden, zum anderen birgt jedwede didaktische Reduktion die Gefahr, dem Text Bedeutungs- und Interpretationspotenziale zu nehmen, die ihn eigentlich auszeichnen. ${ }^{81}$ Viele Forschungsbeiträge setzen am Medienverbund der Serie an: Nickel-Bacon macht den Vorschlag, Harry Potter als Anlass zu nehmen, Mediengenuss und Medienkritik im Sinne von emotionalen und reflektierenden Rezeptionsprozessen zu schulen. ${ }^{82}$ Koberstein und Schmaus sehen dort Anknüpfungspunkte für Projektarbeiten. ${ }^{83}$ Auch die Verwendung unterschiedlicher Literaturtraditionen, Gattungskonventionen sowie die Serialitätsstrukturen der Texte bieten Lernchancen, die selten bei Unterhaltungsliteratur mit ähnlichem qualitativen Standard zu finden sind.

\subsubsection{Die Post-Potter-Texte als Kinder- und Jugendliteratur}

Analog zu Harry Potter können auch die nachfolgenden Werke als doppeladressierte Literatur aufgefasst werden, die den Bedürfnissen jugendlicher offizieller und erwachsener inoffizieller Adressaten nachzukommen versuchen. Dabei werden die Normen, die konventionell für kinder- und jugendliterarische Kommunikate gelten, teilweise eingehalten und teilweise neu ausgehandelt. ${ }^{84}$ Einige der Serien richten sich eher an kindliche Rezipienten, andere erzählen komplexer und verfolgen damit eine ältere Zielgruppe. Auffällig ist, dass die als gattungsweisend zu betrachtende Doppeladressierung bei allen erkennbar ist, indem mit den dafür rele-

\footnotetext{
${ }^{78}$ Vgl. Petzold (2004), S. 88.

${ }^{79}$ Vgl. Karg/Mende (2010), S. 242.

${ }^{80}$ Dies war vergleichsweise früh der Fall: Siehe beispielsweise den Sammelband „Harry Potter in der Schule“ von Jörg Knobloch, der bereits 2001 erschienen ist.

${ }^{81}$ Karg/Mende (2010), S. 59.

${ }^{82}$ Nickel-Bacon (2006b), S. 276 ff.

${ }^{83}$ Koberstein (2001) und Schmaus (2001).

${ }^{84}$ Vgl. Manz (2011), S. 46.
} 
vanten Symbolsystemen operiert wird. Dies soll nun beispielhaft anhand der Bis(s)-Serie sowie an Percy Jackson verdeutlicht werden. Abschließend werden unter Berücksichtigung der Ergebnisse vorangegangener Kapitel die Lernchancen aufgezeigt, die die Texte aufgrund ihrer Vielschichtigkeit bieten.

\subsubsection{Die Bis(s)-Serie als Übergangsliteratur}

Die Protagonistin Bella durchlebt in der vierbändigen Serie entscheidende Phasen ihrer Adoleszenz. Mit 17 Jahren zieht sie nach Forks (BzMo, S. 112), geht dort zur High School (BzMo, S. 17) und erlebt die Höhen und Tiefen des Verliebtseins. Sie schmiedet Pläne, wie es nach der Schule weitergehen soll (BzAb, S. 27), macht mit 18 (BzMi, S. 12) ihren Abschluss, heiratet schließlich und bekommt ihr erstes Kind. Mit ihrem neunzehnten Geburtstag endet der vierte Band (BzEdN, S. 496). Die Geschichte deckt somit zwei Jahre von Bellas Leben im Übergang zum Erwachsenenalter ab, die Spanne der erzählten Zeit ${ }^{85}$ ist dabei von Band zu Band unterschiedlich. ${ }^{86}$ Geht man davon aus, dass altersspezifische Themen stark mit dem Identifikationspotenzial korrelieren, das sie eröffnen, so lässt sich vermuten, dass die Serie Leser anspricht, die sich gerade im Übergang zum Erwachsenenalter befinden, also Teenager, ebenso diejenigen, die die Entwicklung gerade durchlebt haben, also junge Erwachsene. Vordergründig verfolgt Meyer damit eine ähnliche Zielgruppe wie Cassandra Clare mit ihren Chroniken-der-Unterwelt-Romanen, die Autorin äußerte sich hierzu wie folgt:

Als ich anfing, City of Bones zu schreiben, dachte ich zunächst nicht daran, einen Jugendroman zu schreiben, das ganze war als Fantasyroman konzipiert. Aber die Protagonisten waren Jugendliche. Als mein Verleger das Manuskript gelesen hatte, wollte er, dass ich die Personen etwas älter mache. Ich dachte auch eine Zeitlang ernsthaft darüber nach, aber so konnte es nicht funktionieren. Ich wollte eine Geschichte mit Protagonisten an der Schwelle zum Erwachsensein erzählen [...]. ${ }^{87}$

Clare und Meyer stehen damit nicht allein, zumal sie eine Trendzielgruppe ansprechen. Nicht selten wird die Zielgruppe des „Übergangsalters“ auch mit dem All-Age-Phänomen in Zusammenhang gebracht, das im nächsten Kapitel erörtert wird. Es gilt genau zu unterscheiden, was mit dem Begriff „All-Age“ gemeint ist, da er eben auch genau die Adressierung an Jugendliche im Übergang meinen kann und nicht, wie der Begriff zunächst nahelegt, die Adres-

\footnotetext{
${ }^{85}$ Gemeint ist damit der kohärent und chronologisch erzählte Ablauf der Geschichte. Rückblenden in andere Jahrhunderte sind hier außen vor gelassen.

${ }^{86}$ Dies stellt einen Unterschied zu den Potter-Romanen dar, jeder Band ein Jahr der erzählten Zeit abdeckt. Bei Twilight behandelt der erste Teil beispielsweise drei Monate von Bellas Leben, der zweite sechs Monate. Vgl. Fußnote 124, Seite 58.

${ }^{87}$ Informationen für Presse und Veranstalter über Cassandra Clare vom Arena-Verlag. Würzburg 2008.
} 
sierung an Rezipienten aller Altersgruppen: Regina Pantos vom Arbeitskreis für Jugendliteratur e. V. erläutert:

Der Begriff „All-Age-Bücher“ legt die Vermutung nahe, dass es sich um Bücher für Menschen von 0 bis 99 Jahren handelt. Das ist jedoch ein Trugschluss. Es geht in der Regel um Bücher für Jugendliche und junge Erwachsene, etwa um die Altersgruppe von 12 bis $30 .^{88}$

Die Bis(s)-Serie jedenfalls scheint, unabhängig von der Altersfrage, insbesondere weibliche Rezipienten anzusprechen: Die weibliche Protagonistin Bella sowie die Fokussierung auf die Liebesbeziehung, die stark psychologisiert und mit romantischen Elementen ausgeschmückt ist, mögen die Ursachen dafür sein. ${ }^{89}$ Mit einer empfohlenen Altersfreigabe ab vierzehn Jahren scheint das Buch per se an eine ältere Leserschaft gerichtet als Harry Potter. Folglich erlaubt sich die Autorin auch einen freieren Umgang mit den oben beschriebenen Normen, zumal eine Vampirgeschichte nicht gänzlich ohne Blutmotiv und Horror auskommt. Das Werk befindet sich strenggenommen an der Grenze zu dem, was als adäquat für Jugendliche ab 14 zu betrachten ist: Die Cullens selbst jagen zwar keine Menschen, andere Vampire aber schrecken in der Fiktion nicht vor einem Mord zurück, am wenigsten die, die gerade erst zum Vampir geworden sind. Diese „Neugeborenen“ sind „,[b]lutrünstig, wild und ungebremst" (BzAb, S. 33) und haben daher selbstredend sehr wenig Vorbildfunktion. Der vierte Teil der Saga wendet sich gänzlich von den Normen eines Kinderbuchs ab, denn die Schwangerschaft Bellas erinnert stark an das Motiv des Satanskindes, ein typisches Horrormotiv: Der Fötus ernährt sich von Blut und wächst derart schnell, dass es sie fast innerlich zerreißt: „, Eine halbe Sekunde später schrie Bella. Es war nicht nur ein Schrei, es war ein markerschütternder Schmerzenslaut. [...] Ihr Körper zuckte, bog sich in Rosalies Armen, und dann erbrach Bella einen Blutschwall. “ (BzEdN, S. 371). Der auf diese Szene folgende Geburtsvorgang, der aus

\footnotetext{
${ }^{88}$ Trendbericht Kinder- und Jugendbuch vom 19. März 2010. Presseinformation des Börsenvereins des Deutschen Buchhandels: All-Age-Bücher dominieren. Bleibt das Kinderbuch auf der Strecke? Zusammengestellt von Julia Piaseczny; www.boersenverein.de/sixcms/media.php/976/Digitale_Pressemappe_Trendbericht.pdf (9.9.2014).

${ }^{89}$ In der Öffentlichkeit wurde immer wieder auf die nahezu ausschließlich weibliche Leserschaft hingewiesen. Siehe dazu beispielsweise einen Artikel von Albert Attila in $B I L D$ : Warum fasziniert dieser Vampir Millionen Mädchen? www.bild.de/BILD/unterhaltung/kino/2009/01/13/twilight-film/warum-fasziniert-dieser-vampirmillionen-maedchen.html (10.9.2014); oder einen Artikel von Caroline Berger in frauenzimmer.de: www.frauenzimmer.de/cms/html/de/pub/leben-genuss/twilight-vampire-pattinson/twilight-vampireerfolgreich.phtml (10.9.2014). Es sei hier jedoch angemerkt, dass die Bücher auch eine männliche FanGemeinde besitzen. In Amerika sollte ursprünglich sogar direkt nach New Moon, dem ersten Band, der Titel Midnight Sun erscheinen, der die Ereignisse aus New Moon aus Edwards Sicht erzählt, vermutlich um verstärkt männliche Leser anzusprechen, die sich mutmaßlich besser mit einem männlichen Protagonisten identifizieren können. Zu der Veröffentlichung kam es nicht, da angeblich einige Kapitel illegal im Internet veröffentlicht worden seien. Stephenie Meyer hatte bereits das erste Kapitel als Teaser auf ihrer Homepage zur Verfügung gestellt, wo es noch immer zugänglich ist: http://stepheniemeyer.com/midnightsun.html (10.9.2014).
} 
Jacobs Perspektive geschildert wird, ist gekennzeichnet durch Qualen und starke Bilder: Bella stirbt fast bei den Strapazen (BzEdN, S. 375). Insgesamt bleibt aber auch der vierte Band einem Happy End verpflichtet und damit seiner jugendliterarischen Sozialisationsfunktion: Die Familie Cullen, allesamt Gutmenschen, überlebt alle Konflikte, Edward und Bella leben zusammen mit ihrem Kind bis in alle Ewigkeit.

Interessant ist, dass die Texte, obwohl sie sich eindeutig in einer Grauzone bewegen, sowohl in der Forschung als auch in öffentlichen Diskursen der Massenmedien als jugendliterarische Kommunikate wahrgenommen und beurteilt werden. ${ }^{90}$ Ausgehend von der Vorstellung, dass Wertesysteme und gesellschaftliche Schemata durch Literatur vermittelbar sind, wird beispielsweise davon ausgegangen, dass die Bücher keinen unerheblichen Beitrag zur gesellschaftlichen Wahrnehmung von Geschlechterrollen leisten und die Beteiligten am Publikationsprozess eine gewisse Verantwortung in dieser Hinsicht besitzen. ${ }^{91}$ Im deutschsprachigen Raum wurde Stephenie Meyer des Öfteren aufgrund der Propagierung eines schwachen, durch mormonischen Glauben geprägten Frauenbildes kritisiert. Dadurch würden die Texte ihrer sozialisierenden Funktion nicht gerecht: ${ }^{92}$

Im ersten Teil schrieb Bella noch Aufsätze über die Frauenfeindlichkeit in Shakespeares „Macbeth“ [...], im vierten lässt sie sich, eben achtzehn geworden, von Edward über die Schwelle tragen und in den Flitterwochen schwängern, um sich gleich darauf als kompromisslose Abtreibungsgegnerin zu beweisen. ${ }^{93}$

Dem erwachsenen Vermittler könnten noch mehr Anhaltspunkte auffallen, die für ein inadäquates Rollenbild sprechen, etwa dass Bella stets für ihren Vater Einkäufe erledigt und kocht, er selbst ist dazu scheinbar nicht in der Lage (BzMo, S. 37 f., S. 155 f., S. 158; BzAb, S. 13). Er wiederum arbeitet und schaut gerne Sportprogramme im Fernsehen (BzMo, S. 158; BzMo, S. 137; BzMo, S. 204). ${ }^{94}$ Zudem kann der Text dahingehend interpretiert werden, dass Bella oftmals von Männern entmündigt wird, sowohl ihr Vater als auch Jacob und Edward berauben sie des Öfteren ihrer Entscheidungsgewalt. ${ }^{95}$ Die Gesamtaussage ist ebenfalls problematisch:

\footnotetext{
${ }^{90}$ Ausgehend von den Normen einer aufgeklärten, westeuropäischen Gesellschaft.

${ }^{91}$ Zum Einfluss von Kinder- und Jugendliteratur sowie gängigen Rollenkonzeptionen zeitgenössischer Texte, siehe Haller (2004), S. 488-495. Zum Einfluss von Harry Potter siehe Decker (2010), S. 131 ff.

${ }^{92}$ Etwa im Welt-Artikel „Der Unverbesserliche mit dem großen Erfolg“ von Wieland Freund: www.welt.de/die-welt/kultur/literatur/article4280427/Der-Unverbesserliche-mit-dem-grossen-Erfolg.html (10.9.2014).

${ }^{93}$ Wieland Freund in einer Kritik für Welt.de am 14.2.2009: www.welt.de/welt_print/article3203692/Maedchenwollen-wieder-brav-sein.html (10.9.2014).

${ }^{94}$ Dass Mädchen begeistert von Baseball sein könnten, wird sogar von Charly explizit hinterfragt. Siehe BzMo, S. 374.

${ }^{95}$ So zwingt Charly seine Tochter mehr oder weniger dazu, mit Freundinnen auszugehen (BzMi, S. 100-103) und Bella muss geradezu fluchtartig zu ihrem Freund Jacob fahren, da Edward den Umgang mit ihm verbietet
} 
Über lange Passagen geht es um Bellas Sehnsucht nach Edwards Nähe und Liebe; sie tut alles dafür, um mit ihm zusammen zu sein. Letztendlich gibt sie sogar ihre natürliche Daseinsform auf und lässt sich in einen seelenlosen Vampir verwandeln, was durchaus auch als Unterwerfung ausgelegt werden kann. Die harsche Kritik bezüglich der Genderproblematik blieb interessanterweise in den Verfilmungen offenbar nicht unberücksichtigt. Im ersten und zweiten Teil wird Bella nicht beim Kochen und der Verrichtung von Haushaltsarbeiten gezeigt, stattdessen wird mehrfach erzählt, dass sie mit ihrem Vater regelmäßig in einem Restaurant isst (Twilight; 1:10 h). Des Weiteren flossen Dialoge in das Drehbuch ein, die eindeutig emanzipatorische Anklänge besitzen: Während im originären Text von Bis(s) zum Morgengrauen immer wieder die Männer angehalten sind, die Mädchen zu umwerben, damit sie mit ihnen zum Abschlussball gehen (BzMo, S. 76-88), wird im Film ein Gespräch zwischen Bella und Angela gezeigt, das so nicht vorkommt:

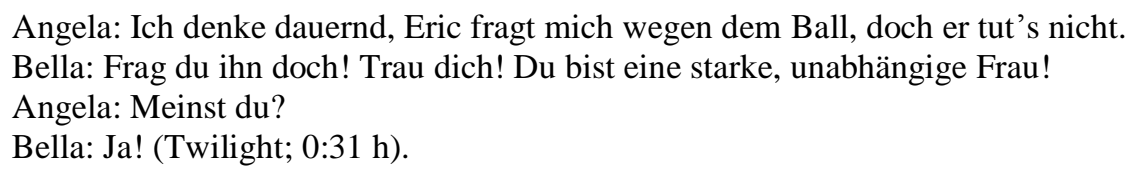

Auch Die Tribute von Panem musste sich der Kritik stellen, der Verantwortung eines jugendliterarischen Kommunikats nicht gerecht zu werden. Ruth Klüger bemängelte etwa in Die Welt die pädagogische Qualität der Serie: „Der Text befriedigt unanalytisch die Fantasien Halbwüchsiger und bestärkt sie, ohne weiterzuführen. “96

\subsubsection{Percy Jackson als Kinderliteratur}

Percy Jackson richtet sich mit einer Altersempfehlung ab zwölf Jahren an eine jüngere Zielgruppe als die Bis(s)-Serie, eher ähnlich der von Harry Potter; beide verhandeln zudem ähnliche Themen der Adoleszenz. ${ }^{97}$ Percy geht zur Schule, pflegt Freundschaften in seiner Altersgruppe und erlebt die erste Liebe. Dabei werden teils klischeehafte Teenagerkonflikte vorgeführt, die der Erfahrungswirklichkeit Pubertierender entsprechen: Percy schämt sich für die Geschichten, die seine Mutter über seine Kindheit erzählt, erst recht wenn sie dies vor seinen Freunden tut (PJ 3, S. 9). Andererseits wendet er sich bei Problemen zuerst an sie, denn er weiß, sie merkt immer, wenn ihn etwas bedrückt (PJ 3, S. 127). Als er zu seinem ers-

(BzAb, S. 103 f.); da sie ihn dennoch besucht, muss sie sich von Edward schwere Vorwürfe anhören (BzAb, S. 147).

${ }^{96}$ www.welt.de/print/die_welt/literatur/article108573647/Etwas-Geknuddel-aber-keine-Sexualitaet.html (19.9.2014).

97 Siehe die Altersempfehlung zur Gesamtausgabe: www.carlsen.de/hardcover/percy-jackson-percy-jacksonschuber-inkl-e-book-kane-chroniken-bd-1/30534\#Inhalt (11.9.2014). 
ten großen Abenteuer aufbricht, wird Percy sich bewusst, dass der Auftrag ihn aus seiner Kinderrolle entlässt und ihm den Weg bereitet, erwachsen zu werden: „Ich war dabei, HalfBlood Hill zu verlassen. Ich war unterwegs nach Westen, ohne von Erwachsenen beaufsichtigt zu werden, ohne Krisenplan, sogar ohne Mobiltelefon. “ (PJ 1, S. 188). Er macht sich auf, ein Held zu werden, also auch einen Reifeprozess zu durchlaufen und die Stellung einzunehmen, die für ihn vorbestimmt ist (PJ 1, S. 435). Von Band zu Band wird er stetig erwachsener, was auch Percys Mutter bewusst wird: „Ich meine... du bist langsam zu alt, als dass ich dir sagen könnte, was du zu tun hast" (PJ 3, S. 127). In Percys Umfeld zeigt sich die Suche nach Identität sowie beruflichem Status und Geschlechterrolle als ebenso allgegenwärtig: Annabeth ist in ihrer Entwicklung immer etwas weiter als Percy, sie weiß schon im ersten Band, dass sie Architektin werden will (PJ 1, S. 242), und verhält sich in der gegenseitigen Annäherung viel souveräner. So hat sie im dritten Band kein Problem damit, auf einer Party mit Percy zu tanzen, während er mit der Situation überfordert ist. Sie sagt: „Ich beiß doch nicht [...]. Also echt, Percy. Wird an deiner Schule denn nie getanzt? “ (PJ 3, S. 20). Percy und sie suchen und finden sich schließlich, der Abschluss des Prozesses markiert gleichzeitig den Abschluss ihrer Pubertät (PJ 5, S. 442). Auch Luke, der sich im ersten Band als Anhänger des Chronos entpuppt, ist auf der Suche nach Identität, diese schließt ebenfalls mit der Serie ab: Im ersten Band von der rechten Bahn abgekommen, stellt er nach und nach eine Armee gegen die Götter auf (PJ 2, S. 322). Sein Vater Hermes sorgt sich um ihn und bittet Percy, seinen Sohn zu retten - im wörtlichen wie im übertragenen Sinne (PJ 2, S. 125). Letztendlich findet Luke seinen Weg, er opfert sich am Ende selbst, um das Gute über das Böse siegen zu lassen. Luke „öffnete die Seitenriemen seiner Rüstung und entblößte ein kleines Stück Haut gleich unter seinem linken Arm, eine Stelle, die sehr schwer zu treffen war. Mit großer Mühe stach er hinein “ (PJ 5, S. 422). Bemüht wird hier ein brutales, aber dennoch starkes Bild, das eine eindeutige Moral vermittelt.

Die Adressierung an Jugendliche bzw. Kinder wird vor allem durch Erzählerkommentare deutlich, die sich direkt an die Leser wenden.

Seid ihr jemals nach Hause gekommen und euer Zimmer war das pure Chaos? Als ob irgendeine hilfsbereite Person (huhu, Mom) versucht hätte ,aufzuräumen“, und plötzlich könnt ihr nichts mehr finden? Und selbst wenn nichts fehlt, habt ihr das unheimliche Gefühl, dass irgendwer in eurem privaten Kram herumgeschnüffelt und alles mit Möbelpolitur mit Zitronenduft übersprüht hat? So ungefähr kam ich mir beim Wiedersehen mit Camp Half-Blood vor. (PJ 2, S. 61)

Die Bücher setzen auf diese Weise unmittelbar an der Erfahrungswirklichkeit jugendlicher Rezipienten an und schaffen eine Kommunikationssituation, die einen erwachsenen Rezipien- 
ten formal ausschließt. Dies ist möglicherweise eine ungünstige Strategie und bei den anderen Texten des Korpus so nicht zu beobachten. Damit wird es nämlich schwierig, ein gleichberechtigtes Symbolsystem für erwachsene Rezipienten aufrecht zu erhalten, das für eine AllAge-Strategie unerlässlich ist. Angesprochen werden Erwachsene allein in ihrer Rolle als Vermittler und Erzieher; ihnen mag das Werk als Lesestoff für Kinder und Jugendliche äußerst geeignet erscheinen, zumal Inhalte der griechischen Mythologie, also bildungsrelevantes und prestigeträchtiges Wissen, vermittelt werden. ${ }^{98}$

\subsubsection{Zu den Lernchancen, die die Werke des Korpus bieten}

Die Lernchancen sind analog zum didaktischen Potenzial der Potter-Texte weitreichend, zumal sich die vielschichtigen Romane ungeheurer Popularität erfreuen. Dabei kommt erwachsenen Vermittlern die Rolle zu, die Komplexität aufzuzeigen und den Vorgang der Distanzierung zu begleiten, der die Strukturen eben jener Texte aufzuzeigen vermag. Folgende Liste gibt unter Berücksichtigung der Ergebnisse der vorigen Kapitel die didaktischen Potenziale wieder, deren Aufarbeitung sicher lohnenswert ist:

- Vor allem unter dem Aspekt der Leseförderung sind die Serien interessant, da sie, ist das Interesse erst einmal geweckt, viel Material zum Weiterlesen zur Verfügung stellen. ${ }^{99} \mathrm{Da}$ es sich um kohärente Fortsetzungen handelt, sind die Rezipienten - anders als bei Episodenserien - dazu angehalten, große Textmengen strukturiert zu überblicken und ständig Einzelpassagen in den Gesamtzusammenhang zu stellen, der sich erst mit Abschluss des letzten Bandes zur Gänze erschließt. Insofern können die Bücher dazu beitragen, sinnige Lesestrategien zu erproben bzw. zu entwickeln, und darüber hinaus strukturiertes Denken schulen.

- Die Publikation der Texte im Medienverbund gibt nicht nur Anlass zur Medienreflexion, sondern liefert medienspezifische Übungsanlässe auf Rezeptions- und Produktionsebene: So kann der Erstzugang mit präferierten Medien geschaffen werden, woraufhin möglicherweise auch andere Rezeptionsweisen attraktiv werden. Sind die Lernenden erst einmal in eine literarische Welt eingetaucht, so die Theorie, liefert dies genug Motivation, eine ungeübtere Rezeptionsweise zu erproben. ${ }^{100}$ Insbesondere das Internet und seine Fan-Foren bieten ausreichend Gelegenheit für authentische Schreibund andere Produktionsanlässe, indem durch sie die medienspezifischen Produkte in einen authentischen Diskurs eingebettet werden. ${ }^{101}$ Fanfiction, die zu allen Serien im

\footnotetext{
98 Angemerkt sei dazu: Da teilweise starke Änderungen in Inhalt und Motiven der mythischen Vorlagen vorgenommen werden, sollte die Lektüre von einem informierten Mitleser begleitet werden, der die innovativen Momente einzuordnen vermag. Das vermittelte Wissen ist ohne eine legitime Kontextualisierung nahezu wertlos.

${ }^{99}$ Wrobel (2010), S. 8.

${ }^{100}$ Steffen Gailberger und Katrin Dammann-Thedens gehen davon aus, dass der Erstzugang mit einem Hörbuch eine gute Strategie darstellt, die Schülerinnen und Schüler zum Weiterlesen motiviert. Gailberg/DammannThedens (2008), S. 35-48.

101 Besonders Ina Karg hat auf darauf hingewiesen, dass Diskursfähigkeit und authentische Schreibanlässe vor
} 
Netz zu finden ist, zeugt davon, dass die Bücher erfolgreich als Schreibanlass dienen, da sie offenbar Gerüste und Gesetzmäßigkeiten zur Verfügung stellen, von denen ausgehend fantasievolle eigene Texte gestaltet werden können. ${ }^{102}$

- Die breite und großflächige Vermarktung vermittelt den Lernenden zudem Einsichten in die Zusammenhänge von Markt- und Publikationskontexten, indem die Bücher nicht nur als ästhetisches Produkt, sondern eben auch als Ware betrachtet werden, die auf dem Markt platziert und beworben wird, um bestmöglichen Profit zu erwirtschaften. ${ }^{103}$

- Weitere Lernchancen bietet der Aufruf von Literaturtraditionen, literarischen Motiven und Topoi sowie verschiedenen Gattungsschemata, sofern die Mechanismen erkannt, aufgezeigt und historisch kontextualisiert werden. Darüber hinaus laden sprechende Namen und intertextuelle Verweise zum Dechiffrieren ein; gerade der attraktive Rätselcharakter verleiht den Werken Motivation für jugendliche Rezipienten. ${ }^{104}$

\subsubsection{Zwischenfazit}

Sowohl die Bis(s)-Serie als auch die Percy-Jackson-Pentalogie behandeln Themen der jugendlichen Lebenswelt, wobei Letztere eher der Erfahrungswirklichkeit pubertierender Jugendlicher entsprechen: Schule, Freundschaften unter Gleichaltrigen, das Verhältnis zu Eltern und Lehrern sowie die erste Liebe. Die Bis(s)-Serie fokussiert Themen, die im Übergang vom Teenager- zum Erwachsenenalter präsent sind: Schulabschluss, Auszug aus dem Elternhaus, die Lösung von den Eltern sowie Hochzeit und Schwangerschaft. Trotz etwas unterschiedlicher Zielgruppe fungieren beide Werke als kinder- und jugendliterarische Kommunikate und nehmen somit zwei implizite Rezipienten in den Blick: jugendliche Leser und erwachsene Mitleser. Als doppeladressierte Literatur weisen beide ein metatextuelles Symbolsystem auf, das der Adäquanz, Funktion und Ästhetik jugendliterarischer Werke entspricht, während sie den dadurch auferlegten Normen auf unterschiedliche Weise begegnen. Meyers Serie liefert ein Beispiel, wie sich ein zeitgenössisches jugendliterarisches Kommunikat inhaltlich deutlich an der Grenze zur Erwachsenenliteratur bewegen vermag, Percy Jackson hingegen verbleibt wie Harry Potter sehr deutlich innerhalb der Normen. ${ }^{105}$ Da alle Texte des Korpus primär als Kinder- und Jugendliteratur vertrieben werden, ist davon auszugehen, dass auch sie die dafür typische doppelte Adressierung vornehmen und die diesbezüglich geltenden gesellschaftlichen Normen einhalten.

\footnotetext{
allem in der Schule von hoher Relevanz sind. Vgl. Karg (2007).

${ }^{102}$ Vgl. Böhme-Dürr (2000), S. 30; www.fanfiktion.de (20.11.2014).

${ }^{103}$ Wrobel (2010), S. 10.

${ }^{104}$ Vgl. Bergenthal (2008), S. $71 \mathrm{ff}$.

105 So kann man sagen, dass die Adressierung der Bis(s)-Serie stärker an die späterer Potter-Bände erinnert und die der Percy-Jackson-Serie stärker an die früherer Potter-Bände.
} 
Das didaktische Potenzial der Korpustexte ähnelt dem von Harry Potter: Die Vielschichtigkeit bietet Anknüpfungspunkte für literarische sowie historische Bildung, wobei eine reflektierende und kontextualisierende Begleitung bei der Lektüre wichtig ist. Dieses Ergebnis sollte dazu ermutigen, die Texte in Lehr- und Lernkontexten einzusetzen, da die aufgezeigten kompositorischen Vorzüge zusammengenommen selten in anderen jugendliterarischen Texten zu finden sind.

\subsection{Harry Potter und die Post-Potter-Texte als All-Age-Literatur}

Mit der altersunspezifischen Adressierung, die neben Kindern und Jugendlichen auch auf erwachsene Adressaten abzielt, greifen die Post-Potter-Texte zweifelsohne eine Strategie des Vorgängers auf, der den akademisch wie auch öffentlich geführten All-Age-Diskurs beflügelt hat. Nicht selten stößt man in der Forschung diesbezüglich auf ebenso plakative wie umstrittene Behauptungen, etwa: „Harry Potter is considered as the crossover title, a kind of prototype of the genre. " ${ }^{106}$ Unbestritten scheint, dass im Zuge der Erfolgsgeschichte des Werks der Begriff All-Age-Literatur eine medienwirksame Renaissance erlebte. ${ }^{107}$ Ebenso scheint es durchaus plausibel, Harry Potter als Auslöser eines All-Age-Trends zu betrachten, der den Buchmarkt der letzten fünfzehn Jahre stark beeinflusst hat. Denn selbst nach 2007 - nach Beendigung von Harry Potter sowie der Tintenwelt-Trilogie - setzt sich der Trend zum Crossover-Titel fort. Der Börsenverein des Deutschen Buchhandels maß dem Phänomen eine solch hohe Bedeutung bei, dass er 2010 eine Pressemappe zum Thema anfertigte, in der es heißt:

Literatur für die junge Zielgruppe ist ein wichtiger und stark wachsender Markt. Das gilt besonders für den Bereich des Jugendbuchs ab 12 Jahren, unter das auch All-Age-Bücher fallen, so Claudia Paul. In diesem Segment gab es 2009 ein Umsatzplus von 44 Prozent. ${ }^{108}$

Eine Studie aus dem Herbst 2012 legte für Deutschland beeindruckende Zahlen vor: Unter 231 neu erschienenen Jugendbüchern (Leseempfehlung ab zwölf Jahre) sind 39 All-Age-Titel zu verzeichnen. ${ }^{109}$

Der Börsenverein machte zudem auf eine Stellungnahme des Arbeitskreises für Jugendliteratur e. V. aufmerksam, die hier von besonderer Bedeutung ist; darin wird konkretisiert, welche

\footnotetext{
${ }^{106}$ Beckett (2009), S. 1.

107 Siehe dazu Beckett (2009); Blümer (2009), S. 111.

${ }^{108}$ Presseinformation des Börsenvereins des Deutschen Buchhandels, zusammengestellt von Julia Piaseczny: All-Age-Bücher dominieren. Bleibt das Kinderbuch auf der Strecke? Allianz der Leseförderer fordert Lesevorbilder für Kinder und Jugendliche: www.boersenverein.de/sixcms/media.php/976/Digitale_Pressemappe_Trendbericht.pdf (9.9.2014).

${ }^{109}$ Presseinformation des Börsenvereins des Deutschen Buchhandels: Neuerscheinungen Jungendbuch (Herbst 2012): www.boersenverein.de/sixcms/media.php/975/Digitale_Pressemappe_Trendbericht.pdf (9.9.2014).
} 
Titel im ersten Jahrzehnt des neuen Jahrtausends von der Öffentlichkeit als All-Age-Literatur wahrgenommen wurden:

Auf der Liste der 20 meistverkauften Bücher von 2002 bis 2009 im Bereich Belletristik finden sich elf All-Age-Titel, das heißt mehr als die Hälfte der Bestseller sind Jugendbücher: Es sind die Harry Potter-, Tintenherz- und Bis(s)-Bände. ${ }^{110}$

Die Zuordnung der genannten Werke zur All-Age-Literatur erschien offenbar heuristisch plausibel - zumal gängige Praxis -, was die Titel als Untersuchungsobjekt interessant macht. Es drängt sich die Frage auf, welche Eigenschaften wohl zu dieser Wahrnehmung führten. Vor dem Hintergrund des Modells zum adressatenbezogenen Symbolsystem werden hier nachfolgend Vorschläge unterbreitet, die die Zuweisung aus literaturwissenschaftlicher Perspektive erläutern.

Nach einem kurzen Abriss über die Geschichte der All-Age-Literatur (Kapitel 6.3.1) werden dazu deren Charakteristika vor dem Hintergrund verschiedener wissenschaftlicher Theoriebildungen zusammengetragen (Kapitel 6.3.2). Diese sollen ausgehend von einem Forschungsüberblick an Rowlings Texten aufgezeigt werden und die gängige Zuordnung zur Adressatengattung All-Age plausibilisieren (Kapitel 6.2.3). Anschließend werden die Bi(s)-Serie und die Tintenwelt-Trilogie stichpunktartig auf die genannten Charakteristika untersucht (Kapitel 6.2.4) sowie im Rahmen eines Fazits die Adressierungsstrategien mit denen von Harry Potter verglichen (Kapitel 6.2.5).

\subsubsection{Zur Geschichte der All-Age-Literatur}

Die Behauptung, dass durch Harry Potter All-Age-Literatur erst aufgekommen sei, ist nicht haltbar, vielmehr wurde Ende der 90er lediglich der Begriff geboren, womit das Phänomen an sich eine neue Ausrichtung gefunden zu haben scheint. ${ }^{111}$ Lange vorher sind beide Richtungen des Crossover in der Literatur- und Rezeptionsgeschichte sowie auch am Buchmarkt erkennbar, indem Kinder oder jugendliche Leser sich stets auch für Erwachsenenliteratur interessiert haben, die, zumal verboten, von besonderem Reiz ist. Insbesondere Krimis, Abenteuerliteratur und erotische Romane üben seit jeher eine enorme Attraktivität aus. Auch dass Erwachsene sich für Kinder- und Jugendliteratur interessieren, ist kein Novum, in vielen Fällen allein schon deswegen, weil Eltern die Lektüre ihrer Kinder aussuchen wollen. Der Selektion scheint dabei ein identifikationsstiftendes Moment innezuwohnen, zahlreiche Klassiker der

\footnotetext{
${ }^{110}$ Regina Pantos vom Arbeitskreis für Jugendliteratur e. V. (AKJ), Trendbericht Kinder- und Jugendbuch vom 19. März 2010: www.boersenverein.de/sixcms/media.php/976/Digitale_Pressemappe_Trendbericht.pdf (9.9.2014).

${ }^{111}$ Vgl. Beckett (2009), S. 85 und Manz (2011), S. 40.
} 
Kinder- und Jugendliteratur haben inzwischen einen regelrechten Kultstatus erlangt, der sich über mehrere Generationen herauskristallisiert hat. ${ }^{112}$ Ebenso finden sich schon lange vor Harry Potter Bücher, die dezidiert für Kinder und Erwachsene geschrieben wurden, insbesondere im Bereich der phantastischen Literatur, beispielsweise Alice's Abenteuer im Wunderland (1869), Der Zauberer von Oz (1940), Peter Pan (1964), Hexen hexen (1986), Der goldene Kompass (1996 ff.) und die Chroniken von Narnia (1957 ff.), Werke von Autoren, die in der Forschung als „pre-Potter children's authors “ bezeichnet werden. ${ }^{113}$ Auch das Opus von Walt Disney wird in diesem Zusammenhang genannt, scheint es doch auffällig altersunspezifisch Gefallen zu finden. ${ }^{114}$ Zudem liegen mehrfach literarische Produkte vor, die sich zwar offiziell an Kinder, durch ihre allegorische Bedeutung aber inoffiziell an Erwachsene richteten. Da Kinder- und Jugendliteratur ein niedriges Ansehen hatte und wenig Aufmerksamkeit auf sich zog, eignete sie sich hervorragend als politisches Instrument, insbesondere um ideologisches Gedankengut zu vermitteln. Folgendes Beispiel kann diesen Sachverhalt illustrieren: In den 30er-Jahren wurde der russische Jugendbuchschreiber Samual Marshak als Anti-Sowjet-Autor festgenommen. ${ }^{115}$ Dies war der doppelten Lesart seiner Texte geschuldet, die auf allegorische Weise das politische Geschehen in der Sowjetunion kritisierten. ${ }^{116}$ In Deutschland trat in ähnlicher Weise Erich Kästner hervor, dessen Kinderbuch Emil und die Detektive, das, 1929 gerade erschienen, zum großen Erfolg avancierte, aufgrund seiner kritischen und satirischen Untertöne unter Hitler aber verboten und verbrannt wurde. Erst nach 1945 konnte es sich zum internationalen Bestseller entwickeln, der bis heute von Jung und Alt gern gelesen wird. ${ }^{117} \mathrm{Ab}$ den 60er-Jahren gilt Letzteres auch für das Werk von Michael Ende: Die Unendliche Geschichte, mit zweifarbigem Druck und Illustrationen 1979 erstmals erschienen, richtet sich sowohl an jugendliche als auch an erwachsene Leser; die Covergestaltung des Buches kann als Vorreiter heutiger All-Age-Ausgaben betrachtet werden. ${ }^{118}$

Doppel- bzw. mehrfachadressierte Werke bezeichnet Blümer als „,Vorfahren“ des aktuellen Crossover-Trends. ${ }^{119}$ Doch sind diese als Einzelphänomene zu betrachten, die eigentliche All-

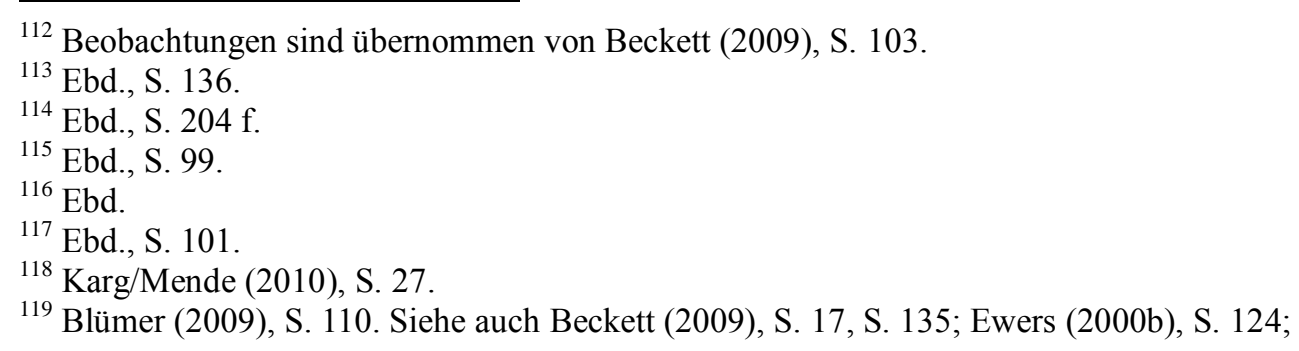


Age-Schwemme begann mit Harry Potter, sie kann somit als „,zeittypische Erscheinung “120 betrachtet werden.

\subsubsection{Zu den Charakteristika der All-Age-Literatur}

Aufgrund der starken Außenwirkung des literarischen Phänomens haben sich im Zuge des Trends zahlreiche literaturwissenschaftliche und didaktische Arbeiten mit dem Phänomen AllAge-Literatur beschäftigt und es dabei auf unterschiedliche Weise modelliert. Da insbesondere literarische Stoffe aus dem Bereich Fantasy von Rezipienten unterschiedlichen Alters geschätzt werden, wird teilweise sogar davon ausgegangen, dass die Crossover-Fiction aus der Phantastik hervorgegangen ist und All-Age-Fantasy damit als Subgenre derselben zu betrachten ist. ${ }^{121}$ Falconer und Beckett sehen das Phänomen hingegen nicht allein auf Fantasy-Texte beschränkt. $^{122}$

All-Age-Literatur Ein literarischer Text ist dann als All-Age-Literatur aufzufassen, wenn er gleichzeitig und gleichberechtigt an erwachsene und kindliche/jugendliche Rezipienten adressiert ist. ${ }^{123}$ Die altersunspezifische Ausrichtung gelingt oftmals durch zwei oder mehrere gleichberechtigt angebotene Lesarten oder Interpretationen. In vielen Fällen wird neben einer wörtlichen/naiven eine oder mehrere allegorische Lesarten zur Verfügung gestellt. Einem erwachsenen Leser kommt dabei nicht mehr allein die Rolle des Vermittlers oder Mitlesers zu, sondern er wird gleichberechtigter Adressat des doppel- oder mehrsinnigen Textes. ${ }^{124}$ Modellbedingt kann davon gesprochen werden, dass das literarische Polysystem eines Textes in zwei Subsysteme zerfällt, das strenggenommen mindestens drei unterschiedliche Interessen befriedigen muss: ${ }^{125}$ die des jugendlichen Rezipienten, die seines erwachsenen Mitlesers und die des offiziellen erwachsenen Rezipienten. Es ist auch möglich, dass ein All-AgeText andere Adressaten impliziert.

Einige Theorien bezeichnen mit dem Begriff auch Hybridtexte, die sich dezidiert an ältere Jugendliche und junge Erwachsene richten und im Übergangsbereich dieser

\footnotetext{
${ }^{120}$ Bergenthal (2008), S. 21.

${ }^{121}$ Vgl. einen Artikel von Rees 2002 im Daily Telegraph und Ewers (2012), S. 37.

${ }^{122}$ Falconer (2009) und Beckett (2009), S. 136.

${ }^{123}$ Blume (2005), S. 33.

${ }^{124}$ Ewers (2000b), S. 124.

${ }^{125}$ Vgl. Shavit (1986), S. 53.
} 
beiden anzusiedeln sind. ${ }^{126}$ Die Literatur kann aber auch als Ergebnis der Annäherung von Allgemeinliteratur auf der einen und Kinder- und Jugendliteratur auf der anderen Seite verstanden werden. ${ }^{127}$ Andere Diskursteilnehmer modellieren All-AgeTexte als mehrfachadressierte Produkte, die keinen Doppelsinn, sondern eine einfache Botschaft aufweisen, die nicht für jeden Rezipienten zur Gänze wahrnehmbar ist. ${ }^{128}$ Die Vorstellung einer All-Age-Gattung geht vor einem soziokulturellen Hintergrund grundsätzlich mit der Auflösung der Konstrukte Jugend und Erwachsenenalter einher, die sich in der Postmoderne auch in anderen kulturellen Kontexten beobachten lässt. $^{129}$

Indem sich jeder All-Age-Text auch an jugendliche Rezipienten richtet, untersteht er konventionell den Anforderungen jugendliterarischer Kommunikate. Daher ist es gängige Praxis, die Handlung im jugendlichen Milieu anzusiedeln, was auch aus strategischen Gründen sinnvoll ist, da sich Erwachsene durchaus rückblickend mit ihrem damaligen Ich identifizieren können, während sich Jugendliche eher weniger mit „Erwachsenenthemen“ auseinandersetzen wollen. ${ }^{130}$ Zudem scheint seitens der Autoren und Verlage davon ausgegangen zu werden, dass die Jugendlichen es schätzen, wenn die Protagonisten gleich alt oder wenige Jahre älter sind. ${ }^{131}$ Darüber hinaus werden in den All-Age-Texten viele Normen eingehalten, die für das Symbolsystem der Kinder- und Jugendliteratur gattungsweisend sind. Trotz der Tendenz zur Revision ist eine übersexualisierte, gewaltbeladene Erzählung mit Doppelmoral und schlechtem Ausgang bei Literatur nicht denkbar, die sich in der Vermarktung eben auch explizit an Jugendliche richtet. ${ }^{132}$ Ewers geht allerdings davon aus, dass in den hier betrachteten Werken Kinder- und Jugendthemen ungeachtet der jugendlichen Protagonisten zusehends zugunsten universeller, altersübergreifender Themen verdrängt werden. ${ }^{133}$

\footnotetext{
${ }^{126}$ Vgl. Beckett (2009), S. 3. Eine solche Zielgruppe wird hier der Jugendliteratur zugeordnet.

${ }^{127}$ Gansel (2010), S. 7.

${ }^{128}$ Vgl. Ewers (2012), S. 51. Die Modelle der Doppel- und Mehrfachadressierung werden an späterer Stelle noch näher erläutert.

${ }^{129}$ Blümer in einem Aufsatz für KinderundJugendmedien.de: www.kinderundjugendmedien.de/index.php/begriffe-und-termini/494-crossoverall-age-literatur (8.9.2014); Blume (2005), S. 34. Zu postmoderner Literatur siehe auch Kapitel 5.

${ }^{130}$ Ebd.

131 Arena-Verlag (Hrsg.): Informationen für Presse und Veranstalter. Cassandra Clare. Würzburg 2008.

132 Beckett geht davon aus, dass einige Normen der Kinder- und Jugendliteratur bei All-Age-Titeln durchaus infrage gestellt werden. Vgl. Beckett (1999), S. xiii.

${ }^{133}$ Ewers (2011), S. 14.
} 
Vom Begriff der All-Age-Literatur ist der des Crosswritings abzugrenzen, der je nach Definition etwas anderes bezeichnet. Kümmerling-Meibauer versteht darunter drei verschiedene Dinge:

[...] erstens die Tatsache, dass viele Kinderbuchautoren auch Werke für Erwachsene schreiben; zweitens das Phänomen, dass ein zunächst als Erwachsenenbuch konzipiertes Werk von demselben Autor als Kinderbuch umgeschrieben wird oder umgekehrt; drittens ein rezipientenübergreifendes Schreiben $[\ldots] .{ }^{134}$

Demzufolge ist All-Age-Literatur als ein Spezialfall des Crosswritings aufzufassen. Inwiefern die doppelte oder mehrfache Adressierung einen literarischen Text auf- oder abwertet, sei hier außen vor gelassen, ${ }^{135}$ vielmehr soll interessieren, ob und wie sich eine solche Adressierung im Text niederschlägt.

Als klar auszumachende Charakteristika der All-Age-Literatur können textexterne Eigenschaften des Publikationsprozesses herangezogen werden. Oft fungiert die offizielle doppelte Adressierung als Verkaufsargument, was entweder in Dual Editions - zwei verschiedenen Ausgaben, eine für Kinder und eine für Erwachsene - zum Ausdruck kommt, in der expliziten Empfehlung für jugendliche und erwachsene Rezipienten oder aber in Form von dezent gestalteten Covern, oftmals unter Verwendung von Symbolen oder Ornamenten, die auf keine spezifische Adressatengruppe abzielt. ${ }^{136}$

Die textimmanenten Merkmale werden in der Forschung kontrovers diskutiert. Blümer macht darauf aufmerksam, dass es neben den äußeren Publikationsmerkmalen unmöglich ist, strukturelle oder stilistische Merkmale auszumachen, die als gattungsweisend betrachtet werden können. ${ }^{137}$ Nichtsdestotrotz würden diesbezüglich in der Forschung unterschiedliche, teilweise auch widersprüchliche Vorschläge gemacht: So werden Ironie und Intertextualität bzw. narrative Komplexität genannt, andere heben gerade die Einfachheit und die Verwendung traditioneller Narrationsstrukturen hervor. ${ }^{138}$ Zudem heißt es, dass die Werke durch ihren breiten Human Appeal für alle Altersstufen attraktiv seien. ${ }^{139}$

Im Rahmen dieser Arbeit werden die strukturgeleiteten Ansätze der Doppel- und Mehrfachadressierung herangezogen, um die Zuordnung zur All-Age-Literatur plausibel zu machen. Bei-

\footnotetext{
${ }^{134}$ Kümmerling-Meibauer (2003), S. 248.

${ }^{135}$ Shavit (1986, S. 55) betrachtet die gleichzeitige Adressierung an Kinder und Erwachsene als Aufwertung.

${ }^{136}$ Blümer in einem Aufsatz über All-Age-Literatur: www.kinderundjugendmedien.de/index.php/begriffe-undtermini/494-crossoverall-age-literatur (8.9.2014).

${ }^{137}$ Ebd.

138 Ebd.

${ }^{139}$ Vgl. Petzold (2004), S. 86.
} 
de argumentieren mit verschiedenen, nebeneinander identifizierbaren Lesarten bzw. Bedeutungsebenen, die in der Rezeption verschiedene Erfahrungshorizonte bzw. Abstraktionskompetenzen voraussetzen. So fußt auch diese Genrezuweisung auf Interpretation, die zwar auf objektive Texteigenschaften verweist, aber nicht als Beweis im engeren Sinne zu werten ist.

- Wird die Doppelsinnstruktur eines Werkes als gattungsweisendes Merkmal von AllAge-Literatur herausgestellt, so bedeutet dies, dass zwei gleichberechtigt nebeneinander existierende Lesarten bzw. Interpretationen angeboten werden, die der Handlungsstruktur nicht im Weg stehen. ${ }^{140}$ Das Modell ist als Komplexitätsreduktion zu verstehen, das nur zwei und nicht mehr Lesarten vorsieht. Demnach besitzt ein Text zwei unabhängige Symbolsysteme als Resultat der Adressierung an zwei Adressatengruppen mit unterschiedlichem Kompetenzniveau. Die Doppelsinnstruktur lässt so neben der naiven wörtlichen Lesart eine weitere, allegorische $\mathrm{zu},{ }^{141}$ welche sich mithilfe einer Übertragungs- und Interpretationsleistung erschließen lässt und die wörtliche Lesart nicht unterläuft. ${ }^{142}$ Modellbedingt kann der Text so als komplexes System aufgefasst werden, das in zwei Subsysteme zerfällt: eine kindliche und eine erwachsene Lesart respektive eine Lesart für unerfahrene und eine für erfahrene Rezipienten. ${ }^{143}$ Letztere Modellierung scheint genauer zu sein, denn sie nimmt auch begabte Kinder und weniger begabte Erwachsene als Rezipienten ernst. Oftmals ergibt sich die allegorische Bedeutung eines doppelsinnigen Textes daraus, dass die Themen, die sich explizit an die Erfahrungswirklichkeit von Kindern und Jugendlichen anlehnen, leicht auf die eines Erwachsenen übertragen lassen, indem etwa ein strenger Lehrer als ein strenger Vorgesetzter oder ein strebsamer Mitschüler als ein Rivale identifiziert werden kann, womit die meist jugendlichen Protagonisten Identifikationsmöglichkeiten für erwachsene Rezipienten bieten. Oftmals ist die allegorische Bedeutung auch religiöser oder politischer Natur, was literaturhistorisch plausibilisiert werden kann. ${ }^{144}$

- Vor dem Modell einer Mehrfachadressierung besitzen Crossover-Texte keinen binären Sinn, sondern lediglich eine ,gleichlautende[] Botschaft", also nur ein Symbolsystem, das mithilfe des jeweiligen Vorwissens rezipiert und entschlüsselt werden kann. ${ }^{145}$ Je nach Wissens- und Erfahrungshorizont vermag also die Botschaft eines Textes ganz oder, in Abstufungen, teilweise erkannt werden. ${ }^{146}$ Gehören etwa intertextuelle Anspielungen und Ironie zur Botschaft, geht dies an manchen Rezipienten vorbei. ${ }^{147}$ Ungeübteren oder jüngeren Lesern bleibt somit ein Teil der literarischen Botschaft verborgen.

Ausgehend von diesen Modellen, sollen nun Harry Potter und seine Nachfolger analysiert werden. Da beide Modelle dazu geeignet scheinen, die Zuweisung eines Textes zur All-AgeLiteratur zu plausibilisieren, wird beispielhaft die Bis(s)-Serie als Text mit Doppelsinnstruktur

\footnotetext{
${ }^{140}$ Mohr (2012), S. 334; Grenz (1986), S. 175.

${ }^{141}$ Grenz (1986), S. 175.

${ }^{142}$ Dabei können beide Lesarten gleich attraktiv sein. Vgl. Nikolajeva (1999), S. 54.

${ }^{143}$ Vgl. Kölzer (2004), S. 18.

144 Beckett (2009), S. 98.

${ }^{145}$ Vgl. Ewers (2012), S. 51.

146 Ebd.

${ }^{147}$ Vgl. Bürvenich (2001), S. 169.
} 
und die Tintenwelt-Trilogie als mehrfachadressierter Text besprochen. Grundsätzlich können alle Texte sowohl mit dem einen als auch mit dem anderen Modell bezüglich ihrer Adressierung untersucht werden. Dies wird zunächst an Harry Potter gezeigt, dessen Zuweisung zur All-Age-Literatur unter Verwendung beider Modelle in der Forschung aufgezeigt worden ist.

\subsubsection{Harry Potter als All-Age-Literatur}

In Deutschland werden die Potter-Bände sowohl in der Forschung als auch vonseiten der Medien als Auslöser einer gesteigerten Nachfrage nach All-Age-Literatur angesehen. ${ }^{148}$ Der Carlsen-Verlag - so wie bereits der Bloomsbury-Verlag in England - reagierte mit Ausgaben im unterschiedlichen Layout für Kinder und Erwachsene. ${ }^{149}$ Zudem werden die Bände im Schuber sowie in Taschenbuchausgaben vertrieben, was ebenfalls die Zielgruppe der Texte erweitert - werden dadurch einerseits doch sogar Sammler angesprochen, andererseits Kunden, die nicht gewillt oder fähig sind, die hohen Kosten für die Hardcoverausgaben zu tragen, ${ }^{150}$ was auch auf Jugendliche zutreffen mag. Die Ursachen für die breite Leserschaft von Rowlings Werk - schätzungsweise machen Erwachsene ca. 40 Prozent aus ${ }^{151}$ - waren mehrfach Gegenstand von Forschungsbeiträgen. Petzold beispielsweise geht davon aus, dass die Gründe im breiten Human Appeal zu suchen sind und die Bücher, ,eine mittlere Lesekompetenz voraussetzend, spannend und zugleich humorvoll erzählen “152.

Blümer bestätigt, dass die Begriffe All-Age und Crossover erst im öffentlichen Diskurs entstanden seien, auch wenn das Phänomen der mehrfachen Adressierung nicht neu sei, sondern hier lediglich Besonderheiten aufweise: ${ }^{153}$ Crossover, Crosswriting bzw. Crossover Fiction sei „,das Harry-Potter-Phänomen “'154. Neu sei die oben angesprochene explizite Vermarktung eines Titels als All-Age-Literatur. Dies sei als innovative Strategie zu betrachten, die bei Harry Potter erstmalig im großen Stil zu beobachten war. ${ }^{155}$ Auch Beckett betont: „, The Potter

\footnotetext{
${ }^{148}$ Siehe dazu einen Artikel der Stuttgarter Zeitung: „All-Age-Literatur. Harry Potter hat die Türen geöffnet“ von Ulrike Frenkel; www.stuttgarter-zeitung.de/inhalt.all-age-literatur-harry-potter-hat-die-tuerengeoeffnet.1 e6547d7-2425-4da6-b399-4df37c47d578.html (11.9.2014).

${ }^{149}$ Unter wikipedia.de lassen sich die Cover teilweise einsehen. Dort findet sich eine Beschreibung im Abgleich mit den Covern der Originalausgabe: http://de.harry-potter.wikia.com/wiki/Ausgabe_f\%C3\%BCr_Erwachsene (11.9.014).

${ }^{150} \mathrm{Karg} /$ Mende (2010), S. 28.

${ }^{151}$ Stubenvoll (2006), S. 213.

${ }^{152}$ Petzold 2004, S. 86.

${ }^{153}$ Blümer (2009), S. $110 \mathrm{f}$.

154 Ebd., S. 112.

${ }^{155}$ Blümer (2009), S. 112.
} 
effect had a monumental impact on the publishing and marketing of major children's titles with crossover potential. " 156

In der Forschung wurde Harry Potter vor dem Hintergrund eines Doppelsinnmodells als AllAge-Text besprochen, der Text halte unterschiedliche Lesarten für unterschiedliche Altersgruppen bereit. ${ }^{157}$ Eine gängige Interpretation betrachtet das Werk als Allegorie auf den Zweiten Weltkrieg und den Nationalsozialismus. Doch auch wenn in der Zaubererwelt die gute Seite siegt, wurde diese Lesart in Deutschland kritisch gesehen, berührt sie doch ein noch immer sensibles Thema. ${ }^{158}$ Cornelius empfindet insbesondere die Blutmetapher als heikel:

Auch scheint mir die Annahme, es gebe unterschiedliche Wertigkeiten des Bluts (besonders derogatorisch erscheinen in manchem Kontext die sog. Schlammblüter, magisch begabte, aber muggelstämmige Kinder), ein gefährliches Moment zu beinhalten. Denn auch die Nationalsozialisten haben ihre Rassenideologie auf solche Wertunterschiede des Blutes aufgebaut und damit die Ausrottung allen jüdischen Blutes gerechtfertigt. ${ }^{159}$

Petzold meint, dass sich in Rowlings Werk ein ironischer Blick auf die heutige Gesellschaft wiederfinde, was ein gewisses Reflexionsniveau voraussetze, ${ }^{160}$ zahllose Anspielungen lüden zum Dechiffrieren ein, was sicherlich nicht jedem Rezipienten gleichermaßen gelänge. ${ }^{161}$ Der Text biete zudem humoristische Elemente unterschiedlicher Niveaustufe an, was auf sein Potenzial hindeute, verschiedene Adressatengruppen zu bedienen. Neben schlichter Situationskomik fänden sich ,,satirische Seitenhiebe auf bestimmte Erscheinungen der modernen Welt wie Starkult und Pressewesen “162. Wrobel wiederum betont, dass sich zuhauf intertextuelle Anspielungen fänden, die je nach literarischen Vorerfahrungen erkannt oder eben nicht erkannt werden könnten. ${ }^{163}$ Stubenvoll bestätigt die genannten Theorien. In ihrer Studie, für die sie drei Generationen einer Familie nach ihren Lesarten befragte, kommt auch sie zu dem Ergebnis, dass Harry Potter unterschiedliche Lesarten und Anknüpfungspunkte für Rezipienten unterschiedlicher Altersstufen anbiete. ${ }^{164}$

Blümer hingegen beäugt die Praxis der Modellierung einer Doppel- und Mehrfachadressierung bei der Analyse der Potter-Bände kritisch, auch wenn sie in der Forschung gängig sei. Darin zeige sich eine komplette Auflösung der Konstrukte Kindheit und Erwachsenenalter,

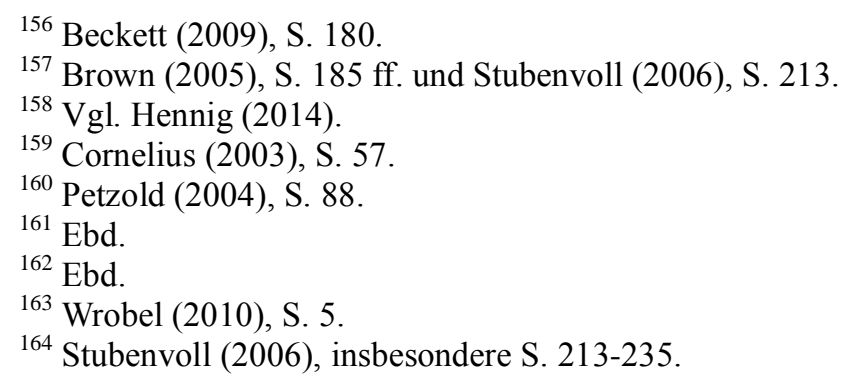


das Werk sei also weder als rein doppel- oder mehrfachadressiert noch als Hybridtext zu begreifen, der den Übergang von Jugend- zu Erwachsenenalter als Zielgruppe in den Blick nehme, vielmehr handele sich um einen durch und durch alterslosen Text. ${ }^{165}$

\subsubsection{Die Post-Potter-Texte als All-Age-Literatur}

Since the debut of Rowling's series, the top children's sellers are often fantasy books that appeal to both children and adults. Fantasy readers are often very loyal fans and children who become addicted to the genre at a young age often remain fantasy readers as adults. ${ }^{166}$

Wie Harry Potter orientieren sich die Texte des Korpus in ihrer Vermarktung an Rezipienten jedes Alters: Entweder zieren schlichte Cover die Bücher, die jugendliche und erwachsene Leser gleichermaßen ansprechen sollen, oder aber die Verlage bieten Jugend-, Erwachsenen-, Taschenbuch- und Schuberausgaben an, um allen Geschmacksrichtungen gerecht zu werden. Auch die Altersempfehlungen bewerben sowohl Jugendliche als auch Erwachsene. Textimmanent lassen sich gleichfalls ähnliche Strategien ausmachen: Sowohl Harry Potter als auch die Post-Potter-Werke stellen mehrfach auslegbare Symbolsysteme zur Verfügung, die Anknüpfungspunkte für Rezipienten mit unterschiedlichem Reflexionsniveau und Erfahrungshorizont bereitstellen, und halten eine Doppelsinnstruktur bereit, wobei entweder beide Lesarten oder nur eine zugänglich sein kann. Somit können die Post-Potter-Werke analog zu Harry Potter als Texte mit altersunspezifischer Adressierung und mit einem Symbolsystem gelten, dessen Komplexität graduell erfassbar ist. Beispielhaft soll dies nun an der Doppelsinnstruktur der Bis(s)-Serie sowie der Mehrfachadressierung der Tintenwelt-Trilogie aufgezeigt werden.

\subsubsection{Zur Bis(s)-Serie als Text mit Doppelsinnstruktur}

Neben seiner Klassifizierung als Jugendbuch darf Stephenie Meyers Serie als Crossover-Titel gelten, was u. a. durch zwei unterschiedliche Bedeutungsebenen plausibilisiert werden kann, die vom erfahrenen Rezipienten nebeneinander identifizierbar sind. Der Carlsen-Verlag vermarktet die Serie als All-Age-Literatur, indem ein Lesealter von 14-99 Jahren empfohlen wird, was sicherlich nicht wörtlich zu nehmen ist, sondern vielmehr darauf aufmerksam machen soll, dass die Bücher bis ins hohe Alter Freude bereiten können. ${ }^{167}$ Dass sie wie die Potter-Texte in beiden Zielgruppen gleichermaßen erfolgreich sind, zeigt ihre Platzierung sowohl

\footnotetext{
165 Blümer (2009), S. 110.

${ }^{166}$ Beckett (2009), S. 135.

${ }^{167}$ Siehe die Angaben zum ersten Band auf der Carlsen-Website: www.bella-und-edward.de/taschenbuch/bellaund-edward-band-1-biss-zum-morgengrauen (10.9.2014).
} 
in der Kinder-und-Jugendbuch- als auch der Hardcover-Bestsellerliste. ${ }^{168}$ Im Anschluss an ihre deutsche Erst- und auch Sammlerausgabe im Schuber erschien eine Sonderausgabe für Erwachsene sowie eine Taschenbuchausgabe im Piper-Verlag. ${ }^{169}$ Die Cover der Jugendausgabe zeigen farblich ausgestaltete Silhouetten weiblicher Gesichtsausschnitte, die der Erwachsenenausgabe spielt mit den symbolträchtigen Motiven der englischen Originalausgabe (Schachfigur, Blume, Apfel und Band), die durch ihre gleiche Farbgebung (rot, schwarz und weiß) ihre formale Zusammengehörigkeit anzeigen. ${ }^{170}$ Dass die Serie speziell bei Frauen Anklang gefunden hat, drückte sich in den ersten Jahren nach der Veröffentlichung auch im deutschsprachigen Raum durch den Fankult der „Twilight-Moms“ bzw. „Twilight-Mütter“ aus, einer Gruppierung begeisterter Leserinnen, die in der Namensgebung darauf hinweisen, dass sie von ihren Töchtern in der Leidenschaft für Meyers Bücher angesteckt wurden. ${ }^{171}$

Vor dem Hintergrund eines Doppelsinnmodells bietet der Text eine allegorische Botschaft für erfahreneren Twilight-Rezipienten an, die im deutschsprachigen Raum nicht selten ebenfalls kritisch rezipiert wird. Sie scheint indirekt eine religiöse Weltsicht zu propagieren, die hierzulande als nicht konsensfähig erachtet wird. Aufgrund ihres mormonischen Glaubens steht zu vermuten, dass die Autorin ihr Werk als propagandistisches Instrument zu nutzen suchte, um einen gesellschaftlichen Beitrag zur Entsexualisierung zu liefern. Stephenie Meyer schürte selbst diese Auslegung, indem sie in Interviews auf ihre Religion einging und darauf verwies, wie wichtig sie ihr sei: ${ }^{172}$ Obwohl die Vampirthematik dies nicht sofort vermuten lasse, thematisierten ihre Bücher Grundsätze des mormonischen Glaubens, und sämtliche Inhalte richteten sich nach dessen Regeln: Nicht nur dass die engelsgleichen Vampire gläubig seien und

\footnotetext{
${ }^{168}$ Die Bestsellerlisten der letzten Jahre können im Archiv von buchreport.de nachgelesen werden, beispielsweise zu Harry Potter und der Stein der Weisen: www.buchreport.de/bestseller/bestseller_einzelansicht.htm?tx_bestseller_pi1[isbn] $=9783551551672$ (10.9.2014); zur Bis(s)-Reihe: www.buchreport.de/bestseller/bestseller_einzelansicht.htm?tx_bestseller_pi1[isbn]=9783551581495 (10.9.2014). Ein ähnliches Ranking verzeichnete im Jahr 2009 auch das „Börsenblatt des Deutschen Buchhandels".

${ }^{169}$ Bardola (2009), S. 47.

${ }^{170}$ Cover von Carlsen: www.bella-und-edward.de/buecher (10.9.2014); von Piper: www.piper.de/autoren/stephenie-meyer-1969 (10.9.2014).

${ }^{171}$ Süddeutsche Zeitung vom 19.11.2009, Artikel von Christina Waechter: ,20 Dinge, die du über Twilight wissen musst“; online unter http://jetzt.sueddeutsche.de/texte/anzeigen/491293/20-Dinge-die-du-ueber-Twilightwissen-musst (10.9.2014).

${ }^{172}$ Siehe beispielsweise den bereits zitierten Artikel von Wieland Freund: ww.welt.de/welt_print/article3203692/Maedchen-wollen-wieder-brav-sein.html (11.9.2014) sowie das Spiegel-Interview von Christoph Dallach mit der Autorin vom 11.6.2008: www.spiegel.de/kultur/literatur/horrorautorin-meyer-vampire-sind-attraktiv-klug-und-cool-a-558826.html (11.9.2014).
} 
über die Ewigkeit sowie Daseinsformen nach dem Tod nachdenken würden, ${ }^{173}$ sie würden auch mit ihrer heroischen Selbstdisziplin einen wichtigen Grundsatz versinnbildlichen: sexuelle Enthaltsamkeit vor der Ehe. ${ }^{174}$ Diese religiöse Lesart der Texte dürfte sich nicht jedem Rezipienten gleichermaßen erschließen, bei genauer Betrachtung aber wird sie greifbar: Nicht nur dass Sex vor der Ehe zwischen den Liebenden bewusst ausgespart bleibt, ${ }^{175}$ es wird zudem als Stärke ausgelegt, seine sexuellen Triebe zu kontrollieren. So wie Edward seine Lust, Bella zu beißen, bei jeder Begegnung von Neuem unterdrücken muss, so - zumindest kann man es so auslegen - sollten sich junge Menschen ihre sexuelle Energie für ihren zukünftigen Ehepartner aufsparen. Die Allegorie wird bis zur letzten Konsequenz durchgehalten: Bella, die über alle Maßen in Edward verliebt ist, besteht darauf, dass er sie durch einen Biss in einen Vampir verwandelt. Sie wünscht ausdrücklich, ,, sein Gift im Körper zu haben. Dadurch würde ich auf eine greifbare, messbare Weise zu ihm gehören “ (BzAb, S. 324). Die Gedanken Bellas drehen sich zudem meist um ihr körperliches Verlangen nach Edward (BzMi, S. 22; BzAb, S. 190). Die Befriedigung aber bleibt ihr aus Sicherheitsgründen - sie würde vermutlich großen körperlichen Schaden dabei erleiden, denn Vampire sind übermenschlich stark und triebhaft - sowie aus moralischen Gründen - Edward favorisiert eindeutig den Beischlaf nach der Ehe (BzAb, S. 439-449)-bis zum vierten Band vorenthalten (BzAb, S. $101 \mathrm{f}$.). Interessanterweise trägt dies nicht gerade dazu bei, Erotik und Sex aus den Texten $\mathrm{zu}$ verbannen, eher im Gegenteil: Es macht beides noch spürbarer. Als es dann im vierten Band nach der Eheschließung zum Geschlechtsverkehr mit Edward kommt, wird Bella sofort schwanger, was den Beischlaf als Fortpflanzungsakt markiert. Noch in den Flitterwochen hat sie mit „Symptomen der Schwangerschaft“ (BzEdN, S. 142) zu kämpfen und zeigt eine „, deutlich erkennbare Wölbung im Unterleib“ (BzEdN, S. 141). Die Doppelsinnstruktur dient solcherart als religiöse Instrumentalisierung sowie als Adressierungsstrategie, indem gleichzeitig mehrere Lesarten angeboten werden.

Ähnlich darf auch Die Tribute von Panem als Text mit Doppelsinnstruktur aufgefasst werden, indem das Werk, welches sich auf der Oberfläche als abenteuerlicher Science-Fiction-Roman darstellt, als gesellschaftskritische Allegorie gelesen werden kann, in der heutige Massenmedien kritisch betrachtet werden und die Frage im Raum steht, inwiefern der gesellschaftliche

\footnotetext{
${ }^{173}$ Der Zusammenhang zum mormonischen Glauben wird in Interviews von Meyer selbst hergestellt. Siehe www.spiegel.de/kultur/literatur/0,1518,558826,00.html (11.9.2014).

174 Siehe ein amerikanisches Interview: www.motleyvision.org/2005/interview-twilight-author-stephenie-meyer/ (11.9.2014)

175 Ebd.
} 
Wert der Menschenwürde vor dem Hintergrund massenmedialer Berichterstattung bewahrt werden kann. Dass dieses Interpretationsangebot durchaus in der Öffentlichkeit wahrgenommen wurde, davon zeugt ein Artikel aus Die Welt vom 20.8.2012:

Sozialkritisch? Sicherlich. Mehr noch: Sozialsatire. Und zwar ganz spezifisch Medienkritik. Die Gesellschaft wird mit Hilfe des Fernsehens unterjocht und unterhalten, durch tödliche Spiele, die bewusst an das Unterhaltungsbedürfnis der antiken römischen Bevölkerung und deren Kampfspiele (daher der Titel: panem et circenses) anknüpft und auf dem modernen Bildschirm wiederaufleben lässt. ${ }^{176}$

Percy Jackson weist ebenfalls eine Tendenz zur Doppelsinnigkeit auf. Dem Thema Naturschutz wird hier ein ganzer Erzählstrang gewidmet: Der sterbende Pan gibt Grover den Auftrag, die Botschaft zu verkünden, dass die Rettung der Wildnis ab jetzt in der Verantwortung des Einzelnen liege (PJ 4, S. 368). Es bedarf nicht vieler Interpretationsarbeit, um die Passage auf zeitgenössische Umweltschutzdebatten zu beziehen.

\subsubsection{Die Tintenwelt-Trilogie als mehrfachadressierter Text mit gleichlautender Botschaft}

Der Dressler-Verlag empfiehlt die Tintenwelt-Trilogie ab einem Alter von 12 Jahren und richtet sich damit zunächst konkret an jugendliche Leser. ${ }^{177}$ Die Cover-Gestaltung jedoch zielt auf alle Altersgruppen ab, so das Ergebnis von Uhlitzsch, die Menschen unterschiedlichen Alters nach ihrer Meinung zu Cover, Titel und Klappentext von Tintenherz befragte und dabei eruierte, dass diese bei allen gleichermaßen Anklang fanden. ${ }^{178}$ Dass eine Vermarktung für Rezipienten unterschiedlichen Alters intendiert ist, scheint daher plausibel.

Weiterhin hält der Text ein Symbolsystem vor, das unterschiedliche Lesarten erlaubt, demnach kann die Tintenwelt-Trilogie als All-Age-Titel aufgefasst werden: ${ }^{179}$ Sie beinhaltet zahlreiche Anspielungen, intertextuelle Verweise, Motive und Metakommentare, die, je nach Rezipient, wahrgenommen und eingeordnet oder aber übergangen werden können. Der Text vermag als Hommage an das Lesen, als Liebeserklärung an das Buch und als Laudatio auf eine bibliophile Gesellschaft verstanden werden: eine „gleichlautende“ Botschaft, die auf unterschiedliche Weise und auf unterschiedlichen Ebenen im Text kommuniziert und chiffriert

\footnotetext{
${ }^{176}$ Artikel von Ruth Klüger: „Warum die Tribute von Panem Literatur sind“; online unter www.welt.de/kultur/literarischewelt/article108597915/Warum-Die-Tribute-von-Panem-Literatur-sind.html (19.9.2014).

177 www.dresslerverlag.de/nc/schnellsuche/titelsuche/details/titel/1304650/6780/3258/Autor/Cornelia/Funke/Tintenherz.html (12.9.2014).

${ }^{178}$ Uhlitzsch (2012), S. 21; Karg/Mende (2010), S. 27.

${ }^{179}$ Eine solche Kategorisierung ist abermals als modellbedingte, subjektive, personen- oder institutionsgebundene Entscheidung aufzufassen, die auf objektiven Beobachtungen beruht.
} 
wird. Evident ist etwa, dass sich sämtliche „Gutmenschen“-Figuren als äußerst bibliophil erweisen. ${ }^{180}$ Was zunächst an den Identifikationsfiguren Meggie und Mo sowie Elinor exemplarisch vorgeführt wird, nämlich dass Büchernarren liebenswürdige Menschen sind, wird sukzessiv zur allgemeingültigen Regel erhoben, die auch den Umkehrschluss zulässt: Diejenigen, die nicht gerne lesen und respektlos mit Büchern umgehen, gehören zur anderen Seite, zu den Bösen. So erscheint es logisch, dass Capricorn und seine Männer aus Boshaftigkeit Elinors Bücher verbrennen (TH, S. 185, S. 246, S. 311), dass Orpheus sich gegenüber dem geschriebenen Wort Fenoglios respektlos verhält, indem er sämtliche Aspekte der Tintenwelt aus Habgier umschreibt (TT, S. 31), und dass der Natternkopf, Antagonist von Band zwei und drei, kein Bücherfreund ist (TB, S. 115). Das Buch, seine Rezeption sowie die Berufe, die mit ihm im Verbindung gebracht werden - Autor, Buchbinder und Buchmaler, aber auch Vorleser, Geschichtenerzähler und Sänger -, nehmen in der Geschichte eine exponierte Stellung ein und leisten so ihren Beitrag zur Hauptbotschaft, dass Bücher „toll“ sind und glücklich machen. ${ }^{181}$ Selbstreferenzielle Metakommentare unterstreichen das Anliegen, wenn auch auf abstraktere Weise. Heber fasst den Sachverhalt treffend zusammen, wenn sie sagt, ,, dass die verschiedenen Arten der Selbstreferenz-indirekte, direkte und metatextuelle-sowohl im Kerntext als auch im Paratext nachweisbar" seien, die Zahl der Metalepsen im Verlauf der Trilogie kontinuierlich ab-, die Zahl der Metaebenen hingegen kontinuierlich zunähme. ${ }^{182}$

Dementsprechend lässt sich beobachten, dass das Bedeutungssystem im Laufe der Handlung zusehends komplexer wird und immer mehr Verständnisebenen anbietet. Denn die Tintenwelt erweist sich nach und nach als Gedankenexperiment Fenoglios (später auch des Orpheus), gemacht und weitergesponnen aus Worten, bei denen lange nicht klar ist, wie Ursache und Wirkung in Beziehung stehen und ob und wie sie von Taten beeinflusst werden können: „Es ist längst nicht mehr deine Geschichte, alter Mann, dachte Mo, während er mit Fegnolio auf die innere Burg zuschritt. Aber wer erzählte sie dann? Orpheus etwa? Oder hatte der Natternkopf das Erzählen übernommen [...]? “ (TT, S. 89). Das Kontingenzproblem kulminiert in der Identitätsfindung der Figuren, die sich innerhalb der Diegese als fremdbestimmte, nämlich vom Autor gesteuerte Rollenträger, ihr Leben als „, Geschehen einer Geschichte“ wahrnehmen

\footnotetext{
${ }^{180}$ Vgl. Zeilinger (2010), S. $103 \mathrm{f}$.

${ }^{181}$ Vereinzelt werden Bücher und das Lesen auch negativ konnotiert: Im ersten Band der Serie wird beispielsweise das Vorlesen dazu genutzt, die gefährliche Kreatur des Schattens heraufzubeschwören. Vgl. TH, S. 437, S. 449.

${ }^{182}$ Heber (2010), S. 80.
} 
und dies auch explizit so artikulieren (TB, S. 66, S. 356 f., S. 592) ${ }^{183}$ So entsteht eine Plattform für selbstreferenzielle Kommentare und Metaebenen, welche die verschiedenen Rezipientengruppen je nach Abstraktions- und Reflexionsniveau zu durchblicken imstande sind, die jedoch in keiner Weise die naive Lesart der Geschichte beeinflusst. Die Figur Mo zum Beispiel ist in mehrfacher Hinsicht sujethaft. Ihr Wesen und ihre Funktion können auf unterschiedlichen Ebenen durchdrungen werden: Mo selbst identifiziert sich sowohl in der Ausgangswelt als auch rückblickend in späteren Bänden mit seinem Beruf, er nimmt sich als Buchbinder wahr, der seine Aufgabe mit Herzblut verrichtet (TT, S. 687). Bereits in Tintenherz wird ihm jedoch die Rolle der „Zauberzunge“ (TH, S. 13) zugewiesen, was auf seine Fähigkeit Bezug nimmt, Figuren aus Geschichten herauszulesen. In der Tintenwelt wird er dann zum Räuber, der die Rolle des Eichelhähers einnimmt, eine literarische Figur aus der Feder Fegnolios, für die Mo zunächst als Vorbild diente. ${ }^{184}$ Tritt Mo als Eichelhäher in Aktion, versteht er sich selbst als Schauspieler, der eine Rolle spielt, die er niemals zugeteilt bekommen wollte (TB, S. 645, S. 681) und die dazu geschrieben wurde, die Geschichte zu einem guten Ende zu bringen. ${ }^{185}$ Er selbst verweist auf die Vielschichtigkeit seiner Figur und sieht gerade in ihr die Rettung für die Tintenwelt, indem er Staubfinger zum Verrat gegen sich selbst anstiftet: „Lass sie den Buchbinder fangen, nicht den Eichelhäher, sie werden den Unterschied nicht merken. Und ich schick den Eichelhäher fort, weit fort, lass ihn schlafen, tief unten in dem Kerkerloch, mit Orpheus' Worten “ (TT, S. 664). So wird, einer simplen Lesart zufolge, Mo der Retter und Held der Geschichte, im übertragenen Sinn fällt diese Rolle einer seiner vielen Übergangspersönlichkeiten zu. Die Motivation der Haupthandlung wird in Tintenblut und Tintentod mit selbstreferenziellen Metakommentaren und diffusen Anspielungen zusehends abstrakter, mehr und mehr werden Spekulationen über den Fortgang der Handlung eingestreut, die meist in Fragen und Überlegungen Fenoglios zum Ausdruck kommen:

„Feder oder Schwert? Wer schreibt die drei Wörter? Wen liebt Violante?“ „Nun, das sind nur einige der Fragen, deren Antworten den Lauf der Geschichte bestimmen werden. Jede gute Geschichte verbirgt sich hinter einem Gewirr von Fragen, und es ist nicht leicht, ihnen auf die Schliche zu kommen." (TT, S. 466).

So wird die Zukunft Dorias durch ein literarisches Zitat angedeutet, dessen Wahrheitsgehalt niemals endgültig geklärt wird. „,Dieser Doria hat eine Frau, von der es heißt, dass sie aus einem fernen Land stammt und ihn oft erst auf seine Ideen gebracht hat. “ (TT, S. 555) Der

\footnotetext{
${ }^{183}$ Heber (2010), S. 51.

${ }^{184}$ Ebd., S. 53.

185 Ebd.
} 
Bezug zu Meggie kann hier als Transferleistung betrachtet werden, der nicht jedem Rezipienten gleichermaßen gelingen muss.

Die intertextuellen Bezüge tragen zu einer differenzierenden Adressierung bei, da sich deren Bedeutung nicht allen Rezipienten gleichermaßen erschließt. Heber macht in ihrer Dissertation bereits explizit auf den differenzierenden Charakter aufmerksam, indem sie zwischen intertextuellen Verweisen in der Serie unterscheidet, die mit „,Titelangabe im Kursivdruck“ oder ,ohne Markierungen durch Kursivdruck“ realisiert sind bzw. zwischen direkten Zitaten „, aus leicht erkennbaren Texten “ und direkten Zitaten ,, aus schwer erkennbaren Texten “. 186 Somit kann man in der Tintenwelt-Trilogie auch eine Einladung zum Rätseln und Dechiffrieren erkennen, die an Harry Potter erinnert.

Die anderen Texte des Korpus dürfen ebenfalls als mehrfachadressierte Texte mit gleichlautender Botschaft aufgefasst werden, die Edelstein-Trilogie mithilfe des Modells zudem als All-Age-Text, denn Motivation und Kausalbeziehungen des Gedankenexperiments Zeitsprung werden mit voranschreitender Handlung zusehends komplexer. So kann auch dort die Rezeption auf unterschiedlichem Abstraktions- und Reflexionsniveau erfolgen, denn die naive wörtliche Lesart bleibt von der komplexeren unberührt. Der bei den Texten des Korpus gängige Aufruf unterschiedlicher Genretraditionen erzeugt ebenfalls mehrfachadressierte Symbolsysteme. Schlachter wies bereits darauf hin, dass jeder auszumachende Genreeinfluss - sie betrachtet ähnliche Texte wie die, die hier im Mittelpunkt stehen - eine eigene Lesart und damit auch eine eigene Bedeutungsschicht eröffnet, und konstatiert, dass sich Reckless von Cornelia Funke ,, sowohl als Abenteuer-oder Actiongeschichte, als Detektivgeschichte (durch das Moment der Verrätselung), als Märchen, stellenweise als Liebesgeschichte und natürlich als Fantasy lesen lässt “187.

\subsubsection{Zwischenfazit}

Sowohl bei der Bis(s)-Serie als auch bei der Tintenwelt-Trilogie kann anhand unterschiedlicher Modelle ihre Lesart als All-Age-Texte plausibel gemacht werden. Die Bis(s)-Serie vermag als Text mit Doppelsinnstruktur gelesen zu werden, denn sie eröffnet neben einer naiven auch eine allegorische Lesart, welche den Rückschluss auf eine religiöse Missionierungsabsicht der Autorin nahelegt, was sich mithilfe einer Übertragungs- und Interpretationsleistung

\footnotetext{
${ }^{186}$ Heber (2010), Inhaltsverzeichnis.

${ }^{187}$ Schlachter (2014), S. 4.
} 
erschließen lässt. Die Tintenwelt-Trilogie kann als mehrfachadressierter Text mit gleichlautender Botschaft aufgefasst werden. Sie weist zahlreiche Anspielungen, intertextuelle Verweise und Metakommentare auf, die vom Rezipienten wahrgenommen oder übergangen werden können, einer naiven Lesart jedoch nicht im Weg stehen. So lässt sich zusammenfassen, dass beide Werke Eigenschaften aufweisen, die Rezipienten unterschiedlichen Alters sowie unterschiedlicher Erfahrungshorizonte bzw. Abstraktionsniveaus bedienen. Die Mehrfachauslegbarkeit der übrigen Korpustexte wurde in den Analysen nur angedeutet, sie ist bei Percy Jackson, der Edelstein- und der Panem-Trilogie erkennbar.

\subsection{Die Post-Potter-Texte und Harry Potter als multiadressierte Literatur}

Eine weitere Möglichkeit, die Texte des Korpus hinsichtlich ihrer Adressatengattung zu klassifizieren, liegt darin, die Nationalität bzw. Kulturalität der impliziten Rezipienten in den Blick zu nehmen. Eine Tendenz, die schon länger erkennbar ist und nunmehr unwiderruflich im Kinder- und Jugendsegment angekommen zu sein scheint, ist die Internationalisierung, die Adressierung an Rezipienten unterschiedlicher Nationalität, unterschiedlicher Ethnien und damit unterschiedlicher kultureller Hintergründe. ${ }^{188}$ Auch Harry Potter weist ein Symbolsystem mit Lesarten für Rezipienten unterschiedlichster kultureller Hintergründe auf, was im Folgenden Multiadressierung genannt wird, ein Text, der eine solche vornimmt, multiadressierter Text. Sie ist bei Harry Potter in mehrfacher Hinsicht gegeben, da das Werk international als Medienverbund rezipiert wurde und dabei derart erfolgreich war, dass man es als Kulturereignis betrachten kann, das die Welt zu einem transkulturellen Raum zu vereinigen imstande ist. ${ }^{189}$ Das Kapitel soll auf folgendem Kulturbegriff fußen:

Kultur Der Begriff umfasst ,, die ästhetische Ausstattung und Bereicherung des Lebens von Individuum und Gesellschaft", die sich in sogenannten Kulturgütern bzw. Kulturerzeugnissen (auch Texten) und Kulturpraktiken (letztlich allen menschlichen Tätigkeiten mit Symbolwert) äußert, die in ihrer Repräsentationsfunktion auf Traditionen der jeweiligen Gesellschaft verweisen, aber auch auf die innovativen Einflüsse gegenwärtiger Kultur, sodass sie ständig Veränderungen unterworfen sind. Sowohl Kulturerzeugnisse als auch Kulturpraktiken übernehmen eine sinngebende und sinnstiftende Funktion innerhalb der Gesellschaft und haben Symbolcharakter; ihre Be-

\footnotetext{
${ }^{188}$ Vgl. Wrobel (2010), S. 9.

${ }^{189}$ Vgl. Weinkauff/von Glasenapp (2010), S. 202; Karg/Mende (2010).
} 
deutung unterliegt den Einflüssen ihres konventionellen Gebrauchs. ${ }^{190}$ Kulturerzeugnisse können entweder der Hoch- oder der Populärkultur der jeweiligen Gesellschaft zugeordnet werden, je nachdem welchen Produktions-, Distributions- und Rezeptionsbedingungen sie unterliegen. ${ }^{191}$

Gerade letztere Trennung scheint - ungeachtet der Problematiken, die mit ihr einhergehen besonders bedeutsam für die hier vorgenommene Analyse. Harry Potter und die Texte des Korpus sind als massenhaft rezipierte und multimedial aufbereitete Texte zu begreifen, die auf Kulturerzeugnisse verweisen, die wiederum Gleiches tun. Sie sind damit zugleich Teil einer plurimedial tradierten Populärkultur sowie eine Reaktion auf ebendiese. ${ }^{192}$ Daran anknüpfend, soll nun gezeigt werden, dass sie analog zu Harry Potter das Potenzial zur Multiadressierung aufweisen, indem Lesarten zur Verfügung gestellt werden, die sich um internationale Anschlussfähigkeit bemühen. Damit mögen die Werke im Bereich der Literatur nicht unwesentlich zu einer internationalen Trans- oder Populärkultur beitragen, wie sie in der Film-, Musik und Modebranche schon seit Jahrzehnten auszumachen ist. ${ }^{193}$

Zunächst soll ein kurzer geschichtlicher Abriss zur übersetzten Kinder- und Jugendliteratur die Bedeutsamkeit international rezipierter Literatur für den deutschen Buchmarkt aufzeigen (Kapitel 6.4.1). Danach werden die Charakteristika multiadressierter bzw. international anschlussfähiger Texte zusammengetragen (Kapitel 6.4.2), die den Ausgangspunkt für die Textanalyse liefern: Zunächst wird die Multiadressierung von Harry Potter zum Thema gemacht (Kapitel 6.4.3), bevor schließlich ausgewählte Post-Potter-Texte bezüglich ihrer international anschlussfähigen Symbolsysteme untersucht werden (6.4.4). Ein Zwischenfazit fasst die Ergebnisse des Kapitels 6.4 zusammen und klärt abschießend die Frage, inwiefern sich die Strategien, ein internationales Publikum anzusprechen, bei Harry Potter und seinen Nachfolgern ähneln (Kapitel 6.4.5).

\subsubsection{Zur Geschichte übersetzter Kinder- und Jugendliteratur in Deutsch- land}

Die wichtigste Strategie, die internationale Rezeption eines literarischen Werkes zu gewährleisten, ist zunächst seine Übersetzung. Vergleichsweise früh wird hierauf in der Geschichte

\footnotetext{
${ }^{190}$ Karg/Mende (2010), S. 74.

${ }^{191}$ Gemeint ist hier ausschließliche eine formale und keine wertende Trennung. Vgl. Hügel (2007), S. 33 ff.

${ }^{192}$ Vgl. Karg/Mende (2010), S. 75.

${ }^{193}$ Weinkauff/von Glasenapp, S. 202 f.
} 
des deutschen Buchhandels zurückgegriffen, und sehr bald kursieren auch kinderliterarische Bücher aus aller Herren Länder. Andererseits präsentiert sich Deutschland vom 18. Jahrhundert an, als spezifische Kinder- und Jugendliteratur entstand, mit Ausnahme der Nazizeit durchgehend als ausgesprochen importierfreudig. ${ }^{194}$ Als erfolgreichstes Jugendwerk der Aufklärung gilt Campes Robinson der Jüngere (1779/1780), die Übertragung von Daniel Defoes englischsprachigem Roman Robinson Crusoe (1720). ${ }^{195}$ Später wurden noch ältere Texte übersetzt, beispielsweise Jonathan Swifts Gullivers Reisen (1727/28), sowie jeweils aktuelle Titel, die aufgrund ihres Erfolgs im Ausgangsland auch Erfolg in Deutschland versprachen. Tatsächlich sind gleich mehrere zu Klassikern avanciert, darunter: Alice's Abenteuer im Wunderland (1869), Pinocchio (1905) und Nils Holgersson (1907). Vor allem nach 1945 sind die Übersetzungen von Kinder- und Jugendliteratur vom Markt nicht mehr wegzudenken. Sie haben großen Anteil an der literarischen Sozialisation deutscher Heranwachsender:

\begin{abstract}
Auch wenn das deutschsprachige Lektüreangebot für junge Leserinnen und Leser traditionell durch literarische Importe aus anderen Sprachen bereichert wurde [...], erreichte die Geschichte des kinder- und jugendliterarischen Übersetzens ins Deutsche in den zurückliegenden sechzig Jahren doch eine bisher unerreichte Dynamik. Mit 20-30 \% der Gesamtproduktion bilden die Übersetzungen einen quantitativ beachtlichen Teil der Kinder- und Jugendliteratur dieses Zeitraums [...]. Die große qualitative Bedeutung der Übersetzungen drückt sich in noch beeindruckenderen Zahlen aus: Annähernd $44 \%$ der Kinder- und Jugendbücher, die zwischen 1956 und 2007 auf die Auswahlliste des Deutschen Jugendliteraturpreises aufgenommen werden, sind Übersetzungen! ${ }^{196}$
\end{abstract}

Gerade in den letzten 60 Jahren ist der Einfluss von Autoren anderer Nationalitäten bedeutsam signifikant gestiegen, was im Übrigen für alle Genres der Kinder- und Jugendliteratur gilt, also auch für das Bilderbuch. ${ }^{197}$ Mit einem Anteil von 44 Prozent nehmen die Bücher eine prominente Stellung in der kulturellen Alltagspraxis deutscher Jugendlicher ein und fungieren gleichzeitig als wichtiges Instrument, kulturelle Inhalte anderer Nationen, meistens die ihres Herkunftslandes, zu vermitteln. Andererseits lässt sich die Tendenz ausmachen, die kulturellen Gepflogenheiten der neuen Leser bei der Übersetzung zu berücksichtigen, nicht selten werden Inhalte bei der Übersetzung kulturell angepasst, damit sie der Erfahrungswirklichkeit der vom Autor unberücksichtigten Rezipienten entsprechen. Weinkauff und von Glasenapp schreiben hierzu:

Die Binsenweisheit, dass jede Übersetzung eine Veränderung des Originaltextes darstellt, gilt für die Kinderliteratur in besonderem Maße. Denn mehr noch als die Übersetzer der allgemeinen Literatur ver-

\footnotetext{
${ }^{194}$ Vgl. Weinkauff/von Glasenapp (2010), S. 196.

195 Dofoes Robinson wiederum geht wohl auf den Seemann und Abenteurer Alexander Selkirk zurück. Vgl. Mitchison (2004).

${ }^{196}$ Weinkauff/von Glasenapp (2010), S. 198f.

${ }^{197}$ Wrobel (2010), S. 9.
} 
stehen sich kinderliterarische Übersetzer als Vermittler, deren Aufgabe darin besteht, einen fremdliterarischen Text dem angenommenen Verstehenshorizont der einheimischen Zielgruppe anzupassen. ${ }^{198}$

Dies ist umso bedauerlicher, bedenkt man, welchen Einfluss die Übersetzungen - gerade in der Nachkriegszeit - nahmen, beispielsweise Astrid Lindgren, die lange Zeit das Schwedenbild der Deutschen prägte und mit ihren Werken seit den 50er-/60er-Jahren eine zunehmende Auseinandersetzung mit dem Land und seiner Literatur anstieß. ${ }^{199}$

Der zunehmenden Globalisierung mag es geschuldet sein, dass sich in den letzten 60 Jahren eine immer stärker werdende Tendenz zur kulturellen Homogenisierung in der übersetzten Kinder- und Jugendliteratur verzeichnen lässt, eine These, die mehrfach in der Forschung vertreten wird, wozu sich prominente Beispiele in der jüngeren Vergangenheit finden lassen. ${ }^{200}$ In der Tat werden heute Bücher, Filme und Comics gezielt und intendiert weltweit vermarktet, zumal die großen, global operierenden Medienunternehmen das dazu nötige Kapital aufbringen können und die Logistik zur Verfügung stellen. Längst scheinen hiesige Konsumenten die ursprünglich fremdsprachigen Kulturgüter nicht nur anzunehmen, sondern den nationalen Eigenproduktionen sogar vorzuziehen. Diese Tendenz lässt sich analog im deutschen Fernsehen beobachten, wo das Serienformat lange Zeit hauptsächlich in Übersetzung vorlag. „Die Stigmatisierung der Serie als triviale Erzählform, aber auch programmpolitische und medienökonomische Aspekte bremsten beispielsweise in der Bundesrepublik lange Zeit das Entstehen einer umfangreichen Produktion von Fernsehserien. “201 Nur langsam setzte man auf eigenproduzierte Serien, zumal das Ansehen amerikanischer Filme eher gering blieb. Das deutsche Publikum zog eigene Serien eindeutig vor, fand aber - vermutlich ein Secondbest-Effect - amerikanische Serien zusehends interessanter. ${ }^{202}$ Heute dominieren Film- und Fernsehproduktionen aus den USA den internationalen Markt und sind der Maßstab, an dem sich kleinere nationale Produktionen zu messen haben.

\subsubsection{Zu den Charakteristika eines multiadressierten Textes}

Bei der internationalen Distribution der betrachteten Medienverbünde kommt der Vermarktung eine wichtige, wenn nicht gar die wichtigste Rolle zu: Damit möglichst viele Adressaten erreicht werden, erfolgen Publikationen in so vielen Sprachen wie möglich und die Vermark-

\footnotetext{
${ }^{198}$ Weinkauff/von Glasenapp (2010), S. 197 f.

199 Vgl. Weinkauff/von Glasenapp (2010), S. 200. Zur Rezeption Lindgrens im deutschsprachigen Raum siehe Lison (2010).

${ }^{200}$ Weinkauff/von Glasenapp (2010), S. 203; Karg/Mende (2010), Schlachter (2014).

${ }^{201}$ Hickethier (1991), S. 19.

202 Ebd., S. 20.
} 
tung in so vielen Ländern wie möglich. ${ }^{203}$ Dabei gilt die Faustregel: Je größer der Medienverbund, desto größer die erwartbaren Kostenersparnisse durch Synergieeffekte. ${ }^{204}$ Der Verkauf eines geeigneten Manuskripts an Medienunternehmen steht somit am Anfang der auf die Buchveröffentlichung folgenden altermedialen Mehrfachverwertung einer literarischen Idee, die meist mit der Verfilmung beginnt. ${ }^{205}$ Während Buchcover von einer kulturbedingt divergenten Bildsprache zeugen, ist die des Films in der Regel international identisch, sie nimmt dadurch großen Einfluss auf die Imagebildung des Verbunds und die Identität der FanGemeinde. ${ }^{206}$ Aber auch dem Text selbst kommt im Prozess eine wichtige Rolle zu, soll er doch möglichst vielen Rezipienten gefallen oder sie zumindest zum Kauf animieren. In der Potter-Forschung wurden bereits mehrfach Thesen aufgestellt, welche Eigenschaften die internationale Rezeption von Rowlings Serie begünstigt haben mögen. Ausgehend von diesen Ergebnissen lässt sich folgender Katalog zusammenstellen, der die Charakteristika eines international anschlussfähigen, multiadressierten Textes zusammenfasst.

- Aufgrund der ungeheuren Popularität von Harry Potter und seinen Nachfolgern auf internationalem Terrain ist deren Beitrag zu einer transkulturellen Populärkultur nicht zu unterschätzen, zumal sie auch auf andere Kulturgüter verweisen, die Gleiches tun: Die Medienverbünde greifen nicht nur auf Themen, Inhalte und Elemente zeitgenössischer Kulturprogramme zurück, sie selbst schreiben sich durch ihre Popularität darin ein, innovieren und bestätigen sie damit zu gleichen Teilen. ${ }^{207}$ So können Harry Potter und die Texte des Korpus als multi- und populärkulturelles Gewebe verstanden werden, indem sie sowohl die Komponenten ihrer Medienverbünde global vermarkten als auch Inhalte aus einer transnationalen Populärkultur schöpfen, die als weltweites Ideen- und Themenreservoir begreifbar ist. ${ }^{208}$ Sie operieren so gesehen mit einem Symbolsystem, das verschiedene Nationen und Kulturen als Rezipienten impliziert und dabei in ständiger Wechselbeziehung zu ähnlichen Systemen steht, vergangenen und zukünftigen. Die Komponenten der populärkulturellen Gewebe sind traditionell aus der jeweiligen Kultur gewachsen, stiften Identität, haben Symbolcharakter und sind emotional konnotiert, sie haben großen Anteil an der konkreten Alltagswirklichkeit der Rezipienten und Einfluss auf deren gegenwärtiges kulturelles Leben.

- Für die internationale Vermarktung scheinen sich vor allem Texte zu eignen, deren fingierte Welt(en) - ausgehend von einer spezifischen Kultur oder Nation, die oftmals als Ausgangswelt der Geschichte dient - der Erfahrungswirklichkeit möglichst vieler anderer Nationen und Kulturen ähnelt, das heißt: für möglichst viele Rezipienten einen Wiedererkennungswert besitzt, für sie verständlich ist. ${ }^{209}$ Dazu werden meist

\footnotetext{
${ }^{203}$ Weinkauff/von Glasenapp (2010), S. 197 und Wrobel (2010), S. 9.

${ }^{204}$ Schlachter (2014), S. 3.

205 Ebd.

${ }^{206}$ Vgl. Karg/Mende (2010), S. 32.

${ }^{207}$ Vgl. Böhme-Dürr (2000), S. 26 f.

${ }^{208}$ Übernommen von Schlachter (2014), S. 3.

${ }^{209}$ Karg/Mende (2010), S. 73; Reichardt (2010), S. 99.
} 
Schemata und Themen in einem kulturübergreifenden Symbolsystem aufgerufen, ${ }^{210}$ zum Beispiel in Form einer phantastischen Welt, die für jede Nation und Kultur in gewissen Aspekten fremdartig ist und sich so als international anschlussfähig erweist. Die Themen, die in der phantastischen Verkleidung als Projektionsfläche dienen, sind in nahezu allen Kulturkreisen bedeutsam und betreffen etwa Politik, Schule, Medien und Sport ${ }^{211}$ bzw. Erzeugnisse der Populärkultur wie Musik, Mode und Lifestyle. Daneben kann der Text ein kulturspezifisches Symbolsystem anbieten, was dazu gereicht, einen interkulturellen Austausch- und Verständigungsprozess anzuregen. Darin werden die gleichen Schemata verhandelt, nur in einer kulturspezifischen Variante. Auch universellere Inhalte wie zwischenmenschliche Konflikte, Familie, Tod sowie Eigen- und Fremdverstehen können zur Anschlussfähigkeit beitragen. Allerdings sind diese Themen in viel geringerem Maße als Indizien einer intendierten Multiadressierung zu betrachten, da sie in so gut wie allen literarischen Texten behandelt werden. $^{212}$

- Dem Ziel einer transnationalen Kultur sowie der Political Correctness verpflichtet, vertreten international anschlussfähige Text eine Weltsicht, die einer multikulturellen Gesellschaft bejahend gegenübersteht, sie schaffen eine Atmosphäre - oder streben sie zumindest an -, die nach westlich geprägten Vorstellungen weltoffen bzw. ethisch vertretbar ist. Bereits die Andeutung eines multikulturellen Austauschs kann genügen, um eine solche Atmosphäre zu schaffen, zum Beispiel durch Verweis auf unterschiedliche Nationen und Ethnien sowie deren kulturelle und religiöse Praxis, durch den Aufruf unterschiedlicher Literaturtraditionen oder internationaler Schauplätze, die durch topografische Marker als solche ausgewiesen werden. ${ }^{213}$ Gerade die Thematisierung von Alterität und Fremdartigkeit avanciert dabei zum identitätsstiftenden Moment, sofern dieses Erleben als Ausgangspunkt gegenseitigen Wertschätzens und Respektierens genutzt wird. Andererseits kann auch die Betonung von Gleichheit eine weltoffene Atmosphäre schaffen, indem zum Beispiel internationale Phänomene der Populärkultur aufgerufen werden, etwa im Bereich Mode, Film und Musik, die in vielen Nationen Anklang finden. In jedem Fall sollte angesichts einer sich zunehmend globalisierenden Welt die Idee einer sich respektierenden und aufeinander zugehenden Bevölkerung transportiert werden, indem möglichst viele Nationen, Ethnien und Kulturen signalhaft im Text aufgerufen werden, die Anknüpfungspunkte für entsprechende Schemata liefern.

Vor dem Hintergrund dieser Angaben ist es möglich, Eigenschaften eines multiadressierten Textes auszumachen, deren Nachweis als objektiv gelten darf, deren Erhebung aber zu gattungsweisenden Eigenschaften, so wird hier abermals betont, als personen- bzw. institutionsgebundene Interpretationsleistung aufzufassen ist. Die nachfolgenden Analysen streben an, zunächst bei Harry Potter, dann bei seinen Nachfolgern, eine intendierte Multiadressierung aufzuzeigen, wie sie modellbedingt nach obigen Charakteristika zum Ausdruck kommt.

\footnotetext{
${ }^{210}$ Siehe Ewers (2011), S. 1.

${ }^{211} \mathrm{Karg} /$ Mende (2010), S. 73-103.

${ }^{212}$ Karg/Mende (2010), insbesondere ab S. 73; Böhme-Dürr (2000), S. 27; Schlachter (2014), S. 3.

${ }^{213}$ Denn durch die Verwendung topografischer Marker wird der Schauplatz der Handlung logisch auf internationalem Terrain verortet. Das Raumschema wird damit erweitert.
} 


\subsubsection{Harry Potter als multiadressierte Literatur}

Auf der ganzen Welt wurde Harry Potter begeistert gelesen, die Serie wurde in über 67 Sprachen übersetzt. ${ }^{214}$ Ausgehend von der Verfilmung, erfolgte die Publikation des Medienverbunds großflächig: Über 300 Unternehmen waren in der Merchandising-Kampagne unter Lizenzvertrag, darunter auch Firmen mit internationalem Wirkungsgebiet wie Achterbahn, Coca Cola, Lego, Hasbro und Mattel. ${ }^{215}$ Auch in Asien war Harry Potter sehr beliebt, gleich mehrere Plagiate erschienen unter dem Label Potter. ${ }^{216}$ Bei der Publikation in Buchform fällt auf, dass die Ausgaben in den diversen Ländern zwar unterschiedliche Cover besitzen, diese jedoch Strukturähnlichkeiten aufweisen und damit als internationales Label fungieren: Sie folgen ,,bestimmten Gestaltungsprinzipien, die sowohl national als auch international einen Wiedererkennungswert haben. Das bedeutet, dass Leser einer Nation ihren Harry erkennen, dass sie aber auch zu einer internationalen Gemeinde gehören “217.

Karg und Mende haben Eigenschaften herausgearbeitet, die die weltweite Rezeption zu begünstigen scheinen, und Anzeichen dafür erkannt, dass Harry Potter als ,,kultureller Text“ auf internationalem Handlungsfeld fungiert. ${ }^{218}$ Mit seiner phantastischen Welt als Projektionsfläche bietet er ein kulturübergreifendes Symbolsystem an, das verschiedene Lesarten ermöglicht. ${ }^{219}$ Indem kulturübergreifende gesellschaftliche Felder wie Schule, Politik, Medien und Sport thematisiert werden, verweist er auf die Traditionen dieser Einrichtungen und bietet so emotionale Anknüpfungspunkte für Rezipienten unterschiedlicher Nation und Kultur an, indem er sich in gegenwärtige kulturelle Diskurse und Alltagserfahrungen einschreibt: ${ }^{220}$ Die Ausbildung in Hogwarts etwa präsentiert eine der Struktur nach in vielen Kulturen ähnliche Schulform: eine Einteilung in Schulfächer, Lehrkräfte diverser pädagogischer und didaktischer Ausrichtung sowie Schülerinnen und Schülern mit unterschiedlichem Erfolg und Strategien beim Lernen. ${ }^{221}$ Mit der unkonventionellen, teilweise auch unfairen Politik des Zaubereiministeriums, welches mehr als einmal das Glück des Einzelnen zugunsten unehrenhafter politischer Ziele zu opfern bereit ist, verweist der Text auf internationale Diskurse der Politikverdrossenheit und ruft Schemata auf, mithilfe dessen ,,das Publikum, gleichgültig welcher

\footnotetext{
${ }^{214}$ www.carlsen.de/uploads/Presse/Harry_Potter_Pressemappe.pdf (13.9.2014).

${ }^{215}$ Frey (2006), S. 190.

${ }^{216}$ Siehe Jörg Burger: „Zauberlehrlinge der Globalisierung“ vom 11.8.2007 bei Zeit Online; www.zeit.de/2007/33/W-Harry-Potter-33 (14.9.2014).

${ }^{217}$ Karg/Mende (2010), S. 25.

${ }^{218}$ Vgl. ebd., S. 244 f.

${ }^{219}$ Vgl. ebd. S. 130.

${ }^{220}$ Ebd., S. 73-103; insbesondere S. 85.

${ }^{221}$ Karg/Mende (2010), S. 80, S. 82, S. 84.
} 
Herkunft und welcher politischen Erfahrung, dann seine eigene Konkretisierung von Politik vornehmen kann“،222. Ähnlich verhält es sich mit dem Journalismus, vertreten durch den „Tagespropheten“, oder „Quidditch“, das als Projektionsfläche für Sportveranstaltungen jeder Größe und Art überall auf der Welt taugt. Sport ist traditionell eine kulturelle Praxis mit großer Außenwirkung und Repräsentationsfunktion, da er durch seine emotionale Komponente identitätsstiftend wirkt, oftmals medial aufbereitet wird und auf Werte und Konzepte wie Sieg, Leistung, Ausdauer, Kameradschaft, Fairness, Kraft und Stärke verweist. Sportliche Wettkämpfe sind international bekannt und national konkretisiert, sie haben heute in Events wie der Fußballweltmeisterschaft auch auf internationaler Ebene sinnstiftende Funktion. ${ }^{223}$

Der Text stellt darüber hinaus ein kulturspezifisches Symbolsystem zur Verfügung, das Einblicke in die englische Gesellschaft sowohl früherer Zeiten als auch von heute gewährt: Neben der Schilderung eines Schulalltags - und dadurch dem Gattungsaufruf der School Novel sowie eines Berufsalltags, vorgeführt an der Familie Dursley, werden kulturelle Schemata in ihrer britischen Variante aufgezeigt. ${ }^{224}$ Bergenthal betont in diesem Zusammenhang, es sei davon auszugehen, dass die ersten Bände der Serie vorrangig britische Rezipienten impliziere und die Adressierung erst in den Folgebänden erweitert wurde: Dafür spreche, dass die „Namen in Harry Potter [ ] auf indische, afrikanische, asiatische, irische und schottische Herkunft" verweisen und damit britische Alltagswelt widerspiegeln. ${ }^{225}$ In späteren Bänden finde sich zunehmend der Versuch, der Kritik entgegenzuwirken, ethnische Vielfalt werde „, lediglich über handlungsirrelevante Nebenfiguren “ kodiert, während ,, die Wahl [ ] der Protagonisten eine kulturelle Norm - white, middle-class and british" festschreibe. ${ }^{226}$ Auffällig sei, dass multikulturelles Miteinander vor allem in ethnisch klassifizierenden Figurennamen angedeutet werde und kulturelle Konventionen anderer Nationen nur klischeehaft zum Ausdruck kämen. 227

Das Bemühen, multikulturelle Lebensläufe aufzuzeigen, ist in den späteren Bänden indes klar erkennbar. Grundsätzlich, so Just, zeige sich Hogwarts als ein Lebensraum, wo Lernende „,unabhängig von Herkunft, Familientradition, Schicht, Religion, ethnischer Zugehörigkeit“

\footnotetext{
${ }^{222}$ Ebd., S. 92.

${ }^{223}$ Vgl. ebd., S. 104.

${ }^{224}$ Vgl. Böhme-Dürr (2000), S. 27.

${ }^{225}$ Bergenthal (2008), S. 92.

${ }^{226}$ Ebd., S. 89 mit Bezug auf Laurie Barth Walczak.

${ }^{227}$ Vgl. Bergenthal (2008), S. 91.
} 
aufgenommen würden. ${ }^{228}$ Insbesondere in Band vier werden interkulturelle Austauschsituationen reflektiert: Hogwarts wird dort klar als eine von drei europäischen Zaubererschulen (neben Beauxbatons und Durmstrang) herausgestellt, die sich regelmäßig beim Trimagischen Turnier begegnen. ${ }^{229}$

\subsubsection{Die Post-Potter-Texte als multiadressierte Literatur}

Das offensichtlichste Indiz einer intendierten Multiadressierung lässt sich bei allen Texten des Korpus finden: Die Vermarktung im Medienverbund erfolgte großflächig mit aufwändigen Kampagnen auf internationaler Ebene. So wurde sogar vonseiten der deutschsprachigen Autoren eine breite Leserschaft erreicht, womit die Bücher angesichts von Produktion, Distribution und Rezeption schlichtweg als Phänomene der Populärkultur zu betrachten sind.

Sowohl die Twilight-Romane als auch die drei Bände des Tribute von Panem-Zyklus' [...] erschienen zusammen mit ihren Medienverbundprodukten [...] in über 50 Ländern. Auch die Edelstein-Trilogie der deutschen Autorin Kerstin Gier wurde in fast 30 Sprachen übersetzt - ein Erfolg, der durch die Verfilmung des ersten Bandes 2013 seine Fortsetzung fand. ${ }^{230}$

Die Verfilmungen nehmen bei der internationalen Distribution eine äußerst wichtige Rolle ein, denn sie sind der Hauptbildlieferant und die wichtigste Komponente bei der Imagebildung. Die Schauplätze changieren oft zwischen landesspezifischem Flair des jeweiligen Handlungsortes und Klischeevorstellungen eines internationalen Phantastik-Settings. ${ }^{231}$ Dabei garantiert die feste Besetzung - häufig aus Schauspielern mit internationalem Renommee -, dass die Rezeption zum Kontinuitäts- und Medienerlebnis wird, welches die Schauspieler gleichermaßen als Symbolträger der literarischen Idee nutzt und zu Komponenten des Medienverbunds stilisiert. ${ }^{232}$ Allerdings ist auch zu beobachten, dass nicht jeder großflächig angelegte Medienverbund erfolgreich war: Trotz des immensen Erfolgs der TintenweltTrilogie in Buchform konnte der Hollywoodfilm des ersten Teils offenbar nicht ausreichend überzeugen, denn es liegt bis heute keine weitere Verfilmung vor. ${ }^{233}$ Ähnlich verhält es sich mit Percy Jackson, wo lediglich die ersten beiden Teile verfilmt wurden.

\footnotetext{
${ }^{228}$ Just (2001a), S. 30.

${ }^{229}$ Beauxbatons wird in Südfrankreich verortet, Durmstang nur sehr vage in Nordosteuropa (HP 4, S. 174 f.).

${ }^{230}$ Schlachter (2014), S. 3.

${ }^{231}$ Karg/Mende (2010), S. 34.

232 Ebd., S. 33.

${ }^{233}$ Wikipedia erläutert hierzu (ohne Angaben von Quellen): „,Ursprünglich war geplant, die komplette Trilogie zu verfilmen, was jedoch fallen gelassen wurde“; http://de.wikipedia.org/wiki/Tintenwelt-Trilogie (14.9.2014). Die Kritiken zur Verfilmung von Tintenherz waren überwiegend negativ. Siehe beispielsweise eine Kritik von David Gaertner: http://www.critic.de/film/tintenherz-1464/ (4.12.2014).
} 
Zudem kann man bei den Post-Potter-Texten auch auf inhaltlicher Ebene das Bemühen um internationale Anschlussfähigkeit beobachten. Um diese These zu belegen, soll im Folgenden zunächst das Modell populärkulturelles Gewebe erläutert werden, welches die Werke zu Kulturgütern auf internationaler Ebene erhebt. Anschließend wird anhand der Bis(s)-Serie exemplarisch aufgezeigt, wie die Texte kulturübergreifende Symbolsysteme zur Verfügung stellen und somit Lesarten für eine internationale Rezepientenschaft anbieten. Das letzte Unterkapitel widmet sich den Entwürfen multikulturellen Lebens, die in den Post-Potter-Texten zum Ausdruck kommen.

\subsubsection{Die Post-Potter-Texte als populärkulturelles Gewebe}

Was sich in der Bis(s)-Serie schon andeutete, wurde in Giers Edelstein-Trilogie zum dominanten Gestaltungsprinzip: der Aufruf von Praktiken und Erzeugnissen einer sich international etablierenden Populärkultur. Meyer nimmt bereits häufig darauf Bezug: Bella stöbert im Internet, empfindet den Zugang mit einem Modem als veraltet (BzMo, S. 140), schaut Filme auf DVD (BzEdN, S. 115) und berichtet begeistert von Renesmees MP3-Player, ,auf den fünftausend Songs passen “ (BzEdN, S. 583).

Noch expliziter werden die Bezüge in der Edelstein-Trilogie, in der die Protagonistin Gwendolyn gleichsam den durchschnittlichen Klischeeteenager versinnbildlicht, dessen Lifestyle von internationalen populärkulturellen Phänomenen geprägt ist: Sie interessiert sich für „Frisuren, Klamotten, Filme und Popstars“ (RR, S. 254), und ihr Gehirn ist „zugestopft mit den Namen von Boygroupmitgliedern und elend langen Besetzungslisten von kitschigen Liebesfilmen “ (SB, S. 267). Wie ihre Mitschüler ist sie an einen Medienalltag gewohnt, der sich aus modernster Technik speist und den alle frei ausleben: Beispielsweise wird gegoogelt (RR, S. 58 f.) und bei Wikipedia recherchiert (RR, S. 94). Zudem verweisen intertextuelle Bezüge auf Kulturerzeugnisse mit internationaler Erfolgsgeschichte, sie werden sogar explizit im inneren Kommunikationssystem als solche markiert: ${ }^{234}$ Charlotte singt betrunken auf einer Party „Paparazzi“ von Lady Gaga (SG, S. 403), einen Song, der es 2009 in Deutschland auf Platz eins der Singlecharts gebracht hat und auch international größte Erfolge feierte; Gwendolyn hört beim Zähneputzen ABBA: „The winner takes it all“ (SB, S. 227) und gibt bei einer Veranstaltung im 18. Jahrhundert „Memory“ aus dem Musical Cats zum Besten, das ebenfalls international bekannt sein dürfte (SB, S. 306). Die Bezugnahme auf Star Wars ist ebenfalls

\footnotetext{
${ }^{234}$ Nach Genette handelt es sich hierbei um intertextuelle Phänomene im engeren Sinne. Siehe dazu Kapitel 5.2.2.
} 
eindeutig, indem der röchelnde, bösartige Geist mit Maske von Gwendolyn durchgängig als „Darth Vader“ (SG, S. 476) bezeichnet wird. Schlachter hat darauf hingewiesen, dass die Formel „Bereit, wenn du es bist“, die Gwendolyn und Gideon vor jeder Zeitreise gebrauchen, sowohl auf den Film Das Schweigen der Lämmer (1991) referiert, der in den fünf bedeutendsten Kategorien den Oscar gewann, als auch wörtlich im Slogan einer Apple-Werbung auftaucht, einem Unternehmen, das international zu den einflussreichsten im Bereich der Kommunikationstechnik gehört. ${ }^{235}$ Die Edelstein-Trilogie stellt somit klar ein Symbolsystem zur Verfügung, das auf eine internationale Populärkultur abhebt, und präsentiert sich mit seinen Verfilmungen und medialen Rezeptionsangeboten gleichzeitig als neues Erzeugnis derselben. Ähnliches gilt für die anderen Texte des Korpus: Auch Die Tribute von Panem kann als populärkulturelles Gewebe aufgefasst werden, wenngleich dort die intertextuellen Bezüge gänzlich unmarkiert bleiben. Schlachter sieht hier Referenzen zum japanischen Roman Battle Royale, zu Stephen Kings Der Todesmarsch sowie zum Fernsehfilm Das Millionenspiel. ${ }^{236}$

Besonders bedeutsam ist, dass die Texte teilweise explizit auf Harry Potter referieren, dessen Stellung im populärkulturellen Gewebe der Gegenwart als gesichert gelten darf. Funke etwa nutzt in Tintentod eine Passage aus dem vierten Band als Eingangszitat für ein Kapitel (TT, S. 53) und beendet ihr Werk nahezu wörtlich mit dem Satz, mit dem schon Rowling ihre Serie beschloss: „, Und alles war gut.“"237 Gier stellt im inneren Kommunikationssystem ebenfalls einen klaren Bezug her, indem ihre Protagonistin feststellt: „Ich gucke ein bisschen so wie Helena Bonham-Carter als Bellatrix Lestrange in Harry Potter. Ziemlich bedrohlich " (SG, S. 74). Nimmt man weitere phantastische Kinder- und Jugendbuchserien in den Blick, finden sich Verweise auf Rowlings Serie zuhauf. In der Für-immer-Serie von Cynthia J. Omololu beispielsweise erläutert die Protagonistin, eine herausragende Cellistin, mit folgenden Worten, warum sie ihren Instrumenten keine Namen mehr gibt: „, Ich habe es versucht und mein erstes Cello nach der Hauptfigur aus meinem Lieblingsbuch benannt, aber jedes Mal wenn ich Harry zu ihm sagte, kam ich mir wie ein Idiot vor" (FidS, S. 61).

\subsubsection{Der Aufruf kulturübergreifender Schemata in den Post-Potter-Texten}

Auch der Aufruf kulturübergreifender Schemata, die in einem entsprechenden Symbolsystem zur Verfügung gestellt werden, weisen die hier fokussierten Serien als multiadressierte Texte

\footnotetext{
${ }^{235}$ Schlachter (2014), S. 4.

${ }^{236}$ Ebd.

${ }^{237}$ Auf diesen intertextuellen Verweis macht auch Wikipedia aufmerksam: http://de.wikipedia.org/wiki/Tintenwelt-Trilogie (27.10.2014).
} 
aus. Ewers etwa mutmaßt, dass phantastische Stoffe leichter global zu vermitteln seien als realistische, welche kulturell stärker gebunden seien. ${ }^{238}$ Tatsächlich wird in den meisten Texten des Korpus die Strategie verfolgt, Themen - analog zu Harry Potter - wie Schule, Politik, Medien und Sport sowie Mode, Musik und Lifestyle in eine phantastische Hülle zu kleiden und so Anknüpfungspunkte für Rezipienten unterschiedlichster Herkunft zu schaffen. Manche stellen parallel dazu - ebenfalls analog zu Harry Potter - ein weiteres, kulturspezifisches Symbolsystem bereit, indem sie gleiche Themen in einer realhistorisch und einer kulturgebundenen Variante verhandeln und damit ihren Beitrag zur interkulturellen Verständigung leisten. Die beiden unabhängige Symbolsysteme ermöglichen, dass sich Texte in eine spezifische Kultur einschreiben, deren Inhalte und Traditionen sie dadurch an andere zu vermitteln imstande sind, aber auch gleichzeitig eine kulturübergreifende Projektionsfläche anbieten, die auf internationalem Terrain Identifikationsmöglichkeiten bietet. Wichtig erscheint dabei, dass die Themen nicht nur gestreift, sondern als Schemata kultureller Praxis im Text entfaltet werden und für die jeweiligen Figuren von Bedeutung sind. Denn nur so können die Anknüpfungspunkte letztlich ihr Identifikationspotenzial entfalten.

Folgende Tabelle führt die kulturellen Schemata der Bis(s)-Serie sowohl in ihrer kulturspezifischen als auch in ihrer kulturübergreifenden Variante auf:

\begin{tabular}{|c|c|c|}
\hline & $\begin{array}{l}\text { Kulturübergreifendes Symbolsys- } \\
\text { tem in Form von phantastischer } \\
\text { Projektionsfläche }\end{array}$ & Kulturspezifisches Symbolsystem \\
\hline $\begin{array}{l}\text { Schule/ } \\
\text { Ausbildung }\end{array}$ & $\begin{array}{l}\text { Kampfausbildung zur Verteidigung } \\
\text { gegen andere Vampire und Neuge- } \\
\text { borene (BzEdN, S. 646); } \\
\text { Kampftraining (BzAb, S. 395); } \\
\text { Aushandeln von Strategien } \\
\text { (BzEdN, S. 405); Ausbildung eines } \\
\text { neugeborenen Vampirs: Kontrolle } \\
\text { über Jagdinstinkt erlangen zum } \\
\text { Schutz der Menschen (BzEdN, } \\
\text { S. 431); Gleiten, Weitsprung und } \\
\text { Hochsprung (BzEdN, S. 432); } \\
\text { Konzentration (BzEdN, S. 434); } \\
\text { Kontrolle über Kräfte, Schnelligkeit } \\
\text { und Fähigkeiten (BzEdN, S. 624) }\end{array}$ & $\begin{array}{l}\text { High School in amerikanischer Klein- } \\
\text { stadt Forks (BzMo, S. 16); ,Ansamm- } \\
\text { lung identischer Bauten aus roten Zie- } \\
\text { geln" (BzMo, S. 17); im Stundenplan } \\
\text { enthalten sind Politik (BzMo, S. 21), } \\
\text { Mathematik (BzMo, S. 22), Spanisch } \\
\text { (BzMo, S. 22), Englisch (BzMo, S. 22), } \\
\text { Biologie (BzMo, S. 28) und Sport } \\
\text { (BzMo, S. 31); zum alljährlichen Jah- } \\
\text { resabschlussball sollte man mit einer } \\
\text { Begleitung erscheinen (BzMo; S. 84); } \\
\text { eine volle Ausbildung sieht nach der } \\
\text { Highschool das College (BzMi, S. 544) } \\
\text { und schließlich die Universität vor } \\
\text { (BzAb, S. 23) }\end{array}$ \\
\hline
\end{tabular}

\footnotetext{
${ }^{238}$ Ewers (2011), S. 1.
} 


\begin{tabular}{|c|c|c|}
\hline $\begin{array}{l}\text { Politik/ } \\
\text { Politiker }\end{array}$ & $\begin{array}{l}\text { Volturi-Clan als mächtige, ,könig- } \\
\text { liche“ (BzMi, S. 25) Vam- } \\
\text { pirfamilie; sie stellen Gesetze auf, } \\
\text { an die sich alle Vampire halten } \\
\text { müssen (BzEdNa, S. 688) }\end{array}$ & $\begin{array}{l}\text { Die Polizei kann die Morde nicht auf- } \\
\text { klären, die sich zutragen, weil sie das } \\
\text { nötige Wissen um Vampire nicht besitzt } \\
\text { (BzAb, S. 33, S. 280); Staatsverschul- } \\
\text { dung (BzEdN, S. 517); Einteilung in } \\
\text { Nord- und Südstaaten (BzAb, S. 284, } \\
\text { S. 293); }\end{array}$ \\
\hline $\begin{array}{l}\text { Medien/ } \\
\text { Kommuni- } \\
\text { kation }\end{array}$ & $\begin{array}{l}\text { Edward kann Gedanken lesen } \\
\text { (BzMo, S. 325) und Alice die Zu- } \\
\text { kunft vorhersagen (BzMo, S. 325); } \\
\text { Wolfskommunikation durch Ge- } \\
\text { dankenübertragung (BzMi, S. 317); } \\
\text { Jasper kontrolliert Gefühle (BzMo, } \\
\text { S. 347) }\end{array}$ & $\begin{array}{l}\text { Berichterstattung in der Tageszeitung } \\
\text { (BzMi, S. 399) Seattle Times (BzAb, } \\
\text { S. 230); Nachrichten im Fernsehen } \\
\text { (BzAb, S. 284); Internet (BzMo, S. 38, } \\
\text { S. 140); E-Mails (CD-Player (BzMo, } \\
\text { S. 126); MP3-Player (BzEdN, .S. 683); } \\
\text { Mobiltelefone (BzMi, S. 412); DVDs } \\
\text { (BzEdN, S. 115); }\end{array}$ \\
\hline $\begin{array}{l}\text { Sport/ } \\
\text { Wettkampf }\end{array}$ & Vampir-Baseball (BzMo, S. 382f) & $\begin{array}{l}\text { Phil arbeitet als Basketballtrainer bei } \\
\text { den „Suns“ (BzMo, S. 479); }\end{array}$ \\
\hline Hobbys & Vampirschach $^{239}$ (BzAb, S. 65) & $\begin{array}{l}\text { Renée besucht einen Lesekreis und ei- } \\
\text { nen Meditationskurs (BzMi, S. 154) }\end{array}$ \\
\hline Lifestyle & $\begin{array}{l}\text { Vampire ernähren sich von Tier- } \\
\text { oder Menschenblut (BzMo, S. 198); } \\
\text { Jagd nach Tierblut zur Nahrungsbe- } \\
\text { schaffung (BzEdN, S. 355); Vampi- } \\
\text { re wechseln ständig den Wohnort, } \\
\text { weil sie nicht altern, oder leben als } \\
\text { Nomaden (BzMo, S. 305f); schla- } \\
\text { fen nicht (BzMo, S. 196); vertreten } \\
\text { Moralvorstellungen und die Kultur } \\
\text { vorangegangener Generationen } \\
\text { (BzAb, S. 439-449) }\end{array}$ & $\begin{array}{l}\text { Amerikanische Kleinstadt Forks, ,in der } \\
\text { alle aufeinanderhock[ ]en“, jeder kennt } \\
\text { jeden (BzMo, S. 36); das Indianerreser- } \\
\text { vat von La Push ist in der Nähe, an der } \\
\text { Küste gelegen (BzMo, S. 11); Auto als } \\
\text { wichtigstes Verkehrsmittel (BzMo, } \\
\text { S. 10); Bella kocht für sich und ihren } \\
\text { Vater (BzMo, S. 85), isst in der Cafete- } \\
\text { ria (BzMo, S. 20) und geht mit Edward } \\
\text { im Restaurant essen (BzMo, S. 164); im } \\
\text { Fernseher laufen Baseball und Sitcoms } \\
\text { (BzMo, S. 158) }\end{array}$ \\
\hline
\end{tabular}

Tabelle 4: Aufruf kulturspezifischer und kulturübergreifender Schemata in der Bis(s)-Serie

Die Edelstein-Trilogie, Percy Jackson und Artemis Fowl stellen ebenfalls neben phantastischen realistische Symbolsysteme bestimmter Kulturkreise zur Verfügung, wobei der englischsprachige Raum zentraler Motivlieferant ist: Während die Bis(s)-Serie Einblicke ins amerikanische Kleinstadtleben gewährt (BzMo, S. 7, BzMi, S. 8, BzAb, S. 8, BzEdN, S. 8), führt

\footnotetext{
${ }^{239}$ Die Parallele zu Harry Potter ist augenscheinlich, wo ebenfalls das Schachspiel als Repräsentationsfläche genutzt wird.
} 
Percy Jackson ins Großstadtleben ein, indem New York den Haupthandlungsort stellt (PJ 1, S. 10, S. 166, S. 179, PJ 2, S. 7, PJ 3, S. 7) bzw. die Ostküste der USA.

Die Tribute von Panem hingegen ist zwar auch in Amerika verortet (TS, S. 23), führt aber aufgrund der Zukunftsperspektive nicht die Kultur heutiger Nordstaaten vor, sondern bietet eine kulturübergreifende Projektionsfläche an, bei der insbesondere die Themen Politik, Medien und Kommunikation Beachtung finden. Die Edelstein-Trilogie (RR, S. 7, SB, S. 7, SG, S. 7), Artemis Fowl (AF 2, S. 11), die Für-immer-Trilogie (FI 1, S. 9) spielen analog zu Harry Potter (HP 1, S. 23) in London und spiegeln die kulturellen Gepflogenheiten der englischen Gesellschaft im beginnenden 21. Jahrhundert wider.

\subsubsection{Die Post-Potter-Texte als Entwürfe multikulturellen Lebens}

Die Multiadressierung der Post-Potter-Texte kommt auch dadurch zum Ausdruck, dass sie Entwürfe multikulturellen Lebens reflektieren und als positiv markieren. Damit erschaffen sie kulturell tendenziell offene Atmosphären, indem sie eine Erfahrungswirklichkeit aufzeigen, bei der Alterität als dominante Erfahrungsprinzipien herausgestellt und akzeptiert wird. Zumeist wird durch bloße Erwähnung von Kontinenten, Ländern und Städten oder den Auftritt von Figuren unterschiedlichster Nationalität eine Perspektive erreicht, durch welche multikulturelles Leben als Standard der Erfahrungswirklichkeit erscheint. Manchmal werden sogar interkulturelle Austauschsituationen explizit angesprochen.

Auch wenn die Schauplätze der Bis(s)-Saga sich hauptsächlich in den USA befinden, u. a. La Push (BzMo, S. 121), Forks (BzMo, S. 14), Port Angeles (BzMo, S. 159), Phoenix (BzMo, S. 176), Seattle (BzMo, S. 43) und New York (BzMi, S. 430), finden sich daneben auch europäische Schauplätze wie die italienischen Städte Volterra (BzMi, S. 441) und Florenz (BzMi, S. 438). Genannt werden zudem häufig topografische Marker, die auf realistische Raumschemata außerhalb der USA verweisen, zum Beispiel Paris (BzMi, S. 369), London (BzEdN, S. 561), Afrika (BzMi, S. 30) und Asien (BzEdN, S. 737), wodurch sich der Handlungsraum global erstreckt.

Die Personen im Buch weisen zudem zwar eine Nähe zur Wirklichkeitserfahrung nordwestamerikanischer Einwohner auf, manifestieren daneben aber auch interkulturellen Austausch als festes Prinzip: So wird ein Bild von der amerikanischen Bevölkerung etabliert, das sich aus Menschen „, unterschiedlicher Herkunft und Hautfarbe“ (BzAb, S. 280) zusammensetzt, aus „Weiße[n]“, „Afroamerikaner[n]“, „Hispanoamerikaner[n]“, „Asiate[n]“ (BzAb, S. 280) sowie amerikanischen Ureinwohnern (BzMi, S. 84), insbesondere denen des Quileute- 
Stamms, die in der Nähe von Forks in einem Reservat leben. Darüber hinaus wird auf europäische Kulturkreise hingewiesen, vor allem in Form von Vampirzirkeln bzw. -figuren: Die Volturi fungieren (BzMi, S. 25) als Repräsentanten Italiens, Stefan und Wladimir (BzE, S. 657) als Repräsentanten Rumäniens und Amum, Kebi, Benjamin und Tia (BzE, S. 658) als Repräsentanten Ägyptens. Maggie, Siobhan und Liam (BzE, S. 658) stehen für Irland, Laurant für Frankreich, Alistair für England (BzEdN, S. 642) und Zafrina sowie Senna für die Südstaaten (BzEdN, S. 643), während James und Victoria Nomaden darstellen (BzMo S. 392). Dabei wird das Miteinander der Kulturen nicht nur als Normalität, sondern auch als bereichernd dargestellt wird. Die Familie Cullen kann etwa letztlich nur mithilfe verbündeter Zirkel unterschiedlichster Herkunft (BzEdN, S. 709) die Auseinandersetzung mit den Volturi überstehen; die Clans wohnen sogar vorübergehend zusammen, sodass diese phantastische Zusammenkunft als Projektions- und Reflexionsfläche multikulturellen Austauschs dienen kann: „, In dem riesigen Haus der Cullens waren so viele Gäste; man hätte es kaum für möglich gehalten, dass es bequem sein könnte. “ (BzEdN, S. 637). Diesbezüglich werden nicht nur die unterschiedlichen Charakterzüge der Gäste hervorgehoben, sondern auch, wie friedlich sie miteinander umgehen, was angesichts ihrer Spezies ungewöhnlich ist (BzEdN, S. 641 ff.): „Mit Ausnahme der Volturi war es wahrscheinlich die größte friedliche Versammlung in der Geschichte der Unsterblichen “ (BzEdN, S. 658).

Die Edelstein-Trilogie verweist ebenfalls auf multikulturelle Lebensentwürfe. Neben dem Ausgangsland England werden die Lebensräume Amerika und Jamaika (RR, S. 248), Deutschland (RR, S. 286), Frankreich (RR, S. 246), Spanien (RR, S. 287), Italien (RR, S. 287) sowie Indien und China (SB, S. 361) erwähnt. Auch hier werden kulturelle Unterschiede reflektiert und als Bereicherung und Lernchance herausgestellt, was u. a. in den Berichten des Grafen zum Ausdruck kommt, der offenbar viel gereist ist: „Auf meinen Reisen [...] habe ich das Glück gehabt, auf viele Lehrer zu treffen, die bereit waren, ihr Wissen weiterzugeben. Ich wurde in die Geheimnissee der Akasha-Chronik eingeweiht und lernte vieles, das das geistige Fassungsvermögen der meisten westlichen Kulturen schlichtweg sprengen würde. " (SB, S. 361) Darüber hinaus wird die Prozesshaftigkeit kultureller Gepflogenheiten betont, die zweifelsohne eine wichtige Komponente kultureller Bildung darstellt. Denn das Gedankenexperiment Zeitreise gewährt Einblicke in Kulturerzeugnisse und -praktiken Englands vergangener Jahrhunderte und stellt sowohl Unterschiede als auch Gemeinsamkeiten zu Aspekten gegenwärtiger englischer Kultur heraus. Gideon und Gwendolyn bekommen bei mehreren ihrer Reisen in die Vergangenheit Scones (RR, S. 323) serviert, was klar die Tradi- 
tion des Gebäcks hervorhebt, anderseits werden etwa Kleidung, medizinische Versorgung, Musik und Tanz als Phänomene vergangener Jahrhunderte beschrieben und als Fremdheitserfahrung gewertet.

\subsubsection{Zwischenfazit}

Die Texte des Korpus verwenden wie Harry Potter mehrere Strategien, die auf eine Multiadressierung schließen lassen. Diese kommen neben Vermarktungsaspekten durch mehrfach auslegbare Symbolsysteme zum Ausdruck, die sich um internationale Anschlussfähigkeit bemühen. So etablieren und tradieren sie ein populärkulturelles Gewebe auf internationaler Ebene, das einen Beitrag zu einer transnationalen Kultur leistet. Des Weiteren stellen sie kulturübergreifende Symbolsysteme zur Verfügung, bei denen auf phantastischer Projektionsfläche universelle Themen kulturellen Lebens verhandelt werden. Im Sinne von Political Correctness kreieren die Post-Potter-Texte Entwürfe multikulturellen Lebens und verorten ihre Handlung durch entsprechende topografische Marker auf internationalem Terrain.

\subsection{Resümee}

Die Betrachtungen haben gezeigt, dass Harry Potter und die Texte des Korpus ähnliche Strategien in der Adressierung verfolgen: Einerseits lässt sich das Bemühen um internationale Anschlussfähigkeit erkennen, indem sie sich in populärkulturelle Gewebe einschreiben, die auf globaler Ebene operieren, kulturübergreifende Symbolsysteme zur Verfügung stellen und multikulturelle Austauschsituationen reflektieren. Andererseits richten sich manche der Symbolsysteme an spezielle Rezipientengruppen. Die Tendenz ist erkennbar, neben einer kulturübergreifenden eine kulturspezifische Variante kulturellen Lebens zu zeigen, die sich konkret in die Alltagswirklichkeit eines bestimmten Kulturkreises einschreibt. Zudem werden Lesarten, die auf bestimmte Altersgruppen abgestimmt sind, angeboten; die Texte operieren mit gesellschaftlichen Normen, die für kinder- und jugendliterarische Kommunikate unumgänglich sind, und stellen Symbolsysteme bereit, die sowohl Heranwachsende als auch erwachsene Mitrezipienten ansprechen sollen, was eine Zuordnung zur Kinder- und Jugendliteratur plausibel macht. Gleichzeitig eröffnen sie durch Polyvalenz allegorische Lesarten, die einen gröBeren Erfahrungshorizont sowie ein höheres Abstraktions- und Reflexionsniveau voraussetzen. Erwachsene Rezipienten werden solcherart als offizielle Adressaten ernstgenommen, was dafür spricht, die Texte der All-Age-Literatur zuzuordnen. Die breite Adressierung zeigt sich dabei auch in der Vermarktung, die ein internationales wie altersunspezifisches Publikum anspricht. Da die Bücher zudem durch den Aufruf unterschiedlicher Genres verschiedene Ge- 
schmäcke bedienen, verfolgen sie zu gleichen Teilen individualisierte Adressatenprofile wie überindividualisierte und kulturunspezifische - eine Strategie, die Bergenthal in Bezug auf Harry Potter ,, individualisierte Multiadressierung “ nennt, ein Begriff, der sich ebenso für die Texte des Korpus anbietet. ${ }^{240}$

${ }^{240}$ Bergenthal (2008), S. $490 \mathrm{f}$. 


\section{Fazit}

Es gilt nun zusammenzufassen, welche gattungskonstitutiven Eigenschaften die Analysen der einzelnen Kapitel ergeben haben. Das Fazit widmet sich dazu zunächst jedem Korpustext einzeln, bevor noch einmal die Gattungsverwandtschaft zu Harry Potter in den Blick genommen wird.

\section{Zur Tintenwelt-Trilogie ${ }^{1}$}

Funkes Text ist als dreiteilige, endlich angelegte Fortsetzungsserie zu klassifizieren. Im ersten Band lässt sich eine hierfür eigentlich untypische inhaltliche Geschlossenheit beobachten, die anhand verschiedener Aspekte zum Ausdruck kommt: Nicht nur dass Tintenherz einen anderen Handlungsort und einen anderen Antagonisten als die beiden anderen Bände besitzt, das Happy End führt dazu, dass zur Weiterführung der Handlung nahezu keine inhaltliche Notwendigkeit besteht. Diese wird erst zu Beginn von Tintenblut geschaffen, indem das harmonische Tableau am Ende von Tintenherz wieder ins Wanken gerät. Band zwei und drei weisen einen stärkeren Bezug zueinander auf, denn am Ende von Tintenblut wird Spannung erzeugt, die auf den Fortgang der Handlung neugierig macht. Kohärenz über alle drei Bände hinweg entsteht durch wiederholt genutzte Schauplätze und ein im Kern festes Figurenpersonal. Der Handlungsraum wird zwar kontinuierlich erweitert, aber nicht konzeptionell revidiert. Im Übergang von Band eins zu zwei kommt die Tintenwelt als Schauplatz hinzu und wird in Tintentod noch räumlich ausgedehnt. Analog dazu steigt die Anzahl der Handlungsträger von Band zu Band, die Hauptprotagonisten wechseln aber nicht.

Den Romanen liegt eine phantastische Diegese mit multipler Weltstruktur zugrunde: Neben der realistisch anmutenden Ausganswelt entfalten sich parallel existierende Buchwelten. Mit der Tintenwelt, dem zentralen Schauplatz von Band zwei und drei, wird ein für die FantasyLiteratur typisches klischeeartiges Mittelaltersetting aufgerufen: Feen, Nachtmahre und Glasmänner, Bader, Gaukler, Räuber und Spielleute bevölkern die Buchwelt, die von Fürsten und gewissenlosen Herrschern regiert wird. Das Spiel mit Realität und Fiktion, Traum und Wirklichkeit sowie Leben und Tod gereicht zum Leitmotiv, der Einfluss von FantasyLiteratur ist auch hier deutlich identifizierbar.

Durch die Mythoshaltigkeit kann die Tintenwelt-Trilogie als moderner Mythos gelesen werden: Numinöse Mächte lenken in der Diegese das Schicksal, was zu einem klar erkennbaren

\footnotetext{
${ }^{1}$ Vgl. speziell Kap. 2.2.3; 3.2.2; 3.3.4.3; 4.2.3.1; 4.2.3.2; 4.2.3.3.; 5.3.2; 6.3.4.
} 
Kontingenzproblem führt. Während Autoren und Zauberzungen das fiktive Geschehen bestimmen, ist der Einfluss anderer Figuren nicht transparent. Mythische Raumschemata offenbaren sich in der Tendenz zur Personalisierung und symbolischen Aufladung; auch Figuren, insbesondere die der Tintenwelt, werden zu Repräsentanten einer mythischen Diegese, indem sie die Sinn- und Symbolhaftigkeit allen Seins zum Ausdruck bringen: Sie weisen mythische Denkweisen auf und besitzen sprechende Namen. Darüber hinaus neigt der Text zu Mythenadaptionen, etwa des Orpheus-Mythos sowie verschiedener Gottkindmythen.

Zahlreiche Anspielungen, intertextuelle Verweise, Motive und Metakommentare können je nach Rezipient wahrgenommen und eingeordnet oder auch übergangen werden. Funkes Werk kann als Hommage an das Lesen, als Liebeserklärung an das Buch und als Laudatio auf eine bibliophile Gesellschaft verstanden werden, womit es sich durch eine „gleichlautende“ Botschaft auszeichnet, die im Text auf diverse Weise und auf unterschiedlichen Ebenen kommuniziert und chiffriert wird. Komplexität, Polyvalenz sowie das programmatische Spiel mit verschiedenen Metaebenen ermöglichen erst die unterschiedlichen Leseniveaus, sodass in Funkes Text eine Mehrfachadressierung auszumachen ist, die den Bedürfnissen jugendlicher und erwachsener Rezipienten zugleich entgegenkommt.

\section{Zur Bis(s)-Serie ${ }^{2}$}

Meyers Werk ist als vierbändige, endlich angelegte Fortsetzungsserie zu klassifizieren. Sie deckt eine erzählte Zeit von ungefähr zwei Jahren ab, wobei jedem Teilband eine deutlich unterschiedlich große Zeitspanne zukommt. Die Ich-Erzählerin Bella sorgt für zeitliche Logik, indem sie zu Beginn jedes neuen Bandes handlungsrelevante Ereignisse der Vorbände zusammenfasst und Zeitraffungen sowie Zeitsprünge als solche markiert. Am Ende von Band eins, zwei und drei wird auf Techniken der Spannungssteigerung zurückgegriffen; die Frage, ob Bella selbst zum Vampir wird, dient jeweils als Cliffhanger.

Der Tetralogie liegt eine phantastische Diegese zugrunde, die zwei Welten nebeneinander stellt, welche wiederum durch Figuren repräsentiert werden: durch die Menschen sowie durch Vampire und Werwölfe. Die Welt der Menschen stellt sich als Alltagswelt heutiger jugendlicher Nordamerikaner dar, die in der Kleinstadt Forks verortet ist; temporale Markierungen verschiedener Art verweisen ebenfalls auf eine zeitgenössische Lebenswelt. In das zunächst als Possible World gekennzeichnete Setting integriert Meyer Vampire und Werwölfe, die

\footnotetext{
${ }^{2}$ Vgl. speziell Kap. 2.2.3; 3.2.2; 3.3.4; 4.2.3.4; 5.3.2; 5.4.1; 6.2.4; 6.3.4; 6.4.3.
} 
durch ihr Aussehen sowie ihre Lebens- und Denkweisen einen zur empirischen Realität divergenten Wirklichkeitsentwurf darstellen, der sich durch eine überlegene Weltsicht auszeichnet: Sie kennen die Welt der Menschen, andersherum ist den Menschen die Welt der Vampire und Werwölfe vor allem gedanklich nicht zugänglich. Mit Renesmee, halb Mensch, halb Vampir, wird eine Grenzfigur eingeführt, die beide Welten miteinander verknüpft.

Auf Ebene der Serienhandlung dominiert der Liebesplot, der sich über alle vier Bände erstreckt und überwiegend aus Bellas Perspektive erzählt wird. Hindernisse aller Art verzögern dabei das Happy End, immer andere Konflikte und Probleme stehen dem Glück im Weg. Jeder Band konzentriert sich dabei auf ein Hindernis, sodass sich eine Verkettung von Bewährungsproben ergibt, wie sie für den Abenteuerroman konstitutiv ist.

Darüber hinaus sind Einflüsse des Thrillers und des Schauerromans bzw. der Gothic Novel erkennbar. Der Vampir Edward wird in dieser Genremixtur zum Frauentraum stilisiert: Er zeigt sich sensibel und besitzt gleichzeitig übermenschliche Kräfte, ihn umgibt eine gefährliche Aura, aber er ist wunderschön. Meyer verweist durch die phantastische, übermenschlichen Attribute ihrer Vampirfigur auf eine Vielzahl von literarischen und cineastischen Prätexten, deren konventionalisiertes Vampirbild sie als Ausgangspunkt der eigenen Interpretation nutzt. Auffällig ist dabei, dass die Neuinterpretation im Text zum Thema gemacht wird, indem die historisch gewachsenen Vampirzeichnungen aufgegriffen werden, was Meyers Bild explizit als Innovation markiert. Die Mixtur aus Teenagerromanze und Schauerroman ist seit dem Erfolg der Romane häufig auf dem Buchmarkt zu beobachten.

Bella befindet sich im Übergang vom Teenager- zum Erwachsenenalter und stellt sich den Herausforderungen, die mit diesem Lebensabschnitt einhergehen: Schulabschluss, Auszug aus dem Elternhaus, das Lösen von den Eltern und deren Erwartungen, das Treffen eigener Entscheidungen, Ausbildung, Hochzeit und Schwangerschaft. Davon ausgehend, dass altersspezifische Themen die Adressierung eines literarischen Werkes mitbestimmen, lässt sich vermuten, dass die Serie jene anspricht, die sich ebenfalls gerade im Übergang zum Erwachsenenalter befinden bzw. diese Entwicklung gerade durchlebt haben. Vermarktet wird sie allerdings als All-Age-Literatur, sie soll also auch Erwachsene jeder Altersgruppe ansprechen. Der Wahl einer weiblichen Hauptfigur sowie dem Fokus auf die Liebesgeschichte mag es geschuldet sein, dass die Romane insbesondere bei weiblichen Rezipienten Anklang finden. Obwohl sich die Texte bezüglich der Motive und Schemata in einer Grauzone zwischen Jugend- und Erwachsenenliteratur bewegen, werden sie sowohl in der Forschung als auch in öffentlichen 
Diskursen als jugendliterarische Kommunikate wahrgenommen und vor dem Hintergrund der Normen beurteilt, die diesen von der Gesellschaft auferlegt werden. Sowohl das vermittelte Frauenbild als auch das allegorische Potenzial, das auf eine religiöse Missionierungsabsicht der Autorin hindeutet, werden kritisch angesehen. Die Serie stellt neben den Lesarten für Rezipienten unterschiedlichen Alters auch solche für Rezipienten unterschiedlicher kultureller Herkunft zur Verfügung, indem kulturelle Konzepte wie Schule, Politik, Medien und Sport in ein phantastisches Gewand gekleidet werden. So kann neben einem kulturspezifischen Symbolsystem, das die Lebenswirklichkeit zeitgenössischer Nordamerikaner widerspiegelt, ein kulturübergreifendes ausgemacht werden, das als Projektionsfläche für Rezipienten unterschiedlicher Herkunft dient. Meyer reflektiert multikulturelles Leben und inszeniert in ihrer als phantastisch gekennzeichneten Welt interkulturelle Austauschsituationen, die sie als bereichernd und erstrebenswert markiert.

\section{Zu Percy Jackson ${ }^{3}$}

Percy Jackson ist eine auf fünf Bände angelegte Fortsetzungsserie. Rick Riordan nutzt bei der temporalen Verortung seiner Erzählung einen Jahresrhythmus als Grundstruktur. Die Erzählzeit eines jeden Bandes umfasst jeweils einige Wochen. Die Gesamthandlung erstreckt sich über vier Jahre. Ausgespart bleibt das jeweils übrige Jahr, dessen Verlauf vom Erzähler zu Beginn eines neuen Bandes in groben Zügen zusammengefasst wird. Intraseriale Kohärenz wird vor allem durch Handlungsschemata geschaffen, die auf Ebene der Serienhandlung operieren. Neben dem Liebesplot zwischen Percy und Annabeth dominiert die Auseinandersetzung zwischen Kronos und den Göttern des Olymps den narratologischen Gesamtzusammenhang: Der Krieg wird im ersten Band entfacht und endet im fünften Band siegreich für die Götter. Auf Ebene der Folgenhandlungen finden häufig die Schemata „Suche“ und „Rettung einer Person“ Verwendung. Die doppelte Formstruktur des Textes wird insbesondere am Schema „Prophezeiung“ deutlich, das auf beiden Handlungsebenen der Erzählung operiert und damit eine wichtige Stellung in Riordans Serialitätskonzept einnimmt. Percy Jackson nutzt zudem Techniken der Informationsvergabe, wie sie für den Kriminalroman typisch sind.

Dem Text liegt eine phantastische Diegese mit binärer Weltstruktur zugrunde. Modellhaft kann zwischen dem Wirklichkeitsentwurf der Normalsterblichen und dem der Götter unterschieden werden, die nebeneinander existieren. Verortet ist die Erzählung in New York bzw. der US-amerikanischen Ostküste, aufgerufen wird die Zeitwelt der Neuesten Zeit. Riordans

\footnotetext{
${ }^{3}$ Vgl. speziell Kap. 2.2.3; 3.2.4; 3.3.4.2; 4.2.3.2; 5.3; 5.4.2; 6.2.4.
} 
Serie bemüht eine Vielzahl von Motiven, die den Konventionen der Fantasy-Literatur entsprechen: Die Alltagswelt des jungen Halbgotts ist unserer zwar ähnlich, aber von den Launen der griechischen Götter abhängig, die übernatürliche Fähigkeiten besitzen und mit magischen Artefakten ausgestattet sind. Percy absolviert auf seinen Missionen zahlreiche Mut- und Bewährungsproben und reift so zu einem Helden heran, der sich nicht nur durch Mut, sondern auch durch moralische Überlegenheit auszeichnet. Der Text kann als abenteuerliche Reise eines Auserwählten gelesen werden, der sich siegreich gegen das Böse durchsetzt.

Der Bezug zu antiken Prätexten ist hier programmatisch, die griechische Mythologie das wichtigste Themenreservoir. So finden sich zuhauf Lokalitäten, Personal, Handlungselemente und kurze Nacherzählungen antiker Texte. Bedeutsame Träume und Weissagungen nehmen einen großen Stellenwert in der Diegese ein, sie werden von den Handlungsträgern als wichtige Informationsquellen ernstgenommen. Die aus antiken Prätexten entlehnten Figuren und Motive werden von Riordan neu interpretiert, die Themen und Konflikte auf die Lebenswelt heutiger Jugendlicher übertragen. Die Zusammenfassungen mythischer Erzählungen garantieren dabei das Fundament der Neuinterpretationen, die sich teilweise weit von der Tradition etablierter Motive entfernen.

Der Text behandelt Themenkreise, die in der Lebens- und Erfahrungswirklichkeit pubertierender Jugendlicher präsent sind: Schule, Freundschaften unter Gleichaltrigen, das Verhältnis zu Eltern und Lehrern und die erste Liebe stehen neben den zahlreichen Abenteuern in Percys Leben im Vordergrund. Der Erzähler richtet sich mehrfach explizit an seine Adressaten und offenbart so, dass vorrangig Jugendliche in den Blick genommen werden, die sich in den frühen Jahren ihrer Pubertät befinden.

\section{Zur Panem-Trilogie ${ }^{4}$}

Die Panem-Trilogie von Suzanne Collins liegt als endlich angelegte Fortsetzungsserie vor. Die Analyse der seriellen Strukturen ergab, dass vor allem die Ankündigung unheilvoller Entwicklungen als dominante Fortsetzungsstrategie ausgemacht werden kann. Sowohl am Ende von Tödliche Spiele als auch von Gefährliche Liebe stehen einerseits ein Happy End, nämlich Katniss' Überleben der Hungerspiele, andererseits eine Mangel- bzw. Notsituation, die Spannung und die inhaltliche Notwendigkeit für die Fortsetzung der Geschichte erzeugt.

\footnotetext{
${ }^{4}$ Vgl. speziell Kap. 2.2.3; 3.2.4; 3.3.4.1; 4.2.3.2; 4.2.3.4; 5.3.2; 5.4.2; 6.3.4.1; 6.4.4.1.
} 
Der Text kann je nach Genre- bzw. Gattungsmodell als Fantasy-Literatur, Science Fiction oder Utopie (bzw. Dystopie) gelesen werden, je nachdem ob man die phantastischen Motive, die Fiktion von zukünftigen wissenschaftlichen Errungenschaften oder aber die Thematisierung einer futuristischen Gesellschaftsstruktur als gattungsweisend betrachtet. Der phantastischen Diegese liegt eine singuläre Weltstruktur zugrunde, die im Nordamerika der Zukunft verortet ist. Das realistische Raumschema als Ausgangspunkt wird durch freie Topografien stark verfremdet. Die von Collins' erschaffene Zeitwelt überschreitet in vielen Fällen das, was in Bezug auf Technik und Medizin in heutigen westlichen Industriestaaten im Bereich des Möglichen liegt. Die kulturellen Gepflogenheiten der beschriebenen Gesellschaft sind fremdartig, die Flora und Fauna weisen irritierende Mutationen auf.

Die Serie Die Tribute von Panem tendiert zur Mythoshaltigkeit. Die Utopie um die tödlichen Hungerspiele lässt sich auf den Theseus-Mythos beziehen: Müssen dem Minotaurus im antiken Mythos jährlich sieben Jünglinge und Jungfrauen geopfert werden, so haben hier jährlich ein Junge und ein Mädchen aus jedem der zwölf Distrikte auf Leben und Tod gegeneinander anzutreten. Katniss selbst erinnert in der labyrinthähnlichen Arena an Artemis, die Göttin der Jagd, weil sie mit Pfeil und Bogen kämpft und als starke und unabhängige Frau charakterisiert wird. Auf struktureller Ebene folgt Collins’ Erzählung dem Schema von Voglers Heldenreise, das sich aus unterschiedlichen mythischen Vorlagen speist.

Die Doppelsinnstruktur der Serie legt nahe, sie der All-Age-Literatur zuzuordnen. Denn der Text kann als gesellschaftskritische Allegorie gelesen werden, welche heutige Massenmedien angeprangert und die Frage aufwirft, wie groß der Schritt von rezenten westlichkapitalistischen Gesellschaftsentwürfen zu der von Collins entworfenen Zwei-KlassenGesellschaft tatsächlich ist, aus der heraus die geschilderten Ungerechtigkeiten und Perversionen plausibel gemacht werden.

\section{Zur Edelstein-Trilogie ${ }^{5}$}

Giers dreiteilige Fortsetzungsserie weist vielerlei Eigenschaften auf, die zur intraserialen Kohärenz des Textes beitragen. Die Zeitsprünge von Gwendolyn und Gideon ereignen sich in der Logik des Textes innerhalb von zwei Wochen und werden durch entsprechende Markierungen in eine chronologische Abfolge gebracht. Insbesondere die „Annalen“ und „Chroniken der Wächter“ liefern einen Beitrag zur temporalen Orientierung, indem sie Ereignisse aus der

\footnotetext{
${ }^{5}$ Vgl. speziell Kap. 2.2.3; 3.2.4; 3.3.4.3; 4.2.3.1; 4.2.3.2-3; 5.3.2; 5.4.2; 6.4.4.1.
} 
Vergangenheit zusammenfassen und genau datieren. Raumschema und Figurenensemble werden von Band zu Band kontinuierlich ausdifferenziert, zudem schaffen häufig verwendete Schauplätze intraseriale Kohärenz.

Der phantastischen Diegese der Edelstein-Trilogie liegt eine multiple Weltstruktur zugrunde, die sich aus den verschiedenen Zeitreisen der Protagonistin ergibt. Da die Geschichte in London spielt, stellt jedes London zu einem spezifischen Datum eine eigene Zeitwelt dar. Vereinfacht lässt sich die Diegese in zwei Welten einteilen: das London der Gegenwart und das der Vergangenheit. Ersteres wird durch zahlreiche Markierungen als der unmittelbaren Jetztzeit zugehörig gekennzeichnet. Beiden Wirklichkeitsentwürfen liegen phantastische Kausalbeziehungen zugrunde, die das Springen in der Zeit erlauben. Ein Bezug zur Fantasy-Literatur kann vor allem mit diesem Motiv plausibilisiert werden. Die beiden Welten konkretisieren sich nicht nur räumlich und zeitlich, sondern zudem auch an Figuren sowie deren Denkweisen, Wissensbeständen und kulturellen Gewohnheiten. Sie können eingeweiht, also über die Möglichkeiten des Zeitsprungs informiert, oder nicht eingeweiht sein und solcherart einen Zeitsprung für rational ausgeschlossen halten. Das Springen von einer Zeitwelt in die andere ist als Grenzüberschreitung anzusehen, die im Text in Form einer abstrakten Reise vonstattengeht.

Das Gedankenexperiment des Zeitsprungs wird zum Anlass genommen, eine mythische Diegese zu kreieren. Prophezeiungen und Visionen bewahrheiten sich in der Logik des Textes zuverlässig. Sie sind wichtige Dokumente bei der Entschlüsselung von Geheimnissen aller Art, Gwendolyn und ihre Freunde müssen sie nur auf die richtige Weise „interpretieren“. Die Zeitstruktur der Diegese ist zyklisch, vereinzelte Schauplätze wie etwa das Haupthaus der Wächter tendieren zur semantischen Aufladung und Personifikation. Zudem ist die Handlung häufig final motiviert. Der Stein der Weisen wird seiner Tradition entsprechend als mythischer Gegenstand eingeführt, erfährt allerdings eine Neuinterpretation als Ergebnis eines technisierten Produktionsvorgangs.

Neben dem Aufruf phantastischer und mythischer Genreschemata operiert auf Ebene der Serienhandlung ein Schema, das für den Liebesroman typisch ist. Die Einführung des zentralen Liebespaares überdauert den kompletten ersten Band der Trilogie: Während Gwendolyn offensichtlich sofort von Gideon verzaubert ist, werden seine Gefühle für sie erst am Ende des Bandes explizit gemacht. Es folgt eine Vielzahl von Hindernissen und Missverständnissen, bis das Paar am Ende glücklich vereint ist und in eine gemeinsame Zukunft startet. Auch Sche- 
mata des Abenteuer- und Kriminalromans werden bemüht: Jeder Zeitsprung Gwendolyns ist als eine Reise ins Unbekannte und damit als Abenteuer zu betrachten, bei dem die Protagonistin ihren Mut unter Beweis zu stellen hat. Das Recherchieren von Informationen und die Überführung des Grafen gestalten über weite Strecken die Serienhandlung. Die Auswertung der Indizien erweist sich in der zyklischen Erzählung als äußerst komplex.

Das Werk verweist vermehrt auf kulturelle Praktiken und Erzeugnisse einer sich international etablierenden Populärkultur und kann vor diesem Hintergrund als mehrfachadressierter Text verstanden werden, der Rezipienten verschiedener Ursprungsländer in den Blick nimmt. So tradiert er das Bild eines zeitgenössischen Teenagers, der einen internationalen Lifestyle pflegt: Gwendolyn und ihre Mitschüler konsumieren nicht nur Filme und Musik von internationalem Renommee, sie leben auch einen Medienalltag, der sich aus modernster Technik speist. Die Komplexität der zyklischen Narration sowie ihre phantastischen Elemente etablieren ein mehrfach auslegbares Symbolsystem, das Rezipienten unterschiedlichen Kompetenzniveaus in den Blick nimmt.

\section{Zu den Ähnlichkeiten von Harry Potter und den Post-Potter-Texten}

Der Blick auf die gattungskonstitutiven Eigenschaften bei Harry Potter und den Texten des Korpus hat eine Menge Gemeinsamkeiten ergeben, die grundlegender sind als Ähnlichkeiten auf Inhalts- und/oder Motivebene.

Beide sind endlich angelegte Fortsetzungsserien mit intendierter Rezeptionsreihenfolge, deren doppelte Formstrukturen durch Handlungsschemata bedient werden. Die Folgenhandlungen weisen zwar inhaltliche Abgeschlossenheit auf, haben aber gleichzeitig Anteil am narratologischen Gesamtzusammenhang. Allesamt erzeugen am Ende eines jeden Bandes auf Ebene der Serienhandlungen Spannung. Die Texte greifen dabei zwar jeweils auf unterschiedliche Strategien zurück, innerhalb einer Serie allerdings ähneln sich die Fortsetzungsstrategien auffällig. Sie erzeugen Kohärenz, indem ihre Handlungen in einen temporalen Kausalzusammenhang gestellt werden, die Chronologie der Ereignisse ist sowohl auf Ebene der Folgen- als auch der Serienhandlungen grundsätzlich rekonstruierbar und lehnt sich an realistische Zeitstrukturen an. Die zugrundeliegenden Raumschemata werden mit voranschreitender Handlung erweitert oder ausdifferenziert, das Ensemble der Handlungsträger um weitere Figuren ergänzt. Ein gänzliches Wechseln des Raumschemas oder des Figurenensembles ist nicht zu beobachten. 
Harry Potter wie die Post-Potter-Texte greifen verstärkt auf phantastische Darstellungsmittel, Figuren und Motive zurück, sodass eine Zuordnung aller zur Gattung der phantastischen Literatur eine plausible Lesart darstellt. Auch die Einteilung als Genre der Fantasy-Literatur ist vor dem Hintergrund der aufgerufenen Motive und Motivkonstellationen einleuchtend. Eine spezifischere Klassifikation der Werke scheint auf Grundlage eines Genremodells wenig sinnvoll, die Zuordnung zu einem Subgenre der Fantasy schwerlich haltbar. Harry Potter und seine Nachfolger tendieren zu gebundenen Topografien sowie einer temporalen Verortung in der Jetztzeit bzw. Neuesten Zeit. Eine Kombination realistischer und phantastischer Schemata ist häufig zu beobachten.

Zudem zeugen alle Romanserien von Mythenadaptionen, vor allem Gottkindmythen, deren Einfluss auf die Konzeption der Protagonistinnen und Protagonisten klar auszumachen ist. Die Entwicklung der zentralen Heldenfiguren gestaltet sich jeweils ähnlich: Die kindlichen bzw. jugendlichen Protagonisten wachsen in prekären Verhältnissen auf, sind Halb- oder Vollwaisen, besitzen übermenschliche Fähigkeiten und ein ausgeprägtes Moralempfinden. Sie werden zunächst geschult, bevor sie den Kampf gegen den Antagonisten antreten. Sie stellen sich den Bewährungsproben, erweisen sich als tapfer und gehen siegreich aus dem Kampf gegen das Böse hervor. Sie sind Auserwählte, ihr Schicksal ist vorherbestimmt. Ihre Entwicklung kann mit Voglers Schema der Heldenreise in Verbindung gebracht werden, das sich aus unterschiedlichen antiken mythischen Vorlagen speist.

Allen gemeinsam ist zudem die Neigung zur Genrehybridität. Neben Einflüssen der FantasyLiteratur und des Mythos finden sich besonders häufig Schemata des Liebesromans, des Abenteuer- und des Kriminalromans. Die Gewichtung fällt dabei zwar unterschiedlich aus, die Tendenz zum Genremix aber ist augenscheinlich. In den Serienhandlungen entspinnt sich jeweils neben den Abenteuerhandlungen ein Liebesplot, bei dem die Protagonistin bzw. der Protagonist eine Hauptrolle einnimmt. Die Helden durchleben Mut- und Bewährungsproben verschiedener Komplexität und Spannweite, besonders häufig lassen sich die Schemata „Rettung einer Person“, „Reise ins Unbekannte“ und „Schlacht“ beobachten. Aus dem Kriminalroman entlehnt sind vor allem das Motiv der Ermittlung und Recherche sowie Strategien der Leserlenkung und Informationsvergabe. Diese Einflüsse sind in der Regel hierarchisch niedriger einzuschätzen. Darüber hinaus sind vereinzelt auch noch Einflüsse weiterer Genretraditionen von Bedeutung. Neben der Neigung zum Genremix wurde bei den betrachteten Texten eine Tendenz zur Neuinterpretation literaturgeschichtlich etablierte Motive deutlich. Beides kann dazu herangezogen werden, die Texte mit der Stilepoche der Postmoderne in 
Verbindung zu bringen. Darüber hinaus tendieren sowohl Harry Potter als auch die Texte des Korpus zur Mehrfachadressierung.

\section{Ausblick: Harry Potter - ein prototypischer Text?}

Die im Rahmen dieser Gattungsdiskussion gesammelten Ergebnisse zeigen zwar deutlich, dass die Texte des Korpus starke konzeptuelle Ähnlichkeiten zu Harry Potter aufweisen, doch decken sie nicht die Ursachen auf. Vor allem zwei Erklärungen erscheinen plausibel: Zum einen ist denkbar, dass sie alle Ausdruck einer allgemeinen, also weder themen- noch medienspezifischen literaturhistorischen Entwicklung sind. Denn der innovative Umgang mit Genrekonventionen sowie die Tendenz zur Mehrfachadressierung lassen sich parallel auch im Bereich der Erwachsenenliteratur sowie bei Film und Fernsehserie beobachten. ${ }^{6}$ Diese Trends scheinen ein postmodernes Phänomen zu sein, das in vielerlei literarischen Medien zum Ausdruck kommt. Zum anderen mag Rowling durch ihren Welterfolg selbst Einfluss auf bestehende Gattungskonventionen genommen haben, und zwar insbesondere in Bezug auf eine literarische Gattung, der in den öffentlichen Medien lange Zeit wenig Beachtung geschenkt wurde, nämlich der phantastischen Kinder- und Jugendliteratur. Zu beobachten ist zweifelsohne: Wir finden nach Harry Potter auffällig viele Werke, die obige Eigenschaften aufweisen und mit diesem Konzept sehr erfolgreich sind. Wäre es also denkbar, dass Harry Potter ein prototypischer Text ist, der eine neue Ära in der Kinder- und Jugendliteratur eingeläutet hat? Dass ein Text ein neues Genre initiiert hat, ist in der Literaturgeschichte jedenfalls schon mehrfach vorgekommen. Immer wieder haben sich Werke hervorgetan, die sich im System der „,wechselseitigen Komplementarität von Gattungserwartungen und Werkantworten “ als normbildend erwiesen, indem sie bestehende Gattungsmodelle maßgeblich prägten oder veränderten. ${ }^{7}$ Robinson Crusoe (1720) oder Der Herr der Ringe (1970) etwa werden bereits seit Längerem als Genrebegründer betrachtet. ${ }^{8}$ Die Annahme, ein zeitgenössischer Text wie Harry Potter habe eine neue literarische Gattung hervorgebracht, mag im höchsten Maße spekulativ sein, ${ }^{9}$ denn noch ist ja nicht absehbar, welche Strukturen und Merkmale langfristig für Gattungsmodelle formgebend sein werden. Abwegig aber ist die These keineswegs, wie die Ergebnisse dieser Arbeit zeigen. Zumindest heute ist ein Ende der Post-Potter-Ära noch längst nicht in Sicht ...

\footnotetext{
${ }^{6}$ Vgl. Hickethier (1991), S. 25 f.

${ }^{7}$ Voßkamp (1977), S. 30. Suerbaum stellt 1993 fest, dass es kaum eine Gattung gibt, die nicht durch einen Prototypen mitbestimmt worden ist. Vgl. Suerbaum (1993), S. 106.

${ }^{8}$ Vgl. in Bezug auf die Robinsonaden Stach (1996) und in Bezug auf Tolkines Fantasy-Genre Gloge (2002).

${ }^{9}$ Zymner (2003a), S. 123.
} 


\section{Literaturverzeichnis}

\section{Primärliteratur}

Suzanne Collins: Die Tribute von Panem - Tödliche Spiele. Deutsch von Sylke Hachmeister und Peter Klöss. Oetinger, Hamburg 2009

Englischsprachige Originalausgabe: The Hunger Games. Scholastic, New York 2008 [zitiert als TS]

Suzanne Collins: Die Tribute von Panem - Gefährliche Liebe. Deutsch von Sylke Hachmeister und Peter Klöss. Oetinger, Hamburg 2010

Englischsprachige Originalausgabe: The Hunger Games. Catching Fire. Scholastic, New York 2009

[zitiert als GL]

Suzanne Collins: Die Tribute von Panem - Flammender Zorn. Deutsch von Sylke Hachmeister und Peter Klöss. Oetinger, Hamburg 2011

Englischsprachige Originalausgabe: The Hunger Games - Mockingjay. Scholastic, New York 2010

[zitiert als FZ]

Cornelia Funke: Tintenherz. Dressler, Hamburg 2003

[zitiert als TH]

Cornelia Funke: Tintenblut. Dressler, Hamburg 2005

[zitiert als TB]

Cornelia Funkte: Tintentod. Dressler, Hamburg 2007 [zitiert als TT]

Kerstin Gier: Rubinrot - Liebe geht durch alle Zeiten. Arena, Würzburg 2012

Deutschsprachige Originalausgabe: Arena, Würzburg 2009

[zitiert als RR]

Kerstin Gier: Saphirblau - Liebe geht durch alle Zeiten. Arena, Würzburg 2014

Deutschsprachige Originalausgabe: Arena, Würzburg 2010

[zitiert als SB]

Kerstin Gier: Smaragdgrün - Liebe geht durch alle Zeiten. Arena, Würzburg 2014

Deutschsprachige Originalausgabe: Arena, Würzburg 2010

[zitiert als SG]

Stephenie Meyer: Bis(s) zum Morgengrauen. Aus dem Englischen von Karsten Kredel. Carlsen, Hamburg 2009

Deutschsprachige Erstausgabe: Carlsen, Hamburg 2006

Englischsprachige Originalausgabe: Twilight. Little, Brown and Company, New York 2005

[zitiert als BzMo]

Stephenie Meyer: Bis(s) zur Mittagsstunde. Aus dem Englischen von Karsten Kredel. Carlsen, Hamburg 2009 
Deutschsprachige Erstausgabe: Carlsen, Hamburg 2007

Englischsprachige Originalausgabe: New Moon. Little, Brown and Company, New York 2006

[zitiert als BzMi]

Stephenie Meyer: Bis(s) zum Abendrot. Aus dem Englischen von Karsten Kredel. Carlsen, Hamburg 2009

Deutschsprachige Erstausgabe: Carlsen, Hamburg 2008

Englischsprachige Originalausgabe: Eclipse. Little, Brown and Company, New York 2007

[zitiert als BzAb]

Stephenie Meyer: Bis(s) zum Ende der Nacht. Aus dem Englischen von Karsten Kredel. Carlsen, Hamburg 2009

Deutschsprachige Erstausgabe: Carlsen, Hamburg 2009

Englischsprachige Originalausgabe: Breaking Dawn. Little, Brown and Company, New York 2008

[zitiert als BzEdN]

Rick Riordan: Percy Jackson - Diebe im Olymp. Aus dem Englischen von Gabriele Haefs. Carlsen, Hamburg 2012

Deutschsprachige Erstausgabe: Carlsen, Hamburg 2006

Englischsprachige Originalausgabe: Percy Jackson and the Olympians - The lightning Thief. Hyperion, New York 2005

[zitiert als PJ 1]

Rick Riordan: Percy Jackson - Im Bann des Zyklopen. Aus dem Englischen von Gabriele Haefs. Carlsen, Hamburg 2012

Deutschsprachige Erstausgabe: Carlsen, Hamburg 2006

Englischsprachige Originalausgabe: Percy Jackson and the Olympians - The Sea of Monsters. Hyperion, New York 2006

[zitiert als PJ 2]

Rick Riordan: Percy Jackson - Der Fluch des Titanen. Aus dem Englischen von Gabriele Haefs. Carlsen, Hamburg 2012

Deutschsprachige Erstausgabe: Carlsen, Hamburg 2010

Englischsprachige Originalausgabe: Percy Jackson and the Olympians: The Titan's Curse. Hyperion, New York 2007

[zitiert als PJ 3]

Rick Riordan: Percy Jackson - Die Schlacht um das Labyrinth. Aus dem Englischen von Gabriele Haefs. Carlsen, Hamburg 2012

Deutschsprachige Erstausgabe: Carlsen, Hamburg 2011

Englischsprachige Originalausgabe: Percy Jackson and the Olympians: The Battle of the Labyrinth. Hyperion, New York 2008

[zitiert als PJ 4]

Rick Riordan: Percy Jackson - Die letzte Göttin. Aus dem Englischen von Gabriele Haefs. Carlsen, Hamburg 2012

Deutschsprachige Erstausgabe: Carlsen, Hamburg 2011 
Englischsprachige Originalausgabe: Percy Jackson and the Olympians: The Last Olympian. Hyperion, New York 2009

[zitiert als PJ 5]

Rowling, J[oanne] K.: Harry Potter und der Stein der Weisen. Aus dem Englischen von Klaus Fritz. Carlsen, Hamburg 1998

Englischsprachige Originalausgabe: Harry Potter and the Philosopher's Stone. Bloomsbury, London 1997

[zitiert als HP 1]

Rowling, J[oanne] K.: Harry Potter und die Kammer des Schreckens. Aus dem Englischen von Klaus Fritz. Carlsen, Hamburg 1999

Englischsprachige Originalausgabe: Harry Potter and the Chamber of Secrets. Bloomsbury, London 1998

[zitiert als HP 2]

Rowling, J[oanne] K.: Harry Potter und der Gefangene von Askaban. Aus dem Englischen von Klaus Fritz. Carlsen, Hamburg 1999

Englischsprachige Originalausgabe: Harry Potter and the Prisoner of Askaban. Bloomsbury, London 1999

[zitiert als HP 3]

Rowling, J[oanne] K.: Harry Potter und der Feuerkelch. Aus dem Englischen von Klaus Fritz. Carlsen, Hamburg 2000

Englischsprachige Originalausgabe: Harry Potter and the Goblet of Fire. Bloomsbury, London 2000

[zitiert als HP 4]

Rowling, J[oanne] K.: Harry Potter und der Orden des Phönix. Aus dem Englischen von Klaus Fritz. Carlsen, Hamburg 2003

Englischsprachige Originalausgabe: Harry Potter and the Order of the Phoenix. Bloomsbury, London 2003

[zitiert als HP 5]

Rowling, J[oanne] K.: Harry Potter und der Halbblutprinz. Aus dem Englischen von Klaus Fritz. Carlsen, Hamburg 2005

Englischsprachige Originalausgabe: Harry Potter and the Half-Blood Prince. Bloomsbury, London 2005

[zitiert als HP 6]

Rowling, J[oanne] K.: Harry Potter und die Heiligtümer des Todes. Aus dem Englischen von Klaus Fritz. Carlsen, Hamburg 2007

Englischsprachige Originalausgabe: Harry Potter and the Deathly Hallows. Bloomsbury, London 2007

[zitiert als HP 7]

\section{Weitere Primärliteratur (außerhalb des zugrundeliegenden Korpus)}

Angoulême, Margarete von: Das Heptameron. Die Erzählungen der Königin von Navarra. Ins Deutsche übersetzt und mit einem Nachwort versehen von Franz Riederer. Antäus, Lübeck 1960 
Apollodor: Bibliotheke. Götter- und Heldensagen. Hrsg., übers. und komm. von Paul Dräger. Artemis \& Winkler, Düsseldorf/Zürich 2005

Aristoteles: Poetik. Übers. und erl. v. Arbogast Schmitt. Akademie Verlag, Berlin $2011^{2}$

Baum, Lyman Frank. Der Zauberer von Oz. Ein Märchen. Aus dem Amerikan. übertr. von Ursula v. Wiese. Morgortan, Zürich 1940

Englischsprachige Originalausgabe: The Wonderful Wizard of Oz. With Pictures by W. W. Denslow. Geo. M. Hill Co., Chicago/New York 1900

Barrie, James M: Peter Pan. Deutsch von Bernd Wilms. Dressler, Hamburg 1993

Deutschsprachige Erstausgabe: Peter Pan. Stocker-Schmid, Dietikon-Zürich 1964

Englischsprachige Originalausgabe: Peter Pan and Wendy. Hodder \& Stoughton, London 1911

Basile, Giambattista: Das Märchen der Märchen: Das Pentamerone. Nach dem neapolitan. Text von 1634/36 vollst. und neu übers. und erl. von Hanno Helbling. Hrsg. von Rudolf Schenda. Beck, München 2000

Bierbaum, Otto Julius: Zäpfel Kerns Abenteuer. Eine deutsche Kasperlegeschichte in $43 \mathrm{Ka}-$ piteln. Frei nach Collodis italienischer Puppenhistorie Pinocchio. Mit 65 Zeichn. von Arpad Schmidhammer. Schaffstein, Köln 1905

Brontë, Emily: Die Sturmhöhe. Roman. Aus dem Engl. übertr. von Grete Rambach. Insel, Leipzig 1938

Deutschsprachige Erstausgabe: Wutheringshöhe. Verlags-Comptoir, Grimma/Leipzig 1851

Englischsprachige Originalausgabe: Ellis Bell [Pseudonym]: Wuthering Heights. Thomas Cautley Newbe, London 1847

Campe, Joachim Heinrich: Robinson der Jüngere. Ein Lesebuch für Kinder. Nachdruck der 58. Auflage der Ausgabe von Braunschweig 1860. Harenberg, Dortmund 1978 [Erstausgabe Bd. 1: Hamburg 1779, Bd. 2: Hamburg 1780]

Carroll, Lewis: Alice im Wunderland. Übers. von Christian Enzensberger. Lappan, Oldenburg 2005

Deutschsprachige Erstausgabe: Alice's Abenteuer im Wunderland. Aus dem Englischen von Antonie Zimmermann. Johann Friedrich Hartknoch, Leipzig 1869

Englischsprachige Originalausgabe: Alice's Adventures in Wonderland. McMillan, London 1865

Clare, Cassandra: City of Bones. Aus dem Amerikan. von Franca Fritz. Arena, Würzburg 2008

Englischsprachige Originalausgabe: City of Bones. M.K. McElderry Books, New York 2007

Colfer, Eoin: Artemis Fowl. Aus dem Englischen von Claudia Feldmann. List, Berlin 2005 Deutsche Erstausgabe: List, Berlin 2001

Englischsprachige Originalausgabe: Artemis Fowl. Penguin, London 2001

[zitiert als AF 1] 
Colfer, Eoin: Artemis Fowl. Die Verschwörung. Aus dem Englischen von Claudia Feldmann. List, Berlin 2005

Deutsche Erstausgabe: List, Berlin 2002

Englischsprachige Originalausgabe: Artemis Fowl. The Arctic Incident. Penguin, London 2002

[zitiert als AF 2]

Collodi, Carlo: Hippeltitsch's Abentuer. Geschichte eines Holzbuben [Pinocchio]. Illustriert von Carlo Chiostri. Siwinna, Kattowitz/Leipzig 1905

Italienischsprachige Originalausgabe: La avventure di Pinocchio. Storia di un burattino. Illustrata da Carlo Chriasti. Bemporad \& figlio, Florenz 1902

Dahl, Roald: Hexen hexen. Dt. von Sybil Gräfin Schönfeldt. Rowohlt, Reinbek bei Hamburg 1986

Englische Originalausgabe: The Witches. Jonathan Cape, London 1983

Defoe, Daniel: Robinson Crusoe. Aus dem Engl. übers. von Hans Reisiger. Nachw. von Jürgen Kaube. Reclam, Stuttgart 2012

Deutschsprachige Erstausgabe: Das Leben und die gantz ungemeine Begebenheiten des berühmten Engelländers, Mr. Robinson CRUSOE, welcher durch Sturm und Schiffbruch, (worinne alle seine Reise-Gefährten elendiglich ertrunken,) auf der Americanischen Küste, vorn an dem grossen Fluß Oroonoko auf ein unbewohntes Eiland gerahten, Acht- und zwantzig Jahre darauf gelebet, und zuletzt durch See-Räuber wunderbahrer Weise davon befreyet worden. Göttlicher Providentz zum Preise, und curiöser Gemühter besonderem Vergnügen, nach der dritten Engelländis. Edition auf vornehmes Begehren ins Teutsche übergesetzet. Hamburg: Thomas von Wierings Erben 1720

Englischsprachige Originalausgabe: Robinson Crusoe. W. Taylor, London 1719

Ende, Michael: Der satanarchäolügenialkohöllische Wunschpunsch. Thienemann, Stuttgart 1989

Ende, Michael: Die unendliche Geschichte. von A bis Z. Thienemann, Stuttgart 1979

Ende, Michael: Jim Knopf und Lukas, der Lokomotivführer. Thienemann, Stuttgart 1960

Eschenbach, Wolfram von: Parzival. Text und Übersetzung. Mhd. Text nach der sechsten Ausgabe von Karl Lachmann, übers. von Peter Knecht. De Gruyter, Berlin/New York $2003^{2}$

Foer, Jonathan Safran: Tiere essen. Aus dem amerikan. Engl. von Isabel Bogdan. Kiepenheuer \& Witsch, Köln 2010

Funke, Cornelia: Reckless. Steinernes Fleisch. Dressler, Hamburg 2010

Gehm, Franziska: Die Vampirschwestern. Ein bissfestes Abenteuer. Loewe, Bindlach 2008

Gehm, Franziska: Die Vampirschwestern. Eine Freundin zum Anbeißen. Loewe, Bindlach 2008

Gehm, Franziska: Die Vampirschwestern. Ein zahnharter Auftrag. Loewe, Bindlach 2008 
Goethe, Johann Wolfgang von: Unterhaltungen deutscher Ausgewanderten. In: Die Horen. Hrsg. von Friedrich Schiller. Cotta, Tübingen 1795, 1. Band, 1. Stück, S. 49-78, 2. Stück, S. 1-28; 2. Band, 4. Stück, S. 41-67; 3. Band, 7. Stück, S. 50-76, 9. Stück, S. 45-52; 4. Band, 10. Stück, S. 108-152

Guggenmos, Josef/Schwab, Gustav: Die schönsten Sagen des klassischen Altertums, gesammelt von Gustav Schwab, neu erzählt von Josef Guggenmos, illustriert von Stephanie Harjes. Ravensburger, Ravensburg 2006

Herder, Johann Gottfried: Sämtliche Werke, hrsg. von Berhard Suphan, Bd. I-XXXII, Weidmannsche Buchhandlung, Berlin 1877-99, Bd. XXXIII, hrsg. von Reinhold Steig 1913

Homer: Ilias. Neue Übertr. von Wolfgang Schadewaldt. Suhrkamp, Frankfurt am Main 1975

Homer: Die Odyssee. Übers. in dt. Prosa von Wolfgang Schadewaldt. Rowohlt, Hamburg 1958

Hesiod: Sämtliche Gedichte. Theogonie. Erga. Frauenkataloge. Übersetzt und erläutert von Walter Marg. Artemis, Zürich/Stuttgart 1970

Juvenal: Satiren. Vollständige metrische Neuübertragung mit Erläuterungen von Wilhelm Plankl. Wilhelm Goldmann Verlag, München 1958

Kästner, Erich: Emil und die Detektive. Ein Roman für Kinder. Williams \& Co., Berlin 1929

Kubin, Alfred: Die andere Seite. Ein phantastischer Roman. G. Müller, München/Leipzig 1909

Lagerlöf, Selma: Wunderbare Reise des kleinen Nils Holgersson mit den Wildgänsen. Einzige berecht. Übers. aus dem Schwed. von Pauline Klaiber. A. Langen, München 1907

Lewis, Clive S: Die Chroniken von Narnia. (7 Bde.) Div. Übersetzer. Brendow Verlag, Moers $1995 \mathrm{ff}$.

Deutschsprachige Erstausgaben: Die Abenteuer im Wandschrank. Herder, Freiburg $1957 \mathrm{ff}$.

Englischsprachige Originalausgaben: The Chronicles of Narnia. Harper Collins, New York $1950 \mathrm{ff}$.

Lindgren, Astrid: Pippi Langstrumpf. Aus d. Schwed. von Cäcilie Heinig. Oetinger, Hamburg 1949

Lorey, Dean: Monsterjäger Akademie - Das Portal des Barakkas. Ravensburger, Ravensburg 2008

Maar, Paul: Eine Woche voller Samstage. Oetinger, Hamburg 1973

Henry H. Neff: Schule der Magier - das geheime Portal. Band 1. cbj, München 2008

Nimmo, Jenny: Charly Bone und das Geheimnis der sprechenden Bilder. Ravensburger, Ravensburg 2003

Nöstlinger, Christine: Wir pfeifen auf den Gurkenkönig. Beltz, Weinheim/Basel 1972 
Omololu, Cynthia J.: Für immer die Seele. Aus dem Amerikanischen von Jutta Wurm. Dressler, Hamburg 2013

Englischsprachige Originalausgabe: Transcendence. Walker Childrens, London 2012 [zitiert als FidS]

P. Ovidius Naso: Metamorphosen. Lateinisch/Deutsch, übersetzt und hrsg. von Michael von Albrecht. Reclam, Stuttgart 1994

Pausewang, Gudrun: Die Wolke. Jetzt werden wir nicht mehr sagen können, wir hätten von nichts gewusst. Ravensburger, Ravensburg 1987

Pullman, Philip: Der goldene Kompass. Aus dem Engl. von Wolfram Ströle und Andrea Kann. Carlsen, Hamburg 1996

Englischsprachige Originalausgabe: Northern Lights. Scholastic, London [u. a.] 1995

Raven, Lynn: Der Kuss des Dämons. Ueberreuter, Wien 2008

Rhoden, Emmy von: Der Trotzkopf. Eine Pensionsgeschichte für erwachsene Mädchen. Vorwort von Franz Hirsch. Gustav Wiese, Stuttgart 1885

Riordan, Rick: Helden des Olymp. Aus dem Engl. von Gabriele Haefs. Carlsen, Hamburg $2012 \mathrm{ff}$. [diverse Bände]

Sages, Angle: Septimus Heap - Magyk. Band 1. Hanser, München 2005

Salamanda, Drake: Die Schule der Drachenreiter. Aus dem Engl. von Anne Braun. (Innenill.: Petra Kolitsch). cbj, München 2007

Schadewaldt, Wolfgang: Griechische Sternsagen. Fischer, Frankfurt a. M./Hamburg 1956

Schröder, Patricia: Vollmondkuss. Ein Vampirroman. Fischer, Frankfurt a. M. 2008

Sue, Eugen: Die Geheimnisse von Paris. Mit zeitgenössischen Abbildungen von Daumier und anderen. In neuer Bearbeitung von Bernhard Jolles. Mit einem Vorwort von Victor Klemperer. Avalun, Hellerau bei Dresden 1926

Swift, Jonathan: Gullivers Reisen. Übers. aus dem Engl. von Franz Kottenkamp. Bearb. von Alice Sellin. Ill. Hans Baltzer. Kinderbuchverlag, Berlin 1958

Deutschsprachige Erstausgabe: Des Capitain Lemuel Gullivers Reisen in neu entlegene Länder. Wiering, Hamburg/Leipzig 1727/1728

Englischsprachige Originalausgabe: Travels into Several Remote Nations of the World in Four Parts By Lemuel Gulliver, first a Surgeon, and then a Captain of Several Ships. Benj. Motte, London 1726

Tausendundeine Nacht. Aus dem Arabischen erstmals ins Deutsche übertragen und umfassend kommentiert von Claudia Ott. Nach der andalusischen Handschrift des Aga Khan Museum. Manesse, München 2012

Tolkien, John Ronald Reuel: Der Herr der Ringe. 3 Bde. Aus d. Engl. übers. von Margaret Carroux. Gedichtübertr. von E.-M. Freymann. Klett, Stuttgart 1969/1970

Englischsprachige Originalausgabe: The Lord of the Rings. George Allen \& Unwin, London 1954/1955 


\section{Filme}

Coppola, Francis Ford [Regie]: Bram Stoker's Dracula. Drehbuch: James V. Hart, Bram Stoker. Produktion: Michael Apted, Fred Fuchs, Charles Mulvehill. Columbia Pictures 13.11.1992; DVD: Sony Pictures Home Entertainment 21.3.2002

Fisher, Terence [Regie]: Dracula. Drehbuch: Jimmy Sangster, Bram Stoker. Produktion: Michael Carreras, Anthony Hinds, Anthony Nelson Keys. Hammer Film Productions 12.12.1958; DVD: Warner Home Video - DVD 2.10.2002

Hardwicke, Cathrine [Regie]: Twilight. Bis(s) zum Morgengrauen. Drehbuch: Melissa Rosenberg, Stephenie Meyer. Produktion: Greg Mooradian, Marc Morgan, Karen Rosenfelt. Summit Entertainment 17.11.2008; DVD: 2 Disc Fan Edition, Concorde Home Entertainment 10.6.2009

Herzog, Werner [Regie]: Nosferatu - Phantom der Nacht. Drehbuch: Werner Herzog. Produktion: Werner Herzog. Twentieth Century Fox 5.10.1979; DVD: Arthaus Collection 12.10.2007

Jordan, Neil [Regie]: Interview mit einem Vampir. Drehbuch: Neil Jordan, Anne Rice. Produktion: Stephen Woolley, David Geffen. Warner BroS. 11.11.1994; DVD: Warner Home Video - DVD 25.11.1998

Wiseman, Len [Regie]: Underworld. Drehbuch: Danny McBride, Kevin Grivioux. Produktion: Gary Lucchesi, Tom Rosenberg, Richard S. Wright. Screen Gems. Pictures 19.9.2003. DVD: Concorde Video 6.10.2004

\section{Fernsehserien}

Moonlight. Warner Bros. Television, Silver Pictures

Erstausstrahlung im amerikanischen Fernsehen: 28.9.2007

Deutsche Erstausstrahlung: 23.6.2008

True Blood. Your Face Goes Here Entertainment, HBO

Erstausstrahlung bei HBO: 7.9.2008

Deutsche Erstausstrahlung: 11.5.2009

Vampire Diaries. Alloy Entertainment, Warner Bros. Television, CBS Television, Oeterbanks Entertainment

Erstausstrahlung im amerikanischen Fernsehen: 10.9.2009

Deutsche Erstausstrahlung: 20.1.2010

\section{Sekundärliteratur}

Abraham, Ulf: Fantastik in Literatur und Film. Eine Einführung für Schule und Hochschule. Berlin $2010^{2}$

Achtner, Wolfgang et al. (Hrsg.): Notwendige Fundamente - gefährlicher Fundamentalismus. Teil II: Heilige Texte und neue Mythen. Hrsg. von Wolfgang Achtner. Gießen 2004

Alefeld, Yvonne-Patricia: Göttliche Kinder. Die Kindheitsideologie in der Romantik. Paderborn 1996 
Allrath, Gaby/Gymnich, Marion/Suhrkamp, Carola: Introduction. Towards a Narratology of TV Series. In: Narrative Strategies in Television Series. Hrsg. von Gaby Allrath und Marion Gymnich. London 2005, S. 1-43

Alton, Anne Hiebert: Generic Fusion and the Mosaic of „Harry Potter“. In: Harry Potter’s World. Multidisciplinary Critical Perspectives. Hrsg. von Elizabeth E. Heilman. New York/London 2003, S. 141-162

Anderson, Richard C./Pearson, David P.: A Schema-Theoretic View of Basic Process in Reading Comprehension. In: Handbook of Reading Research. Hrsg. von dens. London 1984, S. 255-291

Auer, Manfred/Diedrichs, Frank A.: Werbung-Below the Line, Product Placement, TVSponsoring, Licensing ... Landsberg/Lech 1993

Bach, Christina: Fanfiction im Deutschunterricht: Beispiel „Tintenherz“. In: Computer + Unterricht 24 (2014), H. 94, S. 42

Bak, Sandra: Harry Potter. Auf den Spuren eines zauberhaften Bestsellers. Frankfurt a. M. 2004

Baldick, Chris: The Concise Oxford Dictionary of Literary Terms. Oxford $2008^{3}$

Bardola, Nicola: Interview mit Eoin Colfer. In: Eselsohr. Fachzeitschrift für Kinder- und Jugendmedien 12 (2001), S. 29

Bardola, Nicola: Bestseller mit Biss. Liebe, Freundschaft und Vampire - alles über die Autorin Stephenie Meyer. München 2009

Baßler, Moritz: Gattungsmischung, Gattungsübergänge, Unbestimmbarkeit. In: Zymner (2010), S. 52-54

Batteux, Charles [Schlegel, Johann Adolf]: Herrn Abt Batteux Einschränkung der Schönen Künste auf einen einzigen Grundsatz. Aus dem Französischen übersetzt und mit verschiedenen eignen damit verwandten Abhandlungen begleitet von Johann Adolf Schlegeln. Leipzig 1751

Baumgarten, Alexander Gottlieb: Aestetica (1750-1758). Dt/lt. in zwei Bänden. Hrsg. von H. R. Schweizer. Hamburg $1988^{2}$

Beckett, Sandra L.: Introduction. Transcending Boundaries. Writing for a Dual Audience of Children and Adults. Hrsg. von Sandra L. Beckett. New York 1999, S. XI-XX

Beckett, Sandra L.: Crossover Fiction. Global and Historical Perspectives. London/New York 2009

Bergenthal, Ursula: Des Zauberlehrlings Künste. „Harry Potter“ als Beispiel für literarische Massenkommunikation in der modernen Mediengesellschaft. Phil. Diss. Göttingen 2008

Biesterfeld, Wolfgang: Utopie, Science-Fiction, Phantastik, Fantasy und phantastische Kinder- und Jugendliteratur: Vorschläge zur Definition. In: Literarische und didaktische 
Aspekte der Kinder- und Jugendliteratur. Hrsg. von Günter Lange und Wilhelm Steffens. Würzburg 1993, S. 71-80

Biskop, Benjamin: Zusammenfassung des Vortrages „Archetypen europäischer Märchen in der Romanreihe Harry Potter" vom 23. Mai 2012; www.edb-stiftung.de/team/vorstand/robert-benjamin-biskop/vortraege/vortraege2012/maerchen (31.7.2014)

Blake, Andrew: The Irresistible Rise of Harry Potter. London 2002

Blanchet, Robert/Köhler, Kristina/Smid, Tereza/Zutavern, Julia (Hrsg.): Serielle Formen. Von den frühen Film-Serials zu aktuellen Quality-TV und Online Serien. Marburg 2011, S. $37-72$

Blanchet, Robert: Quality TV. Eine kurze Einführung in die Geschichte und Ästhetik neuer amerikanischer Fernsehserien. In: Blanchet/Köhler/Smid/Zutavern (2011), S. 37-72

Bleicher, Joan Kristin: Fernsehen als Mythos. Poetik eines narrativen Erkenntnissystems. Opladen 1999

Blümer, Agnes: Crossover/All-Age-Literatur; www.kinderundjugendmedien.de/index.php/begriffe-und-termini/494-crossoverall-ageliteratur (8.9.2014)

Blümer, Agnes: Das Konzept Crossover - eine Differenzierung gegenüber Mehrfachadressiertheit und Doppeladressiertheit. In: Kinder- und Jugendliteraturforschung 2008/2009. Hrsg. vom Institut für Jugendbuchforschung der Johann Wolfgang Goethe-Universität und der Staatsbibliothek Preußischer Kulturbesitz, Kinder- und Jugendbuchabteilung. Frankfurt a. M. 2009, S. 105-116

Blume, Svenja: Texte ohne Grenzen für Leser jeden Alters. Zur Neustrukturierung des Jugendliteraturbegriffs in der literarischen Postmoderne. Freiburg 2005

Blumenberg, Hans: Arbeit am Mythos. Frankfurt a. M. 2006 (folgt der sechsten Auflage von 2001, die wiederum auf der dritten, neu durchgesehenen Auflage von 1984 beruht; Erstauflage: 1805)

Bock-Lindenbeck, Nicola: Letzte Welten - neue Mythen. Der Mythos in der deutschen Gegenwartsliteratur. Köln 1999

Böhme-Dürr, Karin: Jenseits von „Harrycane“. In: Televizion 13 (2000), H. 1, S. 25-31

Bonacker, Maren (Hrsg.): Peter Pans Kinder. Doppelte Adressiertheit in phantastischen Texten. Tagungsband zum Wissenschaftlichen Symposium 16. bis 18. Mai 2003. Trier 2004

Bonacker, Maren: Eskapismus, Schmutz und Schund?! Fantasy als besonders umstrittene fantastische Literatur. In: Knobloch/Stenzel (2006), S. 64-70

Broich, Ulrich/Pfister, Manfred: Intertextualität. Formen, Funktionen, anglistische Fallstudien. Tübingen 1985 [zitiert als Broich/Pfister (1985a)] 
Broich, Ulrich/Pfister, Manfred: Bezugsfelder der Intertextualität. In: Broich/Pfister (1985), S. 48-77 [zitiert als Broich/Pfister (1985b)]

Broich, Ulrich: Formen der Markierung von Intertextualität. In: Broich/Pfister (1985), S. 3147

Brown, Stephan: Die Botschaft des Zauberlehrlings. Die Magie der Marke Harry Potter. München 2005

Buddecke, Wolfram: Phantastik in Kunstmärchen und Jugendliteratur am Beispiel motivverwandter Texte. In: Literarische und didaktische Aspekte der Kinder- und Jugendliteratur. Hrsg. von Günter Lange und Wilhelm Steffens. Würzburg 1993, S. 51-69

Burkert, Walter: Kulte des Altertums. Biologische Grundlagen der Religion. München 1998

Burkhardt, Sabine: Symbol und Motiv im mythologischen und philosophischen Kontext. Die fantastischen Romane von Rowling, Colfer und O’Shaughnessy. Aachen 2012

Bürvenich, Paul: Der Zauber des Harry Potter. Analyse eines literarischen Welterfolgs. Frankfurt a. M. 2001

Buß, Angelika: Intertextualität als Herausforderung für den Literaturunterricht. Am Beispiel von Patrick Süskinds „Das Parfum“. Frankfurt a. M. 2005

Campbell, Joseph: Der Heros in tausend Gestalten. [Im Original: The Heros with a Thousand Faces] Aus dem Amerikanischen von Karl Koehne. Frankfurt a. M $1999^{6}$ [New York 1949]

Callois, Roger: Das Bild des Phantastischen. Vom Märchen bis zur Science Fiction. In: Phaicon 1. Almanach der phantastischen Literatur. Hrsg. von Rain A. Zondergeld. Mit Illustrationen von Dieter Asmus, Jörg Kirchbaum, Friedrich Meckseper, Reiner Schwarz. Frankfurt a. M. 1974, S. 44-84

Cassirer, Ernst: Gesammelte Werke. Hamburger Ausgabe. Hrsg.von Birgit Recki. Bd. 12: Philosophie der symbolischen Formen. Zweiter Teil: Das mythische Denken. Text und Anmerkungen bearbeitet von Claus Rosenkrank. Darmstadt 2002 [Erstauflage Berlin 1924]

Cornelius, Corinna: Harry Potter - geretteter Retter im Kampf gegen dunkle Mächte? Religionspädagogischer Blick auf religiöse Implikationen, archaisch-mythologische Motive und supranaturale Elemente. Münster 2003

Croce, Bernedetto: Estetica come scienza dell'espressione e linguistic generale. Mailand 1902 (hier: Ästhetik als Wissenschaft vom Ausdruck und allgemeine Sprachwissenschaft, Theorie und Geschichte. Nach der 6. erw. ital. Ausgabe, übertragen von Hans Feist und Richard Peters. Tübingen 1930)

Däschler, Eberhard: Mythos. In: Metzler Literatur Lexikon. Begriffe und Definitionen. Hrsg. von Günther und Irmgard Schweikle. Stuttgart 1990, S. 316-317

Das große Vornamenlexikon. Bearbeitet von Rosa und Volker Kohlheim. Mannheim [u. a.] $2007^{3}$ 
Decker, Jan-Oliver: „Alles war gut“. Zur Konzeption von Person, Familie und Erzählen in J. K. Rowlings Harry Potter und die Heiligtümer des Todes (2007). In: Mitteilungen des Deutschen Germanistikverbandes 57 (2010), Ausgabe 2, S. 131-147

Detjen, Joachim: Politische Bildung. Geschichte und Gegenwart in Deutschland. München 2013

Deyneka, Leah: May the Myth Be with You, Always: Archetypes, Mythic Elements, and Aspects of Joseph Campbell's Heroic Monomyth in the Original Star Wars Trilogy. In: Myth, Media, and Culture in Star Wars: An Anthology. Hrsg. von Douglas Brode und Leah Deyneka. Lanham M. D. 2012, S. 31-46

van Dijk, Teun Adrianus/Kintsch, Walter: Strategies of Discourse Comprehension. New York 1983

Dinter, Astrid/Söderblom, Kerstin (Hrsg.): Vom Logos zum Mythos. „Herr der Ringe“ und „Harry Potter“ als zentrale Grunderzählungen des 21. Jahrhunderts. Praktischtheologische und religionsdidaktische Analysen. Berlin 2010

Dinter, Astrid: Zwischen Harry Potter und Herr der Ringe. Sinngenese Jugendlicher zu Beginn des 21. Jahrhunderts. In: Dinter/Söderblom (2010), S. 15-40

Dolle-Winkauff, Bernd/Ewers, Hans-Heino (Hrsg.): Theorien der Jugendlektüre. Beiträge zur Kinder- und Jugendliteraturkritik seit Heinrich Wolgast. Weinheim/München 1996

Dücker, Burckhard: Rituale. Formen - Funktionen - Geschichte. Eine Einführung in die Ritualwissenschaft. Stuttgart 2006

Dunker, Axel: Gattungssystematiken. In: Zymner (2010), S. 12-15

Durst, Uwe: Theorie der phantastischen Literatur. Tübingen 2001

Durzak, Manfred: Postmoderne und Spätmoderne. Erzählerische Tendenzen der achtziger Jahre. In: Geschichte der deutschen Literatur von 1945 bis zur Gegenwart. Hrsg. von Wilfried Barner. München 1994, S. 814-828

Eco, Umberto: Die Innovation im Seriellen. In: Über Spiegel und andere Phänomene. Hrsg. von dems. München 1988, S. 155-188 [Original: L'innovazione nel seriale. In: Sugli specchi e altri saggi. Mailand 1985, S. 125-146]

Ehgartner, Reinhard: Leseräume. Lesefaszination und literarische Raum- und Figurenkonstellationen. In: Ide 30 (2006), H. 1, S. 38-42

Elstner, Robert: Der Millionenerfolg „Harry Potter“. In: Julit 1 (2004), S. 3-11

Ernst, Alexandra: Schwellende Lippen, salzige Haut, blutiger Biss. Sinnlichkeit und Erotik in der aktuellen Fantasy-Literatur. In: Bulletin Jugend \& Literatur 5 (2008), S. 21-26

Ewers, Hans-Heino: Kinderliteraturtheorie der Nachkriegszeit. Progressive Aspekte der Theorie des ,guten Jugendbuchs“ der 50er und 60er Jahre. In: Dolle-Weinkauff/Ewers (1996), S. 165-178 
Ewers, Hans-Heino: Auf der Suche nach den Umrissen einer zukünftigen Kinder- und Jugendliteratur. Ein Versuch, die gegenwärtigen kinder- und jugendliterarischen Veränderungen einzuschätzen. In: Kinder- und Jugendliteratur zur Jahrtausendwende. Autoren Themen - Vermittlung. Hrsg. von Kurt Franz u. a. Baltmannsweiler 2000, S. 2-21 [zitiert als Ewers (2000a)]

Ewers, Hans-Heino: Kinder- und Jugendliteratur zwischen Pädagogik und Dichtung. Über die Fragwürdigkeit einer angeblichen Schicksalsfrage. Mit einer Gesamtbibliographie der Veröffentlichungen des Jahres 1999. In: Kinder- und Jugendliteraturforschung 1999/2000. Hrsg. vom Institut für Jugendbuchforschung der Johann Wolfgang GoetheUniversität und der Staatsbibliothek Preußischer Kulturbesitz, Kinder- und Jugendbuchabteilung. Stuttgart/Weimar 2000, S. 98-114 [zitiert als Ewers (2000b)]

Ewers, Hans-Heino: Literatur für Kinder- und Jugendliche. Eine Einführung in grundlegende Aspekte des Handlungs- und Symbolsystems Kinder- und Jugendliteratur. Mit einer Auswahlbibliographie Kinder- und Jugendliteraturwissenschaft. München 2000 [zitiert als Ewers (2000c)]

Ewers, Hans-Heino: Die Göttersagen der Gegenwart - Die Medienverbundangebote sind die großen Narrationen unserer Zeit. In: 1000 und 1 Buch Buch 2 (2004), S. 4-10

Ewers, Hans-Heino: Die Heldensagen der Gegenwart. Die Medienverbundangebote sind die großen Narrationen unserer Zeit. In: Garbe/Philipp (2006), S. 297-312

Ewers, Hans-Heino: Fantasy - Heldendichtung unserer Zeit. Versuch einer Gattungsdifferenzierung. 2011; http://user.uni-frankfurt.de/ ewers/word-dl/Fantasy\%2018-2-2011.pdf (17.8.2014)

Ewers, Hans-Heino: Literatur für Kinder- und Jugendliche. Eine Einführung in Grundbegriffe der Kinder- und Jugendliteraturforschung. Paderborn $2012^{2}$

Ewers, Hans-Heino: Jugendroman und Jugendromanforschung. Eine erneute Bestandsaufnahme. In: Kinder- und Jugendliteraturforschung 2012/2013. Hrsg. vom Institut für Jugendbuchforschung der Johann Wolfgang Goethe-Universität und der Staatsbibliothek Preußischer Kulturbesitz, Kinder- und Jugendbuchabteilung. Frankfurt a. M. 2013, S. $105-118$

Falconer, Rachel: The Crossover Novel. Contemporary Children's Fiction and Its Adult Readership. London/New York 2009

Faulstich, Werner: Serialität aus kulturwissenschaftlicher Sicht. In: Endlose Geschichten. Serialität in den Medien. Hrsg. von Günter Giesenfeld. Hildesheim/Zürich/New York 1994, S. 46-54

Fenkart, Gabriele: Die Tribute von Panem - The Hunger Games. Szenario des Lesens und Schreibens. In: ide 1 (2013), S. 30-34.

Fenske, Claudia: Muggles, Monsters and Magicians: A Literary Analysis of the Harry Potter Series. Marburg 2008

Fludernik, M.: Towards a ,Natural‘ Narratology. London/New York 1996 
Frederking, Volker/Josting, Petra: Der Vielfalt eine Chance. Medienintegration und Medienverbund im Deutschunterricht. In: Medienintegration und Medienverbund im Deutschunterricht. Hrsg. von dens. Baltmannsweiler 2005, S. 1-18

Freund, Winfried: Deutsche Phantastik. München u. a. 1999

Fricke, Harald: Norm und Abweichung. Eine Philosophie der Literatur. München 1981

Fricke, Harald: Definieren von Gattungen. In: Zymner (2010), S. 10-12 [zitiert als Fricke (2010a)]

Fricke, Harald: Invarianz und Variabilität von Gattungen. In: Zymner (2010), S. 19-23. [zitiert als Fricke (2010b)]

Friedrich, Hans-Edwin: Science Fiction in der deutschsprachigen Literatur. Wien 1995.

Frey, Andrea: Alles fauler Zauber? Theorien und Hintergründe zum Harry PotterMerchandising. In: Garbe/Philipp (2006), S. 182-210

Galynski, Karl: The Herakles Theme. The Adaptions of the Hero in Literature from Homer to the Twentieth Century. Littlefield 1972

Garbe, Christine/Philipp, Maik (Hrsg.): Harry Potter - ein Literatur- und Medienereignis im Blickpunkt interdisziplinärer Forschung. Hamburg 2006

Gansberg, Fritz: Schaffensfreude. Anregungen zur Belebung des Unterrichts. Leipzig $1912^{4}$

Gansel, Carsten: Phantastisches und moderne Literatur für Kinder und junge Erwachsene. In: Der Deutschunterricht 50 (1998), H. 6, S. 78-82 [zitiert als Gansel (1998a)]

Gansel, Carsten: Von Gespenstern, Cyberspace und Abgründen des Ich. Zu Aspekten von Spannung und Phantastik im Subsystem Kinder- und Jugendliteratur. In: 1000 und 1 Buch 2 (1998), S. 15-26 [zitiert als Gansel (1998b)]

Gansel, Carsten: Moderne Kinder- und Jugendliteratur. Vorschläge für einen kompetenzorientierten Unterricht. Berlin $2010^{4}$

Gailberger, Steffen/Dammann-Thedens, Katrin: Förderung schwacher und schwächster Leser durch Hörbücher im Deutschunterricht. In: kjl\&m 60 (2008), S. 35-48

Génette, Gerard: Paratexte [Palimpsestes]. Frankfurt a. M. 1992 [Paris 1982]

Giesenfeld, Günter: Serialität als Erzählstrategie in der Literatur. In: Endlose Geschichten. Serialität in den Medien. Hrsg. von dems. Hildesheim 1994, S. 1-54

Gloge, Andreas: J. R. R. Tolkiens „Der Herr der Ringe“. Vom Mythos zum Begründer eines Genres. Passau 2002

Gora, Stephan: Buchners Lektürebegleiter Deutsch. Cornelia Funke: Tintenherz. Bamberg $2007^{2}$.

Gottsched, Johann Christoph: Versuch einer critischen Dichtkunst. 5., unveränd. Aufl. Unveränd. photomechan. Nachdr. der 4., verm. Aufl., Leipzig 1751. Darmstadt 1962 
Grandpair, Holger de: Wie man einen Fantasy-Bestseller schreibt. An den Beispielen Harry Potter, Biss und Die Zwei Schwerter. Norderstedt 2011

Grandpair, Holger de: Wie man einen Fantasy-Bestseller schreibt, Teil 2. Am Beispiel der erfolgreichsten Fantasy-Romane. Norderstedt 2013

Grenz, Dagmar: Die Abwehr des Verdrängten. Zur Rezeption von Ch. Nöstlingers phantastischer Erzählung: Wir pfeifen auf den Gurkenkönig. In: Wirkendes Wort 36 (1986), H. 6, S. 455-467.

Grenz, Dagmar/Wilkending, Gisela (Hrsg.): Geschichte der Mädchenlektüre. Mädchenliteratur und die gesellschaftliche Situation der Frauen. Weinheim/München 1997

Grenz, Dagmar: Von der Nützlichkeit und der Schädlichkeit des Lesens. Lektüreempfehlungen in der Mädchenliteratur des 18. Jahrhunderts. In: Grenz/Wilkending (1997), S. 1534. [zitiert als Grenz (1997a)]

Grenz, Dagmar: „Der Trotzkopf“ - ein Bestseller damals und heute. In: Grenz/Wilkending (1997), S. 115-122. [zitiert als Grenz (1997b)]

Grimes, M. Katherine: Harry Potter. Fairy Tale Prince, Real Boy, and Archetypal Hero. In: The Ivory Tower and Harry Potter. Perspectives on a Literary Phenomenon. Hrsg. von Lena A. Whited. Columbia/London 2002, S. 89-122

Grimm, Gunter: Abenteuerroman. In: Metzler Literatur Lexikon. Begriffe und Definitionen. Hrsg. von Günther und Irmgard Schweikle. Stuttgart $1990^{2}$, S. 1

Gross, Mirjana: Von der Antike bis zur Postmoderne. Die zeitgenössische Geschichtsschreibung und ihre Wurzeln. Wien [u. a.] 1998

Grün, Paula: Liebe inbegriffen! Fantasy für Mädchen. In: Eselsohr. Zeitschrift für Kinderund Jugendmedien 10 (2007), S. 10-11

Haas, Gerhard: „Harry Potter“ im Kontext der fantastischen Kinder- und Jugendliteratur. In: Harry Potter in der Schule. Hrsg. von Jörg Knobloch. Mülheim an der Ruhr 2001, S. 1526

Haas, Gerhard: Literarische Phantastik. Strukturelle, geistesgeschichtliche und thematische Aspekte. In: Am Anfang war das Staunen. Wirklichkeitsentwürfe in der Kinder- und Jugendliteratur. Hrsg. von Gerhard Härle und Gina Weinkauff. Baltmannsweiler 2005, S. 117-134

Haller, Karin: Von Marsmädchen und Jupiterjungs. Zur Gender-Perspektive in der Kinderund Jugendliteratur. In: Erziehung und Unterricht 5-6 (2004), S. 488-495

Hallenberg, Gerd: Medien. In: Reallexikon der deutschen Literaturwissenschaft. Hrsg. von Harald Fricke, Neubearbeitung gemeinsam mit Georg Braungart, Klaus Grubmüller, Jan-Dirk Müller, Friedrich Vollhardt, Klaus Weimar. Bd. 2. Berlin/New York 2000, S. 551-554

Heber, Saskia: Das Buch im Buch. Selbstreferenz, Intertextualität und Mythenadaption in Cornelia Funkes Tinten-Trilogie. Phil. Diss. Kiel 2010 
Heiser, Ines: „Mögen die Gottheiten des Olymps (die es nicht gibt!) über euch wachen“. Rick Riordans Percy Jackson und der Perseus-Mythos. In: Praxis Deutsch 247 (2014), S. 3340

Helbig, Jörg: Intertextualität und Markierung. Untersuchungen zur Systematik und Funktion der Signalisierung von Intertextualität. Heidelberg 1995

Hennig, Hans Joachim: Halbblüter und Zwischenwesen: Rassismus in Harry Potter. In: Kurwinkel/Schmerheim/Kurwinkel (2014), S. 211-224

Herzog, Markwart: Von Narnia über Hogwarts und Zamonien nach Fowl Manor. Unterweltfahrten in der zeitgenössischen fantastischen Kinder- und Jugendliteratur. In: HöllenFahrten: Geschichte und Aktualität eines Mythos. Hrsg. von dems. Stuttgart 2006, S. 213-243

Hickethier, Knut: Die Fernsehserie und das Serielle des Fernsehens. Lüneburg 1991

Hickethier, Knut: Serie. In: Handbuch Populäre Kultur. Begriffe, Theorien, Definitionen. Hrsg. von Hans-Otto Hügel. Stuttgart, 2003, S. 397-403

Hickethier, Knut: Film- und Fernsehanalysen. Frankfurt a. M. 2007

Höcker, Angelika: Business Hero. Eine Heldenreise in 7 Etappen. Offenbach 2010

Horn, András: Theorie der literarischen Gattungen. Ein Handbuch für Studierende der Literaturwissenschaft. Würzburg 1998

Horstkotte, Martin: The Postmodern Fantastic in Contemporary British Fiction. Trier 2004

Huber, Melanie: Harry Potter and its Success as a Mass Phenomenon. Innsbruck 2004

Huey, Peggy J.: A Basilisk, a Phoenix and a Philosopher's Stone: Harry Potters Myths and Legends. In: Scholarly Studies in Harry Potter. Applying Academic Methods to a Popular Text. Hrsg. von Cynthia Whitney Hallet. New York 2005, S. 65-83

Hume, Kathryn: Fantasy and Mimesis. Responses to Reality in Western Literature. New York 1984

Hügel, Hans-Otto: Lob des Mainstreams. Zu Begriff und Geschichte von Unterhaltung und populärer Kultur. Köln 2007

Hurrelmann, Bettina: Kinder- und Jugendliteratur in der literarischen Sozialisation. In: Taschenbuch der Kinder- und Jugendliteratur. Hrsg. von Günter Lange, Bd. 2. Medien und Sachbuch, ausgewählte thematische Aspekte, ausgewählte poetologische Aspekte, Produktion und Rezeption, KJL im Unterricht. Baltmannsweiler 2000, S. 901-920

Ingarden, Roman: Vom Erkennen des literarischen Kunstwerks. Tübingen 1968

Jahraus, Oliver: Literatur als Medium. Sinnkonstitution und Subjekterfahrung zwischen Bewußtsein und Kommunikation. Weilerswist 2003

Jelinek, Linda: Das Phänomen Harry Potter. Eine literaturwissenschaftliche Analyse des Welterfolgs. Saarbrücken 2006 
Joannidis, Melanie/Weppler, Nicole: Gefunden und Verloren: Vaterfiguren in den Harry Potter-Filmadaptionen am Beispiel von Albus Dumbledore und Sirius Black. In: Kurwinkel/Schmerheim/Kurwinkel (2014), S. 177-192

Jung, Carl Gutstav/Kerényi, Karl: Einführung in das Wesen der Mythologie. Das göttliche Kind. Das göttliche Mädchen. Zürich $1951^{4}$

Jung, Carl Gustav: Über die Archetypen des kollektiven Bewußten. In: Eranos-Jahrbuch 1937, S. 179-229

Just, Martin-Christoph: J. K. Rowlings Zaubererschule „Hogwarts“ aus pädagogischer Sicht. In: Knobloch (2001), S. 45-62 [zitiert als Just (2001a)]

Just, Martin-Christoph: „Harry Potter“ versus Hermine Granger. Zum Frauen- und Mädchenbild in den „Harry Potter“-Romanen. In: Knobloch (2001), S. 63-80 [zitiert als Just (2001b)]

Just, Martin-Christoph: Harry Potter - Ein postmodernes Kinderbuch!? In: Garbe/Philipp (2006), S. 49-71

Kahrmann, Cordula/Reiß, Günter/Schlachter, Manfred: Erzähltextanalyse. Eine Einführung. Königsstein 1986

Kaiser, Gerhard R.: Zur Dynamik der literarischen Gattungen. In: Die Gattungen in der vergleichenden Literaturwissenschaft. Hrsg. von Horst Rüdiger. Berlin [u. a.] 1974, S. 3262

Karg, Ina: Mythos PISA. Vermeintliche Vergleichbarkeit und die Wirklichkeit eines Vergleichs. Göttingen 2005

Karg, Ina: Diskursfähigkeit als Paradigma schulischen Schreibens. Ein Weg aus dem Dilemma zwischen Aufsatz und Schreiben. Frankfurt a. M. 2007

Karg, Ina/Mende, Iris: Kulturphänomen Harry Potter. Multiadressiertheit und Internationalität eines nationalen Literatur- und Medienevents. Göttingen 2010

Karstens, Eric/Schütte, Jörg: Praxishandbuch Fernsehen. Wie TV-Sender arbeiten. Wiesbaden 2010

Kaulen, Heinrich: Wunder und Wirklichkeit. Zur Definition, Funktionsvielfalt und Gattungsgeschichte der phantastischen Kinder- und Jugendliteratur. In: Julit 1 (2004), S. 12-20

Kayser, Wolfgang: Das sprachliche Kunstwerk. Bern $1978^{16}$

Kelleter, Frank: Populäre Serialität. Eine Einführung. In: Populäre Serialität. Narration Evolution - Distinktion. Hrsg. von dems. Bielefeld 2012, S. 11-46

Kellner, Rolf: Fantasy. In: Metzler Literatur Lexikon. Begriffe und Definitionen. Hrsg. von Günther und Irmgard Schweikle. Stuttgart $1990^{2}$, S. 150-151

Kermode, Frank: The Sense of an Ending. Studies in the Theory of Fiction. New York 1967 
Kesting, Marianne: Negation und Konstruktion. Aspekte der Phantasiearchitektur in der modernen Dichtung. In: Positionen der Negativität. Hrsg. von Harald Weinrich. München 1975, S. 367-392

Klein, Thomas: Diskurs im Spiel. Überlegungen zu einer medienwissenschaftlichen Theorie serieller Komplexität. In: Populäre Serialität. Narration - Evolution - Distinktion. Hrsg. von Frank Kelleter. Bielefeld 2012, S. 225-239

Kließ, Werner: Die Fernsehserie. Forderungen an eine Ästhetik der Serie. In: Endlose Geschichten. Serialität in den Medien. Hrsg. von Günter Giesenfeld. Hildesheim 1994, S. $170-178$

Klewer, Detlef: Die Kinder der Nacht. Vampire in Film und Literatur. Frankfurt a. M. 2007

Klingberg, Göte: Die phantastische Kinder- und Jugenderzählung. In: Kinder- und Jugendliteratur. Zur Typologie und Funktion einer literarischen Gattung. Hrsg. von Gerhard Haas. Stuttgart 1976, S. 220-241

Klingberg, Göte: Erscheinungsformen, Strukturen und Funktionen der phantastischen Kinderund Jugendliteratur. In: Kinder- und Jugendliteratur. Ein Handbuch. Hrsg. von Gerhard Haas. Stuttgart $1984^{3}$, S. 269-284

Knobloch, Jörg (Hrsg.): Harry Potter in der Schule. Didaktische Annäherungen an ein Phänomen. Mülheim a. d. Ruhr 2001

Knobloch, Jörg/Stenzel, Gudrun (Hrsg): Zauberland und Tintenwelt. Fantastik in der Kinderund Jugendliteratur. Weinheim 2006

Koberstein, Eva-Maria: „Wir haben Harry Potter verfilmt!“ Ein Videoprojekt im Schullandheim. In: Knobloch (2001), S. 175-182

Köhler, Ulrike Christina: Gezähmtes Naturkind und dankbarer Sklave. Figurenstereotypen in den Harry Potter-Romanen. In: Kinder- und Jugendliteraturforschung Frankfurt. Aus der Arbeit des Instituts und der Bibliothek für Jugendbuchforschung 2 (2004), S. 20-24

Kölzer, Christian: Warum Erwachsene „Jugendbücher“ lesen dürfen - und andersherum! Dual Address in Philip Pullmans Fantasy-Trilogie His Dark Materials. In: Bonacker (2004), S. $16-26$

Köppl, Rainer M.: Der Vampir sind wir. Der unsterbliche Mythos von Dracula bis Twilight. St. Pölten/Salzburg 2010

Kohl, Stephan: Realismus. Theorie und Geschichte. München 1977

Kotzloff, Sarah: Narrative Theory and Television. In: Channels of Discourse, Reassembled. Television and Contemporary Criticism. Hrsg. von Robert Allan. London 1992, S. 67100

Krah, Hans: Erzählen in Folge. Eine Systematisierung narrativer Fortsetzungszusammenhänge. In: Strategien der Filmanalyse. Hrsg. von Michael Schaudig. München 2010, S. 85114 
Kreuter, Peter M.: Der Vampirglaube in Südosteuropa. Studie zur Genese, Bedeutung und Funktion. Rumänien und der Balkanraum. Berlin 2001

Kreuzer, Helmut: Fernsehserien - trivialisierbar, aber nicht notwendig trivial. Aspekte einer literaturwissenschaftlichen Fernsehforschung. In: Kirche und Rundfunk 46 (1974), S. 24

Kristeva, Julia: Bachtin, das Wort, der Dialog und der Roman. In: Literaturwissenschaft und Linguistik. Ergebnisse und Perspektiven. Hrsg. von Jens Ihwe. Bd. 3: Zur linguistischen Basis der Literaturwissenschaft II. Frankfurt a. M. 1972, S. 345-375

Krützen, Michaela: Daily Soaps. Ein Arbeitsheft zur Analyse von Soap Operas. Köln 1998

Kümmerling-Meibauer, Bettina: The Status of Sequels in Children's Literature. The Long Secret and Beyond the Chocolate War. In: Reflections of Change. Children's Literature Since 1945. Westport 1997, S. 65-73

Kümmerling-Meibauer, Bettina: Kommunikative und ästhetische Funktionen des modernen Kinder- und Jugendbuchs. In: Medienwissenschaft. Ein Handbuch zur Entwicklung der Medien- und Kommunikationsformen. Hrsg. von Joachim-Felix Leonhardt [u. a.]. Bd. 2. Berlin [u. a.] 2001, S. 1585-1594

Kümmerling-Meibauer, Bettina: Kinderliteratur, Kanonbildung und literarische Wertung. Stuttgart/Weimar 2003

Kurwinkel, Tobias/Schmerheim, Philipp/Kurwinkel, Annika (Hrsg): Harry Potter Intermedial. Untersuchungen zu den (Film-)Welten von Joanne K. Rowling. Würzburg 2014

Lachmann, Renate: Ebenen des Intertextualitätsbegriffs. In: Das Gespräch. Hrsg. von Karlheinz Stierle und Rainer Warning. München 1984, S. 133-138

Lachmann, Renate/Schahadat, Shamma: Intertextualität. In: Literaturwissenschaft. Ein Grundkurs. Hrsg. von Helmut Brackert und Jörn Stückrath. Reinbek 1995, S. 677-686

Lafontaine, Silvia: Harry Potter and his Readers. Results of an Empirical Reader Study Conducted in a German Bookshop. In: Harry Potter's World Wide Influence. Hrsg. von Diana Patterson. Newcastle 2009, S. 91-117

Lamping, Dieter: Einführung: Literaturwissenschaftliche Gattungsforschung. In: Handbuch der literarischen Gattungen. Hrsg. von dems. Stuttgart 2009, S. XV-XXVI

Langer, Daniela: Die Mythen des James Cameron. Motive, Diegesen und narrative Formen von Camerons Filmen unter besonderer Berücksichtigung der Terminator-Filme und Titanic. In: Mythen - Mütter - Maschinen. Das Universum des James Cameron. Hrsg. von Eckhard Pabst. Kiel 2005, S. 213-243

Larsson, Clarence: Identity Through the Other. Canadian Adventure Romance for Adolescents. Umeå 1996

Laue, Mara: Von der Idee zum fertigen Text. Norderstedt 2011 
Lecke, Bodo: Einleitung. In: Mediengeschichte, Intermedialität und Literaturdidaktik. Hrsg. von dems. Frankfurt 2008, S. 9-78

Lehmann, Jürgen: Phantastik als Schwellen- und Ambivalenzphänomen. In: Phantastik - Kult oder Kultur? Aspekte eines Phänomens in Kunst, Literatur und Film. Hrsg. von Christine Ivanović/Jürgen Lehmann/Markus May. Stuttgart 2003, S. 25-39

Lévi-Strauss, Claude: Die Struktur des Mythen. In: Strukturalismus in der Literaturwissenschaft. Hrsg. von Heinz Blumensath. Köln 1972, S. 26-46

Lévi-Strauss, Claude: Das wilde Denken. Frankfurt a. M. 1973

Lexe, Heidi: Pippi, Pan und Potter: Zur Motivkonstellation in den Klassikern der Kinderliteratur. Wien 2003

Lexe, Heidi: Phantastische Freakshow? Zur Rückkehr absonderlicher Wesen in der KJL. In: 1000 und 1 Buch 1 (2004), S. 28-32

Link, Hannelore: Rezeptionsforschung. Eine Einführung in Methoden und Probleme. Stuttgart [u. a.] 1976

Link, Charlotte/Brohn, Doris/Kutzmutz, Olaf: „Für mein Empfinden war Schriftsteller kein Beruf". Charlotte Link im Gespräch mit Doris Brohn und Olaf Kutzmutz über ihren Debütroman Die schöne Helena. In: Bestseller. Das Beispiel Charlotte Link. Hrsg. von Olaf Kutzmutz. Wolfenbüttel 2010, S. 54-68

Lison, Inger: „Du kennst mich nicht und schreibst trotzdem genau, wie es mir geht!“ Erfolgreiche Rezeption und Innovation in ausgewählten Werken Astrid Lindgrens. Frankfurt a. M. 2010

Löffler, Wolfgang: Bibliotheken als Motiv der Fantastischen Kinder- und Jugendliteratur. In: Knobloch/Stenzel (2006), S. 98-108

Lugowski, Clemens: Die Form der Individualität im Roman. Mit einer Einleitung von Heinz Schaffer. Frankfurt a. M. $1994^{2}$

Lundt, Bea: Von Merlin bis Harry Potter. Über die Anfänge des Zauberers im Mittelalter und seine Aktualität in der Postmoderne. In: Märchenfiguren in der Literatur des Nord- und Ostseeraumes. Hrsg. von Helga Bleckwenn. Baltmannsweiler 2011, S. 174-199

Lützeler, Paul: Einleitung. Von der Spätmoderne zur Postmoderne. In: Spätmoderne und Postmoderne. Beiträge zur deutschsprachigen Gegenwartsliteratur. Hrsg. von dems. Frankfurt a. M. 1991, S. 11-22

Lyotard, Jean-François: Das postmoderne Wissen. Ein Bericht. Bremen 1982

Lypp, Maria: Einfachheit als Kategorie der Kinderliteratur. Frankfurt a. M. 1984

Maar, Michael: Warum Nabokov Harry Potter gemocht hätte. Berlin 2002

Magdanz, Jana: Spuren des Geistigen. Die Macht des Mythos in Medien und Werbung. Wiesbaden 2012 
Mahne, Nicole: Transmediale Erzähltheorie. Eine Einführung. Göttingen 2007

Maier, Karl Ernst: Jugendliteratur. Formen, Inhalte, pädagogische Bedeutung. Regensburg 1980

Maiwald, Klaus: Auf rauer See? Lesen und Leseförderung in einer Kultur der Bilder. In: Kinder- und Jugendliteraturforschung 2008/2009. Hrsg. vom Institut für Jugendbuchforschung der Johann Wolfgang Goethe-Universität und der Staatsbibliothek Preußischer Kulturbesitz, Kinder- und Jugendbuchabteilung. Frankfurt a. M. 2009, S. 75-86

Manlove, Colin: The Fantasy Literature of England. London 1999

Manz, Katrin: Die Post-Potter-Ära. Ein Blick auf Ersatzlesestoffe und ihre Machart. In: Harry, hol schon mal den Besen! Ein Kehraus nach zehn Potter-Jahren. Hrsg. von Olaf Kutzmutz. Wolfenbüttel 2009, S. 65-85

Manz, Katrin: Phantastische Kinder- und Jugendliteratur zu Beginn des 21. Jahrhunderts. Dissertation Erlangen 2011;

http://digisrv-1.biblio.etc.tu-bs.de:8080/docportal/servlets/MCRFileNodeServlet /DocPortal_derivate_00020935/110901_Dissertation_Manz_Druckversion.pdf (9.9.2014)

Markert, Dorothee: Momo, Pippi, Rote Zora ... was dann? Leseerziehung, weibliche Autorität und Geschlechterdemokratie. Phil. Diss. Freiburg 1998

Markus, Hazel: Self-Schemata and Processing Information About the Self. In: Journal of Personality and Social Psychology V. 35, N. 2 (1977), S. 63-78

Martinez, Matias/Scheffel, Michael: Einführung in die Erzähltheorie. München $2005^{6}$

Mattenklott, Gundel: Zu Hause in der phantastischen Fremde. Harry Potter und seine Leser. In: PÄD Forum 1 (2001), S. 28-34. [zitiert als Mattenklott (2001a)]

Mattenklott, Gundel: Text aus Texten. In: Harry Potter oder Warum wir Zauberer brauchen. Hrsg. von Olaf Kutzmutz. Wolfenbüttel 2001, S. 33-43 [zitiert als Mattenklott (2001b)]

McCormick, Thomas W.: Theories of Reading in Dialogue. An Interdisciplinary Study. New York 1988

Mende, Iris: Das Mittelalter; www.kinderundjugendmedien.de/index.php/stoffe-undmotive/527-das-mittelalter (19.8.2014)

Mende, Iris: Vermitteltes Mittelalter? Schulische und außerschulische Potentiale moderner Mittelalterrezeption. Frankfurt a. M. 2012

Mende, Jacqueline: Meyer, Stephenie: Twilight-Die „Bis(s) _..“-Reihe; www.kinderundjugendmedien.de/index.php/werke/223-twillight-die-biss-reihe $(31.10 .2014)$

Meißner, Wolfgang: Phantastik in der Kinder- und Jugendliteratur der Gegenwart. Theorie und exemplarische Analyse von Erzähltexten der Jahre 1983 und 1984. Würzburg 1989 
Meyer, Peter: Mythos und Fantasy. Oder: Was Theologie und Religionspädagogik von den populären Erzählphänomenen der Gegenwart lernen können. In: Dinter/Söderblom (2010), S. 63-108

Mielke, Christine: Zyklisch-serielle Narrationen. Erzähltes Erzählen von 1001 Nacht bis zur TV-Serie. Berlin/New York 2006

Mikos, Lothar: Es wird dein Leben! Familienserien im Fernsehen und im Alltag der Zuschauer. Münster 1994

Mitchison, Amanda: Alexander Selkirk. Survivor on a Desert Island. London 2004

Mittel, Jason: Serial Boxes. DVD-Editionen und der kulturelle Wert amerikanischer Fernsehserien. In: Blanchet/Köhler/Smid/Zutavern (2011), S. 133-152

Mohr, Judith: Zwischen Mittelerde und Tintenwelt. Zur Struktur Fantastischer Welten in der Fantasy. Phil. Diss. Frankfurt a. M. 2012

Müller, Ralph: Script-Theorie. In: Reallexikon der deutschen Literaturwissenschaft. Hrsg. von Jan-Dirk Müller. Bd. 3: P-Z. Berlin/New York 2003, S. 414-416

Müller, Ralph: Kategorisieren. In: Zymner (2010), S. 21-23

Nel, Philip: J. K. Rowling’s Harry Potter Novels. A Reader's Guide. New York 2001

Nickel-Bacon, Irmgard: Vom Kunstmärchen zur Fantasy. Literarische Gattungstraditionen im zeitgenössischen Kinderfilm und genreadäquate Rezeptionsformen. In: Kindermedien nutzen. Medienkompetenz als Herausforderung für Erziehung und Unterricht. Hrsg. von Bettina Hurrelmann und Susanne Becker. München 2003, S. 146-161

Nickel-Bacon, Irmgard: Alltagstranszendenz. Literaturhistorische Dimensionen kinderliterarischer Fantastik. In: Knobloch/Stenzel (2006), S. 39-51 [zitiert als Nickel-Bacon (2006a)]

Nickel-Bacon, Irmgard: Harry Potter und der Stein der Weisen in der Schule: Überlegungen zu einer medienintegrativen Literaturdidaktik. In: Garbe/Philipp (2006), S. 279-300 [zitiert als Nickel-Bacon (2006b)]

Nickel-Bacon, Irmgard: Fantastische Literatur. In: Geschichte der deutschen Kinder- und Jugendliteratur. Hrsg. von Reiner Wild. Stuttgart/Weimar 2008, S. 393-405

Nikolajeva, Maria: The Magic code. The Use of Magical Patterns in Fantasy for Children. Göteborg 1988

Nikolajeva, Maria: Children's, Adult, Human ...? In: Transcending Boundaries. Writing for a Dual Audience of Children and Adults. Hrsg. von Sandra L. Beckett. New York 1999, S. $63-80$

Nünning, Vera/Nünning, Ansgar: Hybride Genres. In: Metzler Lexikon. Literatur- und Kulturtheorie. Ansätze - Personen - Grundbegriffe. Hrsg. von Ansgar Nünning. Stuttgart $2013^{5}$, S. $313-315$ 
Opitz, Martin: Buch von der deutschen Poeterei. Abdruck der ersten Ausgabe von 1624. Halle $1949^{5}$

Ortheil, Hanns-Josef: Was ist moderne Literatur? In: Schauprozesse. Beiträge zur Kultur der 80er Jahre. Hrsg. von dems. München 1990, S. 105-115

O'Sullivan, Emer: Gibt es eine Weltliteratur für Kinder? Internationalität der Kinder- und Jugendliteratur zwischen Mythos und Realität. In: Kinder- und Jugendliteraturforschung 1996/1997. Hrsg. von Hans-Heino Ewers [u. a.]. Stuttgart 1997, S. 86-104

O’Sullivan, Emer: Kinderliterarische Komparatistik. Heidelberg 2000

Otto, Berthold: Kindesmundart. Berlin 1908

Petzold, Dieter: Große Kunst, ,juvenile trash“ oder kollektives Spielzeug? Zum Erfolg der Harry-Potter-Bücher bei Jung und Alt. In: Bonacker (2004), S. 82-93

Picandet, Katharina: Zeitromane der Gegenwart. Frankfurt a. M. 2011

Plett, Heinrich F.: Sprachliche Konstituenten einer intertextuellen Poetik. In: Broich/Pfister (1985), S. 207-224

Pohlmann, Sanna: Phantastisches und Phantastik in der Literatur. $\mathrm{Zu}$ phantastischen Kinderromanen von Astrid Lindgren. Wettenberg 2004

Rahner, Johanna: „Viel mehr als unsere Fähigkeiten sind es unsere Entscheidungen, Harry, die zeigen, wer wir wirklich sind." J. K. Rowlings zauberhafte Ethik und die Frage von Schuld, Reue und Vergebung. In: Dinter/Söderblom (2010), S. 185-208

Rajewski, Irina: Intermedialität - eine Begriffsbestimmung. Tübingen/Basel 2002

Rank, Bernhard: Phantastik im Spannungsfeld zwischen literarischer Moderne und Unterhaltung. Ein Überblick über die Forschungsgeschichte der 90er Jahre. In: Kinder- und Jugendliteraturforschung 2001/2002. Hrsg. von Hans-Heino Ewers. Stuttgart/Weimar 2002, S. 101-125

Rank, Bernhard: Phantastik in der Kinder- und Jugendliteratur. In: Knobloch/Stenzel (2006), S. $10-25$

Rank, Bernhard: Phantastische Kinder- und Jugendliteratur. In: Kinder- und Jugendliteratur der Gegenwart. Grundlagen. Gattungen. Medien. Lesesozialisation und Didaktik. Hrsg. von Günter Lange. Hohengehren 2011, S. 168-192

Rank, Bernhard: Zum Beispiel die jugendliterarische Dystopie. Über die Notwendigkeit eines Perspektivenwechsels bei der Analyse eines aktuell erfolgreichen Genres. In: Zeitschrift für Literalität in Schule und Forschung 1 (2014), S. 1-11; http://leseräume.de/wpcontent/uploads/2014/04/Rank_Dystopien_formatiert_2014-03-03.pdf (11.10.2014)

Reichardt, Ulfried: Globalisierung. Literaturen und Kulturen des Globalen. Berlin 2010

Reincke, Markus: TV-Serien als Megamovies: Die US-Serie Lost als Beispiel einer neuen Seriengeneration. Diplom.de [Online-Verlag] 2007 
Richter, Karin: Kinderliteratur und Kinderliteraturforschung in der DDR. In: DolleWeinkauff/Ewers (1996), S. 191-210

Rosebrock, Bente: Was ist das Erfolgsrezept von Harry Potter? München 2001

Rottensteiner, Franz: Zweifel und Gewissheit. Zu Traditionen, Definitionen und einigen notwendigen Abgrenzungen in der phantastischen Literatur. In: Die dunkle Seite der Wirklichkeit. Aufsätze zur Phantastik. Hrsg. von dems. Frankfurt a. M. 1987, S. 7-20

Rusch, Gebhard: Theorien der Neuen Medien. Kino, Radio, Fernsehen, Computer. Paderborn 2007

Ryan, Marie-Laure: Possible-worlds theory. In: Routledge Encyclopedia of Narrative Theory. Hrsg. von David Herman [u. a.]. London 2005, S. 446-450; http://users.frii.com/mlryan/pws.htm (14.8.2014).

Scharrelmann, Heinrich: Pflege der dichterischen Phantasie der Kinder. In: Roland 2 (1906), H. 8, S. 5-11

Schaudig, Michael: Literatur im Medienwechsel. Gerhart Hauptmanns Tragikomödie „Die Ratten“ und ihre Adaption für Kino, Funk und Fernsehen. Prolegomena zu einer Medienkomparatistik. Phil. Diss. Stuttgart 1992

Schick, Thomas: Filmstil, Differenzqualitäten, Emotionen. Zur affektiven Wirkung von Autorenfilmen am Beispiel der Berliner Schule. Phil. Diss. Wiesbaden 2018

Schilken, Dörthe: Die teleologische Reise. Von der christlichen Pilgerallegorie zu den Gegenwelten der Fantasyliteratur. Würzburg 2002

Schlachter, Birgit: Harry Potter, Twilight, Die Tribute von Panem \& Co - Serielles Erzählen in der aktuellen populären Jugendkultur und im aktuellen Jugendmedienverbünden. In: Kinder- und Jugendliteraturforschung 2012/2013. Hrsg. vom Institut für Jugendbuchforschung der Johann Wolfgang Goethe-Universität und der Staatsbibliothek Preußischer Kulturbesitz, Kinder- und Jugendbuchabteilung. Frankfurt a. M. 2013, S. 105-118

Schlachter, Birgit: Twilight, Die Tribute von Panem \& Co im Deutschunterricht? Zur didaktischen Relevanz der populären Jugendliteratur. In: Zeitschrift für Literalität in Schule und Forschung 1 (2014), S. 1-11; http://leseräume.de/wp-content/uploads/2014/04/schlachter-twilight-2014-1.pdf (11.10.2014)

Schmaus, Geli: Projektarbeit mit Harry Potter. Erfahrungen aus einer Kulturwerkstatt für Kinder und Jugendliche. In: Knobloch (2001), S. 197-206

Schmitz, Manfred: Fernsehen zwischen Apokalypse und Integration. Zur Instrumentalisierung der Fernsehunterhaltung. Baden-Baden 1995

Schmitz-Emans, Monika: Einteilung der Literatur in Gattungen. In: Zymner (2010), S. 109111

Schneider, Michael: Vor dem Dreh kommt das Buch. Ein Leitfaden für das filmische Erzählen. Gerlingen 2001 
Schnur-Wellpott, Margrit: Aporien der Gattungstheorie aus semiotischer Sicht. Tübingen 1983

Schrödter, Hermann: Neomythen. Vom Mythos zum Neomythos. In: Mythos - Neomythos neue Religiosität. Beiheft Nr. 60 der Werkmappe „Sekten, Religiöse Sondergemeinschaften, Weltanschauungen" in Zusammenarbeit mit der Schweizerischen Bischofskonferenz, des Schweizerischen Evangelischen Kirchenbundes und der deutschen Bischofskonferenz. Hrsg. von Linus Hauser und Hermann Schrödter. München 1991, S. 132

Schulz, Dieter: Suche und Abenteuer. Die „Queste“ in der englischen und amerikanischen Erzählkunst der Romantik. Heidelberg 1981

Schwarzenau, Paul: Das göttliche Kind. Der Mythos vom Neubeginn. Zürich 1984

Schweikle. Günther: Märchen. In: Metzler Literatur Lexikon. Begriffe und Definitionen. Hrsg. von Günther und Irmgard Schweikle. Stuttgart $1990^{2}$, S. 292-294 [zitiert als Schweikle (1990a)]

Schweikle, Günther: Sagen. In: Metzler Literatur Lexikon. Begriffe und Definitionen. Hrsg. von Günther und Irmgard Schweikle. Stuttgart 1990², S. 405-406 [zitiert als Schweikle (1990b)]

Seibel, Klaudia: Für wen ist Mittelerde? Thesen zur intendierten und tatsächlichen Rezeption von J.R.R. Tolkien. In: Bonacker (2004), S. 16-26

Shavit, Zohar: Poetics of Children's Literature. Ithaka/New York 1986

Sielke, Sabine: Joy in Repetition. Acht Thesen zum Konzept der Serialität und zum Prinzip der Serie. In: Populäre Serialität. Narration - Evolution - Distinktion. Hrsg. von Frank Kelleter. Bielefeld 2012, S. 383-398

Simonis, Annette: Grenzüberschreitungen in der phantastischen Literatur. Einführung in die Theorie und Geschichte eines narrativen Genres. Heidelberg 2005

Simonis, Annette: Mythos. In: Metzler Lexikon. Literatur- und Kulturtheorie. Ansätze - Personen - Grundbegriffe. Hrsg. von Ansgar Nünning. Stuttgart $2013^{5}$, S. 552

Stach, Reinhard: Robinsonaden. Bestseller der Jugendliteratur. Baltmannsweiler 1996

Steinbrink, Bernd: Abenteuerroman. In: Literaturlexikon. Hrsg. von Walther Killy: Bd. 13. Berlin 2005, S. 13 f.

Steinwachs, Carina: Funke, Cornelia: Die Tintenwelt-Trilogie; www.kinderundjugendmedien.de/index.php/werke/178-die-tintenwelt-trilogie (30.11.2014).

Stenzel, Gudrun: Richtung Phantásien. Fantasy und Märchen. In: Bulletin Jugend \& Literatur 12 (2001), S. 11-17 
Stenzel, Gudrun: Fantastische Kinder- und Jugendliteratur zwischen entwicklungspsychologischen und literarischen Funktionen - Anmerkungen zu Wolfgang Meißner. In: Knobloch/Stenzel (2006), S. 173-191

Stierle, Karlheinz: Werk und Intertextualität. In: Das Gespräch. Hrsg. von dems. und Rainer Warning. München 1984, S. 139-150

Stocker, Peter: Theorie der intertextuellen Lektüre: Modelle und Fallstudien. Paderborn 1998

Stubenvoll, Caroline: Was fasziniert LeserInnen an Harry Potter? Fallstudien zur Romanrezeption von drei LeserInnen einer Familie. In: Garbe/Philipp (2006), S. 213-235

Suerbaum, Ulrich: Text. Gattung. Intertextualität. In: Ein anglistischer Grundkurs. Einführung in die Literaturwissenschaft. Hrsg. von Berhard Fabian. Berlin 1993, S. 81-123

Sullivan III, C.W.: High Fantasy. In: The International Companion Encyclopedia of Children's Literature. Hrsg. von Peter Hunt u. a. London 1996, S. 303-313

Tabbert, Reinbert: Phantastische Kinder- und Jugendliteratur. In: Taschenbuch der Kinderund Jugendliteratur. Hrsg. von Günter Lange: Bd. 1: Grundlagen - Gattungen. Baltmannsweiler 2000, S. 187-200

Tepe, Peter: Vorlesung „Kunst und Mythos“. Heinrich-Heine-Universität Düsseldorf, Sommersemester 1996. Unveröffentlichtes Manuskript

Thornedyke, Perry: Applications of Schema Theory in cognitive Research. In: Tutorials in Learning and Memory. Hrsg. von John R. Anderson. San Francisco/New York 1984, S. 235-255

Titzmann, Michael: Skizze einer integrativen Literaturgeschichte und ihres Ortes in einer Systematik der Literaturwissenschaft. In: Modelle des literarischen Strukturwandels. Hrsg. von dems. Tübingen 1991, S. 395-438

Todorov, Tzvetan: Introduction à la littérature fantastique. Paris 1970

Tolkien, John Ronald Reuel: Beowulf. The Monsters and the Critics. In: The Monsters and the Critics and Other Essays. Hrsg. von Christopher Tolkien. London 1983, S. 5-48 [ursprünglich erschienen in den Proceedings of the British Academy 22 (1936), S. 245295]

Türschmann, Jörg: Spannung und serielles Erzählen. Vom Feuilletonroman zur Fernsehserie. In: Gespannte Erwartungen. Hrsg. von Kathrin Ackermann und Judith Moser-Kroiss. Berlin 2007, S. 201-219

Turner, Victor: Das Ritual. Struktur und Anti-Struktur. Frankfurt a. M. 2005

Uhlitzsch, Julia: Cornelia Funkes Tintenherz - ein All-Age-Buch? Analyse und Auswertung einer Befragung. Seminararbeit Hildesheim. Veröffentlicht als E-Book: Grin 2012

Ulonska, Benjamin R.: Vampires are Sexy: Vampir-Hype, Adoleszenz und Jugendkultur. In: Der Vampir in den Kinder- und Jugendmedien. Hrsg. von Jana Mikota und Sabine Planka. Berlin 2012, S. 311-330 
Vester, Heinz-Günther: Soziologie der Postmoderne. München 1993

Vogler, Christopher: Die Odyssee des Drehbuchschreibers. Über die mythologischen Grundmuster des amerikanischen Kinoerfolgs [Original: The Writer's Journey. Mythic Structure For Storytellers and Screenwriters]. Aus dem Amerikanischen von Frank Kuhnke. Frankfurt a. M. 1999 [London 1998]

Voßkamp, Wilhelm: Gattungen als literarisch-soziale Institutionen. Zu Problemen sozial- und funktionsgeschichtlich orientierter Gattungstheorie und -historie. In: Textsortenlehre Gattungsgeschichte. Hrsg. von Walter Hinck. Heidelberg 1977

Wagner, Annette: Postmoderne im Adoleszenzroman der Gegenwart. Studien zu Bret Easton Ellis, Douglas Coupland, Benjamin von Stuckrad-Barre und Alexa Hennig von Lange. Frankfurt a. M. 2007

Walter, Klaus Peter: Rocambole-Romane. Frankfurt 1986

Weber, Tanja/Junklewitz, Christian: Das Gesetz der Serie - Ansätze zur Definition und Analyse. In: Medienwissenschaft 1 (2008), S. 13-31

Weinkauff, Gina/von Glasenapp, Gabriele: Kinder- und Jugendliteratur. Paderborn 2010

Wermke, Jutta: Kinder- und Jugendliteratur in den Medien oder: Der Medienverbund als ästhetische Herausforderung. In: Ästhetik im Prozess. Hrsg. von Gerhard Rupp. Opladen 1998

Wiemers, Eva: Dystopien in aktueller Kinder- und Jugendliteratur und als Thema im Deutschunterricht. Suzanne Collins’ „Die Tribute von Panem“. Hamburg 2013

Wilkending, Gisela: Reformpädagogik, „Altersmundart“ und Dichtung „,vom Kinde aus“. In: Dolle-Weinkauff/Ewers (1996), S. 27-50 [zitiert als Wilkending (1996a)]

Wilkending, Gisela: Mädchenlektüre und Mädchenliteratur. „Backfischliteratur“ im Widerstreit von Aufklärungspädagogik, Kunsterziehungs- und Frauenbewegung. In: DolleWeinkauff/Ewers (1996), S. 105-126 [zitiert als Wilkending (1996b)]

Williams, Raymond: Television. Technology and Cultural Form. London 1974

Winko, Simone: Diskursanalyse, Diskursgeschichte. In: Grundzüge der Literaturwissenschaft. Hrsg. von Heinz-Ludwig Arnold und Heinrich Detering. München 1996, S. 463-478 [zitiert als Winko (1996a)]

Winko, Simone: Literarische Wertung und Kanonbildung. In: Grundzüge der Literaturwissenschaft. Hrsg. von Heinz-Ludwig Arnold und Heinrich Detering. München 1996, S. 585600 [zitiert als Winko (1996b)]

Winko, Sinome: Literatur-Kanon als ,invisible hand“-Phänomen. In: Literarische Kanonbildung. Sonderband „Text + Kritik“. Hrsg. von Hermann Korte. München 2002, S. 9-25; www.simonewinko.de/Winko_InvisibleHand.pdf (4.12.2014)

Wodianka, Stephanie: Zwischen Mythos und Geschichte. Ästhetik, Medialität und Kulturspezifik der Mittelalterkonjunktur. Berlin 2009 
Wrobel, Dieter: Kinder- und Jugendliteratur nach 2000. In: PD 224 (2010), S. 4-11

Wyss, Ulrich: Jenseits der Schwelle. Die Phantastik der anderen Welt. In: Phantastik - Kult oder Kultur? Aspekte eines Phänomens in Kunst, Literatur und Film. Hrsg. von Christine Ivanović u. a. Stuttgart 2003, S. 41-53

Zeilinger, Verena: Cornelia Funkes Tintenwelttrilogie. Eine Untersuchung zur phantastischen Kinder- und Jugendliteratur. Diplomarbeit. Wien 2010; http://othes.univie.ac.at/12813/1/2010-12-16_9902500.pdf (26.10.2014)

Zgorzelski, Andrzej: Zum Verständnis phantastischer Literatur. In: Phaicon 2. Almanach der phantastischen Literatur. Hrsg. von Rein A. Zondergeld. Frankfurt a. M. 1975, S. 54-63

Zgorzelski, Andrzej: Zur Einteilung der Phantastik. In: Die dunkle Seite der Wirklichkeit. Hrsg. von Franz Rottensteiner. Frankfurt a. M. 1987, S. 21-32

Zichy, Michael: Das humanistische Bildungsideal. In: Formen der Bildung. Einblicke und Perspektiven. Hrsg. von Martina Schmidhuber. Frankfurt a. M. 2010, S. 29-42

Zimmermann, Hans-Dieter: Trivialliteratur? Schemaliteratur! Entstehung, Formen, Bewertung. Stuttgart $1982^{2}$

Zimmermann, Christiane: Der Antigone-Mythos in der antiken Literatur und Kunst. Tübingen 1993

Zöller, Christa: Rockmusik als jugendliche Weltanschauung und Mythologie. Münster 2000

Zymner, Rüdiger: Gattungstheorie. Probleme und Positionen der Literaturwissenschaft. Paderborn 2003 [zitiert als Zymner (2003a)]

Zymner, Rüdiger: Phantastische Sozialisation. In: Phantastik - Kult oder Kultur? Aspekte eines Phänomens in Kunst, Literatur und Film. Hrsg. von Christine Ivanović/Jürgen Lehmann, Markus May. Stuttgart 2003, S. 299-314 [zitiert als Zymner (2003b)]

Zymner, Rüdiger (Hrsg.): Handbuch Gattungstheorie. Stuttgart 2010

\section{Pressemappen}

Arena-Verlag (Hrsg.): Informationen für Presse und Veranstalter. Cassandra Clare. Würzburg 2008

Dressler-Verlag (Hrsg.): Pressemappe zu Cornelia Funke; http://meta.verlagsgruppeoetinger.de/fileadmin/verlagsgruppe-oetinger.de/pdf/autoren/3258.pdf (18.11.2014)

Hogrebe, Katrin: Pressemappe zu Harry Potter; www.carlsen.de/uploads/Presse/Harry_Potter_Pressemappe.pdf (13.9.2014)

Hogrebe, Katrin: Pressemappe zu Stephenie Meyer; www.carlsen.de/uploads/Presse/Pressemappe_Stephenie_Meyer.pdf (10.9.2014)

Oetinger-Verlag (Hrsg.): Suzanne Collins Die Tribute von Panem. Informationen für die Presse; 
www.dietributevonpanem.de/fileadmin/user_upload/Panem/Pressemappe_Collins_Die_ Tribute_von_Panem.pdf (18.11.2014)

Piaseczny, Julia: All-Age-Bücher dominieren: Bleibt das Kinderbuch auf der Strecke? In: Presseinformation. Hrsg. v. Börsenverein des Deutschen Buchhandels e.V. 2010; www.boersenverein.de/sixcms/media.php/976/Digitale_Pressemappe_Trendbericht.pdf $(17.10 .2014)$

Scholastic-Verlag (Hrsg.): Online Press Kit „The Hunger Games Trilogy“; mediaroom.scholastic.com/hungergames (18.11.2014)

\section{Beiträge in Zeitschriften, Zeitungen und Hörfunk}

Albert, Attila: Bis(s) zum Morgengrauen. Warum fasziniert dieser Vampir Millionen Mädchen? In: Bild vom 13.1.2009; www.bild.de/unterhaltung/kino/warum-fasziniert-dieservampir-millionen-maedchen-7045998.bild.html (10.9.2014)

Berg, Insa van den: Moderne Mythen. Zu schön, um falsch zu sein. In: Spiegel Online, 25.5.2009; www.spiegel.de/einestages/moderne-mythen-zu-schoen-um-falsch-zu-seina-948288.html (15.10.2014)

Berger, Caroline: Twilight. Was macht Vampire so erfolgreich? In: frauenzimmer.de, 15.7.2010; www.frauenzimmer.de/cms/html/de/pub/leben-genuss/twilight-vampirepattinson/twilight-vampire-erfolgreich.phtml (10.9.2014)

Brand, Jobst-Ulrich: Interview mit Cornelia Funke: „Wir alle haben profitiert.“ In: Focus Magazin 29 (2007); www.focus.de/kultur/buecher/kultur-wir-alle-habenprofitiert_aid_226916.html (18.11.2014)

Brand, Jobst-Ulrich: Stephenie Meyer. Schauderhafte Potter-Nachfolge. In: Focus Online, 8.8.2008; www.focus.de/kultur/buecher/brands-buecher/stephenie-meyerschauderhafte-potter-nachfolge_aid_323230.html (6.5.2914)

Burger, Jörg: Zauberlehrlinge der Globalisierung. In: Zeit Online, 11.8.2007; www.zeit.de/2007/33/W-Harry-Potter-33 (14.9.2014)

Dallach, Christoph: Horrorautorin Meyer. Vampire sind attraktiv, klug und cool. In: Spiegel Online, 11.6.2008; www.spiegel.de/kultur/literatur/horrorautorin-meyer-vampire-sindattraktiv-klug-und-cool-a-558826.html (11.9.2014)

Dallach, Christoph: Rubinrot, Saphirblau, Smaragdgrün \& 2 x Silber. In: KulturSpiegel 9 (2014); www.spiegel.de/spiegel/kulturspiegel/d-128809895.html (18.11.2014)

Frenkel, Ulrike: All-Age-Literatur. Harry Potter hat die Türen geöffnet. In: Stuttgarter Zeitung, 8.5.2010; www.stuttgarter-zeitung.de/inhalt.all-age-literatur-harry-potter-hat-dietueren-geoeffnet.1e6547d7-2425-4da6-b399-4df37c47d578.html (11.9.2014)

Focus-Schule: Es gibt ein Lesen nach „Harry Potter“. In: Focus-Schule 1 (2010); www.focus.de/familie/kinderspiele/es-gibt-ein-lesen-nach-harry-potter-buecher-fuerkinder_id_1941324.html (27.11.2014) 
Freund, Wieland: Mädchen wollen wieder brav sein. Metaphysische Unterweisung durch die religiöse Rechte: Stephenie Meyer vollendet ihren Weltbestseller „Bis(s)“. In: welt.de, 14.2.2009; www.welt.de/welt_print/article3203692/Maedchen-wollen-wieder-bravsein.html (10.9.2014)

Freund, Wieland: Der Unverbesserliche mit dem großen Erfolg. Erst „Harry Potter“, dann „Bis(s)“. Ein Besuch bei Carlsen-Chef Klaus Humann, Deutschlands Mythen-Logistiker und erfolgreichster Verleger. In: welt.de, 8.8.2009; www.welt.de/diewelt/kultur/literatur/article4280427/Der-Unverbesserliche-mit-dem-grossen-Erfolg.html (10.9.2014)

freundin.de: Die Fantasy Saga geht weiter. Die deutsche Schauspielerin Sibel Kekilli über ihre Rolle in der US-Serie „Game of Thrones“; www.freundin.de/leben-kultur-game-ofthrones-die-fantasy-saga-geht-weiter-191117.html (31.8.2014)

Gaertner, David: Tintenherz. In: critic.de, 9.12.2008; www.critic.de/film/tintenherz-1464/ (4.12.2014)

Gaschke, Susanne: Die Welt liest. Das Phänomen „Harry Potter“: Globalisierung kann angenehm und sehr anspruchsvoll sein. In: Zeit Online, 26.10.2007; www.zeit.de/2007/30/01-Harry-Potter (17.6.2014)

Grossman, Lev: J. K. Rowling Hogwarts And All. In: Time Magazine, 17.7.2005; http://content.time.com/time/magazine/article/0,9171,1083935,00.html (26.10.2014)

Klingenstein, Susanne: Wenn das Zeus wüsste. In: Frankfurter Allgemeine Zeitung, 17.2.2010; www.faz.net/aktuell/feuilleton/jugendliteratur-wenn-das-der-zeus-wuesste1939164.html (18.11.2014)

Klüger, Ruth: Warum die Tribute von Panem Literatur sind. In: welt.de, 20.8.2012; www.welt.de/kultur/literarischewelt/article108597915/Warum-Die-Tribute-von-PanemLiteratur-sind.html (19.9.2014)

Klüger, Ruth: Etwas Geknuddel, aber keine Sexualität. In: welt.de, 11.8.2012; www.welt.de/print/die_welt/literatur/article108573647/Etwas-Geknuddel-aber-keineSexualitaet.html (18.11.2014)

Montgomery, James: Channing Tatum Or Taylor Lautner: MTV Movie Awards Oddsmakers Weigh In!, 4.12.2013; www.mtv.com/news/1705578/2013-movie-awards-oddsmakerswinners/ (2.12.2014)

Morris, William: Interview. Twilight author Stephenie Meyer (Internetseite „A Motley Vision. Mormon literature and culture"), 26.10.2005;

www.motleyvision.org/2005/interview-twilight-author-stephenie-meyer (11.9.2014)

Focus Online: Von Liebe, Halbgöttern und Werwölfen. In: Focus Online, 9.2.2010; www.focus.de/kultur/kino_tv/filmstarts/tid-17086/filmstarts-vom-11-februar-percyjackson-diebe-im-olymp_aid_476326.html (18.11.2014)

Osberghaus, Monica: Cornelia Funke. Die deutsche Rowling. In: Frankfurter Allgemeine Zeitung, 19.7.2002 
Rees, Jasper: We're all Reading Children's Books. In: The Daily Telegraph, 17.11.2003; www.telegraph.co.uk/culture/books/3606678/Were-all-reading-childrens-books.html (17.10.2014)

Rühle, Axel: Genuscheltes Fantasy-Esperanto. In: sueddeutsche.de, 17.5.2010; www.sueddeutsche.de/kultur/fantasy-roman-tintentod-genuscheltes-fantasy-esperanto$1.790358(23.12 .2014)$

rp-online.de: Buchhändlerin gibt Lesetipps. Was kommt nach „Harry Potter“? 27.9.2005; www.rp-online.de/kultur/buch/was-kommt-nach-harry-potter-aid-1.1593911 (7.5.2014)

Schoefer, Christine: Im Reich der starken Männer. In: taz, 14./15.10.2000, S. 11

Spreckelsen, Tilman: Das lange Warten auf den ersten Biss. In: Frankfurter Allgemeine Zeitung, 14.2.2009; www.faz.net/aktuell/feuilleton/buecher/autoren/stephenie-meyerserfolg-das-lange-warten-auf-den-ersten-biss-

1767243.html?printPagedArticle=true\#pageIndex_2 (18.11.2014)

sueddeutsche.de: Bericht über Twilight; www.sueddeutsche.de/kultur/twilight-star-robertpattinson-vampirchen-mit-beisshemmung-1.139979-2 (15.07.2014)

Sulner, Martina: Suzanne Collins’ zweiter „Tribute von Panem“-Roman erscheint. In: Hannoversche Allgemeine, 15.5.2010; www.haz.de/Nachrichten/Kultur/Uebersicht/SuzanneCollins-zweiter-Tribute-von-Panem-Roman-erscheint (18.11.2014)

Thimm, Katja/Weingarten, Susanne: Interview mit Cornelia Funke. Mein gefühltes Alter ist zehn. In: Der Spiegel 50 (2008); www.spiegel.de/spiegel/a-595093.html (18.11.2014)

Waechter, Christina: 20 Dinge, die du über Twilight wissen musst. In: jetzt.de, Süddeutsche Zeitung, 19.11.2009; http://jetzt.sueddeutsche.de/texte/anzeigen/491293/20-Dinge-diedu-ueber-Twilight-wissen-musst (10.9.2014)

welt.de, Feuilleton Kompakt, 18.8.2012;

www.welt.de/print/die_welt/kultur/article108673487/Feuilleton-Kompakt.html (18.11.2014)

\section{Internetseiten}

aeterni.de: Lexikon zu Vampirtypen; www.aeterni.de/Vampires/Lexikon/Lexikon.html (26.10.2014)

amazon.de: Liste „Bestseller in Science Fiction und Fantasy“;

www.amazon.de/gp/bestsellers/books/142/ref=zg_bs_unv_b_2_420066031_1 (31.8.2014)

amazon.de: Liste „Fantasy, Science Fiction und Vampirromane“; www.amazon.de/sciencefiction-fantasy-vampire/b?ie=UTF8\&node=142 (27.11.2014)

amazon.de: Lieblingsliste „Fantasy Saga“; www.amazon.de/FantasySaga/lm/M7WMTH5MTKB4 (31.8.2014) 
amazon.de: Was kommt nach Harry Potter? Diskussionsforum; www.amazon.de/forum/eltern\%20diskutieren?_encoding=UTF8\&cdForum=Fx3AFWY F3B770HX\&cdThread=Tx39TYABKDG7I9P (27.11.2014)

bella-und-edward.de: Werbeseite zum Buch Bis(s) zum Morgengrauen; www.bella-undedward.de/taschenbuch/bella-und-edward-band-1-biss-zum-morgengrauen (10.9.2014)

bella-und-edward.de: Übersicht Twilight-Bände; www.bella-und-edward.de/buecher (26.10.2014)

buchreport.de: Bestseller-Historie zu „Bis(s) zum Morgengrauen“;

www.buchreport.de/bestseller/bestseller_einzelansicht.htm?tx_bestseller_pi1[isbn]=978 3551581495 (10.9.2014);

www.buchreport.de/bestseller/bestseller_einzelansicht.htm?no_cache=1\&tx_bestseller_ pi1[isbn]=9783551356901 (18.11.2014)

buchreport.de: Bestseller-Historie zu „Bis(s) zur Mittagsstunde“;

www.buchreport.de/bestseller/bestseller_einzelansicht.htm?no_cache=1\&tx_bestseller_ pi1[isbn] $=9783551581617(18.11 .2014)$

buchreport.de: Bestseller-Historie zu „Bis(s) zum Abendrot“; www.buchreport.de/bestseller/bestseller_einzelansicht.htm?no_cache=1\&tx_bestseller_ pi1 [isbn] $=9783551581662(18.11 .2014)$

buchreport.de: Bestseller-Historie zu „Bis(s) zum Ende der Nacht“;

www.buchreport.de/bestseller/bestseller_einzelansicht.htm?no_cache=1\&tx_bestseller_ pi1[isbn] $=9783551581990(18.11 .2014)$

buchreport.de: Bestseller-Historie zu „Die Tribute von Panem - Tödliche Spiele“; www.buchreport.de/bestseller/bestseller_einzelansicht.htm?no_cache=1\&tx_bestseller_ pi1 [isbn] $=9783791504650(17.11 .2014)$

buchreport.de: Bestseller-Historie zu „Die Tribute von Panem - Gefährliche Liebe“; www.buchreport.de/bestseller/bestseller_einzelansicht.htm?no_cache=1\&tx_bestseller_ pi1[isbn] $=9783789132193(17.11 .2014)$

buchreport.de: Bestseller-Historie zu „Die Tribute von Panem - Flammender Zorn“; www.buchreport.de/bestseller/bestseller_einzelansicht.htm?no_cache=1\&tx_bestseller_ pi1[isbn] $=9783789132209(17.11 .2014)$

buchreport.de: Bestseller-Historie zu „Harry Potter und der Stein der Weisen“; www.buchreport.de/bestseller/bestseller_einzelansicht.htm?tx_bestseller_pi1[isbn]=978 $3551551672(10.9 .2014)$

buchreport.de: Bestseller-Historie $\mathrm{zu}$ „Rubinrot-Liebe geht durch alle Zeiten“; www.buchreport.de/bestseller/bestseller_einzelansicht.htm?no_cache=1\&tx_bestseller_ pi1 $[$ isbn $]=9783401063348(18.11 .2014)$

buchreport.de: Bestseller-Historie zu „Saphirblau-Liebe geht durch alle Zeiten“; www.buchreport.de/bestseller/bestseller_einzelansicht.htm?no_cache=1\&tx_bestseller_ pi1 [isbn]=9783401063478 (18.11.2014) 
buchreport.de, Bestseller-Historie zu „Smaragdgrün-Liebe geht durch alle Zeiten“; www.buchreport.de/bestseller/bestseller_einzelansicht.htm?no_cache=1\&tx_bestseller_ pi1 [isbn] $=9783401063485(18.11 .2014)$

buchreport.de: Bestseller-Historie zu „Percy Jackson-Diebe im Olymp“; www.buchreport.de/bestseller/bestseller_einzelansicht.htm?no_cache=1\&tx_bestseller_ pi1 [isbn] $=9783551554376(18.11 .2014)$

buchreport.de: Bestseller-Historie zu „Percy Jackson-Im Bann des Zyklopen“; www.buchreport.de/bestseller/bestseller_einzelansicht.htm?no_cache=1\&tx_bestseller_ pi1[isbn]=9783551554383 $(18.11 .2014)$

buchreport.de: Bestseller-Historie zu „Percy Jackson-Der Fluch des Titanen“; www.buchreport.de/bestseller/bestseller_einzelansicht.htm?no_cache=1\&tx_bestseller_ pi1 [isbn] $=9783551555540(18.11 .2014)$

buchreport.de: Bestseller-Historie zu „Percy Jackson-Schlacht um das Labyrinth“; www.buchreport.de/bestseller/bestseller_einzelansicht.htm?no_cache=1\&tx_bestseller_ pi1 $[$ isbn] $=9783551554390(18.11 .2014)$

buchreport.de: Bestseller-Historie zu „Percy Jackson-Die letzte Göttin“; www.buchreport.de/bestseller/bestseller_einzelansicht.htm?no_cache=1\&tx_bestseller_ pi1 $[$ isbn $]=9783551555854(18.11 .2014)$

buchreport.de: Bestseller-Historie zu „Tintenherz“;

www.buchreport.de/bestseller/bestseller_einzelansicht.htm?no_cache=1\&tx_bestseller_ pi1 [isbn] $=9783791504650(17.11 .2014)$

buchreport.de: Bestseller-Historie zu „Tintenblut“;

www.buchreport.de/bestseller/bestseller_einzelansicht.htm?no_cache=1\&tx_bestseller_ pi1 $[$ isbn $]=9783791504674(17.11 .2014)$

buchreport.de: Bestseller-Historie zu „Tintentod“; www.buchreport.de/bestseller/bestseller_einzelansicht.htm?no_cache=1\&tx_bestseller_ pi1[isbn]=9783791504766 (17.11.2014)

carlsen.de: Autorenseite Rick Riordan; www.carlsen.de/urheber/rick-riordan/17714 (18.11.2014)

carlsen.de: Übersicht Serien für junge Erwachsene; www.carlsen.de/junge-erwachsene/serien (31.10.2014)

carlsen.de: Werbetext zu Artemis Fowl; www.carlsen.de/junge-erwachsene/serie/artemisfowl/18619\#In-dieser-Serie (26.8.2014)

carlsen.de: Werbeseite Harry Potter; www.carlsen-harrypotter.de/taschenbuch/harry-potterschuber (7.9.2014)

carlsen.de: Werbetext zu Harry Potter und Übersicht verfügbarer Ausgaben; www.carlsen.de/serie/harry-potter/17132\#In-dieser-Serie (31.10.2014) 
carlsen.de: Werbeseite Percy Jackson; www.carlsen.de/hardcover/percy-jackson-percyjackson-schuber-inkl-e-book-kane-chroniken-bd-1/30634\#Inhalt (11.9.2014)

carlsen.de: Werbetext zu Percy Jackson; www.carlsen.de/serie/percy-jackson/17723\#In- dieser-Serie (26.8.2014)

cornelsen.de: Unterrichtsmaterial zur Tintenwelt-Trilogie; www.cornelsen.de/home/katalog/akd/1.c.1922958.de (9.11.2014)

die-edelstein-trilogie (Fanseite); http://die-edelstein-trilogie.blogspot.de (24.10.2014)

dietributevonpanem.de (Website des Oetinger Verlages); www.dietributevonpanem.de (24.10.2014)

dietributevonpanem.de: Porträt Suzanne Collins; www.dietributevonpanem.de/buecher/autorin (14.10.2014)

dietributevonpanem.de: Werbetext zu Bd. 3; www.dietributevonpanem.de/buecher/flammender-zorn/ (31.8.2014)

dpa: „Rubinrot“-Trilogie millionenfach verkauft, 7.8.2014; beispielsweise einzusehen unter: www.svz.de/nachrichten/deutschland-welt/kultur/rubinrot-trilogie-millionenfachverkauft-id7346851.html (18.8.2014)

dressler-verlag.de: Willkommen in der Welt von Tintenherz; www.dresslerverlag.de/buecher/specials/tintenherz.html (24.10.2014)

dressler-verlag.de: Werbetext zu „Tintenherz“; www.dressler-verlag.de/nc/schnellsuche/titelsuche/details/titel/ 1304650/6780/3258/Autor/Cornelia/Funke/Tintenherz.html (12.9.2014)

fanfiction.de (deutsches Fanfiction-Archiv); www.fanfiktion.de (20.11.2014)

fantasy-forum.net: www.fantasy-forum.net/showthread.php?p=125429 (07.07.2014)

fictionfantasy.de: Die besten Fantasy-Bücher, Platz 1 bis 100; www.fictionfantasy.de/die-besten-fantasy-buecher (26.8.2014)

fischerverlage.de: Über Cornelia Funke; www.fischerverlage.de/autor/cornelia_funke/1661 (6.6.2014)

Harry Potter Wiki: Informationen zu Ausgaben für Erwachsene; http://de.harrypotter.wikia.com/wiki/Ausgabe_f\%C3\%BCr_Erwachsene (11.9.2014)

hbo.com (Homepage zur Serie „True Blood“); www.hbo.com/true-blood\#/ (17. 10 2014)

hogwartsonline.de: Was lesen nach Harry Potter?; http//hogwartsonline.de/2007/10/waslesen-nach-harry-potter-5-martina.html (27.11.2014)

Hörbuchjournal. Hrsg. von MetaGIS-Systems, Ausgabe März 2013; www.metagis.de/fb03/HbJ03-2013.pdf (18.11.2014) 
hpffa.de (Harry-Potter-Fanfiction-Archiv): Exklusivinterview mit Kerstin Gier, 3.6.2012; http://forum.hpffa.de/index.php?page=Thread\&threadID=3036 (18.11.2014)

kinderbuch-couch.de: Interview mit Cornelia Funke; www.kinderbuch-couch.de/interviewcornelia-funke.html (1.11.2014)

kinderundjugendmedien.de. Wissenschaftliches Internetportal für Kindermedien und Jugendmedien; www.kinderundjugendmedien.de/ (26.10.2014)

Lennox High School; http://lennox.k12.sd.us/LHS/default.aspx (23.12.2014)

literaturkritik.de: Charly Bone und der Windschatten Harry Potters; www.literaturkritik.de/public/rezension.php?rez_id=6560 (07.05.2014)

lovelybooks.de: Was soll ich nach Harry Potter lesen?; www.lovelybooks.de/buecher/fantasy/Was-soll-ich-nach-Harry-Potter-lesen-464620402/ (7.5.2014)

lovelybooks.de: Die besten Fantasy Reihen und Serien aller Zeiten - Fantasy Bestseller; www.lovelybooks.de/buecher/fantasy/Die-besten-Fantasy-Reihen-und-Serien-allerZeiten-Fantasy-Bestseller-464906403 (26.8.2014)

Moonlight. Vampir Serien Wiki; http://de.vampirserien.wikia.com/wiki/Moonlight (17.10.2014)

piper.de: Porträt Stephenie Meyer; www.piper.de/autoren/stephenie-meyer-1969 (26.10.2014)

rp-online: Buchhändlerin gibt Lesetipps. Was kommt nach Harry Potter?; www.rponline.de/kultur/buch/was-kommt-nach-harry-potter-aid-1.1593911 (27.11.2014)

stepheniemeyer.com (Homepage von Stephenie Meyer); http://stepheniemeyer.com/midnightsun.html (10.9.2014)

thalia.de: Liste „Fantasy \& Science Fiction“; www.thalia.de/shop/fantasy-science-fiction4/show/?hkkat=special_1 (26.8.2014)

thalia.de: Liste „Vampirromane“; www.thalia.de/shop/vampirromane-11344/show/ (08.05.2014)

vampire-diaries.net: The Vampire Diaries \& The Originals Fansite: www.vampire-diaries.net/ (17. 10. 2014)

vornamenlexikon.de; www.vornamenlexikon.de (17.10.2014)

wikipedia.de: Artemis Fowl. Bearbeitungsstand: 27. Juli 2014, 20:54 UTC; http://de. wikipedia.org/w/index.php?title=Artemis_Fowl\&oldid=132553511 $\quad$ (26. 10. 2014)

wikipedia.de: Bis(s) zum Morgengrauen. Bearbeitungsstand: 12. September 2014, 19:38 UTC; http://de.wikipedia.org/w/index.php?title=Bis(s)_zum_Morgengrauen\&oldid=13397113 $0(31.10 .2014)$ 
wikipedia.de: Cornelia Funke. Bearbeitungsstand: 4. November 2014, 17:46 UTC; http://de.wikipedia.org/wiki/Cornelia_Funke (17.11.2014)

wikipedia.de: Fantasy. Bearbeitungsstand: 1. Oktober 2014, 08:07 UTC; http://de.wikipedia.org/wiki/Fantasy (11.11.2014)

wikipedia.de: Harry Potter. Bearbeitungsstand: 3. September 2014, 14:48 UTC; http://de.wikipedia.org/w/index.php?title=Harry_Potter\&oldid=133697404 $\quad(26 . \quad 10$. 2014)

wikipedia.de: Liebe geht durch alle Zeiten. Bearbeitungsstand: 26. Oktober 2014, 15:54 UTC; http://de.wikipedia.org/w/index.php?title=Liebe_geht_durch_alle_Zeiten\&oldid=13523 7014 (31.10.2014)

wikipedia.de: Moonlight (Fernsehserie). Bearbeitungsstand: 3. September 2014, 18:09 UTC; http://de.wikipedia.org/w/index.php?title=Moonlight_(Fernsehserie)\&oldid=133704536 $(1.12 .2014)$

wikipedia.de: Percy Jackson. Bearbeitungsstand: 30. Oktober 2014, 19:02 UTC; http://de. wikipedia.org/w/index.php?title=Percy_Jackson\&oldid=135366166 (31.10.2014)

wikipedia.de: Tintenwelt-Trilogie. Bearbeitungsstand: 29. Juni 2014, 10:20 UTC; http://de.wikipedia.org/wiki/Tintenwelt-Trilogie (26.10.2014) 